\title{
LOS CRISÓPIDOS DE LA PENÍNSULA IBÉRICA Y BALEARES (INSECTA, NEUROPTERIDA, NEUROPTERA: CHRYSOPIDAE)
}

\begin{abstract}
V. J. Monserrat
Departamento de Zoología y Antropología Física, Facultad de Biología, Universidad Complutense, 28040 Madrid (España). artmad@bio.ucm.es

RESUMEN

Se revisan las especies de crisópidos presentes en la fauna de la Península lbérica e Islas Baleares donde, hasta la fecha, están representadas por 50 especies pertenecientes a 13 géneros. Tras una diagnosis de la familia y citar algunos elementos sobre su historial paleontológico y su distribución, se aportan algunos datos generales sobre su morfología y su biología, sus estadios juveniles y comportamiento, y se comenta una breve introducción sobre la historia en el conocimiento de la familia, y en particular en la Península lbérica y Baleares. Se anotan algunas correcciones en las fechas de publicación de algunos taxa que afectan a la taxonomía, y por ello se propone a Rexa almerai (Navás, 1919) n. comb. como sinónima anterior de Rexa lordina Navás, 1920 n. syn. Se incluye una lista de las especies pertenecientes a la fauna de la Península lbérica y Baleares, una clave de identificación de los imagos de las subfamilias, géneros y especies citadas, y una clave de sus larvas a nivel genérico. De cada una de estas especies se recopilan y se anotan todas las referencias bibliográficas existentes desde 1972, relativas a las especies de la zona estudiada, tanto con la denominación actualmente aceptada, como de sus sinonimias y/o cualquier otra combinación nomenclatural bajo las cuales han sido citadas. También de cada una de las especies se anotan los datos conocidos y los ahora aportados (299 nuevos ejemplares de 25 especies) sobre su distribución general, aspectos de su morfología externa y/o genital, así como de su variabilidad, estadios juveniles, biología, fenología y distribución altitudinal y geográfica en la península y archipiélago balear, en base a un total de 20.667 ejemplares estudiados.
\end{abstract}

http://Isid:zoobank.org:pub:DAF40D47-BB5B-444B-9A3C-463BBB4F5382

Palabras clave: Insecta; Neuroptera; Chrysopidae; Revisión; Taxonomía; Faunística; Morfología; Península Ibérica; Islas Baleares; España; Portugal.

\section{SUMMARY}

\section{Green-lacewings (Insecta, Neuropterida, Neuroptera: Chrysopidae) of the Iberian Peninsula and Balearic Islands}

The present contribution reviews the green lacewing fauna of the Iberian Peninsula and Balearic Islands where, to date, 50 species belonging to 13 genera are known to occur. After a diagnosis of the family Chrysopidae, its paleontological history and distribution, as well as some general data on its morphology and biology, juvenile stages and behavior are presented. This general information is followed by a brief history of studies on the family, and particularly those on the Iberian Peninsula and Balearic Islands. Some corrections are reported for earlier publications dates that have undergone taxonomical changes. Thus, Rexa almerai (Navás, 1919) $\mathbf{n}$. comb. is proposed as junior synonym of Rexa lordina Navás, 1920 n. syn.; and is included in the list of chrysopid species belonging to the fauna of the Iberian Peninsula and Balearic Islands. A key for identifying imagoes of the subfamilies, genera, and species recorded from the region and a generic level key for the larvae are presented. For these species all existing bibliographic references since 1972, are compiled and annotated, both the currently accepted names, their synonyms and/or any other nomenclatural combinations under which they have been recorded. New information is presented on the external and/or genital morphology of most species, and detailed information is compiled on the presently known general distribution of each species with new data (299 new specimens of 25 species). Moreover, the variability, juvenile stages, biology, phenology, and altitudinal and geographic distribution of species from the Peninsula and Balearic Archipelago are assessed on the basis of 20.667 studied specimens.

Key Words: Insecta; Neuroptera; Chrysopidae; Review; Taxonomy; Faunistics; Morphology; Iberian Peninsula; Balearic Islands; Spain; Portugal.

Cómo citar este artículo/Citation: Monserrat, V. J. 2016. Los crisópidos de la Península Ibérica y Baleares (Insecta, Neuropterida, Neuroptera: Chrysopidae). Grae/lsia, 72(1): e037. http://dx.doi.org/10.3989/graellsia.2016.v72.143

Copyright: (C) 2016 SAM y CSIC. Salvo indicación contraria, todos los contenidos de la edición electrónica de Graellsia se distribuyen bajo licencia de uso y distribución Creative Commons Reconocimiento no Comercial 3.0. España (cc-by-nc). 


\section{Introducción}

Anotamos en este primer apartado unas generalidades introductorias sobre la diagnosis y morfología de esta familia, su historial paleontológico y distribución, así como algunos datos generales sobre su biología, comportamiento, estadios juveniles y ciclos biológicos, y finalmente un breve historial sobre su taxonomía y sistemática general y su progresivo conocimiento en la Península Ibérica y Baleares.

GENERALIDADES: DIAGNOSIS, MORFOLOGÍA, HISTORIAL PALEONTOLÓGICO Y DISTRIBUCIÓN

Los crisópidos constituyen una interesante familia de neurópteros, debido a su amplia distribución geográfica, al elevado número de individuos que frecuentemente constituyen sus poblaciones, y especialmente por su utilización como aliados de nuestros intereses, al tratarse de eficaces agentes de control de pequeños artrópodos fitófagos (Killington, 1936, 1937; New, 1975a, 1975b, 1988a, 1999, 2001, 2002; McEwen \& Senior, 1998; McEwen et al., 1998, 2001; Nicoli Aldini, 2002, etc.). Por ello, se trata de la familia de neurópteros que mayor atención ha venido recibiendo en comparación con otras familias, incluso aquellas de interés en el control biológico, sea Coniopterygidae o Hemerobiidae, y por ello son ingentes los datos y publicaciones existentes sobre la distribución, biología, fenología, morfología, histología, fisiología, estadios juveniles y variabilidad de muchas de sus especies, y en particular las utilizadas en Control Biológico, sobre las que se han publicado dos monografías (Canard et al., 1984; McEwen et al., 2001), y existen cientos de artículos de interés aplicado sobre estos insectos.

Por muchos caracteres morfológicos, anatómicos y biológicos, los crisópidos son muy próximos a los hemeróbidos (Killington, 1936; New, 1989), quienes junto a los osmílidos y los sisíridos son su grupo hermano, y junto a otras familias pertenecen al suborden de los Hemerobiiformia, uno de los grandes y más extensos y diversos linajes que constituyen los Neuroptera s.str. (= Planipennia) Handlirsch, 1908 (Tauber \& Adams, 1990; U. Aspöck, 1992, 1993, 1995, 1996; Aspöck \& Aspöck, 1999, 2010, 2013; H. Aspöck et al., 2001; U. Aspöck et al., 2001, 2012; Tauber et al., 2009; Beutel et al., 2010, etc.), y que junto a los Raphidioptera Latreille, 1810 y los Megaloptera Latreille, 1810 forman el Superorden Neuropterida o Neuroptera s.l., que, en su conjunto, está constituido por unas 6.620 especies repartidas en estos tres órdenes citados y habitualmente reconocidos: Megaloptera (c. 380 spp.), Raphidioptera (c. 241 spp.) y Planipennia o Neuroptera s.str. (c. 6.000 spp.) (H. Aspöck et al., 1980, 1991, 2001), cuyas relaciones aún son objeto de amplios estudios y debates (ej.: Tauber \& Adams, 1990; Ren \& Hong, 1994; Whiting et al., 1997; U. Aspöck et al., 2001, 2012, 2015; Winterton, 2003; Haring \& Aspöck, 2004; Winterton et al., 2010;
Zimmermann et al., 2011; Haring et al., 2011; Peters et al., 2014, etc.).

Esta familia es una de las más extensas dentro de los neurópteros, y está constituida por unas 1.200 especies agrupadas en 86 géneros (Aspöck et al., 1980; Brooks \& Barnard, 1990), cifras que han venido incrementándose desde entonces (ver para la fauna del Peleártico occidental H. Aspöck et al., 2001).

Debe indicarse que existen numerosas publicaciones relacionadas con la familia que tratamos, bien sobre fauna de otros continentes o bien locales que escapan a la intención de esta contribución. Para los interesados en conocer información sobre sus subfamilias, tribus, géneros, subgéneros y especies a nivel mundial se recomienda Brooks \& Barnard (1990), quienes revisan y redescriben la inmensa mayoría de los géneros conocidos realizando un estudio cladístico sobre su sistemática y taxonomía, y aportan clave de géneros y subgéneros, y una lista sinonímica de las especies del mundo, y Oswald (2013a) que aporta toda la información sobre cada uno de sus géneros y especies descritas.

Como hemos indicado, la familia está formada por unas 1.200 especies actuales que se consideran válidas, pertenecientes a c. 86 géneros/subgéneros (Brooks \& Barnard, 1990). Hoy día se aceptan las subfamilias Apochrysinae Handlish, 1908, con 6 géneros de distribución Pantropical en las Regiones Afrotropical, Oriental, Australiana, Neotropical y Paleártica oriental, Nothochrysinae Navás, 1910, con 7 géneros de las Regiones Afrotropical, Australiana, Paleártica occidental y Neártica occidental, y Chrysopinae Esben-Petersen, 1918, la más extensa, de distribución cosmopolita, con 56 géneros agrupados en varias tribus: Ankylopterygini (Pantropical) con 5 géneros, Belonopterygini (Cosmopolita) con 14 géneros, Chrysopini (Cosmopolita) con 30 géneros, y Leucochrysini (Neártica, Neotropical) con 7 géneros (Brooks \& Barnard, 1990). Está representada en la fauna del Paleártico Occidental (desde Macaronesia, Norte de África y Europa a Oriente Medio, Cáucaso e Irán) por c. 115 especies (con 6 subespecies), pertenecientes a unos 16 géneros (Brooks, 1984, 1986; Hölzel, 1992; H. Aspöck, 1992, 2002; U. Aspöck et al., 2001, 2015; Winterton \& Brooks, 2002).

La Fauna Ibérico-Balear española posee representantes de todos los géneros de esta familia presentes en la Fauna neuropterológica Europea, y como ocurre en muchos otros órdenes de insectos, es particularmente rica en especies de neurópteros, ya que nada menos que 197 especies están presentes en su fauna: Megaloptera (3 spp.), Raphidioptera (16 spp.) y Planipennia o Neuroptera s.str. (178 spp.), representando en varias familias entre el $100 \%$ a más del $75 \%$ del total de especies europeas conocidas, y en el caso de la familia que tratamos incluye el 68, 49\% de las especies europeas, con 50 especies en la fauna ibérica, de las 73 especies válidas hoy citadas en Europa 
(H. Aspöck et al., 1980, 1991, 2001; H. Aspöck, 1992; Aspöck \& Hölzel, 1996; Monserrat, 2011; Monserrat \& Triviño, 2013; Monserrat et al., 2013, 2014; U. Aspöck et al., 2015), algunas endémicas, y otras únicamente citadas de la Península Ibérica dentro del Continente Europeo. La mayoría de la información corresponde a la zona española, pero también muchas de las especies ibéricas están citadas de Portugal: Carvalho (1997) recoge 25 especies citadas en Portugal continental y Letardi et al. (2013) listan 28 especies en esta parte ibérica de Portugal y alguna otra novedad aportamos en esta contribución (Italochrysa stigmatica, Nothochrysa fulviceps). Obviamente estos porcentajes son relativos, ya que son varias las especies citadas en nuestra fauna que requieren confirmación, otras especies europeas han sido últimamente revalidadas como especies válidas o han sido recientemente descritas (Tillier et al., 2014; Henry et al., 2014) y cabría suponer su presencia en nuestra fauna, y otras están en fase de discusión y/o aceptación generalizada.

La familia Chrysopidae fue definida por Schneider (1851a), que como Chrysopina (corregido por Newman, 1853 a Chrysopidae) la separa con carácter supragenérico del resto de los Hemerobiidae a la que hasta entonces, como otras más, pertenecían sus especies, considerando dos únicos géneros: Chrysopa Leach, 1815 con 53 especies (género descrito por dentro de Hemerobiidae) y Apochrysa Schneider, 1851 (primer género descrito por dentro de Chrysopina) con una única especie. Durante muchos años fueron describiendose multitud de nuevas especies con una taxonomía pobre y confusa (mayoritariamente dentro del género Chrysopa), y posteriores géneros fueron poco a poco describiéndose (hasta alcanzar 75), muchas veces sobre elementos ambiguos e incostistentes, mayoritariamente basados en caracteres de coloración y venación alar (New, 1984a, 2001; Pantaleoni \& Sechi, 2014). La organización taxonómica más objetiva de esta familia empezó con Killington $(1936,1937)$ y más tarde con el inicio en el estudio más intenso de las genitalias por Principi $(1940,1949,1977)$, Kimmins (1952), Adams (1959, 1962, 1967, 1969, 1975, 1977), Acker (1960), Hölzel (1965a, 1965b, 1967, 1970, 1972a, 1972b, 1973a, 1973b, 1974), Tjeder (1966), Kis et al. (1970), Barnard (1978), etc., generalizándose desde entonces su descripción hasta la actualidad. Finalmente Brooks \& Barnard (1990) listan los géneros y especies conocidos y realizan un análisis cladístico de sus géneros, aportando una clave de géneros (imagos) y definiendo sus relaciones filogenéticas. Obviamente, posteriores contribuciones han venido aportándose, comentadas por Brooks (1997) y en especial en las faunas Neártica, Neotropical y Oriental (que escapan a la intención de esta contribución), y nuevos problemas taxonómicos han aparecido recientemente con especies crípticas muy próximas (sibling species) de difícil caracterización morfológica con los métodos tradicionales (Meleoma, Pseudomallada, Chrysoperla, etc.).

Aunque haremos algunas aisladas referencias a ciertas características de taxa no paleárticos, y circunscribiéndonos pues a las especies de nuestras latitudes, esta familia (Figs. 1-12) tiene como caracteres diagnósticos, entre otros, la presencia de cabeza hipognata, fuertemente esclerificada, con vértex prominente, a veces aplanado y con frecuencia (Chrysopa) expandido o elevado respecto al resto de la superficie cefálica, a veces con procesos interantenales con dimorfismo sexual en especies de Meleoma (Adams, 1969; Tauber, 1969; Penny, 2002). Carecen de ocelos y portan dos grandes ojos compuestos (de unas 3.600 omatidias) similares en ambos sexos (Yang et al., 1998b; Zhang et al., 2007), algo menores en Nothochrysinae, ampliamente lateralizados y semiesféricos (ángulo de visión antero-posterior de $180^{\circ}$, dorso-ventral de $200^{\circ}$ ) (Fig. 13), bien negros o con reflejos metálicos dorados o cobrizos, con frecuencia muy brillantes/relucientes (MacLeod \& Sheldon, 1972) que les dan nombre a la familia, también en otros idiomas: Crisopas, Golden-eyes, Goldaugen, Guldøjer, Gullöyne, Guldögon, etc. Hay evidencias de que poseen una excelente visión de amplio espectro, con posibilidad de visión tanto nocturna como diurna, e incluso la posibilidad de distinguir ciertos colores (Ast, 1920; McEwen, 1995; Kral \& Stelzl, 1998; Yang et al., 1998a; Yan et al., 2007). Las antenas son moniliformes, generalmente algo más cortas que las alas anteriores, algo más largas en Brinkcochrysa, (en otros géneros no europeos pueden oscilar entre algo más de la mitad a casi el doble de la longitud de las alas anteriores) y poseen escapo grande, generalmente subcónico o algo aplanado dorsoventralmente y grueso, levemente convexo hacia la línea media interior (Fig. 13), generalmente cónico y a veces relativamente largo (ej.: Nineta vittata, Fig. 138), con cierto dimorfismo sexual (McLachlan, 1883b, 1893b). El pedicelo es subcilíndrico-esférico y normalmente mayor que el primer flagelómero (Fig. 13) y los flagelómeros son cilíndricos, 2-3 veces más largos que anchos, en número variable y portadores de seis (Nothochrysinae) a cuatro (Chrysopinae) anillos de sedas sensoriales, a veces con variaciones sexuales. Aparato bucal masticador con robustas mandíbulas, simétricas en algunos géneros (Nineta, Chrysotropia), asimétricas en otros (Chrysopa, Chrysoperla, etc.) portadoras de un dentículo interno (más desarrollado en la izquierda) (Fig. 15) (Ickert, 1968; Brooks \& Barnard, 1990), y palpo maxilar formado por 5 artejos y labial por 3 (Fig. 14). Las frecuentes manchas sobre las estructuras cefálicas se utilizan en la diferenciación específica en las especies de algunos géneros (Aspöck et al., 1980; Barnard, 1984), y así las utilizaremos en las claves (Figs. 98-120), aunque en ocasiones es bastante variable (McLachlan, 1886a; Principi, 1962; Mantoanelli et al., 2006; Monserrat, 2008), y por 

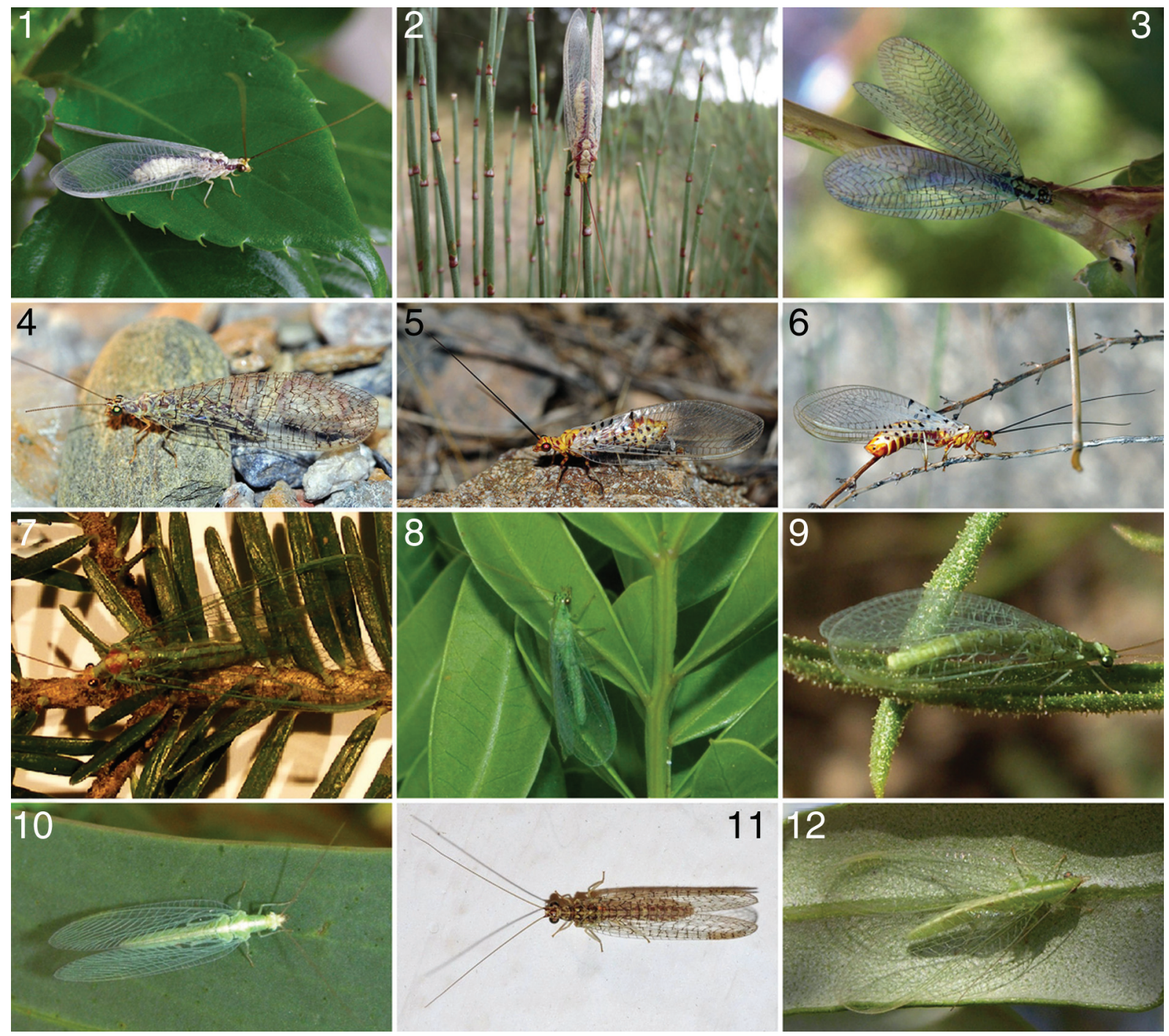

Figs. 1-12.- Especies ibéricas de crisópidos en su ambiente natural. 1: Italochrysa italica, foto de M. González Núñez, 2: Italochrysa italica, foto de C. Escuer, de http://www.flickr.com/photos/38501797@N07/, 3: Chrysopa perla, foto de I. Martínez, 4: Pseudomallada venosus, foto de F. Rodríguez, de http://faluke.blogspot.com.es/search/label/neuroptera, 5, 6: Italochrysa stigmatica, foto de F. Rodríguez, de http://faluke.blogspot.com.es/search/label/neuroptera, 7: Nineta pallida, foto de D. Badano, 8, 9: Chrysopa formosa, foto de P. Guevara, 10: Cunctochrysa albolineata, foto de P. Guevara, 11: Pseudomallada venosus, foto de F. Rodríguez, de http://faluke.blogspot.com.es/search/label/neuroptera, 12: Chrysoperla pallida, foto M. González Núñez.

Figs. 1-12.- Habitus of Iberian green-lacewing species in their habitat. 1: Italochrysa italica, photo by M. González Núñez, 2: Italochrysa italica, photo by C. Escuer, from http://www.flickr.com/photos/38501797@N07/, 3: Chrysopa perla, photo by I. Martínez, 4: Pseudomallada venosus, photo by F. Rodríguez, from http://faluke.blogspot.com.es/search/label/neuroptera, 5, 6: Italochrysa stigmatica, photo by F. Rodríguez, from http://faluke.blogspot.com.es/search/label/neuroptera, 7: Nineta pallida, photo by D. Badano, 8, 9: Chrysopa formosa, photo by P. Guevara, 10: Cunctochrysa albolineata, photo by P. Guevara, 11: Pseudomallada venosus, photo by F. Rodríguez, from http://faluke.blogspot.com.es/search/label/neuroptera, 12: Chrysoperla pallida, photo by M. González Núñez.

ello hay que tomarlas en relación a otros caracteres complementarios.

El tórax es compacto, poco piloso, de similar color que el resto del tegumento, aunque frecuentemente el pronoto posee una coloración diferencial, y es habitual la presencia de una banda media dorsal más pálida, que a veces se prolonga sobre el abdomen (ej.: Nineta, Chrysoperla, Cunctochrysa, Italochrysa) (Figs. 1, 2, 7, 10, 12), porta abundante setación, y su coloración en ocasiones posee cierta importancia taxonómica. Protórax con pronoto transverso, generalmente algo más ancho que largo en Nothochrysinae, y más alargado en Chrysopinae (Figs. 7-12), a veces el pronoto está poco esclerificado en su zona media (ej.: Nothochrysa californica) y/o posee expansiones circulares y setosas laterales. El mesotórax suele estar algo más desarrollado que el metatórax (Figs. 1-12). 


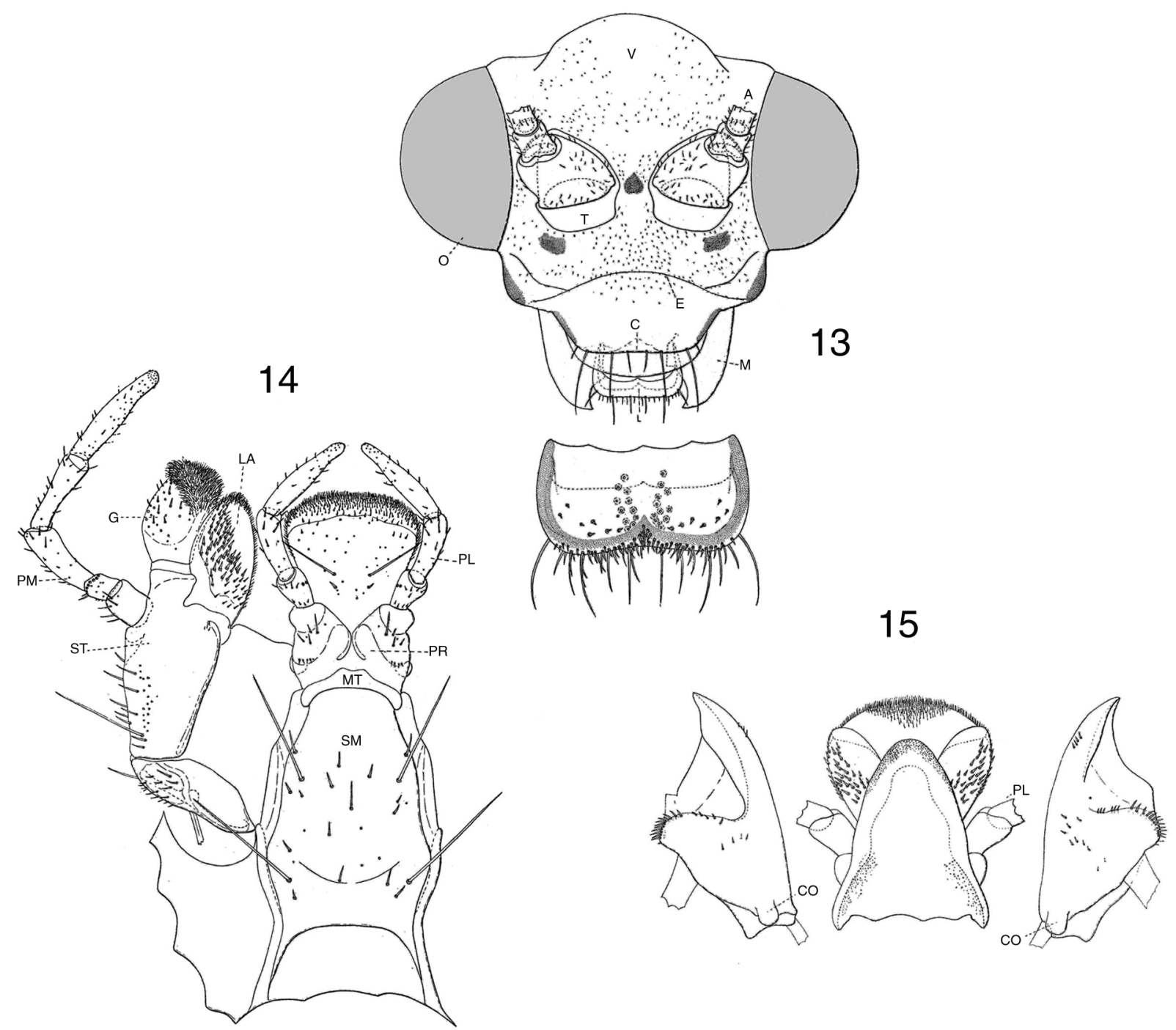

Figs. 13-15.- Cabeza y piezas bucales de Chrysopa pallens, 13: cabeza y labro, 14: maxila y labio (vista ventral), 15: mandibulas y extremo del labio (vista ventral) (A: antena, C: clípeo, CO: cóndilo articular, E: sutura epistomal, G: galea, L: labro, LA: lacinia, M: mandíbula, MT: mentum, O: ojo, PL: palpo labial, PM: palpo maxilar, PR: prementum, SM: submentum, ST: estipe, T: tóruli, V: vértex). De Principi (1940).

Figs. 13-15.- Head and bucal structures of Chrysopa pallens, 13: head and labrum, 14: maxilla and labium (ventral view), 15: mandibles and labium apex (ventral view) (A: antenna, C: clipeus, CO: articular condile, E: epistomal suture, G: galea, L: labrum, LA: lacinia, M: mandible, MT: mentum, O: eye, PL: labial palp, PM: maxillary palp, PR: prementum, SM: submentum, ST: estipe, T: toruli, V: vertex). From Principi (1940).

Las alas están bien desarrolladas, en las alas anteriores su longitud oscila entre los 9 y los $31 \mathrm{~mm}$ (entre 6,5-35 $\mathrm{mm}$ en especies exóticas), son subiguales, ovoides, a veces algo elípticas, arriñonadas o más alargadas y estrechas (Figs. 1-12, 16, 177-198). Aunque las alas posteriores suelen ser algo menores, no hay reducción en las alas posteriores con ejemplares braquípteros, micrópteros o ápteros (ni siquiera en poblaciones isleñas o de alta montaña), ni algo más esclerificadas o coriáceas las anteriores, hecho relativamente habitual en otras familias como Coniopterygidae, Hemerobiidae o Dilaridae. En estado de reposo normalmente adoptan la típica posición "en tejadillo" o tectiformes (Figs. 1-12), aunque algunos géneros (Ankylopteryx) aplican las alas sobre el substrato, quizás como método defensivo para evitar sombras y pasar más inadvertidos (New, 1986a), hecho que se da en alguna de nuestras especies (Chrysoperla ankylopteryformis). Mayoritariamente la membrana alar es transparente, y habitualmente iridiscente, con pterostigma normalmente poco conspicuo. La venación es abundante y compleja (Fig. 16), con notable similitud en Chrysopinae (Figs. 179-198). Venación aparentemente simple (simplificada) en comparación con otras familias de neurópteros (ej.: Myrmeleontidae, Nemopteridae, Ascalaphidae, Osmylidae, Dilaridae, etc.), pero es más compleja y elaborada de lo que aparenta (Fig. 16), y estudios de homologías con la traqueación pupal así 


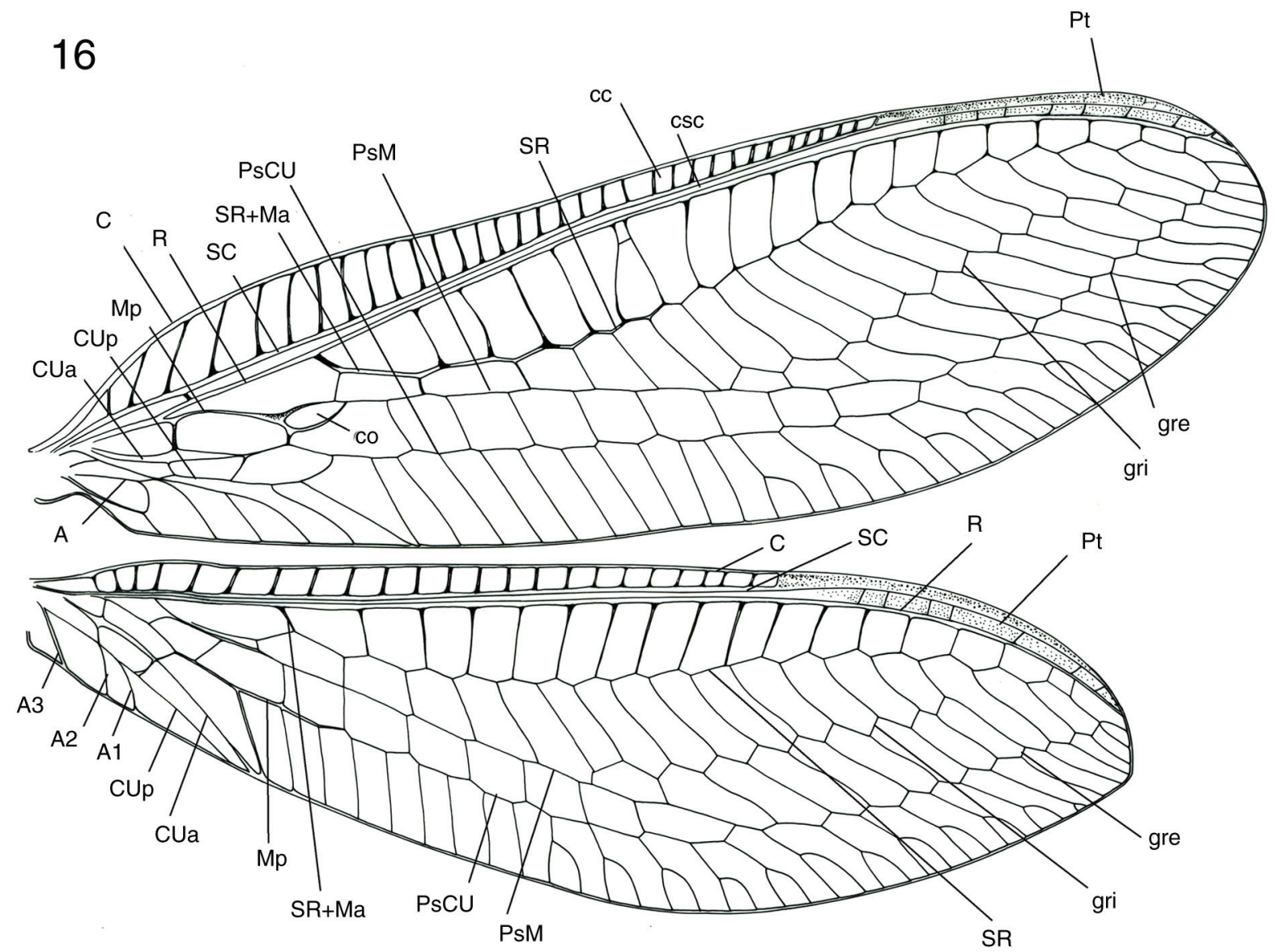

Fig. 16.- Terminología alar de Nineta guadarramensis (A: anal, C: costal, cc: campo costal, co: celdilla oval, csc: campo subcostal, CUa: cubital anterior, CUp: cubital posterior, gre: gradadas externas, gri: gradadas internas, Ma: mediana anterior, Mp: mediana posterior, PsCU: pseudocubital, PsM: pseudomediana, Pt: pterostigma, R: radio, SC: subcostal, SR: sector del radio).

Fig. 16. - Wing terminology of Nineta guadarramensis (A: anal, C: costal, cc: costal field, co: oval cell, csc: subcostal field, CUa: anterior cubital, CUp: posterior cubital, gre: outer gradates, gri: inner gradates, Ma: anterior median, Mp: posterior median, PsCU: pseudocubital, PsM: pseudomediane, Pt: pterostigma, R: radius, SC: subcostal, SR: radial sector).

lo han demostrado (McClendon, 1906; Tillyard, 1916; Comstock, 1918; Barnard, 1984). Porta abundantes venillas transversales paralelas y no bifurcadas y en la región basal del campo costal carecen de venilla humeral recurrente (frecuente en Hemerobiidae). El campo costal a veces es ancho y convexo (en particular en Apochrysinae y otros géneros de Chrysopinae como Ankylopteryx o Chrysoperla) (Figs. 132, 184), ocasionalmente es levemente flexuoso en algunas especies de Nineta (Figs. 136, 189). El campo subcostal es estrecho, con una única venilla transversal en la zona basal y otras tenues bajo el pterostigma. Venas costal y subcostal ocasionalmente fusionadas distalmente (Hypochrysa) (Fig. 178). El sector del radio posee un trayecto en zigzag, corre paralelo a Sc, y finaliza en el margen alar, y posee un número habitualmente elevado de ramas, desde 19-20 (Nothochrysa, Italochrysa, Nineta, Chrysopa) a un menor número (6-7) en otros géneros (Suarius, Brinckochrysa) (Figs. 16, 177-198). La tercera celdilla cubital está subdividida en dos por una venilla (Fig. 16) (celdilla intramediana u oval), siendo éste un carácter de posición taxonómica importante (Figs. 83-85). Venas longitudinales rectas, aparentando continuarse con alguna de las series de venillas gradiformes, bien interna (Figs. 177, 178) o externa (Figs. 16, 179-198), y en nuestras especies estas series de venillas suelen ser dos, en otros taxa pueden ser tres, ej.: en Synthochrysa Needham, 1909, cuatro, ej.: en Anomalochrysa McLachlan, 1883, o sin ellas, ej.: en Turnerochrysa Kimmins, 1935 (Brooks \& Barnard, 1990), regularmente dispuestas y en número variable proporcional al número de ramas del $\mathrm{Sr}$ anteriormente citadas, a veces son tres series e irregularmente dispuestas en Rexa (Fig. 194). Muchas venillas se bifurcan antes de alcanzar el margen alar (Fig. 16). Vena media y cubital bifurcadas cerca de su origen y tres venas anales están presentes. Posee poco desarrollado el lóbulo yugal en la región anal, solo presente en Nothochrysinae (Fig. 14), y por ello en el vuelo las alas no se encuentran acopladas. Alas posteriores con similares elementos con tendencia a la simplificación. El campo costal está menos desarrollado y posee menos venillas, como es menor el número de ramas de su $\mathrm{Sr}$, y sus venillas transversales son mucho menos frecuentes. 
Generalmente portan frénulo, más desarrollado en Apochrysinae y Nothochrysinae (Fig. 177) y menos o nada en Chrysopinae (Fig. 16). Como el tegumento, generalmente la venación suele ser de tono verde, frecuentemente con venillas más oscuras o negras (ocasionalmente en algunas especies de géneros como Italochrysa, Rexa, Suarius, Chrysoperla, Nothochrysa o Pseudomallada la coloración general del cuerpo y/o la venación es más rosácea, amarillenta, parda o rojiza), en especies exóticas son frecuentes bandas, manchas y sombras más oscuras sobre la membrana alar (ej.: Ankylopteryx, Glenochrysa, Leucochrysa, Signochrysa, Semachrysa, Nodochrysa, Loyola, Gonzaga, Kostka, Anapochrysa, Chrysacanthia, etc.), también en alguna de nuestras especies (Italochrysa italica, Pseudomallada alarconi, Suarius tigridis, Suarius walsinghami) (Figs. 180, 192, 196, 197), y sobre ella la setación es normalmente abundante (con microtrichias y macrotrichias sobre la venación (especialmente sobre la zona anal de la vena costal), pero no sobre la membrana, y las alas carecen de tricosoros (pequeños espesamientos sobre la vena costal situados entre los extremos de las bifurcaciones distales de las venas longitudinales), no presentes en las especies actuales (Fig. 16), y sí en algunas especies fósiles (Makarkin \& Archibald, 2013) y carecen de nygmata (pequeños puntos cuticulares oscuros que pueden aparecer en las alas anteriores, posteriores, o en ambas en algunas familias de neurópteros). Pocas veces se ha citado dimorfismo sexual en la venación (Tjeder, 1966), aunque en algunos géneros (Suarius, Pseudomallada) pueden aparecer en los machos espesamientos o setas modificadas en algunas venas (Barnard, 1984). En base a los criterios de Brooks \& Barnard (1990) y Adams (1996), anotamos en la figura 16 la terminología alar utilizada.

Las patas son marchadoras (Figs. 1, 4-12), a veces las anteriores que suelen ser algo más pilosas. Las coxas son libres, los fémures son cilíndricos, y las tibias están comprimidas lateralmente y ensanchadas en su zona media, las patas posteriores son algo más largas, y suelen portar alguna patente espina terminal. Tarsos de 5 segmentos, algo más largo el basal, también portando pequeñas espinas terminales, que utilizan para la locomoción y el aseo, y finalizan en dos uñas tarsales curvas y simples, o fuertemente dilatadas en su base, a veces de forma abrupta (Figs. 19-21, 52, $158,159,173)$, elemento muy utilizado en la diferenciación de taxa, y un característico empodio flexible y adhesivo está presente.

El abdomen está poco esclerificado, porta abundante setación, en ocasiones ésta y su coloración poseen cierta importancia taxonómica. Está formado por diez segmentos claramente separados, con tergos y esternos bien diferenciados y amplias áreas pleurales. Poseen 8 pares de estigmas en los 8 primeros segmentos y de mayor diámetro el más próximo al tórax, y los segmentos distales sexualmente especializados con callo cercal y tricobotrias presentes y estructuras genitales externas e internas bien desarrolladas, especialmente en los $\hat{\jmath} \hat{\partial}$, con elementos característicos que se exponen en cada género (Figs. 22-27, 121-129, 133-135, 140-155, 162-176), y siempre ausencia de ovopositor en las 우우 (Figs. 23, 147, 174). Información sobre anatomía interna en Stitz (1909), Brückner (1935), Principi (1949), Hwang \& Bickley (1961), Philippe (1970, 1972) y Bitsch (1984).

Sobre sus estadios juveniles, y a pesar de su interés en el terreno de la Entomología Aplicada, han despertado menor atención del que se debería, siendo algunos datos antiguos de dudosa asignación específica, dato a tener en cuenta en la relación anotada en cada especie, y solo existen datos precisos para 16 de los más de 75 géneros conocidos (Monserrat et al., 2001; DíazAranda et al., 2001). Aunque hablaremos de ellas en el siguiente apartado sobre la biología de esta familia, adelantemos en este apartado de la introducción que las larvas son depredadoras de huevos y larvas de insectos y de pequeños artrópodos como ácaros, arañas, insectos fitófagos de tegumento blando, etc., y son de tipo campodeiforme (Figs. 36, 37), de vida libre sobre la vegetación (Figs. 63-82), a veces más edáfica o corticícola, o con específicas adaptaciones predando en el interior de hormigueros (Figs. 67, 76). Tras tres estadios, la fase larvaria madura que se dispone a pupar (a veces tras una diapausa), y tras tejer el capullo (Fig. 69), adopta una posición quiescente y curvada en fase de prepupa (Fig. 38) antes de transformarse en pupa. La pupa es activa, dectica y exarada (Fig. 39).

$\mathrm{Su}$ historial paleontológico es rico y extenso (22 géneros y 58 especies nominados), y en su mayoría relativamente "reciente". Aunque ocasionalmente algunas familias han sido asociadas a Chrysopidae (ej.: †Liassochrysidae: †Liassochrysa stigmatica del Jurásico Inferior alemán, con una antigüedad aproximada de 182,7 m.a., hoy transferida a Mantispidae: Wedmann \& Makarkin, 2006), los registros más antiguos relacionados con la familia que nos ocupa corresponden familias próximas que forman el superorden Chrysopoidea (Mesochrysopidae+Ascalochrysidae+ Chrysopidae) y a taxa considerados en ocasiones como familias próximas y enotrasconcategoríade subfamilias de Mesochrysopidae y/o Chrysopidae: $\uparrow$ Allopteridae/ nae, $\uparrow$ Limaiidae/nae y $\uparrow$ Tachinymphidae/nae, y especies como †Protoaristenymphes bascharagensis del Jurásico Inferior con una antigüedad aproximada de 182,7 m.a., †Protoaristenymphes daohugouensis del Jurásico Medio con una antigüedad aproximada de 176-161 m.a., o †Lembochrysa minuscula del Jurásico Superior con una antigüedad aproximada de 160 m.a., y otras especies del Jurásico-Cretácico como †Macronympha elegans, $\uparrow$ Aristenymphes perfectus, †Mesotermes heros, $\uparrow$ Cretachrysa martynovi, $\uparrow$ Mesochrysopa zittelli, $\uparrow$ Mesypochrysa latipennis, $\uparrow$ Mesypochrysa polyclada, $\uparrow$ Mesypochrysa makarkini, $\uparrow$ Mesypochrysa intermedia, $\uparrow$ Mesypochrysa confusa, 
17
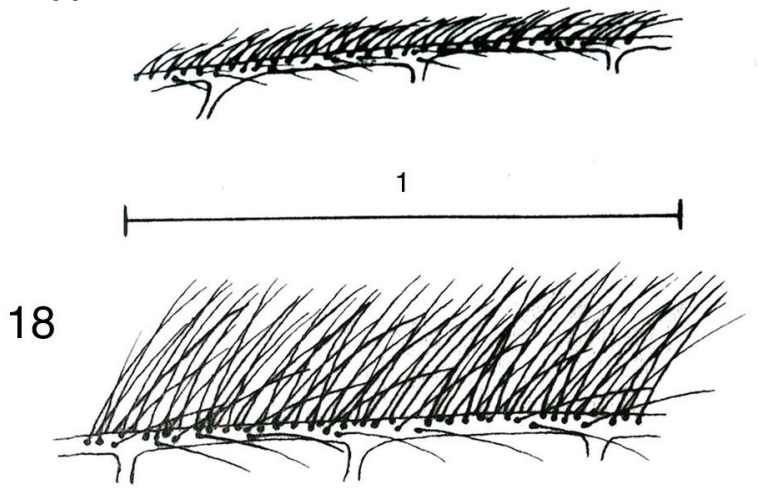

19

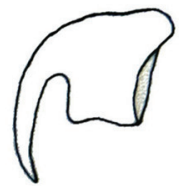

21
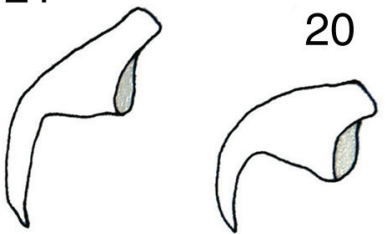

0,2

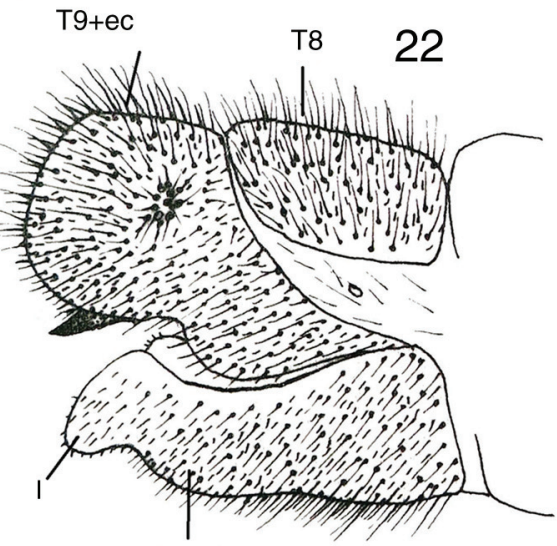

S8+9

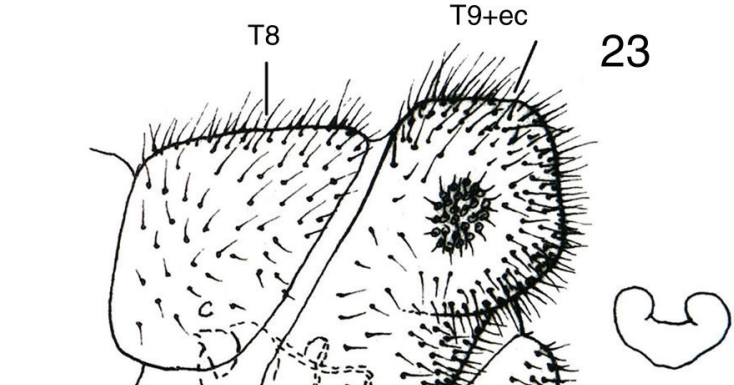

sg
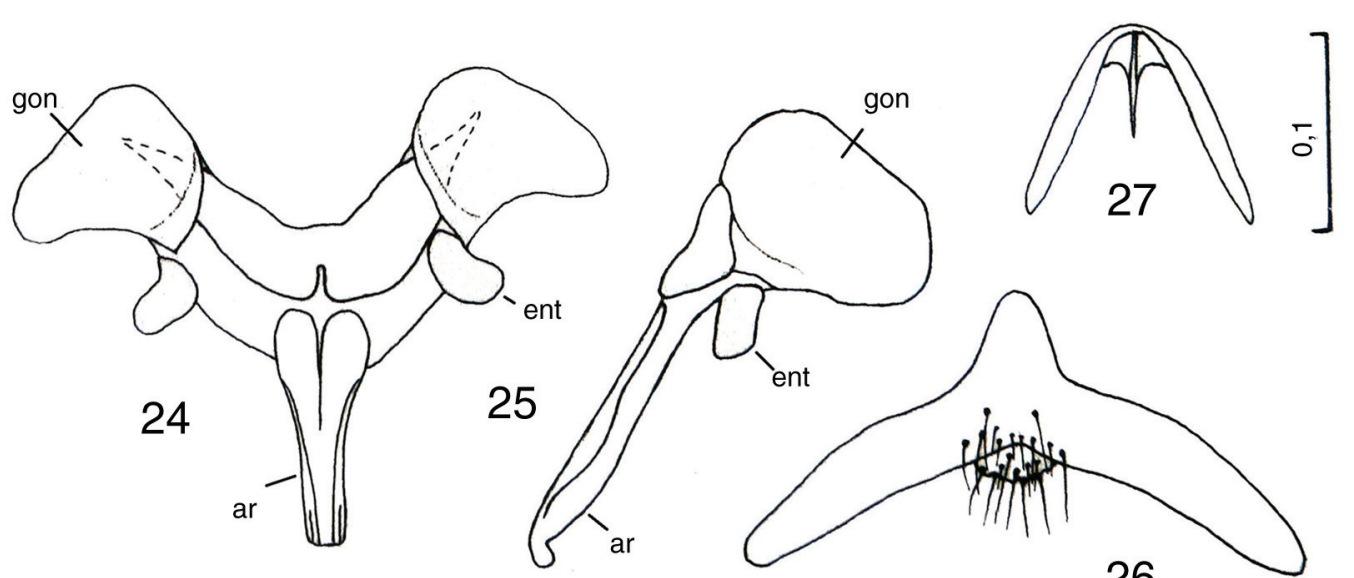

$\mathrm{sp}$

sg

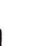

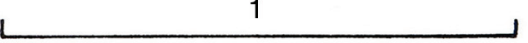


$\uparrow$ Mesypochrysa reducta, $\uparrow$ Mesypochrysa chrysopoides, $\uparrow$ Mesypochrysa angustialata, $\uparrow$ Baisochrysa multinervis, $\uparrow$ Lembochrysa polyneura, $\uparrow$ Mesypochrysa falcata, $\uparrow$ Mesypochrysa magna, $\uparrow$ Caririchrysa criptovenata, $\dagger$ Drakochrysa intermedia, $\uparrow$ Drakochrysa sinica, †Limaia conspicua, †Limaia adicotomica, $\uparrow$ Araripechrysa magnifica, $\uparrow$ Araripechrysa perfecta, $\uparrow$ Hallucinochrysa diogenesi, †Kareninoides lii, $\uparrow$ Longicellochrysa yixiana, †Mesascalaphus yangi, $\uparrow$ Tachinymphes ascalaphoides, $\uparrow$ Tachinymphes delicata, $\uparrow$ Tachinymphes magnifica, $\uparrow$ Allopterus luianus, etc., del Jurásico y del Cretácico alemán, de Kazakstán, Siberia, Mongolia, China, Brasil, Luxemburgo o inglés, y algunos taxa de yacimientos de la Península Ibérica (†Nanochrysopa pumilio, $\uparrow$ Tachinymphes paicheleri, $\uparrow$ Tachinymphes penalveri, $\uparrow$ Kareninoides inexpectus, †Triangulochrysopa sanzi, †Allopterus mayorgai, †Chimerochrysopa incerta), junto a otros taxa de posición incierta o en ocasiones aún considerados como Neuroptera incertae sedis (†Paralembochrysa, $\uparrow$ Chrysoleonites, $\uparrow$ Microsmylus, $\uparrow$ Cratochrysa, $\uparrow$ Nymphoides). Por el contrario, en el Terciario parecen más abundantes, con registros de imagos y larvas (algunas espectaculares) en el ámbar báltico danés y del Eoceno-Oligoceno norteamericano, alemán, suizo, ruso, inglés, danés y francés, así como otros taxa del Plioceno-Oligoceno ( $\uparrow$ Cimbrochrysa moleriensis, †Protochrysa aphrodite, †Protochrysa fuscobasalis, †Danochrysa madseni, †Paleochrysopa monteilsensis, †Okanaganochrysa coltsunae, $\uparrow$ Adamsochrysa aspera, †Adamsochrysa wilsoni, $\uparrow$ Stephenbrooksia multifurcata, $\uparrow$ Pseudochrysopa harveyi, $\uparrow$ Asiachrysa tadushiella, $\uparrow$ Hypochrysodes hercyniensis, $\uparrow$ Palaeochrysa creedei, $\uparrow$ Archaeochrysa creedei, $\uparrow$ Archaeochrysa paranervis, $\uparrow$ Archaeochrysa fracta, $\uparrow$ Archaeochrysa profracta, $\uparrow$ Archaeochrysa sanikwa, †Dyspetochrysa vetuscula, †Tribochrysa firmata, †Tribochrysa inaequalis, †Palaeochrysa concinnula, $\uparrow$ Palaeochrysa wickhami, $\uparrow$ Palaeochrysa stricta, etc.), alguna asignable a †Limaiinae (Jurásico Medio- Cretácico) y en especial a Nothochrysinae (Eoceno-Oligoceno-reciente), y otros registros del Eoceno-Oligoceno-Mioceno (algunos de yacimientos españoles: †Pronothochrysa vivesi del Mioceno) de familias (asignadas a Apochrysinae y Chrysopinae), junto a especies de géneros actuales como Chrysopa, Hypochrysa, Leucochrysa, Nothochrysa, etc. Más información sobre este particular en Hagen (1866a); Brauer (1886); Scudder (1890); Handlirsch (19061908); Cockerell (1908, 1909, 1914); Krüger (1915, 1917, 1923); Henriksen (1922); Martynov (1925, 1927); Carpenter (1935); Statz (1936); Handschin (1937); Carpenter et al. (1938); Barbu (1939); Martynova (1949, 1961); Adams (1967); Larsson (1975, 1978); Schlüter (1975, 1982, 1984, 1986); Wilson (1978); Jarzembowski (1980); Panfilov (1980); Ponomarenko (1985); Nel \& Séméria (1986); Martins-Neto \& Vulcano $(1988,1989)$; Séméria \& Nel (1990); Ansorge \& Schlüter (1990); Makarkin (1991,
1994, 1997, 1998, 2014); Willmann \& Brooks (1991); Zhang (1991); Martins-Neto (1992, 1997); Carpenter (1992); Ponomarenko (1992a, 1992b); Peñalver \& Martínez-Delclòs (1993); Willmann (1993); Nel et al. (1994, 2005); Peñalver et al. (1995); Grimaldi (1996); Ren \& Guo (1996); Weitschat \& Wichard (1998); Grimaldi et al. (2002); Grimaldi \& Engel (2005); Makarkin \& Menon (2005); Engel \& Grimaldi (2007, 2008); Jepson \& Penney (2007); Menon \& Makarkin (2008); Martins-Neto \& Rodrigues (2009); Ren \& Makarkin (2009); Ren et al. (2010); Jepson et al. (2012); Makarkin et al. (2012); Pérez de la Fuente et al. (2012); Yang et al. (2012); Khramov (2013); Makarkin \& Archibald (2013); Archibald \& Makarkin (2015), etc. Para los lectores interesados, una excelente información sobre el registro fósil de esta familia y su bibliografía es aportada por Archibald et al. (2014) y Archibald \& Makarkin (2015).

La familia tiene una distribución cosmopolita, salvo la Antártida (no se conoce de la fauna nativa de Nueva Zelanda) y zonas particularmente elevadas y frías, y es especialmente abundante y frecuente en medios tropicales, subtropicales y templados, evitando en general medios más adversos, aunque son numerosas las especies están adaptadas a medios subdesérticos y xéricos más extremos, así como a ciertas zonas boreales más frías y/o de alta montaña (hasta los $4.000 \mathrm{~m}$ ) que han generado numerosos endemismos y distribuciones relictas y fragmentadas (Carpenter, 1938; Kaisila, 1952; Schedl, 1970; Greve, 1984; New, 1986a, 1989, 2003; Popov, 2002b).

DAtos generales SOBRE SU BIología, COMPORTAMIENTO, ESTADIOS JUVENILES Y CICLOS BIOLÓGICOS

Los crisópidos (Figs. 1-12) son insectos a veces muy abundantes, en ocasiones con poblaciones extremadamente cuantiosas, pero algunas especies son a veces poco frecuentes, están muy localizadas en el espacio y/o en el tiempo, y en ocasiones son "desesperadamente" raras o de muy difícil hallazgo y recolección (varios colegas austriacos y suizos y el propio autor llevamos décadas tratando de recolectar, sin éxito, nuevos ejemplares de Chrysoperla ankylopteryformis o de Chrysopa dubitans, incluso muestreando en las mismas localidades y medios donde han sido halladas/citadas en nuestra fauna). Suelen pasar desapercibidos en la Naturaleza, al tratarse de un grupo de pequeño tamaño, generalmente de actividad nocturna, poco llamativos, y frecuentemente con escasa capacidad de vuelo (New, 1967, 1986a, 1989). En condiciones naturales óptimas, a veces parecen presentar cierta capacidad de agregación, concentrándose numerosos ejemplares en muy pequeño espacio (Canard et al., 2015), aunque normalmente son más escasos y sus poblaciones están más dispersas.

Sobre su biología anotemos que los imagos de nuestras especies son, mayoritariamente, insectos de actividad crepuscular/nocturna, iniciando su actividad de vuelo después del atardecer (cuando la iluminación 
cae a c. 20 lux) (Duelli, 1984a, 1984b; Ábrahám \& Vas, 1999; Ábrahám \& Mészáros, 2006, etc.) hasta poco antes del amanecer, con máxima actividad entre las 22-24 h. Alguna de nuestras especies (ej.: C. perla, C. dorsalis) inician su actividad algo antes del atardecer y no vuelan ya entrada la noche, otras inician su actividad incluso antes: 16-19 h. (ej.: $C$. pallens, C. formosa, P. ventralis, P. flavifrons, N. guadarramensis) y están activas hasta el amanecer, otras parecen de actividad marcadamente nocturna (ej.: Pseudomallada alarconi), y algunas (ej.: C. perla, H. elegans, P. gracilis) se mantienen activas durante el día o poseen actividad de vuelo marcadamente diurna (obviamente estas especies no suelen recolectarse a la luz artificial), y en cualquier caso, y quizás excepción en las especies de Chrysoperla, no permanecen inactivos durante las horas del día (ej.: C. ciliata), curiosamente, algunas especies aumentan su actividad antes de una tormenta (Killington, 1936; Banks, 1952; Lewis \& Taylor, 1964; Monserrat, 1977a; Duelli, 1984a, 1984b, 1986a; Paulian, 1996; Ábrahám \& Vas, 1999; Vas et al., 1999; Szentkirályi, 2001a; Ábrahám et al., 2003; Ábrahám \& Mészáros, 2006; Canard et al., 2015). Con tiempo frío reducen notablemente su actividad. Se mueven mucho por la vegetación, pero vuelan poco y generalmente en cortos trayectos. $\mathrm{Su}$ capacidad de vuelo está relacionada con la temperatura ambiente y con la longitud de sus alas, Duelli \& Johnson (1982) o Duelli (1984a, 1984b) citan algunos ejemplos con frecuencias de batida de entre $24-38 \mathrm{~Hz}$, vuelos ininterrumpidos de hasta $10 \mathrm{~h}$, y medias de 3.7 horas de vuelo/noche, y Lewis \& Taylor (1964) o Duelli (1980a, 1980b) registran velocidades alcanzadas de entre $0,6-0,7 \mathrm{~m} / \mathrm{sg}$. Tanto machos como hembras son atraídos por fuentes de luz artificial (Williams \& Killington, 1935; Killington, 1936, 1937; Lewis \& Taylor, 1964; Andersen \& Greve, 1975; Zelený, 1984a; Honěk \& Kocourek, 1986; New, 1986a, 1989; Günther, 1991; Paulian, 1992b; Greve \& Kobro, 1998; Paulian et al., 2001; Ábrahám et al., 2003; Gruppe \& Müller, 2007; Penny et al., 2007, etc.), y ciertas especies de algunos géneros como Pseudomallada, Suarius o Chrysoperla se han recolectado mayoritariamente con este medio. Como reconocerán muchos de los lectores, también son habituales visitantes de nuestras propias viviendas atraídas por la luz artificial o las radiaciones de TV (Monserrat, 1977a; Plant, 1994; Monserrat et al., 1999; Ábrahám et al., 2003), y quizás por ser relativamente "familiares", en castellano las hemos encontrado en el lenguaje popular citadas con el simpático nombre de "virulis". Con frecuencia han sido citados como transportados por el viento, incluso a largas distancias y/o elevaciones, y algunos estudios han demostrado una sorprendente capacidad de dispersión, con capturas hasta a $200 \mathrm{~m}$ sobre el nivel del suelo, e incluso mar adentro (Dannreuthers, 1934; Greve, 1969; Cheng \& Birch, 1978; Eglin-Dederding, 1982; Sémeria \& Vannier, 1984; Duelli, 1984b; Hardy \& Cheng, 1986; Szentkirályi, 1989, 2001a; Sugg et al.,
1994; Duelli, 1999; Monserrat et al., 1999; Chapman et al., 2004, 2006).

En especies tropicales hay una gran profusión de colores en los adultos (ej.: Belonopterygini, Laucochrysini, Nothochrysinae), con elementos crípticos muy marcados (Eremochrysa, Yomachrysa), pero entre nuestras especies, la coloración verde es la generalizada dentro de esta familia (Figs. 3, 7-10, 11), unas veces más oscura (Pseudomallada alarconi, Chrysoperla mediterranea, Nineta pallida), más pálida (Cunctochrysa), verde manzana (Chrysopa viridana, Nineta guadarramensis), etc., y así se confunden con el tipo de entorno vegetal sobre el que habitualmente se hallan los imagos. En muchos casos es destacable y significativa la similitud entre su críptica coloración general y la vegetación circundante donde habitualmente viven (es remarcable la coincidencia de color y tono entre $N$. guadarramensis y el verde glauco de los quejigos, entre $N$. pallida y el verde oscuro de las coníferas, entre $P$. alarconi y los enebros, entre I. italica y las gramíneas agostadas, etc.) (Figs. 1, 2, 7), y con mucha frecuencia manchas oscuras en la cabeza y las alas (Chrysopa, Pseudomallada, Suarius, Italochrysa) contribuyen como elementos disruptivos de su silueta, evidentemente esto está potenciado por otros elementos como la presencia de diferente coloración de la cabeza respecto al resto del cuerpo (Nothochrysa, Hypochrysa, Kimochrysa) o de distinto color sobre la línea media dorsal del tórax-abdomen (Cunctochrysa, Brinckochrysa, Pseudomallada, Italochrysa, Suarius, Nothochrysa, Chrysoperla, Nineta) (Figs. 1, 2, 7, $10,12)$, contribuyendo también a confundirse con la nerviación del envés de las hojas y/o con las acículas. Algunas especies de los géneros Pseudomallada, Italochrysa, Chrysoperla y/o Suarius, adaptadas a zonas más xéricas, presentan coloración más parda o pajiza, que les sirve de defensa pasiva en las zonas bien de umbría, bien agostadas o bien rocosas o arenosas, cavidades o cortezas donde habitualmente se encuentran los imagos (Figs. 1, 2, 4-6, 11), y a veces poseen coloraciones tegumentarias más llamativas, incluso vivamente coloreadas (Italochrysa, Hypochrysa, Nineta, Nothochrysa, etc.). Elementos similares de todo esto también lo citaremos en la coloración de sus fases larvarias (Figs. 63-68).

Como hemos indicado, en algunas especies (como ocurre también en hemeróbidos: Notiobiella, Annandalia) las alas están capacitadas para aplicarse sobre el sustrato, evitando sombras y haciéndolos menos visibles a los depredadores (C. ankylopteryformis), o poseen coloración verde o parda en función de sus poblaciones ( $P$. clathratus, Chrysoperla) o varían su coloración al entrar en diapausa y fase de hibernación (Chrysoperla) (Duelli, 1992; Thierry et al., 1994), y estos mecanismos de defensa están asociados a particulares comportamientos activos de defensa ante situaciones de peligro, menos extendido en esta familia que en otras familias (Hemerobiidae, Sisyridae, Dilaridae, Coniopterygidae, etc.), al plegar las alas, recoger entre 
ellas cabeza, antenas y patas, dejarse caer al sustrato, y adoptar por un tiempo un comportamiento de tanatosis y así disuadir o mitigar el interés del potencial depredador (New, 1986a). Muchas especies (en nuestra fauna por ejemplo las del género Chrysopa y alguna del género Cunctochrysa) segregan sustancias malolientes (trideceno en un $90 \%$ ), que producen glándulas en el protórax y estas alomonas actúan como mecanismo de defensa ante potenciales depredadores (McDunnough, 1909; Sulc, 1914; Principi, 1954a; Blum et al., 1973; Noirot \& Quennedey, 1974, 1991; Monserrat, 1980b; Güsten \& Dettner, 1991; Güsten, 1996; Monserrat et al., 2014, etc.), y ocasionalmente se ha citado mimetismo batesiano entre especies malolientes-inodoras (Séméria, 1984c).

La biología de estos insectos ha sido motivo de atención, especialmente desde finales del s. XIX (Müller, 1872; Girault, 1907; ver historial en Philippe, 1970 y Aspöck \& Aspöck, 2007), y aunque históricamente se había creído de forma generalizada que en estado adulto los crisópidos eran depredadores generalistas (aphid lions) de pequeños artrópodos fitófagos de movimientos lentos y tegumento blando, especialmente homópteros: áfidos, aleiródidos y cóccidos, también tíngidos, membrácidos, fulgóridos, jásidos, psíllidos, trips, psocópteros, arañas, ácaros, huevos y larvas de otros insectos, y se han hallado en el interior de su tubo digestivo restos de dípteros o escamas de mariposas, hechos que no parecen casuales (Canard, 2001; Nave et al., 2012; Monserrat et al., 2014), no lo son tanto, como ahora anotaremos. Se ha citado canibalismo, y en ocasiones las $O+{ }$ en cautividad, particularmente si son vírgenes, devoran sus propios huevos recién puestos (Canard \& Duelli, 1984; Bar \& Gerling, 1985; New, 1986a; Mochizuki \& Mitsunaga, 2005; Mochizuki et al., 2006).

Esta capacidad depredadora en los imagos se había considerado generalizada, y así ha venido citándose en la bibliografia histórica (Principi \& Canard, 1984; Canard, 2001), pero recientes estudios (ver Brooks \& Barnard, 1990) han venido comprobando que "que no era tan fiero el león como lo pintaban", y en realidad sólo lo eran, entre nuestras especies, las del género Chrysopa (también otros géneros como Atlantochrysa de las islas atlánticas o Anomalochrysa de las islas Hawái), mientras que los en los imagos de los otros géneros se ha demostrado mayoritariamente una dieta más vegetariana con habitual ingesta de néctar, polen, levaduras (probablemente simbióticas), etc., así como esporas y hongos, que han sido hallados en su tubo digestivo, y sus piezas bucales están adaptadas a una u otra dieta (Smith, 1921, 1922a; Cole, 1925, 1933; Killington, 1936; Tjeder, 1966; Philippe, 1970; Hagen \& Tassan, 1970; Neuenschwander \& Michelakis, 1980; Canard, 1981; Grimal, 1984; Principi \& Canard, 1984; Canard \& Labrique, 1989; Duelli, 1989; Pantaleoni, 1990; Canard et al., 1990; Brooks \& Barnard, 1990; Stelzl, 1991, 1992; Carvalho, 1992; Bozsik, 1992a; Monserrat \& Rodrigo, 1992; Villenave et al., 2005,
2006; Nguyen et al., 2006, 2007; Monserrat, 2008; Robinson et al., 2008; Duelli et al., 2010; Nave et al., 2012; Monserrat et al., 2014, etc.). En cualquier caso, sean sus imagos o sus larvas (como veremos más adelante), son excelentes aliados de nuestros intereses en la Agricultura-Silvicultura. Para el lector interesado recomendamos Canard (2001: 118) que aporta una recopilación de diferentes presas mencionadas en la bibliografía, y citemos a Robinson, 1951; Zimmerman, 1957; New, 1975a, 1975b, 1980, 1984b, 1986a, 1988a, 1989, 1999, 2001, 2002; Neuenschwander et al., 1975; Muma et al., 1975; Miszczak \& Niemczyk, 1978; Szabó \& Szentkirályi, 1981; Canard et al., 1984; Principi, 1984; Peng, 1988; Brooks \& Barnard, 1990; Wu, 1992; Welty, 1995; Shakarami, 1997; Dinter, 1998a, 1998b; McEwen \& Senior, 1998; McEwen et al., 1998, 2001; Stelzl \& Devetak, 1999; Duelli, 2001; McEwen et al., 2001; Pantaleoni, 2001; Pantaleoni \& Alma, 2001; Senior \& McEwen, 2001; Szentkirályi, 2001a, 2001b, 2001c; Khan et al., 2004; Miller et al., 2004; Khan \& Fent, 2005; Pappas et al., 2008c, 2011; Monserrat, 2008; Hassanpour et al., 2009; Devetak, 2014, etc., que, entre otros muchos, comentan su interés aplicado de esta familia en diversos cultivos e intereses humanos, y Principi \& Canard (1984) y Pappas et al. (2007) recopilan interesante información sobre su desarrollo en función del tipo y cantidad de presas consumidas. Por todo ello son excelentes elementos contra muchos dañinos insectos, y de hecho, algunas especies exóticas se han introducido (también involuntariamente) en numerosos países para su utilización como agentes de control de determinadas plagas (ejs.: Chrysopa spp. en Hawái o C. pallens en la Isla de Mauricio, Taiwán y Camboya) (Zimmerman, 1957). Obviamente, dada su utilidad aplicada, algunas especies de crisópidos están disponibles en el marcado, como cualquier otro insecto de interés comercial (Tauber et al., 2000), si bien las enormes diferencias en la biología y preferencias de hábitats entre lo que como uniforme se comercializa, puede generar estrepitosos fracasos (Pantaleoni \& Sechi, 2014), al margen del peligro que supone la posibilidad de introducir estas especies como fauna exótica (Mochizuki \& Mitsunaga, 2005; Mochizuki et al., 2006, 2007).

Por todo ello son motivo de multitud de artículos relacionados con la Entomología Aplicada, y aunque citaremos algunos que nos competen, escapan a la intención de esta contribución. Por su valiosa colaboración y aplicación en nuestros intereses agrícolas y forestales, Chrysoperla carnea (Stephens, 1836) fue declarada insecto del año 1999 (Dathe, 1999).

Durante la alimentación de las especies depredadoras, y al margen de asir a su presa con las mandíbulas, suelen ayudarse con las patas anteriores para sujetarla mejor mientras la succionan y devoran, y el aseo de antenas, piezas y palpos bucales y patas anteriores es obligado tras cada ingesta (Nasir, 1947). Sin duda la mayor o menor longitud de sus piezas bucales (Figs. 70-82) está en función del tamaño y la capacidad 
de moción de sus presas (New, 1986a). La localización de sus presas a través de sus secreciones, kairomonas, alomonas y/o feromonas ha sido frecuentemente registrada, y sobre ellas pueden llegar a ser extremadamente voraces (Withycombe, 1925; Principi, 1954b, 1984; Tjeder, 1966; Canard, 1973a, 1973b; Wattebled et al., 1978; Samson \& Blood, 1979, 1980; Canard \& Duelli, 1984; New, 1986a, 1988a, 1989, 2001; Duelli, 1987b; Frazer, 1988; Szentkirályi, 1989, 2001a; McEwen et al., 1993a, 2001; Růžička, 1994, 1997a, 1997b, 1998, 2010; Mendel et al., 1997, 2004; Boo et al., 1998, 1999, 2003; Bakthavatsalam \& Singh, 1999; Nelson et al., 2001; Canard \& Volkovich, 2001; Penny, 2002; Branco et al., 2006a, 2006b; Schwartzberg et al., 2008; Koczor et al., 2010, 2015, etc.).

En ocasiones habían sido observados imagos de varias especies sobre flores o atraídos por ellas (Knuth, 1906-1909; Robertson, 1917; Killington, 1928a, 1936; Lacroix, 1929; Morley, 1931; Ishii, 1964; Bugg, 1987; Duelli et al., 2010; Koczor et al., 2010, etc.) y ahora sabemos por qué, ya que, como hemos indicado, muchas especies parecen ser más omnívoras, pues ingieren polen y néctar o se han hallado levaduras, hifas y esporas de hongos en su tubo digestivo, que complementan su dieta o la sustituyen en ausencia de presas (Tjeder, 1966; Neuenschwander \& Michelakis, 1980; Stelzl, 1991, 1992; Bozsik, 1992a, 1992b, 1994; Monserrat \& Rodrigo, 1992; Villenave et al., 2005, 2006; Monserrat, 2008; Robinson et al., 2008).

Respecto a su preferencia o asociación con las plantas, en ocasiones, algunas especies, incluyendo algunas de las nuestras, parecen ser verdaderamente estenotópicas en relación al tipo de substrato vegetal elegido (Zelený, 1984b; Monserrat \& Marín, 1994, 2001), siendo capaces de detectar sustancias volátiles específicas de ellas que actúan como sinomonas de atracción (Dicke \& Sabelis, 1988; Dodds \& McEwen, 1998; Szentkirályi, 2001a, 2001b) y, consecuentemente, quedan indirectamente asociadas a las potenciales presas que se hallan sobre ellas (ver preferencia de plantas substrato de Nineta guadarramensis, N. pallida, Hypochrysa elegans, Brinckochrysa nachoi, Chrysopa nigricostata, C. dorsalis, Chrysoperla mediterranea, Pseudomallada alarconi, P. genei, Cunctochrysa cosmia, Rexa almerai, etc.) (Zelený, 1984b; Canard \& Labrique, 1989; Monserrat \& Marín, 1994, 2001) hecho que limita su distribución, y consecuentemente muestran una marcada especificidad en sus presas (estenofagia), dato que, entre otros elementos ambientales, les genera indirectamente una marcada especificidad en el tipo de medio y plantas substrato sobre el que los hallamos, sean coníferas, planifolios, vegetación herbácea, etc. Otras especies, por el contrario, son más euritópicas, dentro de una amplia gama de plantas, si bien particulares de determinados ambientes o hábitats (ver preferencia de plantas substrato de Nothochrysa capitata, Pseudomallada flavifrons, $P$. ibericus, $P$. ventralis, Chrysopa viridana, C. perla, C. formosa, Cunctochrysa albolineata, $C$. baetica, etc.), mientras que otras son declaradamente generalistas (Pseudomallada prasinus, Chrysopa pallens) o en otros casos no tenemos ninguna seguridad sobre su preferencia de sustrato (Pseudomallada granadensis, Suarius spp.), habiéndose recolectado mayoritariamente a la luz (Nakahara, 1964; Monserrat, 1977a; New, 1984b; Séméria, 1984b; Zelený, 1984b; Kovrigina, 1985; Bozsik, 1992b, 1994; Monserrat \& Marín, 1994, 2001; Gepp, 1999, etc.).

Se ha demostrado una estratificación de las diferentes especies en función de la altura del dosel arbóreo/ vegetal, incluso en plantas cultivadas (Séméria, 1974; Nielsen, 1977; New, 1984b; Zelený, 1984a, 1984b; Coderre \& Tourneur, 1986; Szentkirályi, 1989, 2001a, 2001b, 2001c; Bozsik, 1992b, 1994; Paulian, 1992a; Hollier \& Belshaw, 1993; Sziráki, 1996; Duelli et al., 2002, etc.).

Sobre su biología reproductora, curiosamente, en la bibliografía general, e incluso en relación a la fauna europea en particular, no existen muchos datos sobre el comportamiento de los individuos durante el cortejo y la cópula (Smith, 1922a, 1922b; Killington, 1936, 1937; Nasir, 1947; Principi, 1949; Toschi, 1965; Ickert, 1968; Henry, 1968, 1979a, 1979b, 1980c, 1984; Philippe, 1970; Eichele, 1972; Wattebled \& Canard, 1981; Henry \& Busher, 1987, etc.), con lagunas en ciertos elementos, como si existen sucesivos cortejos/ cópulas, que han sido observados en especies de algunos géneros (Philippe, 1970; Henry \& Busher, 1987), producción de espermatóforos, que no ha sido nunca observado en algunos géneros (Killington, 1936; Principi, 1949, 1986; Tjeder, 1966; Henry, 1984), etc. Los imagos neonatos requieren de unos días (2-3) para que sus gónadas maduren antes de iniciar su fase reproductora (Killington, 1936; Canard \& Principi, 1984; Carvalho et al., 1996; Canard \& Volkovich, 2001).

La emisión-recepción de sonidos es extremadamente importante en la localización y selección sexual entre individuos, y Adams (1962), Tjeder (1966), Miller \& MacLeod (1966), Riek (1967), Miller (1968, 1970, 1971, 1975, 1983, 1984), Tauber (1969), Eichele \& Villiger (1974), Henry (1979a, 1979b, 1980a, 1980b, 1980c, 1983a, 1994), Miller \& Olesen (1979), Duelli \& Johnson (1982), Bitsch (1984), Brooks (1987), Henry et al. (2011) o Archibald et al. (2014) citan y/o describen estructuras alares con órganos timpánicos sobre un espesamiento en la base de la vena radial (sólo ausente en Nothochrysinae) para recepción acústica de otros ejemplares o predadores (murciélagos). También existen formaciones alares, torácicas (metanoto) y abdominales (esternitos) en esta familia con funciones estridulatorias, que rozan con las alas o con formaciones en los fémures (análogas a lo que encontramos en Acrididae), y también estructuras relacionadas con esta función estridulatoria/auditiva, hechos que parecen generalizados (en ambos sexos), y mediante cantos contribuye a la localización y comunicación de los ejemplares (Adams, 1962; Miller, 1970, 1971, 1975, 1984; Séméria, 1980; Henry, 1984). Se han detectado sensilas campaniformes y órganos subgenuales, 
escolopales y cordotonales ubicados en las tibias y fémures de todas las patas como órganos sensoriales de captación de las citadas vibraciones (rango de frecuencia mínimo de 0,1-0,5 KHz/máximo de 1,5-2,0 KHz) (Pabst \& Devetak, 1992; Devetak, 1992, 1998; Devetak \& Pabst, 1994; Lipovšek et al., 1999; Devetak et al., 2004), por lo que la comunicación acústica debe realizar una importante misión. Resulta curioso, y así se ha citado (New, 1988a; Van Noort, 1995), que el sonido de las cigarras (Homoptera: Cicadidae) atraiga algunas especie de crisopas (Italochrysa). En general los cantos nupciales de las crisopas poseen frecuencias medias muy bajas, entre 20 y $120 \mathrm{~Hz}$.

Los machos con intención reproductora realizan cantos de territorialidad y de reclamo durante días, generalmente al atardecer, pero también durante las horas de luz (Philippe, 1970; Henry, 1979a, 1979b, 1984). Estos cantos son reconocidos y son reproducidos alternadamente por las hembras receptivas como condición previa y necesaria para alcanzar el apareamiento y la cópula (Henry \& Wells, 1990a, 1990b, 2006, 2009, 2010, 2015; Henry et al., 1993, 1999, etc.). Reconocidos los individuos, y en presencia de hembras receptivas, los machos agitan las antenas y extienden parcialmente las alas sobre la horizontal y practican una cierta danza de atracción, y generan vigorosas vibraciones verticales del abdomen practicando un pequeño arco, efectuando así sus cantos de proclamación y cortejo que han sido observados (vibraciones que se trasmiten por el aire o a través de las patas al sustrato), y también han sido registradas emisiones de sonidos mediante vibraciones de las alas y tremulaciones en vuelo asociadas al cortejo (Adams, 1962; Riek, 1967; Eichele \& Villiger, 1974; Henry, 1979a, 1979b, 1980a, 1980b, 1980c; Duelli \& Johnson, 1982; New, 1986a; Henry \& Johnson, 1989; Henry \& Wells, 1990a, 1990b, 2009, 2010, 2015; Pantaleoni \& Sechi, 2014, etc.), y su canto actúa como mecanismo de atracción, y la hembra, de estar receptiva, responde de forma idéntica generando un alternado dueto, por lo que el reconocimiento específico de este canto actúa como barreras reproductivas entre especies próximas (song-species) reproductivamente aisladas por el canto (ver género Chrysoperla). De hecho se ha descubierto multitud de nuevas song-species aisladas genéticamente por el canto (ej.: Chrysoperla, Chrysopiella, etc.).

El macho, estimulado por la reacción de la hembra, inicia un desplazamiento aparentemente errático manteniendo su canto y moviendo vigorosamente las antenas de forma circular hasta que contacta físicamente con la hembra, y en breve, los dos individuos se reconocen e incrementan su canto y su relación (frecuentemente en el envés de las hojas). Cabeza frente a cabeza, el macho retrae las antenas hacia atrás y en la hembra el tocamiento del macho con sus antenas y piezas bucales se acelera (se tocan con los palpos y la trofalaxia parece inevitable), las alas vibran y la hembra le acompaña con estos movimientos. Rotando los cuerpos y ya paralelos, las alas siguen vibrando y rozándose, y con el giro del abdomen masculino hacia el extremo del femenino se establece el contacto entre los extremos abdominales, primero lateralmente con las alas elevadas y posteriormente con abdómenes opuestos (Nasir, 1947; Principi, 1949; Henry, 1968, 1979a, 1979b, 1980b, 1982, 1983a, 1983b, 1984, 1985, 1989, 1991, 1993; Henry \& Busher, 1987, etc.), y si la hembra está dispuesta, las piezas genitales del macho culminan la cópula, manteniendo la hembra las alas plegadas. La cópula se mantiene unos 5-7, 7-8, $8-10,19-65$ minutos, generalmente bajo superficies horizontales, y a veces sobre superficies verticales en las que la hembra puede quedar suspendida en el aire, o en ocasiones el macho es arrastrado por ella durante la cópula (Henry, 1979a; Pantaleoni \& Sechi, 2014), y el aseo posterior, especialmente en el macho, es común.

Aunque es un tema muy debatido, en algunos géneros se ha detectado un pequeño espermatóforo globoso y/o bicameral de color blanco (Chrysopa) o transparente (Hypochrysa), algo mayor en otros géneros (Meleoma, Nothochrysa, Rexa), que la hembra devora poco después de la cópula, cuando su contenido ya ha alcanzado las vías genitales femeninas, aunque hay datos contradictorios o nunca observados en otros géneros (Killington, 1936, 1937; Principi, 1949, 1956b, 1986; Toschi, 1965; Tauber, 1969; Philippe, 1970, 1972; Henry, 1984; Canard \& Volkovich, 2001; Monserrat, 2008; Pantaleoni \& Sechi, 2014), pero el acto de curvar el abdomen, sujetarlo con las patas y acercar la boca al orificio genital ha sido observado en otros géneros, con lo que se deduce la existencia algo más generalizada de espermatóforo. Ocasionalmente se ha observado más de una cópula a lo largo de la vida, más en los machos que en las hembras (Smith, 1922a; Principi, 1949; Tjeder, 1966; Henry, 1984; Henry \& Busher, 1987, etc.).

Aparte de las citadas barreras reproductivas derivadas del canto, recientemente también se ha detectado la presencia de numerosos grupos de especies reproductivamente aisladas por específicas feromonas (ver género Pseudomallada), y por ello, también la secreción de feromonas a través de glándulas protorácicas o de membranas eversibles en la genitalia masculina (Principi, 1949; Wattebled et al., 1978; Wattebled \& Canard, 1981; Mouloud et al., 2002) (Figs. 121, 122, 165, 166) contribuye a la atracción y reconocimiento entre individuos de la misma especie (Chrysopa, Chrysoperla, Pseudomallada, Brinckochrysa, Meleoma), al margen de la emisión de sustancias malolientes, que sin duda poseen función defensiva (ej.: Chrysopa, Cunctochrysa, Glenochrysa), segregadas por glándulas en el protórax (McDunnough, 1909; Sulc, 1914; Duelli, 2004; Winterton \& Garzón-Orduña, 2015). También la presencia de glándulas tegumentarias exocrinas, bien en el protórax o el abdomen, al margen de las citadas estructuras evaginables en la genitalia masculina (Killington, 1936; Principi, 1949; Brooks \& Barnard, 1990) están 
sin duda vinculadas con la emisión de sustancias relacionadas con la reproducción y/o la percepción-emisión de feromonas (Wattebled et al., 1978; Wattebled \& Canard, 1981; Szentkirályi, 2001a; Zhang et al., 2006a) que sin duda intervienen en este proceso de reconocimiento y reproducción.

Con mucha frecuencia se recolectan imagos mediante atrayentes químicos, y muchas especies de diferentes géneros (Suarius, Rexa, Brinckochrysa, Chrysoperla, etc.) han sido recolectadas con trampas McPhail utilizando como atrayentes cariofileno, L-triptófano, fenilacetaldehído, iridodial o fosfato amónico+bórax, etc. (Hagen et al., 1976; Canard \& Laudého, 1977, 1980; Canard et al., 1979; Flint et al., 1979; Canard, 1981; McEwen et al., 1993a, 1994; Bakthavatsalam \& Singh, 1996; Ahn et al., 2001; Tóth et al., 2006, 2009; Zhang et al., 2006b; Monserrat, 2008, etc.) (ver Suarius walsinghami).

Sobre otros elementos de su biología, citemos que la longevidad de los imagos está condicionada por factores ambientales naturales (fotoperiodo, humedad relativa, temperatura, alimento, etc.) y/o por supuesto elementos fitosanitarios utilizados (Philippe, 1970; Kuznetsova, 1970; Principi et al., 1975; Henry \& Busher, 1987; Monserrat \& Rodrigo, 1992; Carvalho, 1992; Orlova, 1998; Corrales \& Campos, 2004; Pappas et al., 2008a, 2008b, 2011; Pappas \& Koveos, 2011, etc.), y si las condiciones son favorables es proporcionalmente elevada para insectos de este tamaño, pudiendo alcanzar hasta nueve meses de vida, sobre todo en especies que hibernan en estado adulto (Chrysoperla) o poseen diapausa estival (Meleoma, Nineta, Suarius). Por citar algunos ejemplos, Carvalho et al. (1996) citan entre 72-141 días de vida para machos y 83-153 días para las hembras en especies de Chrysoperla, Canard \& Labrique (1989) mencionan 54 días para Rexa almerai, y Canard \& Volkovich (2001) aportan datos de longevidad de diferentes especies y autores. No parece existir apreciables diferencias significativas entre los

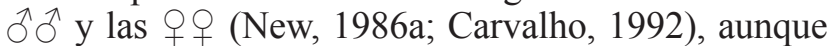
Killington (1936), Tauber (1969) o Philippe (1970) citan a las +9 más longevas y, consecuentemente, más abundantes en las capturas, siendo el caso más extremo el que cita Monserrat (2008) para lo que ahora conocemos como Rexa almerai (sex ratio $\hat{\partial} \hat{\partial} / 0$ 우: 1: 56). Las hembras de Nineta pueden llegar a ser muy longevas, entre 3 semanas a 3 meses (hasta 100 días y más de 200 días en condiciones experimentales) (Canard, 1986a).

Tras la cópula, en las hembras suele existir un periodo de pre-ovoposición de 5-8 días, aunque la puesta de huevos comienza, en condiciones experimentales, desde pocas horas a varios días después de la cópula, pudiéndose prolongar durante unos pocos días a semanas, incluso meses. Los sustratos elegidos, a veces muy selectivos, suelen ser el haz, el envés, extremo o márgenes de las hojas, y en especies habitantes de aciculifolios en el extremo de las acículas y hojas, y así lo hemos observado en especies de Pseudomallada habitantes de enebros, de Cunctochrysa y Nineta sobre coníferas o de Suarius sobre tamariscos (Duelli, 1986c también cita este hecho en otros géneros neárticos como Eremochrysa o Chrysopiella), o bien sobre cortezas (Italochrysa), a veces próximos a las colonias de futuras potenciales presas, aunque otros sustratos más diversos han sido citados (paredes, tapias, cortinas, objetos próximos a una fuente de luz) (Killington, 1936). Ha sido demostrada en algunas especies (Chrysopa, Chrysoperla) la secreción de sustancias disuasivas durante la puesta y también por las larvas para disuadir a posibles depredadores y/o evitar nuevas puestas y una potencial competencia en los recursos (Růžička, 1994, 1996, 1997a, 1997b, 1998, 2010; Eisner et al., 1996, 2000; Růžička \& Havelka, 1998). En contrapartida, también se ha observado en ciertas potenciales presas que procuran no efectuar sus puestas donde existen puestas de crisopas (Legaspi et al., 1996).

Generalmente, y salvo el género hawaiano Anomalochrysa (Fig. 30) que no los produce (Zimmerman, 1957; Duelli, 1984c; New, 1986a), durante la puesta, los huevos quedan adheridos al sustrato sobre un pedúnculo característico ( similar en otras familias como Mantispidae, Berothidae o Nymphidae) (Figs. 32-35, 61,62 ), merced a secreciones de las glándulas de cemento, que son segregadas simultáneamente durante la propia puesta. Para ello la hembra deposita sobre el sustrato una cierta cantidad de fluido viscoso, rico en aminoácidos (Lucas et al., 1957), que servirá de base para la sujeción del futuro pedúnculo, levanta despacio el abdomen, unos $60^{\circ}$, manteniendo la secreción, que en contacto con el aire empieza a endurecerse (Zimmerman, 1957), y deposita el huevo con una leve vibración, quedando el huevo fijado sobre su polo no micropilar, nunca el micropilar, que es el último en salir de las vías genitales femeninas (Duelli, 1984c) (Figs. 28, 29, 32-35, 61, 62). Esta característica forma de depositar los huevos en pedúnculos está registrada en ámbar canadiense desde el Cretácico (Engel \& Grimaldi, 2008).

Los huevos son generalmente fusiformes y/o elípticos, algo más del doble de largos que de diámetro, de extremos redondeados (Figs. 28, 31-35, 61, 62), más apuntados en Italochrysa (Fig. 29) (Principi, 1946; Monserrat et al., 2014). En general, la longitud del huevo y del pedúnculo varía en función de la especie y del tamaño de la hembra, y el pedúnculo posee longitudes variables según los géneros, e incluso entre especies del mismo género (ej.: Nineta), oscilando en los géneros europeos entre $0.70-2.73 \mathrm{~mm}$ para el huevo, y de 2,0-4,5 $\mathrm{mm}$ a 7,0-15,0 $\mathrm{mm}$ para el pedúnculo (Principi, 1946; Neumark, 1952; Ickert, 1968; Gepp, 1984b; Canard et al., 1998). Monserrat \& Díaz-Aranda (2012) aportan dimensiones de huevos y pedúnculos en nuestras especies: huevo 0,8-0,9 $\mathrm{mm}$ a 2,0-2,5 $\mathrm{mm}$; pedúnculo $3,0-3,5 \mathrm{~mm}$ a 10,0-15,0 mm, desde las especies más pequeñas de Suarius o Cunctochrysa a las más grandes de Italochrysa o Nothochrysa. 

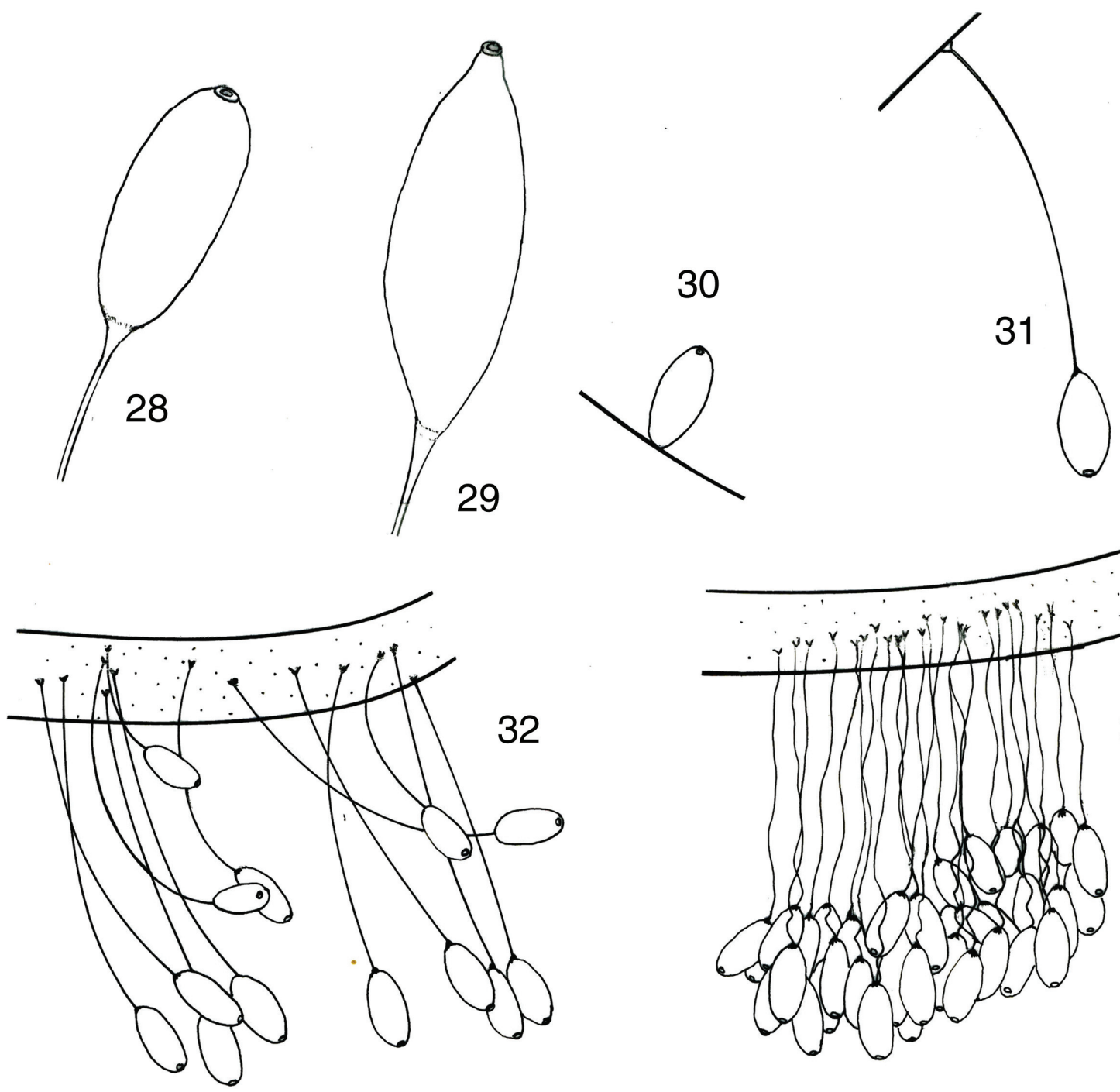

30

31
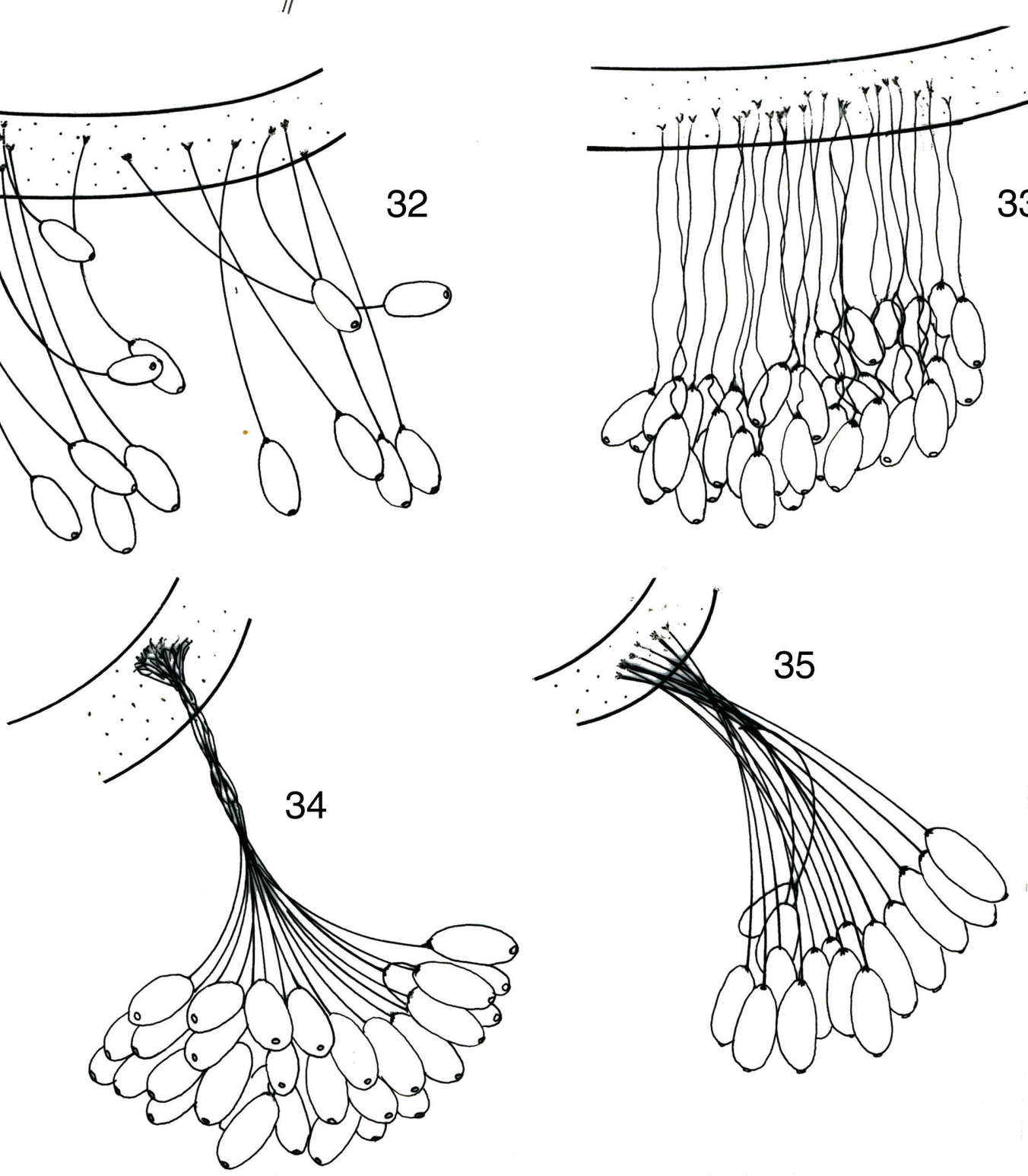

Figs. 28-35.- Tipos de huevos en Chrysopidae: 28: huevo elipsoide típico, 29: huevo del género Italochrysa, 30: huevo sin pedúnculo del género Anomalochrysa, 31: puesta aislada, 32, 33: puestas en grupos, 34, 35: puestas en racimos. De Monserrat \& Díaz-Aranda (2012).

Figs. 28-35.- Egg types in Chrysopidae: 28: tipical ellipsoid egg, 29: fusiform egg of Italochrysa, 30: unstalked egg of Anomalochrysa, 31: isolated egg, 32, 33: oviposition in groups, 34, 35: oviposition in clusters. From Monserrat \& Díaz-Aranda (2012). 
Pueden ser de color crema o amarillo pálido, a veces rosados, pero generalmente son verdosos o blancos muy pálidos (Figs. 61, 62), color que va cambiando conforme el desarrollo embrionario progresa, apareciendo por transparencia las bandas metaméricas pardas y los estemas más oscuros (Pariser, 1919; Bock, 1939; Gepp, 1984b), y el progresivo oscurecimiento del huevo los hace menos conspicuos. En algunos géneros (Nineta) resisten bien el frío o hibernan en esta fase (Vannier \& Canard, 1989; Canard \& Vannier, 1992). Poseen micropilo aparente (Figs. 28-35), a veces blanco muy llamativo, y poseen frecuentes esculturas sobre el corion y dispersos aeropilos (Smith, 1921, 1922a; Withycombe, 1925; Killington, 1936; Mazzini, 1976; Duelli, 1984c; Gepp, 1984a, 1984b, 1990, 1999; Monserrat, 1984c, 2008; Grimal, 1986), que a veces le dan al huevo, incluso a simple vista, un aspecto aterciopelado.

Este curioso proceso de ovoposición se repite con breves pausas, tantas veces como huevos han madurado, y los huevos se depositan uno a uno, bien aislados (Peyerimhoffina, Suarius, Rexa, Chrysoperla, Cunctochrysa) (Figs. 31, 62), a veces, quizás accidentalmente, uno sobre el pedúnculo de otro (Suarius), alineados o próximos (Nothochrysa, Chrysopa) (Figs. 32, 33) o en pequeños grupos o racimos (clusters) de entre 5-40 huevos, bien con pedúnculos aislados e independientes (Pseudomallada, Nineta) (Fig. 35) o trenzados-enlazados (Pseudomallada, Nineta) (Figs. 34, 61), aunque puede haber cierta variabilidad entre especies del mismo género (Nineta, Pseudomallada) (Canard et al., 1998). En especies de algunos géneros (Pseudomallada) la extrema flacidez del pedúnculo (Fig. 33) sugiere puestas colgantes depositadas en el envés de las hojas (Killington, 1936; Principi, 1947, 1956a, 1956b; Canard, 1984; Gepp, 1984b; DíazAranda \& Monserrat, 1988d, 1990b; Duelli \& Johnson, 1992; Monserrat \& Díaz-Aranda, 2012). Parker \& Rudall (1957) y Lucas et al. (1957) aportan interesantes datos sobre la estructura y composición química de estos pedúnculos.

Habitualmente se ha sugerido la presencia de este tipo de puestas sobre pedúnculos como mecanismos de defensa ante el canibalismo, el parasitismo y/o la predación (Smith, 1922a; Chen \& Young, 1941; Canard, 1970b; Duelli, 1984c, 1986c; Gepp, 1989; Duelli \& Johnson, 1992; Růžička, 1997c), aunque a pesar de este obvio mecanismo evolutivo antipredador, otros autores indicaban que podría favorecer la respiración del embrión (Pariser, 1919) o servir como defensa de la humedad o de las secreciones de los áfidos (Stitz, 1927). A pesar de la existencia de este original mecanismo, sus puestas no dejan de tener predadores, sean larvas de coccinélidos, de sírfidos, hormigas, incluso imagos y larvas de otras especies de crisopas (Canard, 1970b, 1984; Canard \& Duelli, 1984; Duelli \& Johnson, 1992; Morris et al., 1998).

Generalmente la puesta se efectúa a lo largo de varios días (entre 6-41 días cita Philippe, 1970 en C. perla), habitualmente en dos fases separadas por un periodo de descanso. En condiciones experimentales se han citado en diferentes especies periodos de 32-64 días en los que las hembras depositan huevos fértiles, habiéndose citado puestas de 1-6, 12-28, 15, 20-40, 48 huevos/día-noche (cada ovario posee 12 ovariolas, y cada una puede producir dos óvulos al día, Duelli, 1984c), y puestas de $6-8,9,15-58,25,86,93,132,158,160$, $321,336,340,376,480,485,512,520,530,550,617$, $638,653,683,700-1000,725,733,744,761,769,780$, $905,924,926,958,991,1159,1207,1286,1461,1767$, 2160 y 2304 huevos por hembra, incluso cifras mayores han sido citadas (Okamoto, 1919; Smith, 1921, 1922a, 1922b; Withycombe, 1925; Killington, 1936; Tauber, 1969; Philippe, 1970; Hagen \& Tassan, 1970; Canard, 1975; Lee \& Shih, 1982; Duelli, 1984c; Henry \& Busher, 1987; Díaz-Aranda \& Monserrat, 1988d; Carvalho, 1992; Carvalho et al., 1996; Albuquerque et al, 1997; Canard \& Volkovich, 2001; Monserrat et al., 2014, etc.), y lógicamente la fertilidad no solo depende de las condiciones ambientales y la densidad de las poblaciones, sino de su anterior desarrollo larvario, su alimentación y del propio tamaño de las hembras (Canard, 1970a, 1970b, 1973a, 1973b, 1975; Philippe, 1970; Rousset, 1984; Duelli, 1984c, 1987b; Carvalho, 1992; Zheng et al., 1993a, 1993b; McEwen \& Kidd, 1995; Carvalho et al., 1996, 1998, 2002; Yadav \& Pathak, 2010). Canard \& Volkovich (2001) aportan datos de fertilidad de diferentes especies, según condiciones y autores. En algunos géneros (ej.: Chrysopa) se ha observado oofagia (Killington, 1936; Ickert, 1968; Philippe, 1970; Canard, 1970c; New, 1986a; Růžička, 1997c).

Lógicamente también el tiempo de desarrollo del huevo varía en función de las condiciones externas, en especial de la temperatura, oscilando en las especies europeas entre 3 y 12 días (Smith, 1921, 1922a; Killington, 1936, 1937; Principi, 1943; Canard \& Labrique, 1989; Pappas et al., 2008a; Carvalho, 1992; Monserrat et al., 2014). Destacamos Canard \& Principi (1984) y Canard \& Volkovich (2001) que aportan una relación de tiempos en el desarrollo de diferentes especies anotados por diferentes autores en diferentes condiciones, y Monserrat \& Díaz-Aranda (2012) anotan los tiempos de desarrollo embrionario para muchas de nuestras especies $(4-5,4-9,5-6,6$, 6-7, 7-8, 9-10 días, según especies).

La ruptura del huevo se practica mediante una incisión ventral y sobre $1 / 3$ del eje longitudinal, y se realiza merced al concurso de un ovirruptor embrional aserrado, al que a veces se le ha asignado interés taxonómico (Hagen, 1859b; Smith, 1921, 1922a, 1922b; Lacroix, 1923; Withycombe, 1925; Killington, 1936; Principi, 1940; Nasir, 1947; Toschi, 1965; New, 1975b, 1986a, 1989; Monserrat, 1984c, 1989; Gepp, 1984b; Canard \& Principi, 1984; New, 1986b; DíazAranda \& Monserrat, 1988d, 1990a, 1990b, 1992, 1994, 1996; Narasimham, 1992; Canard \& Volkovich, 2001; Monserrat \& Díaz-Aranda, 2012) y que queda 
adherido al tegumento (clípeo-labro) embrionario y a la porción cefálica del corion abandonados. Movimientos peristálticos del neonato contribuyen a su emergencia, siendo el extremo abdominal lo último en zafarse. El proceso del nacimiento es detalladamente descrito por Pariser (1919), Killington (1936), Frankenberg (1938), Principi (1940) o Nasir (1947).

Las larvas neonatas permanecen entre unas horas (3-12) a 1-2 días sobre/junto al huevo antes de descender por el pedúnculo e iniciar su actividad y dispersión (Killington, 1936, 1937; Frankenberg, 1938; Principi, 1943; Gepp, 1984b; Monserrat, 1984c; DíazAranda \& Monserrat, 1988d, 1991, 1996; El Arnaouty \& Ferran, 1992; Duelli \& Johnson, 1992; Canard \& Volkovich, 2001; Monserrat \& Díaz-Aranda, 2012), en caso de huevos en clusters, la eclosión no suele ser simultánea, y aquellas larvas que se cubren con elementos externos (ver más adelante), su primer comportamiento es buscar y colocarse estos elementos (a veces su propio corion-pedúnculo) (Figs. 65, 67). Principi (1956a) y Monserrat \& Díaz-Aranda (2012) describen este comportamiento en neonatas de Pseudomallada e Italochrysa.

Las larvas son de tipo campodeiforme (Figs. 36, 37, 63-68), similares a las de otras especies de neurópteros (Rousset, 1966; Peterson, 1967), especialmente a las de Hemerobiidae, y son muy activas (Bänsch, 1964), especialmente en el primer estadio, y son depredadoras de pequeños fitófagos relativamente sedentarios, especialmente áfidos, aleiródidos y cóccidos, aunque otros muchos grupos han sido citados entre sus presas (adélgidos, taumastocóridos, filoxéridos, etc.) (Figs. 63, 64), siendo, especialmente en estos estadios larvario, excelentes aliados contra estos fitófagos (New, 1988b; McEwen et al., 2001; Miller et al., 2004), y a veces son muy selectivas, elemento que contribuye a la citada especificidad de sustrato sobre los que a veces hallamos los imagos de algunas especies. A veces son predadoras de huevos de otras especies de crisopas o de otros insectos (Canard, 1970b, 1984; Carvalho et al., 1998), y complementan su dieta con levaduras, polen y néctar (Hagen \& Tassan, 1970; Patt et al., 2003), y en más de una ocasión (y no es broma) el autor ha observado alguna "osada larva antropófaga" introduciéndome sus mandíbulas por algún pliegue de mi piel con la "maliciosa" intención de obtener de mí algún fluido como alimento.

Ocasionalmente, y entre nuestras especies, algunas larvas son corticícolas (Brinckochrysa) predando sobre fitófagos en este medio (Díaz-Aranda \& Monserrat, 1992), y otras especies de la tribu Belonopterygini (Italochrysa, Nacarina, Nadiva, Calochrysa) poseen curiosas especializaciones y predan exclusivamente en el interior de hormigueros (Crematogaster, Camponotus), bien sobre sus larvas o sus pupas (Weber, 1942; Principi, 1943, 1946; New, 1983, 1986b) (Figs. 67, 76).

Se desplazan activamente ayudándose (haciendo palanca) con el extremo del abdomen y mueven lateralmente la cabeza a uno y otro lado buscando ávidamente sus presas. Sus primeros días de actividad son críticos y cruciales para su supervivencia (Canard, 1970b), existiendo una elevada mortalidad. Localizan a sus presas por contacto (Fleschner, 1950; Bänsch, 1964; Arzet, 1973; Canard \& Duelli, 1984; Canard, 2001), y sin duda existe un reconocimiento químico, pues pueden localizar a sus presas en total oscuridad (Canard \& Duelli, 1984). Ha sido demostrada en algunas especies (Chrysopa, Chrysoperla) la secreción de sustancias disuasivas por las larvas para evitar nuevas puestas y potencial competencia en los recursos (Růžička, 1994, 1996, 1997a, 1997b, 1998, 2010), así como secreción por el ano de sustancias defensivas que repelen el ataque de depredadores (Kennett, 1948; Szentkirályi, 2001a; Monserrat \& Díaz-Aranda, 2012).

Atacan a sus presas sin aparentemente elegir una posición determinada (Figs. 63, 64), con frecuencia la levantan del sustrato una vez asidas, mediante un característico movimiento, arqueando hacia arriba de la cabeza y el tórax, y mientras la succionan dirigen los palpos hacia adelante y abajo y arquean las antenas hacia los lados y hacia atrás (Killington, 1936; Canard \& Duelli, 1984; Monserrat, 1984c, 1989; Monserrat \& Díaz-Aranda, 2012). Las secreciones salivares inyectadas a la presa las paralizan y predigieren sus órganos internos (Alrouechdi, 1981; Canard, 2001). Hemos observado con frecuencia que muchas larvas "rebañan" pacientemente los intersticios de su cada vez más arrugados restos de su presa, introduciendo sus mandíbulasmaxilas en los intersticios de su tegumento donde pueda seguir quedando alimento y succionando con delicadeza todo tipo de líquido que quede en cualquier resquicio (Díaz-Aranda \& Monserrat, 1988d). A veces se ha observado canibalismo, bien sobre otras larvas o sobre huevos, en ocasiones generalizado (Lacroix, 1922; Smith, 1922a; New, 1975b; Duelli, 1981a; Canard \& Duelli, 1984; Růžička, 1997c), y Monserrat \& Díaz-Aranda (2012) anotan que en las larvas sometidas a falta de alimento se observó un elevado porcentaje de canibalismo en todas las especies ibéricas. Nosotros hemos observado posteriormente canibalismo generalizado en larvas neonatas de Chrysopa y Nineta con puestas en racimos, y en larvas neonatas de Pseudomallada o Suarius únicamente hemos observado canibalismo en las larvas neonatas sometidas a falta de alimento, e inmediatamente después de su eclosión. También hemos observado que el nivel de canibalismo en larvas con capa de camuflaje ha sido considerablemente inferior a lo observado en las larvas desnudas, y en las larvas neonatas de $C$. formosa y C. pallens hemos observado, además, oofagia, y las larvas recién nacidas de estas especies, inmediatamente después de abandonar el huevo, emprenden una ávida búsqueda de presas, y si encuentran otro huevo próximo, ascienden por su pedúnculo y lo devoran. Destacamos el hecho de que sean precisamente estas dos especies las únicas especies ibéricas de este género que depositan los huevos en grupo. 


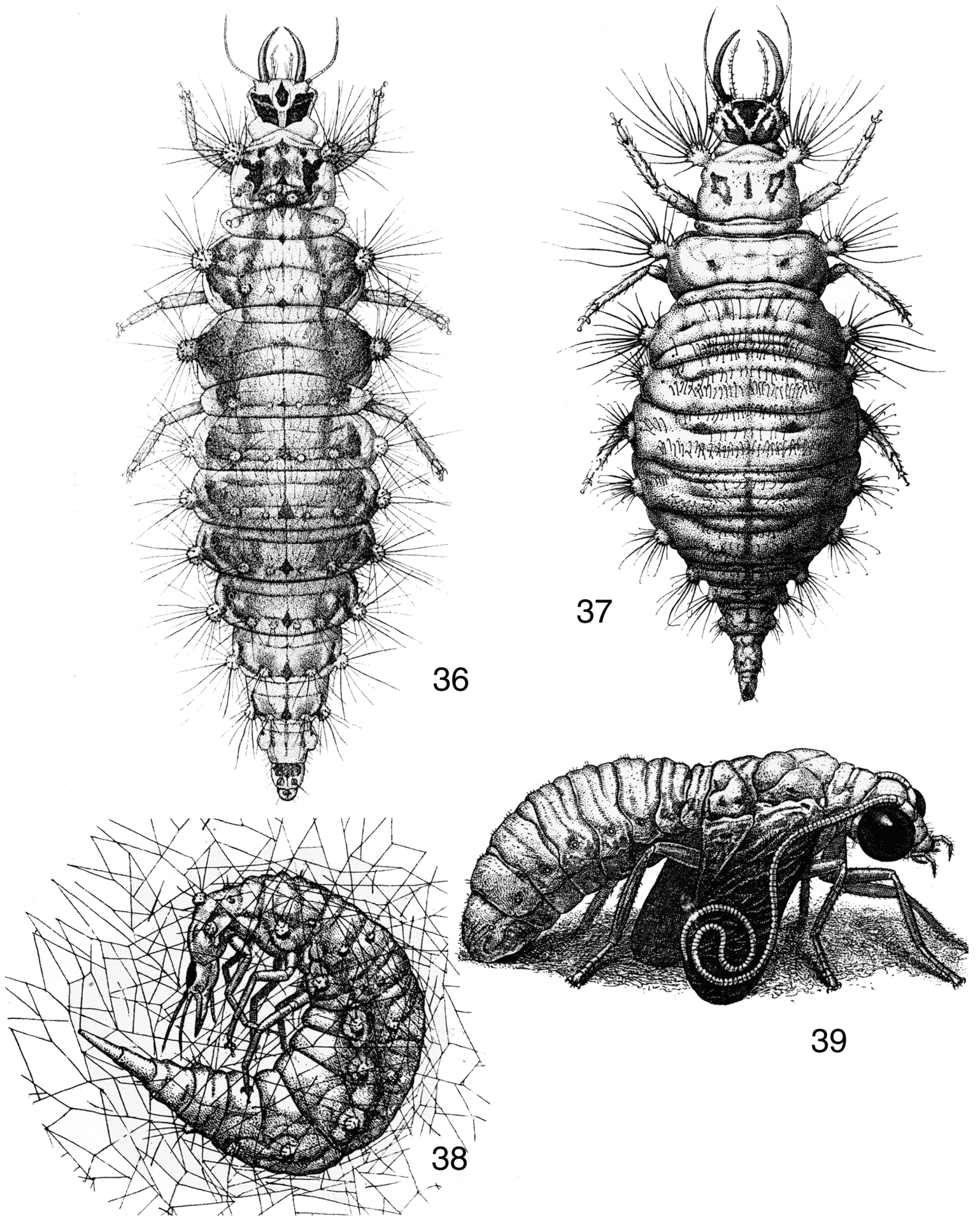

Figs. 36-39.- Larvas, prepupa y pupa en Chrysopidae: 36: Larva desnuda, L-3 (tercer estadio larvario), de Chrysopa pallens, 37: Larva portadora de capa de camuflaje (omitida), L-3, de Pseudomallada prasinus, 38: L-3 de C. pallens fabricando el capullo para pasar a fase prepupa. Adaptado de Principi (1940). 39: Pupa de P. prasinus. Adaptado de Principi (1956a).

Figs. 36-39.- Larvae, prepupa and pupa in Chrysopidae: 36: Naked Larva, L-3 (third instar larva) of Chrysopa pallens, 37: Trash carrying larva (debris omitted), L-3, of Pseudomallada prasinus, 38: L-3 of C. pallens making a cocoon becoming prepupa. Adapted from Principi (1940). 39: Pupa of P. prasinus. Adapted from Principi (1956a).

Tras la alimentación el aseo de las piezas bucales es obligatorio (a veces rozándolas contra el sustrato) (Díaz-Aranda \& Monserrat, 1988d; Canard, 2001; Monserrat \& Díaz-Aranda, 2012), y si la larva está saciada, un periodo de descanso, a modo de "siesta", es frecuente al abrigo de cualquier zona protegida. Algunas larvas (Suarius) muestran un marcado fototactismo negativo (Díaz-Aranda \& Monserrat, 1996). 
Pueden llegar a ser extremadamente voraces, habiéndose citado, por ejemplo en especies de Chrysoperla, Nineta o Chrysopa, consumos de 71-91, 111-142, 129-156, 139-172, 900-2000 áfidos a lo largo de su desarrollo, de hasta 75 aleiródidos diarios, o consumos de 3780 cóccidos, 531 huevos de Bemisia tabaci (Homoptera: Aleyrodidae) diarios, o más de 600 huevos de Laspeyresia molesta (Lepidoptera: Tortricidae) (Feytaud, 1913; Okamoto, 1919; Smith, 1921; Withycombe, 1922, 1923; Matsuda, 1928, 1929; Briand, 1931; Edwards, 1932; Putman, 1932; Killington, 1936; Toschi, 1965; New, 1988b; Milbrath et al., 1993, 1994; Legaspi et al., 1994, 1996; El Arnaouty et al., 1996; Miller et al., 2004, etc.). Principi \& Canard (1984) recopilan interesante información sobre el tipo y cantidad de presas consumidas en diferentes observaciones, y Monserrat \& Díaz-Aranda (2012) para algunas de nuestras especies. También, y por citar otros ejemplos en el solar ibérico, Boelpaepe et al. (1992), Núñez Pérez et al. (1992) o Michelena \& Sanchís (1997) ofrecen datos de algunas especies en relación con pulgones en diferentes cultivos ibéricos.

Obviamente el número y tipo de presas consumidas va a estar condicionada por el tamaño/sexo/ longevidad del individuo (Principi \& Canard, 1984; McEwen \& Kidd, 1995; Venzon et al., 1996; Carvalho et al., 1996; Pappas et al., 2007, 2011; Mantoanelli \& Albuquerque, 2007), e influirá en su potencial reproductor (Canard, 2001). Durante su desarrollo, y debido a su actividad, pueden recorrer, a pesar de su pequeño tamaño, proporcionalmente largas distancias (El Arnaouty \& Ferran, 1992 anotan para Chrysoperla carnea $268.7 \pm 95.4 \mathrm{~cm}$ ). En algunos géneros (Nineta, Pseudomallada) resisten bien el frío o hibernan en esta fase (Sagné \& Canard, 1984; Vannier \& Canard, 1989; Canard \& Vannier, 1992; Canard et al., 1992a, 1996).

Presentan cabeza pequeña y antenas relativamente largas de proporciones y antenómero distal diferente según subfamilias y tribus (Figs. 47, 53), formadas por tres segmentos, al igual que los palpos labiales (Figs. 36, 37, 40, 41, 48, 54), y tienen piezas bucales típicas de Neuropteroidea (Hemerobiiformia), con mandíbulas curvas, muy levemente dentadas hacia el ápice y de longitud variable según los géneros, y maxilas curvadas, no dentadas y con canal alimentario por donde únicamente pueden alimentarse (el orificio bucal está obliterado y está clausurado por el tegumento en esta fase) (Figs. 36, 37, 40, 41, 44, 45,49 ), y succionan los líquidos de sus presas (no pueden ingerir por tanto otro alimento que no sea líquido) (Withycombe, 1925; Killington, 1936; Ickert, 1968; Canard, 2001), y palpo labial trisegmentado de longitud variable, con el último palpómero subsegmentado (Figs. 40, 41, 48). Poseen seis estemas (Paulus, 1986) y la quetotaxia y pigmentación cefálica es característica de cada género/especie (Figs. 40-43, 55-60), utilizándose en su diagnosis, aunque puede variar en función de las condiciones de su desarrollo
(Mochizuki et al., 2010). Frecuentemente la cabeza se encuentra parcialmente embutida en la parte anterior del tórax (Figs. 70-82).

El tórax es sencillo, con patas marchadoras, con tarsos cortos acabados en un par de curvas uñas, engrosadas o no en la base (Fig. 52), aspecto que conservarán los imagos, y en todos los estadios finaliza en un empodio alargado, flexible y adherente en forma de embudo/espátula (Principi, 1940; Kirby, 1984) (Figs. 36, 37, 50, 51).

El abdomen consta de diez segmentos, es subcilíndrico, a veces globoso, algo más abombado en su zona media y apuntado hacia el extremo (Figs. 36, $37,64,66,70-82$ ). Puede portar setas y/o tubérculos portadores de setas. Los últimos segmentos abdominales van adelgazándose (Figs. 36, 37, 63-68, 70-82) y frecuentemente lo utilizan a modo de palanca sobre el sustrato, para favorecer la locomoción y también se utiliza para segregar sustancias que actúan como mecanismo de defensa ante potenciales depredadores, tejer el capullo o son utilizadas para fijar la larva por este extremo durante la ecdisis (Smith, 1921, 1922a, 1922b; Killington, 1936; Kennett, 1948; Spiegler, 1962; Gepp, 1984b; Monserrat \& Freitas, 2005; Monserrat \& Díaz-Aranda, 2012). El último segmento posee dos pequeñas estructuras eversibles bilobuladas (Withycombe, 1925; Killington, 1936) que contribuyen a la locomoción (Figs. 78, 79). Monserrat \& Díaz-Aranda (2012) demuestran la importancia de los caracteres larvarios en la taxonomía general de la familia.

Existen géneros con especies de larvas desnudas (Figs. 63, 64, 66, 68, 77-82), fusiformes, aplanadas y extremadamente ágiles (Peyerimhoffina, Chrysopa, Chrysoperla, Brinckochrysa, Nineta, Hypochrysa, Anomalochrysa, etc.), y especies de otros géneros poseen curiosas estrategias, ya que se cubren (camuflan a modo de "lobo con piel de cordero") con restos de elementos externos, sean elementos vegetales del entorno (hasta líquenes vivos), cera de otros insectos o restos de sus presas (o sus propias exuvias) (Figs. 65, 67, 70-76), a veces de compleja labor (Ceraeochrysa, Yumachrysa, Leucochrysa, Glenochrysa, Nodita, y entre nuestros géneros Nothochrysa, Rexa, Chrysotropia, Suarius, Pseudomallada o Italochrysa), o solo parecen fabricarla en el tercer estadio (Cunctochrysa) (Smith, 1922a, 1926; Principi, 1940; Tjeder, 1966; New, 1969, 1986a; Tauber, 1969, 1974, 1975; Eisner et al., 1978, 2002; Monserrat, 1984c; Eisner \& Silberglied, 1988; Canard \& Labrique, 1989; Díaz-Aranda \& Monserrat, 1990b, 1991; Mason et al., 1991; Tauber et al., 1995, 2011, 2014; Díaz-Aranda et al., 2001; Szentkirályi, 2001a; Monserrat \& Díaz-Aranda, 2012), en ocasiones generando volúmenes que se nos antojan desproporcionados, casi grotescos (Fig. 67), cubriéndose prácticamente todo el cuerpo (Chrysotropia, Italochrysa, Suarius, Pseudomallada), salvo ambos extremos, siendo estas larvas de aspecto más globoso (Fig. 37), que suelen ser menos activas, con un típico movimiento de balanceo 

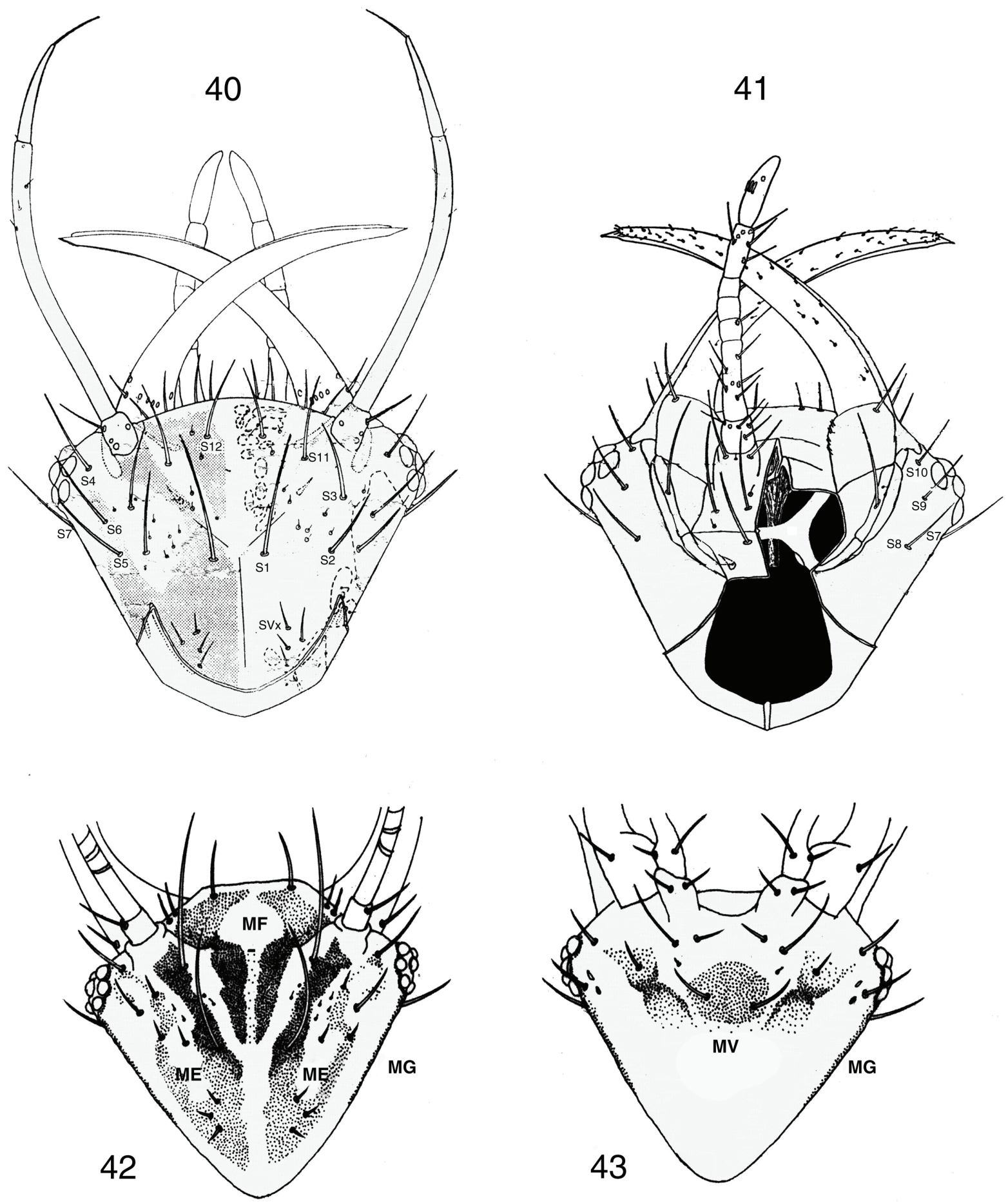

Figs. 40-43.- Terminología de la quetotaxia y pigmentación cefálica de las larvas de Chrysopidae: 40: cabeza (vista dorsal), 41: ídem (vista ventral). Adaptado de Rousset (1966). 42: pigmentación cefálica (vista dorsal), 43: ídem (vista ventral) (ME: Manchas epicraneales, MF: Mancha frontoclipeal, MG: Manchas genales, MV: Manchas ventrales, S: numeración de setas). De Monserrat \& Díaz-Aranda (2012).

Figs. 40-43.- Terminology of Chrysopidae larval cephalic chaetotaxy and pigmentation: 40: head (dorsal view), 41: ditto (ventral view). Adapted from Rousset (1966). 42: cephalic pigmentation (dorsal view), 43: ditto (ventral view) (ME: Epicranial marking, MF: Frontoclypeal marking, MG: genal marking, MV: ventral marking, S: numeration of setae). From Monserrat \& Díaz-Aranda (2012).

lateral cuando se desplazan, y en ellas son frecuentes la presencia de especiales elementos, setación especializada, tubérculos con setas, frecuentemente ganchudas, etc., para fijar estos elementos exógenos, tanto en el tórax, como en el abdomen (Figs. 37, 57, 70-75) (Eisner et al., 1978, 2002; Monserrat, 1984c, 1989; Eisner \& Silberglied, 1988; Hölzel \& Monserrat, 1992; Milbrath et al., 1993, 1994; Díaz-Aranda \& Monserrat, 1996; 

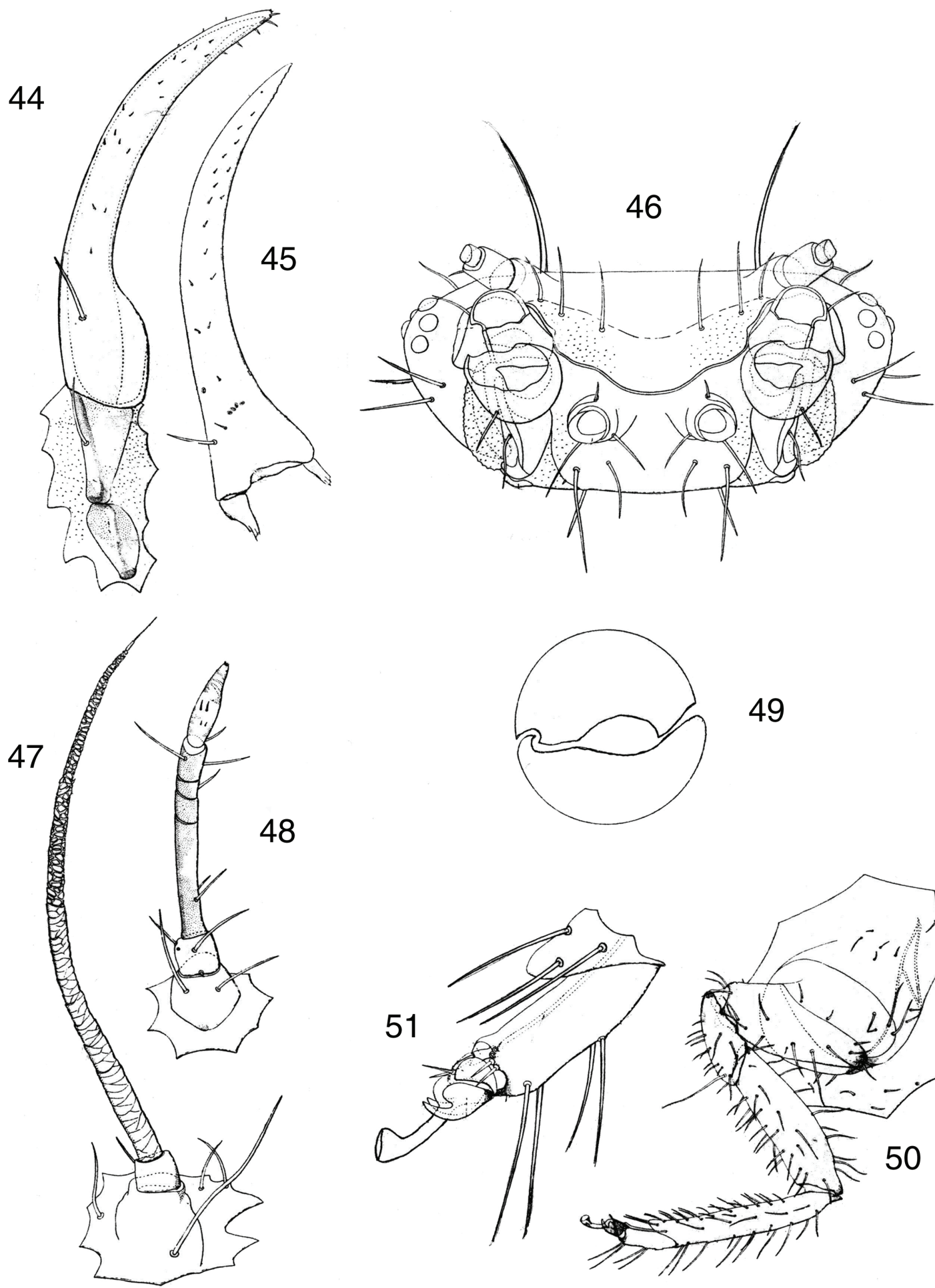

49

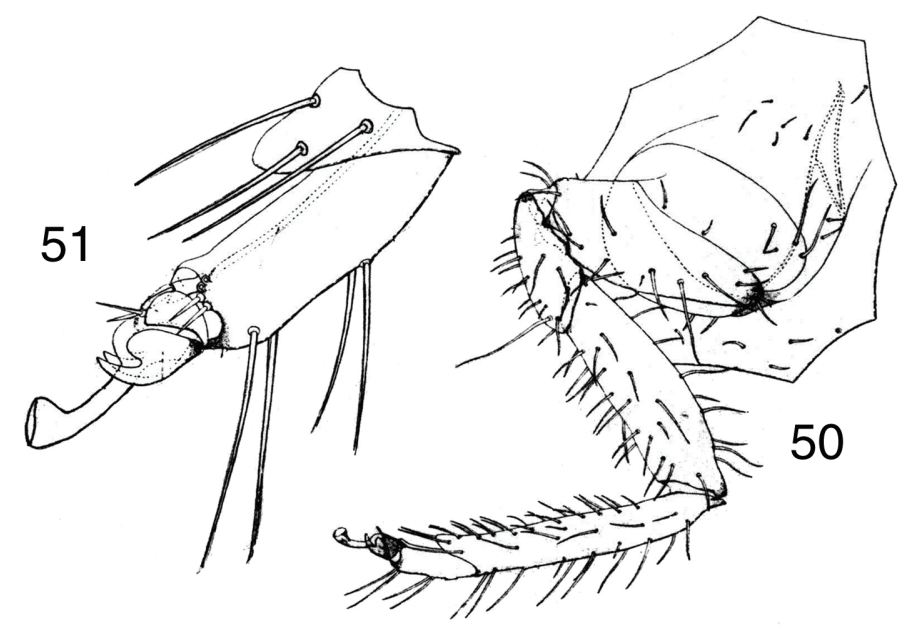

Figs. 44-51.- Morfología larvaria: 44: maxila (vista ventral), 45: mandíbula (vista dorsal), 46: cápsula cefálica (vista frontal), 47: antena, 48: palpo labial, 49: corte transversal del tubo de succión mandibula-maxila, 50: pata, 51: detalle del empodio y uñas. A diferentes escalas. Adaptado de Principi (1940).

Figs. 44-51.- Larval morphology: 44: maxilla (ventral view), 45: mandible (dorsal view), 46: head capsule (frontal view), 47: antenna, 48: labial palp, 49: cross section of the suction mandible-maxillary channel, 50: leg, 51: detail of empodium and claws. At different scales. Adapted from Principi (1940).

Díaz-Aranda et al., 2001; Monserrat \& Freitas, 2005; Haruyama et al., 2012; Monserrat \& Díaz-Aranda, 2012 , etc.).
Como habíamos referido en los imagos, muchas larvas, especialmente las que no se cubren con restos para camuflarse, poseen coloración críptica o disruptiva que 


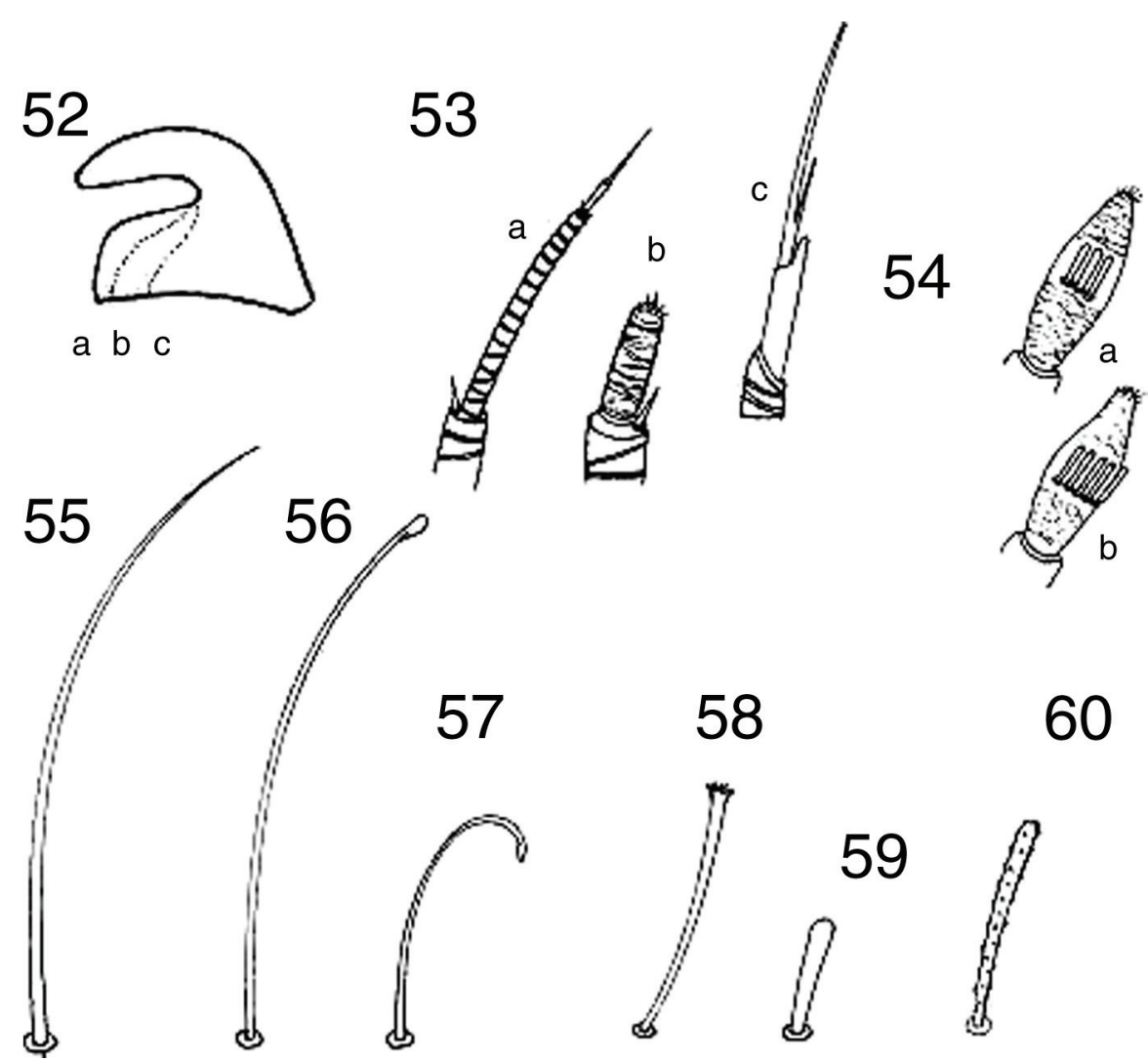

Figs. 52-60.- Morfología larvaria: 52: tipos de uñas, a: con base cuadrangular, b: triangular dilatada en su base, c: triangular no dilatada en su base, 53: segmento distal de la antena, a: Chrysopinae, Chrysopini, b: Nothochrysinae, c: Chrysopinae, Belenopterygini, 54: segmento distal del palpo labial, a: Chrysopinae, b: Nothochrysinae, 55-60: tipos de setas: 55: filiforme, 56: espatulada, 57: uncinada, 58: truncada, 59: baciliforme, 60: denticulada. A diferentes escalas. De Monserrat \& Díaz-Aranda (2012).

Figs. 52-60.- Larval morphology: 52: claw types, a: quadrangular basis, b: triangular dilated basis, c: triangular undilated basis, 53: distal segment of antenna, a: Chrysopinae, Chrysopini, b: Nothochrysinae, c: Chrysopinae, Belenopterygini, 54: distal segment of labial palp, a: Chrysopinae, b: Nothochrysinae, 55-60: setae types: 55: filiform, 56: spatulate, 57: uncinate, 58: truncate, 59: bacilliform, 60: denticulate. At different scales. From Monserrat \& Díaz-Aranda (2012).

las confunden con el entorno o distorsionan su silueta, y la larva verde con cabeza amarilla de Hypochrysa es un buen ejemplo, y en otras ocasiones su coloración es marcadamente disruptiva (Brinckochrysa), con marcadas manchas blancas, negras o rojizas que contribuye a desfigurar su silueta (Fig. 77). También comportamientos defensivo, curvar el abdomen, expeler sustancias líquidas por el ano o dejarse caer cuando son molestadas, se han citado como mecanismos de defensa en fases larvarias, bien contra depredadores (a los que en ocasiones paralizan) o contra ejemplares congéneres caníbales (Kennett, 1948; Spiegler, 1962; Canard \& Principi, 1984; LaMunyon \& Adams, 1987; Mantoanelli \& Albuquerque, 2007; Monserrat \& DíazAranda, 2012, etc.). Algunas larvas son particularmente pendencieras y agresivas ante un potencial peligro (Nineta) u ofrecen el dorso cubierto de restos hacia el agresor a modo de escudo (Rexa, Pseudomallada) (Díaz-Aranda \& Monserrat, 1988d; Monserrat \& DíazAranda, 2012).
$\mathrm{Su}$ desarrollo exige tres estadios, y si no entran en diapausa o invernan, son algo más breves los dos primeros. El tiempo de desarrollo larvario generalmente oscila entre uno y dos meses, dependiendo de las condiciones ambientales, fotoperiodo, del alimento disponible y de su eficiencia como depredador, aunque desarrollos más breves han sido citados: entre 24-76 días cita Canard et al., 1996), entre 12-16 y 14-17 días citan El Arnaouty et al. (1996) en diferentes especies, o 27-53 días cita McEwen (1996) usando diferente tipo de dietas. Otros tiempos más largos, hasta casi un año han sido citados en Italochrysa (Principi, 1946) o más de nueve meses en Nineta (Canard et al., 2014). Canard \& Volkovich (2001) aportan tiempos observados por diferentes autores en diferentes especies según diferentes presas y condiciones. El primer estadio exige tiempos de 2.3-12.0 días, el segundo de 2.1-14.7 días, y el tercero, generalmente más largo, de 2.3 a 16-33 días (Killington, 1936, 1937; Duelli, 1990; 
Canard, 1990; Canard \& Volkovich, 2001; Monserrat \& Díaz-Aranda, 2012). Citemos a Neuenschwander et al. (1975), New (1984b), McEwen et al. (1993a, 1993b), Zheng et al. (1993a, 1993b) o Legaspi et al. (1994) quienes, entre muchos otros autores, aportan interesantes datos sobre el desarrollo larvario de diferentes especies en condiciones experimentales, Canard \& Principi (1984) quienes aportan una relación de tiempos en el desarrollo de diferentes especies anotados por diferentes autores en diferentes condiciones y Monserrat \& Díaz-Aranda (2012) quienes anotan los tiempos de desarrollo larvario para algunas de nuestras especies $\left(\mathrm{L}_{1}: 2-3,3-4,4,5-\right.$ 6, 6, 6-7, 7-8 días; $\mathrm{L}_{2}: 2-3,3-4,5-12,6,6-7,7-9$, 7-10, 9-10, 9-13 días; $\mathrm{L}_{3}: 2-3,5,5-6,7-8,7-10$, 8-12, 10-20, 15, 15-18, 15-20 días, según especies). El mecanismo de las mudas es detallado por Smith (1921, 1922a), Withycombe (1925), Principi (1940) o Spiegler (1962). Muchas especies resisten en estas fases larvarias temperaturas extremas, tanto frías, hasta $-25^{\circ} \mathrm{C}$ (Nineta), como cálidas, hasta $40-42^{\circ} \mathrm{C}$ (Suarius) (Canard \& Principi, 1984; Monserrat \& Díaz-Aranda, 2012).

Sobre la morfología de las fases larvarias (Figs. 36, 37, 63-68, 70-82) conviene mencionar que, a nivel general, son escasamente conocidas, desconociéndose en la mayoría/muchas de sus especies (incluso en la fauna europea: Gepp, 1984a, 1984b, 1986, 1990). Sobre las fases larvarias de esta familia citemos que, en muchos casos, son de difícil obtención o cría en laboratorio, bien porque no se obtienen hembras grávidas (ej.: Chrysopa nierembergi, C. phyllochroma, C. nigricostata, etc.), o bien porque difícilmente se induce a la ovoposición en los imagos (ej.: el autor lleva varias décadas intentando, sin éxito, obtener puestas de Pseudomallada alarconi), incluso a partir de hembras grávidas (ej.: Chrysoperla mutata), amén de la curiosa especificidad que poseen muchas especies en el tipo de superficie que eligen para efectuar las puestas, sea su textura, la proximidad de potenciales presas o el régimen alimentario de sus larvas (Duelli, 1987b) o bien porque, obtenida la puesta, los huevos no prosperan y mueren antes de eclosionar (ej.: Nothochrysa fulviceps o Nothochrysa capitata), o las larvas no se les proporciona el alimento o las condiciones que precisan (Monserrat \& Díaz-Aranda, 2012), al margen de la alta mortalidad en condiciones experimentales, o en la especificidad en el tipo de presas requeridas en ciertos casos (ej.: el autor lleva varias décadas intentando, sin éxito, criar ejemplares a partir de puestas de Italochrysa stigmatica), por lo que en muchos casos no es un tema fácil (Monserrat \& Díaz-Aranda, 2012).

Sobre la identificación de las fases larvarias, y para el lector interesado, aportamos una sencilla clave general de las larvas ibéricas a nivel de género
(Figs. 70-82), y recomendamos Gepp (1984a, 1984b, 1986) y Brooks \& Barnard (1990) y Díaz-Aranda et al. (2001), quienes recopilan los datos existentes sobre la descripción de los estadios preimaginales, bien europeas o bien de las especies entonces conocidas, incluidas muchas de las especies ibéricas y, en nuestro caso, recomendamos Monserrat \& DíazAranda (2012), quienes describen los estadios preimaginales de la mayoría de nuestras especies y recopilan la información existente. Más información sobre la morfología de las fases preimaginales puede recabarse en la citada bibliografía adjunta, y de las especies presentes en la Península Ibérica/Baleares anotamos, en cada una de ellas, las referencias existentes en la bibliografía, si bien pudieron ser descritas bajo denominaciones que no se corresponden con las actuales o, en algunos casos, se requiere confirmación en las identificaciones.

Completado su desarrollo, y tras uno o dos días sin captar alimento, se inicia la pupación, mediante la fabricación de un capullo de seda (Figs. 38, 69) merced a una sustancia segregada por los tubos de Malpighi y que sale por el ano, utilizando eficazmente los ágiles últimos segmentos abdominales para su ejecución y tejido (Smith, 1922a; Lacroix, 1925, 1930; Principi, 1940; Ickert, 1968; Canard \& Principi, 1984; Canard \& Volkovich, 2001). Pueden tardar entre uno y dos días en completar su elaboración. Suele estar formado por una doble capa, una primera y más externa, escueta y laxa, que se fijará al medio elegido (en algunos géneros como Chrysopa forma una especie de irregular tela de araña para sujetar el todo al medio), y una posterior, más compacta e interna, que es muy tenaz, ovoide, de extremos redondeados, o esférica (Fig. 69), y de dimensiones variables según el tamaño de las larvas, oscilando entre 1,5-3,5 $\mathrm{mm}$ a 4,5-7 $\mathrm{mm}$ de largo (en general menores en los individuos que serán machos), en ocasiones se distingue una (a veces subdividida) ancha banda ecuatorial pálida o traslúcida sobre este capullo (Killington, 1936; Canard \& Volkovich, 2001). Externamente suele ser de color blanco, amarillento y otras veces más rosáceo (Rexa). En la parte exterior suelen quedar adheridos las setas y los elementos de las larvas que portan para camuflarse, que también actúan con este fin durante esta fase. Suelen elegir zonas protegidas, sin excesiva humedad y/o alejadas del agua líquida eventual para efectuar la construcción del capullo, sean hojas secas, entre la base de las acículas, bajo cortezas, entre fisuras, en pies de árboles, entre las raicillas, a veces a cierta profundidad en el suelo (especialmente si hibernan en esta fase), o entre la hojarasca (no demasiado lejos de las plantas donde las colonias de sus futuras presas abundan), en el interior de piñas o de agallas, en nidos de pájaros e incluso exuvias pupales de otros insectos, dependiendo de las 

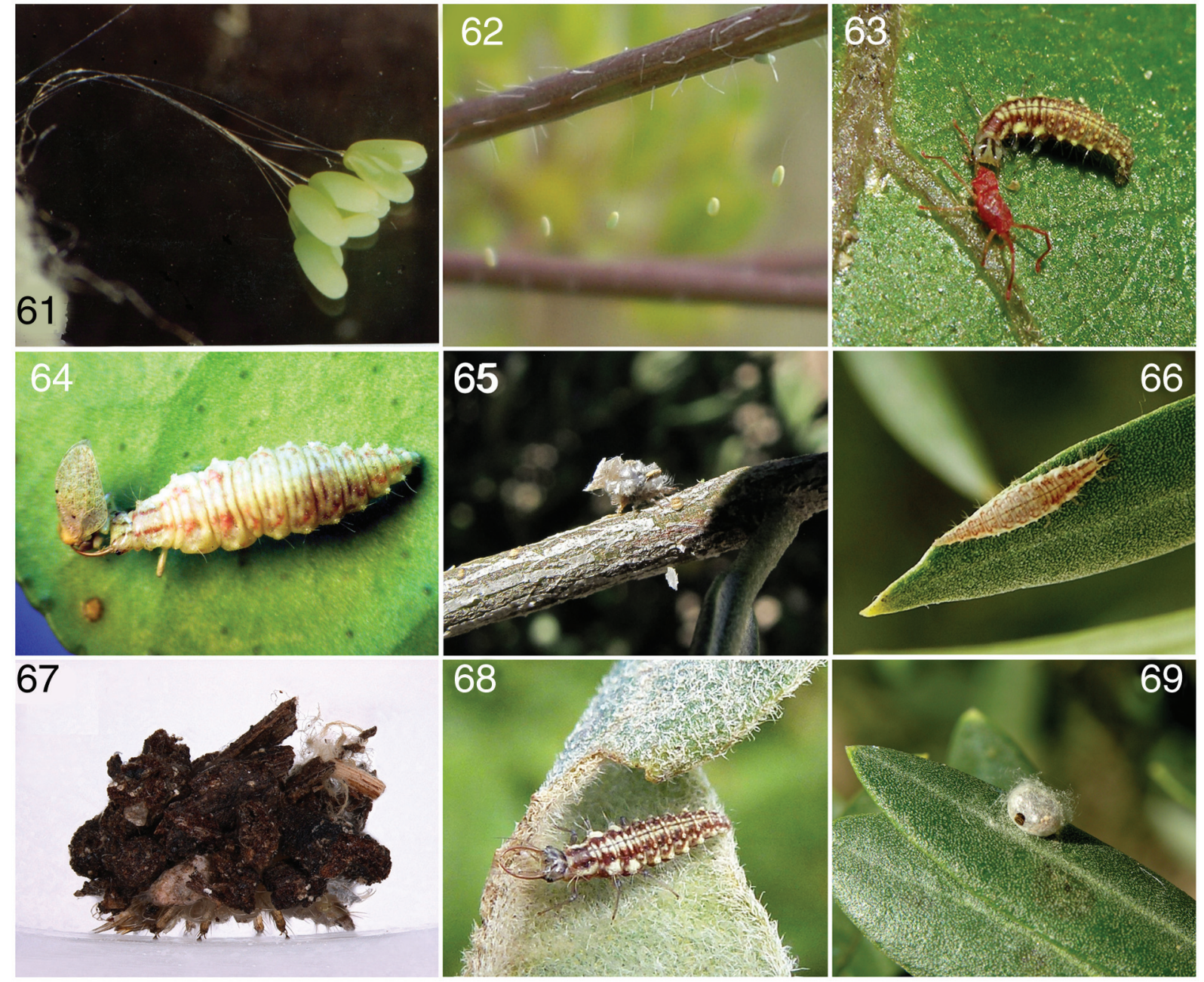

Figs. 61-69.- Estadios preimaginales de especies ibéricas de crisópidos en su ambiente natural. 61: puesta en racimo, 62: puesta de huevos aislados, 63: larva devorando un ácaro (Erythraeidae), 64: larva devorando un ejemplar de Euphyllura olivina (Costa, 1839) (Homoptera: Psyllidae), 65: larva cubierta de restos (Pseudomallada), 66: larva desnuda (Chrysoperla), 67: larva cubierta de restos (Italochrysa), 68: larva desnuda (Chrysopa), 69: capullo pupal parasitizado. (61: fotografía de L.M. Díaz-Aranda, 62: fotografía de P. Guevara, 63, 64, 65, 69: fotografías de M. González Núñez, 67: fotografía de C. Cesaroni, con permiso de R.A. Pantaleoni, 68: fotografía de S. Pagola).

Figs. 61-69.- Habitus of pre-imaginal lberian green-lacewings species in their habitats: 61: eggs in cluster, 62: isolated laying of eggs, 63: larva devouring a mite (Erythraeidae), 64: larva devouring a specimen of Euphyllura olivina (Costa, 1839) (Homoptera: Psyllidae), 65: debris-covered larva (Pseudomallada), 66: naked larva (Chrysoperla), 67: debris-covered larva (Italochrysa), 68: naked larva (Chrysopa), 69: parasitized pupal cocoon. (61: Photograph by L. M. Díaz-Aranda, 62: Photograph by P. Guevara, 63, 64, 65, 69: Photographs by M. González Núñez, 67: Photograph by C. Cesaroni, with permission of R.A. Pantaleoni, 68: Photograph by S. Pagola).

especies (Smith, 1921; Killington, 1936; Principi, 1940, 1947, 1956a; Tjeder, 1966; Canard \& Principi, 1984; Monserrat, 1984b; Gepp, 1989; Canard \& Volkovich, 2001, etc.). Según la época del año y especies, la fase de prepupa, ya incapaz de desplazarse y fuertemente recurvada sobre sí misma en sus extremos dentro del capullo (Fig. 38), pierde su coloración original como larva o su capacidad de recuperar su forma normal anterior, y en función de la temperatura puede durar 4-5 días a tres semanas, desde que se tejió el capullo, antes de pasar a la fase de pupa (Fig. 39), o mantenerse en este estadio para pasar el invierno o la diapausa (ej.: Rexa o Cunctochrysa).
La pupa (Fig. 39) es activa, de tipo dectica y exarata, de color crema en un principio, adopta posteriormente la coloración que tendrá el adulto. Posee mandíbulas simétricas portadoras de pequeños dientes en la cara interna y apical, y como las antenas, son libres, hecho habitual en los Neuropterida, aunque acopladas sobre el margen superior de los ojos antes de finalizar en un bucle sobre las pterotecas (Fig. 39).

El periodo pupal es relativamente corto, y la emergencia del imago, generalmente al atardecer, acontece como media a los 15-20 días, según observaciones en diferentes especies, más tempranos los machos. Monserrat \& Díaz-Aranda (2012) anotan, en 

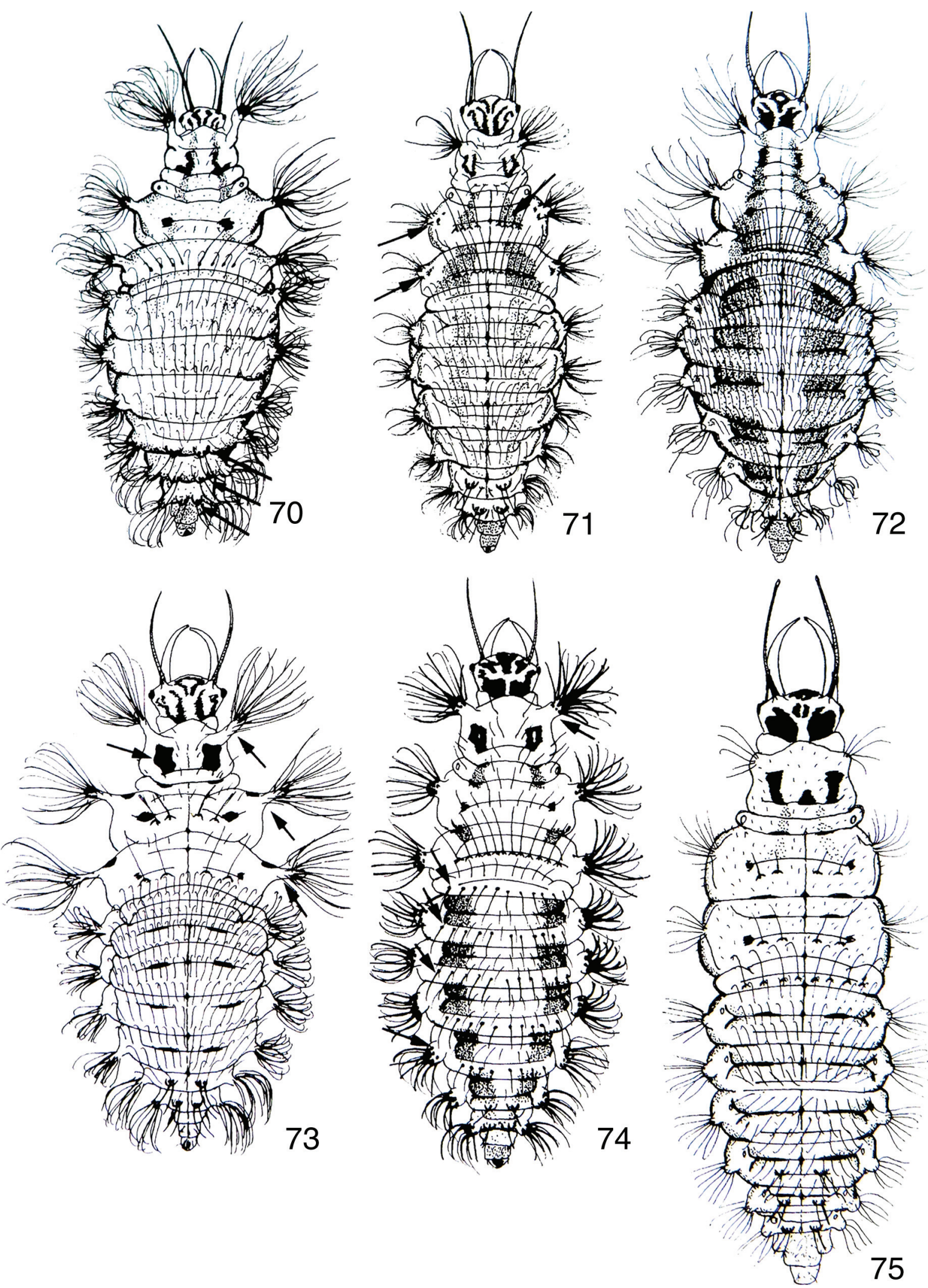

Figs. 70-75.- Esquemas de larvas de tercer estadio (L-3) de Chrysopidae ibéricos que se cubren con restos (omitidos), 70: Pseudomallada (P. venosus), 71: Cunctochrysa (C. baetica), 72: Suarius (S. walsinghami), 73: Chrysopidia (C. ciliata), 74: Rexa (R. almerai), 75: Nothochrysa (N. fulviceps). Las flechas señalan algunos caracteres usados en las claves. A diferentes escalas. De Díaz-Aranda \& Monserrat (1995).

Figs. 70-75.- Third instar larvae (L-3) schemes of Iberian Chrysopidae that coat themselves with debris (ommited), 70: Pseudomallada (P. venosus), 71: Cunctochrysa (C. baetica), 72: Suarius (S. walsinghami), 73: Chrysopidia (C. ciliata), 74: Rexa (R. almerai), 75: Nothochrysa (N. fulviceps). Arrows indicate some characters used in keys. At different scales. From Díaz-Aranda \& Monserrat (1995). 

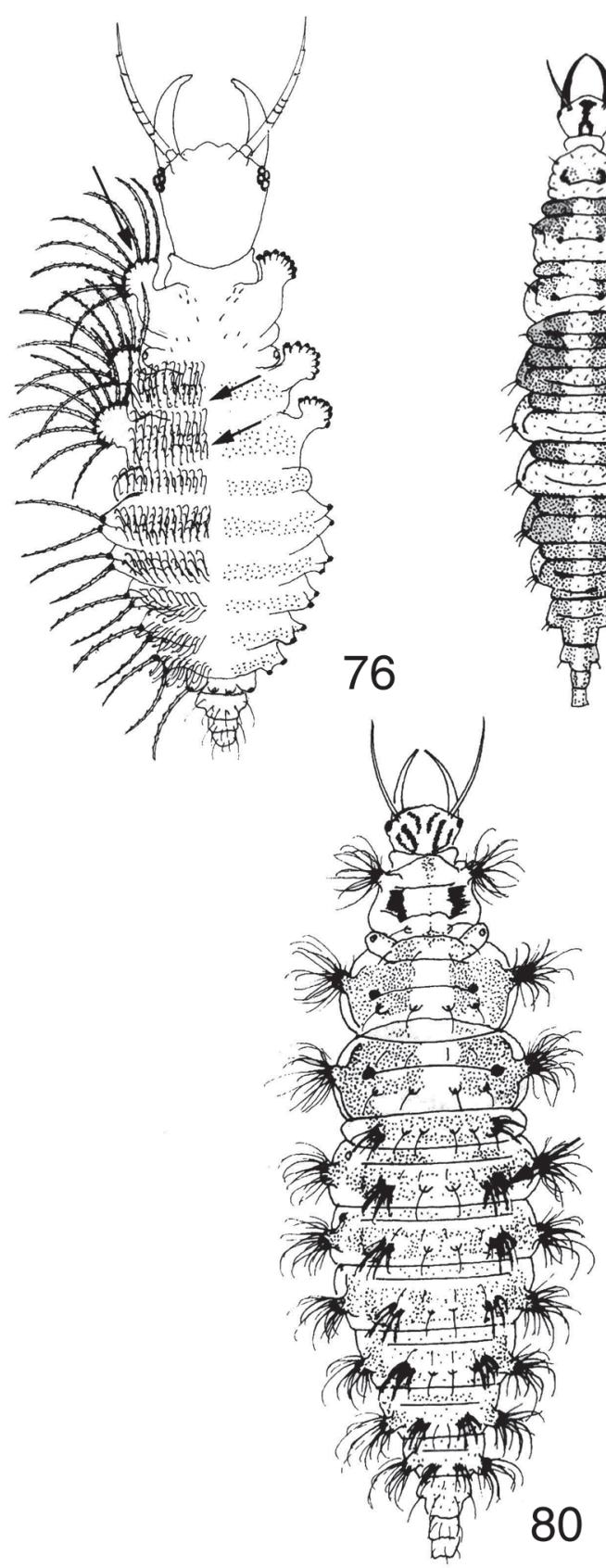

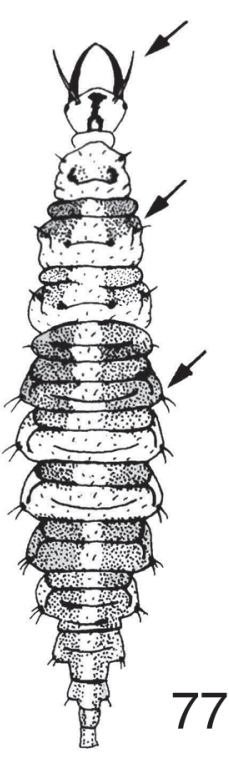

77

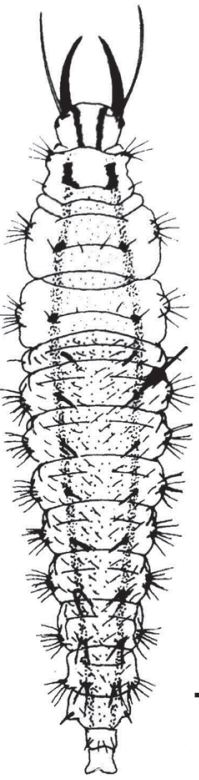

78
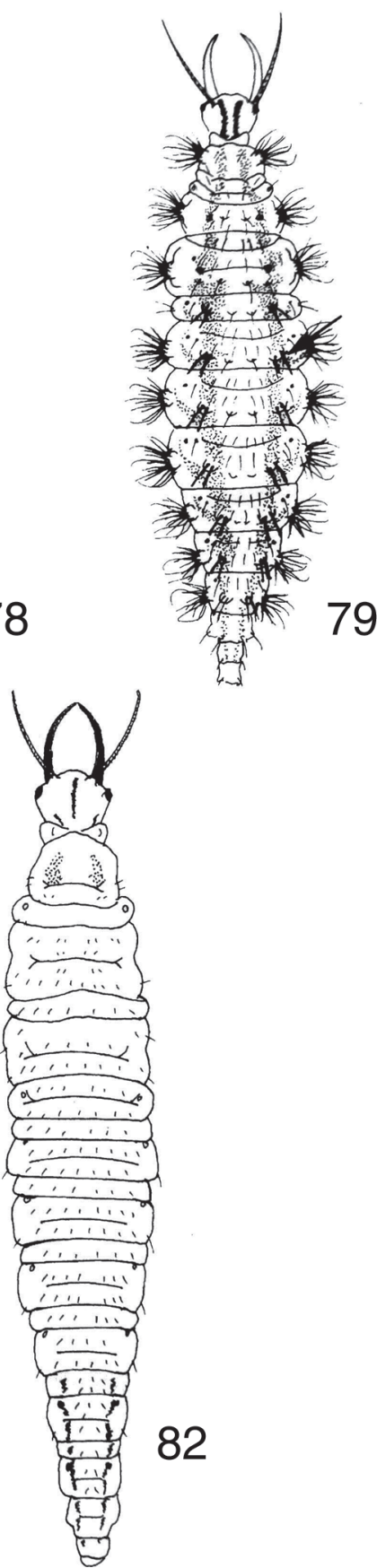

Figs. 76-82.- Esquemas de larvas de Chrysopidae ibéricos: 76: primer estadio (L-1) de larva que se cubre con restos (omitidos) de Italochrysa (I. stigmatica). 77-82: tercer estadio (L-3) de larvas desnudas de: 77: Brinckochrysa (B. nachoi), 78: Peyerimhoffina (P. gracilis), 79: Chrysoperla (C. mediterranea), 80: Chrysopa (C. dorsalis), 81: Nineta (N. guadarramensis), 82: Hypochrysa ( $H$. elegans). Las flechas señalan algunos caracteres usados en las claves. A diferentes escalas. De Díaz-Aranda \& Monserrat (1995).

Figs. 76-82.- Larvae schemes of Iberian Chrysopidae: 76: first instar (L-1) of larva that coat themselves with debris (ommited) of Italochrysa (I. stigmatica). 77-82: third instar (L-3) naked larvae of: 77: Brinckochrysa (B. nachoi), 78: Peyerimhoffina (P. gracilis), 79: Chrysoperla (C. mediterranea), 80: Chrysopa (C. dorsalis), 81: Nineta (N. guadarramensis), 82: Hypochrysa ( $H$. elegans). Arrows indicate some characters used in keys. At different scales. From Díaz-Aranda \& Monserrat (1995).

condiciones de laboratorio, los tiempos de desarrollo pupal para algunas de nuestras especies $(8-13,10-13$, 10-20,11-13,15, 15-20,18-20, 25-30 días, según especies). La pupa corta con sus mandíbulas y con extrema regularidad el capullo pupal practicando una fisura transversal sobre casi todo el tercio anterior del capullo o éste se fractura por presiones internas (Smith, 1921, 1922a; Principi, 1940), y practicado este orificio, 
sale por él, dejando una parte semicircular que queda adherida al resto a modo de "tapadera". Tras la emergencia, y caminando un trecho (Fig. 39), busca una superficie vertical y se desprende de la exuvia pupal para favorecer la expansión y endurecimiento de sus alas, y en una media hora quedarán las alas extendidas y el tegumento del imago listo para su vida como adulto.

Tras expeler el sólido meconio (restos del contenido acumulado en el tubo digestivo que no ha podido ser eliminado por el ano con anterioridad, debido a la falta de conexión entre el mesodeo y proctodeo, elemento que, salvo en Coniopterygidae que es semilíquido, caracteriza a todos los neurópteros tras su emergencia como imagos después de la fase pupal) es finalmente expulsado (su tamaño varía en función de las especies, entre $118 \mu \mathrm{g}$ en Peyerimhoffina a $1.357 \mu \mathrm{g}$ en Nineta según citan Canard \& Volkovich, 2001), y en una hora está listo para volar. Estos procesos son descritos con todo detalle por Smith (1921, 1922a), Killington (1936), Principi (1940), LaMunyon (1988), etc. Esta vulnerable fase de emergencia del imago es extremadamente crítica (Canard \& Principi, 1984; Canard \& Volkovich, 2001). Canard \& Volkovich (2001) aportan datos de periodos de larva, prepupa y pupa de diferentes especies y autores.

En un periodo previo a la maduración de las gónadas (Rousset, 1984), en 3-10 días, dependiendo de factores externos y algo más corto en machos, este tipo de insectos suelen dispersarse, incluso varios kilómetros en una noche. Esta capacidad nómada se mantiene en muchas especies a lo largo de su vida, con largos vuelos en busca de nuevas fuentes de alimento (Killington, 1936; New, 1967, 1968, 1984b; Duelli, 1980a, 1980b, 1981b, 1984a, 1984b, 1986a, 2001; Canard \& Principi, 1984; Volkovich, 1998; Dodds \& McEwen, 1998; Canard \& Volkovich, 2001; Chapman et al., 2006). Tras este periodo de dispersión, se inicia la fase reproductora y están listas para el cortejo y la cópula.

Mayoritariamente en zonas tropicales las generaciones se suceden de forma continua (New, 1984b, 1986a, 1988a; Penny, 2002), mientras que en nuestras latitudes las poblaciones se desarrollan mayoritariamente durante los meses de primavera y verano, sucediéndose en muchas especies varias generaciones, incluso tres o más anuales (ej.: Pseudomallada, Chrysoperla) en función de la temperatura, humedad, fotoperiodo, de los recursos del medio, etc., y en zonas más térmicas con recursos limitados durante los meses más cálidos parecen sucederse ciclos bivoltinos con una generación primaveral y otra al final del verano-otoño (Monserrat, 1977a; Alrouechdi et al., 1980a, 1980b; Marín \& Monserrat, 1987; Marín, 1994, etc.). En nuestras latitudes la mayoría de las especies parecen tener ciclos bi-trivoltinos, y se han citado sucesivas generaciones anuales en numerosas especies con ciclos polivoltinos (Chrysoperla, Chrysopa, Pseudomallada, etc.) (Hinke, 1975; Canard, 1987; Volkovich, 1998; Szentkirályi, 2001a). En zonas de la península litorales y/o más meridionales (probablemente también en Baleares) las poblaciones de ciertas especies se desarrollan con solapamiento de generaciones y se suceden a lo largo de todo el año, inclusive en los meses de invierno, hecho evidente en especies como Pseudomallada flavifrons o Chrysoperla, que poseen también actividad ya pasado el otoño, incluso en invierno, con actividad a lo largo de todo el año en estas zonas, e incluso alguna especie, quizás para evitar la competencia con otras especies o para sortear los meses más calurosos, parece tener mayor actividad durante estos meses de otoño (ver fenologías de las especies en cada caso).

Por el contrario, en nuestras latitudes, algunas especies de varios géneros son marcadamente monovoltinas (Rexa, Nineta, Peyerimhoffina, Nothochrysa, Italochrysa, Hypochrysa, Pseudomallada (part.), etc.), bien con aparición de imagos más primaverales o más estivales, y otras especies polivoltinas pueden adaptarse a ciclos monovoltinos en determinados medios montanos (ej.: algunas especies de Chrysopa o Chrysoperla), y lógicamente las elevadas altitudes y latitudes limitan sus poblaciones (Killington, 1929, 1936, 1937; Zelený, 1971a, 1984a, 1984b; Neuenschwander et al., 1975; Monserrat, 1977a, 2008; Samson \& Blood, 1979; Greve, 1984; Sagné \& Canard, 1984; Canard, 1985, 1986a, 1986b, 1987, 1997; Duelli, 1986b; New, 1986a, 1989; Vannier, 1986, 1987; Vannier \& Canard, 1989; Pantaleoni, 1990; Canard et al., 1992a, 1996; Canard \& Vannier, 1992; Duelli, 1992; Volkovich, 1998; Szentkirályi, 2001a; Horton et al., 2002; Penny et al., 2007, etc.).

En ciertas condiciones, especialmente en zonas de alta montaña o latitudes más septentrionales y medios más rigurosos, algunas especies que, en otras condiciones, poseen varias generaciones anuales, se adaptan a tener ciclos monovoltinos (Chrysopa abbreviata, C. perla, etc.) (Killington, 1936, 1937; Greve, 1984; Szentkirályi, 2001a), aunque en algunos casos esto puede variar y adaptarse a la latitud y la altitud de las poblaciones, o los imagos, en función del fotoperiodo/temperatura media, entran en diapausa invernal (Principi \& Castellari, 1970; Volkovich, 1987, 1988, 1996, 1997, 1998, 2003; Canard \& Grimal, 1990; Duelli, 1990; Canard, 1997, 1998; Volkovich \& Blumental, 1997; Volkovich \& Sokolova, 2000, etc.). Canard \& Volkovich (2001) aportan datos de factores que afectan a la inducción a la diapausa de diferentes especies según diferentes autores.

La diapausa estival es un hecho conocido en alguna de nuestras especies de Chrysopidae (Hypochrysa elegans, Nineta pallida, probablemente también en Suarius, y alguna especie de Pseudomallada y Chrysoperla), bien por estar poco adaptadas a determinados medios/periodos termófilos, o como consecuencia de la reducción de potenciales presas en este periodo (Marín, 1994), y también han sido descritos ciclos de desarrollo de dos años con una prolongada diapausa intermedia (Chrysopa dorsalis) (Canard \& Principi, 1984; Canard, 1985, 1998; Grimal \& Canard, 
1996; Volkovich, 1998; Canard \& Volkovich, 2001, etc.) y, en cualquier caso, la relativamente larga longevidad de las hembras (hasta 35 meses) y su prolongado periodo reproductor hace dificultoso calibrar el número de generaciones reales en las poblaciones de la mayoría de nuestras especies, dado que se solapan las diferentes poblaciones o las derivadas del periodo reproductor de una misma hembra (Canard \& Principi, 1984; New, 1986a; Canard \& Volkovich, 2001). Killington (1936: 149) anota las fenologías de las especies del Reino Unido.

Según anotaremos en cada caso, en la mayoría de nuestras especies la hibernación suele producirse en fase de prepupa o de larva, más raramente en fase de pupa, y ocasionalmente en cualquier fase desde huevo a imagos (Lacroix, 1926; Principi, 1956b; Principi \& Castellari, 1970; Canard \& Principi, 1984; Canard, 1987; Mantoanelli et al., 2006), éstos con cambios de coloración en algunos géneros, y conocido es el caso de Chrysoperla o Leucochrysa (Lacroix, 1926; Tauber et al., 1986; Duelli, 1999; Duelli et al., 2014; Price et al., 2015, etc.), aunque larvas de varios géneros mantienen su actividad a bajas temperaturas e incluso pasar varios inviernos en esta fase (Nineta, Chrysoperla, Pseudomallada).

Por último, diversos tipos de parásitos e hiperparásitos han sido citados en esta familia, especialmente sobre sus huevos, sus larvas o emergiendo de sus capullos (Fig. 69), incluso parasitando imagos, especialmente himenópteros parásitos, parasitoides e hiperparásitos: Hymenoptera, Apocrita, Cynipoidea: Figitidae, Anacharitinae (Anacharis, Aegilips); Chalcidoidea: Eupelmidae (Eupelmus, Arachnophaga), Encyrtidae (Isodromus, Eupoecilopoda, Chrysopophagus), Eulophidae (Goniocerus, Tetrastichus, Tetrastichichodes), Perilampidae (Perilampus), Pteromalidae (Dibrachys, Pachyneuron), Trichogrammidae (Trichogramma); Ichneumonoidea: Ichneumonidae (Gelis, Hemiteles, Mesochorus, Phaenogenes), Braconidae (Microgaster, Chrysopophthorus); Platygastroidea: Platygastridae (Telenomus); Proctotrupoidea: Heloridae (Helorus, Phanurus), etc., o bien citados como Chalcididae, Ceraphronidae, Proctotrupidae, Scelionidae, Anacharitidae, etc.) (ver sumario en New, 1984c), alcanzando en ocasiones porcentajes superiores al 50 \% (McGregor, 1914; Smith, 1922a; Lacroix, 1923; Killington, 1932b, 1936; Putman, 1937; Eglin, 1940; Principi, 1940, 1947, 1948, 1956a, 1956b; Clancy, 1946; Neumark, 1952; Muma, 1959; Ickert, 1968; Agekyan, 1973; New, 1975b; Principi et al., 1978; Aspöck et al., 1980; Alrouechdi \& Panis, 1980; Séméria, 1981; Johnson \& Bin, 1982; New, 1982; Grimal, 1984; Alrouechdi et al., 1984; Pantaleoni, 1984; Ruberson et al., 1989; Duelli \& Johnson, 1992; Shaw, 1996; Loiácono et al., 2006). También ácaros, gregarinas, hongos y ciertos virus se han citado como parásitos de larvas, pupas e imagos (Hartzell, 1918; Principi, 1956a; Sidor, 1960; Geus, 1969; Canard, 1985; Ventura et al., 1996, 2000; Sewify \&
El Arnaouty, 1998; Pappas et al., 2008c, etc.), alcanzando en ocasiones mortalidades de hasta un $19 \%$ de los huevos y un $82 \%$ de insectos infectados. También se han citado varias especies de Forcipomyia (Diptera: Ceratopogonidae) como ectoparásitos de alguna especie de Chrysopidae (Forsius, 1924; Edwards, 1932; Mayer, 1934; Tjeder, 1944; Toschi, 1965; Greve, 1968; Pantaleoni, 1984; Dobosz, 1991, etc.). Killington (1932b) o Campos (1986) anotan interesantes datos al respecto en algunas de nuestras especies, y Killington (1936: 176-179) ofrece una detallada información de parásitos de especies británicas en sus diferentes fases.

Obviamente las crisopas también son presas (como larvas o imagos) de artrópodos depredadores, principalmente ácaros, arañas, diplópodos, larvas de coccinélidos y sírfidos (y de crisopas), hormigas, odonatos, esfécidos, asílidos, etc., y de otros animales predadores como anfibios, reptiles, aves y murciélagos (Feytaud, 1913; Wildermuth, 1916; Killington, 1929, 1932a, 1932c, 1932d, 1936; Hobby, 1933; Principi, 1956a; New, 1975b, 1986a; Alrouechdi et al., 1984; Monserrat, 1985b; Masters \& Eisner, 1990; El Arnaouty \& Ferran, 1992; Morris et al., 1998; Daane, 2001; Szentkirályi \& Kristín, 2002; Miller et al., 2004, etc.). Resulta muy curiosa su relación con los murciélagos, y Miller $(1971,1975,1983,1984)$ y Miller \& Olesen (1979) aportan sorprendentes e interesantes datos sobre mecanismos de defensa de las crisopas ante los ultrasonidos de estos depredadores mamíferos, y Archibald et al. (2014) sostienen que estos recursos (ausentes en Nothochrysinae), junto a su mayor adaptabilidad y tolerancia a más diversas y extremas climatologías (especialmente rango de más bajas temperaturas), han dado a los Apochrysinae y especialmente a los Chrysopinae, el éxito evolutivo que hoy día poseen frente a los Nothochrysinae, mayoritarios y dominantes durante el Eoceno-Plioceno (12 géneros y 23 species de Europa, Asia y Norteamérica), pero ya en declive en el Neógeno (Mioceno, 3 spp.- Plioceno, $1 \mathrm{sp}$.), y hoy casi relictos (Apochrysinae: 6 géneros y 27 especies actuales, Chrysopinae: 56 géneros y 1.158 especies actuales, frente a Nothochrysinae: 7 géneros y 28 especies actuales, del total de los 75 géneros y las c. 1.200 especies actuales conocidas) (Adams, 1967, 1978; Brooks \& Barnard, 1990; Adams \& Penny,1992; Winterton \& Brooks, 2002; Duelli et al., 2010; Archibald \& Makarkin, 2015).

\section{BREVE HISTORIAL SOBRE SU TAXONOMÍA Y SU CONOCIMIENTO}

Desde los inicios de la Taxonomía y Nomenclatura modernas, el concepto de los "actuales" crisópidos estaba mezclado, especialmente con los hemeróbidos (Hemerobiidae), desde Linnaeus (1758), quien describe la primera especie de esta familia con el nombre de Hemerobius perla. Posteriormente son muchas las especies de crisópidos que fueron descritas originalmente como pertenecientes al género Hemerobius (ver descripciones originales en la relación de especies), género que incluía en los inicios a muchas de las 
familias que hoy día constituyen el Orden Neuroptera y que, por otra parte y desde el concepto linneano, se ha ido desglosando en diferentes órdenes y familias actualmente reconocidos. Para información sobre el concepto linneano de la familia y su evolución se recomienda Tjeder (1952) y Pantaleoni (2010), y para autores previos a Linnaeus e historial de la primera literatura sobre la familia se recomienda Aspöck \& Aspöck (2007).

Tras las primeras ediciones y descripciones acabarán apareciendo las primeras revisiones y monografías, y a su vez los primeros intentos en organizar su taxonomía y su sistemática, conforme se iban desglosando algunos taxa supragenéricos en familias distintas, y aún algunas (Osmylidae, Sisyridae, Nevrorthidae, Crocidae, etc.) tardarían en constituirse, y poco a poco los neurópteros, y la familia Chrysopidae, iban adquiriendo entidad (Linnaeus, 1758, 1761, 1767; Geoffroy, 1762; Scopoli, 1763; Fabricius, 1775, 1777, 1778, 1781, 1793, 1798;De Geer, 1778, 1783; Schrank, 1781; Rossi, 1790; Olivier, 1792; Latreille, 1796, 1802, 1804, 1810, 1825, 1831; Leach, 1815; Cuvier, 1817; Curtis, 1834; Stephens, 1836; Rambur, 1838, 1842; Burmeister, 1839; Wesmael, 1841; Schneider, 1845, 1851a, 1851b; Hagen, 1850, $1851,1854,1856,1858,1859 \mathrm{a}, 1859 \mathrm{~b}, 1861,1862$, 1863, 1866a, 1866b, 1866c; Brauer, 1851, 1852, 1855, 1856, 1857, 1864, 1866, 1868, 1876; Newman, 1853; Walker, 1853; Brauer \& Löw, 1857; Costa, 1860-1870, 1863; Gerstaecker, 1863; Wallengren, 1863, 1871; Pictet, 1865; McLachlan, 1867, 1868, 1880b, 1883a, 1884a, 1887, 1898; Albarda, 1889; Klapalek, 1899; Perkins, 1899, 1910; Handlirsch, 1906-1908, etc.). Ver un buen análisis de esta evolución en Krüger (1915), siendo Tillyard (1916) quien la dejó inequívocamente definida.

Obviamente, a lo largo del pasado siglo y del presente se han ido publicando multitud de artículos y revisiones relativas a faunas de diferentes países y continentes, así como centenares de publicaciones relacionadas con su Citología/Histología, Anatomía, Fisiología, Comportamiento, Biogeografía, etc., y especialmente en relación con la Entomología Aplicada y/o con las faunas locales, que escapan a la intención de esta contribución.

Como está ocurriendo en la Zoología y la Entomología en general, con las nuevas herramientas moleculares han venido apareciendo artículos que pueden modificar la situación de numerosas especies y la posición de muchos taxa se va a ver, sin duda, afectada en un futuro (Tauber \& Tauber, 1977a, 1977b, 1989; Bullini et al., 1983a, 1983b, 1984; Bullini \& Cianchi, 1984; Cianchi \& Bullini, 1992; Winterton, 2003; Haring \& Aspöck, 2004; Lourenço et al., 2006; Winterton \& Freitas, 2006; Haruyama et al., 2008; Winterton et al., 2010; Morinière et al., 2014; Price et al., 2015, etc.).

A nivel genérico, su taxonomía y sistemática ha sido recientemente tratada (Brooks \& Barnard, 1990). Sin embargo, su estado general de conocimiento es aún muy incompleto, siendo francamente escasos los trabajos de revisión global en la mayoría de sus géneros, son muchas las especies inadecuadamente descritas y/o tipificadas, otras apenas han sido citadas posteriormente desde su descripción original, y otras son muy parcialmente conocidas, siendo muy parco el conocimiento sobre su morfología, venación, genitalia y variabilidad en muchas especies, hecho que conlleva a errores de identificación (que en muchos casos no es en absoluto cómoda ni fácil) y que provoca confusiones en su identificación $\mathrm{y}$, consecuentemente, en los datos que sobre ellas poseemos y, lógicamente en su distribución geográfica real (New, 1980; Monserrat et al., 2014). Por ello, de forma global, y aunque a nivel genérico está bien estudiada (Brooks \& Barnard, 1990), puede decirse que la situación taxonómica y sistemática de la mayoría de las especies de esta familia es aún bastante incompleta y fragmentaria (New, 1984a).

Sin duda, las faunas Paleártica, Neártica y Australiana son las mejor conocidas sobre este particular, si bien el límite real de distribución de muchas especies es, con frecuencia, impreciso o incompleto y, en ocasiones, los datos sobre su biología son escasos y el nivel de conocimiento de las faunas de muchos países, incluso en zonas relativamente bien estudiadas como Europa y Estados Unidos y recientemente China, es aún poco satisfactorio. Este hecho es aún más evidente en faunas de otros continentes, y nuevas obras han sido afrontadas, y desde el último tercio del pasado siglo al presente nuevos trabajos van aportando nuevos datos que van completando las lagunas existentes sobre su taxonomía, distribución, faunística, biología y catalogación, siendo ingente el número de publicaciones que han aparecido, y en relación a nuestra región biogeográfica mayoritariamente han sido recogidas por H. Aspöck et al. (1980, 2001). Para los interesados en conocer información sobre los taxa de esta familia puede consultarse Brooks \& Barnard (1990) y Oswald \& Penny (1991), y sobre la bibliografía de esta familia se recomienda Oswald (2013b).

\section{Sobre su Conocimiento en la Península Ibérica y} Baleares. Problemática de las citas antiguas

En lo que respecta a la Fauna Ibérica, es Rambur $(1838,1842)$ el que nomina, dibuja, describe y cita por primera vez varias especies de crisópidos en la Península Ibérica (sobre la corrección en las fechas habitualmente utilizadas al mencionar posteriormente estas especies hablaremos más adelante), apareciendo con el tiempo algunos trabajos posteriores del siglo XIX con descripciones, citas o referencias sobre la fauna Ibérica (Walker, 1853; Rosenhauer, 1856; Costa, 1860-1870; Girard, 1862; Brauer, 1864, 1876; Hagen, 1863, 1866a, 1866b, 1866c; Pictet, 1865; McLachlan, 1867, 1868, 1880a, 1880b, 1884b, 1886a, 1889, 1893a; Bolívar, 1873, 1878, 1890; Cuní y Martorell, 1879, 1880, 1881, 1882, 1888, 1889, 1897, 1899; Novak, 1891; Dziędzielewicz, 1891, etc.). 
Durante los dos primeros tercios del siglo XX, y al margen de la extensa obra de L. Navás, autor del que ahora hablaremos, diferentes entomólogos han citado material ibérico o han hecho referencia a alguno de los países de la Península Ibérica al citar la distribución general de algunas especies (McLachlan, 1902a, 1902b, 1903; Vicente, 1902; Cuní y Martorell, 1902; Gaspar, 1903; Melón, 1903; Ventalló, 1904; Lucas, 1905, 1906; Pueyo, 1906; Fuente, 1906, 1929; Marcet, 1908, 1909; Macho Bariego, 1909; Cáceres, 1909; Andréu, 1909; Klapálek, 1909; Morton, 1912, 1925; Pongrácz, 1912; Codina, 1913; Gil, 1915; Lacroix, 1916, 1921b, 1922; Coma, 1918; Cervera, 1922; Bertrand, 1923; Dusmet, 1928; Esben-Petersen, 1931; Mosely, 1932; Killington, 1935a; Vidal y López, 1943; Kimmins, 1950; Principi, 1952, 1954b, 1956a, 1958, 1962; Auber, 1958; Nagler, 1958; Berland, 1962; Zelený, 1964, 1971a, 1971b; Compte, 1967, 1968; Eglin, 1968, etc.), que ya enlazan con los autores contemporáneos. Para los lectores que deseen información y bibliografía sobre todos estos autores españoles (entre 1758-1990) se recomienda Martín Albaladejo (1994), y para los autores nacionales o no, que se interesaron en los neurópteros ibéricos se recomienda Monserrat \& Triviño (2013).

Centrándonos más en lo que nos compete, y al margen de los citados autores del siglo XIX y primera mitad del XX que puntualmente han aportado algún registro de especies de esta familia en nuestra fauna y que anteriormente hemos citado, no sería posible concebir el estudio de los neurópteros en general, y de los crisópidos ibéricos (incluidos los de Andorra, España y Portugal) en particular, sin las numerosas publicaciones del autor español Longinos Navás (1858-1938), prolífico, heterogéneo y controvertido autor en numerosos campos, quien durante casi cuarenta años centró la mayoría de sus estudios en la taxonomía, sistemática y faunística de este grupo de insectos, y que en el caso de la familia que nos ocupa y por su extensión, no hemos pormenorizado en la relación de autores y obras anteriormente citada. En ellas se describen numerosos nuevos taxa (Bastero Monserrat, 1989; Monserrat, 1986c), muchos de ellos de nuestra fauna, y se incluyen multitud de citas de crisópidos en ella. Lamentablemente muchos de los criterios taxonómicos seguidos por él han resultado ser de escaso valor y rigor científico, y sus identificaciones y descripciones de nuevos taxa han sido frecuentemente propuestas en sinonimias o en duda, ya que mayoritariamente en sus identificaciones no tenían en cuenta la genitalia, y basaba sus estudios casi exclusivamente en caracteres irrelevantes de la venación o coloración alar y tegumentaria (en gran parte muy variables o sin verdadero interés), y por ello sus trabajos consisten en un compendio de taxa nuevos, que más que un avance, aportando mucha confusión (ver como ejemplos el caso de Chrysopa montanal Chrysopa palpalis en Monserrat, 2011, o sobre sus citas de Nineta flava y/o N. vittata), y por ello su obra ha sido permanentemente motivo de controversia.
Como ejemplos de su hacer relacionados con la familia que tratamos, citemos que Monserrat (1986c) recoge nada menos que 50 géneros, 680 especies y 225 variedades de crisópidos descritos por este autor a lo largo de su vida. El grado de confusión creado por este autor en la taxonomía de esta familia fue comentado por Brooks \& Barnard (1990), y como algunos ejemplos de su labor, citemos que Monserrat (1984f), ante la cantidad de errores de identificación, propone no tener en cuenta sus citas de Coniopterygidae, Monserrat (1990) quien revisa las 28 especies descritas por este autor pertenecientes al género Micromus (Hemerobiidae), y solo 7 permanecieron como válidas, Monserrat (2011) quien propone como sinonimias de especies previamente por él descritas o confirma las sinonimias de cuatro de sus especies de nuestra fauna, o Monserrat (1985a, 1986a, 1986b, 1986c, 1991, 2011) quien detecta numerosos errores de identificación que hacen frecuentemente dudosos sus datos faunísticos. Estos elementos se repiten en otros órdenes de insectos por él tratados (ej.: Hubbard, 1990).

Como sacerdote y católico fue "lógicamente" un buen creacionista. Piénsese que a lo largo de su vida describió más de 3.300 taxa (Bastero Monserrat, 1989; Monserrat, 2011), y que sólo de estos tres órdenes de insectos (Neuropterida) describió aproximadamente 375 géneros, 2.173 especies y 301 variedades (Monserrat, 1986c), es decir 2.849 taxa, del total de 388 géneros y 2.684 especies por él descritos de diferentes órdenes de insectos y arácnidos (Monserrat, 1985a, 1986c, 2011; Bastero Monserrat, 1989; Aspöck \& Aspöck, 2014), y en lo que a nuestra fauna incumbe, de todos estos taxa, multitud de géneros, y nada menos que 152 especies y 149 variedades de Neuropterida fueron descritas por él en la Fauna Ibero-Balear, que sumadas a las descritas de las Islas Canarias $(\mathrm{Ohm} \&$ Báez, 2004; Báez \& Oromí, 2010) alcanzan un total de 239 taxa: 4 de Megaloptera y 208 de Neuroptera ( +15 de Canarias).

De la familia que ahora nos compete, por la que este autor sentía especial interés (Navás, 1913b: "que siempre he mirado con predilección"; Navás, 1934: "Par leur bel aspect, ils sont très sympathiques à l'homme") publicó varios artículos monográficos sobre las crisopas de nuestra fauna (Navás, 1901, 1904b, 1905a, 1905c, 1908a, 1924a, 1925) e infinidad de descripciones de especies y variedades y miles de datos faunísticos, al margen de su monografía sobre las crisopas de la fauna europea (Navás, 1915a) y multitud de publicaciones de otras faunas (para las descritas en la Península Ibérica puede consultarse Monserrat, 2011; Monserrat \& Triviño, 2013; Monserrat et al., 2014, y/o el listado de taxa que ahora anotamos). Por tanto, el gran legado de Navás, incluso habiendo publicado complejas monografías sobre esta familia, ha quedado reducido realmente a algún taxa descrito que ha mantenido su validez taxonómica (ver listado de especies consideradas y sus sinonimias) y a ciertos datos sobre la potencial distribución geográfica de algunas especies. 
Desafortunadamente casi son solo sus publicaciones las que nos quedan, ya que su colección privada sufrió diversas y penosas vicisitudes a lo largo de los años (Monserrat, 1985a, 1986c), y por tanto, los ejemplares con los que contamos actualmente depositados en instituciones para revisar su labor son proporcionalmente escasos. Según Monserrat (1985a), de las 680 especies nominales de esta familia por él descritas, en su colección solo se conservaron tipos de 56 de ellas ( $\sin$ contar variedades). Aún así, y ya que tenía la costumbre de depositar ejemplares en instituciones y museos con los que mantenía buenas relaciones (Leraut, 1982; Monserrat et al., 2013, 2014), otro material ha podido conservarse. Por citar algunos ejemplos que ilustren su desordenada (e ingente) labor, mencionamos a Brooks \& Barnard (1990) en su listado de especies del mundo mencionan 17 géneros y nada menos que 179 especies nominales descritas por este autor (muchas a partir del propio material del Natural History Museum de Londres: Navás, 1913a, 1914b) que consideran como sinónimos de taxa previamente descritos, y por lo anteriormente anotado, nada menos que 146 especies nominales suyas en incertae sedis cuyo material tipo se ha destruido o no ha sido hallado para su adecuado estudio, o citemos a Legrand et al. (2008), quienes listan los tipos de especies de crisopas descritas por él, bien por él depositados en el Museo de Historia Natural de París (cedió material a esta institución durante 25 años, entre el 10 de julio de 1907 al 12 de noviembre de 1932, según consta en los archivos de donaciones de este museo) o bien presuntamente descritos a partir de material de esta institución, y mencionan 174 especies por él tipificadas y allí conservadas, y de ellas estos autores tuvieron que designar 88 lectotipos y detectaron la presencia de sintipos de otras 10 especies, aparte de proponer numerosas sinonimias de especies previamente descritas (incluso por él mismo) u otras especies problemáticas, bien ( $8 \mathrm{spp}$.) nomina dubia (con presunto extravío del material tipo) o bien (6 spp.) con ejemplares tipificados sobre especies nominadas que no se llegaron a describir. Todo esto nos ha inducido a no considerar, tampoco en este caso, las miles de citas de esta familia dadas por este autor en nuestra fauna, como anotaremos más adelante.

Pues bien, al margen de estos datos históricos, y en lo que respecta a la Fauna Ibero-Balear, se ha venido aportando más recientemente abundante información sobre esta familia, aunque aún existen multitud de lagunas y de áreas completamente inexploradas sobre este grupo, especialmente en Portugal y Baleares. Sobre ello, Monserrat \& Triviño (2013) anotan que sólo un $57,55 \%$ de la superficie ibérica y balear ha sido muestreada con el específico fin de recolectar neurópteros, y que sólo en un 30,82 \% de su superficie se han hallado estos insectos hasta aquella fecha, porcentaje que incrementamos con el abundante nuevo material ahora citado (para las especies de las Islas Canarias se recomienda Ohm \& Báez, 2004; Monserrat, 2008;
Báez \& Oromí, 2010 y Monserrat et al., 2014). Aunque anotaremos algunas referencias previas, debemos partir de Hölzel \& Ohm (1972) como punto de inicio para el estudio de los crisópidos ibero-baleares desde el punto de vista de la Entomología Contemporánea, obra que fijó la taxonomía y presencia de numerosas especies de nuestra fauna y aportó el límite occidental de numerosas especies europeas, hasta entonces impreciso. A esta obra le siguieron las aportaciones inmediatamente posteriores (Hölzel, 1972a, 1972b, 1973a, 1973b, 1974; Monserrat, 1977a, 1977b, 1978a, 1978b, 1979a, 1979b, 1979c).

Hace algunas décadas se publicó una obra de capital importancia: Aspöck et al. (1980), quienes revisan las especies europeas (en esta obra aún quedaban 19 especies nominales descritas por Navás de Europa, 4 de ellas crisópidos, en Nomina dubia), y más tarde se han venido aportando nuevas contribuciones con infinidad de nuevos datos faunísticos con muestreos en nuestra fauna sobre delimitación provincial que han ido rellenando muchas de las lagunas que poseíamos en nuestra fauna (ver Monserrat \& Triviño, 2013). A las especies de esta familia más comunes y habituales que históricamente fueron descritas o iban siendo conocidas en la Península Ibérica y/o Baleares, se han venido añadiendo más recientemente nuevas especies para nuestra fauna (Pseudomallada zelleri, Chrysopa dubitans, Brinckochrysa nachoi, Hypochrysa elegans, Nineta pallida, Chrysoperla mediterranea, C. ankylopteryformis, C. pallida, C. lucasina, C. agilis, C. mutata, Cunctochrysa baetica, Cunctochrysa cosmia, Suarius iberiensis, S. tigridis, S. walsinghami, etc.) (ver referencias en cada una de las especies), así como infinidad de nuevas citas, opiniones, sinonimias y nuevos elementos (Monserrat \& Díaz-Aranda, 1989a, 1989c; Monserrat \& Rodrigo, 1992; Carvalho, 1997; Henry et al., 2002, 2003; Monserrat, 2005, 2008, 2010, 2011; Monserrat et al., 2013, 2014, etc.).

Al margen de la corología, sobre la biología de las especies ibéricas, y de entre toda esta información que se iba recabando, destaca F. Marín (Marín \& Monserrat, 1987, 1991b; Marín, 1994) con los primeros estudios ibéricos sobre comunidades de crisópidos, bien a nivel de determinado ecosistemas o bien de una circunscripción provincial, y Monserrat \& Marín $(1994,2001)$ compendiando toda la información existente hasta entonces sobre su preferencia de sustrato vegetal de las distintas especies de nuestra fauna, información que se complementa con la excelente labor de L.M. Díaz-Aranda en el conocimiento sobre las fases juveniles de la mayoría de nuestras especies (Díaz-Aranda \& Monserrat, 1988d, 1990a, 1990b, 1991, 1992, 1994, 1995, 1996; Monserrat \& Díaz-Aranda, 1989a, 1989b, 1989c, 2012; DíazAranda, 1992; Díaz-Aranda et al., 2001).

Ante todo ello, y dada la multitud de artículos faunísticos y de otra índole que han aportado numerosos datos sobre la taxonomía, la morfología, la corología, los estadios larvarios y la biología de las especies 
ibero-baleares, puede indicarse que en el caso de la Fauna Ibérica, y para la parte española en particular, han acabado por conformar una de las familias mejor conocida y más rica en especies dentro de la Fauna Europea, representando la fauna más abundante y diversa del Continente Europeo, ya que en ella están representados todos los géneros conocidos en Europa (Hölzel \& Ohm, 1972; H. Aspöck et al., 1980, 2001; H. Aspöck, 1992; Monserrat \& Díaz-Aranda, 2012), y en ella están presentes 50 especies dentro de la Fauna Europea (73 spp.) (H. Aspöck et al., 1980, 2001; Monserrat \& Triviño, 2013), que en esta contribución revisamos. Como anteriormente hemos indicado, también muchas de las especies ibéricas están citadas de Portugal: Carvalho (1997) recoge 25 especies citadas en Portugal continental y Letardi et al. (2013) listan 28 especies en esta parte ibérica de Portugal (si bien alguna de estas citas, como Chrysopa nigricostata o $C$. regalis han cambiado de estatus) y alguna otra novedad aportamos en esta contribución (Italochrysa stigmatica, Nothochrysa fulviceps). Con respecto a la fauna de las Islas Baleares (no existe, de momento, ningún endemismo conocido), Monserrat (2005) recopila toda la información bibliográfica existente, y anota 15 especies, pone en duda algunas citas antiguas y aporta nuevos elementos faunísticos, y Monserrat (2008) aportan nuevas correcciones a citas pretéritas, anotando numerosas citas inéditas.

También Monserrat (2011) ha resuelto la posición taxonómica de las especies ibéricas pertenecientes a esta familia que, hasta entonces, poseían una situación taxonómica dudosa o sin resolver, y Monserrat \& Triviño (2013) aportan la lista de las especies ibero-baleares de esta familia con sus sinonimias y diferentes combinaciones nomenclaturales bajo las cuales han sido citadas en la bibliografía, ponen en cuestión la validez de algunas citas más recientes: Chrysopa abbreviata Curtis, 1834, Chrysopa dubitans (McLachlan, 1887) y Chrysopa walkeri McLachlan, 1893, y en base a las citas fiables existentes y a material inédito, aportan un cartografiado de la distribución de las especies ibero-baleares, poniendo en evidencia que existen enormes áreas aún no prospectadas, y es de esperar que nuevas sorpresas nos depare el futuro. Por último Monserrat et al. (2014) aportan numerosas de estas citas inéditas e incrementan el número de especies conocidas en las faunas canaria, ibérica y europea, revalidando Cunctochrysa cosmia (anteriormente considerada sinónima de Chrysopa nigricostata) como especie válida.

En cualquier caso, la situación no está completamente resuelta, ya que recientemente nuevos elementos han aparecido dentro del complejo y problemático género Chrysoperla (Cianchi \& Bullini, 1992; Thierry et al., 1992, 1994, 1996, 1998, 2011; Brooks, 1994; Henry, 1994; Duelli, 1995, 2009; Henry et al., 1999, 2001, 2002, 2003, 2011, 2013, 2014, 2015; Duelli et al., 2014, 2015, etc.), así como en el grupo de especies de Pseudomallada prasinus (Pantaleoni, 1988,
1990; Duelli, 1989; Letardi \& Pantaleoni, 1996; Hölzel, 1998; Hölzel \& Weisser, 1999; H. Aspöck et al., 2001; Duelli et al., 2002, etc.), que han introducido nuevas problemáticas y cuestiones por revisar y/o solucionar.

Con respecto a la multitud de citas bibliográficas existentes sobre nuestra fauna dentro de esta familia, conviene detenerse y comentar al lector algunos puntos. Partimos de la base que se trata de la familia que incluye, dentro de los neurópteros, una mayor cantidad de especies, sinonimias, variedades y combinaciones citadas (ver cada caso en cada una de las especies), y comentemos que transcribir a la presente contribución toda esta información recopilada durante estas pasadas décadas, sería una estéril e inútil labor, sin más interés que el meramente enciclopédico, ya que estamos hablando de miles de registros bibliográfícos, muchos de ellos sin ningún valor taxonómico o faunístico real, especialmente en el caso de la mayor parte de las cientos de variedades descritas y citadas en nuestra fauna por L. Navás (a veces la misma variedad nominal en especies diferentes), muchos otros de identificación cuestionable dadas por numerosos autores, mayoritariamente aficionados o no especialistas, del siglo pasado (ver más adelante por ejemplo la cita de Nineta vittata en Málaga de Walker, 1853), y otros muchos hoy día de muy dudosa asignación al haber cambiado la situación taxonómica de muchas especies y haberse desglosado y descrito nuevas especies próximas que anteriormente no podrían haber sido consideradas (Chrysopa, Cunctochrysa, Brinckochrysa, Chrysoperla, Pseudomallada, etc.), y por ello es hora de abandonar este lastre bibliográficonomenclatural-faunístico y basarnos en información más reciente (últimos 40-45 años) dada por autores mucho más solventes. Por ello, solo registraremos las citas bibliográficas donde cada especie se describió, lo hayan sido o no en base a material ibérico, y únicamente daremos las citas antiguas y haremos los comentarios pertinentes sobre los taxa más problemáticos que hayan de comentarse. Bajo este criterio, y aunque existen algunos artículos de autores solventes que hacen referencia a alguno de los países ibéricos en la distribución de alguna especie, y así las hemos recogido en cada caso, para esta recopilación bibliográfica partimos de los artículos de H. Hölzel, y en particular de Hölzel \& Ohm (1972) que, como hemos indicado, representa el primer artículo que trata con rigor contemporáneo a los crisópidos de la Península Ibérica, y solo vamos a recopilar las citas dadas posteriormente en el último tercio del pasado siglo y el presente por autores solventes, obviando pues las citas antiguas.

No obstante, es cierto que algunas citas antiguas sí podrían comentarse y/o considerarse, y Monserrat \& Triviño (2013) ya indicaban que muchas especies son inequívocas y fácilmente distinguibles en base a caracteres de morfología externa, y con respecto a sus citas antiguas, cabe suponer que algunas de estas especies son/eran inconfundibles por los autores que las citaron 
(bajo diferentes denominaciones) en base a esta morfología externa (Italochrysa italica, Italochrysa stigmatica, Nothochrysa capitata, Nothochrysa fulviceps, Rexa almerai, Hypochrysa elegans, Chrysotropia ciliata o la mayoría de las especies de Chrysopa, que ahora mencionaremos), con lo que podrían, sin gran margen de riesgo, ser consideradas, aunque más de una vez se han detectado errores de identificación en estas especies (Monserrat, 1986b).

Más problemático es el género Pseudomallada, pero igual creemos que ocurre con alguna de sus más inconfundibles especies (Pseudomallada alarconi, $P$. ventralis, $P$. genei, $P$. granadensis, $P$. ibericus, $P$. subcubitalis, $P$. venosus) cuyas citas, sin gran margen de riesgo, podrían ser consideradas. Dentro de este género, también debemos referirnos a Pseudomallada abdominalis (Brauer, 1856), especie centroeuropea de la que más adelante hablaremos.

También son problemáticas las citas antiguas de ciertos géneros como Nineta, especialmente sus hembras, y no sólo referencias antiguas (alguna corregida por Hölzel, 1965b y Monserrat, 1986b), sino alguna mucho más reciente, y ejemplo tenemos en la cita de Nineta flava en Las Alpujarras, Granada, dada por Hölzel \& Ohm (1972), que siempre nos había parecido dudosa o cuestionable (Monserrat, 2010, 2011), y que con el nuevo material recientemente recolectado en esta zona (Monserrat, 2013), hemos definitivamente asignado a $N$. guadarramensis, que era lo sospechado por nosotros y que es más acorde con su distribución en la península de ambas especies. Por todo ello, en las especies de este género, sólo han de tenerse en cuenta las citas confirmadas o dadas por autores de reconocida solvencia (ver más adelante $N$. vittata y $N$. flava).

Similar comentario debemos hacer respecto a algunas especies pertenecientes al género Chrysopa, como es el caso de Chrysopa walkeri McLachlan, 1893, ya que desde que Navás (1924a: 159) la cita como probable en Cataluña y la incluye en la clave de especies de esta región, y posteriormente (Navás, 1925: 73) la incluye en su clave de especies ibéricas, aún mencionando expresamente que no existe en la Península Ibérica (Navás, 1925: 75), son numerosas las reseñas bibliográficas que comentan o hacen referencia a la península (España) en la distribución de esta especie (Nagler, 1958: 301; Hölzel, 1964a: 43; Eglin, 1968: 320; Ohm \& Remane, 1968: 224; Sengonça, 1980: 54), pero no hay datos que lo avalen (Hölzel \& Ohm, 1972), por ello esta especie, de momento, no ha sido considerada. Tampoco hemos considerado como ibérica a Chrysopa abbreviata Curtis, 1834, especie sibérica, marcadamente estenotópica y asociada a medios halófilos, dunares y costeros, a veces en latitudes boreales (Stitz, 1928; Greve, 1984; Plant, 1994; Letardi, 1997) y a vegetación de rivera, herbácea y baja en medios inalterados (Zelený, 1971a; Kovrigina, 1985; Bozsik, 1994), desde zonas costeras a altitudes de hasta $2.000 \mathrm{~m}$ en Asia central, ya que la única cita de esta especie en la fauna ibérica fue dada por
Whittington (2002: 378) con referencia: Spain (sin más datos). Ya Monserrat (2011) discutía y descartaba varias citas cuestionables o erróneas dadas por este autor para la fauna de la Península Ibérica, que fueron desechadas, y salvo esta cita, que consideramos muy poco fiable/creíble, esta especie no ha sido nunca relacionada con nuestra fauna (H. Aspöck et al., 1980, 2001), por lo que tampoco ha sido considerada en este estudio. También debemos mencionar que seguimos manteniendo nuestras reservas sobre la cita en Murcia de Chrysopa dubitans (McLachlan, 1887) dada por Hölzel \& Ohm (1972) y que ha generado varias referencias posteriores para la fauna ibérica (ver más adelante Chrysopa dubitans), ya que siendo precisamente ésta una zona especial- e intensamente muestreada por nosotros (Monserrat, 1984d, 1985b, 1987; Díaz-Aranda \& Monserrat, 1988a, 1988c; Monserrat \& Díaz-Aranda, 1989a, 1989c; Marín \& Monserrat, 1991a; Monserrat \& Rodrigo, 1992), nunca la hemos hallado, y nos reservamos cuestionar la autenticidad de la identificación, aún así ha sido incluida en nuestro estudio, a la espera de que nuevos datos nos lo confirmen. La especie es conocida del Mediterráneo oriental (Egeo, Chipre, Israel, Palestina, Turquía, Líbano, Cáucaso, Irán, Afganistán, Pakistán, Kazakstán, Mongolia y China).

También resultan problemáticas, y por ello no han de considerarse, las numerosas citas antiguas de Chrysoperla carnea s.l. y sus sinonimias, confundibles con especies de este género posteriormente descritas, ante la alta posibilidad de mezclar datos de unas y otras, hecho que afecta al material no revisado o a citas anteriores de descubrirse el conjunto de especies crípticas que conforman Chrysoperla carnea s.l., según comentaremos al tratar este género.

Por todo ello, y de todas estas especies problemáticas, sólo han sido contempladas las citas basadas en material que ha sido posteriormente revisado (Hölzel \& Ohm, 1972; Aspöck et al., 1980; Monserrat, 2008, 2010, 2011; Monserrat et al., 2014) y, en cualquier caso, anotadas algunas correcciones en las fechas reales de publicación de algunos taxa, aportamos en la lista de especies según el criterio adoptado, y partiendo del trabajo de Hölzel \& Ohm (1972), se han teniendo en cuenta todas las recientes aportaciones, y que, como hemos indicado, han llevado a esta familia a ser una de las más ricas en especies dentro del continente europeo (ver listado de taxa), y en base a ello nos limitaremos a recopilar de cada especie su distribución real en la Península Ibérica y Baleares hoy conocida, y los datos de fenología y distribución altitudinal revisada y constatada de cada una de ellas, así como los datos existentes sobre sus fases preimaginales, reseñando la reciente contribución de Monserrat \& Díaz-Aranda (2012) sobre los estadios juveniles de la mayoría de las especies ahora tratadas.

Obviamente, al tratarse de un grupo con interés en la Entomología Aplicada, existen multitud de artículos en los que se cita la presencia de la familia Chrysopidae 
en diversos estudios aplicados realizados en el solar ibérico, así como multitud de artículos de interés aplicado que la citan, sean sobre sus imagos o sus larvas, en diferentes cultivos, referencias que mayoritariamente escapan a la intención de esta contribución (ejs.: Campos \& Ramos, 1983, 1985; Ramos et al., 1983; Campos, 1986, 1989, 2001; Ros et al., 1988; Bichão \& Araújo, 1989; Araújo \& Bichão, 1990; Boelpaepe et al., 1992; Núñez Pérez et al., 1992; Pantaleão et al., 1993; McEwen \& Ruiz, 1994; McEwen et al., 1994; Pantaleão, 1994; Montiel \& Santaella, 1995; Viñuela et al., 1996; Carvalho, 1997; Michelena \& Sanchís, 1997; Morris et al., 1998; Vilajeliu et al., 1998; Martins et al., 1999, 2002; Morris \& Campos, 2000, 2006; Ocete et al., 2000; Ruiz Torres \& Montiel Bueno, 2000, 2001, 2002; Ruano et al., 2001, 2004; Urbaneja et al., 2001; Alvis et al., 2003; Corrales \& Campos, 2004; Pérez Otero et al., 2005; Porcel et al., 2011, 2013; Nave et al., 2012, etc., por citar algunos).

Como en muchas otras familias de neurópteros, muchas especies de crisópidos son excelentes bioindicadores de la calidad y grado de conservación del Medio Ambiente (New, 1991, 1998; Gepp, 1999), y quizás conviene aprovechar esta oportunidad para mencionar un pequeño apunte sobre nuestra experiencia en la recolecta de crisópidos en la Península Ibérica durante las últimas cuatro décadas, en las que, como hemos observado en otros grupos de neurópteros, hemos percibido una franca regresión en sus poblaciones, con una progresiva disminución de sus efectivos dentro de numerosas poblaciones respecto a lo que, no hace demasiado tiempo, antes obteníamos, incluso potenciando más recientemente las unidades de esfuerzo, intensidad y número de investigadores para recolectarlos, y son un ejemplo más del silencioso e imparable deterioro sobre la Naturaleza que las acciones del hombre están provocando (Tellería, 2013) sin que apenas sea perceptible, salvo que la edad de algunos entomólogos lo aprecie, y lo que es más grave, sin que, en muchos casos, las autoridades "competentes" hagan nada (o casi nada) por detener este lamentable deterioro. Esto ya se ha manifestado en otras zonas, algunas muy distantes (y así lo comenta Zimmerman, 1957 en los crisópidos de Hawái), hasta el punto de que algunas especies forman parte de la lista de especies amenazadas o en peligro de extinción (Gepp, 1981, 1983a, 1999; Saure \& Getsberger, 1991; New, 1991; Pröse, 1992; Tröger, 1993; Duelli, 1994; Röhricht \& Tröger, 1998; Ivanov \& Krivokhatsky, 1999, 2002, 2004; Pröse \& Gruppe, 2003; Röhricht, 2004, etc.).

Como no podía ser de otra forma, también los crisópidos son actualmente objeto de atención en Internet (McEwen \& Oswald, 1998; Röhricht, 2002; Letardi, 2002, etc.), y especialmente lo son en multitud de foros que recientemente han aparecido, y por la misma razón aducida para las citas bibliográficas de nuestras especies, estos registros podrían considerarse (siempre que los datos aportados en estas webs sean los correctos), y así lo hemos en tenido en cuenta en algunos casos al anotar parte del nuevo material ahora citado.

Como conclusión de este apartado, indiquemos que a pesar de toda la información publicada hasta la fecha, y en lo que respecta a la Fauna Ibero-Balear, la familia Chrysopidae no ha sido objeto de una revisión general basada en toda la información y el estudio del material del que disponemos en la actualidad. Por otra parte, toda la información existente sobre este orden de insectos en la Península Ibérica y Baleares está muy dispersa o aún es parcialmente desconocida, y consideramos que es de gran importancia subsanar dicha laguna aportando unas claves actualizadas en castellano para la identificación de las especies y efectuando una revisión completa, que es lo que pretendemos en la presente contribución.

En ella se realiza una revisión de la familia Chrysopidae de la Península Ibérica e Islas Baleares, en base a toda la información bibliográfica existente relacionada con sus especies, sobre sus sinonimias comúnmente aceptadas y sobre las diferentes combinaciones nomenclaturales bajo las cuales han sido citadas en la bibliografía (siempre nos quedará alguna en el "tintero") y sobre el nuevo material inédito ahora estudiado, aportando el listado taxonómico actualizado de las especies conocidas en la zona (introduciéndose algunos cambios nomenclaturales y de correcta datación de algunas especies respecto a lo que sobre ellas ha venido considerándose), así como una clave de identificación de sus subfamilias y géneros (imagos y larvas) y sus especies (imagos), y de cada una de ellas, anotamos, cuando sea preciso, datos sobre su taxonomía, morfología y/o variabilidad, y los datos conocidos sobre sus estadios juveniles, cuando existan, así como toda la información recabada sobre su biología, distribución geográfica, fenológica y altitudinal, tanto en general, como referente a los datos conocidos en nuestra fauna.

\section{Material y métodos}

Para la realización de esta revisión, y sobre la base de la información general conocida sobre esta familia que nos pueda interesar (1.041 referencias bibliográficas consultadas y citadas), se han tenido en cuenta todos los taxa citados en nuestra fauna a partir de toda la información bibliográfica existente sobre ella (160 referencias bibliográficas consultadas y citadas), así como todo el material que previamente hemos estudiado (19.699 ejemplares), que sumado al material considerado previamente citado por otros autores alcanza los 20.368 ejemplares, y que con el nuevo material ahora anotado para 25 especies (299 ejemplares), hacen un total de 20.667 ejemplares en los que basamos esta revisión.

Anotada la relación taxonómica y sistemática de los taxa que nos competen, sobre la que se proponen algunas consideraciones taxonómicas y de correcta 
datación, se aporta una clave de identificación para los imagos de las subfamilias, géneros y especies y una clave a nivel genérico de sus fases larvarias. Para la realización de estas claves aportamos imágenes de las alas de casi todas las especies (Figs. 86-97, 130-132, $156,157,160,177-198)$, así como otros detalles de las mismas (Figs. 17, 18, 83-85, 136, 137), junto a caracteres de morfología y/o pigmentación tegumentaria necesarios para la identificación específica (Figs. 19-21, 98-120, 138, 139, 158, 159, 161, 173), y las imágenes del natural anotadas (Figs. 1-12) pueden ayudar puntualmente en este cometido. Para comodidad del lector y para facilitar su detección, señalamos con asteriscos, letras y/o flechas los elementos morfológicos a destacar (Figs. 83-97). En la morfología alar (Fig. 16) anotada indicamos los elementos y terminología que son habitualmente utilizados. Como información complementaria aportamos ejemplos de la genitalia masculina y/o femenina en la mayoría de los géneros tratados, anotando la terminología habitualmente utilizada (Figs. 22-27, 121-129, 133-135, 140-155, 162-176).

En esta revisión, y de cada una de las especies tratadas, aportamos la información sobre su denominación original con el autor y año de su descripción (aunque hubiera sido basada en material no ibero-balear), y recopilamos y ordenamos toda la información existente recientemente publicada sobre nuestra fauna (partiendo, como hemos dicho, de Hölzel \& Ohm, 1972), referente a los crisópidos ibérico-baleares, datos que se exponen en cada una de las especies tratadas, recopilando, cronológicamente ordenadas, todas las referencias bibliográficas existentes, a partir de las cuales recabamos la información existente sobre cada una de ellas en nuestra fauna. Anotamos los autores de estas citas, su fecha de publicación y la/s página/s donde se aporta información sobre su biología (bio), descripción original (d), distribución geográfica (dis), morfología del huevo (h), inclusión en claves (key), larva (1), aparezca en un listado (list), morfología del imago (mf), pupa (p), simple referencia a alguno de los países de la Península Ibérica, o nota sobre la especie (rf), o sobre su taxonomía (tx).

Los taxa y sus referencias bibliográficas se exponen tanto bajo la denominación nomenclatural actualmente aceptada, como bajo las sinonimias habitualmente reconocidas $\mathrm{u}$ otras combinaciones nomenclaturales en las que han sido citadas en la bibliografía iberobalear, pero anotamos que aunque mayoritariamente este listado es taxonómico-nomenclatural, en algún caso (ej.: Brinckochrysa) alguna de las especies citadas no son sinónimas de la especie que se está tratando, sino que, siendo especies válidas, así han sido citadas en nuestra fauna, aunque posteriormente se hayan corregido estas citas y/o se hayan asignado a la especie tratada. En las obras de carácter general, solo se han anotado los datos referentes al material ibérico citado. Así mismo, y alfabéticamente ordenadas, anotamos para cada especie el listado de las diferentes combinaciones nomenclaturales y especies sinónimas y categorías infra-subespecíficas (variedades, aberraciones, formas) bajo las que, anteriores a Hölzel \& Ohm (1972), han sido citadas en la bibliografía ibero-balear, sin que esta recopilación implique la total aceptación de estas citas antiguas, ni su vinculación taxonómica real.

Como hemos anotado en el apartado anterior, en principio, y por las particulares diferencias morfológicas existentes en alguna de las diferentes especies que tratamos, cabría suponer que algunas de las identificaciones dadas por los autores pretéritos podrían ser acertadas, sin embargo estaríamos hablando de dos, tres, cuatro especies y muy pocas citas en comparación con las miles de citas existentes sobre el grueso de especies de nuestra fauna. Por todo ello, para evitar la utilización de datos poco fiables citados en la bibliografía y correr el riesgo de asumir como ciertos datos basados en identificaciones erróneas o incorrectas, mezclando información de unas y otras especies, y habida cuenta del abundante material que hemos estudiado, para la realización del estudio comparativo sobre la biología, fenología y distribución geográfica, altitudinal y fenológica de las especies ibéricas, sólo se ha tenido en cuenta el material revisado y estudiado por nosotros, sea el material que ya hemos estudiado perteneciente a diferentes colecciones e instituciones o sea el material recolectado por nosotros en los cuarenta últimos años en diferentes puntos de la Península Ibérica y Baleares, $y$ que en ambos casos ya ha sido publicado, o sea el nuevo material inédito por nosotros recolectado o estudiado, y que ahora anotamos. También puntualmente se han tenido en cuenta los datos aportados por autores recientes de reconocida solvencia.

Tras este apartado bibliográfico, y para cada una de las especies, se citan los datos generales conocidos sobre ellas (distribución general, hábitat y plantas soporte sobre las que han sido mayoritariamente recolectadas, fenología y distribución altitudinal), y estos elementos son posteriormente expuestos exclusivamente en base a los datos conocidos y corroborados para nuestra fauna, bien sobre su biología (anotándose el hábitat y las plantas sobre las que mayoritariamente han sido halladas), su distribución geográfica conocida en la zona de estudio, su fenología (en números romanos para indicar los meses en los que han sido recolectado los imagos, no habiendo sido considerados los datos de los ejemplares obtenidos ex ovo y/o cultivados artificialmente en condiciones no naturales, y con indicación de interrogación si algún dato es dudoso), su distribución altitudinal, así como la información existente sobre sus fases juveniles (en su caso conocidas).

Cuando hemos considerado necesario citamos los datos más destacables sobre su taxonomía, morfología externa y/o variabilidad, y para las especies de identidad más problemática o con citas cuestionables y/o dudosas en nuestra fauna se anota un apartado donde se aportan los datos que hemos considerado necesario comentar. 
Aunque mayoritariamente existen datos en la morfología externa que ayudan a la identificación de las especies ibérico-baleares de esta familia, y así los utilizamos en las claves, el estudio de la genitalia es recomendado para especies menos definidas externamente respecto a otras (Brinckochrysa, Peyerimhoffina, Chrysotropia) (Figs. 133-135, 144-146, 165-176), y es necesario para la segura y correcta identificación, especialmente en todas las especies de algunos géneros (Nineta) (Figs. 140-143) y en ejemplares inmaduros o escasamente pigmentados de algunas especies. Para ello se procedió a la separación de los últimos cuatro segmentos del abdomen mediante disección. $\mathrm{Si}$ el material estaba conservado en seco se ha hidratado previamente durante 24 horas por inmersión en agua, y posteriormente se han aclarado estos últimos segmentos con hidróxido potásico al $10 \%$ templado para acceder a las estructuras genitales. Una vez realizado este proceso hemos introducido la genitalia en glicerina dentro de un portaobjetos excavado para su observación mediante un estéreo-microscopio ZEISS ${ }^{\circledR}$ STEMI-SV8 con cámara clara de dibujo incorporada, que también ha sido utilizado para la observación, identificación y descripción de la mayoría de los ejemplares.

El material estudiado se cita ordenado alfabéticay cronológicamente, indicándose en función de los datos de captura disponibles y por este orden: país, provincia/isla, localidad de captura, coordenadas, altitud en msnm (consideramos $10 \mathrm{~m}$ como dato a nivel del mar), fecha de captura, número de $\widehat{\widehat{\partial}} \hat{\text {, de }}$ 우 $\mathrm{y} / \mathrm{o}$ de larvas estudiados, plantas, substrato o medio sobre el que han sido recolectados (por economía de espacio, los géneros de las plantas sobre las que se han hallado los ejemplares se citan apocopados, una vez han sido citados dentro de cada una de las especies mencionadas) y recolector (por igual motivo, sólo se anota su recolector si no ha sido el autor de esta contribución). El material citado permanece en la colección de V. J. Monserrat (depositado en la Universidad Complutense de Madrid, España), salvo el correspondiente a la valiosa información amablemente cedida por el Dr. Axel Gruppe (indicado en el material estudiado como A. Gruppe), parte de la cual ha sido incorporada en esta contribución.

Las fotografías de realizaron por los autores que en cada caso se indican, y en las páginas web anotadas puede recabarse información complementaria. Los dibujos se realizaron a mano alzada con cámara clara y, tras pasarse a tinta china sobre papel vegetal, se escanearon y se retocaron utilizando el programa de diseño Corel Paint Shop Pro Photo XI, y el software Adobe Photoshop CS5 Extended Version 12.0 fue utilizado para el procesamiento de alguna de las imágenes.

Para la ordenación sistemática general se sigue a Brooks \& Barnard (1990) con las modificaciones que han aparecido posteriormente. Para la distribución general de las especies se ha seguido a H. Aspöck et al. $(1980,2001)$, y sobre la preferencia de sustrato vegetal de las especies citadas puede consultarse Aspöck et al. (1980), Zelený (1984b), y en nuestra fauna Monserrat \& Marín (1994, 2001).

\section{Los Chrysopidae de la Península Ibérica y Baleares}

Como hemos indicado, y como paso previo al listado de los taxa considerados, es necesario realizar y comentar algunos cambios nomenclaturales y de correcta datación en la descripción original de algunas especies respecto a lo que sobre ellas ha venido considerándose.

\section{CAMBIOS NOMENCLATURALES Y EN LA CORRECTA DATACIÓN DE ALGUNAS ESPECIES}

Consideramos necesario comentar algunos elementos de especies ibéricas descritas por autores previos, sean de Rambur o de Navás.

Ya hemos citado la obra de J.P. Rambur (18011870), autor francés de especial interés en nuestra fauna, pues fue el que inició la andadura en el conocimiento de los neurópteros ibéricos. Pues bien, es conocido que en su obra Rambur (1837-1840), Faune entomologique de l'Andalousie. Vol. 2. Paris, la parte de neurópteros nunca fue publicada, salvo la lámina 9 , fechada el 31 de Diciembre de 1838 (Higgins, 1958: 315). En esta lámina varias especies nominales de neurópteros (no sólo de la familia que tratamos) son mencionadas e ilustradas, y son bien reconocibles dentro de las especies ibéricas/andaluzas. Estas especies, junto a otras, serán formalmente descritas en su obra posterior Rambur (1842), Histoire Naturelle des Insectes, Névroptères. Librairie encyclopédique de Roret. Fain et Thunot, Paris. Para la fecha de publicación de esta obra, Esben-Petersen (1922: 621) anota "Rambur's work was published in the week ending 31st December, 1842, ...", y así ha sido aceptado desde entonces.

Pues bien, en toda la bibliografía posterior, estos taxa han sido citados como Rambur (1839), como Rambur (1842) o indistintamente como Rambur (1839) o Rambur (1842). Según lo establecido en el Código Internacional de Nomenclatura Zoológica (ICZN) Capítulo 4 (Art. 12.2.7), hasta el 1 de enero de 1931, una imagen sola con un nombre científico hace disponible este último por indicación. Los nombres de las especies nominales nuevas están disponibles en la lámina 9, de Rambur (1838), y las citas de 1942 deben considerarse como un uso posterior y no como una nueva descripción. Igual ocurre con todas las referencias bibliográficas posteriores dadas sobre ellas de forma incorrecta, y aunque así fueron citadas, ahora lo reparamos en la relación de citas de cada una de ellas mencionadas en la bibliografía, independientemente de la fecha utilizada por cada autor. 
Por ello, consideramos que han de utilizarse: Hemerobius stigmaticus Rambur, 1838 non $1842=$ Italochrysa stigmatica (Rambur, 1838) Hemerobius venosus Rambur, 1838 non $1842=$ Pseudomallada venosus (Rambur, 1838) Hemerobius grandis Rambur, 1838 non $1842=$ Italochrysa italica (Rossi, 1790) y

Hemerobius pallens Rambur, 1838 non $1842=$ Chrysopa pallens (Rambur, 1838)

Aprovechamos esta oportunidad para mencionar que igual ocurre en esta obra (Rambur, 1838) con otros géneros y/o especies nominales de otras familias/géneros de neurópteros, que mayoritariamente han sido citados con datación incorrecta en la bibliografía posterior:

Ascalaphus agrionoides Rambur, 1838 non $1842=$ Bubopsis agrionoides (Rambur, 1838). Este nombre: Bubopsis agrionoides (Rambur, 1838) y no el utilizado por Rambur, 1842: 353 (Bubopsis agrioides) es el que debe usarse (a pesar de la histórica e indistinta utilización de uno u otro nombre), y no puede considerarse como nomen nudum, según indicaba Weele (1909: 272).

Ascalaphus baeticus Rambur, 1838 non $1842=$ Libelloides baeticus (Rambur, 1838)

Dilar Rambur, 1838 non 1842

Dilar nevadensis Rambur, 1838 non 1842

Respecto a las especies nominales descritas por Navás en nuestra fauna también debemos hacer algún comentario.

\section{Chrysopa almerai Navás, 1919}

Esta especie fue descrita de España (Murcia) por Navás (1919: 15) y fue considerada por Hölzel (1973a: 78) como sinónima posterior de Rexa lordina Navás, 1920, especie tipo del género, y descrita de Argelia (Hammam R'irha). Según Hölzel (1973a): Rexa lordina Navás, 1919= Chrysopa almerai Navás, 1920) (sic), y como tal y con estos datos ha sido desde entonces considerada.

Sin embargo las fechas supuestas por Hölzel (1973a) son erróneas. En la cubierta y la portada del volumen donde esta especie fue descrita reza: "Memorie della Pontificia Accademia Romana dei Nuovi Lincei. Serie Seconda iniziata per ordine della Santità di Nostro Signore Papa Benedetto XV. Volume Quinto. Roma Tipografia Pontificia nell'Istituto Pio IX (Via S. Prisca N. 8-9), 1919" (sin otra más precisa información), fecha confirmada por el Dr. Alessandro Romanello de la Biblioteca dei Lincei, y que se ajusta a las anotaciones de L. Navás: "Caesaraugustae (Zaragoza), 16 Aprilis 1918 (V SERIES), 10 dec. 1918 (VI SERIES), 29 Ianuarii 1919" (VII SERIES) del artículo, y a la dedicatoria de Chrysopa almerai "Scribebam mense Martii 1919". Por ello, y ya que no existe otra fecha más precisa, según el capítulo 5, artículo 21.2 y 21.3 del Código Internacional de Nomenclatura Zoológica (ICZN), la fecha de publicación de esta especie sería el 31 de diciembre de 1919.

Por el contrario, en la página vii del volumen donde fue descrita Rexa lordina, reza: "No. 2. Containing pages 253-358 and Plates I.-VI., issued January 20th, 1920", datos que se repiten en la portada del vol. XXVI "No.2. Pages 253-358. Plates I.-VI. Issued January 20th, 1920", por lo que la fecha de publicación de esta especie es el 20 de enero de 1920.

Ante todo ello, y según el capítulo 6, artículo 23 del citado Código, se propone esta nueva datación y combinación y se reestructura la anterior sinonimia:

Rexa Navás, 1919 non 1920

Rexa almerai $($ Navás, 1919) n. comb. $=($ Rexa lordina Navás, 1920) n. syn.

Siendo pues Rexa almerai sinónima anterior de Rexa lordina, y es este nombre el que debe usarse.

LISTADO TAXONÓMICO DE SUBFAMILIAS, TRIBUS, GÉNEROS Y ESPECIES CONSIDERADOS*

Chrysopidae Schneider, 1851

Nothochrysinae Navás, 1910

Género tipo: Nothochrysa McLachlan, 1868

Género Nothochrysa McLachlan, 1868

Especie tipo: Chrysopa fulviceps Stephens, 1836

Nothochrysa capitata (Fabricius, 1793)

Nothochrysa fulviceps (Stephens, 1836)

Género Hypochrysa Hagen, 1866

Especie tipo: Chrysopa nobilis Schneider, 1851

Hypochrysa elegans (Burmeister, 1839)

Chrysopinae Schneider, 1851

Género tipo: Chrysopa Leach, 1815

Tribu Belonopterygini Navás, 1913

Género tipo: Belonopteryx Gerstaecker, 1863

Género Italochrysa Principi, 1946

Especie tipo: Hemerobius italicus Rossi, 1790

Italochrysa italica (Rossi, 1790)

Italochrysa stigmatica (Rambur, 1838)

Tribu Chrysopini Schneider, 1851

Género tipo: Chrysopa Leach, 1815

Género Chrysopa Leach, 1815

Especie tipo: Hemerobius perla Linnaeus, 1758

Chrysopa dorsalis Burmeister, 1839

Chrysopa dubitans McLachlan, 1887 (?)

Chrysopa formosa Brauer, 1851

Chrysopa nierembergi Navás, 1908

Chrysopa nigricostata Brauer, 1851

Chrysopa pallens (Rambur, 1838)

Chrysopa perla (Linnaeus, 1758)

Chrysopa phyllochroma Wesmael, 1841 (?)

Chrysopa viridana Schneider, 1845

Género Chrysoperla Steinmann, 1964

Especie tipo: Chrysopa carnea Stephens, 1836

Chrysoperla agilis Henry, Brooks, Duelli \& Johnson, 2003 
Chrysoperla ankylopteryformis Monserrat \& Díaz-Aranda, 1989

Chrysoperla carnea (Stephens, 1836)

Chrysoperla lucasina (Lacroix, 1912)

Chrysoperla mediterranea (Hölzel, 1972)

Chrysoperla mutata (McLachlan, 1898)

Chrysoperla pallida Henry et al., 2002

Género Chrysotropia Navás, 1911

Especie tipo: Chrysopa lacroixi Navás, $1911=$

Chrysopa ciliata Wesmael, 1841

Chrysotropia ciliata (Wesmael, 1841)

Género Cunctochrysa Hölzel, 1970

Especie tipo: Chrysopa albolineata Killington, 1935

Cunctochrysa albolineata (Killington, 1935)

Cunctochrysa baetica (Hölzel, 1972)

Cunctochrysa cosmia (Navás, 1918)

Género Pseudomallada Tsukaguchi, 1995

Especie tipo: Chrysopa cognatella Okamoto, 1914

Pseudomallada abdominalis (Brauer, 1856)

Pseudomallada alarconi (Navás, 1915)

Pseudomallada clathratus (Schneider, 1845)

Pseudomallada flavifrons (Brauer, 1851)

Pseudomallada genei (Rambur, 1842)

Pseudomallada granadensis (Pictet, 1865)

Pseudomallada ibericus (Navás, 1903)

Pseudomallada inornatus (Navás, 1901)

Pseudomallada marianus (Navás, 1905)

Pseudomallada picteti (McLachlan, 1880)

Pseudomallada prasinus (Burmeister, 1839)

Pseudomallada subcubitalis (Navás, 1901)

Pseudomallada venosus (Rambur, 1838)

Pseudomallada ventralis (Curtis, 1834)

Pseudomallada zelleri (Schneider, 1851)

Género Nineta Navás, 1912

Especie tipo: Hemerobius flavus Scopoli, 1763

Nineta flava (Scopoli, 1763)

Nineta guadarramensis (Pictet, 1865)

Nineta pallida (Schneider, 1851)

Nineta vittata (Wesmael, 1841) (?)

Género Peyerimhoffina Lacroix, 1920

Especie tipo: $($ Peyerimhoffina pudica Lacroix, 1920) $=$

Chrysopa gracilis Schneider, 1851

Peyerimhoffina gracilis (Schneider, 1851)

Género Rexa Navás, 1920

Especie tipo: Rexa lordina Navás, 1920=Rexa almerai

(Navás, 1919) n. comb., n. syn.

Rexa almerai (Navás, 1919) n. comb.

Género Suarius Navás, 1914

Especie tipo: Suarius walsinghami Navás, 1914

Suarius iberiensis Hölzel, 1974

Suarius tigridis (Morton, 1921)

Suarius walsinghami Navás, 1914

Género Brinckochrysa Tjeder, 1966

Especie tipo: Chrysopa (Brinckochrysa) peri Tjeder, 1966

Brinckochrysa nachoi Monserrat, 1977

\footnotetext{
*El orden de los géneros dentro de cada categoría superior no implica mayor o menor posible relación entre ellos, y tampoco el
}

de las especies dentro de cada género, que para comodidad del lector, están ordenadas alfabéticamente. Las especies señaladas con una interrogación (?) están pendientes de ser confirmadas en la fauna ibérica.

\section{Clave de subfamilias, géneros y especies de Chrysopidae de la Península Ibérica e Islas Baleares}

En comparación con otras familias de neurópteros, resulta curiosa la similitud en la morfología externa existente entre los distintos géneros de crisópidos, en especial dentro de Chrysopinae (Figs. 177-198), hecho que hace a veces dificultosa la identificación, especialmente en el caso de las hembras (Penny, 2002), y los caracteres de genitalia, especialmente masculina, aun siendo muy diferentes entre las especies de muchos géneros, se ha utilizado poco (en comparación con otras familias como Hemerobiidae, Coniopterygidae, Sisyridae, Dilaridae, etc.) y requiere paciencia y experiencia, y no siempre es clarificadora a nivel de diferenciación específica en algunos géneros como Chrysoperla o Cunctochrysa (Leraut, 1991; Brooks, 1994; Monserrat et al., 2014).

Por ello hemos preferido utilizar caracteres de morfología alar, pigmentación y setación tegumentaria, tipo de uñas, etc., que son caracteres externos que habitualmente se usan en las claves y que utilizamos por ser lo más accesibles y sencillos posibles, y que en muchos casos son suficientes para llegar a nivel de género, con el que, en el caso de algunos géneros monoespecíficos (Hypochrysa, Peyerimhoffina, Rexa, Chrysotropia, Brinckochrysa), se alcanza el nivel de especie. En otros géneros, solo en algunos casos (Nineta) consideramos necesario incluir sus caracteres de su genitalia masculina (Figs. 140-143), aún así, y para información del lector, anotaremos elementos de la genitalia masculina o femenina de la mayoría de los restantes géneros (Figs. 22-27, 121-129, 133-135, 144-155, 162-176).

En algunos casos (Chrysoperla, Pseudomallada), nuevas especies están siendo actualmente segregadas y designadas en base a elementos del canto, feromonas, isoenzimas, etc., que actúan como barreras biológicas/reproductivas, sin que se apenas manifiesten caracteres externos, a veces no demasiado sencillos de delimitar, por lo que solicitamos al lector dedicación y paciencia, y se comentan en cada caso. También debe anotarse que los ejemplares no son clones, sino que, dentro de las diferentes poblaciones, están sometidos a un cierto grado de variabilidad, y aunque se han utilizado caracteres que se expresan mayoritariamente en sus poblaciones, pueden darse casos que no se cumplan en determinados individuos (ej.: posición de la venilla respecto a la celdilla oval en las alas anteriores: Figs. 83-85).

En las figuras anotadas, y para facilitar al lector el acceso a los caracteres de morfología, venación o pigmentación tegumentaria y/o alar (Figs. 83-97), se resaltan con flechas o signos (letras o asteriscos) los caracteres empleados para hacerlos más accesibles. 
Estos elementos más sencillos son los habitualmente utilizados para la identificación específica, datos a los que, en algún caso, añadiremos algunos elementos sobre la biología y/o distribución de las especies que ayuden a su identificación.

Ofrecemos una clave de subfamilias y géneros de Chrysopidae presentes en la Península Ibérica e Islas Baleares, posteriormente otra de las especies de cada uno de los géneros (imagos en ambos casos) y por último una clave a nivel de género de sus fases larvarias (Figs. 36, 37, 52-60, 70-82).

\section{Clave de subfamilias y géneros de Chrysopidae de la Península Ibérica e Islas Baleares:}

1 Alas anteriores con lóbulo yugal presente y con vena pseudomediana (Psm) aparentemente continuada con las gradadas internas (Figs. 86, 87). Nothochrysinae 2 Alas anteriores con lóbulo yugal reducido o ausente y con vena pseudomediana (Psm) aparentemente continuada con las gradadas externas (Figs. 16, 88, 89, 93, 94)

Chrysopinae 3

2 Alas anteriores con venas costal y subcostal no fusionadas, transcurriendo paralelas e independientemente bajo el pterostigma, y con la tercera celdilla basal, bajo el inicio del sector del radio $(\mathrm{Sr}+\mathrm{Ma})$, subdividida en dos celdillas subiguales (Fig. $86 \mathrm{x}$ ). Ambas alas con 15 o más venillas transversales en el campo costal, y celdillas (Fig. 86*) entre el $\mathrm{Sr}$ y las gradadas internas alargadas (Fig. 86). Especies de gran tamaño, longitud del ala anterior entre $13-25 \mathrm{~mm}$.

Nothochrysa

Alas anteriores con venas costal y subcostal fusionadas antes del pterostigma, y con la tercera celdilla basal, bajo el inicio del sector del radio $(\mathrm{Sr}+\mathrm{Ma})$, subdividida en dos celdillas muy diferentes (Fig. $87 \mathrm{x}$ ). Ambas alas con menos de 15 venillas transversales en el campo costal, y celdillas (Fig. 87*) entre el Sr y las gradadas internas hexagonales (Fig. 87). Especie de menor tamaño, longitud del ala anterior entre 8-10 $\mathrm{mm}$

Hypochrysa

3 Alas anteriores con la tercera celdilla basal, bajo el inicio del sector del radio $(\mathrm{Sr}+\mathrm{Ma})$, subdividida por una venilla longitudinal en dos celdillas subiguales (Figs. 88 x, $95 x$ )

Alas anteriores con la tercera celdilla basal, bajo el inicio del sector del radio (Rs+Ma), subdividida por una venilla oblicua en dos celdillas $(x)$ de muy diferente tamaño (celdilla oval) (Figs. 89 x, 93 x, 94 x)...

4 Alas anteriorescon venillas entre pseudomedian (Psm) marcadamente continuada con las gradadas externas, y con dos series de venillas gradiformes regularmente dispuestas, sin venillas transversales entre ellas. Primera celdilla cubital $\left(\mathrm{Cu}_{1}\right)$ mayor la segunda $\left(\mathrm{Cu}_{2}\right)$. Uñas abruptamente dilatadas en su base. Especies de gran tamaño, longitud de las alas anteriores entre 20-25 mm (Figs. 16, 88). Especies asociadas a medios térmicos mediterráneos.

Italochrysa

- Alas anteriores con venillas entre R-Sr con frecuencia bifurcadas, vena pseudomediana (Psm) no marcadamente continuada con las gradadas externas y con dos series de venillas gradiformes irregulares y con numerosas venillas transversales entre ellas. Primera celdilla cubital $\left(\mathrm{Cu}_{1}\right)$ menor o igual que la segunda $\left(\mathrm{Cu}_{2}\right)($ Fig. 95). Uñas progresivamente dilatadas hacia su base. Especie de menor tamaño, longitud de las alas anteriores entre 14-16 mm (Fig. 36). Especie marcadamente asociada a olivos.

Rexa

5 Especies de gran tamaño, longitud de las alas anteriores mayor de $16 \mathrm{~mm}$ (hasta $26 \mathrm{~mm}$ ), sin punto oscuro en la base de la vena costal (Fig. 94). Cabeza sin manchas entre las antenas [algunas especies de Pseudomallada pueden alcanzar $16-18 \mathrm{~mm}$, pero algunas tienen una mancha entre las antenas (Fig. 117), y todas siempre tienen una mancha oscura sobre la vena costal en la base de las alas (Fig. 93), hechos que nunca ocurren en Nineta]. Genitalia masculina con ectoprocto y el $9^{\circ} \mathrm{ST}$ prolongado en procesos caudales (Figs. 140-143) .................. Nineta Especies de menor tamaño, longitud de las alas anteriores menor de $16 \mathrm{~mm}$. Cabeza con o sin manchas. Genitalia masculina con ectoprocto $y / 09^{\circ} \mathrm{ST}$ prolongado o no en procesos caudales, pero nunca ambos a la vez (Figs. 121,

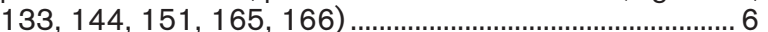

6 Alas anteriores con pocas (2-3) venillas en la serie gradada externa, y con la primera venilla entre el inicio del sector del radio $(\mathrm{Sr}+\mathrm{Ma})$ y la pseudomediana (Psm) situada justo en el extremo distal de la celdilla oval, ni antes, ni después (Fig. 84 co). Alas siempre muy estrechas y muy iridiscentes. Uñas nunca abruptamente dilatadas en su base

Peyerimhoffina

Alas anteriores con numerosas (3-7) venillas en la serie gradada externa, y con la primera venilla entre el inicio del sector del radio $(\mathrm{Sr}+\mathrm{Ma})$ y la pseudomediana (Psm) situada antes o después del extremo distal de la celdilla oval (Figs. $83 \mathrm{co}, 85 \mathrm{co}$ ). Salvo una especie de Chrysoperla (C. mediterranea) (Figs. 131, 138), las alas no son ni muy estrechas, ni especialmente iridiscentes. Uñas sí o no abruptamente dilatadas en su base .............. 7

7 Alas anteriores con las venillas basales del campo costal levemente sinuosas, y con la primera venilla entre el inicio del sector del radio ( $\mathrm{Rs}+\mathrm{Ma}$ ) y la pseudomediana (Psm) situada después del extremo distal de la celdilla oval (Figs. $83 \mathrm{co}, 90 \mathrm{co}$ ) .....

Chrysoperla Alas anteriores con las venillas basales del campo costal rectas o levemente arqueadas, y con la primera venilla entre el inicio del sector del radio $(\mathrm{Rs}+\mathrm{Ma})$ y la
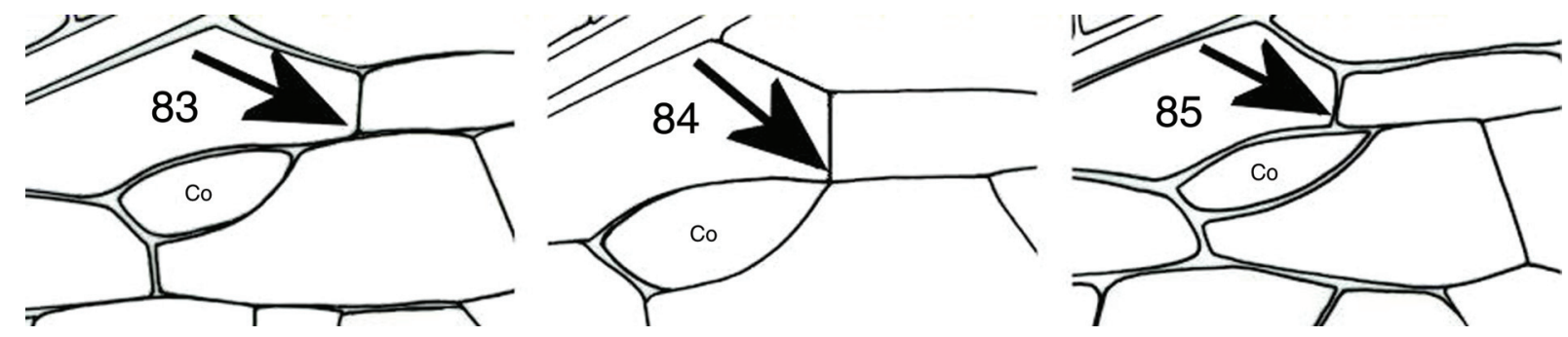

Figs. 83-85.- Posición de la vena transversal respecto a la celdilla oval (co) en las alas anteriores de: 83 (Chrysoperla), 84 (Peyerimhoffina), 85 (Brinckochrysa).

Figs. 83-85.- Transverse vein position relative to the oval cell (co) in the forewings of: 83 (Chrysoperla), 84 (Peyerimhoffina), 85 (Brinckochrysa). 

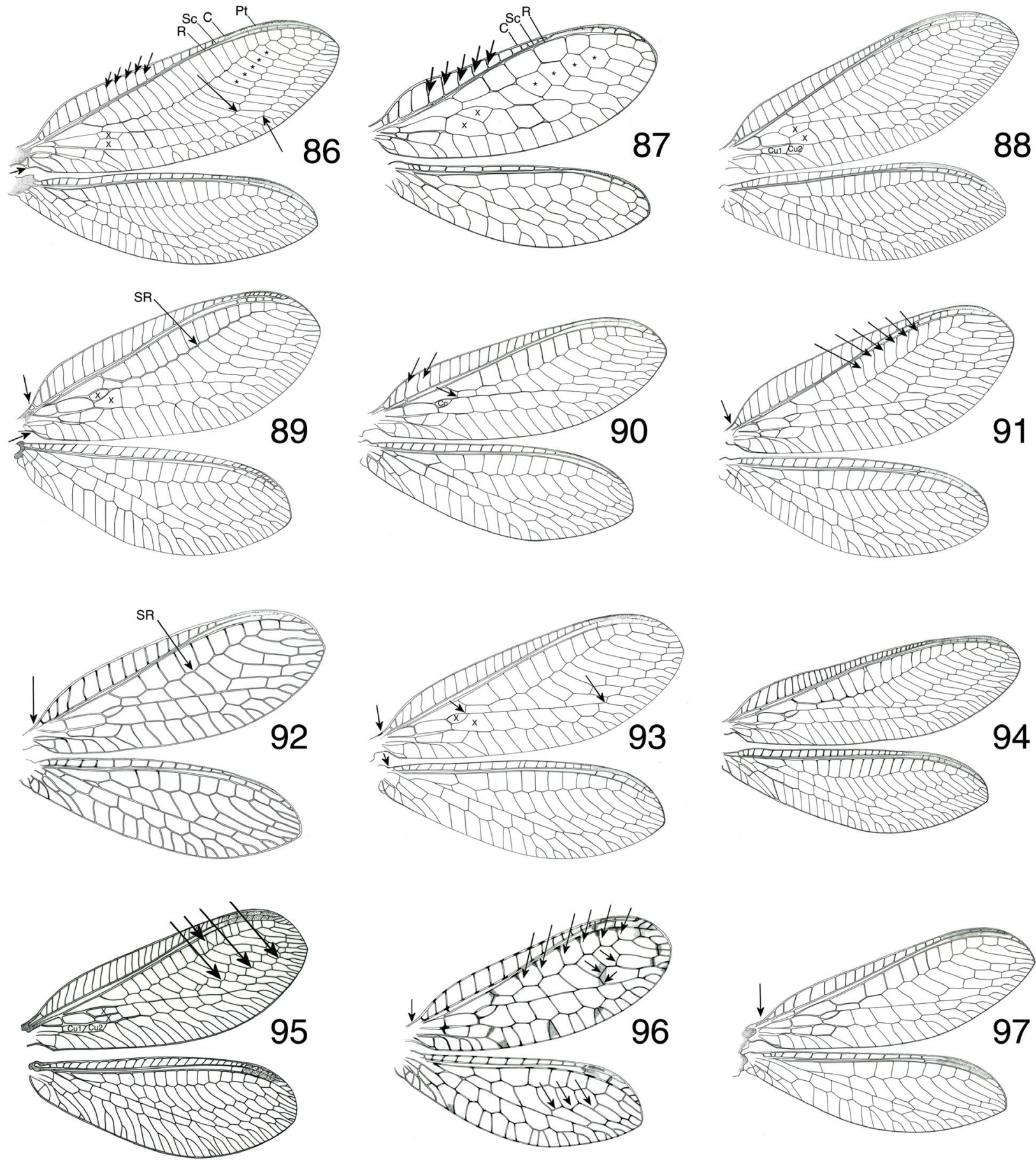

Figs. 86-97.- Esquema de las alas de diferentes géneros ibéricos de Chrysopidae. Se señalan con flechas, $\mathrm{X}$ o asteriscos los caracteres utilizados en las claves para resaltarlos. 86: Nothochrysa, 87: Hypochrysa, 88: Italochrysa, 89: Chrysopa, 90: Chrysoperla, 91: Chrysotropia, 92: Cunctochrysa, 93: Pseudomallada, 94: Nineta, 95: Rexa, 96: Suarius, 97: Brinckochrysa (C: costal, Co: celdilla oval, Cu: cubital, Pt: pterostigma, R: radio, Sc: subcostal, SR: sector del radio). A diferentes escalas.

Figs. 86-97.- Wing schemes in different Iberian Chrysopidae genera. Characters highlighted in the keys are indicated by arrows, X or asterisks. 86: Nothochrysa, 87: Hypochrysa, 88: Italochrysa, 89: Chrysopa, 90: Chrysoperla, 91: Chrysotropia, 92: Cunctochrysa, 93: Pseudomallada, 94: Nineta, 95: Rexa, 96: Suarius, 97: Brinckochrysa (C: costal, Co: oval cell, Cu: cubital, Pt: pterostigma, R: radius, Sc: subcostal, SR: radial sector). At different scales.

pseudomediana (Psm) situada antes del extremo distal de la celdilla oval (Figs. $85 \mathrm{co}, 93 \mathrm{x}, 96,97)$

8 Alas con un punto oscuro sobre el inicio de la vena costal (Fig. 93) Pseudomallada

- Alas sin un punto oscuro sobre el inicio de la vena costal (Figs. 89, 91, 92)
9 Alas anteriores con setas largas y suaves sobre la vena costal (parecido a Fig. 18) y venillas entre R-Sr bajo el pterostigma sinuosas.

Chrysotropia

- Alas anteriores con setas cortas y recurvadas sobre la vena costal (parecido a Fig. 17) y venillas entre R-Sr bajo el pterostigma rectas (Figs. 89, 96, 97) 
10 Antenas algo más largas que las alas anteriores. Genitalia masculina con dos procesos ventrales de aspecto triangular, fuertemente denticulados (Figs. 165, 166)

Brinckochrysa

Antenas algo más cortas que las alas anteriores. Genitalia masculina sin dos procesos ventrales de aspecto triangular, fuertemente denticulados (Figs. 121-124) .............. 11

11 Alas anteriores con 6-8 venillas, como máximo, entre R-Sr, y 3-4 venillas, como máximo, en cada serie de gradadas, y en ellas, la más posterior de la serie interna no contacta directamente con la Psm. Alas posteriores con 1-2 venillas, como máximo, en cada serie de gradadas (Figs. 96, 156, 157, 160, 196-198)

Suarius Alas anteriores con 9 o más venillas entre R-Sr, y más de 3-4 venillas en cada serie de gradadas, y en ellas, la más posterior de la serie interna contacta directamente con la Psm. Alas posteriores con más de 1-2 venillas en cada serie de gradadas (Figs. 89, 92, 181, 186-188) ..................... 12

12 Alas anteriores con $\mathrm{Sr}$ casi recto, en apenas marcado zig-zag (Figs. 89, 181). Región dorsal de la cabeza con abundantes manchas negras, al menos siempre una entre las antenas, o más sobre el vértex (salvo $C$. nigricostata y C. viridana que no las poseen, pero la primera posee setas negras y rígidas sobre el pronoto y la segunda tiene llamativas manchas rojizas sobre las genas). Especies de gran tamaño, longitud de las alas anteriores de 10-21 $\mathrm{mm}$

Chrysopa

Alas anteriores con Sr en marcado zig-zag (Figs. 92, $187,188)$. Región dorsal de la cabeza sin manchas negras, ni setas negras y rígidas sobre el pronoto, ni llamativas manchas rojizas sobre las genas. Especies de menor tamaño, longitud de las alas anteriores de 7-13 $\mathrm{mm}$

Cunctochrysa

\section{Clave de especies de Chrysopidae de la Península Ibérica e Islas Baleares}

Género Nothochrysa (Figs. 86, 110, 177)

1 Uñas abruptamente dilatadas en su base (parecido a Figs. 19, 52a). Pronoto con dos bandas pardas a ambos lados de la zona media amarillenta más pálida (Fig. 110)

Nothochrysa fulviceps

Uñas progresivamente dilatadas hacia su base (parecido a Figs. 20, 52c). Pronoto pardo-rojizo-anaranjado sin dos bandas pardas a ambos lados de la zona media, sino que todo es de color uniforme

Nothochrysa capitata

Género Hypochrysa (Figs. 87, 107, 178)

Especie única: Hypochrysa elegans

Género Italochrysa (Figs. 1, 2, 5, 6, 88, 109, 179, 180)

1 Alas anteriores con patentes manchas negras sobre la membrana (Figs. 5, 6, 180) ....... Italochrysa stigmatica Alas anteriores sin manchas negras sobre la membrana (Figs. 1, 2, 179) Italochrysa italica

Género Rexa (Figs. 95, 194)

Especie única: Rexa almerai

Género Nineta (Figs. 7, 16, 94, 108, 136-143, 189-191)

1 Alas anteriores con el campo costal abrupta- y fuertemente convexo en el tercio basal (Fig. 136) (este carácter es menos acusado en las hembras)... ..... 2 Alas anteriores con el campo costal uniformemente convexo en el tercio basal (Fig. 137)

2 Alas anteriores con venillas del campo costal y venillas gradadas oscuras. Banda mediana sobre tórax y abdomen blancuzca. Genitalia masculina según figura 140

Nineta guadarramensis Alas anteriores con venillas del campo costal y venillas gradadas verdes. Banda mediana sobre tórax y abdomen amarillenta. Genitalia masculina según figura 142 ................................................................ Nineta flava

3 Escapo casi doble de largo que de ancho (Fig. 138). Pronoto verde, sin dos bandas laterales de color pardo-rojizo. Alas anteriores con vena PsM verde, como las restantes venas longitudinales. Genitalia masculina según figura 141

Nineta vittata Escapo un poco más largo que ancho (Fig. 139). Pronoto con dos bandas laterales de color pardo-rojizo (Fig. 7). Alas anteriores con vena PsM negra, contrastando con las restantes venas longitudinales, que son verdes en ejemplares vivos (pueden ser más amarillentas en ejemplares secos). Genitalia masculina según figura 143

Nineta pallida

Género Peyerimhoffina (Figs. 84, 144-146)

Especie única: Peyerimhoffina gracilis. Genitalia masculina según figuras.144-146.

Género Chrysoperla (Figs. 12, 17-27, 83, 90, 130-132, 182-184)

Varias especies crípticas de difícil diferenciación en base a su morfología externa, señaladas con*.

1 Uñas progresivamente dilatadas hacia su base, la cual posee un aspecto triangular (Figs. 20, 21) ....................... 2 Uñas abruptamente dilatadas hacia su base, la cual posee un aspecto cuadrangular (Fig. 19) ...................................... 3

2 Color del cuerpo de aspecto rosáceo. En vivo las alas se disponen en reposo paralelas al sustrato y no son especialmente iridiscentes. Las anteriores ovoides, con ápice redondeado, portando largas setas pálidas sobre la vena costal (Fig. 18), con campo costal ancho y uniformemente convexo, margen posterior levemente cóncavo (Figs. 132, 184). Margen interno de las uñas acodado en ángulo recto (Fig. 21). Genitalia según figuras 22-23. Especie asociada ramblas y cañaverales a medios xéricos y térmicos .................. Chrysoperla ankylopteryformis Color del cuerpo verde intenso con una banda amarilla sobre la línea media dorsal (parecido a Fig. 12). En vivo las alas se disponen en reposo perpendiculares al sustrato y son muy iridiscentes. Las anteriores alargadas, con ápice apuntado (Figs. 131, 183), portando cortas setas oscuras sobre la vena costal (Fig. 17), campo costal estrecho y algo más convexo en el tercio basal, margen posterior recto o levemente convexo (Figs. 131, 183). Margen interno de las uñas curvo, no acodado (Fig. 20). Especie asociada a coníferas en medios mediterráneos Chrysoperla mediterranea

3 Alas anteriores con venas gradiformes oscuras, casi negras ................................................ Chrysoperla mutata Alas anteriores con venas gradiformes verdes ................... 4

4 Mancha lateral de la cabeza (genas y parte lateral del clípeo) rojiza. Alas anteriores con ápice levemente apuntado, setas costales cortas $(<1 \mathrm{~mm})$ y con las venillas transversales del campo subcostal enteramente verdes. Membrana pleural del segundo segmento abdominal con una estrecha banda oscura y oblicua bajo el terguito, a veces presente en los segmentos $3^{\circ}-6^{\circ}$. Los individuos hibernantes no cambian de color. Deposita sus huevos de forma aislada (tipo Fig. 31) ........ Chrysoperla lucasina Mancha lateral de la cabeza (genas y parte lateral del clípeo) parda-negra. Alas anteriores con ápice redondeado, setas costales largas ( $>1 \mathrm{~mm}$ ) y con las venillas transversales del campo subcostal levemente oscuras en su contacto con la vena subcostal. Membrana pleural del segundo segmento abdominal sin una estrecha banda oscura y oblicua bajo el terguito. Los individuos hibernantes adquieren coloración rosácea o amarillenta-parda. Deposita sus huevos agrupados 0 aislados (tipo Figs. 31, 32) ............................ 5 
5 Estipe con una línea oscura abarcando la mitad o algo más de la mitad de su longitud. Setas de los esternitos del abdomen mayoritariamente negras. Terminalia del macho con el labio del S 8+9 ancho y alargado, con todas las setas terminales largas y oscuras. Especie de vegetación herbácea en campos abiertos. Los individuos hibernantes adquieren coloración rosácea. Puesta de huevos aislados

Chrysoperla carnea*

- Estipe con una línea oscura abarcando menos de la mitad de su longitud. Setas de los esternitos del abdomen mayoritariamente pálidas. Terminalia del macho con el labio del S $8+9$ corto y estrecho, con todas las setas terminales cortas y pálidas, o cortas y pálidas alternadas con algunas largas y oscuras. Especies de vegetación arbórea o herbácea en campos abiertos. Los individuos hibernantes no adquieren coloración rosácea, sino amarillenta o pardo amarillenta. Puesta de huevos aislados o en grupos

6 Setas de los esternitos del abdomen pálidas. Terminalia del macho con el labio del S $8+9$ con todas las setas terminales cortas y pálidas. Especie de vegetación arbórea o de matorrales altos. Los individuos hibernantes adquieren coloración amarillenta. Puesta de huevos en grupos

Chrysoperla pallida*

- Setas de los esternitos del abdomen mayoritariamente pálidas alternadas con otras oscuras. Terminalia del macho con el labio del S 8+9 con las setas terminales cortas y pálidas alternadas con setas más largas y oscuras. Especie de vegetación baja y zonas cultivadas. Los individuos hibernantes adquieren coloración pardo-amarillenta. Deposita sus huevos aislados

Chrysoperla agilis*

*Según se conoce, la mayoría de los datos anotados se dan en un alto porcentaje de los ejemplares, pero muchos casos hay ejemplares con elementos compartidos o variables de muy difícil asignación específica en base a estos caracteres.
Género Pseudomallada (Figs. 4, 11, 93, 100, 111, 115-120, 147-155, 192, 193)

Varias especies crípticas de difícil diferenciación en base a su morfología externa, señaladas con*.

1 Uñas progresivamente dilatadas hacia su base (parecido a Figs. 20, 21, 52b, c)

... 2

Uñas abruptamente dilatadas en su base (parecido a Figs. 19, 52a)

2 Color del cuerpo pardo y venación alar mayoritariamente marrón oscura (Figs. 4, 11) ................................................. 3 Color del cuerpo verde o amarillento y venación alar mayoritariamente verde (parecido a Figs. 8-10) ............... 4

3 Pronoto con dos bandas laterales oscuras bien definidas (Fig. 118) Pseudomallada genei Pronoto con zonas pardas irregularmente dispuestas, sin formar dos bandas laterales oscuras bien definidas (Figs. 11, 120)

Pseudomallada venosus

4 Cabeza verde, sin manchas rojizas en sus zonas dorsal y/o lateral. Antenas con una mancha negra sobre la zona lateral externa del escapo y el pedicelo (Fig. 119)

Pseudomallada subcubitalis

- Cabeza amarilla/amarillenta, con manchas rojizas en sus zonas dorsal y lateral. Antenas sin una mancha negra sobre la zona lateral externa del escapo y el pedicelo

Pseudomallada ibericus

5 Alas anteriores con manchas oscuras sobre su membrana (Fig. 192). Genitalia según figuras 147-154

Pseudomallada alarconi

- Alas anteriores sin manchas oscuras sobre su membrana (Fig. 193) 6

6 Esternitos abdominales negros

Pseudomallada ventralis

Esternitos abdominales verdes 7

7 Cabeza sin un punto negro entre la base de las antenas (Fig. 116)
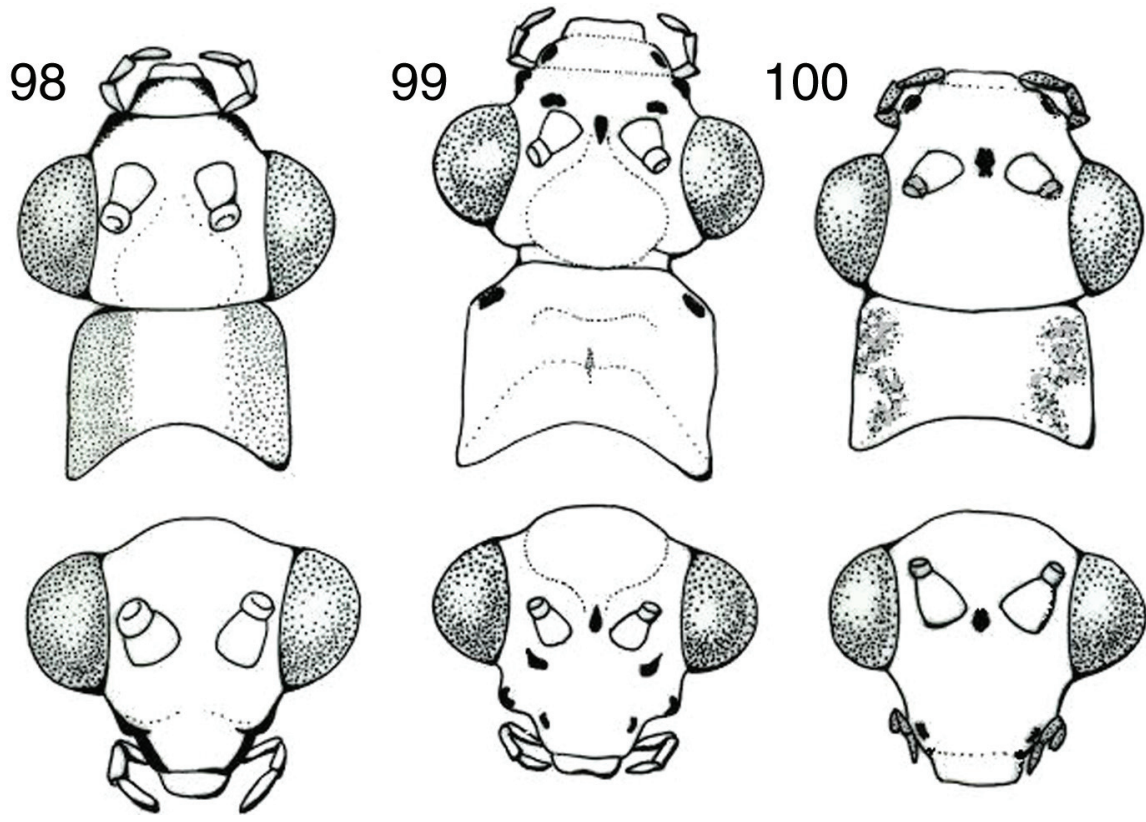

101
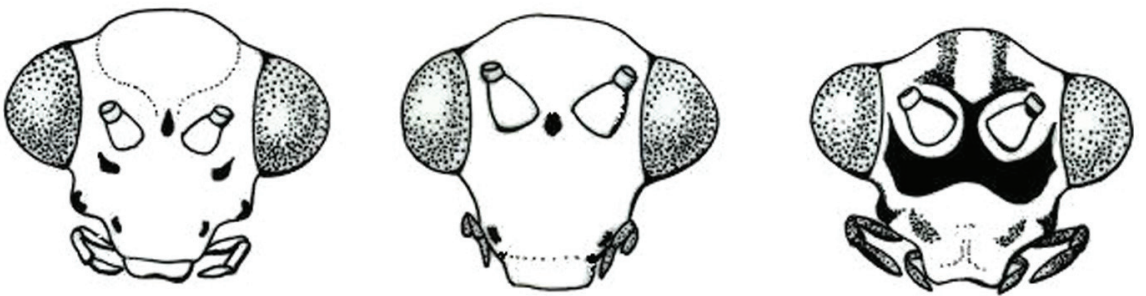

Figs. 98-101.- Cabeza, vista dorsal y frontal de: 98: Chrysopa viridana, 99: Chrysopa pallens, 100: Pseudomallada prasinus, 101: Chrysopa dorsalis. A diferentes escalas.

Figs. 98-101.- Head, dorsal and frontal view of: 98: Chrysopa viridana, 99: Chrysopa pallens, 100: Pseudomallada prasinus, 101: Chrysopa dorsalis. At different scales. 

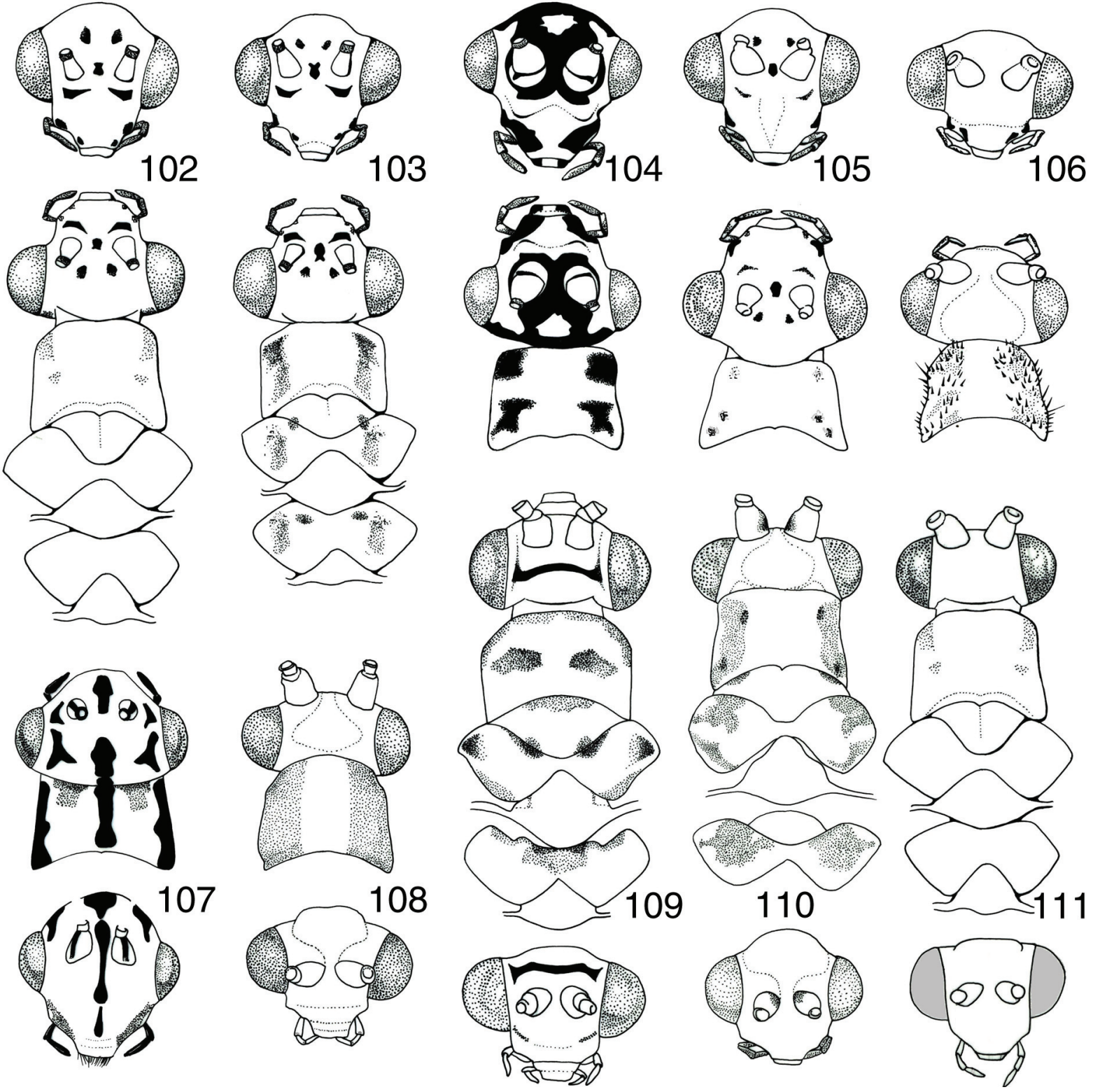

Figs. 102-111.- Cabeza, vista dorsal y frontal y pronoto/tórax, vista dorsal de: 102: Chrysopa formosa, 103: Chrysopa nierembergi, 104: Chrysopa perla, 105: Chrysopa phyllochroma, 106: Chrysopa nigricostata, 107: Hypochrysa elegans, 108: Nineta flava, 109: Italochrysa stigmatica, 110: Nothochrysa fulviceps, 111: Pseudomallada inornatus. A diferentes escalas.

Figs. 102-111. - Head, dorsal and frontal view, and pronotum/thorax, dorsal view of: 102: Chrysopa formosa, 103: Chrysopa nierembergi, 104: Chrysopa perla, 105: Chrysopa phyllochroma, 106: Chrysopa nigricostata, 107: Hypochrysa elegans, 108: Nineta flava, 109: Italochrysa stigmatica, 110: Nothochrysa fulviceps, 111: Pseudomallada inornatus. At different scales.

Cabeza con un punto negro entre la base de las antenas (Figs. 100, 117)

... 11

8 Alas anteriores con venillas del campo costal enteramente oscuras.

Pseudomallada clathratus

- Alas anteriores con venillas del campo costal verdes, solamente oscuras en sus extremos, en su contacto con las venas costal y subcostal

9 Color general del cuerpo de aspecto rosáceo pálido. Cabeza con abundantes manchas rojizas en sus zonas dorsal y lateral (Fig. 116)

\section{Pseudomallada granadensis}

Color general del cuerpo de aspecto verde o amarillento. Cabeza sin abundantes manchas rojizas en sus zonas dorsal y lateral (Fig. 117)
10 Cabeza amarilla, con manchas oscuras y rojizas en las genas. Alas anteriores con las venillas gradiformes $y$ todas las venas transversales de los 2/3 externos oscuras, al menos en sus extremos

Pseudomallada flavifrons

- Cabeza verde, sin manchas oscuras o rojizas en las genas (Fig. 111). Alas anteriores con las venillas gradiformes y todas las venas transversales de los $2 / 3$ externos verdes

Pseudomallada inornatus

11 Cabeza con el punto entre las antenas prolongado en forma de I, y presencia de dos puntos pardo oscuros sobre el vértex

Pseudomallada zelleri

Cabeza con el punto entre las antenas no prolongado en forma de I, y sin dos puntos pardo oscuros sobre el vértex (Fig. 117). 

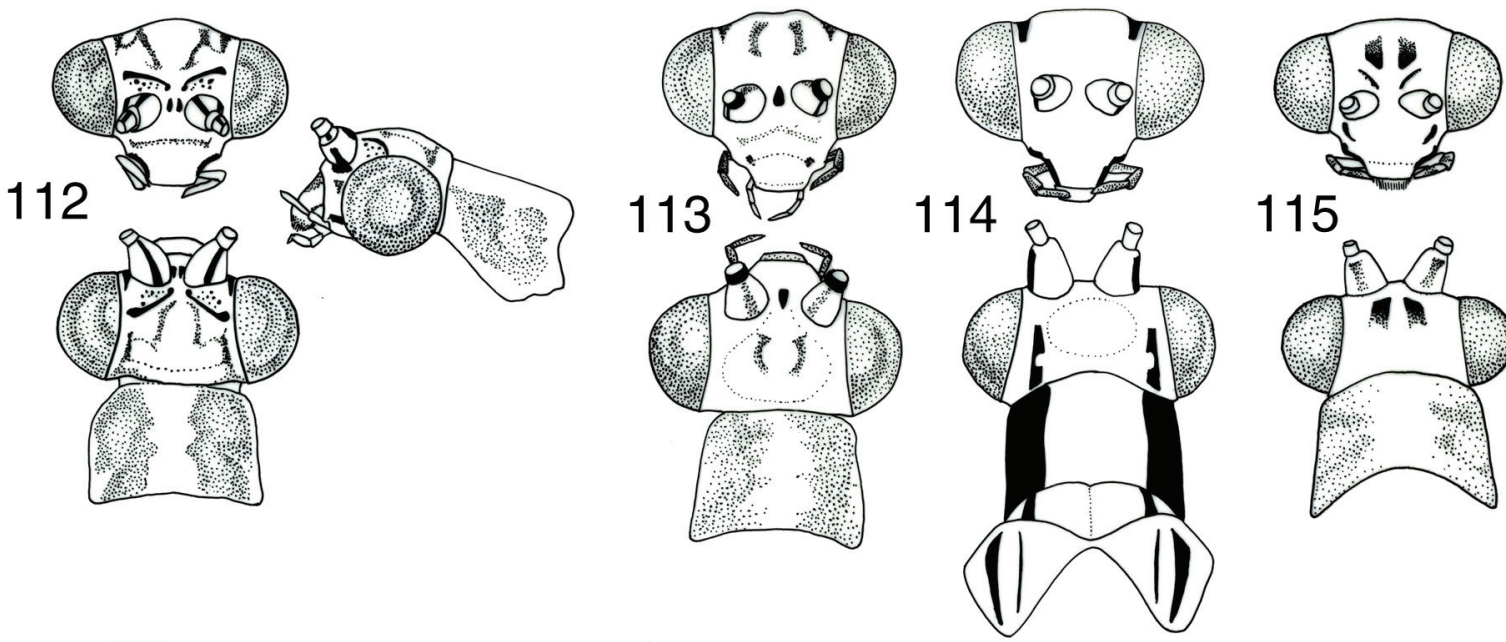

115
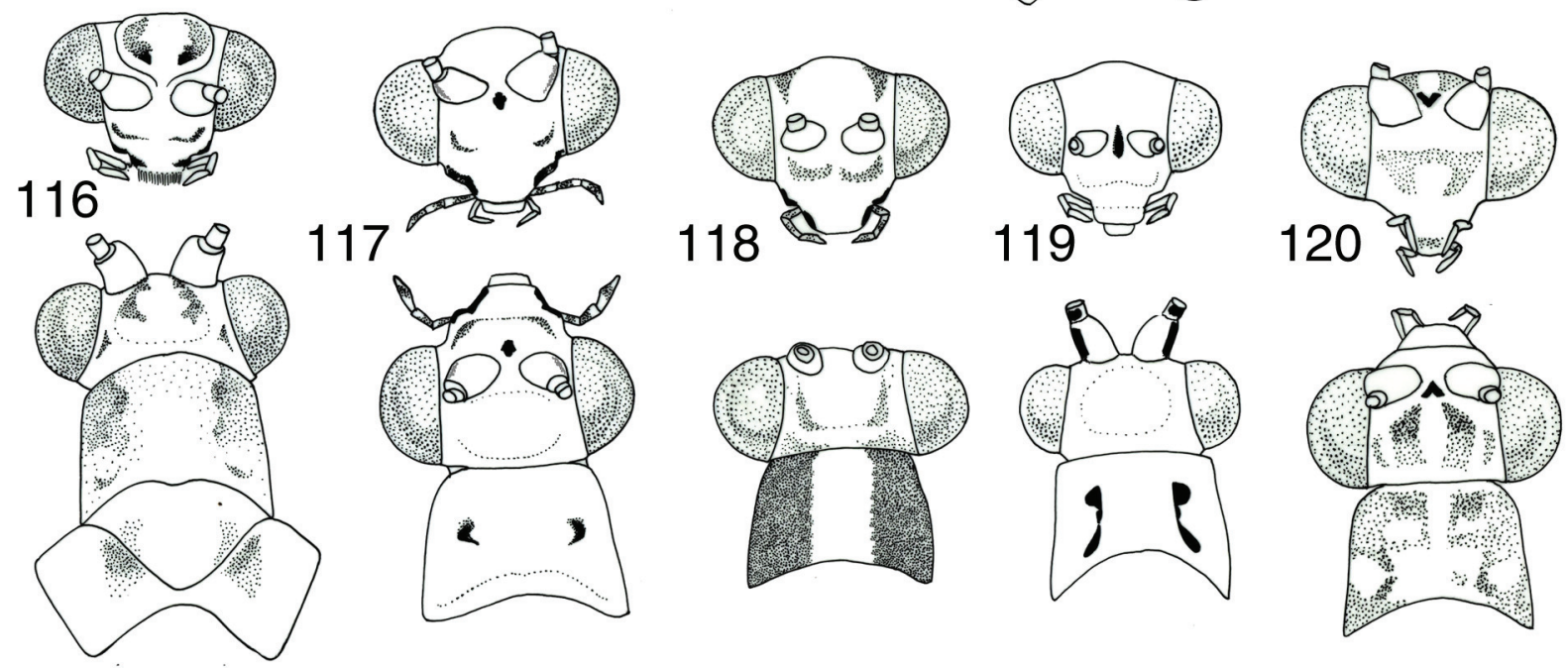

Figs. 112-120.-Cabeza, vista dorsal, frontal y lateral y pronoto/mesotórax, vista dorsal/lateral de: 112: Suarius tigridis, 113: Suarius iberiensis, 114: Suarius walsinghami, 115: Pseudomallada alarconi, 116: Pseudomallada granadensis, 117: Pseudomallada picteti, 118: Pseudomallada genei, 119: Pseudomallada subcubitalis, 120: Pseudomallada venosus. A diferentes escalas.

Figs. 112-120.- Head, dorsal, frontal and lateral view, and pronotum/mesothorax, dorsal/lateral view of: 112: Suarius tigridis, 113: Suarius iberiensis, 114: Suarius walsinghami, 115: Pseudomallada alarconi, 116: Pseudomallada granadensis, 117: Pseudomallada picteti, 118: Pseudomallada genei, 119: Pseudomallada subcubitalis, 120: Pseudomallada venosus. At different scales.

12 Antenas con una banda rojiza en el margen lateral del escapo y una estría semilunar rojiza bajo la base de las antenas (Fig. 117)

Pseudomallada picteti

- Antenas sin una banda rojiza en el margen lateral del escapo y sin una estría semilunar rojiza bajo la base de las antenas.

....13

13 Longitud de las alas anteriores menor de $12 \mathrm{~mm}$. Escapo sin un punto lateral oscuro Puestas en huevos aislados

Pseudomallada prasinus*

- $\quad$ Longitud de las alas anteriores de 12-18 mm. Escapo con o sin un punto lateral oscuro. Puestas en huevos aislados o en racimos

.... 14

14 Longitud de las alas anteriores de 12-18 $\mathrm{mm}$. Cabeza con mancha entre las antenas triangular, levemente prolongada en forma de Y. Escapo con un punto oscuro lateral. Alas anteriores con 5-6 venillas gradadas, casi todas las venas costales y transversales enteramente oscuras/ negras, también las del sector radial, el cúbito en su origen y las anales. Cada tergo y esterno abdominales con dos oblicuas manchas pardo-rojizas. Especie de alta montaña, que vive principalmente sobre coniferas. Puestas en huevos aislados
Longitud de las alas anteriores de 13-16 mm. Cabeza con mancha entre las antenas circular o levemente prolongada en forma banda. Escapo sin un punto oscuro lateral. Alas anteriores con 6-8 venillas gradadas, con casi todas las venas costales y transversales enteramente verdes en su mayoría, solo algunas oscurecidas en los extremos, y el cúbito es verde en su origen, y también son verdes las anales. Tergos y esternos abdominales sin manchas pardo-rojizas. Especie de cotas medias y bajas, que vive sobre planifolios y caducifolios, no en coníferas. Puestas en huevos en racimos

Pseudomallada marianus**

* Probablemente estemos ante un conjunto de especies y nuevos estudios moleculares demuestren la existencia de especies nuevas en lo que hoy conocemos como $P$. parasinus.

** Recientemente se han segregado como especies válidas respecto a $P$. prasinus por marcadas diferencias en su biología y hábitat, pero resultan muy problemáticas a la hora de su diferenciación en base a la morfología externa. 
Género Chrysotropia (Figs. 91, 133-135, 185)

Especie única: Chrysotropia ciliata. Genitalia masculina según figuras 133-135.

Género Brinckochrysa (Figs. 97, 85, 165-176, 198)

Especie única: Brinckochrysa nachoi. Genitalia según figuras 165-176.

Género Suarius (Figs. 96, 112-114, 156-164, 195-197)

1 Alas sin manchas oscuras sobre su membrana (Figs. 156, 195)

Suarius iberiensis

Alas con manchas oscuras sobre su membrana (Figs. 157, 160, 196, 197)

2 Pronoto amarillento con dos bandas laterales pardas muy oscuras y bien delimitadas. Antenas con una banda parda sobre el margen lateral externo del escapo (Fig. 114). Membrana de las alas anteriores con pequeñas manchas pardas en las intersecciones de las venas, destacando por su tamaño e intensidad la situada entre Cua y Cup. Membrana de las alas posteriores con pequeñas manchas pardas poco conspicuas (Figs. 157, 197)

Suarius walsinghami Pronoto pardo amarillento con dos bandas laterales pardas pálido de límites difusos. Antenas con una banda parda sobre el margen lateral externo y otra pardo rojiza sobre la zona dorsal del escapo (Figs. 112, 161). Membrana de las alas anteriores con patentes manchas pardas en las intersecciones de las venas, de similar intensidad. Membrana de las alas posteriores con varias manchas pardas conspicuas en la región pterostigmática y en el margen alar donde contactan los campos cubital y medial (Figs. 160, 196). Genitalia masculina según figuras $162-164$

Suarius tigridis

Género Chrysopa (Figs. 3, 8, 9, 13-15, 89, 98, 99, 101-106, 121-129, 181)

Alguna especie de identificación problemática, se señala con *

1 Cabeza siempre con un punto oscuro entre las antenas, a veces extendido en forma de $X$ o presentando otras manchas circulares oscuras situadas sobre el vértex (Figs. 99,

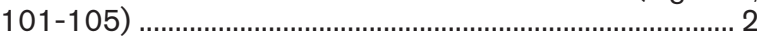
Cabeza sin un punto oscuro entre las antenas (Figs. 98, 106)

2 Cabeza con un punto oscuro entre las antenas, sin que esté extendido en forma de $\mathrm{X}$, pudiendo tener otras manchas circulares oscuras sobre la frente $y / 0$ el vértex (Figs. 99, 102, 103, 105)

Cabeza con un punto oscuro entre las antenas, ext sobre el vértex en forma de X (Figs. 101, 104) ................. 7

3 Cabeza solo con un punto oscuro entre las antenas, sin tener otras manchas circulares oscuras sobre el vértex (Fig. 99)

Chrysopa pallens Cabeza con un punto oscuro entre las antenas y con otras manchas circulares oscuras sobre el vértex (Figs. 102, 103, 105)

4 Uñas abruptamente dilatadas en su base (parecido a Figs. 19, 52a) ................................................................... 5 Uñas progresivamente dilatadas hacia su base (parecido a Figs. 20, 52c) ........................ Chrysopa phyllochroma

5 Alas anteriores con venillas del campo costal verdes, sólo más oscuras en su contacto con la vena costal

Chrysopa dubitans Alas anteriores con venillas del campo costal negras ....... 6

6 Cabeza y escapo verdes (Figs. 8-9). Alas anteriores con venillas que forman la celdilla oval verdes y negras. Mesoy metanoto verdes, sin manchas patentes (Fig. 102). Segmentos del abdomen sin una estría lateral oscura a cada lado del dorso

Chrysopa formosa* Cabeza y escapo amarillo-anaranjados. Alas anteriores con venillas que forman la celdilla oval negras. Meso- y metanoto portando dos patentes manchas negras (Fig. 103). Segmentos del abdomen con una estría lateral oscura a cada lado del dorso ..................... Chrysopa nierembergi*

7 Mancha negra entre las antenas extendida ampliamente sobre el margen occipital de la cabeza (Figs. 3, 104). Uñas abruptamente dilatadas en su base (parecido a Figs. 19, 52a) .............................................. Chrysopa perla Mancha negra entre las antenas prolongada en dos bandas longitudinales sin extenderse sobre el margen occipital de la cabeza (Fig. 101). Uñas progresivamente dilatadas hacia su base (parecido a Figs. 20, 52b, c)

Chrysopa dorsalis

8 Color general verde manzana. Región lateral de la cabeza con manchas pardas de color miel y abundantes manchas rojizas sobre las genas. Setas del pronoto largas y suaves. Alas anteriores con vena costal verde en toda su extensión. Especie asociada a esclerófilos mediterráneos (Fig. 98)...

Chrysopa viridana Color general verde limón. Región lateral de la cabeza con manchas pardas, sin manchas rojizas sobre las genas. Setas del pronoto cortas y rígidas (Fig. 106). Alas anteriores con vena costal amarilla en la zona cubital y anal. Genitalia masculina según figuras 121-129. Especie asociada a chopos y álamos.......

Chrysopa nigricostata

* Datos de los ejemplares típicos, pero puede existir mucha variación.

Género Cunctochrysa (Figs. 10, 92, 186-188)

1 Alas anteriores con todas las venas trasversales del campo costal completamente oscuras (Fig. 188). Pedicelo levemente oscuro en su mitad externa. Pronoto con una banda media blanco-amarillenta marginada a cada lado de verde primero y verdosa negruzco intenso más externamente. Abdomen con región pleural pardo verdoso oscuro, formando dos bandas llamativas negruzcas a lo largo del abdomen. Especie asociada a coníferas ................................... Cunctochrysa cosmia Alas anteriores con la primera vena trasversal del campo costal pálida, o si es oscura, sólo son completamente oscuras las restantes en sus extremos distales en su contacto con vena costal y subcostal (Figs. 186, 187). Pedicelo verde, no oscuro en su mitad externa. Pronoto con pequeñas manchas circulares oscuras, pero sin que la banda media blanco-verdosa esté marginada a cada lado de verde negruzco intenso. Abdomen con región pleural pardo verdosa, sin formar dos bandas llamativas negruzcas a lo largo del abdomen. Especies no asociadas a coniferas .............. 2

2 Alas anteriores con la primera vena trasversal del campo costal pálida y las restantes oscuras en toda su extensión o bien solo en sus extremos (Fig. 186). Pronoto con dos pequeñas manchas circulares oscuras sobre el tercio posterior mucho mayores y más intensas que las dos situadas sobre el margen anterior. Banda media dorsal blanquecina (Fig. 10). Especie de medios eurosiberianos ............................ Cunctochrysa albolineata Alas anteriores con la primera vena trasversal del campo costal oscura y las restantes oscuras solo en sus extremos (Fig. 187). Pronoto con dos manchas circulares oscuras sobre el tercio posterior similares en tamaño e intensidad a las dos situadas sobre el margen anterior. Banda media dorsal más amarillenta. Especie de medios mediterráneos

Cunctochrysa baetica

\section{Clave de géneros de las larvas de Chrysopidae de la Península Ibérica e Islas Baleares}

En función de los datos disponibles, las larvas de las especies de esta familia sólo pueden diferenciarse con seguridad a partir del segundo estadio. Obviamente la 
morfología general y la quetotaxia cefálica y tegumentaria son diagnósticas a nivel de género y en muchos casos a nivel de especie (Figs. 40-43, 52-60), pero advertimos al lector que se requiere cierta experiencia (y paciencia) en la observación de algunos caracteres. La presencia de larvas desnudas (Figs. 36, 63, 64, 66,68 ) o de las que se cubren con restos (Figs. 37, $65,67)$ ayuda a la identificación. También muchas especies poseen en vivo caracteres de pigmentación muy característicos que son utilizados para su diferenciación específica (Figs. 63-68), pero parte de esta coloración (la no estructural) se pierde en material conservado en alcohol. Para reconocimiento en el campo se recomienda Pantaleoni (1983).

Intentamos aportar una clave general a nivel de género, utilizando caracteres lo más sencillos posible y los más fácilmente accesibles. Para el lector interesado se recomienda Díaz-Aranda \& Monserrat (1995) y Díaz-Aranda et al. (2001) que aportan una clave de géneros europeos, y Monserrat \& Díaz-Aranda (2012), donde se describen con detalle las fases larvarias de la mayoría de nuestras especies y se aporta una clave de larvas neonatas y maduras de ellas. Para las especies del género Nineta también se recomienda Canard et al. (1998). En cualquier caso, en cada especie se pormenoriza la información disponible sobre sus estados preimaginales.

1 Antenas con segmento distal piriforme, unas 10 veces más corto que el segmento medio (Fig. 75), portador de varias pequeñas y cortas sedas terminales (Fig. 53b). Último segmento del palpo labial con 4 o más sensilas (Fig. 54b) (Nothochrysinae) 2

- Antenas con segmento distal alargado, unas 3-6 veces más corto que el segmento medio (Fig. 47), portador una larga y robusta seta distal (Fig. 53a, c). Último segmento del palpo labial con 3 sensilas como máximo (Figs. 48, 54a) ...........................................................(Chrysopinae) 3

2 Larva desnuda (sin capa de camuflaje), de cuerpo alargado y estrecho. Sin tubérculos laterales, ni setas densamente desarrolladas sobre el tegumento, éstas muy cortas y finalizadas en una pequeña maza. Color general verde intenso, con cabeza amarilla, portadora de una mancha a modo de estrecha banda longitudinal oscura sobre la línea media dorsal y dos pequeñas manchas oblicuas sobre el vértex (Fig. 82).

Hypochrysa

- Larva cubierta (con capa de camuflaje), con abdomen ligeramente abombado. Con pequeños tubérculos laterales portando una brocha de setas densamente desarrolladas, y tegumento con abundantes setas largas, filiformes o finalizadas en un pequeño anzuelo. Color general amarillo o pardo, y cabeza con abundantes manchas oscuras ocupando la casi totalidad de su superficie dorsal (Fig. 75)...

. Nothochrysa

3 Mandíbulas-maxilas notablemente más cortas que la cápsula cefálica (Fig. 76). Seta terminal de la antena como en figura 53c. Tubérculos laterales del tórax de aspecto palmeado portando 8-10 setas (Fig. 76). Setas cefálicas y laterales del tórax y abdomen con aspecto aserrado-denticulado (Figs. 60, 76), y setas dorsales del meso-metatórax y del abdomen ganchudas (Figs. 57, 76). Larvas asociadas a hormigueros ..... . (Belenopterygini) Italochrysa Mandíbulas-maxilas de similar longitud o notablemente más largas que la cápsula cefálica (Figs. 70-74, 77-81). Seta terminal de la antena como en figura 53a. Tubérculos laterales del tórax apenas desarrollados o de aspecto semiesférico o digitiforme, nunca palmeado, portando 3 setas como máximo (Figs. 70-74, 77-81). Setas cefálicas y laterales del tórax y abdomen sin aspecto aserrado, las dorsales del meso-metatórax no ganchudas (Figs. 70-74, 77-81). Larvas de vida libre, no asociadas a hormigueros ................................................. (Chrysopini) 4

4 Larva siempre cubierta (con capa de camuflaje). Tórax con tubérculos laterales bien desarrollados, alargados y portadores de largas setas (Figs. 70-74). Abdomen fuertemente convexo, con tubérculos laterales semiesféricos, portadores de abundantes setas curvas (Figs. 37, 70-74). Segmentos abdominales con arcos dorsales de setas acabadas en anzuelo (Fig. 57) ............................................... 5 Larva normalmente desnuda (sin capa de camuflaje). Tórax sin tubérculos laterales bien desarrollados ni alargados, aunque en ocasiones portadores de más cortas setas no recurvadas. Abdomen más o menos aplanado, cónico-cilíndrico, con pequeños tubérculos laterales semiesféricos, portadores de 2-5 pequeñas setas cortas, y segmentos con arcos dorsales de setas rectas, no acabadas en anzuelo (Figs. 77-81).

5 Mandíbulas-maxilas tan largas como la cápsula cefálica (Fig. 74). Tubérculos laterales del tórax con pedúnculo grueso. Todas las setas del tórax y abdomen con base espesa negra. Segmentos abdominales con 3-4 arcos dorsales de setas uncinadas, de los que el más posterior es más llamativo, sus setas son más largas y gruesas, y parten de pequeños tubérculos oscuros (Fig. 74) ................. Rexa Mandibulas-maxilas más largas que la cápsula cefálica (Figs. 37, 70, 71, 73). Tubérculos laterales del tórax con pedúnculo fino. No todas las setas del tórax y abdomen poseen base espesa negra. Segmentos abdominales con arcos dorsales de setas de similar aspecto, y sus setas no parten de pequeños tubérculos (Figs. 70-73) .................. 6

6 Cápsula cefálica con seta $S_{12}$ ausente o microscópica. Segmentos abdominales V-VII con dos pequeños tubérculos dorsales portadores cada uno de ellos de dos largas setas (Fig. 70)

Pseudomallada

Cápsula cefálica con seta $\mathrm{S}_{12}$ presente (Fig. 40). Segmentos abdominales VI-VII con dos pequeños tubérculos dorsales portadores cada uno de ellos de dos largas setas (Figs. 71-73).

7 Tubérculos laterales del tórax largos, digitiformes, de similar longitud, y no ensanchados en el extremo. Color general blanco, sin manchas pardas o rojizas. Pronoto con llamativas manchas oscuras que destacan sobre las demás (Fig. 73)

Chrysotropia

Tubérculos laterales del protórax más largos que los restantes, todos levemente ensanchados en el extremo (Figs. 71, 72). Color general blanco con manchas pardas o rojizas en tórax y abdomen. Pronoto sin llamativas manchas oscuras que destaquen sobre las demás (Figs. 71, 72)

8 Tubérculos laterales del meso-metatórax semiesféricos, poco desarrollados. Mesotórax con un arco dorsal de setas largas. Manchas dorsales del tórax interrumpidas. Abdomen moderadamente convexo, cubierto con pocos restos, con tubérculos laterales portadores de setas filiformes (Fig. 71)

Cunctochrysa Tubérculos laterales del meso-metatórax digitiformes, bien desarrollados. Mesotórax sin un arco dorsal de setas largas. Manchas dorsales del tórax en dos bandas oblicuas continuadas. Abdomen extremadamente convexo, cubierto con multitud de restos, con tubérculos laterales portadores de setas uncinadas (Fig. 72)

Suarius

9 Antenas más cortas que mandíbulas-maxilas (Fig. 77). Setas torácicas y abdominales de aspecto truncado y estrellado en su extremo (Fig. 58). Tubérculos laterales del tórax y abdomen no desarrollados, portando en su posición 
una única seta en los del tórax y dos en los del abdomen. Coloración disruptiva con patente interrupción y contraste entre las zonas negro-rojizas pigmentadas y las blancas no pigmentadas (Fig. 77).....

Brinckochrysa Antenas más largas que mandíbulas-maxilas (Figs. 78-80). Setas torácicas y abdominales adelgazadas hacia su extremo, mazudas o ganchudas, pero nunca truncadas y de aspecto estrellado (Figs. 55-57). Tubérculos laterales del tórax y abdomen bien desarrollados, portando numerosas setas. Coloración no disruptiva, sino pálidas o con bandas longitudinales continuas alternando las zonas pigmentadas y no pigmentadas (Figs. 78-80) ...................... 10

10 Tubérculos laterales del tórax y abdomen ausentes o muy pequeños. Abdomen sin hileras de tubérculos dorsales a ambos lados de la línea media, en su lugar existen hileras transversales de setas de extremo espatulado y marcadamente orientadas hacia la línea media dorsal (Fig. 78) .

Peyerimhoffina

Tubérculos laterales del tórax y abdomen presentes, más o menos desarrollados. Abdomen con hileras de tubérculos dorsales presentes a ambos lados de la línea media, más o menos desarrollados, con setas de extremo adelgazado y marcadamente orientadas lateralmente hacia el exterior (Figs. 79-81)

. .11

11 Aspecto alargado y estrecho. Longitud total (incluyendo piezas bucales) de c. 12-14 mm. Longitud de las mandíbulas-maxilas entre 2-3 veces la de cabeza. Tubérculos laterales del tórax muy poco desarrollados y portadores de setas cortas. Primer segmento abdominal con un pequeño tubérculo lateral portador de varias setas (Fig. 81)

Nineta

Aspecto fusiforme y más grueso. Longitud total (incluyendo piezas bucales) menor de c. $11 \mathrm{~mm}$. Longitud de las mandíbulas-maxilas 1.5 veces la de cabeza. Tubérculos laterales del tórax bien desarrollados y portadores de setas largas. Primer segmento abdominal sin un pequeño tubérculo lateral portador de varias setas (excepto Chrysopa viridana y Chrysopa pallens) (Figs. 79, 80)

12 Cápsula cefálica con seta $S_{12}$ presente y mancha frontoclipeal ausente o poco desarrollada (Figs. 40, 79). Tubérculos dorso- laterales del abdomen con dos setas como máximo (Fig. 79)

Chrysoperla

Cápsula cefálica con seta $S_{12}$ ausente (excepto Chrysopa viridana) y mancha fronto-clipeal presente y bien desarrollada (Figs. 42, 80). Tubérculos dorso-laterales del abdomen con más de dos setas, hasta cinco (Fig. 80) ...... Chrysopa

Más información en Pantaleoni (1983), Babrikova (1984), Gepp (1984a, 1984b, 1986, 1990), Monserrat (1984c, 1989), Díaz-Aranda \& Monserrat (1988d, 1990a, 1990b, 1991, 1992, 1994, 1995, 1996), DíazAranda (1992), Díaz-Aranda et al. (2001) y Monserrat \& Díaz-Aranda (2012).

\section{Las especies de CRisópidos de la Península Ibérica y BALEARES}

(El orden de las especies dentro de cada género es meramente alfabético, y no implica mayor o menor posible relación entre ellas).

Chrysopidae Schneider, 1851

Nothochrysinae Navás, 1910

Género Nothochrysa McLachlan, 1868

Representado en nuestra fauna por dos especies inconfundibles.
Nothochrysa capitata (Fabricius, 1793)

Hemerobius capitatus Fabricius, 1793

Fabricius, 1793: 82 (d).

Nothochrysa capitata (Fabricius, 1793)

Hölzel \& Ohm, 1972: 128 (dis, nt), 144 (nt); Aspöck et al., 1980:

236 (rf); Alrouechdi et al., 1980b: 175 (rf); Monserrat, 1986b:

100 (dis); Popov, 1990: 48 (rf); Monserrat \& Rodrigo, 1992:

124 (dis); Canard et al., 1992b: 96 (list); Monserrat \& Marín,

1994: 121 (rf); H. Aspöck et al., 2001: 71 (rf); Monserrat, 2005:

76 (dis); Monserrat, 2008: 173 (dis).

Nathanica capitata (Fabricius, 1793)

Eglin, 1940: 300 (rf); Berland, 1962: 71 (rf).

Especie europea expansiva hasta Argelia y Túnez, asociada a coníferas, también citada sobre endrinos, robles, hayas, tejos, incluso zonas ajardinadas, normalmente en medios húmedos y boscosos. Está mayoritariamente citada entre V-IX, en altitudes de entre 600 hasta $1.560 \mathrm{~m}$. Parece asegurado que hiberna en fase de prepupa (Aspöck et al., 1980).

En nuestra fauna tiene una clara tendencia eurosiberiana, ocupando el extremo más oriental (Gerona, Barcelona, Lérida, Huesca y Baleares: Mallorca), aunque no descartamos su presencia en otras zonas del tercio septentrional, y ha sido citada sobre robles, abetos y hayas, entre $\mathrm{V}-\mathrm{X}$, en altitudes que oscilan entre 30-850 m.

El huevo, la larva y la pupación de esta especie fueron descritos por Withycombe (1922), Killington (1937), Kimmins (1939), Gepp (1983b, 1989), DíazAranda (1992) y Monserrat \& Díaz-Aranda (2012).

Nuevo material estudiado o anotado: ESPAÑA: Vizcaya, Ubide, Motxotegi beech forest, 30TWN2564, $700 \mathrm{~m}, 17-23$.

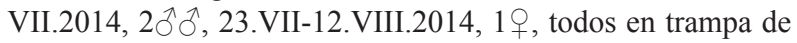
vino+cerveza, S. Pagola.

Nothochrysa fulviceps (Stephens, 1836) (Figs. 75, 86, 110, 177)

Chrysopa fulviceps Stephens, 1836

Stephens, 1836: 101 (d).

Nothochrysa fulviceps (Stephens, 1836)

Hölzel \& Ohm, 1972: 129 (rf), 144 (nt); Monserrat, 1978a: 176 (bio, dis); Aspöck et al., 1980: 236 (rf); Monserrat, 1984e: 156 (bio, dis); Grimal, 1984: 10 (rf); Canard, 1985: 176 (dis, 1); Díaz-Aranda \& Monserrat, 1988b: 222 (bio, dis); Monserrat \& Díaz-Aranda, 1989c: 253 (dis); Marín \& Monserrat, 1989: 293 (bio, dis); Popov, 1990: 48 (rf); Marín \& Monserrat, 1991b: 190-196 (bio, dis); Monserrat \& Rodrigo, 1992: 124 (bio, dis); Canard et al., 1992b: 96 (list); Monserrat \& Marín, 1994: 122 (bio); Monserrat et al., 1994: 49 (bio, dis); Marín \& Monserrat, 1995a: 115 (bio, dis); Monserrat, 1996: 14 (list); H. Aspöck et al., 2001: 70 (rf); Whittington, 2002: 379 (rf); Canard et al., 2007: 292-297 (rf); Monserrat, 2008: 173 (dis).

También citada en la fauna ibero-balear como Nathanica fulviceps (Stephens, 1836) y Nathanica fulviceps flavida Navás, 1919.

Especie europea extra-mediterránea. Está mayoritariamente citada sobre robles, arces, carpinos y coníferas, donde parece ocupar sus estratos más elevados, ocasionalmente sobre hierba, entre V-IX, en altitudes 
de 100 hasta $800 \mathrm{~m}$. Parece asegurado que hiberna en fase de prepupa (Aspöck et al., 1980).

En nuestra fauna tiene una clara tendencia eurosiberiana (Gerona, Barcelona, Lérida, Cantabria, Orense), con citas puntuales más meridionales (Teruel, Zaragoza, Zamora, Salamanca, Madrid, Guadalajara) y conocemos su presencia en Bragança (NE de Portugal), y ha sido recolectada sobre robles, quejigos, hayas y abedules en medios húmedos, entre VI-VIII, en altitudes montanas que oscilan entre 400-1.620 m.

El huevo y la larva de esta especie fueron descritos por Killington (1936, 1937), Gepp (1984b, 1989, 1990), Díaz-Aranda \& Monserrat (1995), Díaz-Aranda et al. (2001) y Monserrat \& Díaz-Aranda (2012). Canard (1985) cita una larva en Lérida.

\section{Género Hypochrysa Hagen, 1866}

Representado en nuestra fauna por una única e inconfundible especie.

Hypochrysa elegans (Burmeister, 1839) (Figs. 82, 87, 107, 178)

Chrysopa elegans Burmeister, 1839

Burmeister, 1839: 981 (d).

Hypochrysa elegans (Burmeister, 1839)

Monserrat, 1984a: 36 (dis); Marín \& Monserrat, 1989: 293

(dis); Canard et al., 1992b: 96 (list); Monserrat \& Marín, 1994: 122 (bio); Monserrat, 1996: 14 (list); H. Aspöck et al., 2001: 72 (rf); Canard et al., 2007: 292-297 (rf); Monserrat, 2008: 173 (dis); Ocharan et al., 2012: 425 (bio, dis); Monserrat et al., 2013: 46 (bio, dis), 2014: 4 (bio, dis); Dvořák \& Gabriš, 2015: 45 (rf)

Especie europea extendida a Anatolia e Irán. Está mayoritariamente citada sobre planifolios (Carpinus, Rhamnus, Castanea, Fagus, Acer, Quercus, Corylus, Ostrya, etc.), a veces sobre flores, entre IV-VII, en altitudes de entre 280 hasta $1.500 \mathrm{~m}$. Es una de las pocas especies con marcada actividad diurna (Canard et al., 2015). Es una especie monovoltina y parece tener diapausa estival (Pantaleoni, 1990; Grimal \& Canard, 1996) e hiberna en fase de pupa (Principi, 1956b; Aspöck et al., 1980).

En nuestra fauna ha sido muy poco citada y tiene una clara tendencia eurosiberiana, ocupando el tercio septentrional de la península (Asturias, Guipúzcoa, Álava, Santander, Navarra, Gerona y Huesca), y ha sido citada generalmente en zonas montanas y húmedas, tanto sobre coníferas como sobre planifolios (Abies, Fagus, Quercus y Crataegus, también sobre Platanus y sobre hierba), entre IV-VIII, en altitudes que oscilan entre 150-1.400 m.

El huevo y la larva de esta especie fueron descritos por Brauer (1851, 1867), Principi (1956b), Gepp (1983b, 1989, 1999), Grimal (1986), Díaz-Aranda \& Monserrat (1995), Díaz-Aranda et al. (2001), Duelli et al. (2010) y Monserrat \& Díaz-Aranda (2012). Monserrat et al. (2013) citan una larva en Navarra.
Chrysopinae Schneider, 1851

Chrysopini Schneider, 1851

\section{Género Chrysopa Leach, 1815}

Muy bien representado en nuestra fauna. Muchas especies son inconfundibles, mientras que otras son algo más problemáticas.

Chrysopa perla (Linnaeus, 1758) (Figs. 3, 89, 104, 181)

Hemerobius perla Linnaeus, 1758

Linnaeus, 1758: 911 (d).

Chrysopa perla (Linnaeus, 1758)

Eglin, 1940: 293 (rf); Zelený, 1971b: 159 (rf); Hölzel \& Ohm, 1972: 129 (dis), 144 (nt); Monserrat, 1978a: 178 (bio, dis); Aspöck et al., 1980: 245 (rf); Monserrat, 1984a: 37 (bio, dis), 1984e: 157 (bio, dis); Monserrat \& Díaz-Aranda, 1989c: 254 (bio, dis); Marín \& Monserrat, 1989: 293 (dis); Monserrat \& Rodrigo, 1992: 126 (dis); Canard et al., 1992b: 96 (list); Monserrat \& Marín, 1994: 122 (bio); Monserrat et al., 1994: 50 (dis); Monserrat, 1996: 14 (list); H. Aspöck et al., 2001: 81 (rf); Canard et al., 2007: 292-297 (rf); Ocharan et al., 2012: 425 (bio, dis); Monserrat et al., 2013: 48 (bio, dis), 2014: 6 (bio, dis).

También citada en la fauna ibero-balear como Hemerobius perla Linnaeus, 1758, Chrysopa perla nothochrysiformis Lacroix, 1915, Cintameva perla (Linnaeus, 1758) y Cintameva perla nothochrysiformis Lacroix, 1915.

Es una de las especies más estudiada. Posee una distribución eurosiberiana, desde Europa, Anatolia y Cáucaso a Mongolia y Siberia. Está citada en medios húmedos sobre una gran variedad de plantas, sean olmos, abetos, nogales, avellanos, caducifolios bajos, vegetación de rivera, ortigas, jardines, matorrales, setos, etc., y con cierta frecuencia sobre herbáceas, de voltinismo variable según latitudes y altitudes, ha sido recolectada entre IV-IX (X?), en altitud de 100 hasta $1.600 \mathrm{~m}$. Parece demostrado que hiberna en fase de prepupa (Aspöck et al., 1980).

En nuestra fauna tiene una clara tendencia eurosiberiana y se circunscribe a su tercio septentrional, y ha sido citada en medios muy húmedos sobre robles, avellanos, hayas, rosales, hierba, sauces y vegetación de rivera, ocasionalmente sobre pinos, es una especie bastante localizada pero a veces extremadamente abundante, entre V-VIII, con varias generaciones anuales, en altitudes generalmente montanas que oscilan entre 650-1.890 m.

El huevo, la larva y la pupación de esta especie fueron descritos por Brauer (1851), Schneider (1851a), Pariser (1919), Withycombe (1922), Killington (1937), Philippe (1970), Canard (1971, 1973a, 1976), Gepp (1983b, 1984b, 1986, 1989, 1999) y Monserrat \& Díaz-Aranda (2012).

Nuevo material estudiado o anotado: ESPAÑA: Huesca, Benasque, 11.VIII.2007, 1§, I. Martínez (Fig. 3), Valle de Hecho, Aragües del Puerto, 950 m, 19.VII.2007, 3 ej., E. Aistleitner (A. Gruppe). 
Chrysopa dorsalis Burmeister, 1839 (Figs. 80, 101) Burmeister, 1839: 981 (d); Eglin, 1940: 293 (rf); Hölzel \& Ohm, 1972: 129 (nt); Monserrat, 1977a: 20 (list), 107 (key), 111 (bio, dis, tx), 2008: 175 (bio, dis, 1, tx); Monserrat et al., 2014: 6 (bio, dis).

Chrysopa regalis Navás, 1915

Navás, 1914a: 40 (rf), 1915a: 79 (d); Hölzel \& Ohm, 1972: 129 (dis, nt), 137 (dis), 143 (nt); Hölzel, 1973a: 66 (dis, nt); Aspöck et al., 1980: 10, 11, 110, 192 (dis, mf), 247 (rf); Hölzel, 1984: 62 (rf); Canard, 1986b: 27-30 (bio, dis); Monserrat \& DíazAranda, 1987: 180 (bio, dis); Díaz-Aranda \& Monserrat, 1988b: 223 (bio, dis), 1988c: 220 (rf); Monserrat \& Díaz-Aranda, 1988: 91 (bio, dis), 1989b: 51 (dis), 1989c: 256 (bio, dis); Marín \& Monserrat, 1990: 225 (dis), 1991a: 181 (bio, dis); Monserrat \& Rodrigo, 1992: 127 (bio, dis); Canard et al., 1992b: 96 (list); Marín, 1994: 247-302 (bio, dis); Monserrat \& Marín, 1994: 122 (bio); Monserrat et al., 1994: 51 (bio, dis); Marín \& Monserrat, 1995a: 116 (bio, dis); Monserrat, 1996: 14 (list); Carvalho, 1997: 5, 6 (dis); H. Aspöck et al., 2001: 83 (rf); Canard et al., 2007: 292-297 (rf); Monserrat, 2008: 180 (tx); Letardi et al., 2013: 35 (list); Monserrat, 2013: 291 (rf); Monserrat et al., 2014: 6 (rf).

También citada en la fauna ibero-balear como Cintameva regalis (Navás, 1915).

Especie mediterránea septentrional extendida hacia Israel, Anatolia, Georgia, Cáucaso y Kazakstán. Está mayoritariamente recolectada sobre coníferas (Pinus, Juniperus), citada entre V-IX, y de tendencia orófila, en altitudes de 100 hasta $1.640 \mathrm{~m}$. Parece demostrado que hiberna en fase de prepupa (Aspöck et al., 1980).

En nuestra fauna tiene una clara tendencia montana, está citada del norte y centro peninsular, con citas puntuales más meridionales (Granada, Jaén, Albacete), posee una cierta tendencia orófila y una marcada preferencia por las coníferas, y ha sido citada sobre pinos, especialmente Pinus sylvestris, P. pinaster, también sobre enebros, sabinas, y puntualmente sobre hayas, robles, quejigos y encinas, entre V-IX, en altitudes que oscilan entre 90-1.610 m.

El huevo, la larva y la pupación de esta especie fueron descritos por Brauer (1851), Alderson (1911a), Pariser (1919), Withycombe (1922, 1923), Killington (1937), Fraser (1945), Gepp (1983b, 1986, 1989), Díaz-Aranda (1992), Díaz-Aranda \& Monserrat (1995), Díaz-Aranda et al. (2001), Monserrat (2008) y Monserrat \& Díaz-Aranda (2012).

Nuevo material estudiado o anotado: ESPAÑA: Albacete, Riópar, 1.200 m, 13.VIII.1988, 1 ej., E. Aistleitner (A. Gruppe), Nerpio, Sierra de las Cabras, Fuente de Arroyo Blanco, 1.610 m, 10.VII.1997, 2 ej., J.L. Lencina (A. Gruppe).

\section{Chrysopa formosa Brauer, 1851 (Figs. 8, 9, 102)}

Brauer, 1851: 8 (d); Stitz, 1927: 16 (rf); Berland, 1962: 70 (rf); Hölzel \& Ohm, 1972: 130 (dis), 143 (nt); Monserrat, 1977a: 20 (list), 107 (key), 114 (bio, dis); Monserrat, 1978b: 62 (bio, dis); Monserrat, 1979b: 20 (bio, dis); Aspöck et al., 1980: 11, 192 (dis, mf), 250 (rf); Sengonça, 1980: 66 (rf); Monserrat, 1980a: 174 (bio, dis), 1980b: 186 (bio, dis), 1981a: 154 (bio, dis), 1982: 76 (bio, dis); Campos \& Ramos, 1983: 222 (bio, dis); Monserrat, 1984a: 37 (bio, dis), 1984d: 100 (bio, dis), 1985b: 85 (bio, dis); Díaz-Aranda et al., 1986b: 1139 (bio, dis); Monserrat, 1986b: 101 (dis), 1987: 138 (dis); Monserrat \& Díaz-Aranda, 1987: 180 (bio, dis); Séméria \& Berland, 1988: 123 (rf); Díaz-Aranda \& Monserrat, 1988a: 118 (bio, dis), 1988b: 223 (bio, dis), 1988c: 220 (bio, dis); Monserrat \& Díaz-Aranda, 1988: 91 (bio, dis), 1989b: 51 (bio, dis), 1989c: 255 (bio, dis); Canard et al., 1992b: 97 (rf); Monserrat \& Rodrigo, 1992: 126 (bio, dis); Boelpaepe et al., 1992: 22 (bio, dis); Pantaleão et al., 1993: 429 (bio, dis); Monserrat \& Marín, 1994: 122 (bio); Monserrat et al., 1994: 51 (bio, dis); Marín \& Monserrat, 1995a: 115 (bio, dis), 1995b: 40 (bio, dis); Monserrat, 1996: 14 (list); Carvalho, 1997: 5, 6 (dis); H. Aspöck et al., 2001: 86 (rf); Monserrat, 2005: 77 (bio, dis); Canard et al., 2007: 292-297 (rf); Monserrat, 2008: 181 (dis), 2013: 290 (bio, dis); Monserrat et al., 2013: 48 (bio, dis); Letardi et al., 2013: 35 (list); Monserrat et al., 2014: 7 (bio, dis). Chrysopa burmeisteri Schneider, 1851

Schneider, 1851a: 123 (d).

Chrysopa formosa bufona Navás, 1915

Monserrat, 1977a: 115 (dis, rf).

Cintameva pyrenaea Navás, 1930

Navás, 1930: 161 (d); Hölzel \& Ohm, 1972: 130 (nt).

También citada en la fauna ibero-balear como Chrysopa formosa atomaria Navás, 1908, Chrysopa formosa boguniana Navás, 1919, Chrysopa formosa foedata Navás, 1919, Chrysopa formosa gundisalvi Navás, 1915, Chrysopa formosa laletana Navás, 1909, Cintameva formosa (Brauer, 1851), Cintameva formosa atomaria Navás, 1908, Cintameva formosa boguniana Navás, 1919, Cintameva formosa bufona Navás, 1915, Cintameva formosa frontalis Pongraz, 1912, Cintameva formosa gundisalvi Navás, 1915, Cintameva formosa sobradielina Navás, 1932, Cintameva pyrenda Navás, 1930 (lapsus) y Chrysopa pyrenaea (Navás, 1930).

Especie paleártica, marcadamente eurioica. Está mayoritariamente citada entre V-IX, por lo que varias generaciones se suceden, en altitudes de 100 hasta $2.000 \mathrm{~m}$. Parece demostrado que hiberna en fase de prepupa (Aspöck et al., 1980).

Ampliamente citada en nuestra fauna, incluyendo Baleares (Mallorca, Ibiza, Formentera, Menorca), donde ha sido citada en medios muy diversos, frecuentemente mediterráneos sobre encinas, sauces, algarrobos, almendros, acacias, también castaños, coníferas, arbustos (Genista, Nerium, Tamarix, Atriplex, etc.), hierbas, hiedras, helechos, etc., entre IV-X, aunque existen capturas, $\mathrm{y}$ ahora citamos alguna, que sugieren su actividad todo el año, al menos en zonas peninsulares más meridionales (I, XII), en altitudes que oscilan entre $10-1.750 \mathrm{~m}$.

El huevo y la larva de esta especie fueron descritos por Schneider (1851a), Pariser (1919), Principi (1947), Tsukaguchi (1978, 1995), Gepp (1983b), Pantaleoni (1983) y Monserrat \& Díaz-Aranda (2012).

Nuevo material estudiado o ANOtado: ESPAÑA: Baleares, Mallorca, Colonia de Sant Jordi, 10 m, 30.VIII.2008, 5 ej., E. Aistleitner (A. Gruppe). Granada, La Herradura, Punta de la Mona, 21.XII.2014, 1 ㅇ a la luz, 28.XII.2014, 1 ㅇ a la luz, 2.I.2015, 1 ㅇ sobre Citrus. Madrid, El Escorial, Abantos, 19.VI.2014, 
1 오 sobre Pinus sylvestris, F. Acevedo. Tarragona, La Selva del Camp, $41^{\circ} 13^{\prime} 07.67^{\prime \prime} \mathrm{N} 1^{\circ} 08^{\prime} 36.94^{\prime \prime} \mathrm{E}, 224$ m, 18.VI.2007, 10, 1 우 sobre Citrus clementina, N. Cañellas. PORTUGAL: Algarve,

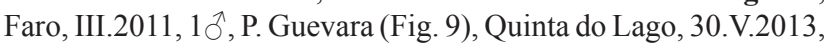

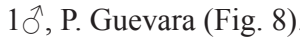

Chrysopa nierembergi Navás, 1908 (Fig. 103)

Navás, 1908b: 401 (d); Hölzel \& Ohm, 1972: 130 (dis), 143 (nt); Hölzel, 1973a: 67 (dis, mf, nt); Aspöck et al., 1980: 10, 11, 193 (dis, mf), 250 (rf); Hölzel, 1984: 62 (rf); Monserrat, 1984d: 113 (rf); Díaz-Aranda et al., 1986b: 1139 (bio, dis); Díaz-Aranda \& Monserrat, 1988c: 220 (rf); Monserrat \& Díaz-Aranda, 1989c: 256 (dis); Monserrat \& Rodrigo, 1992: 127 (dis); Monserrat \& Marín, 1994: 122 (bio); Marín \& Monserrat, 1995a: 116 (bio, dis); Monserrat, 1996: 14 (list); Carvalho, 1997: 5, 6 (dis); H. Aspöck et al., 2001: 87 (rf); Canard et al., 2007: 292-297 (rf); Monserrat, 2008: 181 (bio, dis), 2013: 29 (rf); Letardi et al., 2013: 35 (list); Monserrat et al., 2014: 19 (bio, dis).

También citada en la fauna ibero-balear como Chrysopa nierembergi andreui Navás, 1910, Chrysopa nierembergi clara Navás, 1915, Chrysopa nierembergi nitens Navás, 1909, Cintameva nierembergi (Navás, 1908), Cintameva nierembergi andreui Navás, 1910, Cintameva nierembergi clara Navás, 1915 y Cintameva nierembergi nitens Navás, 1908.

Seguimos manteniendo nuestras reservas sobre la validez de esta especie respecto a Chrysopa formosa Brauer, 1851, aún así nos mantenemos a la espera de nuevos datos.

Especie conocida del S.E. de la Península Ibérica. Por lo que todos los datos conocidos de esta especie se corresponden con nuestra fauna. En ella tiene una clara tendencia litoral termo-mediterránea, con citas puntuales más interiores (Guadalajara, Madrid, Teruel, Zaragoza y San Fiel en Portugal), no siempre incuestionables, $\mathrm{y}$ ha sido citada mayoritariamente asociada a medios xéricos y cálidos, sobre enebros, quejigos, genistas y algarrobos, sin conocerse ninguna especial preferencia, entre V-IX, en altitudes que oscilan entre $10-1.410 \mathrm{~m}$.

Nuevo material estudiado o anotado: ESPAÑa: Albacete, Bogarra, Los Cucos, 830 m, 1.VI.2007, 1 ej., J.L. Lencina (A. Gruppe).

\section{Chrysopa dubitans McLachlan, 1887}

McLachlan, 1887: 448 (d); Hölzel \& Ohm, 1972: 130 (dis), 142 (dis), 144 (nt); Popov, 1977: 273 (rf); Hölzel, 1980c: 193 (rf); Aspöck et al., 1980: 250 (rf); Sengonça, 1980: 63 (rf); Hölzel, 1984: 62 (rf); Monserrat, 1985b: 91 (rf). Monserrat \& Marín, 1994: 121 (rf); Paulian \& Canard, 2000: 250 (rf); Paulian et al., 2001: 27 (rf); H. Aspöck et al., 2001: 87 (rf); Paulian, 2002: 267 (rf); Canard et al., 2010: 131 (rf).

Como en algún otro caso que citamos, seguimos manteniendo nuestras reservas sobre la cita en Totana (Murcia) de Chrysopa dubitans McLachlan, 1887, dada por Hölzel \& Ohm (1972: 130, 141), y que ha generado varias referencias posteriores para la fauna ibérica que anotamos. Esta cita ha sido cuestionada por nosotros con frecuencia, ya que siendo precisamente esta zona del S.E. peninsular, una zona intensa- y especialmente muestreada por nosotros (Monserrat, 1984d, 1985b, 1987; Díaz-Aranda \& Monserrat, 1988a, 1988c; Monserrat \& Díaz-Aranda, 1989c; Marín \& Monserrat, 1991a; Monserrat \& Rodrigo, 1992; Monserrat \& Marín, 1994, etc.), nunca la hemos hallado, y nos reservamos, una vez más, cuestionar la autenticidad de la identificación, máxime cuando se trata de una especie eremial esencialmente asiática (Irán, Afganistán, Pakistán, Turkmenistán, Uzbekistán, Kazakstán, Kirgisistán, Mongolia y China) y rara en Europa, citada del este de Francia y de Rumanía, y especialmente del Mediterráneo oriental (Egeo, Chipre, Creta, Israel, Palestina, Turquía, Líbano, Cáucaso), también de Argelia y, consecuentemente, presumida del sur de la Península Ibérica (Paulian, 2002; Canard \& Jacquemin, 2006; Canard et al., 2007, 2010).

Es cierto que varias especies presentan similar distribución en zonas eremiales del Paleártico occidental que alcanzan el S.E. peninsular, aunque quizás, como en el caso de Chrysopa phyllochroma o de Chrysopa nigricostata/Cunctochrysa cosmia (ver más adelante), probablemente se estén mezclando elementos de dos especies diferentes (Monserrat et al., 2014), aún así ha sido incluida en nuestro estudio, a la espera de que nuevos datos nos lo confirmen.

De biología esencialmente desconocida, probablemente esté asociada a medios esteparios con vegetación escasa y baja, sobre vegetación herbácea y está mayoritariamente citada entre IV-IX, en altitudes de hasta $2.000 \mathrm{~m}$. Parece demostrado que hiberna en fase de prepupa (Aspöck et al., 1980).

En nuestra fauna solo existe la cita de Hölzel \& Ohm (1972), VI, 270 m.

\section{Chrysopa phyllochroma Wesmael, 1841 (Fig. 105)}

Wesmael, 1841: 209 (d); Navás, 1909a: 175 (dis); Klapálek, 1909: 30 (dis); Navás, 1915a: 74 (dis, mf), 1915b: 80 (dis); Stitz, 1927: 16 (rf); Eglin, 1940: 295 (rf); Hölzel, 1964b: 147 (rf); Hölzel \& Ohm, 1972: 130 (dis), 144 (nt); Hölzel et al., 1980: 14 (rf); Aspöck et al., 1980: 251 (rf); Monserrat, 1984d: 113 (rf), 1987: 137 (bio, dis); Díaz-Aranda \& Monserrat, 1988b: 223 (rf), 1988c: 220 (rf); Monserrat \& Díaz-Aranda, 1989c: 254 (dis); Canard et al., 1992b: 97 (rf); Monserrat \& Marín, 1994: 122 (bio); Monserrat, 1996: 14 (list); H. Aspöck et al., 2001: 89 (rf); Monserrat, 2005: 77 (rf); Canard et al., 2007: 292-297 (rf); Monserrat, 2013: 291 (rf); Monserrat et al., 2014: 6 (bio, dis). Cintameva phyllochroma (Wesmael, 1841)

Navás, 1924a: 168 (dis, mf), 1925: 74 (key), 79 (dis); Vidal y López, 1943: 21 (dis).

Especie sibérica extra-mediterránea, conocida desde Europa central y septentrional y el Cáucaso a Siberia, Mongolia y China. Está mayoritariamente citada en vegetación baja, herbácea y flores, principalmente de crucíferas, leguminosas o solanáceas (Achillea, Vicia, Medicago, Solanum, Beta, Artemisia, Sinapis, Pisum, Hordeum, Trifolium, etc.), también sobre Ulmus, Crataegus, etc. (Zelený, 1965; Hölzel \& Ohm, 1972), habitualmente con poblaciones de cortas fenologías, 
citada entre V-IX, en altitudes de hasta $2.000 \mathrm{~m}$. Parece demostrado que hiberna en fase de prepupa (Aspöck et al., 1980).

En el caso de esta especie, hemos anotado todos los registros antiguos y referencias consecuentes a nuestra fauna, dado las dudas existentes sobre muchas de estas citas. En nuestra fauna apenas existen datos bibliográficos (Zaragoza, Mallorca, Granada, Lérida, Alicante y Almería), existiendo identificaciones, no siempre incuestionables, de escasos ejemplares y siempre hembras entre los recolectados por nosotros. Siendo una especie de montaña, claramente alpinasubalpina, las citas de Navás (1915a: 74, 1924a: 169, 1925: 79) en Orihuela (Alicante) siempre nos ha parecido muy dudosas, muy imprecisa la referencia de Klapálek (1909: 30) (Montseny?, Montserrat?, Monistrol?, Algeciras?, VI, 1907), siendo más probable la de Navás (1915b: 80) en el Valle de Arán (Lérida) (VI), que parecen confirmar Hölzel \& Ohm (1972), quienes la citan de esta provincia en Sudanell (sobre Ulmus, Crataegus, VI, c. $160 \mathrm{~m}$, la altitud ha sido estimada por nosotros). Los datos de Baleares (Mallorca) siempre nos habían parecido muy dudosos, y fueron corregidos por Monserrat (2005), y Monserrat et al. (2014) ponen en duda la veracidad de otras citas, incluso recientes, dadas en nuestra fauna en medios mediterráneos meridionales y térmicos, como es el caso de la dada por Monserrat \& DíazAranda (1989c: 254) y Monserrat et al. (2014: 6) de Almería o de Hölzel \& Ohm (1972: 130) en Sierra Nevada (VI-VII), ya que se trata de una especie con tendencia marcadamente septentrional y montana. Por ejemplo en Italia (R.A. Pantaleoni, com. pers.) esta especie posee una distribución marcadamente alpina, y está ausente en áreas más meridionales, hecho que nos plantea serias dudas sobre las citas ibéricas meridionales (quizás con posible excepción de las de Sierra Nevada en Granada, si es correcta la cita de Hölzel \& Ohm, 1972, y allí permanece una población relicta), no digamos en áreas marcadamente xero-térmicas, y probablemente solo las citas de Lérida sean válida.

Como en el caso de Chrysopa dubitans (anteriormente citada) o de Chrysopa nigricostata/Cunctochrysa cosmia (ver más adelante), probablemente se estén mezclando elementos de dos especies (Monserrat et al., 2014), y para los datos más meridionales, se trate de alguna especie norteafricana o por describir (Zelený, 1971a o Séméria, 1984b la citan como de fácil confusión con otras especies). Hasta no recolectar algún ejemplar macho en los que corroborar nuestras citas (Monserrat, 1987; Monserrat \& DíazAranda, 1989c; Monserrat et al., 2014), mantenemos esta situación a la espera de que pueda ser adecuadamente resuelta y, por ello, ha sido incluida en nuestro estudio, a la espera de que nuevos datos nos confirmen su situación. Ha sido citada sobre Ulmus, Nerium y Crataegus, entre VI-VII, en altitudes que oscilan entre $10-1.500 \mathrm{~m}$.
El huevo, la larva y la pupación de esta especie fueron descritos por Withycombe (1924, 1925), Killington (1937), Tsukaguchi (1978) y Gepp (1983b, 1984b, 1989).

Chrysopa nigricostata Brauer, 1851 (Figs. 106, 121-129)

Brauer, 1851: 6 (d); Hölzel, 1965c: 76 (rf); Hölzel \& Ohm, 1972: 132 (dis, nt); Hölzel, 1973a: 66 (nt, tx); Monserrat, 1977a: 20 (list), 107 (key), 108 (bio, dis), 1978a: 178 (bio, dis), 1980b: 186 (bio, dis); Aspöck et al., 1980: 254 (rf); Sengonça, 1980: 43 (rf); Monserrat, 1984a: 37 (dis), 1984e: 156 (bio, dis); Díaz-Aranda et al., 1986b: 1139 (bio, dis); DíazAranda \& Monserrat, 1988b: 223 (bio, dis), 1988c: 220 (bio, dis); Monserrat \& Díaz-Aranda, 1989c: 256 (bio, dis); Canard et al., 1992b: 96 (list); Monserrat \& Rodrigo, 1992: 127 (bio, dis); Monserrat \& Marín, 1994: 122 (bio); Marín \& Monserrat, 1995a: 116 (bio, dis); Monserrat, 1996: 14 (list); Carvalho, 1997: 5, 6 (dis); H. Aspöck et al., 2001: 90 (rf); Canard et al., 2007: 292-297 (rf); Monserrat, 2008: 181 (bio, dis), 2013: 29 (rf); Letardi et al., 2013: 35 (list); Monserrat et al., 2013: 48 (bio, dis), 2014: 7 (bio, dis, mf, tx).

Chrysopa cosmia Navás, 1918

Navás, 1917d: 87 (rf), 1918: 19 (d); Hölzel, 1973a: 66 (tx) (ver Cunctochrysa cosmia).

Chrysopa nigricostata marginata Navás, 1904

Monserrat, 1977a: 109 (rf).

También citada en la fauna ibero-balear como Chrysopa nigricostata ataresi Navás, 1914.

Según referían Monserrat et al. (2014) e indicamos más adelante, mayoritariamente todas estas citas mencionadas se corresponden con Cunctochrysa cosmia (Navás, 1918). Se trata de una especie frecuentemente citada, también en nuestra fauna, mayoritariamente confundida con Cunctochrysa cosmia, siendo aclaradas alguna de estas citas y la mayoría de las ibéricas por Monserrat et al. (2014), por lo que los datos bibliográficos correspondientes a ambas especies están parcialmente mezclados.

Especie holomediterránea expansiva hacia el centro de Europa, Anatolia, el Cáucaso, Armenia, Irak, Irán, Afganistán, Turkmenistán, Azerbaiyán, Tadschikistán, Kirguistán, Tayikistán y Kazakstán. Marcadamente estenotópica y frecuentemente citada en la bibliografía asociada a choperas y bosques de galería y a pinares, robles, encinas, etc. en medios mediterráneos. Los datos más fidedignos sobre esta especie la asocian a chopos y álamos, incluso dentro de sus agallas (ej.: Homoptera: Aphididae, Pemphigus spyrothecae Passerini, 1860), bosques de galería/riveras, parques y zonas urbanas o zonas arenosas y de vegetación baja, vinculada a medios térmicos y esteparios surcados por cauces rivereños más húmedos con chopos y álamos (Populus nigra, P. tremula, P. alba, etc.) y los restantes datos (especialmente sobre coníferas) deben asociarse a Cunctochrysa cosmia. Está mayoritariamente citada entre V-IX, y aunque ha sido citada como orófila, incluso marcadamente alpina (c. 500-1000 m en Centroeuropa, hasta $1.800 \mathrm{~m}$ en el sur de Europa y hasta 3.000-4.600 m en Próximo Oriente y Asia Central), también en su 


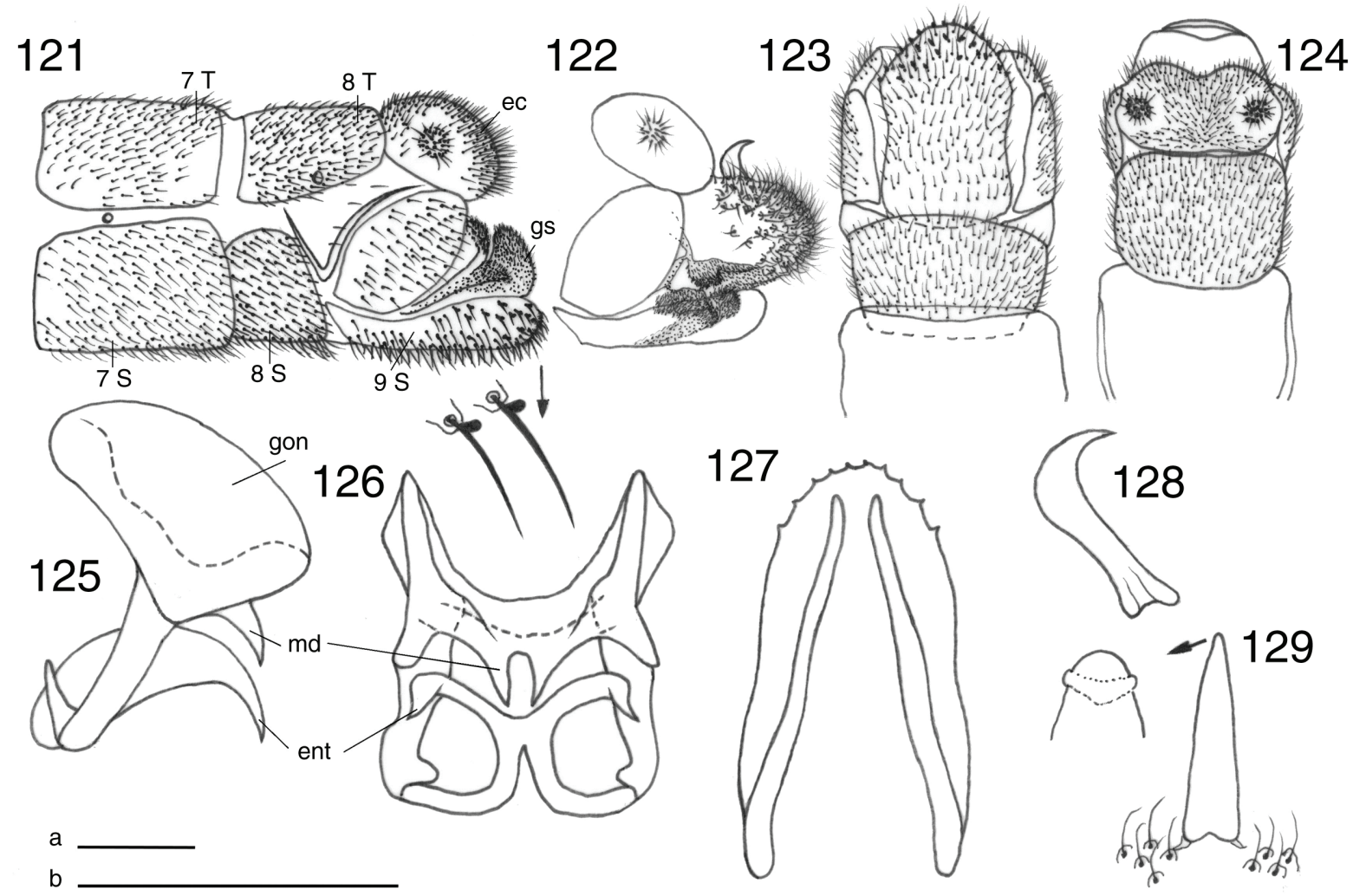

Figs. 121-129.- Chrysopa nigricostata, 3̂. 121: extremo abdominal, vista lateral (aumentadas dos setas), 122: ídem, con gonosaco evaginado, 123: ídem, vista ventral, 124: ídem, vista dorsal, 125: complejo gonarco-mediuncos-entoprocesos, vista lateral, 126: ídem, vista caudal, 127: apodemas del noveno esternito, vista interior dorsal, 128: arceso, vista lateral, 129: ídem, vista dorsal (aumentado el ápice) (ec: ectoprocto, ent: entoproceso, gon: gonarco, gs: gonosaco, md: mediunco, S: esternito, T: terguito. Escalas 0,5 mm, a: 1-4, b: 5-9). Adaptado de Monserrat et al. (2014).

Figs. 121-129.- Chrysopa nigricostata, 3 . 121: abdominal apex, lateral view (two setae magnified), 122: ditto, with gonosacus evaginated, 123: ditto, ventral view, 124: ditto, dorsal view, 125: complex gonarcus-mediuncus-entoprocessus, lateral view, 126: ditto, caudal view, 127: apodemes of ninth sternite, dorsal interior view, 128: arcessus, lateral view, 129: ditto, dorsal view (magnified apex) (ec: ectoproct, ent: entoprocessus, gon: gonarcus, gs: gonosaccus, md: mediuncus, S: sternite, T: tergite. Scale bar 0.5 mm, a: 1-4, b: 5-9). Adapted from Monserrat et al. (2014).

distribución altitudinal los datos puedan estar mezclados, probablemente correspondiendo las citas de cotas medias y altas entre 670-2.100/3.000 $\mathrm{m}$ a Cunctochrysa cosmia, y limitando la especie que tratamos en nuestras latitudes a altitudes de 100 hasta $930 \mathrm{~m}$.

Descartadas las citas anteriores erróneas (Monserrat et al., 2014), en nuestra fauna existen pocos datos (Burgos, Zaragoza, Madrid, Navarra) que parecen asociarla a medios xéricos, térmicos, esteparios y/o gipsícolas. Todos los ejemplares ibéricos conocidos se han mayoritariamente recolectados a la luz en estos medios esteparios y secos con vegetación xerófila, donde no descartamos la existencia de chopos y/o álamos en vaguadas próximas con mayor humedad endorreica, recolectada en V-VIII, en altitudes que oscilan entre 225-930 m. (Aunque aquí los hemos recogido tal cual fueron citados, los datos bibliográficos en la Península Ibérica a mayores cotas de 670-2.100 m corresponden a Cunctochrysa cosmia).

Sus estadios preimaginales son fragmentariamente conocidos (Brauer, 1851; anotado por Gepp, 1983b, 1989 y Hölzel, 1998).
Chrysopa pallens (Rambur, 1838) (Figs. 13, 14, 15, $36,38,99)$

Hemerobius pallens Rambur, 1838

Rambur, 1838: pl. 9, Fig. 9 (d, tx).

Chrysopa pallens (Rambur, 1838)

Marín \& Monserrat, 1990: 225 (rf), 1991a: 181 (bio, dis); Monserrat \& Rodrigo, 1992: 126 (bio, dis); Núñez Pérez et al., 1992: 390 (bio, dis); Canard et al., 1992 b: 96 (list); Pantaleão et al., 1993: 429 (bio, dis); Monserrat \& Marín, 1994: 122 (bio); Monserrat et al., 1994: 51 (bio, dis); Monserrat, 1996: 14 (list); Carvalho, 1997: 5, 6 (dis); H. Aspöck et al., 2001: 92 (rf); Monserrat, 2005: 77 (rf); Canard et al., 2007: 292-297 (rf); Monserrat, 2008: 175 (dis); Ocharan et al., 2012: 425 (rf); Monserrat, 2013: 291 (rf); Letardi et al., 2013: 35 (list); Monserrat et al., 2014: 6 (bio, dis).

Chrysopa septempunctata Wesmael, 1841

Wesmael, 1841: 210 (d); Stitz, 1927: 16 (rf); Eglin, 1940: 295 (rf); Hölzel, 1964b: 147 (rf); Hölzel \& Ohm, 1972: 132 (dis), 143 (nt); Monserrat, 1977a: 20 (list), 107 (key), 112 (bio, dis), 1978a: 178 (bio, dis), 1978b: 62 (bio, dis), 1979b: 20 (bio, dis); Aspöck et al., 1980: 255 (rf); Monserrat, 1980a: 174 (bio, dis), 1980b: 186 (bio, dis), 1981a: 154 (bio, dis), 1982: 76 (bio, dis); Campos \& Ramos, 1983: 220 (bio, dis); Monserrat, 1984a: 37 (bio, dis), 1984b: 170 (bio, dis), 1984d: 99 (bio, dis), 
1984e: 157 (bio, dis), 1985b: 85 (bio, dis), 1985c: 92 (bio, dis), 1986b: 101 (bio, dis); Díaz-Aranda et al., 1986b: 1138 (bio, dis); Monserrat \& Díaz-Aranda, 1987: 179 (bio, dis); Marín \& Monserrat, 1987: 350-359 (bio, dis); Monserrat \& DíazAranda, 1988: 91 (bio, dis); Díaz-Aranda \& Monserrat, 1988a: 117 (rf), 1988c: 220 (bio, dis); Monserrat \& Díaz-Aranda, 1989b: 51 (bio, dis), 1989c: 255 (bio, dis); Boelpaepe et al., 1992: 22 (bio, dis); Torralba Burrial, 1995: 49 (dis); Alvis et al., 2003: 186 (bio, dis).

Chrysopa septempunctata pallens Rambur, 1838

Monserrat, 1977a: 113 (rf).

Parachrysopa pallens (Rambur, 1838)

Séméria \& Vannier, 1983: 206 (rf).

También citada en la fauna ibero-balear como Chrysopa septempunctata polysticta Navás, 1915, Chrysopa septempunctata pallens (Rambur, 1838), Chrysopa septempumtata (sic) punctulata Navás, 1916, Chrysopa septempunctata puncticollis Navás, 1915, Chrysopa 7-punctata Wesmael, 1841, Chrysopa 7-punctata hernandezi Navás, 1918, Chrysopa 7-punctata pallens Rambur, 1838, Chrysopa 7-punctata punctulata Navás, 1916, Cintameva septempunctata (Wesmael, 1841), Cintameva septempunctata hernandezi Navás, 1918, Cintameva septempunctata pallens (Rambur, 1838), Cintameva septempunctata polysticta (Navás, 1915), Cintameva septempunctata punctulata (Navás, 1916), Cintameva septempunctata rubriceps (Navás, 1932), Cintameva 7-punctata Wesmael, 1841 y Cintameva 7-punctata hernandezi Navás, 1918.

En relación a esta común especie, ha de indicarse que una de sus especies sinónimas previamente propuestas: Chrysopa gibeauxi (Leraut, 1989), ha sido recientemente revalidada como especie válida (Leraut, 1992b; Tillier et al., 2014; Devetak et al., 2015) en base a ciertas diferencias de coloración tegumentaria y de la venación alar, setación del pronoto, etc., y especialmente en el aspecto y forma de las gonochorista y complejo gonarco-entoprocesos en la genitalia masculina. Esta especie parece asociada a pinos, mayoritariamente en medios alpinos (900-1.900 m), y ha sido hallada en Francia, Croacia, Eslovenia, Serbia, Polonia, Finlandia y Corea del Norte, por lo que no se descarta su presencia en nuestra fauna, y probablemente pertenezcan a ella ejemplares ibéricos recolectados sobre coníferas en estos medios montanos, anteriormente identificados como Chrysopa pallens.

Especie paleártica introducida por acción humana a otras zonas (Mauricio, Taiwán y Camboya) y probablemente en Canarias. Es francamente eurioica, y está citada sobre una gran variedad de medios, jardines urbanos, frutales, caducifolios, etc., mayoritariamente entre V-XI, en altitudes de 100 hasta $2.000 \mathrm{~m}$. Parece demostrado que hiberna en fase de prepupa (Aspöck et al., 1980).

Ampliamente distribuida en nuestra fauna, incluyendo Baleares (Mallorca, Menorca), marcadamente eurioica y generalmente asociada a medios arbóreos abiertos y soleados donde ha sido citada sobre una enorme variedad de sustratos vegetales, bien planifolios o, en menor medida, coníferas, frutales, etc., entre IV-IX, en altitudes que oscilan entre $10-1.340 \mathrm{~m}$.

La puesta, el huevo, la larva y la pupa de esta especie fueron descritos por Pariser (1919), Whitycombe (1922), Lacroix (1929), Killington (1936, 1937), Principi (1940), Agekyan (1973), Tsukaguchi (1978, 1995), Gepp (1983b, 1989, 1999), Pantaleoni (1983) y Monserrat \& Díaz-Aranda (2012).

Chrysopa viridana Schneider, 1845 (Fig. 98)

Schneider, 1845: 345 (d); Principi, 1952: 13 (rf), 1954b: 360 (dis); Tjeder, 1971: 112 (rf); Hölzel \& Ohm, 1972: 132 (dis), 143 (nt); Monserrat, 1977a: 20 (list), 107 (key), 110 (bio, dis), 1978b: 62 (bio, dis), 1979a: 412 (bio, dis), 1980a: 174 (dis), 1980b: 186 (bio, dis); Aspöck et al., 1980: 253 (rf); Sengonça, 1980: 40 (rf); Monserrat, 1981a: 154 (bio, dis), 1982: 76 (bio, dis); Campos \& Ramos, 1983: 222 (dis, bio); Marín, 1994: 247-302 (bio, dis); Monserrat, 1984a: 46 (rf), 1984b: 170 (bio, dis), 1984e: 157 (dis, bio), 1985b: 85 (bio, dis); Díaz-Aranda et al., 1986a: 1125 (bio, dis), 1986b: 1138 (bio, dis); Monserrat, 1986b: 101 (bio, dis), 1987: 137 (bio, dis); Monserrat \& Díaz-Aranda, 1987: 179 (bio, dis); Marín \& Monserrat, 1987: 350-359 (bio, dis); Díaz-Aranda \& Monserrat, 1988a: 118 (bio, dis), 1988b: 233 (dis), 1988c: 220 (bio, dis); Monserrat \& Díaz-Aranda, 1989c: 255 (dis, bio); Marín \& Monserrat, 1990: 225 (dis, bio), 1991a: 181 (dis, bio); Canard et al., 1992b: 97 (rf); Monserrat \& Rodrigo, 1992: 126 (dis, bio); Pantaleão et al., 1993: 429 (bio, dis); Monserrat \& Marín, 1994: 122 (bio); Marín, 1994: 260 (bio, dis); Monserrat et al., 1994: 51 (bio, dis); Marín \& Monserrat, 1995a: 115 (bio, dis), 1995b: 40 (bio, dis); Monserrat, 1996: 14 (list); Carvalho, 1997: 5 (dis); H. Aspöck et al., 2001: 90 (rf); Monserrat, 2005: 77 (rf); Canard et al., 2007: 292-297 (rf); Monserrat, 2008: 181 (dis); Ocharan et al., 2012: 425 (rf); Monserrat et al., 2013: 48 (bio, dis); Letardi et al., 2013: 35 (list); Monserrat, 2013: 291 (bio, dis); Monserrat et al., 2014: 6 (bio, dis, mf).

Chrysopa galaica Navás, 1927

Navás, 1927: 51 (d); Hölzel, 1973a: 67 (tax).

Chrysopa geniculata Pictet, 1865

Pictet, 1865: 62 (d).

Chrysopa hilaris Navás, 1915

Navás, 1915b: 79 (d).

Chrysopa marginalis Navás, 1905

Navás, 1905e: 122 (d); Monserrat, 1977a: 20 (list), 110 (rf).

Chrysopa montana Navás, 1917

Navás, 1917c: 169 (d, tx); Monserrat, 2011: 170 (tx).

Chrysopa palpalis Navás, 1917

Navás, 1917c: 169 (“d”, tx); Monserrat, 2011: 170 (tx).

Chrysopa viridana marginalis Navás, 1905

Monserrat, 1977a: 110 (rf)

Chrysopa viridana montana Navás, 1915

Monserrat, 1977a: 110 (rf)

También citada en la fauna ibero-balear como Chrysopa viridana adaequata Navás, 1915, Chrysopa viridana ditata Navás, 1919, Chrysopa viridana dives Navás, 1922, Chrysopa viridana hilaris Navás, 1923 y Chrysopa viridana marialis Navás, 1917.

La ubicación de esta especie dentro de este género es muy problemática, no solo por ser excepción dentro del género en ciertos caracteres de morfología externa (ver clave de especies) y genitalia (Brooks \& Barnard, 1990; Canard et al., 1990; Canard, 2001; Monserrat 
et al., 2013, 2014, etc.), sino en relación a otro tipo de estudios, y por citar algunos, mencionemos a Bullini et al. (1983a, 1983b, 1984) o Bullini \& Cianchi (1984), quienes mediante la realización de estudios electroforéticos de enzimas, anotan que $C$. viridana es una especie genéticamente muy diferente a las otras especies del género Chrysopa estudiadas en dichos trabajos. Recientes estudios han demostrado nuevas vías moleculares aplicables a la taxonomía y sistemática de la familia Chrysopidae, y entre ellos, Cadena et al. (2007) sostienen la presencia de especies y géneros morfológicamente muy semejantes que requieren un examen más cuidadoso, y Haruyama et al. (2008), y en lo que respecta a esta especie, anotan que $C$. viridana se separa en un exclusivo cluster respecto a las restantes especies de este género por ellos consideradas, de hecho esta especie es también excepción en la clave de especies ibérica que hemos anotado. También en aspectos de la morfología de sus estadios larvarios se separa de lo conocido en otras especies del género, y así Monserrat \& Díaz-Aranda (2012) la citan como permanente excepción en los caracteres que definen las larvas de este género. Todos estos hechos alejan a esta especie de su posición taxonómica actual dentro del género Chrysopa donde está habitualmente aceptada, y prueban, una vez más, la necesaria revisión a fondo del género Chrysopa, hecho que ya ha sido sugerido por numerosos autores (Naville \& Beaumont, 1933, 1936; Killington, 1937; Adams, 1975; Principi, 1977; New, 1984a; Séméria, 1984a; Brooks \& Barnard, 1990; Cadena et al., 2007; Monserrat et al., 2014, etc.).

Especie holomediterránea expandida hacia Armenia, el Cáucaso, Irán, Afganistán y Turkmenistán. Está asociada a medios mediterráneos, mayoritariamente hallada sobre Quercus esclerófilos en estos medios mediterráneos, y también recolectada sobre una amplia gama de sustratos vegetales (oleáceas, salicáceas, sapindáceas, coníferas, cultivos, jardines, etc.), entre IV-IX, en altitudes de 100 hasta $2.000 \mathrm{~m}$. Parece demostrado que hiberna en fase de prepupa (Aspöck et al., 1980).

En nuestra fauna tiene una clara tendencia continental mediterránea, incluyendo Baleares (Mallorca), con citas puntuales más septentrionales (Asturias, Pontevedra, León, Zamora, Salamanca, Lérida, Huesca), y ha sido citada en medios mediterráneos sobre encinas, alcornoques, robles, quejigos, puntualmente sobre olivos, pinos, enebros, sabinas, alisos, castaños, olmos, pistáceas, alnueces, frutales, etc., entre V-X, en altitudes mayoritariamente medias, y que oscilan entre $10-2.250 \mathrm{~m}$.

La larva de esta especie fue descrita por Lacroix (1921a), Principi (1954b), Gepp (1983b), Pantaleoni (1983) y Monserrat \& Díaz-Aranda (2012).

Nuevo material estudiado o anotado: ESPAÑA: Granada, Dehesa del Generalife, VII.2013, 1ㅇ, F. Ruano, La Herradura, 28.V.2015, $1 \overbrace{}^{\lambda}$ sobre Prunus persica. Madrid, San Fernando de Henares, 24.VI.2012, 1어, J.I. López Colón.
130

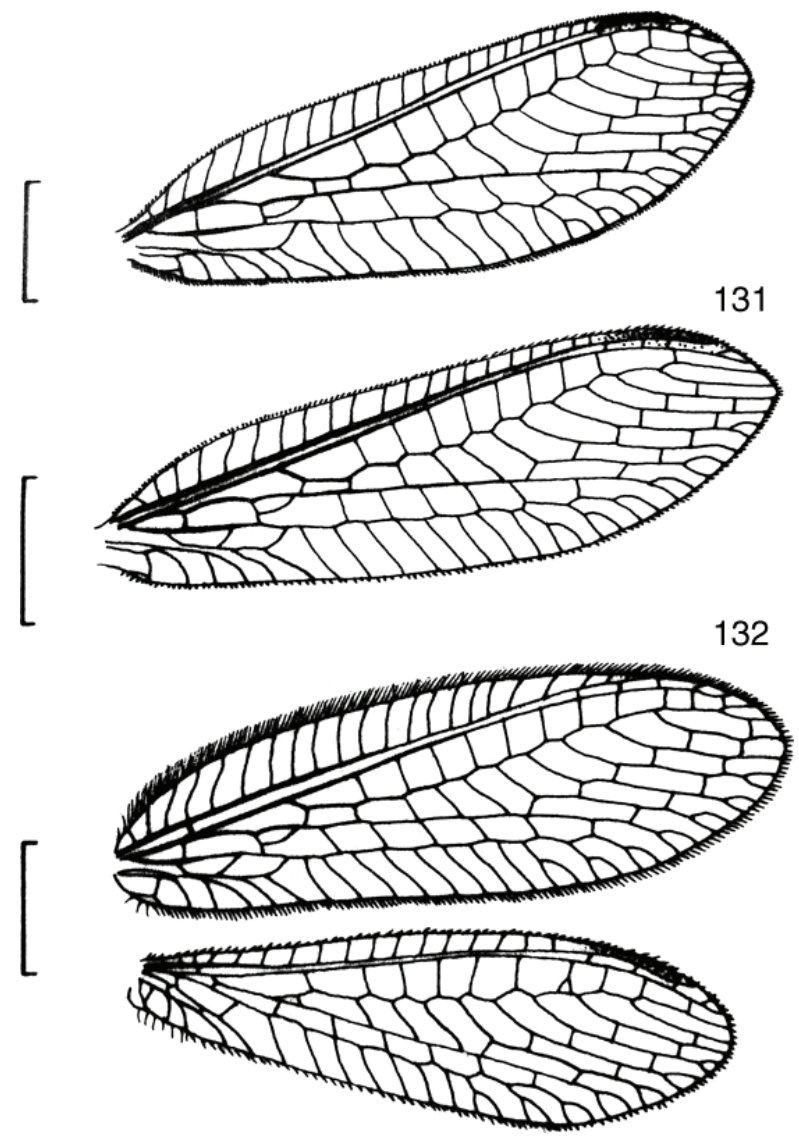

Figs. 130-132.- Alas de Chrysoperla spp. 130: ala anterior de C. carnea (s.l.), 131: ala anterior de C. mediterranea, 132: alas de C. ankylopteryformis. Escala $2 \mathrm{~mm}$. De Monserrat \& Díaz-Aranda (1989c).

Figs. 130-132.- Wings of Chrysoperla spp. 130: forewing of C. carnea (s.l.), 131: forewing of C. mediterranea, 132: wings of C. ankylopteryformis. Scale bar $2 \mathrm{~mm}$. From Monserrat \& Díaz-Aranda (1989c).

\section{Género Chrysoperla Steinmann, 1964}

Como se anotó en la introducción, la situación taxonómica de algunas especies del género Chrysoperla, en particular de la Región Holártica, Paleártica Occidental, y de las europeas en particular, dista mucho de estar consensuada y resuelta.

Este género fue revisado por Brooks (1994), quien considera 36 especies que principalmente diferencia en función de caracteres de tamaño, setación, morfología de las uñas, venación y genitalia. Sin embargo han venido aparecido multitud de trabajos, especialmente en relación al complejo C. carnea s.l., que han abierto nuevas interrogantes, ya que marcadas diferencias en el canto de apareamiento induce a asegurar que están aisladas reproductivamente (song species), y por lo tanto son, o podría tratarse, de hasta 21 especies diferentes distribuidas en el Hemisferio Norte y Región Afrotropical (Tauber \& Tauber, 1973; Henry, 1979a, 1979b, 1982, 1983a, 1983b, 1984, 1985, 1989, 1991, 1992, 1993, 1994; Hölzel, 1980a, 1984, 1990, 1995, 
2002; Henry \& Wells, 1990a, 1990b, 2006, 2009, 2010, 2015; Cianchi \& Bullini, 1992; Wells \& Henry, 1992a, 1992b, 1994, 1998; Henry et al., 1993, 1996, 1999, 2001, 2002, 2003, 2011, 2013, 2014, 2015; Wells, 1993, 1994; Thierry et al., 1994, 1997, 2013; Duelli, 1999; Pantaleoni \& Sechi, 2014; Price et al., 2015 , etc.), sin que, en muchos casos, exista una clara y definitiva diferenciación morfológica que permita la identificación de los ejemplares por los métodos tradicionales (Tjeder, 1966; Jedlicka \& Jedlickova, 2000; Henry et al., 2001; Canard \& Thierry, 2007, 2013).

En base a estudios sobre valores en la distancia genérica entre poblaciones del "complejo carnea" en poblaciones del Viejo Mundo, Cianchi \& Bullini (1992) encuentran que es relativamente bajo (índice de Nei, 1972: $\mathrm{D}=0,02-0,13)$, concluyendo que según los parámetros del reloj molecular, este proceso de especiación parece haberse iniciado en el Pleistoceno, hace 500-100.000 años (ver más adelante género Pseudomallada).

Aunque estos datos han abierto un interesante campo en el estudio de estas especies crípticas, normalmente son de difícil distinción morfológica, habiéndose llagado a crear una situación nomenclatural y taxonómica francamente compleja y abiertamente descoordinada entre sus hacedores (principalmente entre las escuelas francesa y americana), en ocasiones muy apartada del sistema linneano que ha de seguirse, con denominaciones francamente confusas (Duelli, 1995, 2009; Henry et al., 1996, 1999; Jedlicka \& Jedlickova, 2000; Canard \& Thierry, 2007; Thierry et al., 2013; Pantaleoni \& Sechi, 2014) y desde nuestro punto de vista poco recomendables.

Aunque algunas especies parecen bien definidas y pueden diferenciarse en base a caracteres de morfología y/o hábitats, muchas otras aún no lo están adecuadamente, y otras constituyen un conjunto de especies de difícil asignación por otras vías que no sean las diferencias moleculares, especialmente marcadores con técnicas electroforéticas y ADN mitocondrial y técnicas genéticas más modernas llamadas Secuenciación de Nueva Generación (Next Generation Sequencing, NGS), etc., y/o las observadas en sus cantos (Tauber \& Tauber, 1977a, 1977b, 1989; Henry, 1979b; Bullini et al., 1983a, 1983b, 1984; Bullini \& Cianchi, 1984; Cianchi \& Bullini, 1992; Henry et al., 1996, 1999, 2001, 2003; Whiting et al., 1997; Canard \& Thierry, 2007; Pantaleoni \& Sechi, 2014; Price et al., 2015, etc.).

La variabilidad morfológica citada dentro de una misma especie, la ausencia de caracteres externos concluyentes que permitan su diferenciación (al margen del canto), la presencia de poblaciones con similar canto y diferentes caracteres morfológicos, la presencia de similar tipo de canto independientemente adquirido evolutivamente de forma convergente en especies diferentes y alejadas geográficamente (ejs.: entre la especie norteamericana $C$. adamsi y un taxón todavía no descrito en Kyrgyzstán, entre la especie europea C. pallida y una especie de la Sierra Nevada en California: $C$. calocedrii, o ver más adelante la presencia de C. agilis en Alaska), la influencia de la temperatura en el tipo de canto, su variación en función de las poblaciones de una misma especie, y/o la demostración de posibles hibridaciones entre diferentes poblaciones con descendencias viables, etc., han complicado aún más la situación (Tauber \& Tauber, 1977a, 1977b, 1981, 2015; Henry, 1983b; Duelli, 1987a; Henry \& Wells, 1990b, 2006, 2009, 2010; Wells, 1993; Henry et al., 1993, 1999; Brooks, 1994; Wells \& Henry, 1994; Tauber et al., 1995; Naka et al., 2005, 2006; Thierry et al., 2013; Pantaleoni \& Sechi, 2014; Duelli et al., 2015, etc.).

Todo esto ha creado una situación taxonómica y nomenclatural especialmente compleja en el grupo de Chrysoperla carnea s.l. que ahora tratamos, con vivas discusiones, contribuciones e incluso nuevos datos y nuevas formas y especies siguen describiéndose (Bullini et al., 1983b; Henry, 1989, 1991, 1993, 1994; Brooks \& Barnard, 1990; Henry \& Wells, 1990a, 1990b; Wells \& Henry, 1992b; Thierry \& Adams, 1992; Cianchi \& Bullini, 1992; Thierry et al., 1992, 1996, 1997, 1998; Henry et al., 1993, 1996, 2001, 2002, 2003, 2014, 2015; Brooks, 1994; Ventura et al., 2002; Fernández, 2003; Lourenço et al., 2006, etc.).

Al margen de las diferencias moleculares y del canto, ciertos caracteres, tanto biológicos: tipos de puesta, de preferencia de sustratos y comportamiento ante la hibernación (Duelli et al., 2002), como morfológicos: aspecto y coloración de las manchas cefálicas de sus larvas, y en imagos de las manchas cefálicas laterales, de las piezas bucales o de las pleuras, métricos de genitalia interna masculina o de las uñas, longitud y tinte de algunas setas costales, torácicas o abdominales, anchura de las alas y forma del extremo alar, etc., parecen mostrar ciertas leves diferencias (a veces de interpretaciones subjetivas) entre algunas de las distintas especies, aunque muchas veces irrealizables sobre ejemplares muertos no conservados en alcohol, e inaccesibles para los entomólogos "de a pie" con los métodos tradicionales o bien resultan francamente tediosos (Tjeder, 1966; Brooks \& Barnard, 1990; Leraut, 1991, 1992a; Séméria, 1992; Thierry \& Adams, 1992; Thierry et al., 1992, 1996, 1997, 1998; Malet et al., 1994; Duelli, 1995; Duelli et al., 1996; Henry et al., 1999; Çaldumbide et al., 2001; Canard et al., 2002; Gruppe, 2002; Lourenço et al., 2006; Canard \& Thierry, 2007, 2013; Pantaleoni \& Sechi, 2014).

Ante esta situación, adelantamos al lector que entramos en un género complejo, aún no definitivamente aclarado, y por nuestra parte intentaremos acercarnos lo más posible para aportar la mayor y más accesible información sobre nuestras especies, y hemos utilizado en las claves los caracteres que, dentro de las limitaciones existentes, puedan ayudar a la diferenciación específica de los ejemplares.

En función de las especies de este género que han sido citadas en nuestra fauna, citaremos, como cualquier otra recogida en esta contribución, las especies 
bien definidas y no problemáticas, y comentaremos y discutiremos la situación taxonómica de otras especies citadas en la fauna ibérica: Chrysoperla kolthoffi (Navás, 1927), Chrysoperla affinis (Stephens, 1836), que, por diferentes motivos, no hemos considerado. Empecemos por ellas.

Chrysoperla kolthoffi (Navás, 1927) - Chrysoperla affinis (Stephens, 1836)

Chrysoperla kolthoffi es una especie conocida de Asia Central y Oriental(China, Japón, Corea, Mongolia, Filipinas y este de Rusia. Como tal (Chrysoperla kolthoffi) está citada de Francia, Polonia, y de forma algo imprecisa en Portugal (Lisboa, Oporto, Evora) según Thierry et al. (1992, 1994, 1996, 2002; Ventura et al., 1996, 2000; Lemesle et al., 1998; Trouvé et al., 2002; Mouloud et al., 2002, etc.). Estas citas aportan datos sobre su biología algo dispares, y ha sido citada asociada a vegetación herbácea y base de las ramas de arbustos o asociada a pinos, y parece poseer varias generaciones anuales, hiberna como imago, frecuentemente en construcciones humanas.

Por estar relacionada con nuestra fauna (Portugal), la recogemos en esta contribución y la citamos como ejemplo del grado de imprecisión y confusión taxonómica dentro de este género, con especies en fase de especiación, sin demasiados caracteres diagnósticos en su morfología.

Esta especie posee un largo historial taxonómico (Brooks, 1994), ya que fue sinonimizada a C. carnea por Tjeder (1936), y Leraut (1991) asume esta sinonimia y designa su lectotipo. Posteriormente es revalidada como especie válida por Leraut (1992a), y más tarde Brooks (1994) cuestiona y difiere en los caracteres diagnósticos de los ejemplares europeos de C. kolthoffi frente a los hallados en $C$. carnea y designa a $C$. kolthoffi como sinónima posterior de $C$. nipponensis (Okamoto, 1914), y así ha sido posteriormente considerada (Henry et al., 2015).

Thierry et al. (1992, 1994, 1996, 2013) y Canard et al. (2002) aportan algunos elementos morfológicos y aspectos morfométricos de las uñas (bastante livianos o tediosos para el gran público) que permitirían diferenciar a Chrysoperla kolthoffi y Chrysoperla carnea s.str. de Chrysoperla lucasina (con membrana pleural del segundo segmento abdominal sin una estrecha banda oscura bajo el esternito y setas del campo costal algo más largas), y ambas entre sí (estipes normalmente con/sin mancha parda y esternitos abdominales con/sin numerosas setas negras o levemente oscuras), y según estos autores Chrysoperla kolthoffi posee uñas dilatadas con base de ángulo muy agudo, setas pardas en los esternitos abdominales y una banda parda esclerificada entre los esternitos y terguitos basales, caracteres que, coincidiendo en un mismo ejemplar, se nos antojan característicos y diagnósticos de dos especies distintas: $C$. carnea y $C$. lucasina, hecho que sugiere hibridación entre diferentes especies y poblaciones con descendencias viables, hechos ya demostrados con cierta frecuencia, también en este género (Duelli, 1987a; Wells, 1993; Brooks, 1994; Wells \& Henry, 1994; Tauber et al., 1995; Naka et al., 2005, 2006; Tauber \& Tauber, 2015, etc.).

Para complicar aún más la cuestión, según Thierry (com. per.), estas citas anteriormente mencionadas de Chrysoperla kolthoffi (de Francia, Polonia, y de Portugal) deben corregirse y asignarse a Chrysoperla affinis, especie considerada sinónima de C. carnea desde Schneider (1851a) a Brooks (1994). Posteriormente Price et al. (2015) demuestran mediante estudios moleculares que Chrysoperla affinis es sinónima de la verdadera $C$. carnea, hecho ya sugerido por Henry et al. (2002), por lo que estas citas, incluidas las de Portugal (Chrysoperla kolthoffi - Chrysoperla affinis) deberían asignarse a C. carnea (según Henry et al., 2002), hecho que aún así nos sugiere ciertas dudas sobre su presencia en Lisboa y Evora, algo menos en Oporto, pues esta especie (C. carnea) solo es conocida en nuestra fauna de la región pirenaica y no nos parecen lógicas estas citas tan meridionales (y de ser correcta la cita en Oporto, quizás sea probable su presencia en todo el tercio septentrional).

Poco, o mejor dicho nada, se diferencian de $C$. carnea los caracteres diagnósticos anotados en Thierry et al. (2013) para C. affinis (ver caracteres en la clave de C. carnea y los empleados por Thierry et al., 2013), y ante todo ello, nosotros nos sumamos a no considerar la validez de esta especie frente a $C$. carnea.

Por otra parte es interesante señalar que poco se han considerado en la resolución de la identidades de las especies crípticas de este confuso género los decenas de taxa descritos como variedades de Chrysopa vulgaris (históricamente asociada a Chrysoperla carnea s.l.) por autores anteriores, y en lo que compete a la fauna europea, sea por J.L. Lacroix, principalmente en fauna francesa (Leraut, 1982) o, en nuestro caso, por L. Navás (ver como ejemplo para la fauna ibérica la lista de sus taxa en C. carnea), hecho mayoritariamente ignorado (Brooks, 1994; Pantaleoni \& Sechi, 2014), y desde nuestro punto de vista está siendo un hecho taxonómica-nomenclaturalmente bastante lamentable. Y en el caso de la especie que ahora nos ocupa (Chrysoperla kolthoffi), podría tratarse del mismo taxa conocido como Chrysopa proxima Navás, 1918, posteriormente considerado por Navás (1924a) como Chrysopa vulgaris var. proxima Navás, 1918. De ser así (Chrysoperla kolthoffi sinónima de $C$. carnea), y supuestas sus identificaciones como correctas, estaría citada de Huesca (VIII, 600 m), datos que sí coinciden con la distribución prevista de $C$. carnea en nuestra fauna, y especie que ahora abordamos.

Chrysoperla carnea (Stephens, 1836) (Figs. 19, 90)

Chrysopa carnea Stephens, 1836

Stephens, 1836: 103 (d).

Chrysoperla carnea (Stephens, 1836) s.l. + s.str.

Monserrat, 1979a: 413 (bio, dis), 1981a: 155 (bio, dis), 1982:

77 (bio, dis); Campos \& Ramos, 1983: 220, 221 (bio, dis); 
Ramos et al., 1983: 31 (bio, dis); Marín, 1994: 247-302 (bio, dis); Monserrat, 1984a: 40 (bio, dis), 1984b: 172 (bio, dis), 1984d: 100 (bio, dis), 1984e: 158 (bio, dis), 1985b: 87 (bio, dis), 1985c: 92 (bio, dis); Campos \& Ramos, 1985: 237 (bio, dis); Campos, 1986: 99 (bio, dis); Monserrat, 1986b: 101 (bio, dis); Díaz-Aranda et al., 1986a: 1125 (bio, dis), 1986b: 1140 (bio, dis); Marín \& Monserrat, 1987: 347-359 (bio, dis); Monserrat, 1987: 140 (bio, dis); Monserrat \& Díaz-Aranda, 1987: 181 (bio, dis), 1988: 92 (bio, dis); Matias et al., 1988: 94-199 (bio, dis); Díaz-Aranda \& Monserrat, 1988a: 119 (bio, dis), 1988b: 225 (bio, dis), 1988c: 222 (bio, dis); Monserrat \& Díaz-Aranda, 1989b: 53 (bio, dis), 1989c: 260 (bio, dis); Marín \& Monserrat, 1989: 295 (bio, dis); Campos, 1989: 159 (bio, dis); Díaz-Aranda \& Monserrat, 1990a: 676 (bio, dis); Marín \& Monserrat, 1990: 226 (bio, dis), 1991a: 182 (bio, dis), 1991b: 190-196 (bio, dis); Leraut, 1991: 80 (rf); Monserrat \& Rodrigo, 1992: 130 (bio, dis); Boelpaepe et al., 1992: 22 (bio, dis); Núñez Pérez et al., 1992: 390 (bio, dis); Canard et al., 1992b: 96 (list); Pantaleão et al., 1993: 429 (bio, dis); Monserrat \& Marín, 1994: 122 (bio); Brooks, 1994: 149 (rf), 178 (rf); Monserrat et al., 1994: 54 (bio, dis); Marín, 1994: 260 (bio, dis); Montiel \& Santaella, 1995: 454 (bio, dis); Marín \& Monserrat, 1995a: 117 (bio, dis), 1995b: 42 (bio, dis); Monserrat, 1996: 14 (list); Michelena \& Sanchís, 1997: 249 (bio, dis), 252 (bio, dis); Carvalho, 1997: 5, 6 (dis); Ribeiro, 1997: 258 (bio, dis); Monserrat et al., 1999: 42 (bio, dis); Ruiz Torres \& Montiel Bueno, 2000: 137 (bio, dis); Morris \& Campos, 2000: 69 (bio, dis); Blasco-Zumeta, 2000: 98 (bio, dis); Ocete et al., 2000: 182: (bio, dis); Whittington, 2002: 379 (rf); Alvis et al., 2003: 186 (bio, dis); Corrales \& Campos, 2004: 1613-1619 (bio, dis); Monserrat, 2005: 70 (bio, dis); Canard et al., 2007: 292-297 (rf); Monserrat, 2008: 188 (bio, dis); Porcel et al., 2011: 89-104 (bio, dis); Ocharan et al., 2012: 426 (bio, dis); Monserrat et al., 2013: 47 (ref); Letardi et al., 2013: 35 (list); Monserrat, 2013: 291 (rf).

Anisochrysa carnea (Stephens, 1836)

Hölzel \& Ohm, 1972: 128 (nt), 142 (nt); Monserrat, 1977a: 20 (list), 118 (key), 121 (bio, dis), 1978b: 62 (bio, dis).

Anisochrysa (Chrysoperla) carnea (Stephens, 1836)

Hölzel \& Ohm, 1972: 140 (dis); Monserrat, 1978a: 180 (bio, dis), 1979b: 21 (bio, dis), 1980a: 176 (bio, dis), 1980b: 189 (bio, dis).

Chrysopa carnea (Stephens, 1836)

Morgan, 1980: 119 (dis); Ros et al., 1988: 7, 8, 9 (dis); Urbaneja et al., 2001: 65 (bio, dis).

Chrysopa microcephala Brauer, 1851

Brauer, 1851: 6 (d); Stitz, 1927: 15 (rf); Monserrat, 1977a: 21 (list), 128 (rf).

Chrysopa proxima Navás, 1918

Navás, 1917d: 87 (rf), 1918: 18 (d).

Chrysopa vulgaris Schneider, 1851

Schneider, 1851a: 68 (d); Monserrat, 1977a: 21 (list), 129 (rf),

Chrysopa vulgaris aequata Navás, 1905

Monserrat, 1977a: 129 (rf).

Chrysopa vulgaris haematodes Navás, 1915

Monserrat, 1977a: 129 (rf).

Chrysopa vulgaris microcephala Brauer, 1851

Monserrat, 1977a: 129 (rf).

Chrysopa vulgaris radialis Navás, 1905

Monserrat, 1977a: 129 (rf).

También citada en la fauna ibero-balear como Chrysopa vulgaris albidella Navás, 1919, Chrysopa vulgaris apostata Navás, 1919, Chrysopa vulgaris aragonica Navás, 1915, Chrysopa vulgaris barnolai Navás, 1906, Chrysopa vulgaris bilineata Navás, 1915,
Chrysopa vulgaris biseriata Schneider, 1851, Chrysopa vulgaris buchi Navás, 1915, Chrysopa vulgaris carnea Stephens, 1836, Chrysopa vulgaris catalaunica Navás, 1915, Chrysopa vulgaris disticha Navás, 1915, Chrysopa vulgaris ditata Navás, 1915, Chrysopa vulgaris entoneura Navás, 1917, Chrysopa vulgaris festiva Navás, 1918, Chrysopa vulgaris gemella Navás, 1918, Chrysopa vulgaris inversa Navás, 1918, Chrysopa vulgaris lulliana Navás, 1910, Chrysopa vulgaris moneri Navás, 1919, Chrysopa vulgaris ornata Navás, 1915, Chrysopa vulgaris perezacostai Navás, 1919, Chrysopa vulgaris prothoracica Navás, 1919, Chrysopa vulgaris proxima Navás, 1918, Chrysopa vulgaris rubricata Navás, 1905, Chrysopa vulgaris seriata Navás, 1919, Chrysopa vulgaris seroi Navás, 1919, Chrysopa vulgaris striolata Navás, 1916, Chrysopa vulgaris thoracica Navás, 1915, Chrysopa vulgaris tristicta Navás, 1915, Chrysopa vulgaris viridella Navás, 1911, Chrysopa vulgaris vitellina Navás, 1930 y Chysopa vulgaris microcephala Brauer, 1851.

Evidentemente la situación taxonómica de todos estos taxa está por resolver, y será un laborioso estudio de muchos años poder conseguirlo, y en lo que respecta a estas citas ibéricas en relación a la especie que tratamos a nuestra fauna, su listado es, por el momento, testimonial. Duelli (2001) anota que más del $80 \%$ de las citas de interés aplicado que han aparecido desde 1970 relativas a las crisopas, se refieren (nominalmente) a esta especie, por lo que la información existente es desbordante, y es obvio que muchas de las identificaciones en este grupo de especies (C. carnea s.l.), incluso las nuestras, sean incorrectas y estén probablemente mezcladas.

Ya hemos tratado suficientemente la problemática de esta especie (desglosada en un complejo grupo de especies de taxonomía y diferenciación problemática), y el estatus de esta especie (Chrysoperla carnea s.str.) parece haber sido por fin resuelto y dilucidado de forma definitiva por Price et al. (2015). Aún así, coincidimos con Henry et al. (2003) y Thierry et al. (2013) y consideramos que es de difícil diferenciación morfológica con C. agilis y C. pallida (ver clave de especies). Sobre sus diferencias con Chrysoperla lucasina ver más adelante en la discusión de esta especie.

Conocido su historial, es lógico que Chrysoperla carnea s.str. sea una especie de distribución geográfica (real) problemática, a causa de la infinidad de citas existentes y su reciente segregación en numerosas nuevas especies. En principio ha de considerarse paleártica, y parece ser una especie ampliamente distribuida en el hemisferio norte, desde el Círculo Polar de Europa, Macaronesia, norte de África hasta Sudán y en Asia (Georgia, Rusia, Japón). Citada sobre una gran variedad de plantas, mayoritariamente sobre vegetación baja, su actividad puede mantenerse todo el año, e hiberna entre las hojas y la hojarasca de vegetación caducifolia o marcescente, cambiando de coloración en fase hibernante y su coloración vira a rosa/carne, hecho que probablemente le dio originalmente su nombre. 
En lo que respecta a nuestra fauna, y al margen de las citas históricas y consecuentemente problemáticas (Díaz-Aranda \& Monserrat, 1990a), no dudamos que alguna de ellas (y/o de sus múltiples variedades citadas en nuestra fauna) pudiera pertenecer a la especie que tratamos, y revisar todo el material disponible (miles de ejemplares) sería una labor titánica, y se lo dejamos encargado a las nuevas generaciones.

Aunque hay pocos datos precisos, más recientemente, C. carnea (s.str.) está citada en España (Granada) y Portugal (Oporto, Lisboa, Evora) por Leraut (1991) o Brooks (1994) (Hölzel \& Ohm, 1972 la citaban con reservas de Granada a $2.300 \mathrm{~m}$ sobre Berberis), pero hoy día, dudamos de alguna de estas identificaciones, dadas antes de que otras especies fueran posteriormente segregadas, y tenemos muchas dudas sobre la autenticidad de estas citas tan meridionales, ya que en nuestra fauna esta especie tiene una clara tendencia eurosiberiana y parece confinada a su región pirenaica y probablemente a su región eurosiberiana, hecho confirmado con citas posteriores en Guipúzcoa y Navarra (Monserrat, 2008) (la referencia anteriormente mencionada en Huesca parece corroborar esta distribución). Está citada en VI, sobre vegetación herbácea, cultivos, ocasionalmente sobre Fagus, en altitudes generalmente bajas, de 410-900 m.

La especie deposita sus huevos aislados. Como en el caso de los imagos, las fases larvarias, profusamente descritas para $C$. carnea s.l., y son de muy difícil asignación. Como huevo, larva o pupa de esta especie existen numerosas descripciones (Schneider, 1851a; Pariser, 1919; Smith, 1922a; Withycombe, 1922; Killington, 1928a, 1937; Lacroix, 1929, 1933; Neumark, 1952; Putman, 1956; Fleshner \& Scriven, 1957; Muma, 1959; Toschi, 1965; Tsukaguchi, 1977; Gepp, 1983b, 1990; Pantaleoni, 1983; Duelli, 1984c; Díaz-Aranda \& Monserrat, 1990a; Díaz-Aranda et al., 2001; Henry et al., 2003, 2014; Monserrat \& DíazAranda, 2012, etc.), pero dada la situación de esta especie (conjunto de especies), hoy es difícil su asignación, y parece que sólo mediante tediosos y complejos métodos estadísticos (Thierry et al., 1992; Henry et al., 1999, 2002, 2003, 2011) podrían dar algo de luz al respecto, y nuevos datos al respecto son aportados por Canard \& Thierry (2007).

Chrysoperla lucasina (Lacroix, 1912) (Figs. 83, 130, 182)

Chrysopa lucasina Lacroix, 1912

Lacroix, 1912: 203 (d).

Chrysoperla lucasina (Lacroix, 1912)

Leraut, 1991: 78 (rf); Henry et al., 1996: 207 (bio, dis); H. Aspöck et al., 2001: 113 (rf); Henry et al., 2002: 174 (dis); Monserrat, 2005: 79 (bio, dis), 2008: 188 (bio, dis); Ocharan et al., 2012: 426 (rf); Monserrat et al., 2013: 50 (bio, dis); Letardi et al., 2013: 35 (list); Monserrat, 2013: 292 (bio, dis); Monserrat et al., 2014: 23 (bio, dis).

Desde que esta especie fue aceptada como especie válida (históricamente considerada como sinónima de
C. carnea), ha sido una especie generalmente reconocida y fue citada de España (Leraut, 1991), y lo ha sido posteriormente (ver referencias anteriormente anotadas). Aunque Brooks (1994) cuestiona su validez como especie, y considera a $C$. lucasina sinónima de $C$. carnea (y desde el punto de vista nomenclatural nuevas formas y nombres se han venido dando, complicando, aún más, la situación) y difiere en sus caracteres diagnósticos frente a la variabilidad hallada en $C$. carnea, especialmente en sus poblaciones europeas meridionales, del norte de África y de Próximo Oriente, Henry et al. (1996) la confirman como especie válida tras estudiar su canto.

No obstante es una especie de difícil diferenciación morfológica (ver clave de especies). Leraut (1991), Paulian et al. (1996) o Ventura et al. (2002) intentan diferenciar $C$. carnea de $C$. lucasina en base caracteres que se nos antojan demasiado ambiguos y livianos, en ocasiones de difícil decisión sin ambas opciones delante, y en otras ocasiones definitivamente inviables, ya que las regiones pleurales se retraen tras la muerte del ejemplar o sobre ejemplares conservados en alcohol que están muy decolorados si han sido recolectados desde hace tiempo (Canard \& Thierry, 2007), como son setas costales algo más largas y pardas $(C$. carnea)/cortas y negras (C. lucasina), ápice alar más (C. lucasina)/menos apuntado (C. carnea), mancha sobre las genas parda (C. lucasina)/negruzca (C. carnea), venillas transversales completamente verdes $(C$. lucasina)/parcialmente oscuras $(C$. carnea). Por otra parte Thierry et al. (1992) o Ventura et al. (2002) aportan ciertos datos diferenciales bastante tediosos y aplicables con métodos estadístico sobre la coloración sus larvas. Como vemos pues, la situación es problemática y para los lectores interesados les sugerimos los autores citados. Es obvio que estamos ante un pull de especies crípticas (Thierry et al., 1992, 2002; Leraut, 1991; Paulian et al., 1996; Henry et al., 2002; Zimmermann, 2005; Canard \& Thierry, 2007) de difícil y ambigua diferenciación externa. En los ejemplares típicos la estría oscura en la región pleural del $2^{\circ}$ segmento abdominal parece un carácter destacable $\mathrm{y}$, en cualquier caso, sinceramente, ante estos elementos mantenemos esta especie a la espera que nuevos datos, más accesibles, sean publicados.

Como podría aplicarse a varias especies de este género, recientemente descritas sin tener en cuenta (o no poder tener en cuenta) los taxa anteriormente descritos que tendrían prioridad taxonómica y nomenclatural, tenemos serias dudas sobre la identidad de esta especie respecto a Chrysopa vulgaris var. aragonica Navás, 1915 (citada en la bibliografía de Aragón y Andorra), y podrían tratarse del mismo taxón que ahora tratamos. En principio, y aunque coincidimos con Brooks (1994) en haber estudiado numerosos ejemplares intermedios de difícil asignación, la consideramos como especie válida y la incluimos en este estudio. 
Especie holomediterránea citada desde Canarias, Azores y Madeira a Chipre, Anatolia, Cáucaso y el norte de África, extendida al Chad y de Escocia.

Considerada una especie ubiquista, probablemente eurioica. Citada sobre una gran variedad de sustratos vegetales (Acer, Pinus, Quercus, etc.), pero mayoritariamente asociada a vegetación baja y herbácea, también en cultivos de alfalfa, se ha citado entre IV-XII, parece ser de tendencia montana, y ha sido citada desde 10 hasta $2.000 \mathrm{~m}$. No cambia de coloración en fase hibernante y deposita los huevos aislados.

En la fauna peninsular está ampliamente citada, incluyendo Baleares y Portugal, mayoritariamente entre I-X, aunque puede aparecer activa durante todo el año (y así lo demostramos en el nuevo material estudiado), en altitudes desde 10 hasta $2.800 \mathrm{~m}$, con cierta tendencia montana, y se ha citado como asociada a vegetación herbácea, aunque también lo ha sido sobre una amplia gama de sustratos, generalmente planifolios (Acer, Quercus, Corylus, Fraxinus, Betula, Fagus, Castanea), también citada sobre coníferas y muchas otras plantas (Abies, Pinus, Juniperus, Buxus, Prunus, Annona, Platanus, Ceratonia, Retama, Nerium, Eucaliptus, Olea, Celtis, Chamaerops, Retama, Tamarix, Pistacea, Thuja, Cistus, Nicotiana, Atriplex, etc.).

Datos sobre la larva en Henry et al., 1996 y Ventura et al., 2002.

Nuevo material estudiado o anotado: ESPAÑA: Ávila, Burgohondo, 1400 m, 11.VI.2004, 3 ej., 12.VI.2004, 9 ej., A. Gruppe (A. Gruppe). Cáceres, Plasencia, 420 m, 15.VI.2004, 27 ej.,A. Gruppe (A. Gruppe). Guipúzcoa, Ataun, Aralar P.N. 614 m, 30TWN6858, 1-14.VI.2014, 1 ㅇ en trampa de vino+cerveza, S. Pagola. Huesca, Biescas, 890 m, 27.VI.2003, 1 ej., A. Gruppe (A. Gruppe). Madrid, Aranjuez, 540 m, 26.V.2005, 3 ej., A. Gruppe (A. Gruppe), El Escorial, Abantos, 19.VI.2014, 19 sobre Pinus sylvestris, F. Acevedo. Murcia, Jumilla, Sierra del Carche, 990 m, 17.VII.2009, 1 ej., J.L. Lencina (A. Gruppe), Moratalla, Sierra Seca, 1750 m, 19.IX.2007, 3 ej., J.L. Lencina (A. Gruppe). Tarragona, La Selva del Camp, $41^{\circ} 13^{\prime} 07.67^{\prime \prime} \mathrm{N} 1^{\circ} 08^{\prime} 36.94^{\prime \prime} \mathrm{E}, 224$ m, 20.XI.2005, 1ð, 2 우오, 27.XII.2005, 1q, 12.II.2008, 1ㅇ, 8.III.2008, 1ㅇ, 21.VIII.2008, 1 ○, 15.IX.2008, 1ठ, 21.X.2008, 1ㅇ, 18.XI.2008, 1ठ, 12.XII.2008,

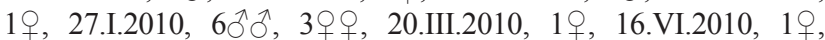
17.VIII.2010, 1§, 1 $q$, 20.X.2010, 1q, 9.XI.2010, 1q, 19.XI.2010,

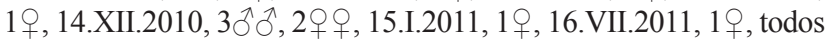
sobre Citrus clementina, N. Cañellas. PORTUGAL: Guarda, Seia, Senora de Pestero, 800 m, 20.VI.2011, 3 ej., A. Gruppe (A. Gruppe).

Chrysoperla mediterranea (Hölzel, 1972) (Figs. 17, 20, 79, 131, 183)

Anisochrysa (Chrysoperla) mediterranea Hölzel, 1972

Hölzel, 1972b: 81 (d); Hölzel \& Ohm, 1972: 140 (dis); Monserrat, 1980a: 176 (dis).

Anisochrysa mediterranea (Hölzel, 1972)

Hölzel \& Ohm, 1972: 128 (nt), 131 (dis),142 (nt); Monserrat, 1977a: 21 (list), 118 (key), 130 (bio, dis), 1978b: 63 (bio, dis). Chrysoperla mediterranea (Hölzel, 1972)

Aspöck et al., 1980: 10, 113 (dis, mf), 269 (rf); Canard, 1981: 100 (rf); Monserrat, 1982: 78 (bio, dis), 1984a: 41 (bio, dis), 1984d: 101 (bio, dis), 1985b: 87 (bio, dis); Díaz-Aranda et al., 1986a: 1125 (bio, dis), 1986b: 1141 (bio, dis); Canard, 1987: 282 (rf); Monserrat, 1987: 140 (bio, dis); Duelli, 1987a: 304 (rf);
Monserrat \& Díaz-Aranda, 1987: 181 (bio, dis), 1988: 92 (bio, dis); Díaz-Aranda \& Monserrat, 1988a: 119 (bio, dis), 1988b: 225 (bio, dis), 1988c: 223 (bio, dis); Monserrat \& Díaz-Aranda, 1989b: 53 (bio, dis), 1989c: 260 (bio, dis); Díaz-Aranda \& Monserrat, 1990a: 677 (bio, dis); Marín \& Monserrat, 1991a: 182 (bio, dis); Leraut, 1991: 75 (rf); Monserrat \& Rodrigo, 1992: 132 (bio, dis); Canard et al., 1992b: 96 (list); Carvalho, 1992: 9, 10, 11 (rf); Monserrat \& Marín, 1994: 122 (bio); Brooks, 1994: 155 (rf); Marín, 1994: 260 (bio, dis); Monserrat et al., 1994: 55 (bio, dis); Marín \& Monserrat, 1995a: 117 (bio, dis), 1995b: 42 (bio, dis); Monserrat, 1996: 14 (list); Carvalho, 1997: 5, 6 (dis); Henry et al., 1999: 336, 339, 348 (bio, dis, 1); Jedlicka \& Jedlickova, 2000: 66 (rf); H. Aspöck et al., 2001: 114 (rf); Henry et al., 2002: 174 (dis); Monserrat, 2005: 79 (bio, dis); Canard et al., 2007: 292-297 (rf); Monserrat, 2008: 189 (bio, dis); Monserrat et al., 2013: 50 (bio, dis); Letardi et al., 2013: 35 (list); Monserrat, 2013: 291 (rf); Monserrat et al., 2014: 24 (bio, dis).

Especie atlantomediterránea conocida de la región meridional europea, Marruecos y Túnez, con poblaciones aisladas en Europa central y oriental, y extendida hacia el Cáucaso, probablemente sea circunmediterránea expansiva, aunque las poblaciones al norte de los Alpes y centro y este europeo parecen diferenciarse de las del S.O. europeo (Henry et al., 1999; Duelli et al., 2015).

Está mayoritariamente citada sobre coníferas, sucediéndose varias (mínimo 3) generaciones entre III-X, aunque puede aparecer activa durante todo el año, hibernando en estado adulto, sin cambiar de coloración en fase hibernante. Recolectada en altitudes de 10 hasta $1.600 \mathrm{~m}$. y deposita los huevos en grupos.

En nuestra fauna tiene una clara tendencia termófila, $\mathrm{y}$ es habitual en pinares de medios meridionales y mediterráneos con preferencia litoral, incluyendo Baleares (Mallorca, Formentera, Ibiza), aunque también ha sido hallada, en menor abundancia, en zonas más continentales y septentrionales, especialmente de su mitad sudoriental. Ha sido mayoritariamente citada sobre pinos, especialmente Pinus halepensis, sobre el que se han recolectado la mayoría de los ejemplares, también sobre cedros, enebros y sabinas, y puntualmente sobre castaños, algarrobos, tamarindos y encinas próximos a pinares, entre I-XII, y posee pues actividad durante todo el año, pasando el invierno en fase de imago. Citada en altitudes que oscilan entre 10-2.000 m.

Las fases juveniles fueron descritas por Duelli (1987a), Díaz-Aranda \& Monserrat (1990a, 1995), Henry et al. (1999) y Monserrat \& Díaz-Aranda (2012).

Chrysoperla mutata (McLachlan, 1898)

Chrysopa mutata McLachlan, 1898

McLachlan, 1898: 167 (d).

Chrysoperla mutata (McLachlan, 1898)

Monserrat \& Rodrigo, 1992: 131 (bio, dis); Brooks, 1994: 163 (rf); Monserrat \& Marín, 1994: 122 (bio); Carvalho, 1994: ¿? (dis); Marín \& Monserrat, 1995b: 42 (bio, dis); Carvalho, 1997: 5, 7 (dis); H. Aspöck et al., 2001: 115 (rf); Thierry et al., 2004: 346 (rf); Canard et al., 2007: 292-297 (rf); Monserrat, 2008: 188 (bio, dis); Letardi et al., 2013: 35 (list); Monserrat, 2013: 291 (bio, dis); Canard \& Thierry, 2014: 407 (rf); Monserrat et al., 2014: 23 (bio, dis). 
Especie eremial, termófila y xerófila de distribución holomediterránea expansiva, conocida entre el Trópico de Cáncer y el paralelo $40^{\circ} \mathrm{N}$ y entre los meridianos $25^{\circ} \mathrm{W}-75^{\circ} \mathrm{E}$, citada desde el norte de África (Marruecos, Argelia, Túnez, Libia, Mauritania, Egipto, Sudán), sur de Europa (Chipre, Grecia insular, sur y centro de España), Anatolia, Israel, Palestina y Jordania, extendida hasta Arabia Saudí, Emiratos Árabes, Kuwait, Irán, Irak, Afganistán, Pakistán e India (Punjab, Rajastán).

De biología muy poco conocida (mayoritariamente recolectada a la luz), está asociada a medios térmicos, zonas desérticas y subdesérticas, oasis, mayoritariamente citada entre III-XII, probablemente hiberne como adulto (Canard \& Thierry, 2014) y se ha recolectado en altitudes de $200 \mathrm{~m}$ bajo el nivel del mar hasta $1.420 \mathrm{~m}$, también sobre Pinus, Phoenix, Olea, Nerium, Eucaliptus, Citrus, Tetraclinis, Prunus, Quercus o Eucaliptus.

En nuestra fauna existen muy pocas citas (Jaén, Almería, Granada, Madrid, Valencia y Ávila en España y Algarve en Portugal), y ha sido citada en medios mediterráneos térmicos (no parece tener una clara tendencia litoral), sobre encinas, eucaliptos, algarrobos u olivos, entre V-X, en altitudes que oscilan entre 270-1.390 m.

Las fases juveniles fueron descritas por Thierry et al. (2004).

Chrysoperla pallida Henry, Brooks, Duelli \& Johnson, 2002 (Fig. 12)

Henry et al., 2002: 174 (d); Fernández, 2003: 117 (dis); Monserrat, 2008: 189 (bio, dis); Monserrat et al., 2013: 50 (bio, dis); Letardi et al., 2013: 35 (list); Monserrat, 2013: 292 (bio, dis); Monserrat et al., 2014: 25 (bio, dis).

La validez de esta especie respecto a Chrysoperla carnea ha sido cuestionada en ocasiones (Canard \& Thierry, 2007; Thierry et al., 2011, 2013) y su estatus como especie válida ha sido descrita por Henry et al. (2002) con escasos caracteres morfológicos diferenciales (ver clave de especies) frente a $C$. carnea (especialmente en la setación del pronoto y abdomen mayoritariamente pálida, terminalia del macho el labio del S 8+9 es corto y estrecho con setas terminales cortas y pálidas en $C$. pallida, y en la setación del pronoto y abdomen mayoritariamente negra, y terminalia del macho el labio del S 8+9 ancho y alargado con setas terminales largas y oscuras en $C$. carnea). Mediante estudios moleculares ha sido recientemente confirmada como especie válida de forma definitiva por Price et al. (2015).

Especie conocida del Reino Unido, España, Portugal, Francia, Suiza, Italia, Alemania, Macedonia, Grecia y Hungría, extendida hasta el Cáucaso (Georgia) e Irán. Mayoritariamente asociada a vegetación arbórea, está citada entre II-XI, en altitudes de hasta $1.440 \mathrm{~m}$. Cambia de coloración en fase hibernante y deposita los huevos en grupos.

En nuestra fauna está poco referida aún, aunque sin duda parece abundante y frecuente, y parece tener una tendencia meridional y mediterránea (Almería, Cádiz, Granada, Málaga, Huelva, Badajoz, Jaén, Beja) con citas puntuales más hacia el interior y norte (Ávila, Madrid, Toledo, Cuenca, Guadalajara, Navarra, Lérida, Asturias, Guipúzcoa, Zamora, Trás os Montes e Alto Douro, Douro Litoral, Beira Alta, Beira Litoral y Baixo Alentejo). Desconocemos sus posibles preferencias de sustrato, y ha sido citada sobre hierba, Tamarix, Pistacia, Rhamnus, Quercus, Corylus, Castanea, Pinus, Juniperus, Fagus, Nerium, Eucaliptus, Amelanchier, Celtis y Olea, entre V-XI (parecen intuirse varias generaciones), en altitudes que oscilan entre 10-2.500 m.

Esta especie deposita sus huevos en grupos. Datos sobre la morfología larvaria en Henry et al. (2002).

Nuevo material estudiado o AnOtado: ESPAÑA: Tarragona, La Selva del Camp, $41^{\circ} 13^{\prime} 07.67^{\prime \prime N} 1^{\circ} 08^{\prime} 36.94^{\prime \prime} \mathrm{E}, 224$ m, 20.XI.2005, 1우 13.X.2007, 1 , , 8.III.2008, 1ㅇ, 19.XI.2010, 1우 15.XI.2011, $1 \widehat{\delta}^{\lambda}$ sobre Citrus clementina, N. Cañellas. PORTUGAL: Aveiro, Buçaco, 430 m, 20.VI.2011, 3 ej., A. Gruppe (A. Gruppe). Guarda, Seia, Senora de Pestero, 800 m, 20.VI.2011, 2 ej., A. Gruppe (A. Gruppe).

Chrysoperla agilis Henry, Brooks, Duelli \& Johnson, 2003

Henry et al., 2003: 133, 143, 145 (bio, d, dis, 1); Fernández, 2003: 117 (bio, dis); Henry et al., 2011: 651 (bio, dis); Letardi et al., 2013: 35 (list).

También tenemos serias dudas sobre la validez de esta especie en relación a Chrysoperla carnea, realmente solo distinguibles a través del canto (Henry et al., 2003; Duelli et al., 2015). Sinceramente, los datos morfológicos y morfométricos anotados para diferenciar esta especie son demasiado sutiles, excesivamente subjetivos, frecuentemente irrealizables en ejemplares secos, diagnósticamente variables, y en ocasiones solapables con otras especies, en especial frente a $C$. carnea y $C$. pallida (ya se anota esta realidad en la propia descripción de esta especie: Henry et al., 2003), que hacen prácticamente indiferenciable estas especies con los métodos que habitualmente dispone cualquier entomólogo, y coincidimos con Canard \& Thierry (2007) y Thierry et al. (2013) en la falta de evidencias para la caracterización de este taxón. Aún así, y dentro de las limitaciones, e incluso de posibles errores de nuestras propias identificaciones, la hemos considerado en este estudio, y algunos de estos caracteres han sido utilizados en las claves que aportamos.

Parece tratarse de una especie común en zonas secas del Paleártico Occidental, donde es conocida en la región europea mediterránea y sus islas y desde Azores, Madeira y Canarias a Israel e Irán, con una posible población en Alaska, de origen desconocido (y desde nuestro punto de vista bastante "sorprendentemente sospechosa" a la hora de diferenciar la identidad específicas en las especies este género en base al canto), y aparentemente de morfología algo variable. Asociada preferentemente a vegetación baja, herbácea, 
cultivos y praderas, cambia de coloración en fase de hibernación a amarillo pardo. Mayoritariamente citada entre VI-X, entre 10-1.390 m.

En nuestra fauna está referenciada del sur de España (Granada, Almería = erróneamente de Alicante) y Portugal (incluido Madeira y Azores), en ocasiones sin localidades precisas (Henry et al., 2003; Fernández, 2003; Henry et al., 2011). Ha sido citada sobre vegetación herbácea, alfalfa, áreas cultivadas y pinos en medios mediterráneos. Entre 10-1.390 m, en VII.

Pone los huevos de forma aislada. Estadios larvarios en Henry et al. (2003).

\section{Chrysoperla ankylopteryformis Monserrat \& Díaz-} Aranda, 1989 (Figs. 18, 21-27, 132, 184)

Monserrat \& Díaz-Aranda, 1989c: 261 (d); Díaz-Aranda \& Monserrat, 1990a: 677 (dis); Monserrat \& Rodrigo, 1992: 132 (dis); Brooks, 1994: 156 (rf, tx); Monserrat \& Marín, 1994: 122 (bio); Paulian et al., 1996: 287 (mf, rf); H. Aspöck et al., 2001: 115 (rf); Henry et al., 2001: 31 (bio, rf); Canard \& Thierry, 2007: 174 (mf, rf); Canard et al., 2007: 292-297 (rf); Monserrat, 2013: 291 (rf).

En base a elementos meramente museísticos, esta especie fue propuesta por Brooks (1994) como sinonimia posterior de Chrysoperla renoni (Lacroix, 1933), especie citada de Francia, Italia, Hungría y Rumanía (Lacroix, 1933; Brooks, 1994; Paulian et al., 1996, 2010; Sziráki, 1998, 2007; H. Aspöck et al., 2001; Canard et al., 2010; Price et al., 2015). La similitud entre ambas especies ya había sido sugerida por Leraut (1991) y H. Aspöck (1992). Esta sinonimia no ha sido plenamente asumida, ha sido cuestionada o se ha puesto en duda por varios autores, tanto por la marcada diferencia de hábitats y distribución entre ambas especies, como por sus características morfológicas (Henry et al., 2001; Canard et al., 2002, 2007; Canard \& Thierry, 2007) y, de hecho, Thierry et al. (1998) o Paulian et al. (1996) las separan en su clave de especies de este género, bien europeas o bien de faunas locales.

Destacan, entre otros caracteres diferenciales en ambas especies, ciertos elementos de morfología externa, especialmente en la coloración tegumentaria, que es rosácea-amarillenta, sin banda pálida media sobre el tórax (C. ankylopteryformis) y no verde-azulada con banda pálida sobre el tórax ( $C$. renoni), y en la morfología alar (Fig. 132), con alas anteriores ovoides y margen posterior levemente cóncavo, con campo costal mucho más ancho con setas muy pálidas (Fig. 18), venación alar pálida-hialina (C. ankylopteryformis), y no con alas más rectas y margen posterior recto, como es habitual en otras especies del género (Figs. 130, 131), con campo costal más estrecho con setas oscurasnegras, venación alar verde-azulada $(C$. renoni), etc., elementos a los que habría que añadir la ausencia de dentículo interior en la parte basal de las uñas (Monserrat \& Díaz-Aranda, 1989c; Leraut, 1991) (Fig. 21), al margen de obvias diferencias en la genitalia, tanto masculina (forma del complejo gonarcoentoproceso-arceso y del tignum), como femenina
(Brooks, 1994: 185; Monserrat \& Díaz-Aranda, 1989c: 263; Leraut, 1991: 77) (Figs. 22-27). También han de anotarse marcadas diferencias en su biología y hábitats, ya que $C$. renoni está fuertemente asociada a zonas boscosas en medios húmedos, sean riveras de grandes ríos, lagos, deltas o zonas pantanosas o inundables del centro y este de Europa (Lacroix, 1933; Leraut, 1991, 2003; Paulian et al., 1996, 2010; Sziráki, 1998; Henry et al., 2001; Canard \& Thierry, 2007), mientras que C. ankylopteryformis está incuestionablemente asociada a ramblas pedregosas y secas, y cañaverales en medios extremadamente térmicos, xéricos y subdesérticos de zonas mediterráneas, desde el árido S. E. de la Península Ibérica a Israel (Monserrat \& Díaz-Aranda, 1989c; Canard et al., 2007). Por todo ello que no asumimos la sinonimia citada.

En nuestra fauna ha sido recolectada mayoritariamente a la luz en ramblas secas y pedregosas con cañas (especialmente Arundo donax) y tarajales (Tamarix gallica), en medios áridos y térmicos del S. y S.E. peninsular (Almería, Málaga), citada en V-VIII, entre 10-40 m.

La larva fue descrita por Díaz-Aranda \& Monserrat (1990a) y Monserrat \& Díaz-Aranda (2012).

\section{Género Cunctochrysa}

Representado en nuestra fauna por tres especies, en ocasiones de identificación problemática. Los datos de biología y distribución geográfica y altitudinal ayudan mucho en este caso.

Cunctochrysa albolineata (Killington, 1935) (Figs. 10, 186)

Chrysopa albolineata Killington, 1935

Killington, 1935b: 87 (d); Eglin, 1940: 292 (rf); Hölzel, 1964b: 143 (rf).

Cunctochrysa albolineata (Killington, 1935)

Aspöck et al., 1980: 272 (rf); Grimal, 1984: 9 (rf); Monserrat, 1984a: 47 (rf), 1984e: 159 (biol, dis); Canard, 1985: 176 (1, rf); Monserrat, 1985c: 94 (biol, dis), 1986b: 101 (biol, dis); DíazAranda et al., 1986b: 1141 (biol, dis); Marín \& Monserrat, 1987: 350-359 (biol, dis); Monserrat \& Díaz-Aranda, 1987: 182 (biol, dis), 1989c: 265 (bio, dis); Marín \& Monserrat, 1989: 295 (bio, dis), 1990: 226 (bio, dis), 1991b: 190-196 (bio, dis); Canard et al., 1992b: 96 (list); Pantaleão et al., 1993: 429 (bio, dis); Monserrat \& Marín, 1994: 122 (bio); Monserrat et al., 1994: 55 (bio, dis); Monserrat, 1996: 14 (list); Carvalho, 1997: 5, 7 (dis); H. Aspöck et al., 2001: 109 (rf); Canard et al., 2007: 292-297 (rf); Monserrat, 2008: 189 (dis); Ocharan et al., 2012: 426 (bio, dis); Letardi et al., 2013: 35 (list); Monserrat et al., 2014: 27 (key), 29 (bio, dis, mf). Anisochrysa albolineata (Killington, 1935)

Hölzel \& Ohm, 1972: 144 (nt); Monserrat, 1977a: 131 (rf); Boelpaepe et al., 1992: 22 (bio, dis).

Anisochrysa (Cunctochrysa) albolineata (Killington, 1935) Hölzel \& Ohm, 1972: 139 (dis); Monserrat, 1978a: 180 (bio, dis); Sengonça, 1980: 106 (rf).

Mallada albolineatus (Killington, 1935) (sic)

Séméria \& Berland, 1988: 134 (rf).

Chrysopa tenella Schneider, 1851

Schneider, 1851a: 94 (d); Stitz, 1927: 15 (rf); Monserrat, 1977a: 131 (rf).

Chrysopa tenella continua Navás, 1919

Monserrat, 1977a: 131 (rf). 
También citada en la fauna ibero-balear como Chrysopa tenella aranensis Navás, 1915, Chrysopa tenella comana Navás, 1919, Chrysopa tenella decora Navás, 1915, Chrysopa tenella detersa Navás, 1918, Chrysopa tenella numerosa Navás, 1915, Chrysopa tenella sacresti Navás, 1928 y Chrysopa tenella virens Navás, 1915.

Especie sibérica ampliamente citada desde Europa y Macaronesia a China y Corea. Aparentemente eurioica y con marcada preferencia a planifolios en zonas húmedas, vegetación herbácea, jardines, frutales, etc. De voltinismo aparentemente variable según latitudes y altitudes, está mayoritariamente citada entre $\mathrm{V}-\mathrm{X}$, en altitudes de hasta $1.500 \mathrm{~m}$ (2.100 m en Asia). Parece demostrado que hiberna en fase de prepupa (Aspöck et al., 1980).

En nuestra fauna tiene una clara tendencia eurosiberiana, marcadamente asociada a medios húmedos, y lógicamente con una distribución mayoritaria en su mitad septentrional, incluyendo Andorra, con citas puntuales en zonas montanas del centro y algo más meridionales (Cuenca, Madrid, Guadalajara, Soria) (las citas de Pantaleão et al., 1993 en Santarém y Setúbal, y la de Boelpaepe et al., 1992 en el Algarve portugués nos habían parecido sorprendentes y sugerían una distribución más meridional en zonas de influencia atlántica, hecho que ahora corroboramos), y ha sido citada sobre planifolios, especialmente robles, avellanos, hayas y vegetación de rivera, entre V-IX, en altitudes que oscilan entre 30-1.650 m.

La puesta, el huevo, la larva y el capullo de esta especie fueron descritos por Withycombe (1922), Killington (1928b, 1936, 1937), Agekyan (1973), Tsukaguchi (1977), Gepp (1983b, 1989), Díaz-Aranda \& Monserrat (1994) y Monserrat \& Díaz-Aranda (2012). Canard (1985) hace referencia de una larva de esta especie en Lérida.

Nuevo material estudiado o ANOTADo: ESPAÑA: Guipúzcoa, Irún, Otzarte, Arako Harria P.N., 500 m, 30TWN994, 25.VI.2014, $1 \hat{\jmath}$, S. Pagola. PORTUGAL: Algarve, Quinta do Lago, $30 \mathrm{~m}$, 30.V.2013, 10, P. Guevara (Fig. 10).

Cunctochrysa baetica (Hölzel, 1972) (Figs. 71, 92, 187) Anisochrysa (Cunctochrysa) baetica Hölzel, 1972

Hölzel, 1972a: 217 (d); Hölzel \& Ohm, 1972: 139 (dis); Sengonça, 1980: 110 (rf).

Anisochrysa baetica Hölzel, 1972

Hölzel \& Ohm, 1972: 128 (nt), 143 (nt); Monserrat, 1977a: 20 (list), 118 (key), 131 (bio, dis), 1978b: 63 (bio, dis); Boelpaepe et al., 1992: 22 (bio, dis).

Cunctochrysa baetica (Hölzel, 1972)

Aspöck et al., 1980: 273 (rf); Monserrat, 1982: 78 (bio, dis); Campos \& Ramos, 1983: 222 (bio, dis); Monserrat, 1984a: 41 (bio, dis), 1984b: 171 (bio, dis), 1984d: 104 (bio, dis), 1984e: 159 (bio, dis), 1985b: 87 (bio, dis), 1986b: 101 (dis); DíazAranda et al., 1986b: 1141 (bio, dis); Monserrat, 1987: 141 (bio, dis); Monserrat \& Díaz-Aranda, 1987: 182 (bio, dis); Marín \& Monserrat, 1987: 350-359 (bio, dis); Díaz-Aranda \& Monserrat, 1988a: 119 (bio, dis), 1988b: 225 (bio, dis), 1988c: 223 (bio, dis); Monserrat \& Díaz-Aranda, 1989c: 265 (bio, dis);
Marín \& Monserrat, 1990: 226 (bio, dis), 1991a: 182 (bio, dis); Monserrat \& Rodrigo, 1992: 132 (dis); Canard et al., 1992b: 97 (list, rf); Pantaleão et al., 1993: 429 (bio, dis); Monserrat \& Marín, 1994: 122 (bio, dis); Marín, 1994: 260 (bio, dis); Monserrat et al., 1994: 55 (bio, dis); Marín \& Monserrat, 1995a: 117 (bio, dis), 1995b: 43 (bio, dis); Monserrat, 1996: 14 (list); Carvalho, 1997: 5, 7 (dis); Paulian \& Canard, 2000: 250 (rf); H. Aspöck et al., 2001: 109 (rf); Monserrat, 2005: 79 (rf); Canard, 2007: 406 (rf); Canard et al., 2007: 292-297 (rf); Monserrat, 2008: 190 (bio, dis); Letardi et al., 2013: 35 (list); Monserrat, 2013: 292 (bio, dis); Monserrat et al., 2014: 27 (key), 29 (bio, dis, mf).

Mallada baeticus (Hölzel, 1972) (sic)

Séméria \& Berland, 1988: 134 (rf).

Especie holomediterránea, con poblaciones aisladas en el centro de Europa. Está mayoritariamente citada en medios arbóreos mediterráneos. De voltinismo aparentemente variable según latitudes y altitudes, está citada entre V-IX, en altitudes de hasta $1.800 \mathrm{~m}$. Parece demostrado que hiberna en fase de prepupa (Aspöck et al., 1980).

En nuestra fauna sustituye mayoritariamente a la especie anterior, y tiene una clara tendencia a ocupar zonas más continentales y térmicas de influencia mediterránea, y por ello con una distribución mayoritaria en su mitad meridional, incluyendo Baleares (Mallorca), con citas puntuales en áreas más continentales $y / 0$ septentrionales, $y$ ha sido citada sobre quejigos, robles, y especialmente sobre encinas, puntualmente sobre pinos, prunos, pistáceas, tojos, eucaliptos y sabinas, entre IV-IX, en altitudes que oscilan entre $10-1.353 \mathrm{~m}$.

Datos sobre sus estadios larvarios descritos por Pantaleoni (1983), Duelli (1989), Díaz-Aranda \& Monserrat (1994, 1995), Díaz-Aranda et al. (2001) y Monserrat \& Díaz-Aranda (2012).

Nuevo material estudiado o Anotado: ESPAÑA: Madrid, San Fernando de Henares, 27.IX.2011, 1q, J.I. López Colón. Murcia, Jumilla, Sierra del Carche, 990 m, 22.VII.2008, 2 ej., Lencina \& Gallego (A. Gruppe). Tarragona, La Selva del Camp, $41^{\circ} 13^{\prime} 07.67^{\prime \prime} \mathrm{N} 1^{\circ} 08^{\prime} 36.94^{\prime \prime} \mathrm{E}, 224 \mathrm{~m}, 15 . \mathrm{IX} .2008,1$ 우 sobre Citrus clementina, N. Cañellas.

\section{Cunctochrysa cosmia (Navás, 1918) (Fig. 188)}

Chrysopa cosmia Navás, 1918

Navás, 1917d: 87 (rf), 1918: 19 (d); Hölzel, 1973a: 66 (tx) (ver referencias de Chrysopa nigricostata).

Cunctochrysa cosmia (Navás, 1918)

Monserrat et al., 2014: 26 (bio, dis, mf, tx), 27 (key).

Esta especie, inicialmente ibérica, fue sinonimizada y confundida con Chrysopa nigricostata Brauer, 1851 por Hölzel (1973a). Este hecho fue aclarado recientemente por Monserrat et al. (2014), quienes la revalidaron como especie auténtica, proponiendo una sinonimia de otra especie posteriormente descrita de Francia (Cunctochrysa bellifontensis Leraut, 1988), siendo muy probable que muchas citas europeas de Chrysopa nigricostata, y especialmente las dadas en zonas elevadas, y en particular sobre Pinus spp. 
y otras coníferas, pertenezcan, en realidad a la especie que ahora tratamos. Por ello, no podemos asegurar su real distribución geográfica y/o altitudinal. Está confirmada su presencia en España, Portugal, sur de Francia y Rumanía, y casi con seguridad de Polonia, Bélgica y Gran Bretaña (Leraut, 1988; Plant, 1993; San Martin, 2004; Monserrat et al., 2014), VI-VII, en altitudes de hasta $840 \mathrm{~m}$.

También en la fauna de la Península Ibérica fue histórica-mayoritariamente confundida con Chrysopa nigricostata, y como tal ha sido frecuentemente citada, aunque la mayoría de los datos existentes de esta especie corresponden a la especie que ahora tratamos (ver Monserrat et al., 2014). En nuestra península tiene una clara tendencia montana, más bien orófila, hecho que genera su disyunta distribución: Pirineos, Sierra de la Culebra, Galicia, Sistema Central, Montes de Toledo, Serranía de Cuenca, Sierra de Cazorla y Sierra Nevada en España y Serra da Estrêla en Portugal (citada en este país como C. nigricostata por Monserrat, 2008 y Hölzel \& Ohm, 1972), y ahora la citamos de zonas más meridionales. Ha sido mayoritariamente citada sobre pinos (tanto imagos como larvas), especialmente sobre Pinus sylvestris, algunos ejemplares sobre $P$. nigra y $P$. pinaster, y apenas una docena de ejemplares en bosques de quercíneas: Quercus pyrenaica, $Q$. robur y $Q$. rotundifolia (mayoritariamente próximos a pinares repoblados en medios mediterráneos), entre IV-IX, en altitudes que oscilan entre $670-2.100 \mathrm{~m}$.
Sortea los fríos meses de invierno dentro del capullo pupal, en fase de larva-prepupa, y pasa a fase de pupa en la siguiente primavera. Algunos datos sobre la morfología y biología de las fases larvarias fueron aportados por Monserrat et al. (2014).

Nuevo material estudiado o anotado: ESPAÑA: Murcia, Moratalla, Sierra Seca, 1.750 m, 19.IX.2007, 1 ej., J.L. Lencina (A. Gruppe).

Género Chrysotropia Navás, 1911

Representado en nuestra fauna por una única e inconfundible especie.

Chrysotropia ciliata (Wesmael, 1841) (Figs. 73, 91, 133-135, 185)

Chrysopa ciliata Wesmael, 1841

Wesmael, 1841: 212 (d).

Chrysotropia ciliata (Wesmael, 1841)

Hölzel \& Ohm, 1972: 140 (dis); 144 (nt); Hölzel, 1973a: 79 (tx); Aspöck et al., 1980: 243 (rf); Sengonça, 1980: 32 (rf); Grimal, 1984: 8 (rf); Monserrat, 1985c: 94 (bio, dis); Monserrat \& Díaz-Aranda, 1989c: 254 (dis); Marín \& Monserrat, 1989: 293 (bio, dis); Monserrat et al., 1994: 50 (dis); H. Aspöck et al., 2001: 80 (rf); Monserrat, 2008: 174 (dis); Ocharan et al., 2012: 425 (bio, dis); Monserrat et al., 2013: 51 (bio, dis), 2014: 5 (bio, dis).

Chrysotropia ciliate (Wesmael, 1841) (lapsus)

Canard et al., 2007: 292-297 (rf).

Chrysopa linensis Navás, 1916

Navás, 1916b: 594 (d); Hölzel, 1973a: 79 (tx).
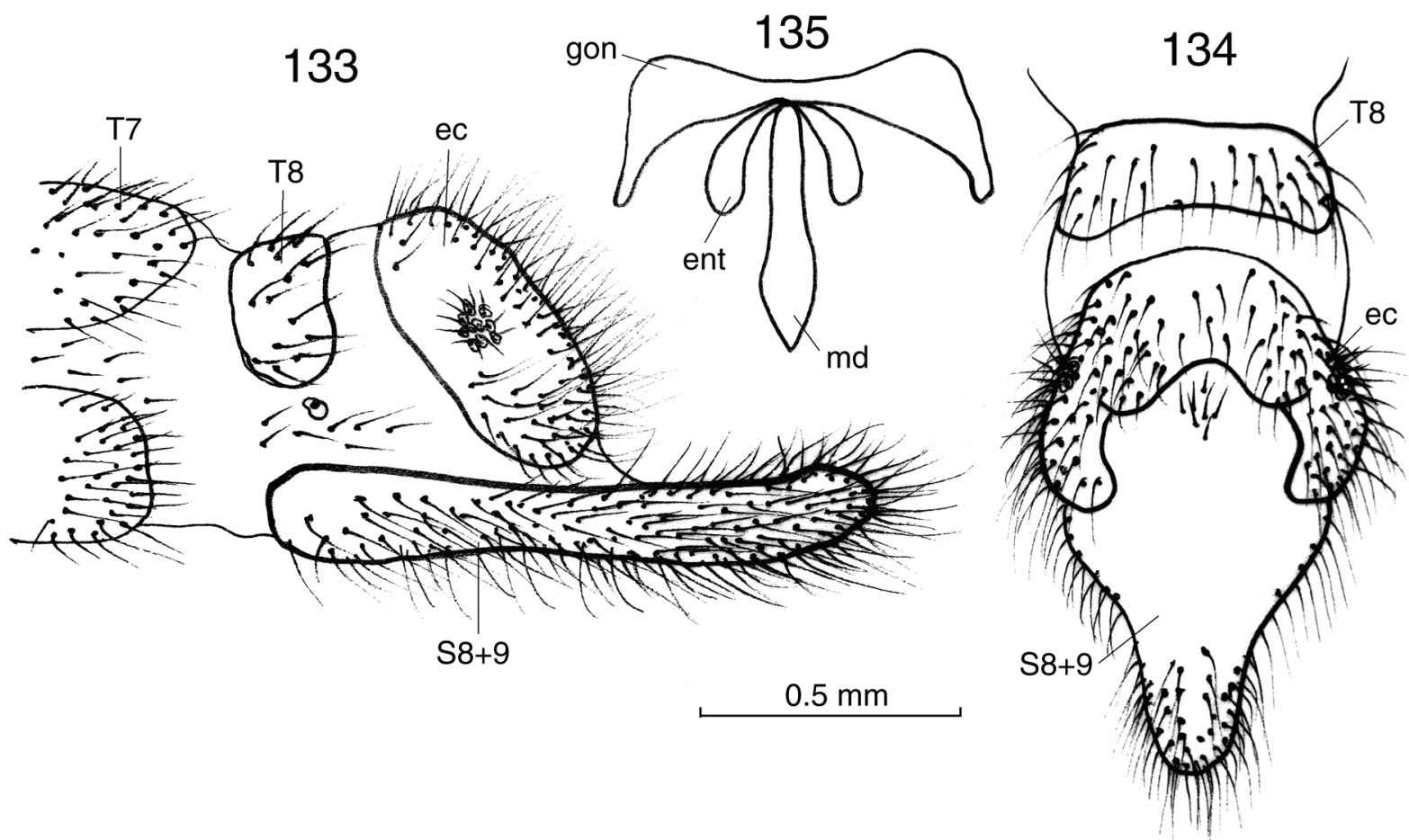

Figs. 133-135.- Chrysotropia ciliata đ̂: 133: extremo abdominal masculino, vista lateral, 134: ídem, vista dorsal, 135: complejo gonarco-mediuncos-entoproceso, vista caudal (ec: ectoprocto, ent: entoproceso, gon: gonarco, md: mediunco, S: esternito, T: terguito).

Figs. 133-135.-Chrysotropia ciliata ${ }^{1}$ : 133: male abdominal apex, lateral view, 134: ditto, dorsal view, 135: complex gonarccusmediuncus-entoprocessus, caudal view (ec: ectoproct, ent: entoprocessus, gon: gonarcus, md: mediuncus, S: sternite, T: tergite). 
Chrysopidia (Chrysotropia) ciliata (Wesmael, 1841) Monserrat \& Rodrigo, 1992: 125 (dis)

Chrysopidia ciliata (Wesmael, 1841) Monserrat \& Marín, 1994: 122 (bio).

Chrysotropia melaneura Navás, 1916

Navás, 1916b: 596 (d); Hölzel, 1973a: 79 (tx).

También citada en la fauna ibero-balear como Chrysopa ciliata Wesmael, 1841, Chrysotropia linensis (Navás, 1916), Chrysotropia linensis melaneura Navás, 1916, Chrysotropia melaneura absona Navás, 1916 y Chrysotropia melaneura furcata Navás, 1916.

Especie eurosiberiana conocida desde Europa y Anatolia a Irán, Corea y Japón. Está mayoritariamente citada en medios húmedos, rivereños y montanos sobre planifolios, sobre todo robles, hayas, tilos, fresnos, sauces y avellanos, entre IV-X, probablemente posea dos generaciones, $\mathrm{y}$ ha sido recolectada en altitudes de 30 hasta $1.600 \mathrm{~m}$. Parece demostrado que hiberna en fase de prepupa (Aspöck et al., 1980).

En nuestra fauna tiene una clara tendencia eurosiberiana, y solo es conocida del tercio septentrional, y ha sido citada sobre avellanos y robles, más puntualmente sobre hayas, sauces, abedules y castaños, entre IV-IX, en altitudes que oscilan entre 30-1.470 m.

Bajo diferentes denominaciones, el huevo, la larva y la pupa de esta especie fueron descritos por Withycombe (1922, 1925), Killington (1937), Gepp (1983b, 1984b, 1989, 1990, 1999), Díaz-Aranda (1992), Díaz-Aranda \& Monserrat (1995), Tsukaguchi (1995), Díaz-Aranda et al. (2001) y Monserrat \& Díaz-Aranda (2012).

\section{Género Nineta Navás, 1912}

Es un género muy bien definido y característico. Algunas de sus especies son de fácil diferenciación (siempre recomendamos el estudio de la genitalia masculina), mientras que otras, especialmente en el caso de las hembras, son más problemáticas. Este hecho ha generado un historial de citas en nuestra fauna muy confusas que ahora trataremos de dilucidar.

Nineta flava (Scopoli, 1763) (Figs. 108, 136, 142, 189)

Hemerobius flavus Scopoli, 1763

Scopoli, 1763: 270 (d).

Chrysopa flava (Scopoli, 1763)

Stitz, 1927: 15 (rf); Hölzel, 1964b: 141 (rf).

Nineta flava (Scopoli, 1763)

Hölzel \& Ohm, 1972: 140 (dis), 144 (nt); Monserrat, 1978a: 178 (bio, dis); Aspöck et al., 1980: 240 (rf); Sengonça, 1980: 35 (rf); Grimal, 1984: 9 (rf); Monserrat, 1984a: 36 (bio, dis), 1984b: 170 (bio, dis), 1985c: 95 (bio, dis), 1986b: 101 (rf); Séméria \& Berland, 1988: 115 (rf); Marín \& Monserrat, 1989: 293 (bio, dis); Monserrat \& Díaz-Aranda, 1989c: 254 (dis); Canard et al., 1992b: 96 (list); Monserrat \& Rodrigo, 1992: 125 (bio, dis); Monserrat \& Marín, 1994: 122 (bio); Monserrat et al., 1994: 50 (bio, dis); Monserrat, 1996: 14 (list); Carvalho, 1997: 5, 7 (dis); H. Aspöck et al., 2001: 76 (rf); Canard, 2004: 154 (rf); Canard et al., 2007: 292-297 (rf); Monserrat, 2008: 174 (dis); Ocharan et al., 2012: 425 (bio, dis); Monserrat et al., 2013: 47 (bio, dis), 2014: 5 (bio, dis).
También citada en la fauna ibero-balear como Nineta flava wesmaeli Navás, 1917

Especie europea de tendencia extra-mediterránea expansiva, extendida hasta Anatolia, Cáucaso, Georgia, Armenia, Azerbayán e Irán. Aparentemente eurioica, está mayoritariamente asociada a planifolios en zonas húmedas y montanas, donde ha sido recolectada sobre vegetación de rivera y en bosques caducifolios (robles, hayas, alisos, nogales, arces, avellanos, laureles), jardines, setos, incluso parques públicos, ocasionalmente sobre pinos, entre IV-X, en altitudes de 1.100 hasta $2.450 \mathrm{~m}$. Las hembras pueden llegar a ser muy longevas (hasta más de 200 días en condiciones experimentales), hiberna en fase de prepupa dentro del capullo (Killington, 1937; Canard, 1986a, 1986b, 1998).

En nuestra fauna, esta especie está inicialmente "citada" de Málaga por Navás (1901: 27) de forma muy confusa: [Ch. flava, Scop.- Málaga (Walker apud Pictet, sub Ch. vittata Wesm.)] (ver más adelante la corrección de esta cita de Walker por McLachlan, 1867 en $N$. vittata). Tratando de dilucidar esta jeroglífica referencia de Navás (1901), es conocido que apud significa "en la obra de" y sub es un prefijo latino de posición que indica que "se sitúa o se realiza bajo algo" o bien "como". No sabemos si Navás se refería a "subespecie de" (y así consideraba una respecto a la otra) o si, como podría pensarse, asigna esta cita a $N$. flava. Más tarde vuelve a citar a $N$. flava, esta vez de Barcelona (Navás, 1904a: 124, 1905d: 55), que fue posteriormente corregida y asignada a $N$. guadarramensis por Navás (1908a: 110), con lo que estas referencias iniciales de $N$. flava en nuestra fauna quedaban descartadas (Monserrat, 1986b: 101). Por ello, años después y refiriéndose a $N$. flava, Navás (1915a: 87) anota: "no l'he vist d'Espanya", y más tarde Navás (1916c: 174) cita a $N$. flava de Galicia (Santiago, Marín) y País Vasco (Deusto) como: "Nueva para la península ibérica" y en Navás (1916a: 190) como "Nueva para España" citándola de Lérida: Es Bòrdes, Lés (VII, VIII, 784 m) (las altitudes han sido estimadas por nosotros), que son, en ese momento, sus únicas citas de esta especie existente en nuestra fauna. Posteriormente (Navás, 1917b: 278) la citará en Cataluña del Valle de Arán (Lérida) (s.f., 784-1.170 m) y Navás (1921: 151) de "Ribas" (Ribas de Fresser) (Gerona) (VIII, 910 m), y Navás (1924b: 25) de Sant Feliu de Pallerols (Gerona) (VII, $473 \mathrm{~m}$ ), aunque debe indicarse que en su monografía de los neurópteros de Cataluña (Navás, 1924a: 176) cita a $N$. flava de Lés e Isil, y de Es Bòrdes a $N$. vittata, y no a $N$. flava (obviando además sus citas de Gerona), datos que repite en su monografía de los neurópteros de la Península Ibérica, donde Navás (1925: 83) cita de esta localidad (Es Bòrdes) a N. vittata, y no a $N$. flava, que solo la refiere de Galicia y Andorra (obviando además su cita de Vizcaya). Estos datos, y al margen de una evidente falta de método, sugieren una cierta confusión en la identificación de estas dos especies (Monserrat, 1986b) y, consecuentemente, en 

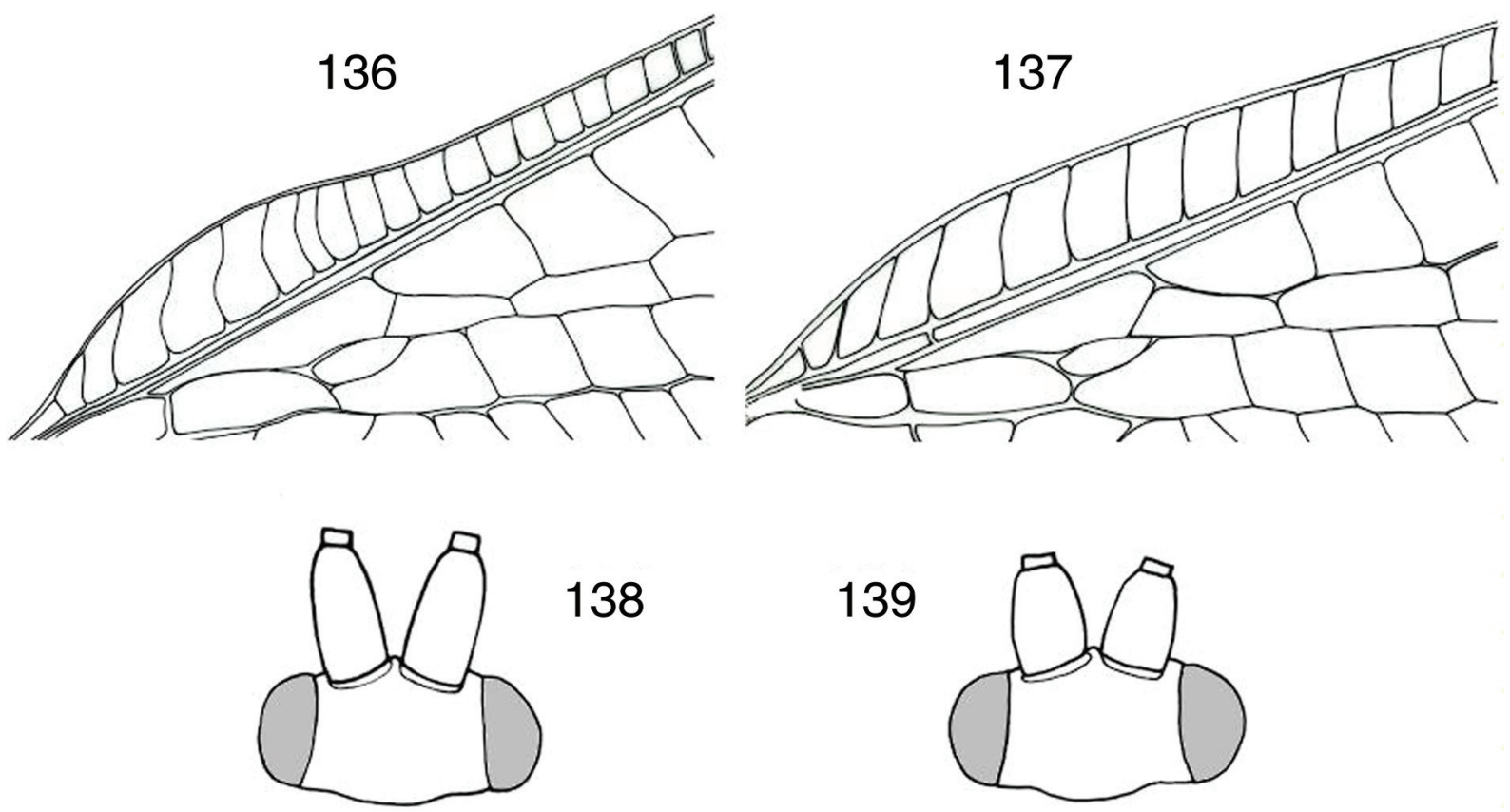

138

139
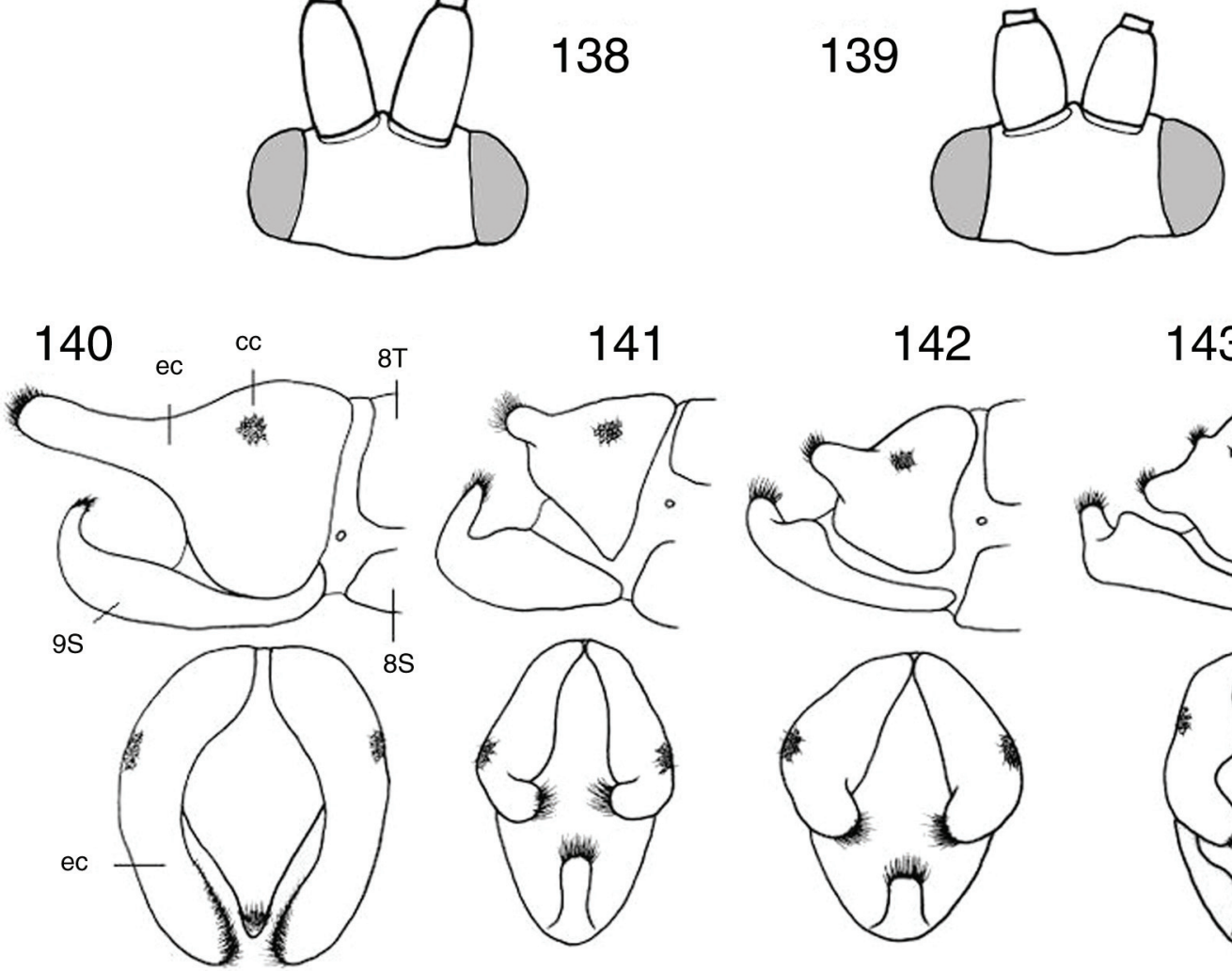

143

Figs. 136-143.- Morfología de Nineta spp. 136-137: campo costal de las alas anteriores de: 136: Nineta flava, 137: Nineta pallida. 138-139: cabeza, escapo y pedicelo en vista dorsal de: 138: Nineta vittata, 139: Nineta pallida. 140-143: esquema del extremo abdominal, vista lateral y dorsal, en el macho de: 140: Nineta guadarramensis, 141: N. vittata, 142: N. flava, 143: N. pallida (cc: callo cercal, ec: ectoprocto, S: esternito, T: terguito). A diferentes escalas.

Figs. 136-143.- Nineta spp. morphology. 136-137: costal field of forewings in: 136: Nineta flava, 137: Nineta pallida. 138-139: head, scape and pedicel in dorsal view of: 138: Nineta vittata, 139: Nineta pallida. 140-143: scheme of the abdominal tip in the male, in lateral and dorsal view, of: 140: Nineta guadarramensis, 141: N. vittata, 142: N. flava, 143: N. pallida (cc: callus cerci, ec: ectoproct, S: sternite, T: tergite). At different scales.

veracidad/autenticidad estas citas. A lo largo de su vida también citará $N$. flava en varias localidades de Gerona, Lérida, Vizcaya, Coruña, Pontevedra, Lugo (Navás, 1917a, 1924c, 1928, 1929, 1930), que mayoritariamente no han sido comprobadas, aunque es probable que alguna pueda ser "correcta" (acertada).

Mucho tiempo después Hölzel \& Ohm (1972: 140) la mencionan de Corconte (Santander) (VII, $847 \mathrm{~m}$ ), cita que estimamos aceptable, no así su cita en Las Alpujarras y Sierra Nevada (Granada) (VI, VII, 1.000 m) que siempre nos había parecido muy dudosa o cuestionable (Monserrat, 2010, 2011), y que fue revisada y corregida por Monserrat (2013), asignándola a N. guadarramensis, en base a nuevo material recientemente recolectado en esta zona tras varios años de muestreos que hemos realizado en Sierra Nevada para tratar de dilucidar esta cita, bien en la localidad o en localidades próximas donde Nineta flava había sido citada. 
Al margen de las citas dudosas y cuestionadas/ nables, en nuestra fauna tiene una clara tendencia eurosiberiana con citas en toda la Cornisa Cantábrica, Galicia y Pirineos, incluyendo Andorra, y otras puntuales algo más meridionales (Madrid, Zaragoza, Soria, Burgos y Salamanca en España y Beira Interior y Litoral en Portugal, etc.), y ha sido recolectada puntualmente sobre pinos y encinas, pero sobre todo sobre planifolios eurosiberianos, robles, quejigos, hayas y avellanos, entre VI-VIII, en altitudes que oscilan entre 400-2.250 m.

La puesta, en clusters de 15-30 huevos (huevo de $0,9 \mathrm{~mm}$ y pedúnculo de $9 \mathrm{~mm}$ ), el huevo, la larva y el capullo de esta especie fueron descritos por Alderson (1911b), Pariser (1919), Withycombe (1922), Killington (1936, 1937), Canard (1983, 1984, 1985), Gepp (1983b, 1984b, 1986, 1989, 1990), Duelli (1984c), Díaz-Aranda (1992), Canard et al. (1998) y Monserrat \& Díaz-Aranda (2012).

Nuevo material estudiado o ANOtAdo: ESPAÑA: Lérida, Llesuí, 4.VIII.2014, 19 en trampa de luz, I. Martínez. PORTUGAL: Guarda, Seia, Senora de Pestero, 800 m, 20.VI.2011, 3 ej., A. Gruppe (A. Gruppe). Viana do Castelo, Serra da Peneda, Lamas de Mouro, 850 m, 17.VI.2011, 2 ej., A. Gruppe (A. Gruppe). Vila Real, Serra do Alvão, Lomas de Olo, 1.000 m, 18.VI.2011, 2 ej., A. Gruppe (A. Gruppe).

Nineta guadarramensis (Pictet, 1865) (Figs. 16, 81, 94, 140, 190)

Chrysopa guadarramensis Pictet, 1865

Pictet, 1865: 65 (d); Hölzel, 1973a: 81 (tx); Monserrat, 1977a: 106 (rf).

Nineta guadarramensis (Pictet, 1865)

Hölzel, 1965b: 91, 93 (rf, tx); Hölzel \& Ohm, 1972: 141 (dis), 143 (nt); Hölzel, 1973a: 80, 81 (dis, mf, tx), 1973b: 504 (rf); Jedlicka \& Jedlickova, 1973: 66 (rf); Gepp, 1977a: 197 (rf); Monserrat, 1977a: 20 (list), 106 (bio, dis), 1978a: 176 (bio, dis), 1978b: 62 (bio, dis); Aspöck et al., 1980: 240 (rf); Monserrat, 1981a: 154 (bio, dis), 1984a: 36 (bio, dis), 1984b: 170 (bio, dis), 1984e: 156 (bio, dis); Grimal, 1984: 9 (rf); Monserrat, 1985c: 95 (bio, dis), 1986b: 101 (dis); Díaz-Aranda et al., 1986a: 1125 (bio, dis), 1986b: 1138 (bio, dis); Marín \& Monserrat, 1987: 350-359 (bio, dis); Díaz-Aranda \& Monserrat, 1988b: 223 (bio, dis); Monserrat \& Díaz-Aranda, 1989c: 254 (dis); Marín \& Monserrat, 1989: 293 (bio, dis), 1990: 225 (bio, dis), 1991b: 190-196 (bio, dis); Canard et al., 1992 b: 96 (list); Monserrat \& Marín, 1994: 122 (bio); Monserrat et al., 1994: 50 (bio, dis); Marín \& Monserrat, 1995a: 115 (bio, dis); Monserrat, 1996: 14 (list); Saure, 1997: 3 (dis); Canard et al., 1998: 328 (dis); Canard, 2004: 155 (rf); Canard et al., 2007: 292-297 (rf); Monserrat, 2008: 174 (dis); Monserrat, 2011: 169 (bio, dis, tx); Ocharan et al., 2012: 425 (bio, dis); Monserrat, 2013: 294 (bio, dis, tx); Letardi et al., 2013: 35 (list); Monserrat et al., 2013: 47 (bio, dis), 2014: 5 (bio, dis).

Chrysopa (Nineta) guadarramensis Pictet, 1865 Hölzel, 1965b: 93 (mf, rf).

Nineta alvesi Navás, 1917

Navás, 1917a: 70 (d); Hölzel, 1965b: 91 (tx), 1973a: 81 (tx); H. Aspöck et al., 2001: 76 (rf); Canard, 2004: 157 (dis, mf, rf); Monserrat, 2011: 169 (tx).

Nineta guadarramensis guadarramensis (Pictet, 1865) Monserrat \& Rodrigo, 1992: 125 (bio, dis).
También citada en la fauna ibero-balear como Nineta flava (Scopoli, 1763) (ver Nineta flava).

Especie frecuentemente citada en el pasado de Europa, Anatolia y norte de África, a la que solo deben adjudicarse las citas correspondientes a la Península Ibérica y Marruecos, perteneciendo las restantes a Nineta principiae Monserrat, 1981, descrita como subespecie de Italia (Monserrat, 1981b), elevada a especie por Canard et al. (1998), y aceptada como tal desde entonces (Nicoli Aldini \& Baviera, 2001; Canard, 2004; Gruppe, 2005, 2006; Letardi \& Biscaccianti, 2007; Carotti et al., 2009; Bozsik, 2009; Nicoli Aldini et al., 2012; Letardi \& Coccia Collepardo, 2015, etc.).

Dejando al margen estas citas incorrectas, es una especie atlantomediterránea de zonas húmedas y montanas de carácter mediterráneo, marcadamente asociada con robles, especialmente a Quercus pyrenaica, $Q$. canariensis y $Q$. robur, puntualmente recolectada sobre Fagus y Castanea, y por lo anteriormente anotado, casi todo lo que se conoce de esta especie corresponde a datos de nuestra fauna, mayoritariamente citada entre VI-VIII, en altitudes de hasta $1.500 \mathrm{~m}$. Parece asegurado que hiberna dentro del capullo en fase de prepupa (Canard et al., 1998).

En nuestra fauna tiene una clara tendencia montana, ocupando robledales de todo el norte y centro, con algunas poblaciones más meridionales (Sierra Nevada en Granada y Sierra de Grazalema en Cádiz), y está marcadamente asociada con robles y quejigos (Quercus faginea, $Q$. canariensis y $Q$. robur), pero especialmente a $Q$. pyrenaica, puntualmente sobre Fagus y Castanea $\mathrm{y}$ vegetación de rivera, entre V-IX (X?), en altitudes que oscilan entre 15-2.000 m (mayoritariamente entre 700-1.400 m).

Por lo anteriormente mencionado, la mayoría de las referencias del huevo y la larva de esta especie desde el norte de Pirineos a Centroeuropa (Gepp, 1983b, 1984a, 1990; Canard et al., 1998) pertenecen a Nineta principiae Monserrat, 1981. La puesta es en racimos, y la larva auténtica de Nineta guadarramensis fue descrita por Díaz-Aranda (1992), DíazAranda \& Monserrat (1995), Canard et al. (1998), Díaz-Aranda et al. (2001) y Monserrat \& DíazAranda (2012).

Nineta pallida (Schneider, 1851) (Figs. 7, 137, 139, 143, 191)

Chrysopa pallida Schneider, 1851

Schneider, 1851a: 99 (d).

Nineta pallida (Schneider, 1851)

Eglin, 1940: 298 (rf); Monserrat, 1984a: 37 (bio, dis); Canard, 1985: 176, 179 (dis); Vannier \& Canard, 1989: 232 (dis); Canard \& Grimal, 1990: 40 (dis); Canard, 1990: 137 (rf); Monserrat \& Rodrigo, 1992: 125 (bio, dis); Canard et al., 1992b: 96 (list); Monserrat \& Marín, 1994: 122 (bio); Monserrat et al., 1994: 50 (bio, dis); Monserrat, 1996: 14 (list); Carvalho, 1997: 5, 7 (dis); H. Aspöck et al., 2001: 78 (rf); Canard, 2004: 155 (rf); Canard et al., 2007: 292-297 (rf); Monserrat, 2010: 25 (bio, dis, mf); Letardi et al., 2013: 35 (list); Monserrat et al., 2013: 47 (bio, dis); Canard et al., 2014: 106 (rf). 
Especie europea extra-mediterránea, conocida de Centroeuropa, Fenoscandia, Ucrania, Reino Unido, Bélgica, Rumanía, Bulgaria, Italia, Francia y norte de la Península Ibérica. Está mayoritariamente recolectada sobre coníferas (Picea, Abies y Pinus), es una especie monovoltina, citada entre VII-X, y bien adaptada a regiones montanas y alpinas, hallada en altitudes de 600 hasta $2.500 \mathrm{~m}$. Parece asegurado que hiberna en fase de larvas de primer estadio (caso único en las crisopas europeas), siendo extremadamente resistentes al frío, hasta $-25^{\circ} \mathrm{C}$, pasando su primera muda en IV, la segunda en VI y la pupa en VII, requiriendo pues un largo desarrollo de nueve meses (Canard, 1985; Vannier \& Canard, 1989; Canard et al., 1998, 2014).

En nuestra fauna tiene una clara tendencia eurosiberiana, con citas en el Pirineo (Huesca, Lérida y Navarra) (la cita de Carvalho, 1997 en Bragança, Portugal, nos parece sorprendente, y tras ella cabe suponer su presencia en toda la región eurosiberiana ibérica), y ha sido mayoritariamente citada sobre Abies alba, Picea excelsa y Pinus sylvestris, puntualmente sobre plantas en márgenes de bosques de coníferas (Corylus, Fagus, Ilex, Buxus y Crataegus), en VII-IX, y en altitudes montanas que oscilan entre $850-1.750 / 1.800 \mathrm{~m}$.

La puesta se practica en el extremo de las acículas o bajo las hojas en planifolios, en racimos de 5-10 huevos, proporcionalmente grandes frente a otras especies del género $(1,25 \mathrm{~mm}$ versus $0,9 \mathrm{~mm}$ en $N$. flava $)$ y su pedúnculo es relativamente corto $(2,5-4,5 \mathrm{~mm}$ versus $9 \mathrm{~mm}$ en $N$. flava). La puesta y larva de esta especie fueron descritas por Brauer (1867), Gepp (1983b, 1986, 1989), Díaz-Aranda (1992), Canard et al. (1998), Monserrat \& Díaz-Aranda (2012) y Canard et al. (2014).

\footnotetext{
Nineta vittata (Wesmael, 1841) (Figs. 138, 141)

Chrysopa vittata Wesmael, 1841

Wesmael, 1841: 211 (d); Stitz, 1927: 15 (rf).

Nineta vittata (Wesmael, 1841)

Eglin, 1940: 298 (rf); Hölzel \& Ohm, 1972: 140 (rf), 144 (nt); Aspöck et al., 1980: 241 (rf); Séméria \& Berland, 1988: 114 (rf); Popov, 1990: 48 (rf); Monserrat \& Marín, 1994: 121 (rf); H. Aspöck et al., 2001: 77 (rf); Canard, 2004: 154 (rf).
}

Especie sibérica conocida desde Europa a China, Kamtschatka y Japón. Es una especie poco frecuente y está mayoritariamente citada sobre planifolios (avellano, roble, haya, boj, endrino y acebo), también en parques y sobre Abies alba y Pinus sylvestris. Podría ser la única especie del género con ciclo bivoltino, pues ha sido recolectada entre V-VIII (IX?, X?), en altitudes de hasta $1.300 \mathrm{~m}$. Parece asegurado que hiberna dentro del capullo en fase de prepupa (Canard et al., 1998).

Esta especie está referida en nuestra fauna desde que Walker (1853: 237) la citara como Chrysopa vittata de Málaga, cita que refiere Pictet $(1865: 59,109)$ y cita que fue revisada y corregida por McLachlan (1867: 268), quien asigna el ejemplar de Málaga a
Chrysopa microcephala Brauer, $1851=$ Chrysoperla carnea (Stephens, 1836), lo que nos puede servir como ejemplo y dar una idea sobre la precaución que debemos tener a la hora de considerar las citas antiguas [ver como otro ejemplo la poética descripción de una crisopa, probablemente Chrysopa perla, que con el nombre de Hemerobius variegatus (Hemerobiidae) citaba Cuní y Martorell, 1890: 14].

Posteriormente Navás (1901: 27) parece hacer referencia de esta cita de forma muy confusa: "Ch. flava, Scop.- Málaga (Walker apud Pictet, sub Ch. vittata Wesm.)". Tratando de resolver este jeroglífico, ya hemos mencionado que apud significa "en la obra de" y sub es un prefijo latino de posición que indica que "se sitúa o se realiza bajo algo" o bien "como", y según anteriormente hemos indicado, no sabemos si Navás se refería a "subespecie de" (y así consideraba una respecto a la otra) o si, como podría pensarse, asigna estas citas a $N$. flava. Más tarde, Navás (1908a: 104, 110), Navás (1909c: 793) y Navás (1915a: 87) recoge esta cita de Málaga, sin anotar nuevo material.

La primera cita real de esta especie es dada por Navás (1916a: 190) quien la cita de Lérida: Artiga de Lin. Sin embargo, hay que indicar que en su monografía sobre los neurópteros de Cataluña (Navás, 1924a: 176) cita $N$. flava de Lés e Isil (Lérida) y a $N$. vittata de Es Bòrdes, Lérida (sin hacer referencia a Artiga de Lin), y ya hemos citado que en su monografía de los neurópteros de la Península Ibérica, Navás (1925: 83) cita de esta localidad (Es Bòrdes) a $N$. vittata, y no a $N$. flava, que solo la refiere de Galicia y Andorra, pero no de Cataluña y/o de Lérida. Como hemos indicado anteriormente, estos datos, y al margen de una evidente falta de método, sugieren una cierta confusión en la identificación de estas dos especies y, consecuentemente, en veracidad/autenticidad estas citas. Es cierto que son sugerentes los datos que Navás (1924a: 175) y Navás (1925: 83) aporta sobre la longitud del escapo, característica en esta especie (Fig. 138), pero es bastante confusa e indescifrable la estructura genital masculina que describe y dibuja (Navás, 1924a: 175, Fig. 63b, Navás, 1925: 82, Fig. 38b).

Quizás por todas estas citas su presencia en nuestra fauna ha sido mantenida hasta la actualidad (Eglin, 1940; Hölzel \& Ohm, 1972; Aspöck et al., 1980; Séméria \& Berland, 1988; Popov, 1990; Monserrat \& Marín, 1994; H. Aspöck et al., 2001; Canard, 2004, etc.), sin que se haya confirmado su presencia con nuevos elementos (Monserrat \& Díaz-Aranda, 2012). Caben pocas dudas de que cualquier cita andaluza de este género se correspondan con Nineta guadarramensis (Pictet, 1865), según demostró Monserrat (1986b, 2013) con otras citas meridionales de otras especies de este género, siendo ésta la única especie del género Nineta conocida de las sierras de Andalucía (Sierra de Grazalema y Sierra Nevada).

Por todo ello, esta especie no fue recogida de nuestra fauna por Monserrat \& Triviño (2013) (tampoco está citada de la Península Ibérica por Canard et al., 2007), 
aunque es probable que alguna de las confusas citas de Lérida sea acertada, y que también habite en los bosques caducifolios de la zona ibérica del Pirineo (Hölzel \& Ohm, 1972), y quizás también en la Cornisa Cantábrica, pero no tenemos datos confirmados, aún así la hemos incluido en este estudio, a la espera que nuevos datos ratifiquen su presencia en la fauna ibérica.

Las fases juveniles están descritas por Schneider (1851a), Withycombe (1924), Killington (1936, 1937), Gepp (1983b, 1984b, 1989, 1999), Tsukaguchi (1995) y Canard et al. (1998).

\section{Género Peyerimhoffina Lacroix, 1920}

Representado en nuestra fauna por una única especie, de aspecto relativamente similar a Chrysoperla mediterranea, aunque poseen hábitats y distribuciones muy diferentes, por ello se recomienda tener en cuenta estos datos y la observación de la genitalia masculina.

Peyerimhoffina gracilis (Schneider, 1851) (Figs. 78, 84, 144-146)

Chrysopa gracilis Schneider, 1851

Schneider, 1851a: 72 (d).

Peyerimhoffina gracilis (Schneider, 1851)

Monserrat \& Rodrigo, 1992: 130 (bio, dis); Canard et al., 1992b: 96 (list); Monserrat \& Marín, 1994: 122 (bio); Monserrat et al., 1994: 54 (bio, dis); Monserrat, 1996: 14 (list); H. Aspöck et al., 2001: 110 (rf); Popov, 2002a: 73 (rf);
Canard et al., 2007: 292-297 (rf); Monserrat, 2008: 174 (dis); Monserrat et al., 2014: 5 (bio, dis).

Tjederina gracilis (Schneider, 1851)

Monserrat, 1984a: 41 (dis); Canard, 1985: 176, 179 (dis):

Monserrat \& Díaz-Aranda, 1989c: 260 (dis).

Especie europea expansiva, extendida hasta Marruecos, Argelia, Anatolia y Cáucaso. Generalmente local, poco frecuente y mayoritariamente asociada a coníferas montanas (Picea, Abies, Pinus), recolectada entre VIII-IX, en realidad casi todo el año (II-XII), en altitudes de 100 hasta $1.700 \mathrm{~m}$. Es una de las pocas especies con marcada actividad diurna, y parece que puede tener dos generaciones y superan el invierno en fase adulta (Aspöck et al., 1980; Canard, 1981; Canard \& Grimal, 1990; Canard et al., 1996, 2015).

En nuestra fauna tiene una clara tendencia montana y eurosiberiana/pirenaica, con citas puntuales más meridionales (Jaén), y ha sido mayoritariamente citada sobre Abies alba, en menor medida sobre pinos, acebos y hayas, entre VI-IX, en altitudes montanas que oscilan entre 700-1.340 m.

Estadios larvarios descritos por Gepp (1983b), DíazAranda (1992), Díaz-Aranda \& Monserrat (1995), DíazAranda et al. (2001) y Monserrat \& Díaz-Aranda (2012).

Nuevo material estudiado o ANotado: ESPAÑA: Vizcaya, Ubide, Motxotegi beech forest, 30TWN2564, 700 m, 23.VII-12. VIII.2014, 10̄, 1 , todos en trampa de vino+cerveza, S. Pagola.

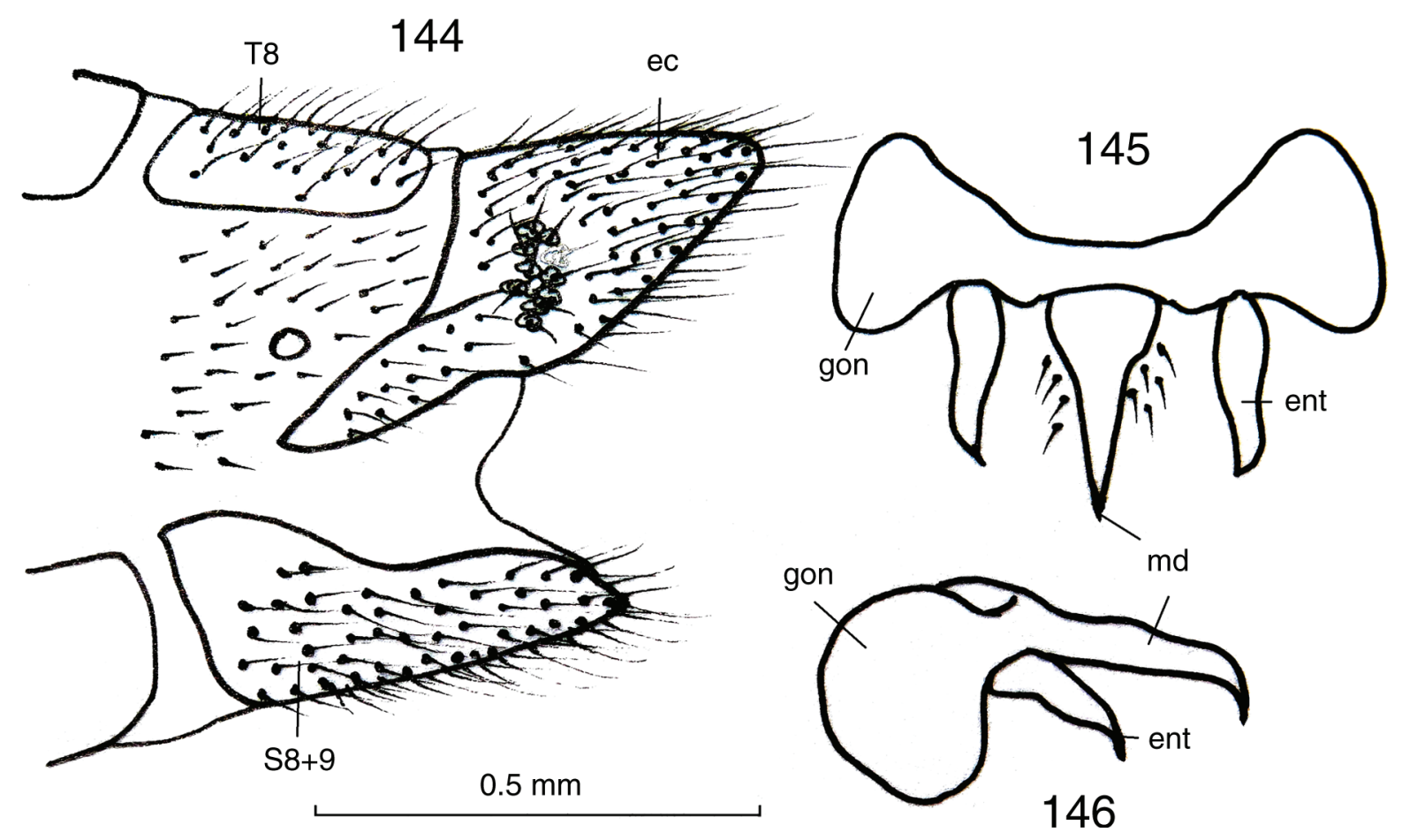

Figs. 144-146.- Peyerimhoffina gracilis $\widehat{\partial}$ : 144: extremo abdominal masculino, vista lateral, 145: complejo gonarco-mediuncosentoproceso, vista caudal, 146: ídem, vista lateral (ec: ectoprocto, ent: entoproceso, gon: gonarco, md: mediunco, S: esternito, T: terguito).

Figs. 144-146.- Peyerimhoffina gracilis ô: 144: male abdominal apex, lateral view, 145: complex gonarccus-mediuncusentoprocessus, caudal view, 146: ditto, lateral view (ec: ectoproct, ent: entoprocessus, gon: gonarcus, md: mediuncus, S: sternite, T: tergite). 


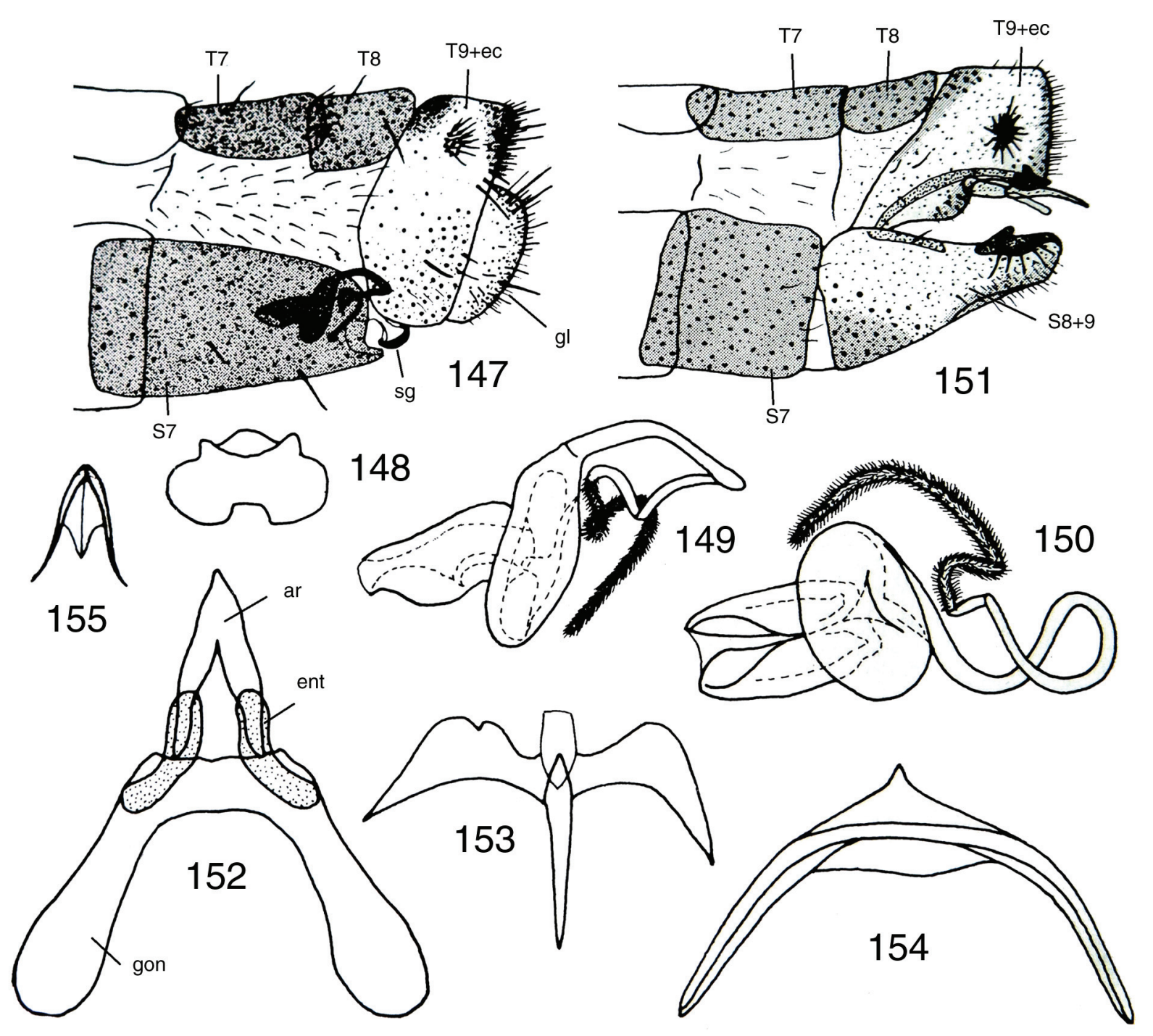

Figs. 147-155.- Pseudomallada alarconi, 147: extremo abdominal femenino, vista lateral, 148: placa subgenital, vista ventral, 149: espermateca, vista lateral, 150: ídem, vista ventral, 151: extremo abdominal masculino, vista lateral, 152: complejo gorarcoentoproceso-arceso, vista dorsal, 153: gonapsis, vista dorsal, 154: tigno, vista dorsal, 155: hipandrio, vista ventral (ar: arceso, ec: ectoprocto, ent: entoproceso, gl: gonapófisis laterales, gon: gonarco, sg: placa subgenital, S: esternito, T: terguito). A diferentes escalas. De Monserrat (1979c).

Figs. 147-155.- Pseudomallada alarconi, 147: female abdominal tip, lateral view, 148: subgenital plate, ventral view, 149: spermatheca, lateral view, 150: ditto, ventral view, 151: male abdominal tip, lateral view, 152: gorarcus-entoprocessusarcessus complex, dorsal view, 153: gonapsis, dorsal view, 154: tignum, dorsal view, 155: hypandrium, ventral view (ar: arcessus, ec: ectoproct, ent: entoprocessus, gl: lateral gonapophyses, gon: gonarcus, sg: subgenital plate, S: sternite, T: tergite). At different scales. From Monserrat (1979c).

\section{Género Pseudomallada}

Como hemos citado al estudiar el género Chrysoperla, similar problemática hallamos en el género Pseudomallada, con grupos de especies de muy escasa diferenciación morfológica, pero aisladas reproductivamente por procesos químicos, específicas feromonas, etc., que no hibridan y que manifiestan marcadas diferencias en sus preferencias de hábitat (Duelli et al., 2002), tipos de puestas, fenologías, etc. No en vano, Monserrat \& Díaz-Aranda (2012), al estudiar los estadios larvarios de diferentes poblaciones ibéricas de P. prasinus, encuentran sorprendentes diferencias, sea en el tipo de puestas o en la morfología de sus larvas, hecho que sugería y parecía corroborar que estábamos tratando un conjunto de especies, y no una única especie. Este hecho ya había sido detectado por Lacroix $(1922,1923,1929)$ o Duelli (1984c).

En base a estudios sobre valores en la distancia genérica entre poblaciones del "complejo prasinus" en poblaciones del Viejo Mundo, Cianchi \& Bullini (1992) encuentran que es relativamente más alto que en el caso que el que hemos citado para las especies del género Chrysoperla (índice de Nei, 1972: $\mathrm{D}=0,20-0,35$ ), concluyendo que según los parámetros del reloj molecular, este proceso de especiación parece haberse iniciado antes del Pleistoceno, hace más de 500.000 años. 
Aunque hay numerosas especies de este género bien caracterizadas que no presentan problemas de identificación, esto afecta especialmente al grupo de especies $P$. prasinus, $P$. flavifrons y $P$. picteti, de las que hablaremos más adelante.

Ante esta situación, adelantamos al lector que entramos en un género complejo, aún no definitivamente aclarado en estos grupos de especies, y por nuestra parte intentaremos acercarnos lo más posible para aportar la mayor y más accesible información sobre nuestras especies, y hemos utilizado en las claves los caracteres que, dentro de las limitaciones existentes, puedan ayudar a la diferenciación específica de los ejemplares.

Pseudomallada alarconi (Navás, 1915) (Figs. 115, 147-155, 192)

Chrysopa alarconi Navás, 1915

Navás, 1914a: 40 (rf), 1915a: 53 (d); Hölzel \& Ohm, 1972: 132 (dis), 137 (dis), 143 (nt); Monserrat, 1979c: 97, 100 (bio, dis, list, $\mathrm{mf}$ ).

Pseudomallada alarconi (Navás, 1915)

Monserrat, 2013: 292 (rf); Monserrat et al., 2014: 22 (bio, dis). Anisochrysa alarconi (Navás, 1915)

Monserrat, 1977a: 20 (list), 118 (key), 139 (bio, dis), 1985b: 87 (bio, dis).

Anisochrysa (Anisochrysa) alarconi (Navás, 1915)

Monserrat, 1979c: 100 (bio, dis, mf).

Dichochrysa alarconi (Navás, 1915)

H. Aspöck et al., 2001: 98 (rf); Canard et al., 2007: 292-297

(rf); Monserrat, 2008: 186 (bio, dis).

Mallada alarconi (Navás, 1915)

Díaz-Aranda et al., 1986b: 1140 (bio, dis); Díaz-Aranda \& Monserrat, 1988a: 119 (bio, dis), 1988b: 224 (bio, dis), 1988c: 222 (bio, dis); Monserrat \& Díaz-Aranda, 1989c: 260 (dis); Marín \& Monserrat, 1991a: 182 (bio, dis); Monserrat \& Rodrigo, 1992: 130 (bio, dis); Marín, 1994: 260 (bio, dis); Monserrat \& Marín, 1994: 122 (bio); Monserrat, 1996: 14 (list).

Especie atlantomediterránea conocida de España y Marruecos. Está mayoritariamente citada entre VI-VIII, en altitudes de hasta $1.350 \mathrm{~m}$.

En nuestra fauna habita en medios mediterráneos continentales y tiene una clara vinculación con los enebros y las sabinas, a los que acompaña en su distribución (Albacete, Granada, Guadalajara, Jaén, Madrid, Murcia y Teruel) y sobre los que se han recolectado la mayoría de los ejemplares no recolectados a la luz, con alguna cita en pinares o sobre pinos, $y$ ha sido citada entre V-IX, y por el carácter continental del clima donde habitan las coníferas sobre las que se desarrolla, quizás sea monovoltina, $\mathrm{y}$ ha sido recolectada en altitudes que oscilan entre $320-1.410 \mathrm{~m}$.

Los estadios larvarios son desconocidos, sólo Marín \& Monserrat (1991a) anotan algún dato sobre una larva recolectada sobre enebro y sobre su biología y desarrollo.

Pseudomallada clathratus (Schneider, 1845)

Chrysopa clathrata Schneider, 1845

Schneider, 1845: 345 (d).
Pseudomallada clathratus (Schneider, 1845)

Letardi et al., 2013: 35 (list); Monserrat, 2013: 292 (rf).

Anisochrysa clathrata (Schneider, 1845)

Monserrat, 1984a: 38 (dis).

Dichochrysa clathrata (Schneider, 1845)

H. Aspöck et al., 2001: 105 (rf); Canard et al., 2007: 292-297

(rf); Monserrat, 2008: 184 (bio, dis); Ocharan et al., 2012: 425 (bio, dis).

Mallada clathratus (Schneider, 1845)

Díaz-Aranda et al., 1986b: 1140 (bio, dis); Séméria \& Berland, 1988: 132 (rf); Díaz-Aranda \& Monserrat, 1988b: 224 (bio, dis), 1988c: 221 (rf); Monserrat \& Díaz-Aranda, 1988: 91 (dis), 1989b: 52 (dis), 1989c: 258 (bio, dis); Marín \& Monserrat, 1989: 294 (bio, dis); Monserrat \& Rodrigo, 1992: 128 (bio, dis); Canard et al., 1992b: 96 (list); Monserrat \& Marín, 1994: 122 (bio); Marín \& Monserrat, 1995a: 116 (bio, dis); Monserrat, 1996: 14 (list).

Mallada clathrata (Schneider, 1845) (sic)

Carvalho, 1997: 5, 7 (dis).

Especie holomediterránea. Está mayoritariamente citada en medios arbóreos y arbustivos xerófilos y mediterráneos, en pinares y también sobre laureles, sauces, tamarindos, olivos, etc., entre V-IX, por lo que es probable una sucesión de varias generaciones, en altitudes de hasta $1.000 \mathrm{~m}$. Parece demostrado que hiberna en tercera fase de larva (Aspöck et al., 1980; Canard et al., 1992a; Principi \& Sgobba, 1993; Volkovich, 1998).

En nuestra fauna parece tener tendencia montana, aunque solo existen citas puntuales (Barcelona, Cantabria, Asturias, Granada, Jaén, Madrid, Segovia, Guadalajara, Cuenca, Soria, Teruel, Zaragoza, Huesca, Lérida, Castellón, Douro Litoral, Minho, etc.), algunas sin duda cuestionables, y ha sido citada sobre pinos, especialmente Pinus sylvestris, enebros y sabinas, con algunas citas sobre robles, encinas y avellanos, entre VI-IX, en altitudes que oscilan entre 200-1.750 m.

El huevo y la larva de esta especie fueron descritos por Principi (1956a) y Pantaleoni (1983).

Nuevo material estudiado o anotado: ESPAÑA: Murcia, Jumilla, los Cucos, 630 m, 10.IX.2002, 1 ej., J.L. Lencina (A. Gruppe). Moratalla, Río el Cenajo, 350 m, 7.VII.2007, 1 ej., J.L. Lencina (A. Gruppe), Sierra Seca, 1.750 m, 19.IX.2007, 1 ej., J.L. Lencina (A. Gruppe).

Pseudomallada flavifrons (Brauer, 1851) (Figs. 93, 193)

Chrysopa flavifrons Brauer, 1851

Brauer, 1851: 6 (d); Stitz, 1927: 16 (rf); Eglin, 1940: 293 (rf); Monserrat, 1977a: 138 (rf).

Pseudomallada flavifrons (Brauer, 1851)

Monserrat et al., 2013: 51 (bio, dis); Letardi et al., 2013: 35 (list); Monserrat, 2013: 292 (bio, dis); Monserrat et al., 2014: 20 (bio, dis).

Anisochrysa flavifrons (Brauer, 1851)

Hölzel \& Ohm, 1972: 134 (dis), 143 (nt); Hölzel, 1973a: 69 (mf, nt, tx), 76 (nt); Monserrat, 1977a: 21 (list), 118 (key), 135 (bio, dis), 1978b: 64 (bio, dis), 1979a: 413 (bio, dis); Aspöck et al., 1980: 257 (rf); Monserrat, 1981a: 154 (bio, dis), 1982: 79 (bio, dis); Campos \& Ramos, 1983: 220, 221 (bio, dis); Ramos et al., 1983: 31 (bio, dis); Monserrat, 1984a: 39 (bio, dis), 1984b: 172 (bio, dis), 1984d: 102 (bio, dis), 1984e: 
158 (bio, dis), 1985b: 86 (bio, dis); Campos, 1986: 99 (dis); Boelpaepe et al., 1992: 22 (bio, dis).

Anisochrysa (Anisochrysa) flavifrons (Brauer, 1851)

Monserrat, 1978a: 179 (bio, dis), 1980a: 175 (bio, dis), 1980b: 188 (bio, dis).

Dichochrysa flavifrons (Brauer, 1851)

H. Aspöck et al., 2001: 95 (rf); Whittington, 2002: 379 (rf); Monserrat, 2005: 77 (bio, dis); Canard et al., 2007: 292-297 (rf); Monserrat, 2008: 184 (bio, dis); Ocharan et al., 2012: 425 (bio, dis).

Dichochrysa flavifrons nigropunctata (Pictet, 1865)

H. Aspöck et al., 2001: 95 (rf).

Chrysopa cosmeta Navás, 1904

Navás, 1904a: 125 (d).

Chrysopa flavifrons geniculata Pictet, 1865

Monserrat, 1977a: 138 (rf).

Chrysopa flavifrons meyeri Pictet, 1865

Hölzel, 1973a: 69 (nt, tx); Monserrat, 1977a: 138 (rf).

Chrysopa flavifrons monticola Pictet, 1865

Hölzel, 1973a: 69 (nt, tx); Monserrat, 1977a: 138 (rf).

Chrysopa flavifrons riparia Pictet, 1865

Monserrat, 1977a: 138 (rf).

Chrysopa flavifrons vestita Navás, 1914

Monserrat, 1977a: 138 (rf).

Chrysopa irenaea Navás, 1915

Navás, 1915c: 195 (d); Hölzel \& Ohm, 1972: 134 (nt).

Chrysopa lineolata McLachlan, 1880

McLachlan, 1880b: 63 (d); Hölzel, 1973a: 69 (tx); Monserrat, 1977a: 21 (list), 138 (rf).

Chrysopa luteola Navás, 1901

Navás, 1901: 24 (d); Hölzel, 1973a: 69 (tx).

Chrysopa meyeri Pictet, 1865

Pictet, 1865: 62 (d); Hölzel, 1973a: 69 (tx).

Chrysopa monticola Pictet, 1865

Pictet, 1865: 70 (d); Hölzel, 1973a: 69 (tx).

Chrysopa narcissina Navás, 1910

Navás, 1910: 243 (d).

Chrysopa nigropunctata Pictet, 1865

Pictet, 1865: 60 (d); Hölzel, 1973a: 69 (nt, tx); Monserrat, 1977a: 21 (list), 138 (rf).

Chrysopa riparia Pictet, 1865

Pictet, 1865: 69 (d); Hölzel, 1973a: 69 (nt, tx).

Chrysopa vulgaris cosmeta Navás, 1904 (ver anteriormente Chrysopa cosmeta Navás, 1904)

Mallada flavifrons (Brauer, 1851)

Monserrat, 1985c: 93 (bio, dis); Díaz-Aranda et al., 1986a: 1125 (bio, dis), 1986b: 1140 (bio, dis); Monserrat, 1986b: 102 (dis), 1987: 139 (bio, dis); Marín \& Monserrat, 1987: 350-359 (bio, dis); Monserrat \& Díaz-Aranda, 1987: 180 (bio, dis), 1988: 91 (bio, dis); Díaz-Aranda \& Monserrat, 1988a: 118 (bio, dis), 1988b: 224 (bio, dis), 1988c: 221 (dis); Monserrat \& DíazAranda, 1989b: 52 (bio, dis), 1989c: 258 (bio, dis); Campos, 1989: 161 (bio, dis); Marín \& Monserrat, 1989: 294 (bio, dis), 1990: 226 (bio, dis), 1991a: 182 (bio, dis), 1991b: 190-196 (bio, dis); Canard et al., 1992b: 96 (list); Monserrat \& Rodrigo, 1992: 128 (bio, dis); Pantaleão et al., 1993: 429 (bio, dis); Marín, 1994: 247-302 (bio, dis); Monserrat \& Marín, 1994: 122 (bio); Monserrat et al., 1994: 52 (bio, dis); Marín \& Monserrat, 1995a: 116 (bio, dis), 1995b: 41 (bio, dis); Monserrat, 1996: 14 (list); Carvalho, 1997: 5, 7 (dis); Ribeiro, 1997: 256 (bio, dis); Monserrat et al., 1999: 42 (bio, dis).

También citada en la fauna ibero-balear como Chrysopa flavifrons antennalis Navás, 1916, Chrysopa flavifrons arnaloti Navás, 1919, Chrysopa flavifrons carrobei Navás, 1915, Chrysopa flavifrons cosmeta Navás, 1904, Chrysopa flavifrons exornata Navás, 1915, Chrysopa flavifrons inclyta Navás, 1918, Chrysopa flavifrons justa Navás, 1915, Chrysopa flavifrons laletana Navás, 1910, Chrysopa flavifrons nigropunctata Pictet, 1865, Chrysopa flavifrons opulenta Navás, 1915, Chrysopa flavifrons superna Navás, 1914, Chrysopa flavifrons vestita Navás, 1915 y Chrysopa flavifrons vulnerata Navás, 1917.

Recientemente se ha adjudicado a los ejemplares ibéricos y norteafricanos (Marruecos, Argelia, Túnez) de esta especie la categoría de subespecie (Pseudomallada flavifrons nigropunctata) en base a Chrysopa nigropunctata descrita por Pictet (1865) (Hölzel \& Ohm, 1999; H. Aspöck et al., 2001). Es tal la variedad hallada en la morfología y la coloración dentro de nuestros ejemplares en esta especie que, de considerar esta subespecie, habría que revisar y probablemente también considerar otras varias, anteriormente recogidas en la lista de variedades y sinonimias ahora anotada, y no solo en el caso de la especie que ahora tratamos, sino en otras, también de morfología y coloración muy variables (Principi, 1962), como $P$. prasinus, $P$. ibericus, $P$. granadensis o $P$. picteti. Por ello esta subespecie no ha sido considerada en esta contribución.

Especie holomediterránea expansiva conocida desde Canarias a Georgia e Irán. Eurioica y generalmente asociada a medios mediterráneos, tanto sobre coníferas como planifolios (hecho poco habitual en las especies de este género). Por esta variedad de medios y sustratos, probablemente tratamos un grupo de especies aún no diferenciadas adecuadamente, hecho ya sugerido por Pantaleoni (1990), y está mayoritariamente citada entre V-IX, sucediéndose varias generaciones, en altitudes de 10 hasta $2.000 \mathrm{~m}$. Parece demostrado que hiberna en tercera fase de larva (Aspöck et al., 1980; Principi \& Sgobba, 1987; Canard et al., 1992a).

Muy ampliamente distribuida en nuestra fauna, incluyendo Baleares (Mallorca, Menorca, Ibiza, Formentera), marcadamente eurioica y ha sido citada en medios tanto eurosiberianos como mediterráneos, sean encinas, olivos, algarrobos, pistáceas, pinos, enebros, sabinas, abetos, adelfas, palmitos, alcornoques, avellanos, robles, arces, hayas, castaños, olmos, granados, acebuches, alnueces, eucaliptos, coscojas, majuelos, torviscos, almendros, helechos, espacios urbanos, etc., entre III-XI (con el nuevo material demostramos su actividad en XII en zonas de influencia mediterránea), en altitudes que oscilan entre 10-2.200 m. Probablemente estemos, también en este caso, ante un grupo de especies aún no diferenciadas adecuadamente.

El huevo, la larva y la pupa de esta especie fueron descritos por Withycombe (1922), Lacroix (1922, 1923, 1925, 1929, 1930), Killington (1937), Principi (1940, 1956a), Gepp (1983b, 1984b, 1989, 1990) у Monserrat \& Díaz-Aranda (2012). 
Nuevo material estudiado o anotado: ESPAÑA: Baleares, Mallorca, Colonia de Sant Jordi, 10 m, 30.VIII.2008, 5 ej., E. Aistleitner (A. Gruppe). Granada, Dehesa del Generalife, IX.2013, 19, F. Ruano, La Herradura, Punta de la Mona, 4.VII.2015, $3 \widehat{\widehat{\jmath},} 3$ 우 sobre Punica granatum, 7.VIII.15, 1 우 a la luz, 24.IX.2015, $1 \sigma^{\widehat{ }}$ sobre Olea europea, Sierra Nevada, Collado de la Sabina, 30SVG6207, 2.050 m, 3.VIII.2015, 10̄, Pinus sylvestris, Guipúzcoa, Ataun, Aralar P.N. 614 m, 30TWN6858, 8-21.VII.2014, $1 \widehat{\partial}$ en trampa de vino+cerveza sobre Quercus ilex ilex, S. Pagola. Lérida, San Juan de Torán, 6.VIII.2014, 1옹. I. Martínez. Madrid, San Fernando de Henares, 15.VI.2012, 10, 1우 J.I. López Colón, 19.VIII.2012, 1ठ, J.I. López Colón, 14.X.2012, 19, J.I. López Colón, 1.IX.2013, 1ठ, 1어, J.I. López Colón, 31.VIII.2014, 2 우, J.I. López Colón, 20.IX.2014, 19, J.I. López Colón, 21.IX.2014, $2 \hat{\jmath}$, 2 우, J.I. López Colón. Murcia, Jumilla, Sierra del Carche, 990 m, 21.VIII.1989, 1 ej., 27.X.2007, 3 ej., Lencina \& Gallego (A. Gruppe). Tarragona, La Selva del Camp, 41 ${ }^{\circ} 13^{\prime} 07.67^{\prime \prime} \mathrm{N}$ $1^{\circ} 08^{\prime} 36.94 " \mathrm{E}, 224$ m, 20.XI.2005, 1ㅇ, 15.IX.2007, 1ㅇ, 14.V.2008,

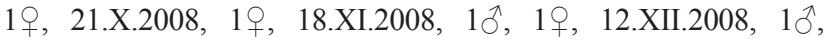
22.IX.2010, 1ㅇ, 14.XII.2010, $1 \hat{\jmath}, 1$ 우, 6.IX.2011, $1 \hat{\jmath}$, todos sobre Citrus clementina, N. Cañellas. PORTUGAL: Aveiro, Buçaco, 430 m, 20.VI.2011, 2 ej., A. Gruppe (A. Gruppe). Guarda, Seia, Senora de Pestero, 800 m, 20.VI.2011, 6 ej., A. Gruppe (A. Gruppe).

Pseudomallada venosus (Rambur, 1838) (Figs. 4, 11, 70, 120)

Hemerobius venosus Rambur, 1838

Rambur, 1838: pl. 9, Fig. 7 (d, tx), 1842: 430 (dis, mf).

Pseudomallada venosus (Rambur, 1838)

Monserrat, 2013: 293 (dis, bio); Monserrat et al., 2013: 50 (bio, dis); Letardi et al., 2013: 35 (list); Monserrat et al., 2014: 20 (bio, dis).

Anisochrysa venosa (Rambur, 1838)

Hölzel, 1971: 101 (rf); Hölzel \& Ohm, 1972: 138 (dis), 141 (dis), 144 (nt); Monserrat, 1977a: 21 (list), 119 (key), 140 (bio, dis); Hölzel, 1980a: 166 (rf); Aspöck et al., 1980: 264 (rf); Monserrat, 1982: 81 (bio, dis); Campos \& Ramos, 1983: 222 (bio, dis); Monserrat, 1984a: 46 (rf), 1984d: 101 (bio, dis), 1984e: 158 (bio, dis), 1985b: 86 (bio, dis); Campos, 1986: 100 (bio, dis).

Anisochrysa (Anisochrysa) venosa (Rambur, 1838)

Monserrat, 1980a: 174 (dis), 1980b: 188 (bio, dis). Sengonça, 1980: 97 (rf).

Dichochrysa venosa (Rambur, 1838)

H. Aspöck et al., 2001: 103 (rf); Whittington, 2002: 379 (rf); Monserrat, 2005: 79 (dis); Canard et al., 2007: 292-297 (rf); Monserrat, 2008: 183 (bio, dis); Canard et al., 2010: 132 (rf).

Chrysopa venosa Rambur, 1838 Monserrat, 1977a: 140 (rf).

Mallada venosus (Rambur, 1838)

Monserrat, 1986b: 102 (dis), 1987: 138 (bio, dis); Séméria \& Berland, 1988: 133 (rf); Monserrat \& Díaz-Aranda, 1988: 91 (rf); Díaz-Aranda \& Monserrat, 1988b: 224 (rf), 1988c: 221 (bio, dis); Monserrat \& Díaz-Aranda, 1989b: 52 (dis, rf), 1989c: 258 (dis); Díaz-Aranda \& Monserrat, 1990b: 96 (dis); Monserrat \& Rodrigo, 1992: 128 (dis); Canard et al., 1992b: 97 (list, rf); Marín, 1994: 260 (bio, dis); Monserrat \& Marín, 1994: 122 (bio); Monserrat et al., 1994: 52 (bio, dis); Marín \& Monserrat, 1995b: 41 (bio, dis); Monserrat, 1996: 14 (list).

Mallada venosa (Rambur, 1838) (sic)

Carvalho, 1997: 5, 7 (dis).

Especie eremial conocida de España, Portugal y Francia en Europa, norte de África (Marruecos, Argelia, Túnez, Sudán, Egipto), y desde Líbano, Anatolia y Península Arábica a Pakistán, Afganistán y Mongolia. Está mayoritariamente citada entre V-IX, en altitudes de 10 hasta $2.100 \mathrm{~m}$.

En nuestra fauna tiene una clara tendencia térmica, tanto continental, como mediterránea, incluyendo Baleares (Mallorca, Ibiza, Formentera), y está fuertemente asociada a medios térmicos y xéricos, y aunque ha sido mayoritariamente recolectada a la luz, también ha sido frecuentemente citada sobre pinos, especialmente Pinus halepensis, también sobre enebros, sabinas, y en menor medida sobre encinas, olmos, alisos, higueras, algarrobos, olivos, etc., y otro tipo de nanofanerófitos (Cistus, Rhamnus, Anthyllis, etc.), con cierta frecuencia se han encontrado ejemplares posados en piedras, paredes arenosas, oquedades, cuevas, arena, etc., y con cuya coloración pasan desapercibidas (Fig. 4), ha sido recolectada entre IV-IX, en altitudes que oscilan entre 10-3.000 m.

Las fases juveniles fueron descritas por DíazAranda \& Monserrat (1990b, 1995), Díaz-Aranda et al. (2001) y Monserrat \& Díaz-Aranda (2012).

Nuevo material estudiado o anotado: ESPAÑA: Murcia, Jumilla, los Cucos, 630 m, 7.VIII.2002, 2 ej., J.L. Lencina (A. Gruppe), $\mathrm{S}^{\mathrm{a}}$. del Carche, $1.000 \mathrm{~m}, 2$. VIII.1990, 1 ej., J.L. Lencina (A. Gruppe).

Pseudomallada genei (Rambur, 1842) (Fig. 118)

Hemerobius genei Rambur, 1842. Rambur, 1842: 430 (d).

Pseudomallada genei (Rambur, 1842)

Monserrat, 2013: 293 (bio, dis); Monserrat et al., 2013: 50 (bio, dis); Letardi et al., 2013: 35 (list); Monserrat et al., 2014: 20 (bio, dis).

Anisochrysa genei (Rambur, 1842)

Hölzel \& Ohm, 1972: 137 (dis), 139 (dis), 143 (nt); Monserrat, 1978b: 64 (bio, dis); Aspöck et al., 1980: 264 (rf); Monserrat, 1982: 81 (bio, dis); Campos \& Ramos, 1983: 221 (bio, dis); Monserrat, 1984a: 38 (dis), 1984c: 13, 16 (bio, dis), 1984d: 102 (bio, dis), 1985b: 86 (bio, dis); Campos, 1986: 100 (bio, dis).

Anisochrysa (Anisochrysa) genei (Rambur, 1842)

Séméria, 1974: 223 (rf); Monserrat, 1979b: 20 (bio, dis), 1980a: 174 (dis); Sengonça, 1980: 96 (rf).

Dichochrysa genei (Rambur, 1842)

H. Aspöck et al., 2001: 102 (rf); Monserrat, 2005: 79 (bio, dis); Canard et al., 2007: 292-297 (rf); Monserrat, 2008: 183 (bio, dis).

Chrysopa genei Rambur, 1842 Capra, 1976: 548 (rf).

Mallada genei (Rambur, 1842)

Monserrat, 1986b: 102 (bio, dis), 1987: 138 (bio, dis); Séméria \& Berland, 1988: 133 (rf); Díaz-Aranda \& Monserrat, 1988a: 118 (dis), 1988c: 221 (dis); Monserrat \& Díaz-Aranda, 1988: 91 (bio, dis), 1989b: 52 (dis), 1989c: 257 (dis); Marín \& Monserrat, 1991a: 181 (bio, dis); Monserrat \& Rodrigo, 1992: 128 (bio, dis); Monserrat \& Marín, 1994: 122 (bio); Marín, 1994: 260 (bio, dis); Monserrat et al., 1994: 52 (bio, dis); Marín \& Monserrat, 1995a: 116 (bio, dis), 1995b: 41 (bio, dis); Monserrat, 1996: 14 (list); Carvalho, 1997: 5, 7 (dis); Alvis et al., 2003: 186 (bio, dis).

También citada en la fauna ibero-balear como Chrysopa genei pupilla Navás, 1919.

Especie holomediterránea. Se ha citado sobre árboles, arbustos y plantas bajas de tipo mediterráneo, pero parece poseer una marcada preferencia por los pinos 
en medios térmicos, también ha sido citada sobre Olea, Tetraclinis, etc. De tendencia costera, recolectada entre V-IX, principalmente bajo $500 \mathrm{~m}$, aisladamente hasta $1.500 \mathrm{~m}$.

En nuestra fauna tiene una clara tendencia mediterránea, y es especialmente frecuente en el sudeste, incluyendo Baleares (Mallorca, Menorca, Ibiza, Formentera), asociada a medios térmicos, tanto litorales como más continentales, y aunque ha sido mayoritariamente recolectada a la luz, ha sido citada sobre una amplia gama de sustratos, con cierta aparente preferencia por las coníferas, sobre todo pinos, y especialmente Pinus halepensis, también sobre enebros y sabinas, en menor medida sobre olivos, coscojas, encinas, algarrobos, lentiscos, palmitos, romeros, tamarindos, granados, genistas, salsolas, etc., y aún en menor medida sobre otros nanofanerófitos y herbáceas (Ziziphus, Atriplex, Carduus, Lygeum, etc.). Como en el caso de la especie anterior, también busca cobijo sobre superficies inorgánicas y ha sido hallada, por ejemplo, sobre rocas y paredes de ramblas, etc., sobre las que pasa desapercibida (ya lo mencionaba Andréu, 1909). Ha sido recolectada entre III-X, en altitudes que oscilan entre $10-1.750 \mathrm{~m}$.

Estadios juveniles descritos por Monserrat (1984c) y Monserrat \& Díaz-Aranda (2012).

Nuevo material estudiado o anotado: ESPAÑA: Albacete, Hellín, 360 m, 25.VIII.2005, 1 ej., E. Aistleitner (A. Gruppe). Murcia, Abarán, 460 m, Sa . de la Pila, 17.VII.1990, 1 ej., J.L. Lencina (A. Gruppe), Jumilla, los Cucos, 630 m, 7.VIII.2002, 1 ej., J.L. Lencina (A. Gruppe), Sa . del Carche, 1.000 m, 2.VIII.1990, 1 ej., J.L. Lencina (A. Gruppe), Moratalla, Río el Cenajo, $350 \mathrm{~m}$, 7.VII.2007, 1 ej., J.L. Lencina (A. Gruppe).

Pseudomallada granadensis (Pictet, 1865) (Fig. 116)

Chrysopa granadensis Pictet, 1865

Pictet, 1865: 69 (d); Hölzel, 1965a: 461 (mf, rf), 1973a: 72 (dis, mf, nt), 72 (mf, rf); Morgan, 1980: 119 (dis).

Pseudomallada granadensis (Pictet, 1865)

Letardi et al., 2013: 35 (list); Monserrat, 2013: 293 (rf); Monserrat et al., 2014: 21 (bio, dis).

Anisochrysa granadensis (Pictet, 1865)

Hölzel \& Ohm, 1972: 135, 136 (dis), 143 (nt); Hölzel, 1973a: 72 (mf, tx), 76 (nt); Monserrat, 1977a: 21 (list), 118 (key), 133 (bio, dis), 1978b: 63 (bio, dis); Monserrat, 1979c: 99 (mf); Aspöck et al., 1980: 258 (rf); Monserrat, 1982: 79 (bio, dis), 1984a: 39 (bio, dis), 1984b: 172 (bio, dis), 1984d: 103 (bio, dis), 1984e: 158 (bio, dis), 1985b: 86 (bio, dis).

Anisochrysa (Anisochrysa) granadensis (Pictet, 1865)

Monserrat, 1978a: 179 (bio, dis), 1980b: 188 (bio, dis).

Anisochrysa granatensis (Pictet, 1865)

Monserrat, 1981a: 154 (bio, dis).

Dichochrysa granatensis (Pictet, 1865)

Monserrat, 2005: 78 (rf); Canard et al., 2007: 292-297 (rf).

Dichochrysa granadensis (Pictet, 1865)

H. Aspöck et al., 2001: 96 (rf); Monserrat, 2008: 185 (bio, dis).

Chrysopa escudera Navás, 1909

Navás, 1909b: 149 (d).

Chrysopa granatensis Pictet, 1865 (sic)

Monserrat, 1977a: 134 (rf).

Mallada granadensis (Pictet, 1865)
Díaz-Aranda et al., 1986a: 1125 (bio, dis), 1986b: 1140 (bio, dis); Monserrat, 1986b: 103 (dis), 1987: 139 (bio, dis), 145 (rf); Monserrat \& Díaz-Aranda, 1987: 180 (bio, dis), Díaz-Aranda \& Monserrat, 1988a: 118 (dis), 1988b: 224 (bio, dis), 1988c: 222 (bio, dis), 1988d: 112, 117, 118 (bio, dis); Monserrat \& Díaz-Aranda, 1988: 91 (bio, dis), 1989b: 52 (bio, dis), 1989c: 258 (dis); Marín \& Monserrat, 1990: 226 (dis), 1991b: 182 (bio, dis); Monserrat \& Rodrigo, 1992: 129 (bio, dis); Canard et al., 1992b: 96 (list); Pantaleão et al., 1993: 429 (bio, dis); Monserrat \& Marín, 1994: 122 (bio); Marín, 1994: 260 (bio, dis); Monserrat et al., 1994: 53 (bio, dis); Marín \& Monserrat, 1995a: 116 (bio, dis), 1995b: 41 (bio, dis); Monserrat, 1996: 14 (list); Carvalho, 1997: 5, 7 (dis).

Mallada granatensis (Pictet, 1865) (sic)

Monserrat, 1985c: 94 (rf).

También citada en la fauna ibero-balear como Chrysopa granatensis edoana Navás, 1919, Chrysopa granatensis escudera Navás, 1908 y Chrysopa granatensis tergata Navás, 1918.

Especie mediterránea occidental conocida de España, Portugal, Francia, Marruecos y Túnez. De biología casi desconocida, frecuentemente sobre Quercus, Ceratonia, etc., está mayoritariamente citada entre V-X, en altitudes de hasta $2.500 \mathrm{~m}$.

En nuestra fauna está asociada a medios térmicos y tiene una clara tendencia tanto mediterránea, incluyendo Baleares (Mallorca), como más continental, con citas puntuales más septentrionales (Andorra, Pontevedra, Coruña, Orense, Huesca, Lérida, Zamora, Salamanca, Setúbal, Santarém, etc.), y ha sido citada en medios térmicos mediterráneos especialmente sobre encinas, aunque en menor medida sobre quejigos, robles, pinos, enebros, sabinas, castaños, olmos, almendros, retamas, olivos, algarrobos, etc., no conocemos una particular vinculación con un tipo de plantas en especial, ya que es desproporcionado el número de ejemplares recolectados a la luz frente a los recolectados sobre cualquier vegetación habitualmente muestreada (Monserrat, 1977a). Posee actividad como imago entre IV-X, en altitudes que oscilan entre $55-1.750 \mathrm{~m}$.

Estadios larvarios descritos por Díaz-Aranda \& Monserrat (1988d) y Monserrat \& Díaz-Aranda (2012).

Nuevo material estudiado o anotado: ESPAÑA: Murcia, Jumilla, Cañada del Águila, 690 m, 5 ej., E. Aistleitner (A. Gruppe), Los Cucos, 630 m, 10.IX.2002, 1 ej., J.L. Lencina (A. Gruppe).

Pseudomallada ibericus (Navás, 1903)

Chrysopa iberica Navás, 1903

Navás, 1903: 99 (d); Principi, 1962: 16 (dis); Hölzel, 1965a: 461 (dis, mf), 1973a: 76 (mf, tx); Monserrat, 1977a: 143 (rf).

Pseudomallada ibericus (Navás, 1903)

Monserrat, 2013: 293 (rf); Monserrat et al., 2013: 51 (bio, dis); Letardi et al., 2013: 35 (list); Monserrat et al., 2014: 22 (bio, dis).

Anisochrysa iberica (Navás, 1903)

Hölzel \& Ohm, 1972: 133, 136 (dis), 142 (nt); Hölzel, 1973a: 76 (dis, mf); Monserrat, 1977a: 21 (list), 120 (key), 143 (bio, dis), 1979a: 413 (bio, dis), 1979c: 99 (mf); Aspöck et al., 1980: 10, 11, 195 (dis, mf), 259 (rf); Monserrat, 1982: 79 (bio, dis), 
1984a: 40 (bio, dis), 1984b: 172 (bio, dis), 1984d: 103 (bio, dis), 1984e: 158 (bio, dis), 1985b: 86 (bio, dis).

Anisochrysa (Anisochrysa) iberica (Navás, 1903)

Monserrat, 1978a: 179 (bio, dis), 1979b: 20 (dis); Inson \& Terzani, 2012: 159 (rf).

Dichochrysa iberica (Navás, 1903)

H. Aspöck et al., 2001: 97 (rf); Canard et al., 2007: 292-297 (rf); Monserrat, 2008: 186 (bio, dis).

Mallada ibericus (Navás, 1903)

Monserrat, 1985c: 94 (bio, dis); Díaz-Aranda et al., 1986b: 1140 (bio, dis); Monserrat, 1986b: 103 (dis), 1987: 140 (bio, dis); Monserrat \& Díaz-Aranda, 1987: 181 (bio, dis), 1988: 92 (bio, dis); Séméria \& Berland, 1988: 131 (rf); Díaz-Aranda \& Monserrat, 1988a: 119 (dis), 1988b: 224 (bio, dis), 1988c: 222 (bio, dis); Labrique \& Canard, 1989: 59 (1, rf); Monserrat \& Díaz-Aranda, 1989b: 53 (bio, dis), 1989c: 259 (bio, dis); Marín \& Monserrat, 1991a: 182 (bio, dis); Monserrat \& Rodrigo, 1992: 130 (bio, dis); Canard et al., 1992b: 96 (list); Monserrat \& Marín, 1994: 122 (bio); Marín, 1994: 260 (bio, dis); Monserrat et al., 1994: 54 (bio, dis); Marín \& Monserrat, 1995a: 117 (bio, dis), 1995b: 41 (bio, dis); Monserrat, 1996: 14 (list).

Mallada iberica (Navás, 1903) (sic)

Carvalho, 1997: 5, 7 (dis).

También citada en la fauna ibero-balear como Chrysopa iberica asticta Navás, 1906, Chrysopa iberica polysticta Navás, 1917 y Chrysopa abdominalis Brauer, 1856 (ver Pseudomallada abdominalis).

Especie atlantomediterránea, probablemente mediterránea occidental, está citada de España, Portugal y Francia, Córcega e Italia (Cerdeña, Liguria, Isla de Capraia) que vive principalmente asociada a medios montanos mediterráneos con cierta preferencia por las coníferas. Está mayoritariamente citada en Arbutus, Pinus, Juniperus, Quercus, entre V-IX, en altitudes de hasta $1.200 \mathrm{~m}$. Parece demostrado que hiberna en tercera fase de larva (Aspöck et al., 1980; Canard et al., 1992a).

En nuestra fauna tiene una clara tendencia térmicomediterránea, ocupando mayoritariamente la mitad oriental, con citas puntuales más septentrionales/occidentales (Cáceres, Salamanca, Zamora, Lugo, Orense, Pontevedra, Navarra, Huesca, Teruel, Minho, Trás os Montes e Alto Douro, Beira Litoral), y ha sido citada asociada a medios mediterráneos con cierta preferencia por las coníferas, sean pinos, sabinas y enebros, en menor medida sobre encinas, coscoja, robles, avellanos, olivos, olmos, algarrobos, granados, tamarindos, prunos, adelfas, genistas, romeros, etc., incluso en medios xéricos o halófilos (Lygeum spartum, Salsola oppositifolia, Atriplex halimus, Adenocarpus complicatus, etc.), entre III-X, en altitudes medias y bajas que oscilan entre 10-1.900 m.

Realiza las puestas en huevos aislados. Estadios larvarios descritos por Labrique \& Canard (1989) y Monserrat \& Díaz-Aranda (2012).

Nuevo material estudiado o anotado: ESPAÑA: Murcia, Jumilla, los Cucos, 630 m, 10.IX.2002, 1 ej., J.L. Lencina (A. Gruppe), Sierra del Carche, 990 m, 21.VIII.1989, 1 ej., J.L. Lencina (A. Gruppe).
Pseudomallada inornatus (Navás, 1901) (Fig. 111)

Chrysopa inornata Navás, 1901

Navás, 1901: 24 (d); Hölzel, 1965a: 462 (dis, mf); Hölzel, 1973a: 71 (nt, tx).

Pseudomallada inornatus (Navás, 1901) Monserrat et al., 2013: 51 (bio, dis); Letardi et al., 2013: 35 (list); Thierry \& Canard, 2015: 22 (rf).

Anisochrysa inornata (Navás, 1901) Hölzel \& Ohm, 1972: 137 (dis), 138 (dis), 143 (nt); Hölzel, 1973a: 71 (mf, tx), 76 (nt); Monserrat, 1977a: 21 (list), 118 (key), 132 (rf); Hölzel et al., 1980: 15 (dis); Aspöck et al., 1980: 259 (rf); Hynd, 1983: 130 (rf); Devetak, 1984: 65 (rf); Monserrat, 1984a: 46 (rf); Boelpaepe et al., 1992: 22 (bio, dis).

Anisochrysa (Anisochrysa) inornata (Navás, 1901)

Gepp, 1977b: 43 (dis); Monserrat, 1978a: 178 (bio, dis); Séméria, 1982: 85 (rf).

Dichochrysa inornata (Navás, 1901)

H. Aspöck et al., 2001: 97 (rf); Canard et al., 2007: 292-297 (rf); Ocharan et al., 2012: 425 (bio, dis).

Chrysopa caverina Navás, 1932

Navás, 1932a: 13 (d); Hölzel, 1973a: 71 (nt, tx).

Chrysopa ciliosa Navás, 1916

Navás, 1916b: 593 (d); Hölzel, 1973a: 71 (nt, tx).

Chrysopa craspedia Navás, 1915

Navás, 1915b: 55 (d); Hölzel, 1973a: 71 (nt, tx).

Chrysopa ecliptica Navás, 1909

Navás, 1909b: 148 (d); Hölzel, 1973a: 71 (nt, tx).

Mallada inornatus (Navás, 1901)

Monserrat, 1985c: 94 (bio, dis), 1986b: 103 (dis); Séméria \& Berland, 1988: 133 (rf); Marín \& Monserrat, 1989: 294 (bio, dis); Monserrat \& Díaz-Aranda, 1989c: 259 (dis); Marín \& Monserrat, 1989: 294 (dis); Monserrat \& Rodrigo, 1992: 129 (bio, dis); Monserrat \& Marín, 1994: 122 (bio); Monserrat et al., 1994: 53 (bio, dis); Marín \& Monserrat, 1995a: 117 (bio, dis); Monserrat, 1996: 14 (list).

Mallada inornata (Navás, 1901) (sic)

Carvalho, 1997: 5, 7 (dis).

También citada en la fauna ibero-balear como Cintameva inornata (Navás, 1901), Cintameva inornata ciliosa Navás, 1916, Cintameva inornata ecliptica (Navás, 1909), Cintameva inornata gradiformis Lacroix, 1916 y Cintameva inornata navasi Lacroix, 1916.

Especie europea expansiva de tendencia extramediterránea, citada del norte de España, Francia (incluida Córcega), Alemania, Austria, Eslovenia, Croacia, Hungría, sur de Italia y Sicilia, y Grecia, extendida hacia Ucrania, Crimea y el Cáucaso (Georgia). Poco frecuente y escasamente citada, lo está mayoritariamente tanto en fagáceas como en coníferas, parece asociada a medios húmedos y pantanosos con alisos, sauces, robles, entre IV-IX, en altitudes de 100 hasta $800 \mathrm{~m}$ (excepcionalmente 1.900 en los Pirineos orientales). Se ha mencionado como monovoltina (Canard \& Jacquemin, 2013), lo que explicaría su baja frecuencia y/o abundancia.

En nuestra fauna tiene una clara tendencia eurosiberiana, ocupando todo el tercio septentrional, con citas puntuales algo más meridionales (Zaragoza, Tarragona), y algunas, incluso recientes, nos parecen dudosas (Boelpaepe et al., 1992 en el Algarve portugués), y ha sido citada sobre encinas, también sobre 
quejigos, robles, abedules, avellanos, vegetación de rivera, etc., aunque su biología es muy desconocida en nuestra fauna, donde ha sido recolectada entre V-VIII, en altitudes que oscilan entre 180-720 m.

La larva de esta especie fue descrita por Lacroix (1923, 1925, 1930) y Gepp (1983b, 1984a, 1989, 1999).

Pseudomallada picteti (McLachlan, 1880) (Fig. 117)

Chrysopa picteti McLachlan, 1880

McLachlan, 1880b: 63 (d); Hölzel, 1965a: 461 (rf), 1973a: 73 (tx); Monserrat, 1977a: 148 (rf).

Pseudomallada picteti (McLachlan, 1880)

Monserrat, 2013: 293 (bio, dis); Letardi et al., 2013: 35 (list); Monserrat et al., 2014: 21 (bio, dis).

Anisochrysa picteti (McLachlan, 1880)

Hölzel \& Ohm, 1972: 131, 134 (dis), 142 (nt); Hölzel, 1973a: 73 (mf, tx), 76 (nt); Séméria, 1974: 91 (dis); Monserrat, 1977a: 21 (list), 119 (key), 132 (bio, dis), 1978b: 64 (bio, dis), 1979a: 413 (bio, dis), 1979c: 99 (mf); Aspöck et al., 1980: 10, 11, 115, 195 (dis, mf), 258 (rf); Monserrat, 1982: 80 (bio, dis); Campos \& Ramos, 1983: 221 (bio, dis); Monserrat, 1984a: 39 (bio, dis), 1984d: 103 (bio, dis), 1984e: 158 (bio, dis), 1985b: 86 (bio, dis); Campos, 1986: 100 (bio, dis).

Anisochrysa (Anisochrysa) picteti (McLachlan, 1880)

Monserrat, 1980b: 188 (bio, dis).

Dichochrysa picteti (McLachlan, 1880)

H. Aspöck et al., 2001: 96 (rf); Monserrat, 2005: 77 (bio, dis); Canard et al., 2007: 292-297 (rf); Monserrat, 2008: 185 (bio, dis).

Chrysopa thoracica Pictet, 1865

Pictet, 1865: 67 (d); Hölzel, 1973a: 69 (tx).

Mallada picteti (McLachlan, 1880)

Monserrat, 1985c: 94 (bio, dis); Díaz-Aranda et al., 1986a: 1125 (bio, dis), 1986b: 1140 (bio, dis); Monserrat, 1986b: 103 (dis), 1987: 139 (bio, dis), 145 (rf); Monserrat \& Díaz-Aranda, 1987: 181 (bio, dis), 1988: 92 (bio, dis); Séméria \& Berland, 1988: 130 (rf); Díaz-Aranda \& Monserrat, 1988a: 119 (dis), 1988b: 224 (bio, dis), 1988c: 222 (bio, dis); Monserrat \& Díaz-Aranda, 1989b: 52 (dis), 1989c: 259 (dis); Díaz-Aranda \& Monserrat, 1991: 141-146 (bio, dis, 1); Marín \& Monserrat, 1991a: 182 (bio, dis); Monserrat \& Rodrigo, 1992: 129 (dis); Canard et al., 1992b: 96 (list); Pantaleão et al., 1993: 429 (bio, dis); Marín, 1994: 247-302 (bio, dis); Monserrat \& Marín, 1994: 122 (bio); Monserrat et al., 1994: 53 (bio, dis); Marín \& Monserrat, 1995a: 117 (bio, dis), 1995b: 41 (bio, dis); Monserrat, 1996: 14 (list); Carvalho, 1997: 5, 7 (dis); Whittington, 2002: 379 (rf).

También citada en la fauna ibero-balear como Chrysopa prasina picteti McLachlan, 1880.

Durante un tiempo considerada como sinónima o variedad de $P$. prasinus, muchos de los datos bibliográficos pueden estar mezclados.

Especie mediterránea occidental conocida de España, Portugal, Francia, Italia, Marruecos y Túnez. Aparentemente eurioica. Está mayoritariamente citada entre V-X, aunque en latitudes más meridionales mantiene su actividad como imagos durante los meses de invierno (ver nuevo material ahora citado), e hiberna en tercera fase larvaria (Canard et al., 1992a). Recolectada sobre muy diversos sustratos vegetales, más frecuentemente de medios térmicos mediterráneos (Olea, Pistacea, Ceratonia, Nerium, Tamarix, etc.). Por esta variedad de medios y sustratos, también en este caso, probablemente tratamos un grupo de especies aún no diferenciadas adecuadamente, hecho ya sugerido por Bullini et al. (1983a, 1983b) y Pantaleoni (1990). Ha sido recolectada en altitudes de hasta $1.500 \mathrm{~m}$.

En nuestra fauna tiene una clara tendencia mediterránea, incluyendo Baleares (Mallorca, Menorca, Ibiza, Formentera), ocupando mayoritariamente los dos tercios sudorientales con citas puntuales más occidentales y septentrionales en Portugal, y parece bastante eurioica, habiendo sido citada mayoritariamente sobre quejigos, robles, encinas, alcornoques, también sobre pinos, abetos, enebros, sabinas, olivos, sauces, chopos, olmos, arces, alnueces, palmitos, eucaliptos, coscojas, endrinos, higueras, granados, chirimollos, algarrobos, acacias, pistáceas, tamarindos, adelfas, orgazas, prunos, hierba, etc., entre III-XII, probablemente presente actividad a lo largo de todo el año en zonas peninsulares más meridionales, ha sido hallada en altitudes bajas y medias que oscilan entre 10-2.000 m. Por esta enorme variabilidad en sus hábitats, es probable que, también en este caso, estemos ante un grupo de especies aún no adecuadamente diferenciadas.

Los estadios juveniles fueron descritos por Duelli (1984c), Labrique (1990), Díaz-Aranda \& Monserrat (1991) y Monserrat \& Díaz-Aranda (2012).

Nuevo material estudiado o ANOtAdo: ESPAÑA: Granada, La Herradura, 23.XII.2014, $1 q$ sobre aguacate, 7.VIII.2015, $1 q$ a la luz. Murcia, Jumilla, Sierra del Carche, 990 m, 14.IX.2007, 1 ej., Lencina \& Gallego (A. Gruppe). PORTUGAL: Aveiro, Buçaco, 430 m, 20.VI.2011, 7 ej., A. Gruppe (A. Gruppe). Guarda, Seia, Senora de Pestero, 800 m, 20.VI.2011, 3 ej., A. Gruppe (A. Gruppe).

Pseudomallada prasinus (Burmeister, 1839) (Figs. $37,39,100)$

Chrysopa prasina Burmeister, 1839

Burmeister, 1839: 981 (d); Eglin, 1940: 294 (rf); Principi, 1956a: 361 (rf); Hölzel, 1973a: 77 (tx); Monserrat, 1977a: 148 (rf).

Pseudomallada prasinus (Burmeister, 1839)

Monserrat, 2013: 293 (bio, dis); Monserrat et al., 2013: 50 (bio, dis); Letardi et al., 2013: 35 (list); Monserrat et al., 2014: 19 (bio, dis).

Anisochrysa prasina (Burmeister, 1839)

Hölzel \& Ohm, 1972: 138 (dis), 143 (nt); Hölzel, 1973a: 74 (mf, tx); Monserrat, 1977a: 21 (list), 120 (key), 144 (bio, dis), 1978b: 64 (bio, dis), 1979a: 413 (bio, dis); Aspöck et al., 1980: 261 (rf); Monserrat, 1982: 79 (bio, dis); Campos \& Ramos, 1983: 221 (bio, dis); Monserrat, 1984a: 39 (bio, dis), 1984b: 171 (bio, dis), 1984d: 101 (bio, dis), 1984e: 157 (bio, dis), 1985b: 85 (bio, dis); Campos, 1986: 99 (bio, dis).

Anisochrysa (Anisochrysa) prasina (Burmeister, 1839) Sengonça, 1980: 87 (rf).

Dichochrysa prasina (Burmeister, 1839)

H. Aspöck et al., 2001: 100 (rf); Whittington, 2002: 379 (rf); Monserrat, 2005: 78 (rf); Canard et al., 2007: 292-297 (rf); Monserrat, 2008: 182 (bio, dis); Ocharan et al., 2012: 426 (bio, dis).

Chrysopa aspersa Wesmael, 1841

Wesmael, 1841: 210 (d); Stitz, 1927: 16 (rf); Monserrat, 1977a: 21 (list), 148 (rf).

Chrysopa prasina adspersa Wesmael, 1841 (sic)

Hölzel, 1973a: 78 (nt); Monserrat, 1977a: 148 (rf). 
Chrysopa prasina punctigera Selys, 1888

Monserrat, 1977a: 148 (rf).

Mallada prasinus (Burmeister, 1839)

Monserrat, 1985c: 93 (bio, dis); Díaz-Aranda et al., 1986a: 1125 (bio, dis), 1986b: 1139 (bio, dis); Monserrat, 1986b: 102 (dis), 1987: 138 (bio, dis); Monserrat \& Díaz-Aranda, 1987: 180 (bio, dis); Marín \& Monserrat, 1987: 350-359 (bio, dis); Díaz-Aranda \& Monserrat, 1988a: 118 (dis), 1988b: 223 (bio, dis), 1988c: 220 (bio, dis); Monserrat \& Díaz-Aranda, 1988: 91 (bio, dis), 1989b: 52 (dis), 1989c: 257 (dis); Marín \& Monserrat, 1989: 294 (bio, dis), 1990: 225 (bio, dis), 1991a: 181 (bio, dis), 1991b: 190-196 (bio, dis); Monserrat \& Rodrigo, 1992: 127 (dis); Núñez Pérez et al., 1992: 391 (bio, dis); Canard et al., 1992b: 96 (list); Monserrat \& Marín, 1994: 122 (bio); Marín, 1994: 260 (bio, dis); Monserrat et al., 1994: 52 (bio, dis); Marín \& Monserrat, 1995a: 116 (bio, dis), 1995b: 40 (bio, dis); Monserrat, 1996: 14 (list); Monserrat et al., 1999: 42 (bio, dis); Alvis et al., 2003: 186 (bio, dis).

Mallada prasina (Burmeister, 1839) (sic)

Pantaleão et al., 1993: 429 (bio, dis); Carvalho, 1997: 5, 7 (dis). Anisochrysa ventralis prasina (Burmeister, 1839)

Monserrat, 1978a: 179 (bio, dis), 1980a: 174 (bio, dis), 1980b: 189 (bio, dis); Boelpaepe et al., 1992: 22 (bio, dis).

Anisochrysa (Anisochrysa) ventralis prasina (Burmeister, 1839) Monserrat, 1981a: 155 (bio, dis).

También citada en la fauna ibero-balear como Chrysopa adspersa (sic) Wesmael, 1841, Chrysopa prasima (sic) Burmeister, 1839, Chrysopa prasina abluta Navás, 1918, Chrysopa prasina amabilis Navás, 1911, Chrysopa prasina bielensis Navás, 1929, Chrysopa prasina coronata Navás, 1915, Chrysopa prasina coronatae Navás, 1915, Chrysopa prasina degradata Navás, 1906, Chrysopa prasina didyma Navás, 1901, Chrysopa prasina disticta Navás, 1907, Chrysopa prasina ditata Navás, 1915, Chrysopa prasina gastrica Navás, 1914, Chrysopa prasina gemina Navás, 1922, Chrysopa prasina geminata Navás, 1919, Chrysopa prasina gerundensis Navás, 1915, Chrysopa prasina guitarti Navás, 1914, Chrysopa prasina luxurians Navás, 1909, Chrysopa prasina modesta Navás, 1906, Chrysopa prasina nigrescens Navás, 1909, Chrysopa prasina nigrescenti Navás, 1909, Chrysopa prasina notha Navás, 1909, Chrysopa prasina obsoleta Navás, 1901, Chrysopa prasina patricia Navás, 1919, Chrysopa prasina respersa Navás, 1911, Chrysopa prasina salvadori Navás, 1915, Chrysopa prasina selysi Navás, 1919, Chrysopa prasina striata Navás, 1904, Chrysopa prasina stricta Navás, 1904, Chrysopa prasina verticalis Navás, 1921, Chrysopa prasina vestita Navás, 1915, Chrysopa prasina villosa Navás, 1919 y Chrysopa prasina virginea Navás, 1921.

Sin duda estamos tratando de un complejo de especies, ya que, al margen de su extrema variabilidad en tamaño y coloración, en diferentes poblaciones se han observado diferencias en el tipo de sus puestas, en sus estrategias de desarrollo larvario, en su diapausa, voltinismo, o diferencias en sus específicas sus feromonas que las aíslan genéticamente, pero que hacen muy difícil su diferenciación morfológica utilizando los métodos habituales (Volkovich, 1998), y entre sus muchas sinonimias previamente propuestas, algunas (ver $P$. marianus o $P$. abdominalis) han sido revalidadas y aceptadas como especies válidas (Pantaleoni, 1988, 1990; Duelli, 1989; Letardi \& Pantaleoni, 1996; Hölzel, 1998; Hölzel \& Weisser, 1999; H. Aspöck et al., 2001; Duelli et al., 2002, etc.), y aún no se han estudiado adecuadamente sus poblaciones genéticamente (Cianchi \& Bullini, 1992), aunque recientes resultados siguen confirmando estos hechos (Bullini \& Cianchi, 1984; Duelli, 1984c). Por ello muchos de los datos asignados a esta especie irán en el futuro desglosándose en otros taxa.

Especie paleártica, marcadamente eurioica. Está mayoritariamente citada entre IV-X, en altitudes de 100 hasta $2.400 \mathrm{~m}$. Parece demostrado que hiberna en fase de larva (Aspöck et al., 1980).

En nuestra fauna tiene una amplia distribución, incluyendo Baleares (Mallorca, Menorca, Ibiza), y ha sido citada en medios mediterráneos sobre encinas, robles, alcornoques, olivos, castaños, pinos, fresnos, alisos, sauces, chopos, olmos, pistáceas, palmitos, alnueces, adelfas, enebros, hiedras, jardines, espacios urbanos, y un largo etc., entre III-X (ahora citamos material que demuestra su actividad en XI-XII en zonas de influencia mediterránea), en altitudes que oscilan entre 10-2.454 m.

Pone sus huevos aisladamente, hiberna en tercera fase larvaria (Canard et al., 1992a), y el huevo y la larva de esta especie fueron descritos por Brauer (1851), Pariser (1919), Withycombe (1922), Principi (1956a), Tsukaguchi (1977), Gepp (1983b, 1990), Duelli (1984c) y Monserrat \& Díaz-Aranda (2012). Es probable que alguno de estos elementos sean adjudicables a las dos especies citadas a continuación.

NueVo material estudiado o anotado: ESPAÑA: Granada, Dehesa del Generalife, VII.2013, 1q, IX.2013, 1 ${ }^{\lambda}$, F. Ruano. Madrid, San Fernando de Henares, 27.IX.2011, 2우, J.I. López Colón, 31.VIII.2014, 1어, J.I. López Colón, 20.IX.2014, 1어, J.I. López Colón, 21.IX.2014, $3 \hat{\jmath}, 4$, 9 , J.I. López Colón. Tarragona, La Selva del Camp, 41 ${ }^{\circ} 13^{\prime} 07.67^{\prime \prime} \mathrm{N} 1^{\circ} 08^{\prime} 36.94^{\prime \prime} \mathrm{E}, 224$ m, 13.X.2007, 1§, 1ㅇ, 16.XI.2007, 10, 14.VII.2008, 1ㅇ, 21.X.2008, 2우,

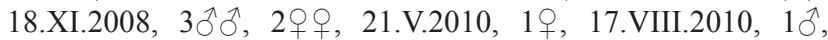
22.IX.2010, 1ठ, 19.XI.2010, $2 \widehat{\jmath}$, 16.VII.2011, 1q, 12.VIII.2011,

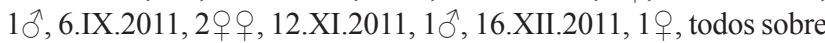
Citrus clementina, N. Cañellas. Vizcaya, Ubide, Motxotegi beech forest, 30TWN2564, 700 m, 23.VII-12.VIII.2014, 1 ㅇ en trampa de vino+cerveza, S. Pagola.

\section{Pseudomallada marianus (Navás, 1905)}

Chrysopa mariana Navás, 1905

Navás, 1905b: 19 (d); Berland, 1962: 68 (rf); Hölzel, 1973a: 77 (tx).

Chrysopa mariana chlorocephala Navás, 1907

Poggi, 1993: 424 (dis, tx).

Mallada marianus (Navás, 1905)

Pantaleoni, 1988: 638 (rf); Duelli, 1989: 347 (rf).

También citada en la fauna ibero-balear como Chrysopa mariana scalaris Navás, 1909, Chrysopa mariana stictocera Navás, 1907, Cintameva mariana 
(Navás, 1905), Cintameva mariana chlorocephala (Navás, 1907) y Cintameva mariana scalaris (Navás, 1909).

Recientemente esta especie ha sido revalidada como especie auténtica y diferente a $P$. prasinus, a la que había sido sinonimizada por Hölzel (1973a), y ha sido posteriormente admitida como tal (Pantaleoni, 1988, 1990; Duelli, 1989; Cianchi \& Bullini, 1992; Badano \& Letardi, 2010; Canard et al., 2010, etc.), por ello muchos datos existentes sobre $P$. prasinus podrían pertenecer a $P$. marianus (y viceversa), y aún no conocemos su real distribución geográfica, fenológica y altitudinal. De difícil diferenciación morfológica con $P$. prasinus, aunque Duelli (1989) demuestra que son especies diferentes y que no hibridan. Durante mucho tiempo (antes de Hölzel, 1973a) ha sido considerada como sinonimia y/o variedad de $P$. prasinus y por ello sus datos bibliográficos pueden estar mezclados. Como ocurre en varias especies de este género, es digno de destacar la profusión de variedades descritas y combinaciones nomenclaturales citadas, tanto de España (ver las anteriormente citadas) como de Francia, algunas tan curiosas como Chrysopa mariana chlorocephala insignata Lacroix, 1915, Chrysopa mariana chlorocephala scalaris Lacroix, 1915, Chrysopa mariana stictocera scalaris Lacroix, 1915, Chrysopa mariana stictocera insignata Lacroix, 1915, e incluso Chrysopa mariana chlorocephala scalaris insignata Lacroix, 1915.

Recientemente ha sido citada de España, Francia, Italia, Suiza, sobre fanerófitos de hoja caduca y en el borde de bosques de pinos, en VII, entre 500-550 m. Pone los huevos en grupos (y no de forma aislada como $P$. prasinus), y entra en diapausa invernal en fase larvaria, pero también si se somete a largos fotoperiodos (16: 8) (Pantaleoni, 1990).

Aunque no es citada en la Península Ibérica por Canard et al. (2007), en la bibliografía ibérica de esta especie, y bajo diferentes denominaciones y variedades, está presuntamente citada de Andorra y en España de Barcelona, Gerona, Lérida, Huesca, Vizcaya, Zaragoza, Logroño, León, Orense y Pontevedra, por lo que, de ser correctos estos datos, parece tener una distribución marcadamente eurosiberiana, hecho que parece corroborar el material ahora citado. Atendiendo a las diferentes denominaciones bajo las cuales ha sido presuntamente citada, en nuestra fauna ha sido recolectada en VII-VIII, entre 10-1.200 m.

Datos de sus puestas y estadios larvarios en Lacroix (1922, 1923, 1929); Duelli (1984c, 1989); Pantaleoni (1990).

Nuevo material estudiado o ANOtAdo: ESPAÑA: Vizcaya, Ubide, Motxotegi beech forest, 30TWN2564, 700 m, 23.VII-12. VIII.2014, 1 + en trampa de vino+cerveza, S. Pagola.

\footnotetext{
Pseudomallada abdominalis (Brauer, 1856)

Chrysopa abdominalis Brauer, 1856.

Brauer, 1856: 705 (d).

Dichochrysa abdominalis (Brauer, 1856)

Paulian et al., 2001: 26 (rf); Monserrat, 2005: 78 (rf).
}

También citada en la fauna ibero-balear como Chrysopa abdominalis Brauer, 1856 y Chrysopa prasina abdominalis Brauer, 1856.

Como en el caso de la especie anterior, el historial taxonómico de $P$. abdominalis (Brauer, 1856) es largo. Considerada por varios autores (Brauer, 1876; McLachlan, 1886b; Rostock, 1888, etc.) bien como sinónima posterior o como variedad de $P$. prasinus, $P$. ventralis o $P$. aspersa, ha sido reconsiderada $\mathrm{y}$ redescrita por Hölzel (1998) como especie válida y diferente a $P$. prasinus, y hoy día es aceptada como tal. También por ello, muchos datos existentes sobre $P$. prasinus o $P$. ventralis podrían pertenecer a $P$. abdominalis (y viceversa), y aún no conocemos su real distribución geográfica, fenológica y altitudinal.

Es una especie europea extra-mediterránea expansiva, citada de Alemania, Austria, Suiza, Macedonia, Rumanía e Italia, extendida hacia el Cáucaso (Georgia). Está citada sobre vegetación baja, Salix, Acer, Picea, Abies, etc., entre VI-IX, hasta $850 \mathrm{~m}$.

En lo que respecta a nuestra fauna, fue presuntamente mencionada por primera vez por Navás (1901: 26, 27) quien cita esta especie en base a material de Madrid y Zaragoza que posteriormente (Navás, 1903: 100) lo adjudica a $P$. ibericus en la descripción de esta especie primero, y más tarde (Navás, 1908a: 112) a $P$. ventralis (Curtis, 1834), por ello estas citas iniciales no merecerían ser consideradas. En cualquier caso, y atendiendo a las diferentes denominaciones bajo las cuales ha sido presuntamente citada en nuestra fauna, habría que dilucidar la identidad de las abundantes citas dadas por este autor como Chrysopa prasina abdominalis, así como revisar el abundante material citado de $P$. prasinus s.l. en la península y Baleares, lo cual representaría una titánica labor, citas que, por el momento, no deben considerarse ante la alta posibilidad de mezclar datos de unas y otras, salvo que el material haya sido revisado.

Bien como especie o como variedad de Pseudomallada prasinus, en la bibliografía ha sido citada de Gerona, Barcelona, Baleares (Mallorca), Lérida, Andorra, Huesca, Zaragoza, Navarra, Tarragona, Vizcaya, León, Lugo, Pontevedra, Orense, La Coruña, Logroño y Madrid, por lo que, de ser correctas estas citas, parece presumirse una distribución con tendencia a ocupar zonas de influencia eurosiberiana, y por su carácter extra-mediterráneo, Monserrat (2005) pone en duda las citas de Baleares (Mallorca). Sin asumir la veracidad de todas estas citas, en nuestra fauna ha sido citada en VII-VIII, entre 200-1.950 m, donde no dudamos pueda existir y por ello la hemos incluido en esta contribución, aunque no es citada de la Península Ibérica por Canard et al. (2007).

\footnotetext{
Pseudomallada subcubitalis (Navás, 1901) (Fig. 119)

Chrysopa subcubitalis Navás, 1901

Navás, 1901: 26 (d); Hölzel, 1965a: 461 (dis, mf), 1973a:

76 (mf, tx); Monserrat, 1977a: 142 (rf).

Pseudomallada subcubitalis (Navás, 1901)
} 
Monserrat, 2013: 293 (bio, dis); Monserrat et al., 2013: 51 (rf); Letardi et al., 2013: 35 (list); Monserrat et al., 2014: 21 (bio, dis). Anisochrysa subcubitalis (Navás, 1901)

Hölzel \& Ohm, 1972: 128, 135, 136, 143 (dis, nt), 143 (nt); Hölzel, 1973a: 76 (dis, mf, nt); Monserrat, 1977a: 21 (list), 120 (key), 141 (bio, dis); Aspöck et al., 1980: 10, 11, 114, 195 (dis, mf), 260 (rf); Monserrat, 1981a: 154 (bio, dis), 1982: 80 (bio, dis); Campos \& Ramos, 1983: 222 (bio, dis); Monserrat, 1984a: 40 (bio, dis), 1984b: 172 (bio, dis), 1984d: 112 (rf), 1984e: 157 (bio, dis), 1985b: 86 (bio, dis).

Anisochrysa (Anisochrysa) subcubitalis (Navás, 1901)

Monserrat, 1980b: 186 (bio, dis).

Dichochrysa subcubitalis (Navás, 1901)

H. Aspöck et al., 2001: 98 (rf); Canard et al., 2007: 292-297 (rf); Monserrat, 2008: 186 (bio, dis).

Mallada subcubitalis (Navás, 1901)

Monserrat, 1986b: 103 (dis); Díaz-Aranda et al., 1986b: 1140 (bio, dis); Monserrat, 1987: 139 (bio, dis); Monserrat \& DíazAranda, 1987: 181 (bio, dis), 1988: 92 (bio, dis); Díaz-Aranda \& Monserrat, 1988a: 119 (dis), 1988b: 224 (bio, dis), 1988c: 222 (bio, dis); Monserrat, 1989: 125 (dis); Monserrat \& Díaz-Aranda, 1989b: 52 (dis), 1989c: 259 (dis); Marín \& Monserrat, 1990: 226 (bio, dis), 1991a: 182 (bio, dis); Monserrat \& Rodrigo, 1992: 130 (dis); Canard et al., 1992b: 97 (list, rf); Monserrat \& Marín, 1994: 122 (bio); Marín, 1994: 260 (bio, dis); Monserrat et al., 1994: 53 (bio, dis); Marín \& Monserrat, 1995a: 117 (bio, dis); Monserrat, 1996: 14 (list); Carvalho, 1997: 5, 7 (rf); Monserrat et al., 1999: 42 (bio, dis).

También citada en la fauna ibero-balear como Chrysopa subcubitalis sordidata Navás, 1906.

Especie mediterránea occidental conocida de España, Portugal, Francia y Marruecos. Está mayoritariamente citada en medios térmicos mediterráneos sobre Pistacia, Tamarix, etc., entre V-IX, en altitudes de 20 hasta $1.000 \mathrm{~m}$.

En nuestra fauna tiene una clara tendencia a ocupar medios térmicos y/o áridos, zonas gipsícolas y salazares de naturaleza mediterránea y continental, con citas puntuales más septentrionales (Salamanca, Zamora, León, Zaragoza, Teruel, Navarra, Lérida, Huesca, Beira Litoral, etc.), y está fuertemente asociada a saladares, ramblas halófilas abiertas y soleadas con Tamarix spp., tamaricáceas sobre las que se ha recolectado con muy marcada preferencia, también se ha citado sobre pinos, enebros, y en menor medida sobre quejigos, encinas, robles, fresnos, olmos, alnueces, castaños, endrinos, eucaliptos, torviscos, olivos, granados, higueras, retamas, sauces, chopos, vegetación de rivera, adelfas, espacios urbanos, etc., y ha sido citada entre IV-X, en altitudes que oscilan entre 10-2.200 m.

Estadios larvarios descritos por Monserrat (1989) y Monserrat \& Díaz-Aranda (2012).

Nuevo material estudiado o anotado: ESPAÑA: Albacete, Hellín, Saladar de Cordovilla, 510 m, 28.VII.2007, 18 ej., J.L. Lencina (A. Gruppe). Lérida, Alcarráz, 3.VIII.2014, 1 q sobre Buxus sempervirens, I. Martínez.

\section{Pseudomallada ventralis (Curtis, 1834)}

Chrysopa ventralis Curtis, 1834

Curtis, 1834: 520 (d); Eglin, 1940: 294 (rf); Principi, 1952: 12 (rf), 1958: 185 (rf). Monserrat, 1977a: 149 (rf); Morgan, 1980: 119 (dis).
Pseudomallada ventralis (Curtis, 1834)

Monserrat et al., 2013: 50 (bio, dis); Thierry \& Canard, 2015: 23 (rf).

Anisochrysa ventralis (Curtis, 1834)

Hölzel \& Ohm, 1972: 138 (dis), 144 (nt); Monserrat, 1977a: 21 (list), 120 (key), 149 (bio, dis); Aspöck et al., 1980: 263 (rf); Monserrat, 1984a: 37 (bio, dis), 1984b: 171 (bio, dis), 1984e: 157 (bio, dis); Boelpaepe et al., 1992: 22 (bio, dis).

Anisochrysa ventralis ventralis (Curtis, 1834)

Monserrat, 1981a: 154 (bio, dis).

Dichochrysa ventralis (Curtis, 1834)

H. Aspöck et al., 2001: 102 (rf); Whittington, 2002: 379 (rf); Monserrat, 2005: 78 (rf); Canard et al., 2007: 292-297 (rf); Monserrat, 2008: 182 (bio, dis).

Mallada ventralis (Curtis, 1834)

Díaz-Aranda \& Monserrat, 1988a: 118 (rf), 1988b: 223 (bio, dis); Marín \& Monserrat, 1989: 293 (bio, dis); Monserrat \& Díaz-Aranda, 1989c: 256 (dis); Monserrat \& Rodrigo, 1992: 127 (bio, dis); Canard et al., 1992b: 96 (list); Monserrat \& Marín, 1994: 122 (bio); Monserrat et al., 1994: 51 (bio, dis); Marín \& Monserrat, 1995a: 116 (bio, dis); Monserrat, 1996: 14 (list).

También citada en la fauna ibero-balear como Chrysopa aspersa ventralis (Curtis, 1834), Chrysopa ventralis decora Navás, 1914, Chrysopa ventralis ditata Navás, 1914, Chrysopa ventralis pullata Navás, 1904, Cintameva ventralis (Curtis, 1834), Cintameva ventralis decora Navás, 1914 y Cintameva ventralis pullata Navás, 1904.

Considerada con frecuencia y durante cierto tiempo sinonimia de $P$. prasinus, por lo que muchos de los datos de ambas especies pueden estar mezclados.

Especie europea de tendencia extramediterránea, característica de medios húmedos y recolectada tanto sobre caducifolios como coníferas, e hiberna en tercera fase larvaria (Canard et al., 1992a; Volkovich, 1998). Está mayoritariamente citada entre V-IX, en altitudes de 100 hasta $1.900 \mathrm{~m}$.

En nuestra fauna se conoce de su mitad septentrional, y tiene una cierta tendencia eurosiberiana, con citas puntuales más meridionales (Zaragoza, Teruel, Logroño, Madrid, Ávila, Segovia, Salamanca, Algarve), habiendo sido cuestionada por Monserrat (2005) la cita de Baleares (Mallorca), y por lo anteriormente indicado, otras citas existentes, aún más meridionales son muy dudosas. Ha sido siempre citada en medios muy húmedos, sobre avellanos, robles, hayas, olmos, sauces y vegetación de rivera, entre V-VIII, en altitudes que oscilan entre 700-1.680 m.

Los estadios preimaginales de esta especie fueron descritos por Withycombe (1922), Lacroix (1923), Killington (1937), Gepp (1983b, 1989) y Monserrat \& Díaz-Aranda (2012).

\section{Pseudomallada zelleri (Schneider, 1851)}

Chrysopa zelleri Schneider, 1851

Schneider, 1851a: 114 (d); Principi, 1961: 111 (rf).

Pseudomallada zelleri (Schneider, 1851)

Monserrat et al., 2013: 51 (rf); Monserrat, 2013: 305 (rf).

Anisochrysa zelleri (Schneider, 1851)

Hölzel \& Ohm, 1972: 138 (nt); Canard \& Laudého, 1977: 70 (rf). 
Chrysopa prasina zelleri Schneider, 1851

Monserrat, 1977a: 148 (rf).

Mallada zelleri (Schneider, 1851)

Díaz-Aranda \& Monserrat, 1988c: 222 (rf).

Dichochrysa zelleri (Schneider, 1851)

Monserrat, 2008: 185 (bio, dis).

Especie xerófila, mayoritariamente conocida del Mediterráneo septentrional y oriental, extendida hacia Irán, muy escasamente citada en nuestra fauna. Está mayoritariamente citada en medios térmicos mediterráneos, sobre robles, olivos, alisos, carpinos, coníferas e incluso estrato herbáceo, entre V-IX, en altitudes de hasta $1.200 \mathrm{~m}$. Parece demostrado que hiberna en tercera fase larvaria (Aspöck et al., 1980; Canard et al., 1992a).

En nuestra fauna está muy poco citada (Madrid, Ciudad Real, Logroño, Navarra, Granada), alguna puesta en duda (Monserrat, 2013) y otras probablemente cuestionables, y en nuestra fauna podría tener una tendencia eurosiberiana con citas puntuales más meridionales, y ha sido citada sobre Quercus, entre $\mathrm{V}-\mathrm{VI}$, en altitudes que no superan los $600 \mathrm{~m}$.

No conocemos que sus fases larvarias hayan sido descritas.

\section{Género Rexa Navás, 1920}

Representado en nuestra fauna por una única e inconfundible especie.

Rexa almerai (Navás, 1919) n. comb. (Figs. 74, 95, 194)

Chrysopa almerai Navás, 1919

Navás, 1919: 15 (d); Hölzel, 1973a: 78, 79 (nt, tx).

Rexa lordina Navás, 1920 n. sin.

Navás, 1920: 289 (d); Hölzel \& Ohm, 1972: 133, 140 (dis), 142 (nt); Hölzel, 1973a: 78 (dis, mf, tx); Aspöck et al., 1980: 12, 198 (dis, mf), 271 (rf); Canard, 1981: 101 (rf); Monserrat, 1982: 78 (dis); Campos \& Ramos, 1983: 221 (bio, dis); Monserrat, 1984a: 41 (dis); Díaz-Aranda \& Monserrat, 1988c: 223 (rf); Monserrat \& Díaz-Aranda, 1989c: 264 (dis); Canard \& Labrique, 1989: 152 (ref); Pantaleão et al., 1993: 429 (bio, dis); Monserrat \& Marín, 1994: 122 (bio); Monserrat, 1996: 14 (list); Carvalho, 1997: 5, 7 (dis); H. Aspöck et al., 2001: 118 (rf); Canard et al., 2007: 292-297 (rf); Monserrat, 2008: 190 (bio, dis); Letardi et al., 2013: 35 (list); Monserrat, 2013: 294 (rf); Monserrat et al., 2014: 29 (bio, dis).

Realizadas las correcciones y la nueva sinonimia anteriormente propuestas, la inmensa mayoría de las citas de esta especie han sido dadas como Rexa lordina Navás, 1920.

Especie mediterránea occidental citada de España oriental y meridional, Portugal, Francia meridional y Córcega, Italia (Lazio, Cerdeña), Croacia, y norte de Africa (Marruecos, Túnez y Argelia). Marcadamente primaveral, es una especie monovoltina que está mayoritariamente citada entre (III) V-VII, en altitudes de hasta $400 \mathrm{~m}$, mayoritariamente sobre oleáceas (Phillyrea y Olea). Parece comprobado que hiberna en fase de prepupa (Canard \& Labrique, 1989).
En nuestra fauna tiene una clara tendencia mediterránea, bien continental o litoral, con poblaciones aparentemente puntuales y bastante locales, aunque a veces puede llegar a ser extremadamente abundante. Asociada a medios térmicos mediterráneos, especialmente citada sobre oleáceas, especialmente olivos y acebuches, también sobre labiérnagos u olivillas (Olea europaea, Phyllyrea angustifolia), siendo una especie relativamente poco citada, habiéndose hallado en Gerona, Huesca, Jaén, Málaga, Granada, Murcia, Cádiz y Cáceres en España y en Algarve y Trás os Montes e Alto Douro en Portugal. También en nuestra fauna es marcadamente primaveral, monovoltina y recolectada entre IV-VI, en altitudes que oscilan entre 50-1.870 m. Curiosa la proporción entre $\delta \hat{\delta} / q Q$ : 1/56 que menciona en esta especie Monserrat (2008).

Estadios larvarios descritos por Canard \& Labrique (1989), Díaz-Aranda (1992), Díaz-Aranda \& Monserrat (1995), Díaz-Aranda et al. (2001) y Monserrat \& DíazAranda (2012).

Género Suarius Navás, 1914

Representado en nuestra fauna por tres inconfundibles especies.

Suarius iberiensis Hölzel, 1974 (Figs. 113, 156, 195) Hölzel, 1974: 257 (d); Aspöck et al., 1980: 12, 199 (dis, mf), 274 (rf); Monserrat, 1987: 141 (dis, bio), 145 (rf); Monserrat \& Díaz-Aranda, 1989a: 407 (rf), 1989c: 266 (dis); Monserrat \& Marín, 1994: 122 (bio); H. Aspöck et al., 2001: 121 (rf); Canard et al., 2007: 292-297 (rf); Monserrat, 2008: 191 (bio, dis), 2013: 294 (rf); Monserrat et al., 2013: 51 (bio, dis), 2014: 30 (bio, dis).

Especie endémica de la Península Ibérica (España), por lo que los datos existentes sobre esta especie son exclusivamente ibéricos.

En nuestra fauna tiene una clara tendencia térmica-xerófila, conocida de Murcia y Almería, con citas puntuales en zonas secas y subdesérticas más hacia el centro peninsular (zonas de yesos de Toledo y sur de Madrid, Las Bárdenas en Navarra y Los Monegros en Zaragoza), y ha sido mayoritariamente recolectada a la luz en saladares, medios gipsícolas y/o halófilos, xéricos, subdesérticos, térmicos. Desconocemos sus plantas soporte, probablemente vegetación baja, leñosa y/o halófila, citada sobre Salsola vermiculata (Chenopodiaceae) y Ammi majus (Umbelliferae), entre V-IX, en altitudes que oscilan entre 30-990 m. Probablemente sufra diapausa estival.

Estadios larvarios descritos por Monserrat \& DíazAranda (2012).

Nuevo material estudiado o anotado: ESPAÑ̃A: Albacete, Hellín, Embalse de Camarillas, 350 m, 19.V.2007, 1 ej., J.L. Lencina (A. Gruppe), Saladar de Cordovilla, 510 m, 28.VII.2007, 1 ej., J.L. Lencina (A. Gruppe), Riopar, 1.200 m, 13.VIII.1988, 1 ej., E. Aistleitner (A. Gruppe). Murcia, Jumilla, Sierra del Carche, 990 m, 6.VIII.2002, 2 ej., J.L. Lencina (A. Gruppe), Cartagena, Los Belones, 30 m, 25.VIII.1988, 1 ej., E. Aistleitner (A. Gruppe). 

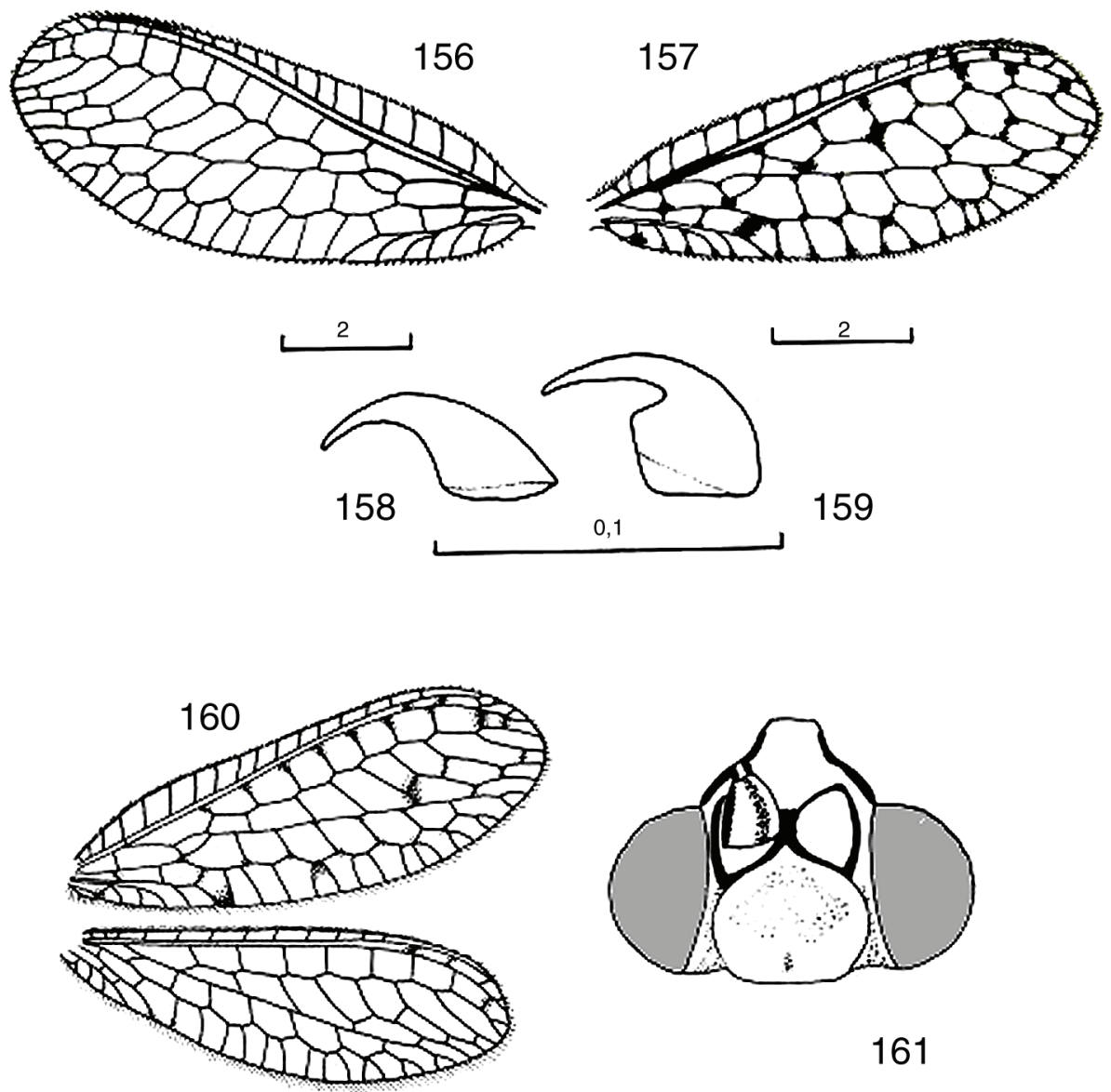

161

3
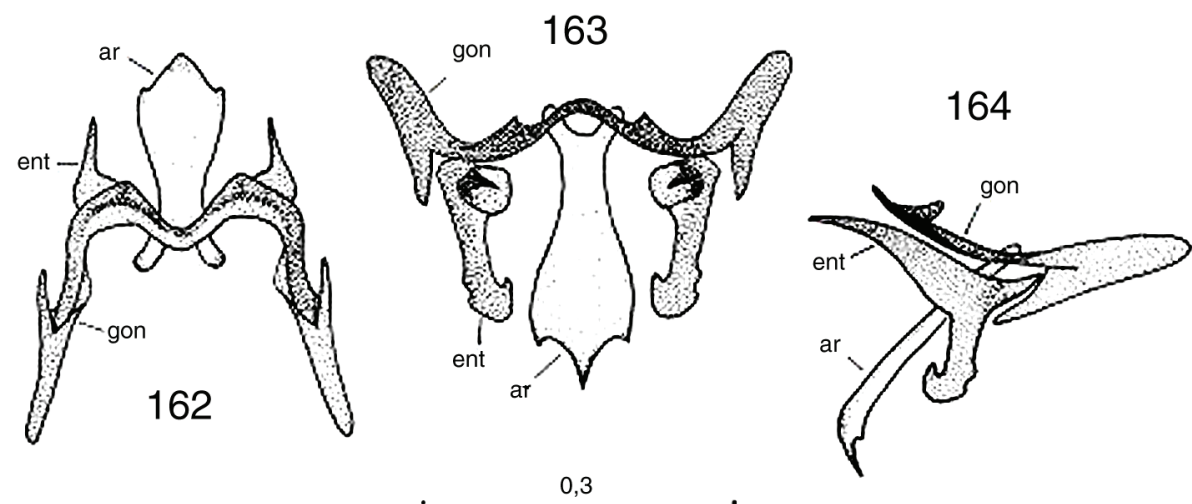

Figs. 156-164.- Morfología de Suarius spp. 156: ala anterior de S. iberiensis, 157: ídem de S. walsinghami, 158: uña de S. walsinghami, 159: ídem de S. nanus, 160-164: S. tigridis, 160: alas, 161: cabeza, vista dorsal, 162: genitalia interna masculina, vista dorsal, 163: ídem, vista caudal, 164: ídem, vista lateral (ar: arceso, ent: entoproceso, gon: gonarco). Escala en mm. 156-159 de Monserrat \& Díaz-Aranda, 1989a, 160-164 de Monserrat et al., 1991.

Figs. 156-164.- Morphology of Suarius spp. 156: forewing of S. iberiensis, 157: ditto of S. walsinghami, 158: claw of S. walsinghami, 159: ditto of S. nanus, 160-164: S. tigridis, 160: wings, 161: head, dorsal view, 162: inner male genitalia, dorsal view, 163: ditto, caudal view, 164: ditto, lateral view (ar: arcessus, ent: entoprocessus, gon: gonarcus). Scale in mm. 156-159 from Monserrat \& Díaz-Aranda, 1989a, 160-164 from Monserrat et al., 1991.

Suarius tigridis (Morton, 1921) (Figs. 96, 112, 160164, 196)

Morton, 1921: 220 (d); Monserrat \& Rodrigo, 1992: 132-135

(bio, dis, key, mf); Monserrat \& Marín, 1994: 122 (bio); H. Aspöck et al., 2001: 120 (rf); Canard et al., 2007: 292-297 (rf); Monserrat, 2008: 191 (bio, dis); Monserrat, 2013: 295 (rf); Monserrat et al., 2014: 30 (bio, dis).
Especie eremial conocida del norte de África (Marruecos, Argelia, Túnez, Egipto), oeste asiático (Israel, Palestina, Irak, Kuwait, Bahréin) y Península Ibérica. Mayoritariamente recolectada a la luz, con pocos datos sobre sus plantas soporte (Pistacia). En Europa está limitada al S. E. árido de la Península 
Ibérica (Almería), y está mayoritariamente citada entre V-IX, en altitudes de 10 hasta $750 \mathrm{~m}$.

En nuestra fauna tiene una clara tendencia termoxerófila, y ha sido mayoritariamente recolectada a la luz en medios muy xéricos y térmicos, zonas litorales y ramblas arenosas o pedregosas (Almería), a veces acude a la luz en sorprendente abundancia. Desconocemos sus plantas soporte, probablemente vegetación baja, leñosa y/o halófila (tipo Salsola, Thymelaea, Nicotiana, Arundo, etc.), ha sido citada puntualmente sobre Tamarix, en VI-IX, probablemente sufra diapausa estival, y ha sido recolectada en altitudes que oscilan entre 10-360 m.

Estadios larvarios descritos por Díaz-Aranda \& Monserrat (1996) y Monserrat \& Díaz-Aranda (2012).

Suarius walsinghami Navás, 1914 (Figs. 72, 114, $157,158,197)$

Navás, 1914b: 74 (d); Monserrat \& Díaz-Aranda, 1989a: 409 (dis); Monserrat \& Rodrigo, 1992: 134-135 (bio, dis, key, mf); Monserrat \& Marín, 1994: 122 (bio); Canard et al., 2007: 292-297 (rf); Monserrat, 2013: 294 (dis).

Suarius walsinghami walsinghami Navás, 1914

H. Aspöck et al., 2001: 120 (rf); Monserrat, 2008: 191 (dis); Monserrat, 2010: 25 (dis); Monserrat et al., 2014: 30 (bio, dis).

Especie eremial conocida del S.O. de la Península Ibérica, tercio norte africano (Marruecos, Argelia, Túnez, Libia, Egipto, Chad, Mauritania, Sudán) y Asia occidental (Sinaí, Israel, Arabia Saudí, Yemen, Irán, Afganistán y Pakistán). Las poblaciones de Irán, Afganistán y Pakistán se han adjudicado a la subespecie Suarius walsinghami orientalis Hölzel, 1978, mientras que las más occidentales, incluyendo nuestra fauna, se han venido adjudicando a la subespecie Suarius walsinghami walsinghami Navás, 1914. Está mayoritariamente citada sobre Acacia, Zizyphus y Phoenix, entre V-VII, en altitudes entre 900-1.360 m.

En Europa esta especie está limitada al S. E. de la Península Ibérica (Almería, Granada y Málaga), y en nuestra fauna tiene una clara tendencia termo-xerófila, y ha sido mayoritariamente recolectada a la luz, a veces de forma muy abundante (también ha sido recolectada con trampas McPhail utilizando como atrayente fosfato amónico $5 \%+$ Bórax $1 \%$ sobre Olea europea) (Monserrat et al., 2014), siempre en medios litorales muy xéricos y térmicos, puntualmente en cotas mayores (Sierra Nevada), y desconocemos sus plantas soporte, seguramente vegetación baja, leñosa y/o halófila, recolectada entre VI-IX, probablemente posea diapausa estival, en altitudes que oscilan entre 30-1.750 m.

Estadios juveniles descritos por Díaz-Aranda \& Monserrat (1995, 1996), Díaz-Aranda et al. (2001) y Monserrat \& Díaz-Aranda (2012).

\section{Género Brinckochrysa}

Con una única especie ibérica, muy local y sin problemas de identificación en los machos, las hembras requieren algo más de atención.
Brinckochrysa nachoi Monserrat, 1977 (Figs. 77, 97, $85,165-176,198)$

Monserrat, 1977b: 268 (d), 1979a: 412 (bio, dis); Aspöck et al., 1980: 10, 119 (dis, mf), 275 (rf); Canard, 1981: 102 (rf); Monserrat, 1982: 78 (bio, dis); Séméria, 1984a: 23 (rf); Hölzel, 1984: 67 (rf); Monserrat \& Díaz-Aranda, 1989c: 266 (bio, dis); Monserrat \& Rodrigo, 1992: 136 (bio, dis); Monserrat \& Marín, 1994: 122 (bio); H. Aspöck et al., 2001: 117 (rf); Canard et al., 2007: 292-297 (rf); Monserrat et al., 2014: 23 (bio, dis).

Brinckochrysa michaelseni (Esben-Petersen, 1928)

Canard \& Laudého, 1977: 70 (rf).

Especie conocida del centro y sur España, Francia e Italia (Cerdeña). Está mayoritariamente citada sobre eucaliptos y olivos, entre VI-IX, en altitudes bajas de hasta $300 \mathrm{~m}$.

En nuestra fauna tiene una clara tendencia meridional, existiendo citas en las provincias de Cádiz y Cáceres, y ha sido recolectada en medios continentales y térmicos, mayoritariamente sobre eucaliptos, también sobre encinas, acebuches y olivos, entre V-VIII, en altitudes que oscilan entre 40-400 m.

Las fases juveniles fueron descritas por DíazAranda \& Monserrat (1992, 1995), Díaz-Aranda et al. (2001) y Monserrat \& Díaz-Aranda (2012). Las larvas son de aspecto inconfundible, con coloración disruptiva (Fig. 77) y de hábitos corticícolas, predando sobre fitófagos en este medio.

\section{Belonopterygini Navás, 1913}

Género Italochrysa Principi, 1946

Representado en nuestra fauna por dos especies inconfundibles.

Italochrysa italica (Rossi, 1790) (Figs. 1, 2, 67, 88, 179) Hemerobius italicus Rossi, 1790.

Rossi, 1790: 14 (d).

Italochrysa italica (Rossi, 1790)

Principi, 1952: 15 (rf); Hölzel \& Ohm, 1972: 141 (dis), 143 (nt); Capra, 1976: 547 (rf); Monserrat, 1978b: 65 (bio, dis); Aspöck et al., 1980: 238 (rf); Sengonça, 1980: 114 (rf); Monserrat, 1980b: 185 (bio, dis), 1981a: 154 (bio, dis), 1982: 76 (bio, dis), 1984d: 99 (bio, dis); Díaz-Aranda et al., 1986b: 1138 (bio, dis); Monserrat, 1986b: 100 (bio, dis), 1987: 137 (bio, dis); Monserrat \& Díaz-Aranda, 1988: 91 (dis); Séméria \& Berland, 1988: 113 (rf); Díaz-Aranda \& Monserrat, 1988a: 117 (dis), 1988b: 222 (bio, dis), 1988c: 219 (dis); Campos, 1989: 161 (bio, dis); Monserrat \& Díaz-Aranda, 1989b: 51 (bio, dis), 1989c: 253 (dis); Marín \& Monserrat, 1991a: 181 (bio, dis); Monserrat \& Rodrigo, 1992: 125 (bio, dis); Pantaleão et al., 1993: 429 (bio, dis); Monserrat \& Marín, 1994: 122 (bio); Marín, 1994: 260 (bio, dis); Monserrat et al., 1994: 49 (bio, dis); Marín \& Monserrat, 1995a: 115 (bio, dis), 1995b: 40 (bio, dis); Monserrat, 1996: 14 (list); Carvalho, 1997: 5, 7 (dis); H. Aspöck et al., 2001: 73 (rf); Whittington, 2002: 379 (rf); González López, 2002: 203 (bio, dis); Monserrat, 2005: 76 (dis); Canard et al., 2007: 292-297 (rf); Monserrat, 2008: 173 (bio, dis); Letardi et al., 2013: 35 (list); Barreda, 2013: 78 (dis); Monserrat, 2013: 293 (bio, dis); Monserrat et al., 2014: 5 (bio, dis).

Hemerobius grandis Rambur, 1838

Rambur, 1838: pl.9, Fig. 6 (d, tx). 

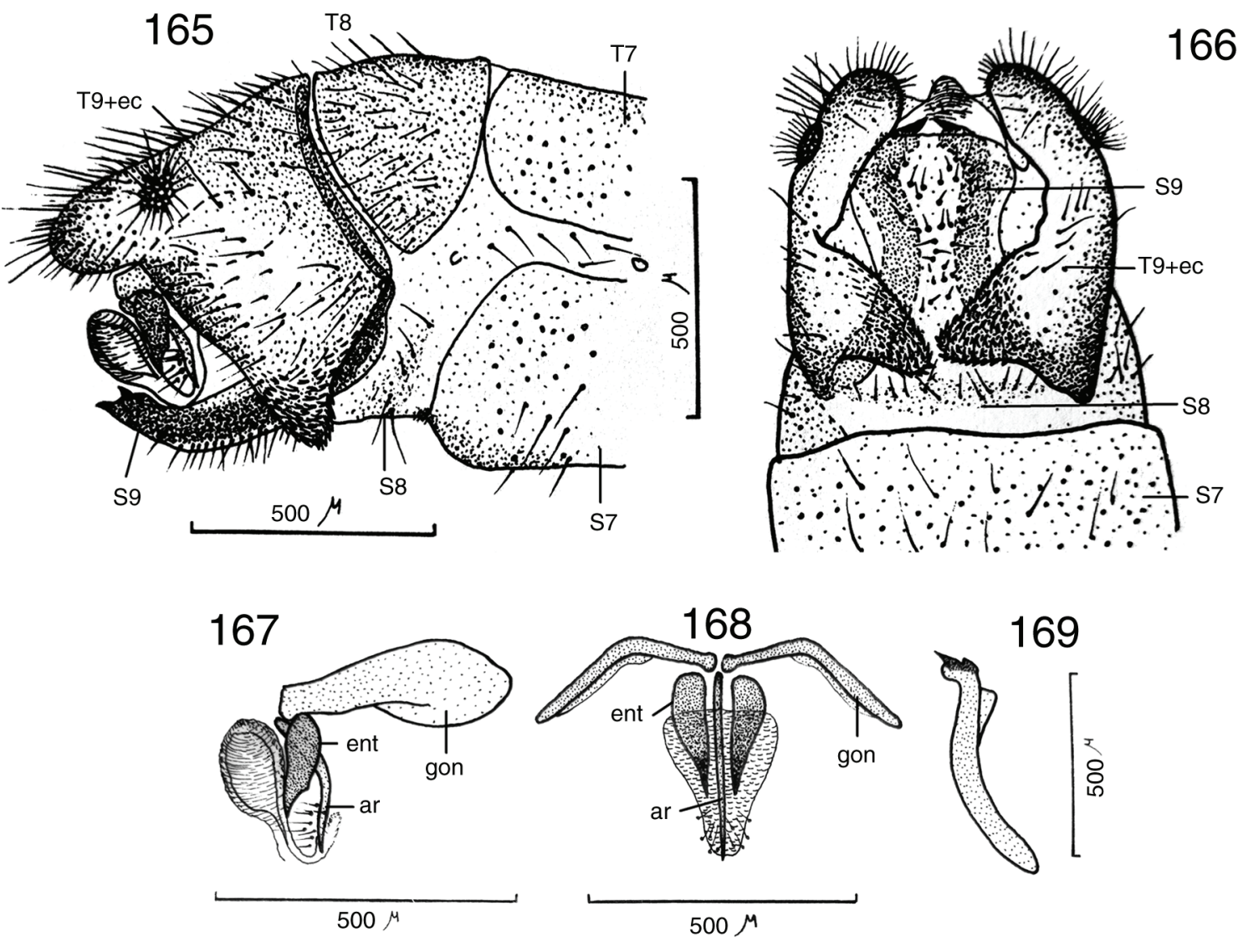

$500 \mu$
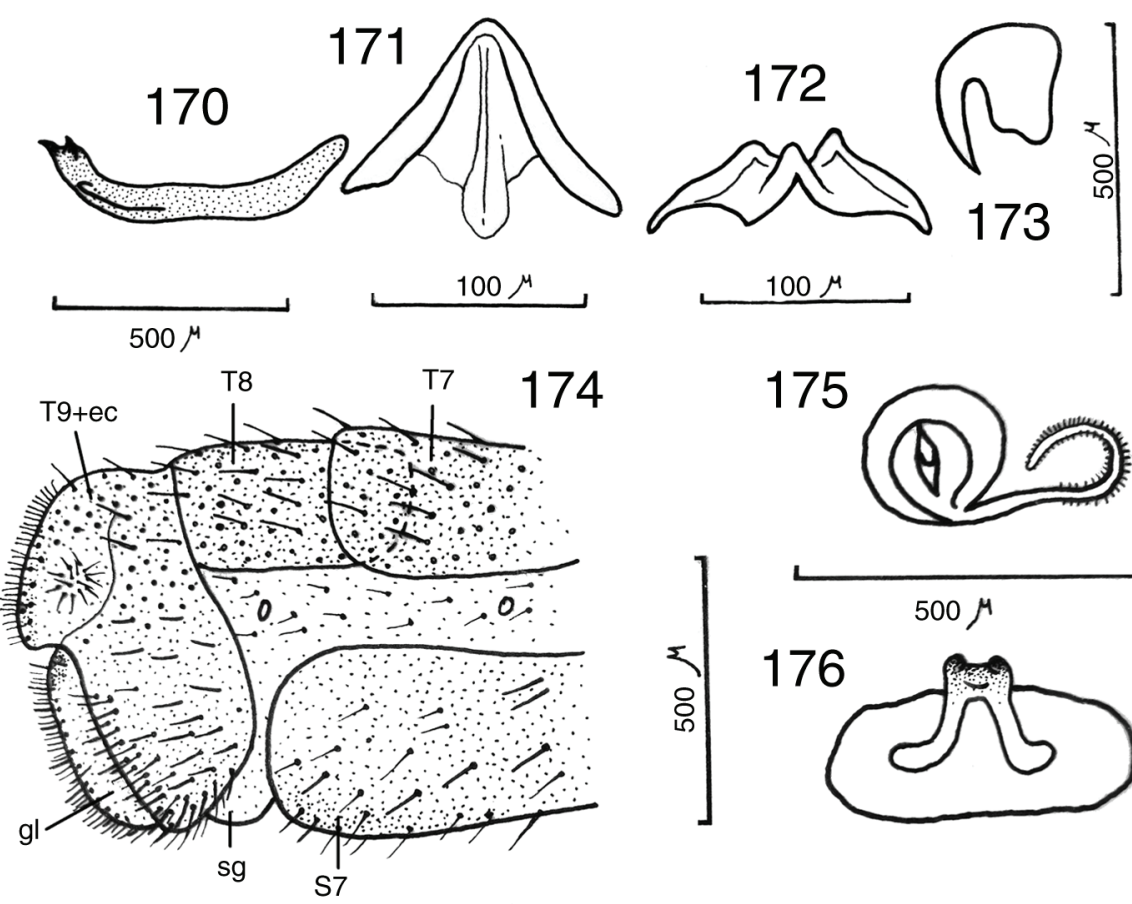

175
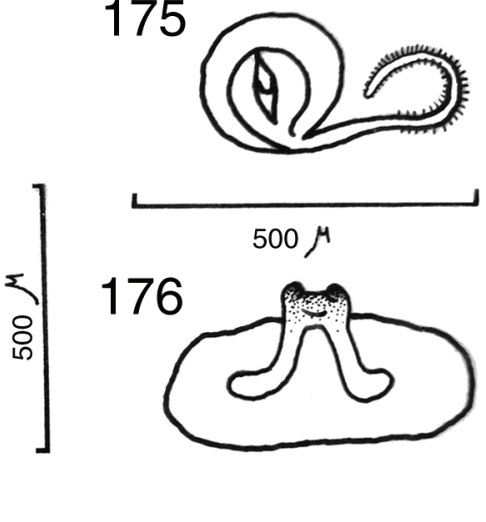

Figs. 165-176.- Brinckochrysa nachoi. 165: Extremo abdominal masculino, vista lateral, 166: ídem, vista ventral, 167: complejo gorarco-entoproceso-arceso, vista lateral, 168: ídem, vista caudal, 169: parámero, vista dorsal, 170: ídem, vista lateral, 171: hipandrio, vista ventral, 172: ídem, vista caudal, 173: uña, vista lateral, 174: extremo abdominal femenino, vista lateral, 175: espermateca, vista ventral, 176: placa subgenital, vista ventral (ar: arceso, ec: ectoprocto, ent: entoproceso, gl: gonapófisis laterales, gon: gonarco, sg: placa subgenital, S: esternito, T: terguito). De Monserrat (1977b).

Figs. 165-176.- Brinckochrysa nachoi. 165: Male abdominal tip, lateral view, 166: ditto, ventral view, 167: complex gorarcusentoprocessus-arcessus, lateral view, 168: ditto, caudal view, 169: paramere, dorsal view, 170: ditto, lateral view, 171: hypandrium, ventral view, 172: ditto, caudal view, 173: claw, lateral view, 174: female abdominal tip, lateral view, 175: spermatheca, ventral view, 176: subgenital plate, ventral view (ar: arcessus, ec: ectoproct, ent: entoprocessus, gl: lateral gonapophyses, gon: gonarcus, sg: subgenital plate, S: sternite, T: tergite). From Monserrat (1977b). 
También citada en la fauna ibero-balear como Chrysopa italica (Rossi, 1790), Hemerobius italicus Rossi, 1790, Hemerobius italicus grandis Rambur, 1838 y Nothochrysa italica (Rossi, 1790).

Especie holomediterránea extendida hasta Irak (bajo el paralelo $46^{\circ} \mathrm{N}$ ). Está mayoritariamente citada entre VI-IX, sobre olivos, acebuches, encinas, robles, en altitudes de hasta $1.000 \mathrm{~m}$. Parece asegurado que hiberna en fase de larva (Aspöck et al., 1980).

En nuestra fauna tiene una clara tendencia mediterránea, con citas en todo el litoral, incluyendo Baleares (Mallorca), y registros puntuales más interiores
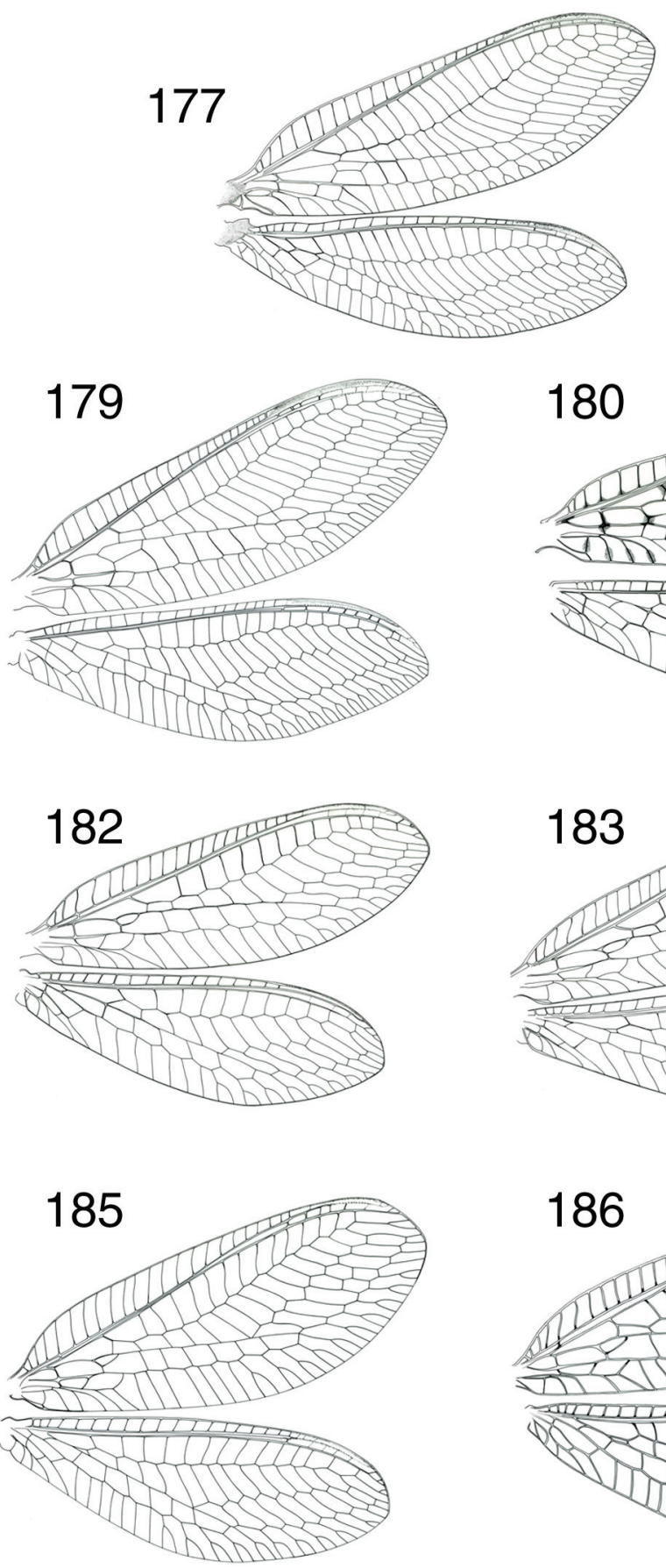

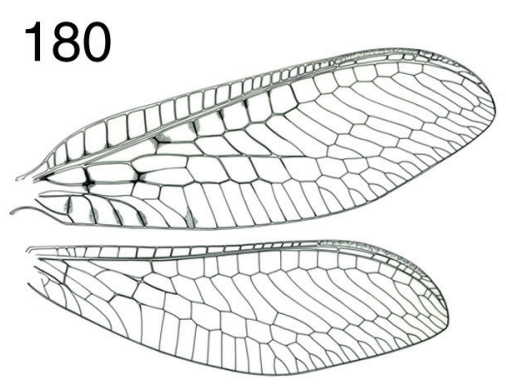

178
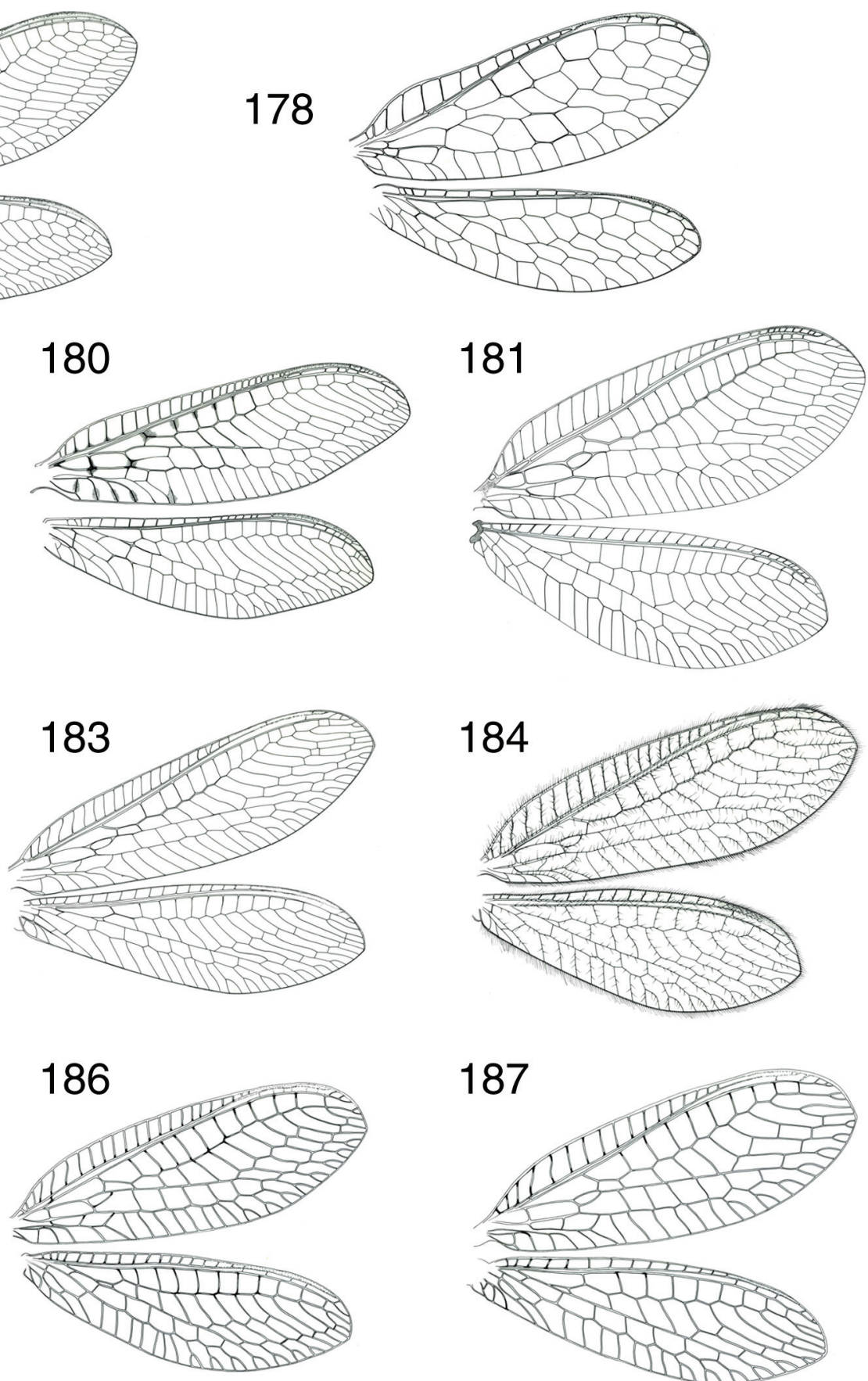

187

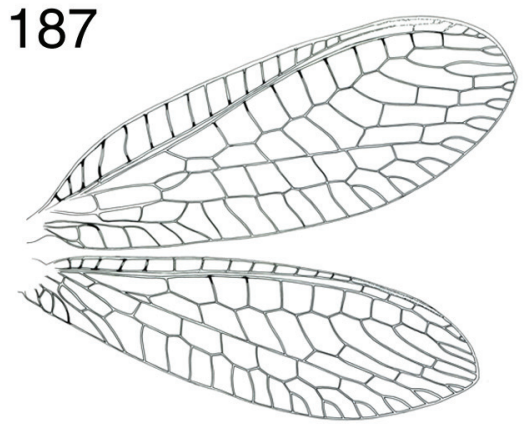

Figs. 177-187.- Alas de crisópidos ibéricos. 177: Nothochrysa fulviceps, 178: Hypochrysa elegans, 179: Italochrysa italica, 180: Italochrysa stigmatica, 181: Chrysopa perla, 182: Chrysoperla carnea s.l., 183: Chrysoperla mediterranea, 184: Chrysoperla ankylopteryformis, 185: Chrysotropia ciliata, 186: Cunctochrysa albolineata, 187: Cunctochrysa baetica. A diferentes escalas.

Figs. 177-187.- Wings of lberian green lacewings. 177: Nothochrysa fulviceps, 178: Hypochrysa elegans, 179: Italochrysa italica, 180: Italochrysa stigmatica, 181: Chrysopa perla, 182: Chrysoperla carnea s.l., 183: Chrysoperla mediterranea, 184: Chrysoperla ankylopteryformis, 185: Chrysotropia ciliata, 186: Cunctochrysa albolineata, 187: Cunctochrysa baetica. At different scales. 
(Albacete, Cáceres, Córdoba, Jaén, Toledo, Madrid, Cuenca, Guadalajara, Zaragoza, Huesca, Lérida y Teruel en España, y Castelo Branco, Beira Litoral, Beira Baixa y Estremadura en Portugal), y ha sido citada en medios térmicos mediterráneos abiertos, sobre encinas y algarrobos, ocasionalmente sobre quejigos, robles, olmos, olivos, plátanos, eucaliptos y pinos, entre VI-IX, en altitudes que oscilan entre $10-2.000 \mathrm{~m}$.

El huevo y la larva de esta especie fueron descritos por Principi (1946). Los huevos son depositados en las cortezas de los árboles próximos a hormigueros de Crematogaster scutellaris (Olivier, 1792), y sus larvas (Fig. 67) penetran en el interior de sus hormigueros
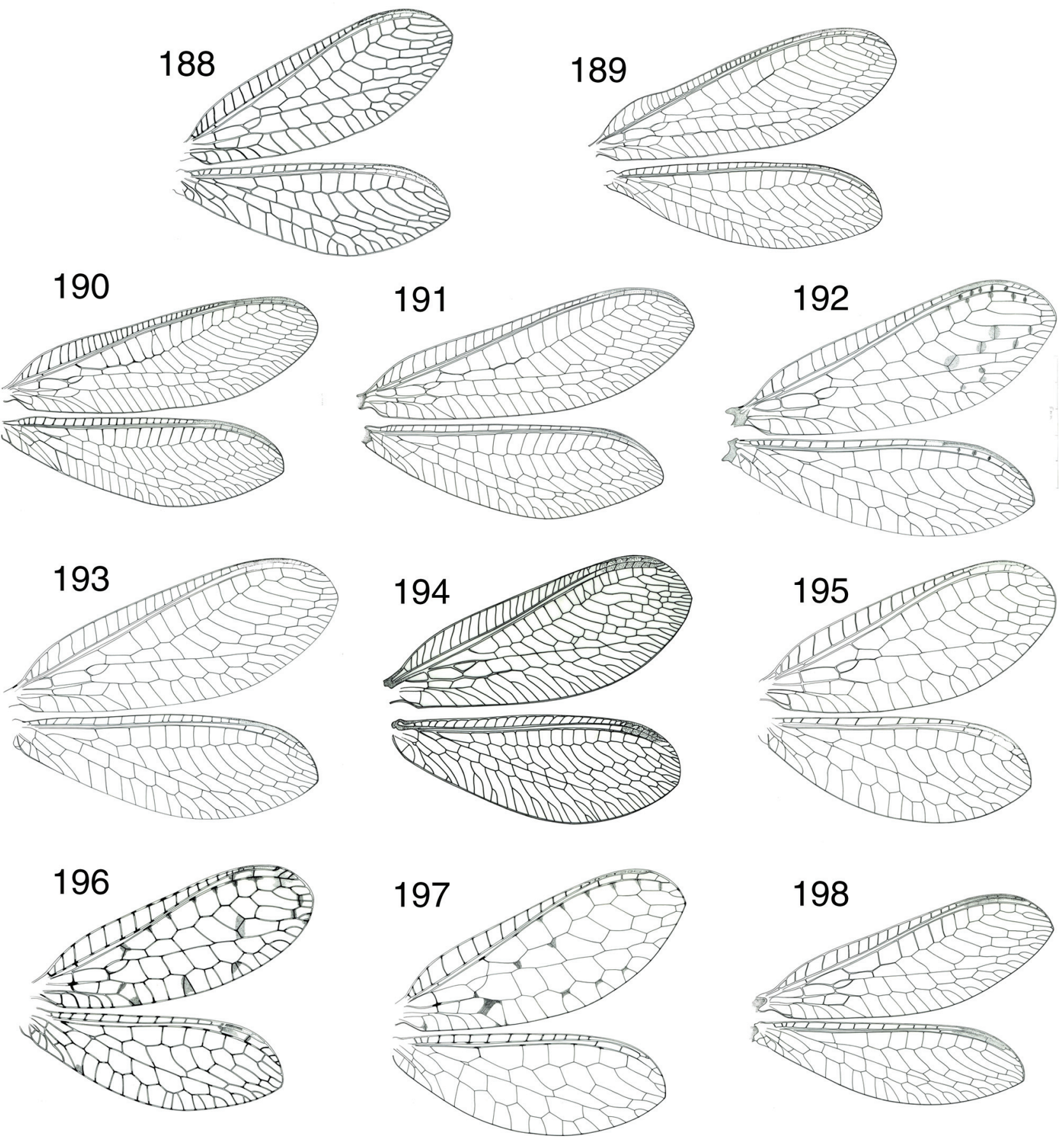

Figs. 188-198.- Alas de crisópidos ibéricos. 188: Cunctochrysa cosmia, 189: Nineta flava, 190: Nineta guadarramensis, 191: Nineta pallida, 192: Pseudomallada alarconi, 193: Pseudomallada flavifrons, 194: Rexa almerai, 195: Suarius iberiensis, 196: Suarius tigridis, 197: Suarius walsinghami, 198: Brinckochrysa nachoi. A diferentes escalas.

Figs. 188-198.- Wings of lberian green lacewings. 188: Cunctochrysa cosmia, 189: Nineta flava, 190: Nineta guadarramensis, 191: Nineta pallida, 192: Pseudomallada alarconi, 193: Pseudomallada flavifrons, 194: Rexa almerai, 195: Suarius iberiensis, 196: Suarius tigridis, 197: Suarius walsinghami, 198: Brinckochrysa nachoi. At different scales. 
y predan exclusivamente sobre sus larvas y pupas. Monserrat (1984d) cita posibles huevos de esta especie sobre gramíneas, y Monserrat et al. (2014) anotan la dificultad de cría de sus larvas.

Nuevo material estudiado o anotado: ESPAÑa: Murcia, Jumilla, Sierra del Carche, 990 m, 9.VIII.2008, 1 ej., J.L. Lencina (A. Gruppe). Huesca, Angües, 500 m, 28.VI 2003, 1 ej., A. Gruppe (A. Gruppe). Zaragoza, Perdiguera, 29.VIII.2013, 1 , C. Escuer (Fig. 2). PORTUGAL: Algarve, Corte Gago, Castro Marim, 3.IX.2010, 1 ind., Valter Jacinto. Guarda, Barca d'Alva, 380 m, 19.VI.2011, 1 ej., A. Gruppe (A. Gruppe).

Italochrysa stigmatica (Rambur, 1838) (Figs. 5, 6, 76, 109, 180)

Hemerobius stigmaticus Rambur, 1838

Rambur, 1838: pl. 9, Fig. 8 (d, tx), 1842: 429 (dis, mf).

Italochrysa stigmatica (Rambur, 1838)

Hölzel, 1967: 21 (rf); Hölzel \& Ohm, 1972: 142, 143 (dis), 144 (nt); Monserrat, 1979b: 20 (dis); Hölzel, 1980a: 165 (rf), 1980b: 100 (rf); Monserrat, 1980a: 173 (dis); Aspöck et al., 1980: 10, 11, 106 (dis, mf), 238 (rf); Monserrat, 1984d: 112 (rf), 1985b: 85 (bio, dis), 1986b: 101 (dis), 1987: 137 (bio, dis); Díaz-Aranda \& Monserrat, 1988a: 117 (dis), 1988c: 219 (dis); Monserrat \& Díaz-Aranda, 1989c: 254 (dis); Monserrat \& Marín, 1994: 122 (bio); H. Aspöck et al., 2001: 74 (rf); Whittington, 2002: 379 (rf); Monserrat, 2005: 76 (dis); Canard et al., 2007: 292-297 (rf); Monserrat, 2008: 173 (dis); Monserrat, 2013: 294 (rf); Monserrat et al., 2014: 5 (bio, dis).

También citada en la fauna ibero-balear como Chrysopa stigmatica (Rambur, 1838) y Nothochrysa stigmatica (Rambur, 1838).

Especie con tendencia eremial, conocida de España (ahora la citamos para Portugal), norte de África (Marruecos, Túnez, Libia, Egipto), Israel, extendida hasta Arabia Saudí, Omán, Irán y Afganistán.

De biología muy poco conocida, está mayoritariamente citada en medios térmicos y abiertos de naturaleza mediterránea, entre VI-IX, en altitudes de 10 hasta $2.000 \mathrm{~m}$.

En nuestra fauna tiene una clara tendencia térmica meridional, y ha sido citada en medios térmicos del litoral mediterráneo, incluyendo Baleares (Mallorca, Ibiza), y ahora la citamos por primera vez en la literatura impresa en el sur de Portugal, con algunas citas más septentrionales y hacia el interior (Madrid, Huesca, Jaén), frecuentemente recolectada a la luz, en ocasiones sobre algarrobos (Ceratonia siliqua) y especialmente gramíneas (Stipa tenacissima), y puntualmente sobre otras plantas (Vicia peregrina, Retama sphaerocarpa, Erica terminalis), entre V-X, en altitudes que oscilan entre $10-1.500 \mathrm{~m}$.

El huevo y el primer estadio larvario fueron descritos por Díaz-Aranda \& Monserrat (1995) y Monserrat \& Díaz-Aranda (2012).

Nuevo material citado: ESPAÑA: Málaga, Sierra de Tejeda, Canillas de Aceituno a La Maroma, 900 m, 9.VI.2015, 1, A. Tinaut. Murcia, Molina de Segura, El Rellano, 400 m, 29.VIII.2009, 2 ej. J.L. Lencina (A. Gruppe). PORTUGAL: Algarve, 10.VIII.2011, 1 ind., Nick Montegriffo, Quinta das Flores, Estoi, Faro, 17.VI.2011, 1 ind., Nelson Fonseca.

\section{Agradecimientos}

Esta contribución forma parte y entre 2011-2013 ha contado con fondos del Proyecto coordinado de $\mathrm{I}+\mathrm{D}+\mathrm{i}$ Fauna Ibérica (Neuroptera) CGL2010-22267-C07-05. Deseamos agradecer la ayuda de numerosos amigos y colegas, y especialmente a Roberto A. Pantaleoni, Miguel A. Alonso-Zarazaga, Vladimir N. Makarkin, Michel Canard, Dominique Thierry, José L. Nieves y Peter Duelli por sus comentarios, y a Axel Gruppe, Mario Porcel, Mercedes Campos, Luisa M. Díaz-Aranda, Santiago Pagola, Carlo Francesco Cesaroni, Manuel González Núñez, Constantino Escuer, P. Guevara, Alberto Tinaut, Xavier Espadaler, Jose Ignacio López Colón, Isidro Martínez, Davide Badano, Francisca Ruano y Francisco Rodríguez por el envío de bibliografía, ejemplares, datos y/o fotos de sus colecciones particulares o de sus centros de investigación. También a Alessandro Romanello, Elena Mercedes Pérez Monserrat, María Victoria Romero Sanz y Raimundo Outerelo por su ayuda en cuestiones bibliográficas, a Teresa Moreno por su apoyo e interés en el tema de los dibujos, y en particular a Zina Deretsky, por su valiosa colaboración en algunos de los dibujos presentados en esta contribución, a Fernando Acevedo y Víctor Triviño por su colaboración en los últimos muestreos realizados, a David Papenberg por su ayuda en la traducción de algunos textos, y a Eduardo Ruiz por su ayuda en el tratamiento del texto y de las imágenes.

\section{Referencias}

Ábrahám, L., Markó, V. \& Vas, J., 2003. Investigations on a neuropteroid community by using different methods. Acta Phytopathologica et Entomologica Hungarica, 38: 199-207.

Ábrahám, L. \& Mészáros, Z., 2006. Further Studies on the Daily Activity Pattern of Neuroptera with some Remarks on the Diurnal Activities. Acta Phytopathologica et Entomologica Hungarica, 41: 275-286.

Ábrahám, L. \& Vas, J., 1999. Preliminary report on study of the daily activity pattern of Neuroptera in Hungary. Acta Phytopathologica et Entomologica Hungarica, 34: 153-164.

Acker, T. S., 1960. The comparative morphology of the male terminalia of Neuroptera (Insecta). Microentomology, 24: $25-84$.

Adams, P. A., 1959. Neuroptera: Myrmeleontidae and Chrysopidae. Insects of Micronesia, 8: 13-33.

Adams, P. A., 1962. A stridulatory structure in Chrysopidae (Neuroptera). Pan-Pacific Entomologist, 38: 178-180.

Adams, P. A., 1967. A review of the Mesochrysinae and Nothochrysinae (Neuroptera: Chrysopidae). Bulletin of the Museum of Comparative Zoology, 135: 215-238.

Adams, P. A., 1969. New species and synonymy in the genus Meleoma (Neuroptera, Chrysopidae), with a discussion of genitalic homologies. Postilla, 136: 1-18.

Adams, P. A., 1975. Status of the genera Ungla and Mallada Navás (Neuroptera: Chrysopidae). Psyche, 82: 167-173. http://dx.doi.org/10.1155/1975/62979

Adams, P. A., 1977. Taxonomy of United States Leucochrysa (Neuroptera: Chrysopidae). Psyche, 84: 92-102. http:// dx.doi.org/10.1155/1977/56815

Adams, P.A., 1978. A new species of Hypochrysa and a new subgenus and species of Mallada. Pan-Pacific Entomologist, 54: 292-296. 
Adams, P. A., 1996. Venational homologies and nomenclature in Chrysopidae, with comments on the Myrmeleontoidea (Insecta: Neuroptera). In: Canard, M., Aspöck, H. \& Mansell, M. W. (eds.). Pure and Applied Research in Neuropterology (Proceedings of the Fifth International Symposium on Neuropterology, Cairo, 1994). Toulouse: 19-30.

Adams, P.A. \& Penny, N.D., 1992. New genera of Nothochrysinae from South America. Pan-Pacific Entomologist, 68(3): 216-221.

Agekyan, N. G., 1973. [Neuroptera feeding on bamboo aphids in Adzharia and their parasites.] Entomologicheskoe Obozrenie, 52: 549-564. (en ruso).

Ahn, Y.-j., Kim, Y.-j. \& Yoo, J.-k., 2001. Toxicity of the herbicide glufosinate-ammonium to predatory insects and mites of Tetranychus urticae (Acari: Tetranychidae) under laboratory conditions. Journal of Economic Entomology, 94(1): 157-161. http://dx.doi.org/10.1603/00220493-94.1.157

Albarda, H., 1889. Catalogue raisonné et synonymique des Nevroptères, observés dans les Pays-Bas et dans les Pays limitrophes. Tijdschrift voor Entomologie, 32: 211-376.

Albuquerque, G. S., Tauber, M. J. \& Tauber, C. A., 1997. Life-history adaptations and reproductive costs associated with specialization in predacious insects. Journal of Animal Ecology, 66: 307-317. http://dx.doi.org/10. $2307 / 5977$

Alderson, E. M., 1911a. Notes of Chrysopa dorsalis, Burm. The Entomologist's Monthly Magazine, 47: 49-54.

Alderson, E. M., 1911b. Notes on the life-history of Chrysopa flava Scopoli. The Entomologist, 44: 126-129.

Alrouechdi, K., 1981. Relations comportementales et trophiques entre Chrysoperla carnea (Stephens) (Neuroptera; Chrysopidae) et trois principaux ravageurs de l'olivier. I. La teigne de l'olivier Prays oleae Bern. (Lep. Hyponomeutidae). Neuroptera International, 1: 122-134.

Alrouechdi, K., Canard, M., Pralavorio, R. \& Arambourg, Y., 1980a. Repartition des adultes et des pontes de chrysopides (Neuroptera) recoltes dans une oliveraie de Provence. Neuroptera International, 1: 65-74.

Alrouechdi, K., Lyon, J. P., Canard, M. \& Fournier, D., 1980b. Les chrysopides (Neuroptera) récoltés dans une oliveraie du sud-est de la France. Acta Oecologica, Oecologia Aplicata, 1(2): 173-180.

Alrouechdi, K. \& Panis, A., 1980. Les parasites de Chrysoperla carnea Steph. (Neuroptera; Chrysopidae) sur Olivier en Provence. Agronomie, 1(2): 139-141.

Alrouechdi, K., Séméria, Y. \& New, T. R., 1984. Ecology of natural enemies. In: Canard, M., Séméria, Y. \& New, T. R. (eds.). Biology of Chrysopidae. W. Junk. The Hague: 187-193.

Alvis, L., Villalba, M., Marzal, C. \& García-Marí, F., 2003. Identification and abundance of Neuropteran species associated with citrus orchards in Valencia, Spain. Integrated Control in Citrus Fruit Crops, 26(6): 185-190.

Andersen, T. \& Greve, L., 1975. Neuroptera in light-traps at Osterøy, Hordaland. Norwegian Journal of Entomology, 22: 123-128.

Andréu, J. M., 1909. Datos para la fauna de la provincia de Alicante. Neurópteros de los alrededores de Orihuela.
Memorias del Primer Congreso de Naturalistas Españoles, Zaragoza, 1908: 159-162.

Ansorge, J. \& Schlüter, T., 1990. The earliest chrysopid: Liassochrysa stigmatica n.g., n.sp. from the Lower Jurassic of Dobbertin, Germany. Neuroptera International, 6: 87-93.

Araújo, J. \& Bichão, M. H., 1990. Biotecnologia de produção de Chrysoperla carnea (Stephens) (Neuroptera, Chrysopidae). Boletín de Sanidad Vegetal, Plagas 16: 113-118.

Archibald, S. B. \& Makarkin, V. N., 2015. A new species of Archaeochrysa Adams (Neuroptera: Chrysopidae) from the early Eocene of Driftwood Canyon, British Columbia, Canada. The Canadian Entomologist, 147: 359-369. http://dx.doi.org/10.4039/tce.2014.53

Archibald, S. B., Makarkin, V. N., Greenwood, D. R. \& Gunnell, G. F., 2014. The Red Queen and court jester in green lacewing evolution: bat predation and global climate change. Palaios, 29: 185-191. http://dx.doi.org/ 10.2110/palo.2013.089

Arzet, H. R., 1973. Suchverhalten der Larven von Chrysopa carnea Steph. (Neuroptera: Chrysopidae). Zeitschrift für Angewandte Entomologie, 74: 64-79. http://dx.doi. org/10.1111/j.1439-0418.1973.tb01781.x

Aspöck, H., 1992. The Neuropteroidea of Europe: a review of present knowledge (Insecta). In: Canard, M., Aspöck, H. \& Mansell, M. W. (eds.). Current Research in Neuropterology (Proceedings of the Fourth International Symposium on Neuropterology, Bagnères-deLuchon, 1991). Toulouse: 43-56.

Aspöck, H., 2002. Die Neuropterida der Westpaläarktis. Galathea, Supplement 13: 11-12.

Aspöck, H. \& Aspöck, U., 2007. Illustrations of Chrysopidae in the early entomological literature. In: Pantaleoni, R. A., Letardi, A. \& Corazza, C. (eds.). Proceedings of the Ninth International Symposium on Neuropterology, Ferrara, 2005. Annali del Museo Civico di Storia Naturale di Ferrara, 8: 27-44.

Aspöck, H. \& Aspöck, U., 2014. Die Autoren der Taxa der rezenten Raphidiopteren (Insecta: Endopterygota). Entomologica Austriaca, 21: 9-152.

Aspöck, H., Aspöck, U. \& Hölzel, H., 1980. Die Neuropteren Europas. 2 vols. Goecke \& Evers. Krefeld. Vol. 1, 495 pp., Vol. 2, 355 pp.

Aspöck, H., Aspöck, U. \& Rausch, H., 1991. Die Raphidiopteren der Erde. Eine monographische Darstellung der Systematik, Taxonomie, Biologie, Ökologie zusammenfassenden bersicht der fossilen Raphidiopteren (Insecta: Neuropteroidea). 2 vols. Goecke \& Evers. Krefeld. Vol. 1, 730 pp., Vol. 2, 550 pp.

Aspöck, H. \& Hölzel, H., 1996. The Neuropteroidea of North Africa, Mediterranean Asia and of Europe: a comparative review (Insecta). In: Canard, M., Aspöck, H. \& Mansell, M. W. (eds.). Pure and Applied Research in Neuropterology (Proceedings of the Fifth International Symposium on Neuropterology, Cairo, 1994). Toulouse: 31-86.

Aspöck, H., Hölzel, H. \& Aspöck, U., 2001. Kommentierter Katalog der Neuropterida (Insecta: Raphidioptera, Megaloptera, Neuroptera) der Westpaläarktis. Denisia, 2: 5-606. 
Aspöck, U., 1992. Crucial points in the phylogeny of the Neuroptera (Insecta). In: Canard, M., Aspöck, H. \& Mansell, M. W. (eds.). Current Research in Neuropterology (Proceedings of the Fourth International Symposium on Neuropterology, Bagnères-de-Luchon, 1991). Toulouse: 63-73.

Aspöck, U., 1993. Geklärtes und ungeklärtes im system der Neuroptera (Insecta: Holometabola). Mitteilungen der Deutschen Gesellschaft für Allgemeine und Angewandte Entomologie, 8: 451-456.

Aspöck, U., 1995. Neue hypothesen zum System der Neuropterida. Mitteilungen der Deutschen Gesellschaft für Allgemeine und Angewandte Entomologie, 10: 633-636.

Aspöck, U., 1996. Classification and phylogeny of the Neuropteroidea: An introduction. Proceedings of the $20^{\text {th }}$ International Congress of Entomology, Firenze: 30.

Aspöck, U. \& Aspöck, H., 1999. Kamelhälse, Schlammfliegen, Ameisenlöwen. Wer sind sie? (Insecta: Neuropterida: Raphidioptera, Megaloptera, Neuroptera). Stapfia, 60: 1-34.

Aspöck, U. \& Aspöck, H., 2010. Landmarks towards a phylogeny-based classification of the Neuropterida (Insecta: Endopterygota). In: Devetak, D., Lipovšek, S. \& Arnett, A. E. (eds.). Proceedings of the $10^{\text {th }}$ International Symposium on Neuropterology, Piran, 2008: 67-74.

Aspöck, U. \& Aspöck, H., 2013. Nevrorthidae, Sisyridae, Coniopterygidae ... - Der Streit um die niederen Ränge im Stammbaum der Neuroptera. DGaaE Nachrichten, 27: 19-20.

Aspöck, U., Aspöck, H., Letardi, A. \& Jong, Y. de, 2015. Fauna Europaea: Neuropterida (Raphidioptera, Megaloptera, Neuroptera). Biodiversity Data Journal, 3: e4830: 1-22. http://dx.doi.org/10.3897/BDJ.3.e4830

Aspöck, U., Haring, E. \& Aspöck, H., 2012 The phylogeny of the Neuropterida: long lasting and current controversies and challenges (Insecta: Endopterygota). Arthropod Systematics \& Phylogeny, 70: 119-129.

Aspöck, U., Plant, J. D. \& Nemeschkal, H. L., 2001. Cladistic analysis of Neuroptera and their systematic position within the Neuropterida (Insecta: Holometabola: Neuropterida: Neuroptera). Systematic Entomology, 26: 73-86. http:// dx.doi.org/10.1046/j.1365-3113.2001.00136.x

Ast, F., 1920. Über den feineren Bau der Facettenaugen bei Neuropteren. Zoologische Jahrbücher. Abteilung für Anatomie und Ontogenie der Tiere, 4: 411-458.

Auber, J., 1958. Faune terrestre et d'eau douce des PyrénéesOrientales. 3. Névroptéroïdes. Vie et Milieu, 9: 1-42.

Babrikova, T., 1984. Identification of the larvae of some species of Chrysopidae and Hemerobiidae families. Rastitelna Zashitita, 32: 42-46.

Badano, D. \& Letardi, A., 2010. A review of the Neuropterida of Liguria (north-west Italy). In: Devetak, D., Lipovšek, S. \& Arnett, A. E. (eds.). Proceedings of the $10^{\text {th }}$ International Symposium on Neuropterology, Piran, 2008: 83-87.

Báez, M. \& Oromí, P., 2010. Lista de especies silvestres de Canarias (hongos, plantas y animales terrestres). In: Arechavaleta Hernández, M. et al. (Coords.). Gobierno de Canarias. La Laguna, 579 pp.

Bakthavatsalam, N. \& Singh, S. P., 1996. L-tryptophan as an ovipositional attractant for Chrysoperla carnea
(Stephens) (Neuroptera: Chrysopidae). Journal of Biological Control, 10: 21-27.

Bakthavatsalam, N. \& Singh S. P., 1999. Behavioural responses of larvae of Chrysoperla carnea (Stephens) to kairomones. Journal of Insect Science, 12: 34-36.

Banks, C. J., 1952. An analysis of captures of Hemerobiidae and Chrysopidae in suction traps at Rothamsted, July, 1949. Proceedings of the Royal Entomological Society of London, Series A, General Entomology, 27: 45-53. http://dx.doi.org/10.1111/j.1365-3032.1952.tb00153.x

Bänsch, R., 1964. Vergleichende Untersuchungen zur Biologie und zum Beutefangverhalten aphidivorer Coccinelliden, Chrysopiden und Syrphiden. Zoologische Jahrbücher. Abteilung für Systematik, Geographie und Biologie, 91: 271-340.

Bar, D. \& Gerling, D., 1985. Cannibalism in Chrysoperla carnea (Stephens) (Neuroptera, Chrysopidae). Israel Journal of Entomology, 19: 13-22.

Barbu, I. Z., 1939. Insectes fossiles du tertiaire de l'Oltenie. Buletinul Societatii Romane de Geologie, 4: 119-128.

Barnard, P. C., 1978. A check-list of the British Neuroptera with taxonomic notes. Entomologist's Gazette, 29: 165-176.

Barnard, P. C., 1984. Adult morphology related to classification. In: Canard, M., Séméria, Y. \& New, T. R. (eds.). Biology of Chrysopidae. W. Junk. The Hague: 19-29.

Barreda, J. M., 2013. Nuevos registros de Chrysopidae y Myrmeleontidae para la provincia de Sevilla (Andalucía, España) (Neuroptera, Planipennia). Boletín de la Sociedad entomológica Aragonesa, 21: 77-81.

Bastero Monserrat, J. J., 1989. Longinos Navás, científico jesuita. Universidad de Zaragoza, Zaragoza. 229 pp.

Berland, L., 1962. Atlas des Névroptères de France, Belgique, Suisse. Mégaloptères, Raphidioptères, Névroptères Planipennes, Mécoptères, Trichoptères. Nérée Boubée \& Cie. Paris. 158 pp.

Bertrand, C., 1923. Excursión entomológica a Cariñena (Zaragoza). Boletín de la Sociedad Entomológica de España, 6: 56-58.

Beutel, R. G., Friedrich, F. \& Aspöck, U., 2010. The larval head of Nevrorthidae and the phylogeny of Neuroptera (Insecta). Zoological Journal of the Linnean Society, 158: 533-562. http://dx.doi.org/10.1111/j.1096-3642. 2009.00560.x

Bichão, M. H. \& Araújo, J., 1989. Mass-rearing of Chrysoperla carnea (Stephens) (Neuroptera. Chrysopidae) larvae: optimization of rearing unit yield. Boletim da Sociedade Portuguesa de Entomologia, 113: 117-128.

Bitsch, J., 1984. Anatomy of adult Chrysopidae. In: Canard, M., Séméria, Y. \& New, T. R. (eds.). Biology of Chrysopidae. W. Junk. The Hague: 29-36.

Blasco-Zumeta, J., 2000. Contribution à l'étude de la faune associée à Juniperus thurifera L. dans Los Monegros (Aragón, Espagne). Le Genévrier thurifère (Juniperus thurifera L.) dans le bassin occidental de la Méditerranée: systématique, écologie, dynamique et gestion (Actes du colloque international de Marignac), 1997: 94-103.

Blum, M. S., Wallace, J. D. \& Fales, H. M. 1973. Skatole and tricedene: identification and possible role in a chrysopid 
secretion. Insect Biochemistry, 3: 353-357. http://dx.doi. org/10.1016/0020-1790(73)90068-1

Bock, E., 1939. Bildung und Differenzierung der Keimblätter bei Chrysopa perla (L.). Zeitschrift für Morphologie und Ökologie der Tiere, 35: 615-702.

Boelpaepe, M. O. C., Forra, M. R. \& Fernandes, J. E., 1992. Aphid pests of vegetable crops and aphidophagous insects caught in a suction trap in Algarve, Portugal. Bulletin OILB/SROP, 15(4): 16-27.

Bolívar, I., 1873. Excursión a La Granja, con indicación de los neurópteros y ortópteros recogidos en ella. Actas y Anales de la Sociedad Española de Historia Natural, 2: 61.

Bolívar, I., 1878. Insectos colectados por M. Cuní y Martorell en las cercanías de Barcelona. Actas y Anales de la Sociedad Española de Historia Natural, 7: 61-64.

Bolívar, I., 1890. Nota. Actas y Anales de la Sociedad Española de Historia Natural, 19: 31.

Boo, K. S., Chung, I. B., Han, K. S., Pickett, J. A. \& Wadhams, L. J., 1998. Response of the lacewing Chrysopa cognata to pheromones of its aphid prey. Journal of Chemical Ecology, 24: 631-643. http://dx.doi.org/10.1023/A: 1022386001722

Boo, K. S., Chung, I. B., Han, K. S., Pickett, J. A. \& Wadhams, L. J., 1999. Field trapping of lacewings with aphid pheromones. IOBC/WPRS Bulletin, 22(9): 35-36.

Boo, K. S., Kang, S. S., Park, J. H., Pickett, J. A. \& Wadhams, L. J., 2003. Field trapping of Chrysopa cognata (Neuroptera: Chrysopidae) with aphid sex pheromone components in Korea. Journal of Asia-Pacific Entomology, 6: 29-36. http://dx.doi.org/10.1016/S1226-8615(08)60164-8

Bozsik, A., 1992a. Natural adult food of some important Chrysopa species (Planipennia: Chrysopidae). Acta Phytopathologica et Entomologica Hungarica, 27: 141-146.

Bozsik, A., 1992b. Influence of vegetational diversity on chrysopid assemblages. In: Zombori, L. \& Peregovits, L. (eds.). Proceedings of the Fourth European Congress of Entomology and XIII'th Internationale Symposium für die Entomofaunistik Mitteleuropas, Gödöllö, 1991. Hungarian Natural History Museum. Budapest: 256-160.

Bozsik, A., 1994. Impact of vegetational diversity on structure parameters of chrysopid assemblages. Redia, 77: 69-77.

Bozsik, A., 2009. Nineta principiae Monserrat 1980 (Neuroptera: Chrysopidae) new to the Belgian fauna. Entomologie Faunistique, 62: 29-33.

Branco, M., Franco, J. C., Dunkelblum, E., Assael, F., Protasov, A., Ofer, D. \& Mendel, Z., 2006a. A common mode of attraction of larvae and adults of insect predators to the sex pheromone of their prey (Hemiptera: Matsucoccidae). Bulletin of Entomological Research, 96: 179-185. http://dx.doi.org/10.1079/BER2005415

Branco, M., Lettere, M., Franco, J. C., Binazzi, A., \& Jactel, H., 2006b. Kairomonal response of predators to three pine bast scale sex pheromones. Journal of Chemical Ecology, 32: 1577-1586. http://dx.doi.org/10.1007/ s10886-006-9071-6

Brauer, F., 1851. Beschreibung und Beobachtung der österreichischen Arten der Gattung Chrysopa. Naturwissenschaftliche Abhandlungen, 4(4): 1-12.

Brauer, F., 1852. Versuch einer Gruppirung der Gattungen in der Zunft Planipennia mit besonderer Rücksicht auf die früheren Stände. Stettiner Entomologische Zeitung, 13: 71-77.

Brauer, F., 1855. Beiträge zur Kenntniss der Verwandlung der Neuropteren. Verhandlungen des Zoologisch-Botanischen Vereins in Wien, 5: 479-484.

Brauer, F., 1856. Rückblick auf die im Jahre 1850 beschriebenen österreischischen Arten der Gattung Chrysopa Leach nebst Beschreibung der Ch. tricolor n. sp. Verhandlungen der Zoologisch-Botanischen Gesellschaft in Wien, 6: 703-708.

Brauer, F., 1857. Chrysopa tricolor, vergleichen mit der Beschreibung von Chrysopa gracilis Heyden und stenoptila Schn. Verhandlungen der Zoologisch-Botanischen Gesellschaft in Wien, 7: 201.

Brauer, F., 1864. Erster Bericht über die auf der Weltfahrt der Kais. Fregatte Novara gesammelten Neuropteren. Verhandlungen der Kaiserlich-Königlichen ZoologischBotanischen Gesellschaft in Wien, 14: 159-164.

Brauer, F., 1866. Zusätze und Berichtigungen zu Hagen's Hemerobidarum Synopsis Synonymica und Beschreibung einer neuen Nymphiden-gattung: Myiodactylus osmyloides aus Australien. Verhandlungen der KaiserlichKöniglichen Zoologisch-Botanischen Gesellschaft in Wien, 16: 983-992.

Brauer, F., 1867. Larve von Hypochrysa nobilis Heyd. Verhandlungen der Kaiserlich-Königlichen ZoologischBotanischen Gesellschaft in Wien, 17: 27-30.

Brauer, F., 1868. Verzeichniss der bis jetzt bekannten Neuropteren in Sinne Linné's. Erster Abschnitt. Verhandlungen der Kaiserlich-Königlichen Zoologisch-Botanischen Gesellschaft in Wien, 18: 359-416, 711-742.

Brauer, F., 1876. Die Neuropteren Europas und insbesondere Oesterreichs mit Rücksicht auf ihre geographische Verbreitung. Festschrift zur Feier des fünfundzwanzigjährigen Bestehen Kaiserlich-Koniglichen Zoologisch-Botanischen Gesellschaft. Wien: 263-300.

Brauer, F., 1886. Ansichten über die paläozoischen Insekten und deren Deutung. Annalen des K.K. Naturhistorisches Hofmuseums, 1: 87-126.

Brauer, F. \& Löw, F., 1857. Neuroptera austriaca. Die im Erzherzogthum Oesterreich bis jetzt aufgefundenen Neuropteren nach der analytischen Methode zusammengestellt, nebst einer kurzen Charakteristik aller europäischen Neuropteren-Gattungen. C. Gerold's Sohn. Wien. xxiii+80 pp.

Briand, L. J., 1931. Notes on Chrysopa oculata Say and its relation to the oriental peach moth (Laspeyresia molesta Busck.) infestation in 1930. The Canadian Entomologist, 63: 123-126.

Brooks, S. J., 1984. A redefinition of the Italochrysini (Chrysopidae), with the description of a new genus from Nigeria. Neuroptera International, 3: 79-88.

Brooks, S. J., 1986. A new genus of Ankylopterygini (Chrysopidae). Neuroptera International, 4: 35-48.

Brooks, S. J., 1987. Stridulatory structures in three green lacewings (Neuroptera: Chrysopidae). International Journal of Insect Morphology and Embryology, 16: 237-244. http://dx.doi.org/10.1016/0020-7322(87)90023-7

Brooks, S. J., 1994. A taxonomic review of the common green lacewing genus Chrysoperla (Neuroptera: Chrysopidae). 
Bulletin of the British Museum of Natural History, Entomology, 63(2): 137-210.

Brooks, S. J., 1997. An overview of the current status of Chrysopidae (Neuroptera) systematics. Deutsche Entomologische Zeitschrift (N.F.), 44: 267-275. http:// dx.doi.org/10.1002/mmnd.19970440212

Brooks, S. J. \& Barnard, P. C., 1990. The green lacewings of the world: a generic review (Neuroptera: Chrysopidae). Bulletin of the British Museum of Natural History, Entomology, 59: 117-286.

Brückner, W. R., 1935. Geschlechtsorgane und Eibildung des Neuropters Chrysopa vulgaris Schneid. Jenaische Zeitschrift für Naturwissenschaft (N.F.), 69: 469-506.

Bugg, R.L., 1987. Observations on Insects Associated with a Nectar-bearing Chilean Tree, Quillaja saponaria Molina (Rosaceae). Pan-Pacific Entomologist, 63(1): 60-64.

Bullini, L. \& Cianchi, R., 1984. Electrophoretic studies of gene-enzyme systems in chrysopid lacewings. In: M. Canard, Y. Séméria \& T. R. New (eds.). Biology of Chrysopidae. W. Junk. The Hague: 48-56.

Bullini, L., Principi, M. M. \& Cianchi, R., 1983a. Ricerche elettroforetiche su specie italiane del genere Chrysopa s.1. (Neuroptera, Chrysopidae). Atti XII Congresso Nazionale Italiano di Entomologia, Roma, 1980: 235-237.

Bullini, L., Principi, M. M., Cianchi, R. \& Pantaleoni, R., 1983b. Nuovi dati sulla tassonomia biochimica delle crisope italiane (Neuroptera, Chrysopidae). Atti XIII Congresso Nazionale Italiano di Entomologia, Sestriere-Torino: 479-483.

Bullini, L., Principi, M. M. \& Cianchi, R., 1984. Eletrophoretic studies in the genus Chrysopa (s.l.), Evolutionary and Phylogenetic Inferences. In: Gepp, J., Aspöck, H. \& Hölzel, H. (eds.). Progress in World's Neuropterology (Proceedings of the 1st International Symposium on Neuropterology, Graz): 57-59.

Burmeister, H. C. C., 1839. Handbuch der Entomologie. Zweiter Band. Besondere Entomologie. Zweite Abtheilung. Kaukerfe. Gymnognatha. (Zweite Hälfte; vulgo Neuroptera). T.C.F. Enslin. Berlin. xii+ 757-1050 pp.

Cáceres, J., 1909. Neurópteros cogidos en Cartagena. Actas de la Real Sociedad Española de Historia Natural, 2, 9: 291.

Cadena, P., Angel, F., Gomez, L. A. \& Gonzalez, R., 2007. Diferenciación morfológica y molecular de especies de crisópidos (Neuroptera: Chrysopidae). Revista Colombiana de Entomología, 33: 171-177.

Çaldumbide, C., Faessel, L., Travers, M., Thierry, D. \& RatMorris, E., 2001. Les chrysopes communes, auxiliaires polyvalents. Phytoma, 540: 14-19

Campos, M., 1986. Influencia del complejo parasitario sobre las poblaciones de Chrysoperla carnea (Neuroptera, Chrysopidae) en olivares del sur de España. Neuroptera International, 4: 97-105.

Campos, M., 1989. Observaciones sobre la bioecología de Chrysoperla carnea (Stephens) (Neuroptera: Chrysopidae) en el sur de España. Neuroptera International, 5(3): 159-164.

Campos, M., 2001. Lacewings in Andalusian olive orchards. In: McEwen, P. K., New, T. R. \& Whittington, A. E. (eds.). Lacewings in the Crop Environment. Cambridge
University Press. Cambridge: 492-497. http://dx.doi. org/10.1017/CBO9780511666117.032

Campos, M. \& Ramos, P., 1983. Chrisopidos (Neuroptera) capturados en un olivar del sur de España. Neuroptera International, 2: 219-227.

Campos, M. \& Ramos, P., 1985. Some relationships between the number of Prays oleae eggs laid on olive fruits and their predation by Chrysoperla carnea. Integrated Pesticide Control Olive-groves (Proceedings of the CEC/ FAO/IOBC International Joint Meeting, Pisa): 237-241.

Canard, M., 1970a. Incidences de la valeur alimentaire de divers pucerons (Homoptera, Aphididae) sur le potentiel de multiplication de Chrysopa perla (L.) (Neuroptera, Chrysopidae). Annales de Zoologie, Écologie Animale, 2: 345-355.

Canard, M., 1970b. Incidences de la valeur alimentaire de divers pucerons (Homoptera, Aphididae) sur le potentiel de multiplication de Chrysopa perla (L.) (Neuroptera, Chrysopidae). Annales de Zoologie, Écologie Animale, 2: 345-355.

Canard, M., 1970c. L'oophagie des larves du premier stade de chrysope (Neuroptera, Chrysopidae). Entomologia Experimentalis et Applicata, 13: 21-36. http://dx.doi.org/ 10.1111/j.1570-7458.1970.tb00082.x

Canard, M., 1971. Les possibilités de conservation de longue durées des cocons d'un prédateur aphidiphage: Chrysopa perla (L.) (Neuroptera, Chrysopidae). Annales de Zoologie, Écologie Animale, 3: 373-377.

Canard, M., 1973a. Influence de l'alimentation sur le développement, la fécondité et la fertilité d'un prédateur aphidiphage: Chrysopa perla (L.) (Neuroptera: Chrysopidae). Thèse Grade de Docteur. Université Paul-Sabatier. Toulouse. $175 \mathrm{pp}$.

Canard, M., 1973b. Voltinisme, diapause et sex-ratio de Chrysopa perla (L.) (Neuroptera, Chrysopidae) dans de sud-ouest. Annales de Zoologie, Écologie Animale, 5: 29-37.

Canard, M., 1975. Comparison of the reproduction rate of three predators: Chrysopa perla (L.), Boriomyia subnebulosa (Steph.) and Eumicromus angulatus (Steph.) (Neuroptera: Chrysopidae, Hemerobiidae) with respect to the aphid prey. Reports and Informations. Section $V$ : Biological and Genetic Control (Eighth International Plant Protection Congress, Moscow: 50-52.

Canard, M., 1976. La diapause chez Chrysopa perla (L.) (Neuroptera, Chrysopidae). Induction et élimination dans des conditions naturelles et expérimentales. Annales de Zoologie, Écologie Animale, 8: 393-404.

Canard, M., 1981. Chrysopes (Neuroptera) peu connues ou nouvelles pour la France. Neuroptera International, 1: 99-109.

Canard, M., 1983. La sensibilité photopériodique de larves de la chrysope Nineta flava. Entomologia Experimentalis et Applicata, 34: 111-118. http://dx.doi.org/10.1111/ j.1570-7458.1983.tb03299.x

Canard, M., 1984. Ecologie des pontes de Nineta flava (Scopoli) (Neuroptera, Chrysopidae): disposition et facteurs biotiques antagonistes. In: Gepp, J., Aspöck, H. \& Hölzel, H. (eds.). Progress in World's Neuropterology (Proceedings of the 1st International Symposium on Neuropterology, Graz): 253-260. 
Canard, M., 1985. Caracteristiques bioecologiques de Nineta pallida (Schneider) (Neuroptera, Chrysopidae) dans les Pyrenees. Neuroptera International, 3: 175-185.

Canard, M., 1986a. A cautious univoltine strategy in the lacewing Nineta flava (Scopoli) (Neuroptera, Chrysopidae). In: Gepp, J., Aspöck, H. \& Hölzel, H. (eds.). Recent Research in Neuropterology (Proceedings of the 2nd International Symposium on Neuropterology, Hamburg, 1984). Graz: 145-150.

Canard, M., 1986b. Is the Iberian lacewing Chrysopa regalis a semivoltine species? Ecological Entomology, 11: 27-30. http://dx.doi.org/10.1111/j.1365-2311.1986.tb00276.x

Canard, M., 1987. Cycle annuel et place de Chrysoperla mediterranea (Hölzel) (Neuroptera, Chrysopidae) en fôret méditerranéenne. Neuroptera International, 4: 279-285.

Canard, M., 1990. Effect of photoperiod on the first-instar development in the lacewing Nineta pallida. Physiological Entomology, 15: 137-140. http://dx.doi.org/10.1111/ j.1365-3032.1990.tb00500.x

Canard, M., 1997. Can lacewings feed on pests in the winter? (Neur: Chrysopidae and Hemerobiidae). Entomophaga, 42: 113-117. http://dx.doi.org/10.1007/BF02769887

Canard, M., 1998. Life history strategies of green lacewings in temperate climates: a review (Neuroptera, Chrysopidae). In: Panelius, S. P. (ed.). Neuropterology 1997 (Proceedings of the Sixth International Symposium on Neuropterology, Helsinki, 1998). Acta Zoologica Fennica, 209: 65-74.

Canard, M., 2001. Natural food and feeding habits of lacewings. In: McEwen, P. K., New, T. R. \& Whittington, A. E. (eds.). Lacewings in the Crop Environment. Cambridge University Press. Cambridge: 116-129. http://dx.doi.org/10.1017/CBO9780511666117.007

Canard, M., 2004. World distribution of the genus Nineta Navás, 1912 (Neuroptera: Chrysopidae), with some taxonomic notes. Denisia, 13: 153-161.

Canard, M., 2007. Deux Chrysopes nouvelles pour la faune de Chypre: Italochrysa italica (Rossi, 1790) et Cunctochrysa baetica (Hölzel, 1972) (Neur., Chrysopidae). Bulletin de la Société Entomologique de France, 112(2): 406.

Canard, M., Cloupeau, R. \& Leraut, P., 1998. Les Chrysopes du genre Nineta Navás, 1912, en France (Neuroptera, Chrysopidae). Bulletin de la Société Entomologique de France, 103(4): 327-336.

Canard, M. \& Duelli, P., 1984. Predatory behavior of larvae and cannibalism. In: Canard, M., Séméria, Y. \& New, T. R. (eds.). Biology of Chrysopidae. W. Junk. The Hague: 92-100.

Canard, M. \& Grimal, A., 1990. The role of photoperiod in the regulation of the annual cycle in two montane conifer-inhabiting green lacewings in southwestern Europe (Insecta: Neuroptera: Chrysopidae). In: Mansell, M. W. \& Aspöck, H. (eds.). Advances in Neuropterology (Proceedings of the Third International Symposium on Neuropterology, Berg en Dal, 1988). South African Department of Agricultural Development. Pretoria: 39-46.

Canard, M., Grimal, A. \& Carvalho, C. F., 1996. Weight changes during preimaginal development in green lacewings (Insecta: Neuroptera: Chrysopidae). In: Canard, M.,
Aspöck, H. \& Mansell, M. W. (eds.). Pure and Applied Research in Neuropterology (Proceedings of the Fifth International Symposium on Neuropterology, Cairo, 1994). Toulouse: 87-101.

Canard, M., Grimal, A. \& Hatté, M., 1992a. How does the green lacewing Mallada picteti (McLachlan) overwinter? (Insecta: Neuroptera: Chrysopidae). In: Canard, M., Aspöck, H. \& Mansell, M. W. (eds.). Current Research in Neuropterology (Proceedings of the Fourth International Symposium on Neuropterology, Bagnères-de-Luchon, 1991). Toulouse: 87-93.

Canard, M., Grimal, A. \& Monserrat, V. J., 1992b. A list of green and brown lacewings recently collected in the central Pyrenees (Insecta: Neuroptera: Chrysopidae, Hemerobiidae). In: Canard, M., Aspöck, H. \& Mansell, M. W. (eds.). Current Research in Neuropterology (Proceedings of the Fourth International Symposium on Neuropterology, Bagnères-de-Luchon, 1991). Toulouse: 95-97.

Canard, M. \& Jacquemin, G., 2006. Capture en France d'une chrysope rare ou méconnue: Chrysopa dubitans McLachlan, 1887 (Neuroptera). Bulletin de la Société Entomologique de France, 111: 483-485.

Canard, M. \& Jacquemin, G., 2013. Présence de Pseudomallada inornatus (Navás) dans le nord-est de la France (Neuroptera, Chrysopidae). Bulletin de la Société Entomologique de France, 118: 489-492.

Canard, M., Jacquemin, G. \& Vallet, A., 2015. Nuées de Chrysopes (Neuropterida Chrysopidae). L'Entomologiste, 71(4): 261-264.

Canard, M., Kokubu, H. \& Duelli, P., 1990. Tracheal Trunks supplying air to the foregut and feeding habits in adults of European lacewing species. In: Mansell, M. W. \& Aspöck, H. (eds.). Advances in Neuropterology (Proceedings of the Third International Symposium on Neuropterology, Berg en Dal, 1988). South African Department of Agricultural Development. Pretoria: 277-286.

Canard, M. \& Labrique, H., 1989. Bioecologie de la chrysope mediterraneenne Rexa lordina Navás (Neuroptera: Chrysopidae) et description de ses stades larvaires. Neuroptera International, 5: 151-158.

Canard, M. \& Laudého, Y., 1977. Les Néuroptères capturés au piège de McPhail dans les oliviers en Grèce. 1: lìle d'aguistri. Biologia Gallo-Hellenica, 7(1-2): 65-75.

Canard, M. \& Laudého, Y., 1980. Les Névroptères capturés au piège de $\mathrm{McPhail}$ dans les oliviers in Grèce. 2: La région d'Akrefnion. Biologia Gallo-Hellenica, 9: 139-146.

Canard, M., Letardi, A. \& Thierry, D., 2007. The rare Chrysopidae (Neuroptera) of southwestern Europe. Acta Oecologica, Oecologia Applicata, 31: 290-298.

Canard, M., Neverschivander, P. \& Michelakis, S., 1979. Les Névroptères capturés au piège de McPhail dans les oliviers in Grèce. 3: La Crète occidentale. Annales de la Société Entomologique de France (N.S.), 15(4): 607-615.

Canard, M. \& Principi, M. M., 1984. Development of Chrysopidae. In: Canard, M., Séméria, Y. \& New, T. R. (eds.). Biology of Chrysopidae. W. Junk. The Hague: 57-75.

Canard, M., Séméria, Y. \& New, T. R. (eds.), 1984. Biology of Chrysopidae. W. Junk. The Hague. 294 pp. 
Canard, M. \& Thierry, D., 2007. A historical perspective on nomenclature within the genus Chrysoperla Steinman, 1964 in Europe: the carnea-complex (Neuroptera Chrysopidae). Annali del Museo Civico di Storia Naturale di Ferrara, 8: 173-179.

Canard M. \& Thierry, D., 2013. Identification des Chrysoperla de France (Neuroptera: Chrysopidae). Revue de l'Association Roussillonnaise d'Entomologie, 22(2): 75-84.

Canard, M. \& Thierry, D., 2014. The distribution of Chrysoperla mutata (McLachlan 1898) and Chrysoperla pudica (Navás 1914) (Neuroptera: Chrysopidae). Entomofauna, 35(17): 405-412.

Canard, M., Thierry, D. \& Cloupeau, R., 2002. Les chrysopes vertes communes comme prédateurs dans les cultures: mais quelles chrysopes? Annales des Communications Orales, 2ème Conférence Internationale sur les moyens alternatifs de lutte contre les organismes nuisibles aux végétaux, Lille: 572-578.

Canard, M., Thierry, D., Whittington, A. E. \& Bozsik, A., 2010. The actual annual occurrence of the green lacewings of northwestern Europe (Neuroptera: Chrysopidae). In: Devetak, D., Lipovšek, S. \& Arnett, A. E. (eds.). Proceedings of the $10^{\text {th }}$ International Symposium on Neuropterology, Piran, 2008: 127-134.

Canard, M. \& Vannier, G., 1992. Adaptations of preimaginal stages of Nineta pallida (Schneider) to frost and heat (Insecta: Neuroptera: Chrysopidae). In: Canard, M., Aspöck, H. \& Mansell, M. W. (eds.). Current Research in Neuropterology (Proceedings of the Fourth International Symposium on Neuropterology, Bagnères-deLuchon, 1991). Toulouse: 75-85.

Canard, M. \& Volkovich, T. A., 2001. Outlines of lacewing development. In: McEwen, P. K., New, T. R. \& Whittington, A. E. (eds.). Lacewings in the Crop Environment. Cambridge University Press. Cambridge: 130-153. http://dx.doi.org/10.1017/CBO9780511666117.008

Canard, M., Vilton, D. \& Plant, C. W., 2014. On the occurrence of Nineta pallida (Schneider, 1846) and N. inpunctata (Reuter, 1894) in the British Isles and remarks on these rare green lacewings (Neu.; Chrysopidae). The Entomologist's Record and Journal of Variation, 126: 97-108.

Capra, F., 1976. Quanto si sa sugli Odonati e Neurotteri dell'Arcipelago Toscano. Lavori della Società Italiana di Biogeografia (N.S.), 5: 541-560.

Carotti, G., Nicoli Aldini, R. \& Letardi, A., 2009. Insecta Neuropterida delle Marche: attuale stato delle conoscenze. Proceedings of the XXII Congresso Nazionale Italiano di Entomologia, Ancona: 62.

Carpenter, F. M., 1935. Tertiary insects of the family Chrysopidae. Journal of Paleontology, 9: 259-271.

Carpenter, F. M., Snyder, T. E., Alexander, C. P., James, M. T. \& Hull, F. M., 1938. Fossil insects from the Creede Formation, Colorado. Part I. Introduction, Neuroptera, Isoptera and Diptera. Psyche, 45: 105-119. http://dx.doi. org/10.1155/1938/46082

Carpenter, F. M., 1992. Treatise on Invertebrate Paleontology. Part R. Arthropoda 4. Vols. 3 and 4: Superclass Hexapoda. The Geological Society of America and The University of Kansas. Vol. 3, xxi+277 pp.; vol. 4, ii $+279-655$.
Carpenter, G. D. H., 1938. Notes on insects collected in West Greenland by the Oxford University Greenland Expedition, 1936. Annals and Magazine of Natural History, 1(11): 529-553. http://dx.doi.org/10.1080/ 00222933808526799

Carvalho, C. F., 1992. Analyse des éléments du potentiel reproducteur en vue de la production de Chrsoperla mediterranea (Hölzel, 1972) (Neuroptera: Chrysopidae). Thèse Grade de Docteur. Université Paul-Sabatier. Toulouse. 164 pp.

Carvalho, C. F., Canard, M. \& Alauzet, C., 1996. Comparison of the fecundities of the Neotropical green lacewing Chrysoperla externa (Hagen) and the West-Palaearctic Chrysoperla mediterranea (Hölzel) (Insecta: Neuroptera: Chrysopidae). In: Canard, M., Aspöck, H. \& Mansell, M. W. (eds.). Pure and Applied Research in Neuropterology (Proceedings of the Fifth International Symposium on Neuropterology, Cairo, 1994). Toulouse: 103-107.

Carvalho, C. F., Canard, M. \& Alauzet, C., 2002. Influence of the density of Chrysoperla mediterranea (Hölzel, 1972) (Neuroptera: Chrysopidae) adults on its laboratory reproduction potential. Acta Zoologica Academiae Scientiarum Hungaricae, 48(Suppl. 2): 61-65.

Carvalho, C. F., Souza, B. \& Santos, T. M., 1998. Predation capacity and reproduction potential of Chrysoperla externa (Hagen) (Neuroptera, Chrysopidae) fed on Alabama argillacea (Hübner) eggs. In: Panelius, S. P. (ed.). Neuropterology 1997 (Proceedings of the Sixth International Symposium on Neuropterology, Helsinki, 1998). Acta Zoologica Fennica, 209: 83-86.

Carvalho, P. J. M. M. P. de, 1994. Die weltweite Bedeutung der Chrysopiden im Pflanzenschutz unter besonder Berücksichtigung der Situation in Portugal. Diplomarbeit Landwirtschaft Fachhochschule Nürtingen.

Carvalho, M. U. M. M. P. de, 1997. Contribuição para o conhecimento dos crisopídeos em Portugal (Neuroptera, Chrysopidae). Agronomia Lusitana, 45(suplemento 1): $1-41$.

Cervera, F., 1922. Algunos insectos recogidos por D. Fermín Cervera en la provincia de Tarragona, Castellón y Valencia. Boletín de la Sociedad Entomológica de España, 5: 147-148.

Chapman, J. W., Reynolds, D. R., Smith, A. D., Smith, E. T. \& Woiwod, I. P., 2004. An aerial netting study of insects migrating at high altitude over England. Bulletin of Entomological Research, 94: 123-136. http://dx.doi. org/10.1079/BER2004287

Chapman, J. W., Reynolds, D. R., Brooks, S. J., Smith, A. D. \& Woiwod, I. P., 2006. Seasonal variation in the migration strategies of the green lacewing Chrysoperla carnea species complex. Ecological Entomology, 31: 378-388. http://dx.doi.org/10.1111/j.1365-2311.2006.00797.x

Chen, S. H. \& Young, B., 1941. On the protective value of the egg-pedicel of Chrysopidae. Sinensia, 12: 211-215.

Cheng, L. \& Birch, M. C., 1978. Insects flotsam: an unstudied marine resource. Ecological Entomology, 3: 87-97. http://dx.doi.org/10.1111/j.1365-2311.1978.tb00907.x

Cianchi, R. \& Bullini, L., 1992. New data on sibling species in chrysopid lacewings: the Chrysoperla carnea (Stephens) and Mallada prasinus (Burmeister) complexes 
(Insecta: Neuroptera: Chrysopidae). In: Canard, M., Aspöck, H. \& Mansell, M. W. (eds.). Current Research in Neuropterology (Proceedings of the Fourth International Symposium on Neuropterology, Bagnères-deLuchon, 1991). Toulouse: 99-104.

Clancy, D. W., 1946. The insect parasites of the Chrysopidae (Neuroptera). University of California Publications in Entomology, 7: 403-496.

Cockerell, T. D. A., 1908. Fossil Chrysopidae. The Canadian Entomologist, 40: 90-91. http://dx.doi.org/10.4039/ Ent4090-3

Cockerell, T. D. A., 1909. Two fossil Chrysopidae. The Canadian Entomologist, 41: 218-219. http://dx.doi.org/ 10.4039/Ent41218-7

Cockerell, T. D. A., 1914. New and little-known insects from the Miocene of Florissant, Colorado. The Journal of Geology, 22: 714-724. http://dx.doi.org/10.1086/ 622186

Coderre, D. \& Tourneur, J.C., 1986. Verticle distribution of aphids and aphidophagous insects on maize. In: Hodek, I. (ed.). Proceedings of the 2nd Symposium on the Ecology of Aphidophaga, 1984. W. Junk: 291-296.

Codina, A., 1913. Comunicacions. Butlletí de la Institució Catalana d'Història Natural, 13(7): 98.

Cole, F. R., 1925. The natural enemies of the citrus aphid, Aphis spiraecola (Patch). Journal of Economic Entomology, 18: 219-223. http://dx.doi.org/10.1093/jee/18. 1.219

Cole, F. R., 1933. Natural control of the citrus mealybug. Journal of Economic Entomology, 26: 855-864. http:// dx.doi.org/10.1093/jee/26.4.855

Coma, P., 1918. Neurópteros de Murcia. Boletín de la Sociedad Entomológica de España, 1(7): 152.

Compte, A., 1967. Resultados de una expedición Zoologica a las Islas Pitiusa. III Neurópteros y Odonatos. Graellsia, 23: $127-142$.

Compte, A., 1968. Orden Neuroptera. In: Sintesis de la fauna de Menorca, su naturaleza y un ensayo acerca de su origen. Revista de Menorca: 142-142.

Comstock, J. H., 1918. The wings of Insects. Comstock Publishing. Ithaca. $430 \mathrm{pp}$.

Corrales, N. \& Campos, M., 2004. Populations, longevity, mortality and fecundity of Chrysoperla carnea (Neuroptera, Chrysopidae) from olive-orchards with different agricultural management systems. Chemosphere, 57: 1613-1619. http://dx.doi.org/10.1016/j. chemosphere.2004.09.019

Costa, A., 1860-1870. Fauna del Regno di Napoli ossia enumerazione di tutti gli animali che abitano le diverse regioni di questo regno e le acque che le bagnano e descrizione de' nuovi o poco esattamente conosciuti con figure ricavate da originali viventi e dipinte al naturale. Stamperia di Antonio Cons. Napoli. Para años de edición ver Sherborn (1937) y/o Pantaleoni (1999).

Costa, A., 1863. Nuovi studii sulla entomologia della Calabria ulteriore. Atti della Accademia delle Scienze Fisiche e Matematiche di Napoli, 1(2): 1-80.

Cuní y Martorell, M., 1879. Excursión entomológica y botánica a la Montaña de Montserrat en Junio de 1878. Imprenta Catalana de Obradors y C. ${ }^{\text {a }} 23$ pp.
Cuní y Martorell, M., 1880. Excursión entomológica y botánica a San Miguel de Fay. Anales de la Sociedad Española de Historia Natural, 9: 204-242.

Cuní y Martorell, M., 1881. Excursión entomológica y botánica a la Cerdaña Española (Cataluña). Anales de la Sociedad Española de Historia Natural, 10: 367-389.

Cuní y Martorell, M., 1882. Resultado de una exploración entomológica y botánica por el término de La Garriga (Cataluña). Anales de la Sociedad Española de Historia Natural, 11: 83-101.

Cuní y Martorell, M., 1888. Insectos observados en los alrededores de Barcelona. Anales de la Sociedad Española de Historia Natural, 17: 133-191.

Cuní y Martorell, M., 1889. Vuyt dias en Camprodon. Bulletí de l'Associació d'Excursions Catalana, 124-126 y 127-129: 5-43.

Cuní y Martorell, M., 1897. Fauna entomológica de la villa de Calella (Cataluña, Provincia de Barcelona). Anales de la Sociedad Española de Historia Natural, 26: 281-339.

Cuní y Martorell, M., 1899. Nueva especie de Neuróptero "Urothemis advena" Selys descubierta en Cataluña. Boletín y Memorias de la Real Academia de Ciencias y Artes de Barcelona, 1899: 1-7.

Cuní y Martorell, M., 1902. Una excursión sin salir de casa. Boletín de la Sociedad Aragonesa de Ciencias Naturales, 7: 152-154.

Curtis, J., 1834. British entomology; being illustrations and descriptions of the genera of insects found in Great Britain and Ireland: containing coloured figures from nature of the most rare and beautiful species, and in many instances of the plants upon which they are found. Vol. IV, Neuroptera. L. Reeve. London. http://dx.doi. org/10.5962/bhl.title. 104503

Cuvier, G. L. C. F. D., 1817. Le règne animal distribué d'après son organisation, pour servir de base à l'histoire naturelle des animaux et d'introduction a l'anatomie comparée. 4 Vols. Deterville. Paris. http://dx.doi.org/10.5962/ bhl.title. 41460

Daane, K. M., 2001. Ecological studies of released lacewings in crops. In: McEwen, P. K., New, T. R. \& Whittington, A. E. (eds.). Lacewings in the Crop Environment. Cambridge University Press. Cambridge: 338-350. http://dx.doi.org/ 10.1017/CBO9780511666117.017

Dannreuthers, T., 1934. Migration records. The Entomologist, 67: 254-257.

Dathe, H. H., 1999. Das erste Insekt des Jahres: die Florfliege Chrysoperla carnea (Stephens, 1836) (Neur., Chrysopidae). Entomologische Nachrichten und Berichte, 43: 1-3.

De Geer, C., 1778. Mémoires pour servir à l'histoire des insectes. Vol. VII. Hosselberg. Stockholm, 950 pp.

De Geer, C., 1783. Genera et species insectorum e generossimi auctoria scriptis. Lebrecht. Lipsiae. 220 pp.

Devetak, D., 1984. Megaloptera, Raphidioptera and Planipennia in Slovenia (Yugoslavia). Faunistical contribution. Neuroptera International, 3: 55-72.

Devetak, D., 1992. Physiology of neuropteran vibration receptors: Chrysoperla carnea (Stephens) as an example (Insecta: Neuroptera: Chrysopidae). In: Canard, M., Aspöck, H. \& Mansell, M. W. (eds.). Current Research in Neuropterology (Proceedings of the Fourth 
International Symposium on Neuropterology, Bagnèresde-Luchon, 1991). Toulouse: 105.

Devetak, D., 1998. Detection of substrate vibration in Neuropteroidea: a review. In: Panelius, S. P. (ed.). Neuropterology 1997 (Proceedings of the Sixth International Symposium on Neuropterology, Helsinki, 1998). Acta Zoologica Fennica, 209: 87-94.

Devetak, D., 2014. Host diversity and seasonality of Hyalospora hemerobii (Apicomplexa: Eugregarinorida: Hirmocystidae) infections in lacewings. Biologia, 69(11): 1585-1592. http://dx.doi.org/10.2478/s11756-0140456-7

Devetak, D., Akšic, P., Koren, T. \& Ivajnšic, D., 2015. Two sibling green lacewing species, Chrysopa pallens and Chrysopa gibeauxi (Insecta: Neuroptera: Chrysopidae) in Slovenia and Western Balkan Countries. Annales, Series Historia Naturalis, 25,1: 47-54.

Devetak, D. \& Pabst, M. A., 1994. Structure of the subgenual organ in the green lacewing, Chrysoperla carnea. Tissue and Cell, 26: 249-257. http://dx.doi.org/10.1016/ 0040-8166(94)90100-7

Devetak, D., Pabst, M. A. \& Lipovsek Delakorda, S., 2004. Leg chordotonal organs and campanifrorm sensilla in Chrysoperla Steinmann 1964 (Neuroptera): structure and function. Denisia, 13: 163-171.

Díaz-Aranda, L. M., 1992. Estadíos preimaginales de los crisópidos ibéricos (Insecta, Neuroptera: Chrysopidae). Ph.D. Dissertation. Facultad de Ciencias, Universidad de Alcalá. 305 pp.

Díaz-Aranda, L. M. \& Monserrat, V. J., 1988a. Contribución al conocimiento de los neurópteros de Jaén. (Insecta, Neuropteroidea). Boletín de la Asociación Española de Entomología, 12: 111-123.

Díaz-Aranda, L. M. \& Monserrat, V.J., 1988b. Contribución al conocimiento de los neurópteros de Teruel (Insecta, Neuropteroidea). Boletín de la Asociación Española de Entomología, 12: 215-231.

Díaz-Aranda, L. M. \& Monserrat, V. J., 1988c. Contribución al conocimiento de los Neurópteros de Granada (Insecta, Neuropteroiea). Actas del III Congreso Ibérico de Entomología, Granada: 211-227.

Díaz-Aranda, L. M. \& Monserrat, V. J., 1988d. Estadios larvarios de los neurópteros ibéricos IV: Mallada granadensis Pictet, 1865 (Planipennia: Chrysopidae). Neuroptera International, 5: 111-119.

Díaz-Aranda, L. M. \& Monserrat, V. J., 1990a. Estadios larvarios de los neurópteros ibéricos VI: Chrysoperla carnea Stephens, 1836, Crysoperla mediterranea Hölzel, 1972 y Chrysoperla ankylopteryformis Monserrat y Díaz-Aranda, 1989 (Insecta, Neuroptera: Chrysopidae). Boletín de Sanidad Vegetal, Plagas, 16: 675-689.

Díaz-Aranda, L. M. \& Monserrat, V. J., 1990b. Estadios larvarios de los neurópteros ibéricos VIII: Mallada venosus Rambur, 1842 (Planipennia: Chrysopidae). Neuroptera International, 6: 95-105.

Díaz-Aranda, L. M. \& Monserrat, V. J., 1991. Estadios larvarios de los neurópteros ibéricos (VII). Mallada picteti (McLachlan, 1880) (Planipennia: Chrysopidae). Neuroptera International, 6: 141-147.

Díaz-Aranda, L. M. \& Monserrat, V. J., 1992. Descripción de los estadios larvarios de Brinckochrysa nachoi
Monserrat, 1977 (Neuroptera, Chrysopidae). Nouvelle Revue d'Entomologie (N.S.), 9: 207-214.

Díaz-Aranda, L. M. \& Monserrat, V. J., 1994. The larval stages of genus Cunctochrysa Hölzel, 1970 in Europe (Neuroptera, Chrysopidae). Deutsche Entomologische Zeitschrift, 41: 163-171. http://dx.doi.org/10.1002/mmnd. 19940410117

Díaz-Aranda, L. M. \& Monserrat, V. J., 1995. Aphidophagous predator diagnosis: key to genera of European chrysopid larvae (Neur.: Chrysopidae). Entomophaga, 40: 169-181. http://dx.doi.org/10.1007/BF02373066

Díaz-Aranda L. M. \& Monserrat, V. J., 1996. On the Larval Stages of Genus Suarius Navás, 1914 in Europe (Neuroptera: Chrysopidae). Deutsche Entomologische Zeitschrift, 43(1): 89-97. http://dx.doi.org/10.1002/mmnd. 19960430109

Díaz-Aranda, L.M., Monserrat, V. J. \& Marín, F., 1986a. Composición biogeográfica de los neurópteros de Guadalajara (Insecta, Neuropteroidea: Planipennia). Actas. VIII Jornadas de la Asociacion Española de Entomologia, Sevilla: 1121-1130.

Díaz-Aranda, L.M., Monserrat, V. J. \& Marín, F., 1986 b. Contribución al conocimiento de los neurópteros de Guadalajara (Insecta, Neuropteroidea). Actas. VIII Jornadas de la Asociacion Española de Entomologia, Sevilla: 1131-1141.

Díaz-Aranda, L. M., Monserrat, V. J. \& Tauber, C. A., 2001. Recognition of larval Neuroptera. Recognition of early stages of Chrysopidae. In: McEwen, P. K., New, T. R. \& Whittington, A. E. (eds.). Lacewings in the Crop Environment. Cambridge University Press. Cambridge: 60-81.

Dicke, M. \& Sabelis, M. W., 1988. Infochemical terminology: based on cost-benefit analysis rather than origin of compounds? Functional Ecology, 2: 131-139. http://dx.doi. org/10.2307/2389687

Dinter, A., 1998a. Interactions between spider and lacewing predators (Araneae: Erigonidae and Neuroptera: Chrysopidae) and their effects on the grain aphid Sitobion avenae Fab. (Homoptera: Aphididae). IOBC/WPRS Bulletin, 21: 91-101.

Dinter, A., 1998b. Intraguild predation between erigonid spiders, lacewing larvae and carabids. Journal of Applied Entomology, 122: 163-167. http://dx.doi.org/ 10.1111/j.1439-0418.1998.tb01479.x

Dobosz, R., 1991. Forcipomyia eques Joh. (Diptera, Ceratopogonidae), an ectoparasite of lace-wings (Planipennia, Chrysopidae) in Poland. Rocznik Muzeum Górnoslaskiego w Bytomiu, Entomologia, 2: 235-237.

Dodds, C. \& McEwen, P. K., 1998. Electroantennogram responses of green lacewings (Chrysoperla carnea) to plant volatiles: preliminary results. In: Panelius, S. P. (ed.). Neuropterology 1997 (Proceedings of the Sixth International Symposium on Neuropterology, Helsinki, 1998). Acta Zoologica Fennica, 209: 99-102.

Duelli, P., 1980a. Adaptive dispersal and appetitive flight in the green lacewing, Chrysopa carnea. Ecological Entomology, 5: 213-220. http://dx.doi.org/10.1111/j.13652311.1980.tb01144.x

Duelli, P., 1980b. Preovipository migration flights in the green lacewing, Chrysopa carnea (Planipennia, Chrysopidae). 
Behavioral Ecology and Sociobiology, 7: 239-246. http:// dx.doi.org/10.1007/BF00299370

Duelli, P., 1981a. Is larval cannibalism in lacewings adaptive? (Neuroptera: Chrysopidae). Researches on Population Ecology, 23: 193-209. http://dx.doi.org/10.1007/ BF02515626

Duelli, P., 1981b. Ein funktionelles Konzept für die Begriffe Dispersal und Migration, dargestellt anhand der Ausbreitungsdynamik der Florfliege Chrysopa carnea Steph. Mitteilungen der Deutschen Gesellschaft für Allgemeine und Angewandte Entomologie, 3: 49-52.

Duelli, P., 1984a. Dispersal and oviposition strategies in Chrysoperla carnea. In: Gepp, J., Aspöck, H. \& Hölzel, H. (eds.). Progress in World's Neuropterology (Proceedings of the 1st International Symposium on Neuropterology, Graz): 133-145.

Duelli, P., 1984b. Flight, dispersal, migration. In: Canard, M., Séméria, Y. \& New, T. R. (eds.). Biology of Chrysopidae. W. Junk. The Hague: 110-116.

Duelli, P., 1984c. Oviposition. In: Canard, M., Séméria, Y. \& New, T. R. (eds.). Biology of Chrysopidae. W. Junk. The Hague: 129-133.

Duelli, P., 1986a. Flight activity patterns in lacewings (Planipennia, Chrysopidae). In: Gepp, J., Aspöck, H. \& Hölzel, H. (eds.). Recent Research in Neuropterology (Proceedings of the 2nd International Symposium on Neuropterology, Hamburg, 1984). Graz: 165-170.

Duelli, P., 1986b. Diapause induction in Chrysoperla carnea: what photoperiodical parameters are actually measured? In: Hodek, I. (ed.). Ecology of Aphidophaga. Academia, Prague \& W. Junk, Dordrecht: 239-244.

Duelli, P., 1986c. A "missing link" in the evolution of the egg pedicel in lacewings? Experientia, 42: 624. http:// dx.doi.org/10.1007/BF01955564

Duelli, P., 1987a. Eine isolierte Reliktpopulation von Chrysoperla mediterranea (Planipennia: Chrysopidae) in der Schweiz. Mitteilungen der Schweizerischen Entomologischen Gesellschaft, 60: 301-306.

Duelli, P., 1987b. The influence of food on the ovipositionsite selection in a predatory and honeydew-feeding lacewing species (Planipennia: Chrysopidae). Neuroptera International, 4: 205-210.

Duelli, P., 1989. Zwei für die Schweiz neue Florfliegenarten aus dem Wallis (Planipennia, Chrysopidae). Mitteilungen der Schweizerischen Entomologischen Gesellschaft, 62: 345-347.

Duelli, P., 1990. Diapause induction in Chrysoperla carnea (Stephens): how to match laboratory results with reality (Insecta: Neuroptera: Chrysopidae). In: Mansell, M. W. \& Aspöck, H. (eds.). Advances in Neuropterology (Proceedings of the Third International Symposium on Neuropterology, Berg en Dal, 1988). South African Department of Agricultural Development. Pretoria: 33-38.

Duelli, P., 1992. Body coloration and colour change in green lacewings (Insecta: Neuroptera: Chrysopidae). In: Canard, M., Aspöck, H. \& Mansell, M. W. (eds.). Current Research in Neuropterology (Proceedings of the Fourth International Symposium on Neuropterology, Bagnères-de-Luchon, 1991). Toulouse: 119-123.

Duelli, P., 1994. Rote Liste der gefährdeten Netzflügler der Schweiz. In: Duelli, P. Rote Listen der gefährdeten
Tierarten der Schweiz. Bundesamt für Umwelt, Wald und Landschaft. BUWAL-Reihe Rote Listen, EDMZ. Bern: 64-65.

Duelli, P., 1995. Neueste Entwicklungen im Chrysopa carnea-Komplex. Galathea, Supplement 2: 6-7.

Duelli, P., 1999. Honigtau und stumme Gesänge: Habitat- und Partnersuche bei Florfliegen (Neuroptera: Chrysopidae). Stapfia, 60: 35-48.

Duelli, P., 2001. Lacewings in field crops. In: McEwen, P. K., New, T. R. \& Whittington, A. E. (eds.). Lacewings in the Crop Environment. Cambridge University Press. Cambridge: 158-171. http://dx.doi.org/10.1017/ CBO9780511666117.010

Duelli, P., 2004. Der Glenofinger, eine spektakuläre prothorakale Drüse bei einer afrotropischen Florfliege (Neuroptera, Chrysopidae). Denisia, 13: 173-175.

Duelli, P., 2009. Neue Erkenntnisse zum Chrysoperla carnea - Komplex. DGaaE Nachrichten, 23: 86-87.

Duelli, P., Bolt, D. \& Henry, C.S., 2015. Neuroptera of the Caucasian Republic of Georgia. Entomological News, 124(4): 229-244. http://dx.doi.org/10.3157/021.124.0401

Duelli, P., Henry, C. S. \& Johnson, J. B. 1996. Kryptische Arten am Beispiel der Florfliegen: eine Herausforderung für die Systematik, die angewandte Entomologie und den Naturschutz (Neuroptera, Chrysopidae). Verhandlungen des XIV Internationalen Symposiums für Entomofaunistik in Mitteleuropa, München, 1994: 383-387.

Duelli, P., Hölzel, H. \& Mansell, M. W., 2010. Habitat and larvae of the enigmatic genus Kimochrysa Tjeder (Neuroptera: Chrysopidae) in South Africa. In: Devetak, D., Lipovšek, S. \& Arnett, A. E. (eds.). Proceedings of the $10^{\text {th }}$ International Symposium on Neuropterology, Piran, 2008: 153-158.

Duelli, P. \& Johnson, J. B., 1982. Behavioral origin of tremulation, and possible stridulation, in green lacewings (Neuroptera, Chrysopidae). Psyche, 88: 375-381. http:// dx.doi.org/10.1155/1981/32704

Duelli, P. \& Johnson, J. B., 1992. Adaptive significance of the egg pedicel in green lacewings (Insecta: Neuroptera: Chrysopidae). In: Canard, M., Aspöck, H. \& Mansell, M. W. (eds.). Current Research in Neuropterology (Proceedings of the Fourth International Symposium on Neuropterology, Bagnères-de-Luchon, 1991). Toulouse: 125-134.

Duelli, P., Johnson, J.B., Waldburger, M. \& Henry, C.S., 2014. A new look at adaptive body coloration and color change in "common green lacewings" of the genus Chrysoperla (Neuroptera: Chrysopidae). Annals of the Entomological Society of America, 107(2): 382-3888. http://dx.doi.org/10.1603/AN13139

Duelli, P., Obrist, M. K. \& Flückiger, P. F., 2002. Forest edges are biodiversity hotspots - also for Neuroptera. Acta Zoologica Academiae Scientiarum Hungaricae, 48(Suppl. 2): 75-87.

Dusmet, J. M., 1928. Insectos neurópteros y afines recogidos por el Sr. Dusmet. Boletín de la Sociedad Entomológica de España, 11: 164.

Dvořák, L. \& Gabriš, R., 2015. Hypochrysa elegans (Burmeister, 1839) (Neuroptera: Chrysopidae) - nová zlatoočka pro Čechy. Západočeské entomologické listy, 6: 44-46.

Dziędzielewicz, J., 1891. Przeglad fauny krajowej Owadow Siatkoskrzydlych (Neuroptera, Pseudoneuroptera). Sprawozdanie Komisji Fizjograficznej, 26: 26-150. 
Edwards, F. W., 1932. A midge attacking lace-wing flies in Britain. The Entomologist's Monthly Magazine, 68: 114-115.

Eglin, W., 1940. Die Neuropteren der Umgebung von Basel. Revue Suisse de Zoologie, 47: 243-358.

Eglin, W. 1968. Chrysopa walkeri, M'L. als Lichtfang in der Schweiz und doch keine Schweizer Neuroptere. Mitteilungen der schweizerischen entomologischen Gesellschaft, 41(1-4): 320-321.

Eglin-Dederding, W., 1982. Modele de dispersion des Nevroptères (Neuroptera). Neuroptera International, 2: 77-78.

Eichele, G., 1972. Über das Sexualverhalten der Florfliege (Chrysopa carnea St.). Schweizer Jugend Forscht, 5(6): 3-7.

Eichele, G. \& Villiger, W., 1974. Untersuchungen an den Stridulationsorganen der Florfliege, Chrysopa carnea (St.) (Neuroptera: Chrysopidae). International Journal of Insect Morphology and Embryology, 3: 41-46. http:// dx.doi.org/10.1016/S0020-7322(74)81005-6

Eisner, T., Attygalle, A. B., Conner, W. E., Eisner, M., MacLeod, E. \& Meinwald, J., 1996. Chemical egg defense in a green lacewing (Ceraeochrysa smithi). Proceedings of the National Academy of Sciences of the United States of America, 93: 3280-3283. http://dx.doi. org/10.1073/pnas.93.8.3280

Eisner, T., Carrel, J. E., Tassell, E. van, Hoebeke, E. R. \& Eisner, M., 2002. Construction of a defensive trash packet from Sycamore leaf trichomes by a chrysopid larva (Neuroptera: Chrysopidae). Proceedings of the Entomological Society of Washington, 104: 437-446.

Eisner, T., Eisner, M., Rossini, C., Iyengar, V. K., Roack, B. L., Benedikt, E. \& Meinwald, J., 2000. Chemical defense against predation in an insect egg. Proceedings of the National Academy of Sciences of the United States of America, 97: 1634-1639. http://dx.doi.org/10.1073/ pnas.030532797

Eisner, T., Hicks, K., Eisner, M. \& Robson, D. S., 1978. "Wolf-in-sheep's-clothing" strategy of a predaceous insect larva. Science (New York), 199: 790-794. http:// dx.doi.org/10.1126/science.199.4330.790

Eisner, T. \& Silberglied, R. E., 1988. A chrysopid larva that cloaks itself in mealybug wax. Psyche, 95: 15-19. http:// dx.doi.org/10.1155/1988/97301

El Arnaouty, S. A. \& Ferran, A., 1992. Activities of Chrysoperla carnea (Stephens) third-instar larvae (Insecta: Neuroptera: Chrysopidae) released on greenpepper plants against Myzus persicae (Sulzer) (Homoptera: Aphididae). In: Canard, M., Aspöck, H. \& Mansell, M. W. (eds.). Current Research in Neuropterology (Proceedings of the Fourth International Symposium on Neuropterology, Bagnères-de-Luchon, 1991). Toulouse: 135-139.

El Arnaouty, S. A., Ferran, A. \& Beyssat-Arnaouty, V., 1996. Food consumption by Chrysoperla carnea (Stephens) and Chrysoperla sinica (Tjeder) of natural and substitute prey: determination of feeding efficiency (Insecta: Neuroptera: Chrysopidae). In: Canard, M., Aspöck, H. \& Mansell, M. W. (eds.). Pure and Applied Research in Neuropterology (Proceedings of the Fifth International Symposium on Neuropterology, Cairo, 1994). Toulouse: 109-117.

Engel, M. S. \& Grimaldi, D. A., 2007. The neuropterid fauna of Dominican and Mexican amber (Neuropterida:
Megaloptera, Neuroptera). American Museum Novitates, 3587: 1-58. http://dx.doi.org/10.1206/0003-0082(2007) 3587\%5B1:TNFODA\%5D2.0.CO;2

Engel, M. S. \& Grimaldi, D. A., 2008. Diverse Neuropterida in Cretaceous amber, with particular reference to the paleofauna of Myanmar (Insecta). Nova Supplementa Entomologica, 20: 1-86.

Esben-Petersen, P., 1922. New species of Neuroptera in the British Museum. Annals and Magazine of Natural History, 10(9): 617-621. http://dx.doi.org/10.1080/ 00222932208632817

Esben-Petersen, P., 1931. Inventa entomologica itineris Hispanici et Maroccani, quod a. 1926 fecerunt Harald et Håkan Lindberg. VIII. Neuroptera. Commentationes Biologicae, 3(13): 1-6.

Fabricius, J. C., 1775. Systema entomologiae, sistens insectorvm classes, ordines, genera, species, adiectis synonymis, locis, descriptionibvs, observationibvs. Kortii. Flensbvrgi et Lipsiae. 832 pp. http://dx.doi.org/10.5962/ bhl.title.36510

Fabricius, J. C., 1777. Genera insectorvm eorvmqve characteres natvrales secvndvm nvmervm, figvram, sitvm et proportionem omnivm partivm oris adiecta mantissa speciervm nvper detectarvm. M.F. Bartsch. Chilonii. 310 pp. http://dx.doi.org/10.5962/bhl.title.12286

Fabricius, J. C., 1778. Philosophia entomologica sistens scientiae fvndamenta adiectis definitionibvs, exemplis, observationibvs, advmbrationibvs. C.E. Bohn. Hambvrgi et Kilonii. [xii]+178 pp. http://dx.doi.org/10.5962/bhl. title. 10672

Fabricius, J. C., 1781. Species insectorvm exhibentes eorvm differentias specificas, synonyma avctorvm, loca natalia, metamorphosin adiectis observationibvs, descriptionibvs. Tome 1. C.E. Bohnii, Hamburgi et Kilonii. 552 pp. http:// dx.doi.org/10.5962/bhl.title. 11658

Fabricius, J. C., 1793. Entomologia systematica emendata et aucta secundum classes, ordines, genera, species adjectis synonimis, locis observationibus, descriptionibus. Tome 2. C.G. Proft. Hafniae. 519 pp.

Fabricius, J. C., 1798. Supplementum entomologiae systematicae. Prof et Storch. Hafniae. 572 pp. http://dx.doi. org/10.5962/bhl.title.65803

Fernández, J., 2003. Noticia de nuevos taxones para la ciencia en el ámbito íbero-balear y macaronésico. Graellsia, 59(1): 101-130. http://dx.doi.org/10.3989/graellsia.2003. v59.11.230

Feytaud, J., 1913. Les Hémérobes ou Chrysopes. Bulletin de la Société d'Études et de Vulgarisation de la Zoologie Agricole, 12: 138-148.

Fleschner, C. A., 1950. Studies on searching capacity of the larvae of three predators of the citrus red mite. Hilgardia, 20: 233-265. http://dx.doi.org/10.3733/hilg. v20n13p233

Fleschner, C. A. \& Scriven, G. T., 1957. Effect of soiltype and DDT on ovipositional response of Chrysopa californica (Coq.) on lemon trees. Journal of Economic Entomology, 50: 221-222.

Flint, H. M., Salter, S. S., Walters, S., 1979. Caryophyllene: an attractant for the green lacewing. Environmental Entomology, 8: 1123-1125. http://dx.doi.org/10.1093/ee/8.6.1123 
Forsius, R., 1924. On Ceratopogoninae as ectoparasites on Neuroptera. Notulae Entomologicae, 4: 98-99.

Frankenberg, G, v., 1938. Das Ei der Florfliege. Natur und Volk, 68(12): 606-612.

Fraser, F. C., 1945. Biological notes on Chrysopa dorsalis Burm. (Neuroptera). Proceedings of the Royal Entomological Society of London, Series A, General Entomology, 20: 116-121. http://dx.doi.org/10.1111/j.1365-3032.1945. tb01055.x

Frazer, B. D., 1988. Predators. In: Minks, A. K. \& Harrewijn, P. (eds). Aphids, their biology, natural enemies and control. Vol. 2B. Elsevier. Amsterdam: 217-230.

Fuente, J. M. de la, 1906. Datos para la fauna de la provincia de Ciudad Real. Boletín de la Real Sociedad Española de Historia Natural, 1906: 284-289.

Fuente, J. M. de la, 1929. La fauna de la Provincia de Ciudad Real. Establecimiento tipográfico del Hospicio Provincial. Ciudad Real. 250 pp.

Gaspar, A., 1903. Especies o fauna nuevas descritas en España en 1902. Boletín de la Sociedad Aragonesa de Ciencias Naturales, 2: 62-63.

Geoffroy, É. L., 1762. Histoire abregée des insectes qui se trouvent aux environs de Paris; dans laquelle ces animaux sont rangés suivant un ordre méthodique. Vol. 2. Durand, Paris. 690 pp. http://dx.doi.org/10.5962/bhl. title. 14710

Gepp, J., 1977a. Die Planipennier der Steiermark (Neuroptera s.str., Neuropteroidea, Insecta): Autökologie und Regionalfaunistik. Mitteilungen des Naturwissenschaftlichen Vereins für Steiermark, 107: 171-206.

Gepp, J., 1977b. Anisochrysa inornata (Navas, 1902) neu für Mitteleuropa (Planipennia, Chrysopidae). Nachrichtenblatt der Bayerischen Entomologen, 26(3): 43-47.

Gepp, J., 1981. Rote Liste der gefährdeten Netzflüglerarten der Steiermark (Megaloptera, Raphidioptera und Planipennia). Steirischer Naturschutzbrief, Sonderheft, 3: 91-96.

Gepp, J., 1983a. Rote Liste der gefährdeten Netzflügler Österreichs (Megaloptera, Raphidioptera und Planipennia). In: Rote Listen gefährdeter Tiere Österreichs. Bundesministeriums für Gesundheit und Umweltschutz. Wien: 145-147.

Gepp, J., 1983b. Schlüssel zur Freilanddiagnose mitteleuropäischer Chrysopidenlarven (Neuroptera, Chrysopidae). Mitteilungen des Naturwissenschaftlichen Vereins für Steiermark, 113: 101-132.

Gepp, J., 1984a. Erforschungsstand der Neuropteren-Larven der Erde (mit einem Schlüssel zur larvaldiagnose der Familien, einer Übersicht von 340 beschreibenen Larven und 600 Literaturzitaten). In: Gepp, J., Aspöck, H. \& Hölzel, H. (eds.). Progress in World's Neuropterology (Proceedings of the 1st International Symposium on Neuropterology, Graz): 183-239.

Gepp, J., 1984b. Morphology and anatomy of the preimaginal stages of Chrysopidae: a short survey. In: Canard, M., Séméria, Y. \& New, T. R. (eds.). Biology of Chrysopidae. W. Junk. The Hague: 9-19.

Gepp, J., 1986. Biology and larval diagnosis of central European Neuroptera (a review of present knowledge). In: Gepp, J., Aspöck, H. \& Hölzel, H. (eds.). Recent Research in Neuropterology (Proceedings of the 2nd International Symposium on Neuropterology, Hamburg, 1984). Graz: 137-144.

Gepp, J., 1989. Zur Ökologischen Differenzierung der präemaginalen Stadien baumbewohnender Chrysopiden im Alpenraum (Planipennia: Chrysopidae). Sitzungsberichte der Österreicheschen Akademie der Wissenschaften, Mathematische-Naturwissenschaftliche Klasse, 197: 1-73.

Gepp, J., 1990. An illustrated review of egg morphology in the families of Neuroptera (Insecta: Neuropteroidea). In: Mansell, M. W. \& Aspöck, H. (eds.). Advances in Neuropterology (Proceedings of the Third International Symposium on Neuropterology, Berg en Dal, 1988). South African Department of Agricultural Development. Pretoria: 131-149.

Gepp, J., 1999. Neuropteren als Indikatoren der Naturraumbewertung. Eignung als Modellgruppe, Methodenwahl, Fallbeispiele sowie Diskussion möglicher Fragestellungen (Neuropterida). Stapfia, 60: 167-208.

Gerstaecker, [C. E.] A., 1863. Ueber einige neue Planipennien aus den familien der Hemerobiiden und Panorpiden. Stettiner Entomologische Zeitung, 24: 168-188.

Geus, A., 1969. Sporentierchen, Sporozoa: die Gregarinida der land- und süßwasserbewohnenden Arthropoden Mitteleuropas. In: Dahl F. (ed.), Die Tierwelt Deutschlands und der angrezenden Meeresteile nach ihren Merkmalen und nach ihrer Lebensweise, T. 57. Gustav Fischer Verlag. Jena: 1-608.

Gil, C., 1915. Excursiones por Benanarre (Huesca). Boletín de la Sociedad Aragonesa de Ciencias Naturales, 14: 24-26.

Girard, M. J. A., 1862. Indication et discussion d'un nouveau caractère générique du genre Hemerobius, tribu des Myrméléoniens, ordre des Névroptères et description de deux espèces nouvelles de ce genre recucillies par le R. P. Montrouzier et désignées par Lui sons les noms de Chloromelas et stigma. Annales de la Société Entomologique de France, 2(4): 597-614.

Girault, A. A., 1907. Oviposition of Chrysopa species. Entomological News, 18: 316.

González López, A. E., 2002. Neurópteros nuevos para Aragón o sus provincias. Boletín de la Sociedad Entomológica Aragonesa, 30: 203.

Greve, L., 1968. Forcipomyia eques, (Diptera), ektoparasitt på Gulloye i Norge. Fauna (Oslo), 21: 59-60.

Greve, L., 1969. An aerial-drift of Neuroptera from Hardangervidda, western Norway. Arbok for Universitetet i Bergen, Matematisk-Naturvitenskapelig, 2: 1-15.

Greve, L., 1984. Chrysopid distribution in northern latitudes. In: Canard, M., Séméria, Y. \& New, T. R. (eds.). Biology of Chrysopidae. W. Junk. The Hague: 180-186.

Greve, L. \& Kobro, S., 1998. Preliminary data on abundance of phototactic Neuroptera and Rephidioptera in SE Norway as indicated by light-trap catches. In: Panelius, S. P. (ed.). Neuropterology 1997 (Proceedings of the Sixth International Symposium on Neuropterology, Helsinki, 1998). Acta Zoologica Fennica, 209: 119-120.

Grimal, A., 1984. La distribution des chrysopides (Neuroptera) dans les Pyrénées centrales françaises: etude preliminare. Neuroptera International, 3(1): 7-12. 
Grimal, A., 1986. Iconographia neuropterorum mundi (II). Structure chorionique externe chez Hypochrysodes elegans (Burmeister) (Neuroptera: Chrysopidae). Neuroptera International, 4: 122-124.

Grimal, A. \& Canard, M., 1996. Preliminary observations on the effect of photoperiod on the life cycle of the green lacewing Hypochrysa elegans (Burmeister) (Insecta: Neuroptera: Chrysopidae: Nothochrysinae). In: Canard, M., Aspöck, H. \& Mansell, M. W. (eds.). Pure and Applied Research in Neuropterology (Proceedings of the Fifth International Symposium on Neuropterology, Cairo, 1994). Toulouse: 119-127.

Grimaldi, D. A., 1996. Amber: window to the past. Harry N. Abrams \& American Museum of Natural History. New York. 216 pp.

Grimaldi, D. A. \& Engel, M. S., 2005. Evolution of the Insects. Cambridge University Press. New York. xv+755 pp.

Grimaldi, D. A., Engel, M. S. \& Nascimbene, P. C., 2002. Fossiliferous Cretaceous amber from Myanmar (Burma): its rediscovery, biotic diversity, and peleontological significance. American Museum Novitates, 3361: 1-72. http://dx.doi.org/10.1206/0003-0082(2002)361\%3C00 01:FCAFMB\%3E2.0.CO;2

Gruppe, A., 2002. Verbreitung der Taxa des Chrysoperla carnea Komplex in Südbayern (Neuroptera: Chrysopidae). Galathea, Supplement 13: 15-19.

Gruppe, A., 2005. Neue Nachweise von Nineta principiae Monserrat 1980 in Bayern (Neuroptera, Chrysopidae). DGaaE Nachrichten, 19: 139-140.

Gruppe, A., 2006. Neue Nachweise von Nineta principiae Monserrat, 1980, in Bayern und Thüringen (Neuroptera, Chrysopidae). Nachrichtenblatt der Bayerischen Entomologen, 55: 23-28.

Gruppe, A. \& Müller, J., 2007. Distribution of Neuropterida in beech dominated forests in southern Germany. In: Pantaleoni, R. A., Letardi, A. \& Corazza, C. (eds.). Proceedings of the Ninth International Symposium on Neuropterology, Ferrara, 2005. Annali del Museo Civico di Storia Naturale di Ferrara, 8: 145-152.

Günther, K. K., 1991. Echte Netzflügler aus Lichtfängen im Stadtgebiet von Berlin (Insecta, Neuroptera). Entomologische Nachrichten und Berichte, 35: 161-170.

Güsten, R., 1996. A review of epidermal glands in the order Neuroptera (Insecta). In: Canard, M., Aspöck, H. \& Mansell, M. W. (eds.). Pure and Applied Research in Neuropterology (Proceedings of the Fifth International Symposium on Neuropterology, Cairo, 1994). Toulouse: 129-146.

Güsten, R. \& Dettner, K., 1991. The prothoracic gland of the Chrysopidae (Neuropteroidea: Planipennia). In: Zombori, L. \& Peregovits, L. (eds.). Proceedings of the 4th European Congress of Entomology and the XIII Internationale Symposium für die Entomofaunistik Mitteleuropas, Gödöllö, 1: 60-65.

Hagen, H. A., 1850. Uebersicht der neueren Literatur, betreffend die Neuroptera Linn. Stettiner Entomologische Zeitung, 11: 67-83, 362-378.

Hagen, H. A., 1851. Uebersicht der neueren Literatur, betreffend die Neuroptera Linn. Stettiner Entomologische Zeitung, 12: 118-128, 185-191, 345-350, 365-375.
Hagen, H. A., 1854. Ueber die Neuropteren der Bernsteinfauna. Verhandlungen des Zoologisch-Botanischen Vereins in Wien, 4: 221-232.

Hagen, H. A., 1856. Die im Bernstein befindlichen Neuropteren der vorwelt bearbeitet von F. J. Pictet-Baraban, und Dr. H. Hagen. In: Die im Bernstein befindlichen organischen reste der Vorwelt gesammelt, in verbindung mit mehreren bearbeitet und herausgegeben von Dr. Georg Carl Berendt, Bd. 2. Nicholaischen Buchhandlung. Berlin: 41-125.

Hagen, H. A., 1858. Synopsis of the British Planipennes. Entomologist's Annual, 1858: 17-33.

Hagen, H. A., 1859a. Synopsis der Neuroptera Ceylons (Pars II.). Verhandlungen der Kaiserlich-Königlichen Zoologisch-Botanischen Gesellschaft in Wien, 9: 199-212.

Hagen, H. A., 1859b. Ausschlüpfen von Chrysopa-Larven. Stettiner Entomologische Zeitung, 20: 333.

Hagen, H. A., 1861. Synopsis of the Neuroptera of North America, with a list of the South American species. Smithsonian Miscellaneous Collections, 4(1): xx+1-347. http://dx.doi.org/10.5962/bhl.title.60275

Hagen, H. A., 1862. Neuroptera. Netzflügler. In: Peters, W. C. H. (ed.). Naturwissenschaftliche Reise nach Mossambique. Vol. 5 (Insecten und Myriopoden). Reimer. Berlin: 57-105.

Hagen, H. A., 1863. Die Odonaten- und Neuropteren-Fauna Syriens und Klein-Asiens. Wiener Entomologische Monatsschrift, 7: 193-199.

Hagen, H. A., 1866a. Hemerobidarum Synopsis synonymica. Stettiner Entomologische Zeitung, 27: 369-462.

Hagen, H. A., 1866b. Monograph of the Hemerobiidae. Part II. Proceedings of the Boston Society of Natural History, 23: 276-292.

Hagen, H. A., 1866c. Die Neuropteren Spaniens nach Ed. Pictet's Synopsis des Neuroptères d'Espagne. Genève 1865. 8. tab. 14 col. und Dr. Staudingers Mittheilungen. Stettiner Entomologische Zeitung, 27: 281-302.

Hagen, K. S., Greany, P., Sawall, E. F., \& Tassan, R. L., 1976. Tryptophan in artificial honeydews as a source of an attractant for adult Chrysopa carnea. Environmental Entomology, 5: 458-468. http://dx.doi.org/10.1093/ee/ 5.3.458

Hagen, K. S. \& Tassan, R. L., 1970. The influence of food Wheast and related Saccharomyces fragilis yeast products on the fecundity of Chrysopa carnea (Neuroptera: Chrysopidae). The Canadian Entomologist, 102: 806-811.

Handlirsch, A., 1906-1908. Die fossilen Insekten und die Phylogenie der rezenten Formen. W. Engelmann. Leipzig. 1430 pp. http://dx.doi.org/10.5962/bhl.title.5636

Handschin, E., 1937. Fossile Insekten aus Siebenbürgen. Mitteilungen der Schweizerischen Entomologischen Gesellschaft, 17: 25-29.

Hardy, A. C. \& Cheng, L., 1986. Studies in the distribution of insects by aerial currents. III. Insect drift over the sea. Ecological Entomology, 11: 283-290. http://dx.doi. org/10.1111/j.1365-2311.1986.tb00304.x

Haring, E., Aspöck, H., Bartel, D. \& Aspöck, U., 2011. Molecular phylogeny of the Raphidiidae (Raphidioptera). Systematic Entomology, 36: 16-30. http://dx.doi.org/ 10.1111/j.1365-3113.2010.00542.x 
Haring, E. \& Aspöck, U., 2004. Phylogeny of the Neuropterida: a first molecular approach. Systematic Entomology, 29: 415-430. http://dx.doi.org/10.1111/j.0307-6970.2004. 00263.x

Hartzell, A., 1918. A chigger mite of Chrysopa larvae. Journal of Economic Entomology, 11: 386.

Haruyama, N., Miyazaki, Y., Nakahira, K., Mochizuki, A. \& Nomura, M., 2012. Developmental time and survival of trash-carrying versus naked green lacewings, with implications for their utility as augmentative biological control agents. Annals of the Entomological Society of America, 105: 846-851. http://dx.doi.org/10.1603/ AN12003

Haruyama, N., Mochizuki, A., Duelli, P., Naka, H. \& Nomura, M., 2008. Green lacewing phylogeny, based on three nuclear genes (Chrysopidae, Neuroptera). Systematic Entomology, 33: 275-288. http://dx.doi.org/10.1111/ j.1365-3113.2008.00418.x

Hassanpour, M., Nouri-Ganbalani, G., Mohaghegh, J. \& Enkegaard, A., 2009. Functional response of different larval instars of the green lacewing, Chrysoperla carnea (Neuroptera: Chrysopidae), to the two-spotted spider mite, Tetranychus urticae (Acari: Tetranychidae). Journal of Food, Agriculture \& Environment, 7: 424-428.

Henriksen, K. L., 1922. Eocene Insects from Denmark. Danmarks Geologiske Undersogelse, 2(37): 1-36.

Henry, C. S., 1968. Courtship and mating behavior of the green lacewing fly, Chrysopa carnea (Fitch), with special emphasis on acoustical communication. Senior honors thesis. Harvard College. Cambridge, Massachusetts. iii $+86 \mathrm{pp}$.

Henry, C. S., 1979a. Acoustical communication during courtship and mating in green lacewings (Neuroptera: Chrysopidae). Journal of the New York Entomological Society, 86: 295-296.

Henry, C. S., 1979b. Acoustical communication during courtship and mating in the green lacewing Chrysopa carnea (Neuroptera: Chrysopidae). Annals of the Entomological Society of America, 72: 68-79. http://dx.doi. org/10.1093/aesa/72.1.68

Henry, C. S., 1980a. Acoustical communication in Chrysopa rufilabris (Neuroptera: Chrysopidae), a green lacewing with two distinct calls. Proceedings of the Entomological Society of Washington, 82: 1-8.

Henry, C. S., 1980b. The courtship call of Chrysopa downesi Banks (Neuroptera: Chrysopidae): its evolutionary significance. Psyche, 86: 291-297. http://dx.doi.org/10.1155/ 1979/53735

Henry, C. S., 1980c. The importance of low-frequency, substrate-borne sounds in lacewing communication (Neuroptera, Chrysopidae). Annals of the Entomological Society of America, 73: 617-621. http://dx.doi.org/ 10.1093/aesa/73.6.617

Henry, C. S., 1982. Reproductive and calling behavior in two closely related, sympatric lacewing species, Chrysopa oculata and Chrysopa chi (Neuroptera, Chrysopidae). Proceedings of the Entomological Society of Washington, 84: 191-203.

Henry, C. S., 1983a. Acoustic recognition of sibling species within the holarctic lacewing Chrysoperla carnea (Neuroptera, Chrysopidae). Systematic Entomology, 8:
293-301. http://dx.doi.org/10.1111/j.1365-3113.1983. tb00483.x

Henry, C. S., 1983b. Temperature-induced changes in the calls of the green lacewing, Chrysoperla plorabunda (Neuroptera: Chrysopidae). Psyche, 85: 343-360. http:// dx.doi.org/10.1155/1983/95104

Henry, C. S., 1984. The sexual behavior of green lacewings. In: Canard, M., Séméria, Y. \& New, T. R. (eds.). Biology of Chrysopidae. W. Junk. The Hague: 101-110.

Henry, C. S., 1985. The proliferation of cryptic species in Chrysoperla green lacewings through song divergence. The Florida Entomologist, 68: 18-38. http://dx.doi. org/10.2307/3494328

Henry, C. S., 1989. The unique purring song of Chrysoperla comanche (Banks), a green lacewing of the rufilabris species group (Neuroptera: Chrysopidae). Proceedings of the Entomological Society of Washington, 91: 133-142.

Henry, C. S., 1991. The status of the P2-song morph, a North American green lacewing of the Chrysoperla carnea species group (Neuroptera, Chrysopidae). Canadian Journal of Zoology, 69: 1805-1813. http://dx.doi.org/10.1139/ z91-249

Henry, C. S., 1992. Chrysoperla mohave (Banks) (Neuroptera: Chrysopidae): two familiar species in an unexpected disguise. Psyche, 99: 291-308. http://dx.doi.org/ 10.1155/1992/16818

Henry, C. S., 1993. Chrysoperla johnsoni (Neuroptera: Chrysopidae): Acoustic evidence for full species status. Annals of the Entomological Society of America, 86: 14-25. http://dx.doi.org/10.1093/aesa/86.1.14

Henry, C. S., 1994. Singing and cryptic speciation in insects. Trends in Ecology and Evolution, 9: 388-392. http:// dx.doi.org/10.1016/0169-5347(94)90061-2

Henry, C. S., Brooks, S. J., Duelli, P. \& Johnson, J. B., 1999. Revised concept of Chrysoperla mediterranea (Hölzel), a green lacewing associated with conifers: courtship songs across 2800 kilometers of Europe (Neuroptera: Chrysopidae). Systematic Entomology, 24: 335-350. http://dx.doi.org/10.1046/j.1365-3113.1999.00085.x

Henry, C. S., Brooks, S. J., Duelli, P. \& Johnson, J. B., 2002. Discovering the true Chrysoperla carnea (Insecta: Neuroptera: Chrysopidae) using song analysis, morphology, and ecology. Annals of the Entomological Society of America, 95: 172-191. http://dx.doi. org/10.1603/0013-8746(2002)095\%5B0172:DTTCCI $\% 5 \mathrm{D} 2.0 . \mathrm{CO} ; 2$

Henry, C. S., Brooks, S. J., Duelli, P. \& Johnson, J. B., 2003. A lacewing with the wanderlust: the European song species "Maltese", Chrysoperla agilis sp. n. of the carnea group of Chrysoperla (Neuroptera: Chrysopidae). Systematic Entomology, 28: 131-148. http://dx.doi. org/10.1046/j.1365-3113.2003.00208.x

Henry, C. S., Brooks, S. J., Duelli, P., Johnson, J. B., Wells, M. L. M. \& Mochizuki A., 2013. Obligatory duetting behavior in the Chrysoperla carnea-group of cryptic species (Neuroptera: Chrysopidae): its role in shaping evolutionary history. Biological Reviews, 88: 787-808. http://dx.doi.org/10.1111/brv.12027

Henry, C. S., Brooks, S. J., Johnson, J. B. \& Duelli, P., 1996. Chrysoperla lucasina (Lacroix): a distinct species of green lacewing, confirmed by acoustical analysis 
(Neuroptera: Chrysopidae). Systematic Entomology, 21: 205-218. http://dx.doi.org/10.1046/j.1365-3113.1996. d01-11.x

Henry, C. S., Brooks, S. J., Johnson, J. B., Haruyama, N., Duelli, P. \& Mochizuki, A., 2015. A new East-Asian species in the Chrysoperla carnea-group of cryptic lacewing species (Neuroptera: Chrysopidae) based on distinct larval morphology and a unique courtship song. Zootaxa, 3918(2): 194-208. http://dx.doi.org/10.11646/ zootaxa.3918.2.2

Henry, C. S., Brooks, S. J., Johnson, Mochizuki, A. \& Duelli, P., 2014. A new cryptic species of the Chrysoperla carnea group (Neuroptera: Chrysopidae) from western Asia: parallel speciation without ecological adaptation. Systematic Entomology, 39(2): 380-393. http://dx.doi.org/10.1111/syen.12061

Henry, C. S., Brooks, S. J., Johnson, J. B., Wells, M. M. \& Duelli, P., 2011. Song Analysis Reveals a Permanent Population of the Mediterranean Lacewing Chrysoperla agilis (Neuroptera: Chrysopidae) Living in Central Alaska. Annals of the Entomological Society of America, 104: 649-657. http://dx.doi.org/10.1603/AN11045

Henry, C. S., Brooks, S. J., Thierry, D., Duelli, P. \& Johnson, J. B., 2001. The common green lacewing (Chrysoperla carnea s. lat.) and the sibling species problem. In: McEwen, P. K., New, T. R. \& Whittington, A. E. (eds.). Lacewings in the Crop Environment. Cambridge University Press. Cambridge: 29-42. http://dx.doi.org/ 10.1017/CBO9780511666117.004

Henry, C. S. \& Busher, C., 1987. Patterns of mating and fecundity in several common green lacewings (Neuroptera: Chrysopidae) of eastern North America. Psyche, 94: 219-244. http://dx.doi.org/10.1155/1987/79165

Henry, C. S. \& Johnson, J. B., 1989. Sexual singing in a nonchrysoperlan green lacewing, Chrysopiella minora Banks (Neuroptera: Chrysopidae). Canadian Journal of Zoology, 67: 1439-1446. http://dx.doi.org/10.1139/ z89-204

Henry, C. S. \& Wells, M. M., 1990a. Sexual singing preceding copulation in Chrysoperla plorabunda green lacewings: observations in a semi-natural environment (Neuroptera: Chrysopidae). The Florida Entomologist, 73: 331-333. http://dx.doi.org/10.2307/3494818

Henry, C. S. \& Wells, M. M., 1990b. Geographical variation in the song of Chrysoperla plorabunda (Neuroptera: Chrysopidae) in North America. Annals of the Entomological Society of America, 83: 317-325. http://dx.doi. org/10.1093/aesa/83.3.317

Henry, C. S. \& Wells, M. M., 2006. Testing the ability of males and females to respond to altered songs in the dueting green lacewing, Chrysoperla plorabunda (Neuroptera: Chrysopidae). Behavioral Ecology and Sociobiology, 61: 39-51. http://dx.doi.org/10.1007/s00265-006-0235-8

Henry, C. S. \& Wells, M. M., 2009. Sexually dimorphic intrasexual duetting in an otherwise monomorphic green lacewing (Neuroptera, Chrysopidae, Chrysoperla plorabunda): sexual selection or sex recognition? Journal of Insect Behavior, 22: 289-312. http://dx.doi.org/10.1007/ s10905-009-9174-3

Henry, C. S. \& Wells, M. M., 2010. Acoustic niche partitioning in two cryptic sibling species of Chrysoperla green lacewings that must duet before mating. Animal Behaviour, 80: 991-1003. http://dx.doi.org/10.1016/j. anbehav.2010.08.021

Henry, C.S. \& Wells, M.M., 2015. Courtship songs of green lacewings filmed in slow motion: how a simple vibrating structure can generate complex signals (Neuroptera: Chrysopidae: Chrysoperla). Journal of Insect Behavior, 28: 89-106. http://dx.doi.org/10.1007/s10905-015-9484-6

Henry, C. S., Wells, M. M. \& Pupedis, R. J., 1993. Hidden taxonomic diversity within Chrysoperla plorabunda (Neuroptera: Chrysopidae): Two new species based on courtship songs. Annals of the Entomological Society of America, 86: 1-13. http://dx.doi.org/10.1093/aesa/86.1.1

Henry, C. S., Wells, M. M. \& Simon, C. M., 1999. Convergent evolution of courtship songs among cryptic species of the carnea group of green lacewings (Neuroptera: Chrysopidae: Chrysoperla). Evolution, 53: 1165-1179. http://dx.doi.org/10.2307/2640820

Higgins, L. G., 1958. A precise collation of Rambur, M. P., Faune Entomologique de L'Andalusie (1837-40). Journal of the Society for the Bibliography of Natural History, 3: 311-318.

Hinke, F., 1975. Autökologische Untersuchungen an mitteleuropäischen Neuropteren. Zoologische Jahrbücher. Abteilung für Systematik, Geographie und Biologie, 102: 303-330.

Hobby, B. M., 1933. The prey of British Dragonflies. Transactions of the Entomological Society of the South of England, 8(2): 65-76.

Hollier, J. A. \& Belshaw, R. D., 1993. Stratification and phenology of a woodland Neuroptera assemblage. The Entomologist, 112: 169-175.

Hölzel, H., 1964a. Bemerkungen zu Chrysopiden. I. Chrysopa walkeri. Nachrichtenblatt der Bayerischen Entomologen, 13(5): 41-43.

Hölzel, H., 1964b. Die Netzflügler Kärntens. Carinthia II, 2: 97-156.

Hölzel, H., 1965a. Neue order wenig bekannte Chrysopiden aus der Sammlung des Naturhistorischen Museumn (Chryopidae, Planipennia). Annalen des Naturhistorischen Museums in Wien, 68: 453-463.

Hölzel, H., 1965b. Beitrag zur Kenntnis der Chrysopidae: Die Nineta Gruppe (Planipennia, Chrysopidae). Zeitschrift der Arbeitsgemeinschaft Österreichischer Entomologen, 17(3): 91-98.

Hölzel, H., 1965c. Bemerkungen zu Chrysopiden II. Chrysopa nigricostata Br. (Neuroptera, Planipennia). Nachrichtenblatt der Bayerischen Entomologen, 14(7/8): 74-76.

Hölzel, H., 1967. Die Neuropteren Vorderasiens II. Chrysopidae. Beiträge zur Naturkundlichen Forschung in Südwestdeutschland, 26: 19-45.

Hölzel, H., 1970. Zur generischen Klassifikation der Paläarktischen Chrysopinae. Eine neue Gattung und zwei neue Untergattungen der Chrysopidae (Planipennia). Zeitschrift der Arbeitsgemeinschaft Österreichischer Entomologen, 22: 44-52.

Hölzel, H., 1971. Remarks on Mongolian Chrysopidae with description of a new species (Planipennia, Chrysopidae). Entomologische Berichten, 31: 101-104. 
Hölzel, H., 1972a. Eine neue Chrysopiden-Art aus Südeuropa - Anisochrysa (Cunctochrysa) baetica n. sp. (Planipennia, Chrysopidae). Entomologische Zeitschrift, 82: 217-221.

Hölzel, H., 1972b. Anisochrysa (Chrysoperla) mediterranea n. sp. eine neue europäische Chrysopiden-Spezies (Planipennia, Chrysopidae). Nachrichtenblatt der Bayerischen Entomologen, 21: 81-83.

Hölzel, H., 1973a. Zur Revision von Typen europäischer Chrysopa-Arten. Revue suisse de Zoologie, 80(1): 65-82.

Hölzel, H., 1973b. Die Netzflügler Kärntens. 1. Nachtrag. Carinthia II, 83: 497-506.

Hölzel, H., 1974. Zwei neue Chrysopiden-Arten aus Südwesteuropa (Planipennia, Chrysopidae). Entomologische Zeitschrift, 84: 257-260.

Hölzel, H., 1980a. Insects of Saudi Arabia. Neuroptera: Fam. Chrysopidae. Fauna of Saudi Arabia, 2: 164-173.

Hölzel, H., 1980b. Italochrysa bimaculata n. sp. - eine neue mediterrane Chrysopiden-Spezies (Planipennia, Chrysopidae). Zeitschrift der Arbeitsgemeinschaft Österreichischer Entomologen, 31: 100-102.

Hölzel, H., 1980c. Planipennia aus den zentralen und westlichen Teilen der Mongolei mit Bemerkungen zur Synonymie mongolischer Chrysopiden (Ergebnisse der Mongolisch-Deutschen Biologischen Expeditionen seit 1962, Nr. 95). Mitteilungen aus dem Zoologischen Museum in Berlin, 56: 191-194.

Hölzel, H., 1984. Chrysopidae of the Palearctic Region - a review. In: Gepp, J., Aspöck, H. \& Hölzel, H. (eds.). Progress in World's Neuropterology (Proceedings of the 1st International Symposium on Neuropterology, Graz): $61-68$

Hölzel, H., 1990. The Chrysopidae of the Afrotropical region (Insecta: Neuroptera). In: Mansell, M. W. \& Aspöck, H. (eds.). Advances in Neuropterology (Proceedings of the Third International Symposium on Neuropterology, Berg en Dal, 1988). South African Department of Agricultural Development. Pretoria: 17-26.

Hölzel, H., 1992. The African species of Ankylopterygini (Insecta: Neuroptera: Chrysopidae). In: Canard, M., Aspöck, H. \& Mansell, M. W. (eds.). Current Research in Neuropterology (Proceedings of the Fourth International Symposium on Neuropterology, Bagnères-de-Luchon, 1991). Toulouse: 159-165.

Hölzel, H., 1995. Beitrag zur Kenntnis der Neuropteren der Arabischen Halbinsel. I. Chrysopidae und Hemerobiidae von Oman und Yemen (Neuroptera: Chrysopidae, Hemerobiidae). Entomofauna, 16: 437-452.

Hölzel, H., 1998. Kommentare zu den von Friedrich Brauer in den Jahren 1850 und 1856 aus Österreich bescriebenen Chrysopa Species (Neuroptera: Chrysopidae). Stapfia, 55: 409-420.

Hölzel, H., 2002. Neuroptera collected by the German Yemen expeditions 1996, 1998 und 2000 (Neuroptera: Chrysopidae, Hemerobiidae, Berothidae, Mantispidae, Nemopteridae, Myrmeleontidae, Ascalaphidae). Esperiana, 9: 129-146.

Hölzel, H., Aspöck, H. \& Aspöck, U., 1980. Catalogus Faunae Austriae. Teil XVII: $\ddot{U}$-Ordn. Neuropteroidea. Verlag der Österreichischen Akademie der Wissenschaften. Wien. 26 pp.
Hölzel, H. \& Ohm, P., 1972. Die Chrysopiden der Iberischen Halbinsel (Planipennia, Chrysopidae). FaunistischÖkologische Mitteilungen, 4: 127-145.

Hölzel, H. \& Ohm, P., 1999. Taxonomie und Chorologie von Chrysopa flavifrons Brauer 1850 s.l., samt Beschreibung einer neuen Art, Dichochrysa viridifrons spec. $\mathrm{n}$. (Neuroptera: Chrysopidae). Entomologische Zeitschrift mit Insektenbörse, 109: 381-388.

Hölzel, H. \& Monserrat, V. J., 1992. Chrysopidae from Equatorial Guinea (Neuroptera, Chrysopidae). Entomofauna, 13(28): 465-476.

Hölzel, H. \& Wiesser, C., 1999. Die Netzflügler Kärntens. Eine zusammenfassende Darstellung der Autökologie und Chorologie der Neuropterida (Megaloptera, Raphidioptera, Neuroptera) Kärntens. Carinthia II, 189/109: 361-429.

Honěk, A. \& Kocourek, F., 1986. The flight of aphid predators to a light trap: possible interpretations. In: Hodek, I. (ed.). Ecology of Aphidophaga. Academia, Prague \& W. Junk, Dordrecht: 333-338.

Horton, D. R., Broers, D. A., Hinojosa, T., Lewis, T. M., Miliczky, E. R. \& Lewis, R. R., 2002. Diversity and phenology of predatory arthropods overwintering in cardboard bands placed in pear and apple orchards of central Washington State. Annals of the Entomological Society of America, 95: 469-480. http://dx.doi. org/10.1603/0013-8746(2002)095[0469:DAPOPA] 2.0.CO;2

Hubbard, M. D., 1990. "Longinos Navás, científico jesuita": Additions and corrections to the Ephemeroptera. Eos, 66(2): 183-186.

Hwang, J. C. \& Bickley, W. E., 1961. The reproductive system of Chrysopa oculata (Neuroptera, Chrysopidae). Annals of the Entomological Society of America, 54: 422-429. http://dx.doi.org/10.1093/aesa/54.3.422

Hynd, W. R. B., 1983. Records of Neuroptera from Corfu, Greece. Entomologist's Gazette, 34: 129-131.

Ickert, G., 1968. Beiträge zur Biologie einheimischer Chrysopiden (Planipennia, Chrysopidae). Entomologische Abhandlungen, 36: 123-192.

Insom, E. \& Terzani, F., 2012. Nuovi dati di rafidiotteri e neurotteri per l'Arcipelago Toscano. Quaderno di Studi e Notizie di Storia Naturale della Romagna, 35: 157-161.

Ishii, S., 1964. An attractant contained in Actinidia polygama Miq. for male lace wing, Chrysopa septempunctata Wesmael. Japanese Journal of Applied Entomology and Zoology, 8: 334-337.

Ivanov, V. D. \& Krivokhatsky, V. A., 1999. Insects and spiders of the Leningrad Region. In: Balashova, N. B. \& Zavarzin, A. A. Biodiversity of the Leningrad Region Algae. Fungi. Lichens. Bryophytes. Invertebrates. Fisches and pisciformes. Transactions of Saint Petersburg Naturalists Society, Saint Petersburg University Press. Saint Petersburg: 339-354.

Ivanov, V. D. \& Krivokhatsky, V. A., 2002. Insects. In: Noskov, G. A. (ed.). Red data book of nature of the Leningrad region. Biological Research Institute of the St. Petersburg State University. Saint Petersburg: Pp. 95-300.

Ivanov, V. D. \& Krivokhatsky, V. A., 2004. Insecta. In: Noskov, G. A. (ed.). Red data book of nature of Saint-Petersburg. 
Biological Research Institute of the St. Petersburg State University. Saint-Petersburg: 179-242.

Jarzembowski, E. A., 1980. Fossil insects from the Bembridge Marls, Palaeogene of the Isle of Wight, southern England. Bulletin of the British Museum of Natural History, Geology, 33: 237-293.

Jedlicka, L. \& Jedlickova, J., 1973. Contribution to the knowledge of the fauna Jursky sur. II. Familly Chrysopidae (Neuroptera). Acta Facultatis Rerum Naturalium Universitatis Comenianae. Zoologia, 19: 65-69.

Jedlicka, L. \& Jedlickova, J., 2000. Problém skupiny Chrysoperla carnea na Slovensku (Neuroptera: Chrysopidae). Entomofauna Carpathica, 12: 65-57.

Jepson, J. E. \& Penney, D., 2007. Neuropteran (Insecta) palaeodiversity with predictions for the Cretaceous fauna of the Wealden. Palaeogeography, Palaeoclimatology, Palaeoecology, 248: 109-118. http://dx.doi. org/10.1016/j.palaeo.2006.11.015

Jepson, J.E., Makarkin, V.N. \& Coramc, R.A., 2012. Lacewings (Insecta: Neuroptera) from the Lower Cretaceous Purbeck Limestone. Group of southern England. Cretaceous Research, 34: 31-47. http://dx.doi.org/10.1016/j. cretres.2011.10.001

Johnson, N. F. \& Bin, F., 1982. Species of Telenomus (Hym., Scelionidae), parasitoids of stalked eggs of Neuroptera (Chrysopidae \& Berothidae). Redia, 65: 189-206.

Kaisila, J., 1952. Insects from arctic mountain snows. Soumen Hyönteistieteellinen Aikakauskirja, 18(1): 8-25.

Kennett, C. E., 1948. Defense mechanism exhibited by larvae of Chrysopa californica Coq. (Neuroptera: Chrysopidae). Pan-Pacific Entomologist, 24: 209-211.

Khan, I. A., Blaeser, P. \& Şengonça, Ç., 2004. Laboratory experiments on prey consumption by Typhlodromus pyri Scheuten (Acari, Phytoseiidae) and Chrysoperla carnea (Stephens) (Neuroptera, Chrysopidae) on different mite pest species of apple orchards and interaction between the two predators. Mitteilungen der Deutschen Gesellschaft für Allgemeine und Angewandte Entomologie, 14: 377-380.

Khan, I. A. \& Fent, M., 2005. Prey preference and consumption by to polyphagous predators Typhlodromus pyri Scheuten (Acari: Phytoseiidae) and Chrysoperla carnea (Stephens) (Neuroptera: Chrysopidae) of different mite pest species of apple orchards. Sarhad Journal of Agriculture, 21: 89-96.

Khramov, A.V., 2013. The lacewing fauna from the Karatau locality (Upper Jurassic, Kazakhstan). Abstracts. The 6th International Congress on Fossil Insects, Arthropods and Amber, Byblos: 14-18.

Killington, F. J., 1928a. Larvae of Chrysopa vulgaris, Schn. (Order Neuroptera) on flower-heads. The Entomologist, 61: 234 .

Killington, F. J., 1928b. Notes on the Neuroptera and Mecoptera of Hampshire, 1928. Transactions of the Hampshire Entomological Society, 1928: 49-52.

Killington, F. J., 1929. A synopsis of British Neuroptera. Transactions of the Entomological Society of the South of England, 5: 1-36.

Killington, F. J., 1932a. Predacious insects as enemies of Neuroptera. Journal of the Entomological Society of the South of England, 1: 31-33.
Killington, F. J., 1932b. The parasites of Neuroptera with special reference to those attacking British species. Transactions of the Entomological Society of the South of England, 8: 84-91.

Killington, F. J., 1932c. Web-making spiders as enemies of Neuroptera. Journal of the Entomological Society of the South of England, 1: 29-31.

Killington, F. J., 1932d. Neuroptera as the prey of bats. Journal of the Entomological Society of the South of England, 1: 28-29.

Killington, F. J., 1935a. Notes on the habitat and life-history of Nathanica (Nothochrysa) fulviceps (Steph.) (Neuropt.). Journal of the Society for British Entomology, 1: 110-113.

Killington, F. J., 1935b. Chrysopa albolineata nom. nov. for Chrysopa tenella Schneid. (Neur.). Journal of the Society for British Entomology, 1: 87.

Killington, F. J., 1936. A monograph of the British Neuroptera. Vol. 1. Ray Society. London. xix +269 pp.

Killington, F. J., 1937. A monograph of the British Neuroptera. Vol. 2. Ray Society. London. xii+306 pp.

Kimmins, D. E., 1939. The first instar larva of Nathanica capitata (Fabr.) (Neur.). Journal of the Society for British Entomology, 1: 240-241.

Kimmins, D. E., 1950. Results of the Armstrong College Expedition to Siwa Oasis (Libyan Desert), 1935, under the leadership of Prof. J. Omer-Cooper. Odonata and Neuroptera. Bulletin de la Société Fouad ler d'Entomologie, 34: 151-157.

Kimmins, D. E., 1952. A revision of the genera of the Apochrysinae (Fam. Chrysopidae). Annals and Magazine of Natural History, 5(12): 929-944. http://dx.doi. org/10.1080/00222935208654370

Kirby, M. A., 1984. The structure of the pretarsus in the third instar larvae of the Chrysopidae. In: Gepp, J., Aspöck, H. \& Hölzel, H. (eds.). Progress in World's Neuropterology (Proceedings of the 1st International Symposium on Neuropterology, Graz): 261-265.

Kis, B., Nagler, C. \& Mândru, C., 1970. Insecta: Neuroptera (Planipennia). Fauna Republicii Socialiste România, 8(6): 1-343.

Klapálek, F., 1899. Bemerkungen über die Trichopteren- und Neuropteren-Fauna Ungarns. Természetrajzi Füzetek, 22: 429-443.

Klapálek, F., 1909. Některé zajímavější Neuropteroidy španělské. Acta Societatis Entomologicae Bohemiae, 6: 130-131.

Knuth, P., 1906-1909. Handbook of flower pollination: based upon Hermann Müller's work 'The fertilisation of flowers by insects'. 2 vols. Clarendon Press. Oxford. Vol. 1, 1906; vol. 2, 1908; vol. 3, 1909.

Koczor, S., Szentkirályi, F., Birkett, M. A., Pickett, J. A., Voigt, E. \& Tóth, M., 2010. Attraction of Chrysoperla carnea complex and Chrysopa spp. lacewings (Neuroptera: Chrysopidae) to aphid sex pheromone components and a synthetic blend of floral compounds in Hungary. Pest Management Science, 66: 1374-1379. http://dx.doi. org/10.1002/ps.2030

Koczor, S., Szentkiralyi, F., Pickett, J.A., Birkett, M.A. \& Toth, M., 2015. Aphid sex pheromone compounds interfere with attraction of common green lacewings 
to floral bait. Journal of Chemical Ecology, 41(6): 1-7. http://dx.doi.org/10.1007/s10886-015-0585-7

Kovrigina, A. M., 1985. Introduction to the ecology of Chrysopidae (Neuroptera) from Middle Volga region. Neuroptera International, 3: 143-144.

Kral, K. \& Stelzl, M., 1998. Daily visual sensitivity pattern in the green lacewing Chrysoperla carnea (Neuroptera: Chrysopidae). European Journal of Entomology, 95: 327-333.

Krüger, L., 1915. Neuroptera. Eine historisch-systematische übersicht. I. Neuroptera L. bis Neuroptera Erichs. Stettiner Entomologische Zeitung, 76: 3-51.

Krüger, L., 1917. Neuroptera. Eine historische-systematische übersicht. II. Phylogenetische Umgrenzung der Echten Neuropteren: Neuropteroidea Hdl. Stettiner Entomologische Zeitung, 78: 116-137.

Krüger, L., 1923. Neuroptera succinica baltica. Die im baltischen Bernstein eingeschlossenen Neuropteren des Westpreussischen Provinzial-Museums (heute Museum für Naturkunde und Vorgeschichte) in Danzig. Stettiner Entomologische Zeitung, 84: 68-92.

Kuznetsova, Y. I., 1970. Issledovanie vozmozhnostei khraneniya yaits zlatoglazki Chrysopa carnea Steph. (Neuroptera, Chrysopidae) pri ponizhennykh temperaturakh. Zoologicheskii Zhurnal, 49(10): 1505-1514.

Labrique, H., 1990. Description de la larve de la chrysope méditerranéenne Mallada picteti (McLachlan, 1880) (Neuroptera, Chrysopidae). Nouvelle Revue d'Entomologie (N.S.), 7: 427-434.

Labrique, H. \& Canard, M., 1989. Description de la larve de Mallada ibericus (Navás) (Neuroptera: Chrysopidae). Bulletin de la Société Entomologique de France, 94: 59-64.

Lacroix, J. L., 1912. Faune névroptérique de l'Algérie et de la Tunisie. I. Deux espèces nouvelles. Insecta (Rennes), 2: 202-206.

Lacroix, J. L., 1916. Notes névroptérologiques. VI. Captures diverses et formes nouvelles. Boletín de la Sociedad Aragonesa de Ciencias Naturales, 15: 211-216.

Lacroix, J. L., 1921a. Description sommaire de la larve de Chrysopa viridana Schneid. [Neur. Chrysopidae]. Bulletin de la Société Entomologique de France, 1921: 182-184.

Lacroix, J. L., 1921b. Études sur les Chrysopides. Premier [I] Mémoire. Annales de la Société Linnéene de Lyon, 68: 51-104.

Lacroix, J. L., 1922. Études sur les Chrysopides. Deuxième [II] Mémoire. Chrysopes du groupe prasina, Burm. Annales de la Société Linnéene de Lyon, 69: 119-144.

Lacroix, J. L., 1923. Études sur les Chrysopides. Notes sur quelques larves du groupe Chrysopa prasina Burm. Annales de la Société Linnéene de Lyon, 70: 153-159.

Lacroix, J. L., 1925. Études sur les Chrysopides. Époque du coconnage chez larves du groupe Chrysopa prasina, Burm. Bulletin de la Société d'Étude des Sciences Naturelles d'Elbeuf, 43: 87-91.

Lacroix, J. L., 1926. Etudes sur les Chrysopides. L'Hibernation chez "Chrysopa vulgaris" Schneider. Bulletin de la Société des Sciences Naturelles de l'Ouest de la France, 6(4):1-24.
Lacroix, J. L., 1929. Quelques mots sur les Chrysopides. Revue de Zoologie Agricole et Appliquée, 28: 129-141.

Lacroix, J. L., 1930. Études sur les Chrysopides. L'époque du coconnage chez les larves du groupe Chrysopa prasina Burm. Bulletin et Annales de la Société Entomologique de Belgique, 70: 93-97.

Lacroix, J. L., 1933. Notes névroptérologiques. XI. Revue Mensuelle de la Société Entomologique Namuroise, 33: 146-152.

LaMunyon, C. W., 1988. Hindgut changes preceding pupation and related cocoon structure in Chrysoperla comanche Banks (Neuroptera, Chrysopidae). Psyche, 95: 203-209. http://dx.doi.org/10.1155/1988/86738

LaMunyon, C. W. \& Adams, P. A., 1987. Use and effect of an anal defensive secretion in larval Chrysopidae (Neuroptera). Annals of the Entomological Society of America, 80: 804-808. http://dx.doi.org/10.1093/aesa/ 80.6.804

Larsson, S. G., 1975. Palaeobiology and mode of burial of the insects of the Lower Eocene Mo-clay of Denmark. Bulletin of the Geological Society of Denmark, 24: 193-209.

Larsson, S. G., 1978. Baltic Amber - A Palaeobiological Study. Entomonograph Volume 1, Scandinavian Science Press. Klampenborg. 192 pp.

Latreille, P. A., 1796. Précis des caractères génériques des insectes disposés dans un ordre naturel. Prèvôt. Paris. 201 pp. http://dx.doi.org/10.5962/bhl.title.58411

Latreille, P. A., 1802. Histoire naturelle, générale et particulière de Crustacés et des Insectes. Vol. 3. Familles naturelles des genres. F. Dufart. Paris. 467 pp. http:// dx.doi.org/10.5962/bhl.title. 15764

Latreille, P. A., 1804. Histoire naturelle, genérale et particuliere, des Crustacés et des Insectes. Vol. 12. F. Dufart. Paris. 382 pp. http://dx.doi.org/10.5962/bhl.title.15764

Latreille, P. A., 1810. Considérations générales sur l'ordre naturel des animaux composant les classes des Crustacés, des Arachnides, et des Insectes; avec un tableau méthodique de leurs genres, disposés en familles. Schoell. Paris. 444 pp. http://dx.doi.org/10.5962/bhl. title. 13342

Latreille, P. A., 1825. Familles naturelles du règne animal, exposées succinctement et dans un ordre analytique, avec l'indications de leurs genres. J.-B. Baillière, Paris. [vi]+570 pp. http://dx.doi.org/10.5962/bhl.title.34914

Latreille, P. A., 1831. Cours d'Entomologie ou de l'histoire naturelle des Crustacées, des Arachnides, des Myriapodes et des Insectes. Roret. Paris. http://dx.doi. org/10.5962/bhl.title.4854

Leach, W. E., 1815. Entomology. Neuroptera. In: Brewster, D. (ed.). Edinburgh Encyclopaedia, 9(1). Edinburgh: 136-139.

Lee, S.-j. \& Shih, C. I. T., 1982. Biology, predation, and field-cage release of Chrysopa boninensis Okamoto on Paurocephala psylloptera Crawford and Corcyra cephalonica Stainton. Journal of Agriculture and Forestry, 31: 129-144.

Legaspi, J. C., Carruthers, R. I. \& Nordlund, D. A., 1994. Life history of Chryoperla rufilabris (Neuroptera: Chrysopidae) provided sweetpotato whitefly Bemisia 
tabaci (Homoptera: Aleyrodidae) and other food. Biological Control, 4: 178-184. http://dx.doi.org/10.1006/ bcon. 1994.1028

Legaspi, J. C., Nordlund, D. A. \& Legaspi, B. C., 1996. Tri-trophic interactions and predation rates in Chrysoperla spp. attacking the silverleaf whitefly. Southwestern Entomologist, 21: 33-42.

Legrand, J., Tauber, C. A., Albuquerque, G. S. \& Tauber, M. J., 2008. Navás' type and non-type specimens of Chrysopidae in the MNHN, Paris [Neuroptera]. Revue Française d'Entomologie (N.S.), 30: 103-183.

Lemesle, A., Thierry, D., Foussard, F. \& Canard, M., 1998. Preliminary study on lipids in Chrysoperla kolthoffi (Navás) during diapause (Neuroptera, Chrysopidae). In: Panelius, S. P. (ed.). Neuropterology 1997 (Proceedings of the Sixth International Symposium on Neuropterology, Helsinki, 1998). Acta Zoologica Fennica, 209: 141-144.

Leraut, P., 1982. Étude de quelques types de Névroptères décrits par J. Lacroix et par L. Navas conservés au Muséum National d'Histoire Naturelle a Paris [Neuroptera]. Revue Française d'Entomologie (N.S.), 4: 48.

Leraut, P., 1988. Cunctochrysa bellifontensis n. sp.: une espèce de chrysope nouvelle pour la science découverte en forêt de Fontainebleau (Neur. Chrysopidae). Bulletin de l'Association des Naturalistes de la Vallée du Loing et du Massif de Fontainebleau, 64: 230-235.

Leraut, P., 1991. Les Chrysoperla de la faune de France (Neur. Chrysopidae). Entomologica Gallica 2: 75-81.

Leraut, P., 1992a. Névroptères des Alpes centrales françaises (Neur.). Entomologica Gallica, 3: 59-65.

Leraut, P., 1992b. Chrysopa gibeauxi (Leraut) stat. rev., une espèce distincte (Neuroptera: Chrysopidae). Entomologica Gallica, 3(1): 24-26.

Leraut, P., 2003. Le guide entomologique. Delachaux et Niestlé. Lonay. 527 pp.

Letardi, A., 1997. Myrmeleon bore (Tjeder, 1941) new to Spain (Neuroptera Myrmeleontidae). Frustula Entomologica (N.S.), 20: 150-151.

Letardi, A., 2002. A web page on Italian Neuropterida. Acta Zoologica Academiae Scientiarum Hungaricae, 48 (Suppl. 2): 155-158.

Letardi, A., Almeida, J. M., Badano, D., Silva, R. R. \& Machado, E., 2013. Contributing to a checklist of Neuropterida in Portugal: the Naturdata project. In: Martins, A. M. F. \& Ventura, M. A. M. (eds.). Proceedings of the Eleventh International Symposium of Neuropterology, Ponta Delgada, 2011. Açoreana, Suplemento 9: 29-38.

Letardi, A. \& Biscaccianti, A. B., 2007. Neuropterida of Majella National Park, Italy. Annali del Museo Civico di Storia Naturale di Ferrara, 8: 107-110.

Letardi, A. \& Coccia Collepardo, F., 2015. Nuove segnalazioni di Nineta principiae Monserrat, 1980 (Neuroptera: Chrysopidae). Onychium, 11: 152-155.

Letardi, A. \& Pantaleoni, R. A., 1996. I neuroptteroidei W-Paleartici della collezione del Museo di Zoologia dell'Università di Roma (Neuropteroidea). Fragmenta Entomologica, 28: 277-305.

Lewis, T. \& Taylor, L. R., 1964. Diurnal periodicity of flight by insects. Transactions of the Royal Entomological Society of London, 116: 393-469. http://dx.doi.org/10.1111/j.13652311.1965.tb02304.x

Linnaeus, C., 1758. Systema naturae per regna tria naturae secundum classes, ordines, genera, species, cum characteribus, differentiis, synonymis, locis. Editio decima, reformata. Tomus I. Salvii. Holmiae. 824 pp. http:// dx.doi.org/10.5962/bhl.title.542

Linnaeus, C., 1761. Fauna Svecica, sistens animalia Sveciae regni: Mammalia, Aves, Amphibia, Pices, Insecta, Vermes distributa per classes \& ordines, genera \& species, cum differentiis specierum, synonymis auctorum, nominibus natalium, descriptionibus insectorum. Editio altera, auctior. Laurentii Salvii. Stockholmiae. 578 pp. http://dx.doi. org/10.5962/bhl.title.46380

Linnaeus, C., 1767. Systema natura per regna tria naturae secundum classes, ordines, genera, species, cum characteribus, differentiis, synonymis, locis. Editio duodecima reformata. Tom. I. Pars II. Laurentii Salvii. Holmiae. pp. 533-1327.

Lipovšek, S., Pabst, M. A. \& Devetak, D., 1999. Femoral chordotonal organ in the legs of an insect, Chrysoperla carnea (Neuroptera). Tissue and Cell, 31: 154-162. http://dx.doi.org/10.1054/tice.1999.0029

Loiácono, M. S., Lanati, S. J. \& Neila, C., 2006. Una especie nueva del género Telenomus (Hymenoptera: Scelionidae) parasitoide de posturas de Chrysopidae (Neuroptera) en Mendoza, Argentina. Revista de la Sociedad Entomológica Argentina (online), 65(1-2): 23-26.

Lourenço, P., Brito, C., Backeljau, T., Thierry, D. \& Ventura, M. A., 2006. Molecular systematics of the Chrysoperla carnea group (Neuroptera: Chrysopidae) in Europe. Journal of Zoological Systematics and Evolutionary Research, 44: 180-184. http://dx.doi.org/10.1111/ j.1439-0469.2006.00352.x

Lucas, F., Shaw, J. T. B. \& Smith, S. G., 1957. Aminoacid composition of the silk of Chrysopa egg-stalks. Nature (London), 179: 906-907. http://dx.doi.org/10. $1038 / 179906 \mathrm{a} 0$

Lucas, W. J., 1905. Neuroptera collected by Dr. T.A. Chapman in France and Spain 1904. The Entomologist, 38: 296-298.

Lucas, W. J., 1906. Neuroptera and Trichoptera taken by Dr. T.A. Chapman in Spain, 1906. The Entomologist, 39: 276-277.

Macho Bariego, V., 1909. Excursión anual de la Sociedad Aragonesa de Ciencias Naturales al Pirineo Aragonés (8-15 Julio de 1907). Boletín de la Sociedad Aragonesa de Ciencias Naturales, 8: 67-79.

MacLeod, E. G. \& Sheldon, J. K., 1972. A dominant mutation modifying the structural eye color in Chrysopa carnea. Journal of Heredity, 63: 63-68.

Makarkin, V. N., 1991. Miotsenovye setchatokrylye (Neuroptera) severnogo Kavkaza i Sikhote-Alinya. Paleontologicheskii Zhurnal, 1991(1): 57-68.

Makarkin, V. N., 1994. Upper Cretaceous Neuroptera from Russia and Kazakhstan. Annales de la Société Entomologique de France, 30: 283-292.

Makarkin, V. N., 1997. Fossil Neuroptera of the Lower Cretaceous of Baisa, East Siberia, Part 3, Chrysopidae. Spixiana, 20: 107-118. 
Makarkin, V. N., 1998. New Tertiary Neuroptera from the Russian Far East. Tertiary Research, 18: 77-83.

Makarkin, V. N., 2014. A new fossil green lacewing (Neuroptera: Chrysopidae) from the Eocene Tadushi formation, Eastern Sikhote-Alin. Far Eastern Entomologist, 272: 1-7.

Makarkin, V. N. \& Archibald, S. B., 2013. A diverse new assemblage of green lacewings (Insecta, Neuroptera, Chrysopidae) from the Early Eocene Okanagan Highlands, western North America. Journal of Paleontology, 87(1): 123-146. http://dx.doi.org/10.1666/12-052R.1

Makarkin, V. N. \& Menon, F., 2005. New species of the Mesochrysopidae (Insecta, Neuroptera) from the Crato Formation of Brazil (Lower Cretaceous), with taxonomic treatment of the family. Cretaceous Research, 26: 801-812. http://dx.doi.org/10.1016/j.cretres.2005.05.009

Makarkin, V. N., Yang, Q., Peng, Y.Y. \& Ren, D., 2012. A comparative overview of the neuropteran assemblage of the Lower Cretaceous Yixian Formation (China), with description of a new genus of Psychopsidae (Insecta: Neuroptera). Cretaceous Research, 35: 57-68. http:// dx.doi.org/10.1016/j.cretres.2011.11.013

Malet, J. C., Noyer, C., Maisonneuve, J. C. \& Canard, M., 1994. Chrysoperla lucasina (Lacroix) (Neur., Chrysopidae), prédateur potentiel du complex méditerranéen des Chrysoperla Steinmann: premier essai de lutte biologique contre Aphis gossypii Glover (Hom., Aphididae) sur melon en France méridionale. Journal of Applied Entomology, 118: 429-436. http://dx.doi.org/10.1111/j.1439-0418.1994. tb00821.x

Mantoanelli, E. \& Albuquerque, G. S., 2007. Desenvolvimento e comportamento larval de Leucochrysa (Leucochrysa) varia (Schneider) (Neuroptera, Chrysopidae) em laboratório. Revista Brasileira de Zoologia, 24: 302-311. http://dx.doi.org/10.1590/S0101-81752007000200006

Mantoanelli, E., Albuquerque, G. S., Tauber, C. A. \& Tauber, M. J., 2006. Leucochrysa (Leucochrysa) varia (Neuroptera: Chrysopidae): larval descriptions, developmental rates, and adult color variation. Annals of the Entomological Society of America, 99: 7-18. http:// dx.doi.org/10.1603/0013-8746(2006)099\%5B0007:LL VNCL\%5D2.0.CO;2

Marcet, A. F., 1908. Una excursión a Valvanera. Boletín de la Sociedad Aragonesa de Ciencias Naturales, 7: 133.

Marcet, A. F., 1909. Excursión al Moncayo. Boletín de la Sociedad Aragonesa de Ciencias Naturales, 8: 135-143.

Marín, F., 1994. Las comunidades de neuropteros de la provincia de Albacete (Insecta: Neuropteroidea). Al-Basit, Estudios albacetenses, 34: 247-304.

Marín, F. \& Monserrat, V. J., 1987. Los neurópteros del encinar ibérico (Insecta, Neuropteroidea). Boletín de Sanidad Vegetal, Plagas, 13: 347-359.

Marín, F. \& Monserrat, V. J., 1989. Contribución al conocimiento de los neurópteros de Cantabria (Insecta, Neuropteroidea). Boletín de la Asociación Española de Entomología, 13: 287-298.

Marín, F. \& Monserrat, V. J., 1990. Contribución al conocimiento de los neurópteros de Soria. (Insecta, Neuropteroidea). Boletín de la Asociación Española de Entomología, 14: 219-230.
Marín, F. \& Monserrat, V. J., 1991a. Contribución al conocimiento de los neurópteros de Albacete (Insecta, Planipennia). Jornadas sobre el Medio Natural Albacetense, Albacete, 1990: 179-184.

Marín, F. \& Monserrat, V. J., 1991b. The Community of Neuropteroidea from Iberian southern beechwoods. In: L. Polgar, R. J. Chambers, A. F. G. Dixon \& I. Hodek (eds). Behaviour and impact of Aphidophaga (Proceedings of the 4th meeting of the IOBC). SPB Academic Publishing. The Hague: 187-198.

Marín, F. \& Monserrat, V. J., 1995a. Contribución al conocimiento de los neurópteros de Zaragoza (Insecta, Neuropteroidea). Zapateri, 5: 109-126.

Marín, F. \& Monserrat, V. J., 1995b. Contribución al conocimiento de los neurópteros de Valencia (Insecta, Neuroptera). Boletín de la Asociación Española de Entomología, 19(3-4): 35-49.

Martín Albaladejo, C., 1994. Bibliografía entomológica de autores españoles (1758-1990). Documentos Fauna Ibérica 1, Museo Nacional de Ciencias Naturales. Madrid. $821 \mathrm{pp}$.

Martins, F. M., Lavadinho, A. M. P. \& Gonçalves, M. L., 1999. Artropodos auxiliares num pomar de pereiras. Boletim da Sociedade Portuguesa de Entomologia, Suplemento, 6: 343-352.

Martins, F. M., Mendoça, T. R., Lavadinho, A. M. P. \& Vieira, M. M., 2002. Entomofauna num pomar de limoeiros, no Escaroupim (Ribatejo), em Portugal. Boletín de Sanidad Vegetal, Plagas, 28: 435-443.

Martins-Neto, R. G., 1992. Neurópteros (Insecta, Planipennia) da Formaçao Santana (Cretáceo Inferior) Bacia do Araripe, Nordeste do Brasil. V - Aspectos filogenéticos, paleoecológicos, paleobiogeograficos e descrição de novos taxa. Anais da Academia Brasileira de Ciencias, 64: 117-148.

Martins-Neto, R. G., 1997. Neurópteros (Insecta, Planipennia) da Formaçao Santana (Cretáceo Inferior), Bacia do Araripe, Nordeste do Brasil. X - Descrição de novos táxons (Chrysopidae, Babinskaiidae, Myrmeleontidae, Ascalaphidae e Psychopsidae). Revista da Universidade de Guarulhos, Série Ciências Exatas e Technológicas, 2(4): 68-83.

Martins-Neto, R. G. \& Rodrigues, V.Z., 2009. New Neuroptera (Insecta, Osmylidae and Mesochrysopidae) from the Santana Formation, Lower Cretaceous of northeast Brazil. Gaea - Journal of Geoscience, 5(1): 15-20. http://dx.doi.org/10.4013/gaea.2009.51.02

Martins-Neto, R. G. \& Vulcano, M. A., 1988. Neurópteros (Insecta: Planipennia) da Formaçao Santana (Cretáceo Inferior), Bacia do Araripe, Nordeste do Brasil. I Família Chrysopidae. Anais da Academia Brasileira de Ciencias, 60: 189-201.

Martins-Neto, R. G. \& Vulcano, M. A., 1989. Neurópteros (Insecta, Planipennia) da Formaçao Santana (Cretáceo Inferior), Bacia do Araripe, nordeste do Brasil. IV Complemento às partes I e II, com descriçao de novos taxa. Anais da Academia Brasileira de Ciencias, 61: 311-318.

Martynov, A. V., 1925. O nekotorykh rezul'tatakh izucheniya nasekomykh yurskikh slantsev Turkestana. Doklady Rossiiskoi Akademii nauk (A), 1925: 105-108. 
Martynov, A. V., 1927. Jurassic fossil insects from Turkestan. 7. Some Odonata, Neuroptera, Thysanoptera. Izvestiya Akademii Nauk SSSR, 21(6): 757-768.

Martynova, O. M., 1949. Mezozoiskie setchatokrylye (Neuroptera) i ikh znachenie dlya ponimaniya filogenii i sistematiki otryada. Trudy Paleontologicheskogo Instituta, 20: 150-170.

Martynova, O. M., 1961. Nadotryad Neuropteroidea. In: Rohdendorf, B. B., Becker-Migdisova, E. E., Martynova, O. M. \& Sharov, A. G. Paleozoiskie nasekomye kuznetskogo basseina. Trudy Paleontologicheskogo Instituta, 85: 469-487, 606, 656-657.

Mason, R. T., Fales, H. M., Eisner, M. \& Eisner, T., 1991. Wax of a whitefly and its utilization by a chrysopid larva. Naturwissenschaften, 78: 28-30. http://dx.doi.org/ 10.1007/BF01134039

Masters, W. M. \& Eisner, T., 1990. The escape strategy of green lacewings from orb webs. Journal of Insect Behavior, 3: 143-157. http://dx.doi.org/10.1007/BF01417908

Matias, C., Nguyen, T.-x. \& Canard, M., 1988. Rôle prédateur possible des chrysopes (Neuroptera: Chrysopidae) a l'encontre des psylles (Homoptera: Psyllidae) du poirier au Portugal. Neuroptera International, 5: 93-101.

Matsuda, M., 1928. Observations on Chrysopa vulgaris Schneider var. anpingensis Petersen. Journal of the Natural History Society of Taiwan, 18: 97-114.

Matsuda, M., 1929. Observations on Chrysopa septempunctata Wesm. subsp. cognata McLach. Dobutsugaku Zasshi, 41: 49-77.

Mayer, K., 1934. Forcipomyia (Lasiohelea) chrysopae n. sp. und Forcipmyia crudelis Karsch., zwei Blutsauger an Insekten. Arbeiten uber Morphologische und Taxonomische Entomologie, 1: 259-260.

Mazzini, M., 1976. Fine structure of the insect micropyle III. Ultrastructure of the egg of Chrysopa carnea Steph. (Neuroptera: Chrysopidae). International Journal of Insect Morphology and Embryology, 5: 273-278. http:// dx.doi.org/10.1016/0020-7322(76)90027-1

McClendon, J. F., 1906. Notes on the true Neuroptera. 2. On venation in Neuroptera. Entomological News, 17: 116-121.

McDunnough, J., 1909. Über den Bau des Darmes und seiner Anhänge von Chrysopa perla L. Archiv für Naturgeschichte, 75: 313-360.

McEwen, P. K., 1995. Attractiveness of yellow sticky traps to green lacewings (Neuropt., Chrysopidae). The Entomologist's Monthly Magazine, 131: 163-166.

McEwen, P. K., 1996. Possible effects of artificial food on the development and survival of Chrysoperla carnea (Stephens) larvae in the laboratory and in the field (Insecta: Neuroptera: Chrysopidae). In: Canard, M., Aspöck, H. \& Mansell, M. W. (eds.). Pure and Applied Research in Neuropterology (Proceedings of the Fifth International Symposium on Neuropterology, Cairo, 1994). Toulouse: 181-186.

McEwen, P. K., Clow, S., Jervis, M. A. \& Kidd, N. A. C., 1993a. Alteration in searching behaviour of adult female green lacewings Chrysoperla carnea (Neur.: Chrysopidae) following contact with honeydew of the black scale Saissetia oleae (Hom.: Coccidae) and solutions containing acidhydrolysed L-tryptophan. Entomophaga, 38: 347-354. http://dx.doi.org/10.1007/BF02374452

McEwen, P. K., Jervis, M. A. \& Kidd, N. A. C., 1993b. Influence of artificial honeydew on larval development and survival in Chrysoperla carnea [Neur., Chrysopidae]. Entomophaga, 38: 241-244. http://dx.doi.org/10.1007/ BF02372559

McEwen, P. K., Jervis, M. A. \& Kidd, N. A. C., 1994. Use of a sprayed L-tryptophan solution to concentrate numbers of the green lacewing Chrysoperla carnea in olive tree canopy. Entomologia Experimentalis et Applicata, 70: 97-99. http://dx.doi.org/10.1111/j.1570-7458.1994. tb01763.x

McEwen, P. K. \& Kidd, N. A. C., 1995. The effects of different components of an artificial food on adult green lacewing (Chrysoperla carnea) fecundity and longevity. Entomologia Experimentalis et Applicata, 77: 343-346. http://dx.doi.org/10.1111/j.1570-7458.1995. tb02332.x

McEwen, P., New, T. R. \& Whittington, A. E., 2001. Lacewings in the Crop Environment, Cambridge University Press. Cambridge. 546 pp. http://dx.doi.org/10.1017/ CBO9780511666117

McEwen, P. K. \& Oswald, J. [D.], 1998. Neuroptera on the Internet. In: Panelius, S. P. (ed.). Neuropterology 1997 (Proceedings of the Sixth International Symposium on Neuropterology, Helsinki, 1998). Acta Zoologica Fennica, 209: 151-152.

McEwen, P. K. \& Ruiz, J., 1994. Relationship between nonolive vegetation and lacewing eggs in a Spanish olive orchard. Antenna, 18: 148-150.

McEwen, P. K. \& Senior, L. J., 1998. The use of common green lacewings in environmentally friendly pest control. Agriculture and Equipment International, 50(5): 132-134.

McEwen, P. K., Senior, L., Shuja, A. \& James, C., 1998. Chrysoperla carnea: a powerful tool for the biological control of insect pests. Antenna, 22: 14-16.

McGregor, E. A., 1914. Some notes on parasitism of chrysopids in South Carolina. The Canadian Entomologist, 46: 306-308. http://dx.doi.org/10.4039/Ent46306-9

McLachlan, R., 1867. New genera and species, \& c., of neuropterous insects; and a revision of Mr. F. Walker's British Museum Catalogue of Neuroptera, part ii. (1853), as far as the end of the genus Myrmeleon. Journal of the Linnean Society of London, Zoology, 9: 230-281.

McLachlan, R., 1868. A monograph of the British NeuropteraPlanipennia. Transactions of the Entomological Society of London, 16: 145-224. http://dx.doi.org/10.1111/ j.1365-2311.1868.tb00622.x

McLachlan, R., 1880a. Notes on the entomology of Portugal. II. Pseudo-Neuroptera (in part) \& NeuropteraPlanipennia. The Entomologist's Monthly Magazine, 17: 103-108.

McLachlan, R., 1880b. Notes on some NeuropteraPlanipennia described by the late Mons. A.-Edouard Pictet, in his "Névroptères d'Espagne" (1865). The Entomologist's Monthly Magazine, 17: 62-64.

McLachlan, R., 1883a. Neuroptera of the Hawaiian Islands.Part II. Planipennia, with general summary. Annals and Magazine of Natural History, 12(5): 298-303. http:// dx.doi.org/10.1080/00222938309459633 
McLachlan, R., 1883b. The distinctive and sexual characters of Chrysopa flava, Scopoli and Ch. vittata, Wesmael. The Entomologist's Monthly Magazine, 20: 161-163.

McLachlan, R., 1884a. On two small collections of Neuroptera from Tachien-lu, in the province of Szechuen, western China, on the frontier of Thibet. Annals and Magazine of Natural History, 13(6): 421-436. http:// dx.doi.org/10.1080/00222939408677723

McLachlan, R., 1884b. Geographical distribution of Chrysopa venosa, Rambur. The Entomologist's Monthly Magazine, 20: 274-275.

McLachlan, R., 1886a. On some points of variation in Chrysopa septempuctata, Wesm. The Entomologist's Monthly Magazine, 23: 36-38.

McLachlan, R., 1886b. Notes concerning Chrysopa ventralis, prasina, abdominalis, aspersa, and zelleri. The Entomologist's Monthly Magazine, 23: 33-36.

McLachlan, R., 1887. Insecta in itinere Cl. N. Przewalskii in Asia centrali novissime lecta. XII. Neuroptera II. Perlides, Planipennes et Trichoptères. Horae Societatis Entomologicae Rossicae, 21: 448-457.

McLachlan, R., 1889. Neuroptera collected by Mr. J. J. Walker, R. N., on both sides of the Straits of Gibraltar. The Entomologist's Monthly Magazine, 25: 344-349.

McLachlan, R., 1893a. On species of Chrysopa observed in the Eastern Pyrenees; together with descriptions of, and notes on, new or little-known Paleartic forms of the genus. Transactions of the Entomological Society of London, 41(3): 227-234. http://dx.doi. org/10.1111/j.1365-2311.1893.tb02067.x

McLachlan, R., 1893b. The distinctive and sexual characters of Chrysopa flava, and Ch. vittata, Wesmael (Second Notice). The Entomologist's Monthly Magazine, 29: 108-109.

McLachlan, R., 1898. Neuroptera-Planipennia collected in Algeria by the Rev. A. E. Eaton. Transactions of the Entomological Society of London, 46: 151-168. http:// dx.doi.org/10.1111/j.1365-2311.1898.tb02372.x

McLachlan, R., 1902a. An annotated list of NeuropteraPlanipennia collected in central Spain by Dr. T. A. Chapman and Mr. G. C. Champion in July and August, 1901. The Entomologist's Monthly Magazine, 38: 129-131.

McLachlan, R., 1902b. Trichoptera, Planipennia, and Odonata collected by Lord Walsingham in the vicinity of Granada (Spain) in 1901. The Entomologist's Monthly Magazine, 38: 33-34.

McLachlan, R., 1903. An annotated list of the Neuroptera Planipennia collected in West Central Spain by Dr. T. A. Chapman and Mr. G. C. Champion in June and July, 1902. The Entomologist's Monthly Magazine, 39: 224-225.

Melón, A. A., 1903. Excursión del dia 26 de Abril de 1903. Boletín de la Sociedad Aragonesa de Ciencias Neturales, 2: 198-301.

Mendel, Z., Adar, K., Nestel, D. \& Dunkelblum, E., 1997. Sex pheromone traps as a tool for the study of population trends of the predator of a scale insect and for the identification of potential predators for biological control. International Organisation for Biological and Integrated Control of Noxious Animals and Plants, Bulletin, 20: 231-240.
Mendel, Z., Assael, F. \& Dunkelblum, E., 2004. Kairomonal attraction of predatory bugs (Heteroptera: Anthocoridae) and brown lacewings (Neuroptera: Hemerobiidae) to sex pheromones of Matsucoccus species (Hemiptera: Matsucoccidae). Biological Control, 30: 134-140. http://dx.doi.org/10.1016/j.biocontrol.2003.06.001

Menon, F. \& Makarkin, V. N., 2008. New fossil lacewings and antlions (Insecta, Neuroptera) from Cretaceous Crato Formation of Brazil. Palaeontology, 51: 149-162. http://dx.doi.org/10.1111/j.1475-4983.2007.00740.x

Michelena, J. M. \& Sanchís, A., 1997. Evolución del parasitismo y fauna útil sobre pulgones en una parcela de cítricos. Boletín de Sanidad Vegetal, Plagas, 23: 241-255.

Milbrath, L. R., Tauber, M. J. \& Tauber, C. A., 1993. Prey specificity in Chrysopa: an interspecific comparison of larval feeding and defensive behavior. Ecology, 74: 1384-1393. http://dx.doi.org/10.2307/1940068

Milbrath, L. R., Tauber, M. J. \& Tauber, C. A., 1994. Larval behavior of predacious sister-species: orientation, molting site, and survival in Chrysopa. Behavioral Ecology and Sociobiology, 35: 85-90. http://dx.doi.org/10.1007/ BF00171497

Miller, G. L., Oswald, J. D. \& Miller, D. R., 2004. Lacewings and scale insects: a review of predator/prey associations between the Neuropterida and Coccoidea (Insecta: Neuroptera, Raphidioptera, Hemiptera). Annals of the Entomological Society of America, 97: 1103-1125. http:// dx.doi.org/10.1603/0013-8746(2004)097\%5B1103:LA SIAR \%5D2.0.CO;2

Miller, L. A., 1968. Hearing in the green lacewing (Chrysopa carnea, Neuroptera). Ph.D. Dissertation. Harvard University, Cambridge, Massachusetts, USA.

Miller, L. A., 1970. Structure of the green lacewing tympanal organ (Chrysopa carnea, Neuroptera). Journal of Morphology, 131: 359-382. http://dx.doi.org/10.1002/ jmor. 1051310402

Miller, L. A., 1971. Physiological responses of green lacewings (Chrysopa, Neuroptera) to ultrasound. Journal of Insect Physiology, 17: 491-506. http://dx.doi.org/ 10.1016/0022-1910(71)90028-X

Miller, L. A., 1975. The behaviour of flying green lacewings Chrysopa carnea in the presence of ultrasound. Journal of Insect Physiology, 21: 205-219. http://dx.doi. org/10.1016/0022-1910(75)90080-3

Miller, L. A., 1983. How insects detect and avoid bats. In: Huber, F. \& Markl, H. (eds.). Neuroethology and behavioral physiology. Springer. Berlin: 251-266.

Miller, L. A., 1984. Hearing in green lacewings and their responses to the cries of bats. In: Canard, M., Séméria, Y. \& New, T. R. (eds.). Biology of Chrysopidae. W. Junk. The Hague: 134-149.

Miller, L. A. \& MacLeod, E. G., 1966. Ultrasonic sensitivity: a tympanal receptor in the green lacewing Chrysopa carnea. Science (New York), 154: 891-893.

Miller, L. A. \& Olesen, J., 1979. Avoidance behavior in green lacewings. I. Behavior of free flying green lacewings to hunting bats and ultrasound. Journal of Comparative Physiology, 131: 113-120.

Miszczak, M. \& Niemczyk, E., 1978. Green lacewing Chrysopa carnea Steph. (Neuroptera, Chrysopidae) as 
a predator of the European mite Panonychus ulmi Koch on apple trees. 2. The effectiveness of Chrysopa carnea larvae in biological control of Panonychus ulmi Koch. Fruit Science Reports, 5(2): 21-31.

Mochizuki, A., Haruyama, N., Naka, H. \& Nomura, M., 2010. Larval head capsule markings of Chrysoperla nipponensis (Neuroptera: Chrysopidae) vary according to rearing temperature. In: Devetak, D., Lipovšek, S. \& Arnett, A. E. (eds.). Proceedings of the $10^{\text {th }}$ International Symposium on Neuropterology, Piran, 2008: 209-214.

Mochizuki, A. \& Mitsunaga, T., 2005. Non-target impact assessment of the introduced green lacewing, Chrysoperla carnea (Stephens) (Neuroptera: Chrysopidae) on the indigenous sibling species, C. nipponensis (Okamoto) through interspecific predation. Applied Entomology and Zoology, 39: 217-219. http://dx.doi.org/10.1303/ aez.2004.217

Mochizuki, A., Naka, H., Hamasaki, K. \& Mitsunaga, T., 2006. Larval cannibalism and intraguild predation between the introduced green lacewing, Chrysoperla carnea, and the indigenous trash-carrying green lacewing, Mallada desjardinsi (Neuroptera: Chrysopidae), as a case study of potential nontarget effect assessment. Environmental Entomology, 35: 1298-1303. http://dx.doi. org/10.1093/ee/35.5.1298

Mochizuki, A., Naka, H., Mitsunaga, T., Haruyama, N. \& Nomura, M., 2007. Is the introduction of the biological control agent, Chrysoperla carnea (Stephens, 1836), risky or beneficial? In: Pantaleoni, R. A., Letardi, A. \& Corazza, C. (eds.). Proceedings of the Ninth International Symposium on Neuropterology, Ferrara, 2005. Annali del Museo Civico di Storia Naturale di Ferrara, 8: 197-202.

Monserrat, V. J., 1977a. Neuroptera (Planipennia) de la Sierra del Guadarrama. Trabajos de la Cátedra de Artrópodos. Facultad de Biología, Universidad Complutense, 19: 1-202.

Monserrat, V. J., 1977b. Brinckochrysa nachoi n. sp. nuevo crisópido en la fauna europea (Insecta, Neuroptera, Chrysopidae). Vie et Milieu C, 27(2): 267-277.

Monserrat, V. J., 1978a. Contribución al conocimiento de los Neurópteros de Orense (Neu. Planipennia). Boletín de la Asociación Española de Entomología, 2: 169-184.

Monserrat, V. J., 1978b. Primera contribución al conocimiento de los Neurópteros de Cádiz (Insecta, Neuroptera, Planipennia). Boletín de la Real Sociedad Española de Historia Natural, Sección Biológica, 76: 57-70.

Monserrat, V. J., 1979a. Segunda contribución al conocimiento de los neurópteros de Cádiz (Insecta, Planipennia). Boletín de la Real Sociedad Española de Historia Natural, Sección Biológica, 77: 409-417.

Monserrat, V. J., 1979b. Sobre los Neurópteros Ibéricos (II) (Neuroptera, Planipennia). Boletín de la Asociación Española de Entomología, 3: 17-21.

Monserrat, V. J., 1979c. Estudio de la armadura genital de Chrysopa alarconi Navás, 1915 y su inclusión en el género Anisochrysa (Neuropt. Chrysopidae). Graellsia, 33: 97-101.

Monserrat, V. J., 1980a. Sobre los Neurópteros Ibéricos (I). (Neuroptera, Planipennia). Graellsia, [1978], 34: 171-176.
Monserrat, V. J., 1980b. Contribución al conocimiento de los Neurópteros de Toledo. Graellsia, [1978], 34: 177-193.

Monserrat, V. J., 1981a. Sobre los Neurópteros Ibéricos (III) (Neuroptera, Planipennia). Boletín de la Asociación Española de Entomología, [1980], 4: 151-156.

Monserrat, V. J., 1981b. Contribución al conocimiento de los Neurópteros de Italia (Neuroptera, Planipennia). Neuroptera International, 1: 48-64.

Monserrat, V. J., 1982. Contribución al conocimiento de los neurópteros de Cáceres (Neur., Planipennia). Graellsia, 38: $67-84$.

Monserrat, V. J., 1984a. Contribución al conocimiento de los neurópteros de Huesca (Neuroptera, Planipennia). Pirineos, 121: 29-50.

Monserrat, V. J., 1984b. Contribución al conocimiento de los neurópteros de Salamanca (Neur., Planipennia). Eos, [1983], 59: 165-177.

Monserrat, V. J., 1984c. Estadios larvarios de los neurópteros ibéricos. III: Anisochrysa genei (Neur., Plan., Chrysopidae). Neuroptera International, 3(1): 13-21.

Monserrat, V. J., 1984d. Contribución al conocimiento de los neurópteros de Alicante (Neur., Planipennia). Mediterránea, Serie de Estudios Biológicos, 7: 91-116.

Monserrat, V. J., 1984e. Contribución al conocimiento de los neurópteros de Zamora (Neur. Planipennia). Miscellània Zoològica, 8: 153-163.

Monserrat, V. J., 1984f. Correcciones a las citas de Coniopterígidos (Insecta, Planipennia, Coniopterygidae) dadas por L. Navás. Miscellània Zoològica, 8: 145-151.

Monserrat, V. J., 1985a. Lista de los tipos de Mecoptera y Neuroptera (Insecta) de la colección L. Navàs, depositados en el Museo de Zoología de Barcelona. Miscellània Zoològica, 9: 233-243.

Monserrat, V. J., 1985b. Contribución al conocimiento de los Neurópteros (Neuroptera: Planipennia) de Murcia. Anales de Biología (Biología Animal), 1: 81-94.

Monserrat, V. J., 1985c. Contribución al conocimiento de los neurópteros de Lugo (Neur., Planipennia). Trabajos Compostelanos de Biología, 12: 87-98.

Monserrat, V. J., 1986a. Sinopsis de los hemeróbidos de la Península Ibérica (Neuroptera, Planipennia, Hemerobiidae). Actas de las VIII Jornadas de la Asociación española de Entomología, Sevilla: 1200-1223.

Monserrat, V. J., 1986b. Sobre los Neurópteros ibéricos (IV) (Neur.). Boletín de la Asociación Española de Entomología, 10: 95-105.

Monserrat, V. J., 1986c. Longinos Navás, his neuropterological work and collection. In: Gepp, J., Aspöck, H. \& Hölzel, H. (eds.). Recent Research in Neuropterology (Proceedings of the 2nd International Symposium on Neuropterology, Hamburg, 1984). Graz: 173-176.

Monserrat, V. J., 1987. Contribución al conocimiento de los Neurópteros de Almería (Neur., Planipennia). Graellsia, [1986], 42: 131-147.

Monserrat, V. J., 1989. Estadios larvarios de los neurópteros ibéricos. II: Mallada subcubitalis (Planipennia: Chrysopidae). Neuroptera International, 5(3): 125-132.

Monserrat, V. J., 1990. Revision de la obra de L. Navas, II: El genero Micromus Rambur, 1842 (Neuropteroidea, Planipennia: Hemerobiidae). Graellsia, 46: 175-190. 
Monserrat, V. J., 1991. Nuevos datos sobre los hemeróbidos ibéricos (Insecta, Neuroptera: Hemerobiidae). Zoologica Baetica, 2: 101-113.

Monserrat, V. J., 1996. Lista de los neurópteros de Aragón (Megaloptera, Raphidioptera, Planipennia). Catalogus de la entomofauna Aragonesa, 11: 11-17.

Monserrat, V. J., 2005. Catálogo de los Neurópteros de Baleares con nuevos datos sobre su fauna (Insecta, Neuroptera). Bolletí de la Societat d'Història Natural de les Balears, 48: 71-85.

Monserrat, V. J., 2008. Nuevos datos sobre algunas especies de crisópidos (Insecta: Neuroptera: Chrysopidae). Heteropterus Revista de Entomología, 8(2): 171-196.

Monserrat, V. J., 2010. Nuevas o interesantes citas de neurópteros en la Península Ibérica (Insecta: Neuroptera). Heteropterus Revista de Entomología, 10(1): 19-34.

Monserrat, V. J., 2011. Sobre algunas especies de neurópteros de la Península Ibérica y de las Islas Canarias de posición taxonómica problemática o con citas dudosas o cuestionables (Insecta, Neuroptera: Megaloptera, Planipennia). Boletín de la Sociedad Entomológica Aragonesa, 49: 153-178.

Monserrat, V. J., 2013. Los Neurópteros (Neuroptera). In: Ruano, F., Tierno de Figueroa, M. y Tinaut, A (eds.). Los Insectos de Sierra Nevada. 200 años de historia. Vol. 1. Asociación española de Entomología. Granada: 281- 309.

Monserrat, V. J., Acevedo, F. \& Pantaleoni, R. A., 2014. Nuevos datos sobre algunas especies de crisópidos de la Península Ibérica, Islas Baleares e Islas Canarias (Insecta, Neuroptera, Chrysopidae). Graellsia, 70(1): e002, 39 pp. http://dx.doi.org/10.3989/graellsia.2014.v70.100

Monserrat, V. J. \& Díaz-Aranda, L. M., 1987. Contribución al conocimiento de los neurópteros (Neur.: Raphidioptera, Planipennia) de Cuenca. Boletín de la Asociación Española de Entomología, 11: 171-189.

Monserrat, V. J. \& Díaz-Aranda, L. M., 1988. Contribución al conocimiento de los Neurópteros de Castellón (Insecta, Neuropteroidea, Planipennia). Mediterránea, Serie de Estudios Biológicos, 10: 87-95.

Monserrat, V. J. \& Díaz-Aranda, L. M., 1989a. Suaris walsinghami Navás, 1914 nuevo crisópido para la fauna europea (Neuroptera, Chrysopidae). Nouvelle Revue d'Entomologie, 6(4): 407-411.

Monserrat, V. J. \& Díaz-Aranda, L. M., 1989b. Contribución al conocimiento de los Neurópteros de Castellón (Insecta, Neuropteroidea, Planipennia). Mediterránea, Serie de Estudios Biológicos, 11: 47-58.

Monserrat, V. J. \& Díaz-Aranda, L. M., 1989c. Nuevos datos sobre los crisópidos ibéricos (Neuroptera, Planipennia: Chrysopidae). Boletín de la Asociación Española de Entomología, 13: 251-267.

Monserrat, V. J. \& Díaz-Aranda, L. M., 2012. Los estadios larvarios de los Crisópidos ibéricos (Insecta, Neuroptera, Chrysopidae), nuevos elementos sobre la morfología larvaria aplicables a la sistemática de la familia. Graellsia, 68(1): 31-158. http://dx.doi.org/10.3989/graellsia.2012. v68.055

Monserrat, V. J., Díaz-Aranda, L. M. \& Hölzel, H., 1991. Contribución al conocimiento de los neurópteros de Marruecos (Insecta, Neuropteroidea). Eos, 66: 101-115.
Monserrat, V. J. \& Freitas, S. de., 2005. Contribución al conocimiento de los crisópidos de Coquimbo, Patagonia y Tierra del Fuego (Argentina, Chile) (Insecta, Neuroptera, Chrysopidae). Graellsia, 61: 163-179. http:// dx.doi.org/10.3989/graellsia.2005.v61.i2.18

Monserrat, V. J., Gamarra, P. \& Deretsky, Z., 1999. The Neuropterological Fauna of the Houses of the City of Madrid. Journal of Neuropterology, 2: 35-44.

Monserrat, V. J. \& Marín, F., 1994. Plant substrate specificity of Iberian Chrysopidae (Insecta: Neuroptera). Acta Oecologica, 15(2): 119-131.

Monserrat, V. J. \& Marín, F., 2001. Comparative plant substrate specificity of Iberian Hemerobiidae, Coniopterygidae and Chrysopidae. In: McEwen, P. K., New, T. R. \& Whittington, A. E. (eds.). Lacewings in the Crop Environment. Cambridge University Press. Cambridge: 424-434. http://dx.doi.org/10.1017/CBO9780511666117.026

Monserrat, V. J., Marín, F. \& Díaz-Aranda, L.M., 1994. Contribución al conocimiento de los neurópteros de Lérida (Insecta, Neuroptera). Zoologica Baetica, 5: 41-64.

Monserrat, V. J., Oswald, J. D., Tauber, C. A. \& DíazAranda, L. M., 2001. Recognition of larval Neuroptera. In: McEwen, P. K., New, T. R. \& Whittington, A. E. (eds.). Lacewings in the Crop Environment. Cambridge University Press. Cambridge: 43-81. http://dx.doi. org/10.1017/CBO9780511666117.005

Monserrat, V. J. \& Rodrigo, F., 1992. Nuevas citas sobre los crisópidos ibéricos (Insecta, Neuroptera: Chrysopidae). Zoologica Baetica, 3: 123-138.

Monserrat, V. J. \& Triviño, V., 2013. Atlas de los neurópteros de la Península Ibérica e Islas Baleares (Insecta, Neuroptera: Megaloptera, Raphidioptera, Planipennia)/Atlas of the Iberian and Balearic lacewings (Insecta, Neuroptera: Megaloptera, Raphidioptera, Planipennia). Monografías de la Sociedad Entomológica Aragonesa, vol. 13. Zaragoza. 154 pp., 136 mapas.

Monserrat, V. J., Triviño, V. \& Acevedo, F., 2013. Contribución al conocimiento de los neurópteros de Navarra (Insecta, Neuroptera). Heteropterus Revista de Entomología, 13(1): 41-58.

Montiel, A. \& Santaella, S., 1995. Evolución de la población de Saissetia oleae OLIV en condiciones naturales. Períodos susceptibles de control biológico. Boletín de Sanidad Vegetal, Plagas, 21: 445-455.

Morgan, M. J., 1980. Contribución al catálogo faunístico del Coto Nacional de las Sierras de Cazorla y Segura. Neuroptera. In: Viedma, M.G. de (ed.). Fauna de Cazorla. Invertebrados. Monografías ICONA, $\mathrm{n}^{\circ} 23$. Ministerio Agricultura. Madrid: 119.

Morinière, J., Hendrich, L., Hausmann, A., Hebert, P., Haszprunar, G. \& Gruppe, A., 2014. Barcoding Fauna Bavarica: $78 \%$ of the Neuropterida Fauna Barcoded! PLoS ONE, 9(10): e109719. http://dx.doi.org/10.1371/ journal.pone.0109719

Morley, C., 1931. The Neuroptera of Suffolk. Transactions of the Suffolk Naturalists 'Society, 1: 181-194.

Morris, T. I. \& Campos, M., 2000. The olive branchs: a passageway for predators? Zoologica Baetica, 11: 67-75

Morris, T. I. \& Campos, M., 2006. Study of Chrysoperla carnea larvae digestion rates (Insect, Planipennia) using immunoassays (ELISAs). Zoologica Baetica, 17: 3-10. 
Morris, T. I., Campos, M., Jervis, M. A., McEwen, P. K. \& Kidd, N. A. C., 1998. Potential effects of various ant species on green lacewing, Chrysoperla carnea (Stnephens) (Neuropt., Chrysopidae) egg numbers. Journal of Applied Entomology, 122: 401-403. http://dx.doi.org/ 10.1111/j.1439-0418.1998.tb01519.x

Morton, K. J., 1912. A collecting trip to the Camargue and the Sierra Albarracin. The Entomologist, 45: 109-114.

Morton, K. J., 1921. Neuroptera, Mecoptera, and Odonata from Mesopotamia and Persia. The Entomologist's Monthly Magazine, 57: 213-225.

Morton, K. J., 1925. Notes on Neuroptera from Palestine, including a description of a new species of Myrmeleonidae. Transactions of the Royal Entomological Society of London, 73: 403-412. http://dx.doi. org/10.1111/j.1365-2311.1926.tb02643.x

Mosely, M. E., 1932. Trichoptera, Neuroptera, etc., collected in the Pyrenees. The Entomologist, 65: 276-282.

Mouloud, M., Chu, N. T., Simo Santalla, P., Gillet, P. \& Thierry, D., 2002. Enzymatic polymorphism in Chrysoperla carnea (Stephens) and C. kolthoffi (Navás) (Neuroptera: Chrysopidae). Acta Zoologica Academiae Scientiarum Hungaricae, 48(Suppl. 2): 203-208.

Müller, A., 1872. Note on the oviposition of Chrysopa. The Entomologist's Monthly Magazine, 9: 60-62.

Muma, M. H., 1959. Hymenopterous parasites of Chrysopidae on Florida citrus. The Florida Entomologist, 42: 149-153. http://dx.doi.org/10.2307/3492229

Muma, M. H., Selhime, A. G. \& Denmark, H. A., 1975. An annotated list of predators and parasites associated with insects and mites of Florida citrus. 3rd Edition. Agricultural Experiment Station, Bulletin, 634B: 1-46.

Nagler, C., 1958. Citeva date privitoare la raspindirea unor Neuroptere (Ord. Planipennia Heymos 1915) in R.P.R. Studii si cercetari stiintifice. Biologie si stiinte agricole. Academia Republicii Populare Romîne, Filiala Iasi, 9(2): 229-303.

Naka, H., Haruyama, N., Ito, K., Mitsunaga, T., Nomura, M. \& Mochizuki, A., 2006. Interspecific hybridization between introduced and indigenous green lacewings (Neurop., Chrysopidae: Chrysoperla) at different adult densities. Journal of Applied Entomology, 130: 426-428. http://dx.doi.org/10.1111/j.1439-0418.2006. 01084.x

Naka, H., Mitsunaga, T. \& Mochizuki, A., 2005. Laboratory hybridization between the introduced and the indigenous green lacewings (Neuroptera: Chrysopidae: Chrysoperla) in Japan. Environmental Entomology, 34: 727-731. http://dx.doi.org/10.1603/0046-225X-34.3.727

Nakahara, W., 1964. Neuroptera of Ryukyu collected chiefly under the auspice of the Japan - U.S. co-operative science program. Konty $\hat{u}, 32: 245-248$.

Narasimham, A. U., 1992. Morphometric studies on egg bursters of some Chrysopidae. Neuroptera International, 7: 1-6.

Nasir, M. M., 1947. Biology of Chrysopa scelestes Banks. Indian Journal of Entomology, 9: 177-192.

Navás, L., 1901. Notas neuropterológicas. III. El género Chrysopa en España. Butlletí de la Institució Catalana d'Història Natural, 1: 23-28.
Navás, L., 1903. Algunos Neurópteros de España nuevos. Boletín de la Sociedad Aragonesa de Ciencias Naturales, 2: 99-109.

Navás, L., 1904a. Notas zoológicas. II. Neurópteros de la provincia de Barcelona cogidos por el P. Eugenio Saz S.J. Boletín de la Sociedad aragonesa de Ciencias Naturales, 3: 10-16, (122-127).

Navás, L. 1904b. Notas Zoológicas. Las Chrysopas (Insectos Neurópteros) de Chamartín de la Rosa (Madrid). Boletín de la Sociedad Aragonesa de Ciencias Naturales, 3: 115-122.

Navás, L., 1905a. Notas entomológicas. XII. Neurópteros de Pozuelo de Calatrava (C. Real). Boletín de la Real Sociedad Española de Historia Natural, 5: 503-509.

Navás, L., 1905b. Notas neuropterológicas. VI. Neurópteros de Montserrat. Butlletí de la Institució Catalana d'Història Natural, 5: 11-21.

Navás, L., 1905c. Catálogo descriptivo de los insectos Neurópteros de los alrededores de Madrid. Revista de la Real Academia de Ciencias Exactas Físicas y Naturales de Madrid, 2(4): 1-54.

Navás, L., 1905d. Notas neuropterológicas. II. Neurópteros del Montseny y Sarriá. Butlletí de la Institució Catalana d'Història Natural, 3(4): 54-55.

Navás, L. 1905e. Notas zoológicas. VIII. Mis excursiones durante el verano de 1904. Boletín de la Sociedad Aragonesa de Ciencias Naturales, 4: 107-131.

Navás, L., 1908a. Neurópteros de España y Portugal. Brotéria (Zoológica), 7: 101-134.

Navás, L., 1908b. Neurópteros nuevos. Memorias de la Real Academia Ciencias Naturales de Barcelona, 6, 25: 401-423.

Navás, L., 1909a. Notas entomológicas V. Neurópteros del Moncayo y Zaragoza. Actas de la Real Sociedad Española de Historia Natural, 29: 172-176.

Navás, L., 1909b. Neurópteros nuevos de la fauna ibérica. Memorias del Primer Congreso de Naturalistas Españoles, Zaragoza, 1908: 143-158.

Navás, L., 1909c. Sur une Chrysopa nouvelle d'Espagne (Neur.). Deutsche Entomologische Zeitschrift, 1909: 793-794.

Navás, L., 1910. Notas entomológicas (2.Serie). 2. Excursiones por Cataluña y Mallorca. Boletín de la Sociedad aragonesa de Ciencias Naturales, 9: 240-248.

Navás, L., 1913a. Les Chrysopides (Ins. Névr.) du Musée de Londres [sic]. Annales de la Société Scientifique de Bruxelles. 37(pt. 2): 292-330.

Navás, L., 1913b. Cuatro pequeñas colecciones de Neurópteros de la Península Ibérica. Boletín Sociedad aragonesa de Ciencias Naturales, 12: 77-91.

Navás, L., 1914a. Algunos neurópteros de los alrededores de Madrid. Boletín de la Sociedad aragonesa de Ciencias Naturales, 13: 38-41.

Navás, L., 1914b. Les Chrysopides (Ins. Névr.) du Musée de Londres [sic]. Annales de la Société Scientifique de Bruxelles, 38(2): 73-114.

Navás, L., 1915a. Crisòpids d'Europa (Ins. Neur.). Arxius de l'Institut de Ciències, 3: 1-99.

Navás, L., 1915b. Notas entomologicas, 2a Serie. Excursiones por Cataluña. Julio 1914. Boletín de la Sociedad 
aragonesa de Ciencias Naturales, 14: 27-32, 35-59, 66-80.

Navás, L., 1915c. Neue Neuropteren. Zweite serie. Entomologische Mitteilungen, 4: 194-202.

Navás, L., 1916a. Notas entomológicas. $2^{\text {a }}$ serie. 13. Excursión al valle de Arán (Lérida) 17-28 de Julio de 1915. Boletín de la Sociedad aragonesa de Ciencias Naturales, 15: 179-194.

Navás, L., 1916b. Neurópteros nuevos de España (segunda serie). Revista de la Real Academia de Ciencias Exactas Físicas y Naturales de Madrid, 14: 593-601.

Navás, L., 1916c. Excursiones por el norte de España. Congreso de la Asociación Española para el Progreso de las Ciencias, 6: 161-179.

Navás, L., 1917a. Algunos Crisópidos (Neur.) de los alrededores de Marín (Pontevedra). Brotéria (Zoológica), 15: 69-71.

Navás, L., 1917b. Neue Neuropteren. Dritte [III] serie. Entomologische Mitteilungen, 6: 274-282.

Navás, L., 1917c. Neurópteros nuevos o poco conocidos $8^{\text {a }}$ serie. Memorias de la Real Academia de Ciencias Naturales de Barcelona, 13: 155-178.

Navás, L., 1917d. Comunicaciones entomológicas. 2. Excursiones entomológicas por Aragón y Navarra. Revista de la Real Academia de Ciencias Exactas, Físico-Químicas y Naturales de Zaragoza, 2: 81-91.

Navás, L., 1918. Insecta nova. IV Series. Memorie dell'Accademia Pontifica dei Nuovi Lincei, 4(2): 13-23.

Navás, L., 1919. Insecta nova. VI Series. Memorie dell'Accademia Pontifica dei Nuovi Lincei, 5(2): 11-19.

Navás, L. 1920. A contribution to the knowledge of the neuropterous insects of Algeria. Novitates Zoologicae, 26: 283-290.

Navás, L., 1921. Mis excursiones del verano de 1919. Memorias de la Real Academia Ciencias Naturales de Barcelona, 17(6): 143-169.

Navás, L., 1924a. Fauna de Catalunya. Entomologia de Catalunya. Neuròpters. Fascicle I. Neuròpters Propis. Publicacions de l'Institut d'Estudis Catalans, seccio de Ciències. Barcelona. 271 pp.

Navás, L., 1924b. Excursió entomológica al Cabrerès (Girona-Barcelona). Musei Barcinonensis Scientiarum Naturalium Opera, 4(10): 1-59.

Navás, L., 1924c. Mis excursiones entomológicas del verano de 1924. Broteria (Zoológica), 21(3): 115-150.

Navás, L., 1925. Sinopsis de los Neurópteros (Ins.) de la península ibérica. Memorias de la Sociedad Ibérica de Ciencias Naturales, 4: 1-149.

Navás, L., 1927. Veinticinco formas nuevas de insectos. Boletín de la Sociedad Ibérica de Ciencias Naturales, 26: 48-75.

Navás, L., 1928. Excursiones por la provincia de Gerona. Butlletí de la Institució Catalana d'Història Natural, 8(1): 37-53.

Navás, L., 1929. Excursiones por la provincia de Gerona en Julio y Agosto de 1928. Butlletí de la Institució Catalana d'Història Natural, 9(2): 27-48.

Navás, L., 1930. Excursió entomológica a la vall de Noguera de Cardós (LLeida). Butlletí de la Institució Catalana d'Història Natural, 10: 156-169.
Navás, L., 1932a. Fáunula de Sobradiel (Zaragoza). Revista de la Real Academia de Ciencias Exactas Físico-Químicas y Naturales de Zaragoza, 16: 11-28.

Navás, L., 1932b. Insectos nuevos de Sobradiel (Zaragoza). Boletín de la Sociedad entomológica de España, 15: 132-133.

Navás, L. 1934. Les Chrysopides (insectes névroptères) du nord de l'Afrique. Compte Rendu de la Session, Association Française pour l'Avancement des Sciences, 58: 168-169.

Nave, A., Gonçalves, F., Rodrigues, M. C., Nunes, F., Campos, M. \& Torres, L., 2012. Preliminary evaluation of sugars from flowering plants as food resources for Chrysoperla carnea (Stephens) (Neuroptera: Chrysopidae) in an olivce agroecosystem. Landscape Management for Functional Biodiversity, 75: 137-141.

Naville, A. \& Beaumont, J. de, 1933. Recherches sur les chromosomes des Névroptères [I]. Archives d'Anatomie Microscopique, 29: 199-243.

Naville, A. \& Beaumont, J. de, 1936. Recherches sur les chromosomes des Névroptères. 2e partie. Archives d'Anatomie Microscopique, 32: 271-302.

Nei, M., 1972. Genetic Distance between Populations. The American Naturalist, 106(949): 283-292. http://dx.doi. org/10.1086/282771

Nel, A., Delclòs, X. \& Hutin, A., 2005. Mesozoic chrysopidlike Planipennia: a phylogenetic approach (Insecta: Neuroptera). Annales de la Société Entomologique de France (N.S.), 41: 29-68.

Nel, A., Peñalver, E. \& Martínez-Delclòs, X., 1994. Presencia de la subfamilia Nothochrysinae (Insecta: Neuroptera: Chrysopidae) en el Mioceno Inferior lacustre de Ribesalbes (Castellón, España). Comunicaciones de las X Jornadas de Paleontología, Madrid: 146-148.

Nel, A. D. \& Séméria, Y., 1986. Une nouvelle espèce de chrysopide fossile du Stampien Superieur (Oligocene) d'Aix-en-Provence Notochrysa [sic] stampieni n. sp. (Neuroptera, Chrysopidae, Notochrysinae [sic]). Neuroptera International, 4: 23-30.

Nelson, J. D., Lambdin, P. L., Grant, J. F. \& Mendel, Z., 2001. Predators attracted to the sex pheromones of Matsucoccus spp. (Margarodidae) in pine dominated forests. Bollettino di Zoologia Agraria e di Bachicoltura, 33: 409-416.

Neuenschwander, P., Hagen, K. S. \& Smith, R. F., 1975. Predation on aphids in California's alfalfa fields. Hilgardia, 43: 53-71. http://dx.doi.org/10.3733/hilg.v43n02p053

Neuenschwander, P. \& Michelakis, S., 1980. The seasonal and spatial distribution of adult and larval chrysopids in olive trees in Crete. Acta Oecologica, Oecologia Applicata, 1: 93-102.

Neumark, S., 1952. Chrysopa carnea Stephens and its enemies in Israel. State of Israel, Ministry of Agriculture, Department of Forests, Forest Research Station. Ilanoth. vii+127 pp.

New, T. R., 1967. The flight activity of some British Hemerobiidae and Chrysopidae, as indicated by suction-trap catches. Proceedings of the Royal Entomological Society of London, Series A, General Entomology, 42: 93-100. http://dx.doi.org/10.1111/j.1365-3032.1967.tb01008.x 
New, T. R., 1968. The dispersal of insects across sandy beaches, with special reference to larvae of Neuroptera. Entomologist's Gazette, 19: 119-125.

New, T. R., 1969. Notes on the debris-carrying habit in larvae of British Chrysopidae (Neuroptera). Entomologist's Gazette, 20: 119-124.

New, T. R., 1975a. Lacewings (Neuroptera) as biological control agents. Victorian Entomologist, 5: 102-103.

New, T. R., 1975b. The biology of Chrysopidae and Hemerobiidae (Neuroptera), with reference to their usage as biocontrol agents: a review. Transactions of the Royal Entomological Society of London, 127: 115-140. http:// dx.doi.org/10.1111/j.1365-2311.1975.tb00561.x

New, T. R., 1980. A revision of the Australian Chrysopidae (Insecta: Neuroptera). Australian Journal of Zoology, Supplementary Series 77: 1-143. http://dx.doi.org/10.1071/ AJZS077

New, T. R., 1982. Hymenopterous parasites of some larval Chrysopidae (Neuroptera) near Melbourne, Australia. Neuroptera International, 2: 33-36.

New, T. R., 1983. The egg and first instar of Italochrysa insignis (Neuroptera, Chrysopidae). Australian Entomological Magazine, 10: 29-32.

New, T. R., 1984a. The need for taxonomic revision in Chrysopidae. In: Canard, M., Séméria, Y. \& New, T. R. (eds.). Biology of Chrysopidae. W. Junk. The Hague: 37-42.

New, T. R., 1984b. Chrysopidae: ecology on field crops. Pp. 160-167. In: Canard, M., Séméria, Y. \& New, T. R. (eds.). Biology of Chrysopidae. W. Junk. The Hague: 160-167.

New, T. R., 1984c. Identification of hymenopterous parasites of Chrysopidae. In: Canard, M., Séméria, Y. \& New, T. R. (eds.). Biology of Chrysopidae. W. Junk. The Hague: 193-204.

New, T. R., 1986a. A review of the biology of Neuroptera Planipennia. Neuroptera International, Supplemental Series, 1: 1-57.

New, T. R., 1986b. Some early stages of Calochrysa Banks (Neuroptera, Chrysopidae). Australian Entomological Magazine, 13: 11-14.

New, T. R., 1988a. Do cicada songs attract Chrysopidae (Neuroptera)? Neuroptera International, 5: 121-122.

New, T. R., 1988b. Neuroptera. In: Minks, A. K. \& Harrewijn, P. (eds). Aphids, their biology, natural enemies and control. Vol. 2B. Elsevier. Amsterdam: 249-258.

New, T. R., 1989. Planipennia, Lacewings. Handbuch der Zoologie, vol. 4(30). Walter de Gruyter. Berlin. 132 pp.

New, T. R., 1991. Commentary: Prospects and priorities for conservation of Neuroptera. Neuroptera International, 6: 195-204.

New, T. R., 1998. Are Neuroptera an informative focal group for conservation assessment? In: Panelius, S. P. (ed.). Neuropterology 1997 (Proceedings of the Sixth International Symposium on Neuropterology, Helsinki, 1998). Acta Zoologica Fennica, 209: 167-174.

New, T. R., 1999. Neuroptera and biological control (Neuropterida). Stapfia, 60: 147-166.

New, T. R., 2001. Introduction to the systematics and distribution of Coniopterygidae, Hemerobiidae, and Chrysopidae used in pest management. In: McEwen, P. K., New, T. R. \& Whittington, A. E. (eds.). Lacewings in the Crop Environment. Cambridge University Press. Cambridge: 6-28. http://dx.doi.org/10.1017/CBO9780511666117.003

New, T. R., 2002. Prospects for extending the use of australian lacewings in biological control. Acta Zoologica Academiae Scientiarum Hungaricae, 48(Suppl. 2): 209-216.

New, T. R., 2003. The Neuroptera of Malesia. Fauna Malesiana, vol. 4. Brill. Leiden. viii+204 pp.

Newman, E., 1853. Proposed division of Neuroptera into two classes. Zoologist, 11(Appendix): clxxxi-cciv.

Nguyen, N. H., Suh, S.-o. \& Blackwell, M., 2007. Five novel Candida species in insect-associated yeast clades isolated from Neuroptera and other insects. Mycologia, 99: 842-858. http://dx.doi.org/10.3852/mycologia.99.6.842

Nguyen, N. H., Suh, S.-o., Erbil, C. K. \& Blackwell, M., 2006. Metschnikowia noctiluminum sp. nov., Metschnikowia corniflorae sp. nov., and Candida chrysomelidarum sp. nov., isolated from green lacewings and beetles. Mycological Research, 110: 346-356. http://dx.doi.org/10.1016/j. mycres.2005.11.010

Nicoli Aldini, R., 2002. Insetti predatori di interesse agrario. Notiziario sulla Protezione delle Piante, 14: 81-106.

Nicoli Aldini, R. \& Baviera, C., 2001. Nuove acquisizioni sulla Neurotterofauna di Sicilia e isole circumsiciliane (Insecta Neuropterida). Il Naturalista siciliano, Serie 4, 25(3-4): 345-376.

Nicoli Aldini, R., Letardi, A. \& Pantaleoni, R. A., 2012. State of the art on Neuropterida of Sicily and Malta. Biodiversity Journal, 3(4): 445-458.

Nielsen, E. S., 1977. En undersøgelse af netvingefaunaen (Neuroptera s.str.) i en dansk bøgeskov. Entomologiske Meddelelser, 45: 45-64.

Noirot, C. \& Quennedey, A., 1974. Fine structure of insects epidermal glands. Annual Review of Entomology, 19: 61-80. http://dx.doi.org/10.1146/annurev.en.19.010174. 000425

Noirot, C. \& Quennedey, A., 1991. Glands, gland cells, glandular units: some comments on terminology and classification. Annales de la Société Entomologique de France (N.S.), 27: 123-128.

Novak, G. B., 1891. Terzo cenno sulla fauna dell'Isola Lesina in Dalmazia. Neuroptera. Societas HistoricoNaturalis Croatica, 6: 50-58.

Núñez Pérez, E., Marín, F. \& Tizado, E. J., 1992. Contribución al conocimiento de los neurópteros (Neur., Hemerobiidae, Chrysopidae) depredadores de pulgones (Hom., Aphididae) sobre plantas cultivadas en León (España). Actas do V Congreso Ibérico de Entomología, Lisboa: 387-393.

Ocete, R., López, M. A., Pérez, M., Arnold, C. \& Ferragut, F., 2000. Prospección de los artrópodos fitófagos, auxiliares y enfermedades en poblaciones europeas de vid silvestre, Vitis vinifera L. subesp. sylvestris (Gmelin) Hegi. Boletín de Sanidad Vegetal, Plagas, 26: 173-186.

Ocharan, R., Ocharan, F. J. \& Anadón, A., 2012. Neurópteros de la Reserva de la Biosfera de Muniellos (Asturias, Norte de España) (Neuroptera s. s., Megaloptera y Raphidioptera). Boletín de la Sociedad entomológica Aragonesa, 50: 421-429. 
Ohm, P. \& Báez, M., 2004. Planippenia. In: Izquierdo Zamora, I., Martín Esquivel, J. L., Zurita Pérez, N. \& Arechavaleta Hernández, M. (eds.). Lista de especies silvestres de Canarias (Hongos, Plantas y Animales Terrestres). Gobierno de Canarias. La Laguna: 207-208.

Ohm, P. \& Remane, R., 1968. Die Neuropterenfauna Hessens und einiger angrenzender Gabiete (zur Verbreitung der Neuropteren in Mitteleuropa). Faunistisch-Ökologische Mitteilungen, 3(6): 209-228.

Okamoto, H., 1919. Studies on the Japanese Chrysopidae. Report of the Hokkaido National Agricultural Experiment Station, 9: 1-76.

Olivier, G. A., 1792. Encyclopedie méthodique. Histoire naturelle. Vol. 7 (Insectes). Panckoucke. Paris. 825 pp. http://dx.doi.org/10.5962/bhl.title.7834

Orlova, N. A., 1998. Effects of photoperiod and temperature on diapause induction in Chrysopa pallens (Rambur) (Neuroptera, Chrysopidae). In: Panelius, S. P. (ed.). Neuropterology 1997 (Proceedings of the Sixth International Symposium on Neuropterology, Helsinki, 1998). Acta Zoologica Fennica, 209: 195-202.

Oswald, J. D., 2013a. Neuropterida species of the world. A catalogue of the Species-Group names of the Extant and Fossil Neuroptera, Megaloptera, Raphidioptera and Glosselytrodea (Insecta: Neuropterida) of the World. Version 3.0. Disponible en: http://lacewing.tamu.edu/ Species-Catalogue/index.html (última consulta, junio 2015).

Oswald, J. D., 2013b. Bibliography of the Neuropterida. An Annotated Bibliography and Digital Library of the Literature of the Extant and Fossil Neuroptera, Megaloptera, Raphidioptera and Glosselytrodea (Insecta: Neuropterida) of the World, Version 10.0. Disponible en: http://lacewing.tamu.edu/Bibliography/index.html (última consulta, junio 2015).

Oswald, J. D. \& Penny, N. D., 1991. Genus-group names of the Neuroptera, Megaloptera and Raphidioptera of the world. Occasional Papers of the California Academy of Sciences, 147: 1-94.

Pabst, M. A. \& Devetak, D., 1992. Subgenual organ in the green lacewing, Chrysoperla carnea. Electron Microscopy, 3: 693-694.

Panfilov, D. V., 1980. Novye predstaviteli setcharokrylykh (Neuroptera) iz yury Karatau. In: Dolin, V. G., Panfilov, D. V., Ponomarenko, A. G. \& Pritykina, L. N., 1980. Iskopaemye nasekomye mezozoya. Akademiya Nauk Ukrainskoi SSR, Institut Zoologii, Naukova Dumka. Kiev: 82-111.

Pantaleão, F. M. C., 1994. Crisopídeos associados a biocenose de dois pomares de citrinos na regão de Setúbal. Relatório do Trabalho de Fim de Curso de Engenharia Agronómica, Instituto Superior de Agronomía. Lisboa.

Pantaleão, F., Carvalho, J. P., Franco, J. C.\& Magro, A., 1993. Crisopídeos associados aos citrinos. I Congresso de Citricultura, Silves: 427-431.

Pantaleoni, R. A., 1983. Riconoscimento in campo delle larve di Crisopidi. Informatore Fitopatologico, 33: 31-36.

Pantaleoni, R. A., 1984. Note su alcuni parassiti (s.l.) di Neurotteri Planipenni con segnalazione del ritrovamento di Acari foretici su di un Crisopide. Bollettino
dell'Istituto di Entomologia "Guido Grandi" della Università degli Studi di Bologna, 38: 193-203.

Pantaleoni, R. A., 1988. La Neurotterofauna dell'Appennino romagnolo. Atti XV Congresso Nazionale Italiano di Entomologia, L'Aquila: 633-644.

Pantaleoni, R. A., 1990. I Neurotteri (Neuropteroidea) della Valle del Bidente-Ronco (Appennino Romagnolo). Bollettino dell'Istituto di Entomologia "Guido Grandi" della Università degli Studi di Bologna, 44: 89-142.

Pantaleoni, R. A., 1999. Neuropterida described by A. Costa with type designation. Deutsche Entomologische Zeitschrift, (N.F.), 46: 249-261. http://dx.doi.org/10.1002/ mmnd.4800460211

Pantaleoni, R. A., 2001. Lacewing occurrence in the agricultural landscape of Pianura Padana. In: McEwen, P. K., New, T. R. \& Whittington, A. E. (eds.). Lacewings in the Crop Environment. Cambridge University Press. Cambridge: 447-470. http://dx.doi.org/10.1017/ CBO9780511666117.028

Pantaleoni, R. A., 2010. Nomenclatural roots of Neuropterida: Linnaeus' era. In: Devetak, D., Lipovšek, S. \& Arnett, A. E. (eds.). Proceedings of the $10^{\text {th }}$ International Symposium on Neuropterology, Piran, 2008: 215-229.

Pantaleoni, R. A. \& Alma, A., 2001. Lacewings and snakeflies in Piedmont vineyards (northwestern Italy). In: McEwen, P. K., New, T. R. \& Whittington, A. E. (eds.). Lacewings in the Crop Environment. Cambridge University Press. Cambridge: 471-480. http://dx.doi.org/10.1017/ CBO9780511666117.029

Pantaleoni, R. A. \& Sechi, P., 2014. ¿Existe realmente Chrysoperla carnea? Historia de la investigación sobre el complejo carnea. In: González Hernández, H., Rodríguez Leyva, E. \& Lomelí Flores, J. R. (eds). Memorias XXV Curso Nacional de Control Biológico, Mérida. Colegio de Postgraduados. Montecillo: 223-236.

Pappas, M. L., Broufas, G. D. \& Koveos, D. S., 2007. Effects of various prey species on development, survival and reproduction of the predatory lacewing Dichochrysa prasina (Neuroptera: Chrysopidae). Biological Control, 43: 163-170. http://dx.doi.org/10.1016/j.biocontrol.2007. 07.006

Pappas, M. L., Broufas, G. D. \& Koveos, D. S., 2008 a. Effect of temperature on survival, development and reproduction of the predatory lacewing Dichochrysa prasina (Neuroptera: Chrysopidae) reared on Ephestia kuehniella eggs (Lepidoptera: Pyralidae). Biological Control, 45: 396-403. http://dx.doi.org/10.1016/j. biocontrol.2008.02.005

Pappas, M. L., Broufas, G. D. \& Koveos, D. S., 2008b. Effect of relative humidity on development, survival and reproduction of the predatory lacewing Dichochrysa prasina (Neuroptera: Chrysopidae). Biological Control, 46: 234-241. http://dx.doi.org/10.1016/j.biocontrol. 2008.03.015

Pappas, M. L., Broufas, G. D. \& Koveos, D. S., 2008c. The two spotted spider mite, Tetranychus urticae (Acari: Tetranychidae), alternative prey for the lacewing Dichochrysa prasina (Neuroptera: Chrysopidae). European Journal of Entomology, 105: 461-466. http:// dx.doi.org/10.14411/eje.2008.059

Pappas, M. L., Broufas, G. D., Tsarsitalidou, O. K. \& Koveos, D. S., 2011. Development and reproduction of 
the lacewings Dichochrysa flavifrons and Dichochrysa zelleri (Neuroptera: Chrysopidae) fed on two prey species. Annals of the Entomological Society of America, 104: 726-732. http://dx.doi.org/10.1603/AN10196

Pappas, M. L. \& Koveos, D. S., 2011. Life-history traits of the predatory lacewing Dichochrysa prasina (Neuroptera: Chrysopidae): temperature-dependent effects when larvae feed on nymphs of Myzus persicae (Hemoptera: Aphididae). Annals of the Entomological Society of America, 104: 43-49. http://dx.doi.org/10.1603/AN10036

Pariser, K., 1919. Beiträge zur Biologie und Morphologie der einheimischen Chrysopiden. Archiv für Naturgeschichte (A), 83(11): 1-57.

Parker, K. D. \& Rudall, K. M., 1957. The Silk of the EggStalk of the Green Lace-Wing Fly: Structure of the silk of Chrysopa egg-stalks. Nature (London), 179: 905-906. http://dx.doi.org/10.1038/179905a0

Patt, J. M., Wainright, S. C., Hamilton, G. C., Whittinghill, D., Bosley, K., Deitrick, J. \& Lashomb, J. H., 2003. Assimilation of carbon and nitrogen from pollen and nectar by predaceous larva and its effects on growth and development. Ecological Entomology, 28: 717-728. http://dx.doi. org/10.1111/j.1365-2311.2003.00556.x

Paulian, M., 1992a. Eco-éthologie des pontes de chrysopes sur maïs en Roumanie (Insecta: Neuroptera: Chrysopidae). In: Canard, M., Aspöck, H. \& Mansell, M. W. (eds.). Current Research in Neuropterology (Proceedings of the Fourth International Symposium on Neuropterology, Bagnères-de-Luchon, 1991). Toulouse: 303-310.

Paulian, M., 1992b. Etude comparative de l'activité de vol de Chrysoperla carnea (Stephens) et Chrysopa formosa Brauer capturées à la lumière artificielle en Roumanie (Insecta: Neuroptera: Chrysopidae). In: Canard, M., Aspöck, H. \& Mansell, M. W. (eds.). Current Research in Neuropterology (Proceedings of the Fourth International Symposium on Neuropterology, Bagnères-deLuchon, 1991). Toulouse: 311-312.

Paulian, M., 1996. Green lacewings from the southeast of the Rumanian Plain, as recorded by light-trapping (Insecta: Neuroptera: Chrysopidae). In: Canard, M., Aspöck, H. \& Mansell, M. W. (eds.). Pure and Applied Research in Neuropterology (Proceedings of the Fifth International Symposium on Neuropterology, Cairo, 1994). Toulouse: 197-202.

Paulian, M., 2002. Recent additions to the green lacewing fauna of Romania (Neuroptera: Chrysopidae). Acta Zoologica Academiae Scientiarum Hungaricae, 48 (Suppl. 2): 265-269.

Paulian, M. \& Canard, M., 2000. Green lacewings new to the fauna of Rumania (Neuroptera: Chrysopidae). Entomofauna, 21: 249-251.

Paulian, M., Canard, M. \& Thierry, D., 2010. Green lacewings assemblages in two fluvial lower valleys in eastern and western Europe (Neuroptera: Chrysopidae). In: Devetak, D., Lipovšek, S. \& Arnett, A. E. (eds.). Proceedings of the $10^{\text {th }}$ International Symposium on Neuropterology, Piran, 2008: 231-238.

Paulian, M., Canard, M., Thierry, D. \& Ciubuc, C., 2001. Survey of green lacewings in southern Transylvania, Rumania, with some ecological notes (Neuroptera: Chrysopidae). Journal of Neuropterology, 3: 25-31.
Paulian, M., Canard, M., Thierry, D. \& Cloupeau, R., 1996. Les Chrysoperla Steinmann de Roumanie (Neuroptera: Chrysopidae). Annales de la Société Entomologique de France (N.S.), 32: 285-290.

Paulus, H. F., 1986. Comparative morphology of the larval eyes of Neuropteroidea. In: Gepp, J., Aspöck, H. \& Hölzel, H. (eds.). Recent Research in Neuropterology (Proceedings of the 2nd International Symposium on Neuropterology, Hamburg, 1984). Graz: 157-164.

Peng, Y. K., 1988. Mass rearing and field release of Chrysopa shansiensis (Neuroptera: Chrysopidae) against citrus red spider mites (Tetranychidae). Chinese Journal of Biological Control, 4: 137.

Penny, N. D., 2002. Family Chrysopidae. In: Penny, N. D. (ed.). A Guide to the Lacewings (Neuroptera) of Costa Rica. Proceedings of the California Academy of Sciences, 53(4): 187-227 (texto), 301-373 (figuras).

Penny, N. D., Arias, J. R. \& Armistead, J. S., 2007. Seasonal emergence of Neuroptera in Fairfax County, Virginia. Proceedings of the California Academy of Sciences, 58(4): 7-19.

Peñalver, E. \& Martínez-Delclòs, X., 1993. Aportaciones a la Paleoentomología del Mioceno Inferior de Ribesalbes (Castellón, España). Comunicaciones de las IX Jornadas de Paleontología, Málaga: 85-90.

Peñalver, E., Nel, A. \& Martínez-Delclòs, X., 1995. New Nothochrysinae from the spanish Miocene (Neuroptera, Chrysopidae). Bulletin de la Société Entomologique de France, 100(5): 481-487.

Pérez de la Fuente, R., Delclòs, X., Peñalver, E., Speranza, M., Wierzchos, J., Ascaso, C. \& Engel, M. S., 2012. Early evolution and ecology of camouflage in insects. Proceedings of the National Academy of Sciences of the United States of America, 109(52): 21414-21419. http:// dx.doi.org/10.1073/pnas.1213775110

Pérez Otero, R., Mansilla Vazquez, J. \& Mansilla Salinero, P., 2005. Distribución y biología de Ctenarytaina spatulata Taylor sobre Eucaliptus globulus Labill. en la provincia de Pontevedra. Boletín de Sanidad Vegetal, Plagas, 31: 27-32.

Perkins, R. C. L., 1899. Neuroptera. In: Sharp, D. (ed.). Fauna Hawaiiensis being the land-fauna of the Hawaiian Islands. Vol. 2, pt. 2 (Neuroptera). Cambridge University Press. London: 31-89. http://dx.doi.org/10.5962/ bhl.title.58534

Perkins, R. C. L., 1910. Supplement to Neuroptera. In: Sharp, D. (ed.). Fauna Hawaiiensis being the landfauna of the Hawaiian Islands. Vol. 2. Cambridge University Press. London: 691-696.

Peters, R. S., Meusemann, K., Petersen, M., Mayer, C., Wilbrandt, J., Ziesmann, T., Donath, A., Kjer, K. M., Aspöck, U., Aspöck, H., Aberer, A., Stamatakis, A., Friedrich, F., Hünefeld, F., Niehuis, O., Beutel, R.G. \& Misof, B., 2014. The evolutionary history of holometabolous insects inferred from transcriptome-based phylogeny and comprehensive morphological data. $B M C$ Evolutionary Biology, 14: 52. http://dx.doi.org/10.1186/ 1471-2148-14-52

Peterson, A., 1967. Larvae of Insects. 6th ed. Vol. 2 (Coleoptera, Diptera, Neuroptera, Siphonaptera, Mecoptera, Trichoptera). Edwards Brothers. Ann Arbor. 416 pp. 
Philippe, R., 1970. Biologie de la reproduction de Chrysopa perla (L.) (Neuroptera, Chrysopidae). Thèse de DocteurIngéneur. Université Paul-Sabatier. Toulouse. 133 pp.

Philippe, R., 1972. Les appareils génitaux male et femelle de Chrysopa perla [Neuroptera] Étude anatomique histologique et fonctionnelle. Annales de la Société Entomologique de France (N.S.), 8: 693-705.

Pictet, A. E., 1865. Synopsis des Névroptères d'Espagne. H. Georg, Genèva \& J. B. Baillière et Fils et F. Savy, Paris. 123 pp.

Plant, C. W., 1993. Cunctochrysa bellifontensis n. sp.: Leraut, 1988 (Neuroptera: Chrysopidae), a lacewing new to Britain, with a note on its identification. Entomologist's Gazette, 44: 41-44.

Plant, C. W., 1994. Provisional atlas of the lacewings and allied insects (Neuroptera, Megaloptera, Raphidioptera \& Mecoptera) of Britain \& Ireland. Institute of Terrestrial Ecology. Huntingdon. 203 pp. 73 maps.

Poggi, R., 1993. Catalogo dei tipi di Neurotteroidei del Museo Civico di Storia Naturale "G. Doria" di Genova (Insecta). Annali del Museo Civico di Storia Naturale Giacomo Doria, 89: 415-444.

Pongrácz, S., 1912. Magyarország Chrysopái alak-és rendszertani tekintetben. Allattani Közlemények, 11: 161-221.

Ponomarenko, A. G., 1985 Setchatokrylye iz yury Sibiri i Zapadnoi Mongolii. In: Rasnitsyn, A. P. (ed.). Yuskie nasekomye Sibiri i Mongolii. Trudy Paleontologicheskogo Instituta, 211: 91-96.

Ponomarenko, A. G., 1992a. Novye setchatokrylye (Insecta, Neuroptera) iz mezozoya Mongolii. In: Grunt, T. A. (ed.). Novye taksony iskopaemykh bespozronochnykh Mongolii. Sovmestnaya Sovetsko-Mongol'skaya Paleontologicheskaya Ekspeditsiya, Trudy, 41: 101-111.

Ponomarenko, A. G., 1992b. Setchatokrylye (Insecta, Neuroptera) iz nizhnego mela Zabaykal'ya. Paleontologicheskii Zhurnal, 1992(3): 43-50.

Popov, A., 1977. 35. Wissenschaftliches Ergebnis der zoologischen Expedition des Nationalmuseums in Prag nach der Türkei. Raphidioptera, Neuroptera und Mecoptera. Acta Entomologica Musei Nationalis Pragae, 39: 271-277.

Popov, A., 1990. Zur Verbreitung der Chrysopiden (Neuroptera) in Bulgarien. Acta Zoologica Bulgarica, 39: 47-52.

Popov, A., 2002a. Rare Chrysopidae and Hemerobiidae (Neuroptera) from Bulgaria. Historia Naturalis Bulgarica, 14: 73-78.

Popov, A., 2002b. Neuropterida of northern Europe. Acta Zoologica Academiae Scientiarum Hungaricae, 48(Suppl. 2): 281-291.

Porcel, M., Cotes, B. \& Campos, M., 2011. Biological and behavioral effects of kaolin particle film on larvae and adults of Chrysoperla carnea (Neuroptera: Chrysopidae). Biological Control, 59: 98-105. http://dx.doi.org/10.1016/ j.biocontrol.2011.07.011

Porcel, M., Ruano, F., Cotes, B., Peña, A. \& Campos, M., 2013. Agricultural Management Systems Affect the Green Lacewing Community (Neuroptera: Chrysopidae) in Olive Orchards in Southern Spain. Environmental Entomology, 42(1): 97-106. http://dx.doi.org/10.1603/EN11338
Price, B. W., Henry, C. S., Hall, A. C., Mochizuki, A., Duelli, P. \& Brooks, S. J., 2015. Singing from the Grave: DNA from a 180 Year Old Type Specimen Confirms the Identity of Chrysoperla carnea (Stephens). PLoS ONE, 10(4): e0121127. http://dx.doi.org/10.1371/journal.pone. 0121127

Principi, M. M., 1940. Contributi allo studio dei Neurotteri Italiani. I. Chrysopa septempunctata Wesm. e Chrysopa flavifrons Brauer. Bollettino dell'Istituto di Entomologia della R. Università degli Studi di Bologna, 12: 63-144.

Principi, M. M., 1943. La Nothochrysa italica Rossi ed i suoi singolari costumi (Neuroptera - Chrysopidae). Bollettino della Società Entomologica Italiana, 75: 117-118.

Principi, M. M., 1946. Contributi allo studio dei Neurotteri Italiani. IV. Nothochrysa italica Rossi. Bollettino dell'Istituto di Entomologia della Università degli Studi di Bologna, 15: 85-102.

Principi, M. M., 1947. Contributi allo studio dei Neurotteri Italiani. V. Ricerche su Chrysopa formosa Brauer e su alcuni suoi parassiti. Bollettino dell'Istituto di Entomologia della Università degli Studi di Bologna, 16: 134-175.

Principi, M. M., 1948. Contributi allo studio dei Neurotteri Italiani. VII. Osservazioni su alcuni parassiti di crisopidi. Bollettino dell'Istituto di Entomologia della Università degli Studi di Bologna, 17: 93-121.

Principi, M. M., 1949. Contributi allo studio dei Neurotteri Italiani. VIII. Morfologia, anatomia e funzionamento degli apparati genitali nel gen. Chrysopa Leach (Chrysopa septempunctata Wesm. e C. formosa Brauer). Bollettino dell'Istituto di Entomologia della Università degli Studi di Bologna, 17: 316-362.

Principi, M. M., 1952. Ricerche Zoologiche sul Massiccio del Pollino (Lucania-Calabria) VI. Neurotteri. Annuario del [R.] Museo Zoologico della R. Università di Napoli, 4(10): 1-22.

Principi, M. M., 1954a. Singolari strutture glandolari nel torace e nell'addome dei maschi di alcune specie di neurotteri crisopidi. Atti dell'Accademia Nazionale dei Lincei, Rendiconti, Classe di Scienze Fisiche, Matematiche e Naturali, 16(8): 678-685.

Principi, M. M., 1954b. Contributi allo studio dei Neurotteri Italiani. XI. Chrysopa viridana Schn. Bollettino dell'Istituto di Entomologia della Università degli Studi di Bologna, 20: 359-376.

Principi, M. M., 1956a. Contributi allo studio dei Neurotteri Italiani. XIII. Studio morfologico, etologico e sistematico di un gruppo omogeneo di specie del Gen. Chrysopa Leach (C. flavifrons Brauer, prasina Burm. e clathrata Schn.). Bollettino dell'Istituto di Entomologia della Università degli Studi di Bologna, 21: 319-410.

Principi, M. M., 1956b. Campagna di ricerche dell'Istituto di Entomologia dell'Università di Bologna nella "Foresta Umbra" (Gargano). IV. Reperti etologici su di un raro neurottero crysopide, l'Hypochrysa nobilis Schneider. Atti dell'Accademia delle Scienze dell'Istituto di Bologna, Rendiconti, Classe di Scienze Fisiche, 3(11): 152-154.

Principi, M. M., 1958. Neurotteri dei Monti Sibillini (Appennino umbro-marchigiano). Memorie del Museo Civico di Storia Naturale di Verona, 6: 175-189. 
Principi, M. M., 1961. Neurotteri dei Monti Picentini (Appennino Campano). Memorie del Museo Civico di Storia Naturale di Verona, 9: 97-114.

Principi, M. M., 1962. Il valore dei caratteri morfologici, cromatici de eto-ecologici nelle discriminazione specifica. Caso di due Neurotteri crisopidi: Chrysopa flavifrons Brauer e C. iberica Navàs. Atti dell'Accademia delle Scienze dell'Istituto di Bologna, Rendiconti, Classe di Scienze Fisiche, 9(11): 16-19.

Principi, M. M., 1977. Contributi allo studio dei Neurotteri Italiani. XXI. La morfologia addominale ed il suo valore per la discriminazione generica nell'ambito delle Chrysopinae. Bollettino dell'Istituto di Entomologia della Università degli Studi di Bologna, 31: 325-360.

Principi, M. M., 1984. I Neurotteri Crisopidi e le possibilità della loro utilizzazione in lotta biologica e in lotta integrata. Bollettino dell'Istituto di Entomologia "Guido Grandi" della Università degli studi di Bologna, 38: 231-262.

Principi, M. M., 1986. [Contributi allo studio dei Neurotteri Italiani. XXXII.] Lo spermatoforo nei Neurotteri Crisopidi. Frustula Entomologica (N.S.), 7-8: 143-159.

Principi, M. M. \& Canard, M., 1984. Feeding habits. In: Canard, M., Séméria, Y. \& New, T. R. (eds.). Biology of Chrysopidae. W. Junk. The Hague: 76-92.

Principi, M. M. \& Castellari, P. L., 1970. Ibernamento e diapausa in alcune specie di crisopidi (Insecta Neuroptera) viventi in Italia. Atti dell'Accademia delle Scienze dell'Istituto di Bologna, Rendiconti, Classe di Scienze Fisiche, 7(12): 75-83.

Principi, M. M., Memmi, M. \& Sgobba, D., 1978. Reperti su Chrysopophthorus chrysopimaginis Goidanich parassita solitario delle immagini di Neurotteri Crisopidi. Bollettino dell'Istituto di Entomologia della Università degli Studi di Bologna, 34: 247-273.

Principi, M. M., Piazzi, P. \& Pasqualini, E., 1975. Influenza del fotoperiodo sul ciclo di sviluppo di Chrysopa flavifrons Brauer (Neuroptera, Chrysopidae). Bollettino dell'Istituto di Entomologia della Università degli Studi di Bologna, 32: 305-322.

Principi, M. M. \& Sgobba, D., 1987. La diapausa larvale in Mallada (=Anisochrysa) flavifrons (Brauer) (Neuroptera Chrysopidae): cicli fotoperiodici responsabili dell'induzione, sviluppo di diapausa e attivazione, accrescimento ponderale dello stadio con diapausa. Bollettino dell'Istituto di Entomologia "Guido Grandi" della Università degli studi di Bologna, 41: 209-231.

Principi, M. M. \& Sgobba, D., 1993. La diapausa larvale in Mallada clathratus (Schneider) (Neuroptera Chrysopidae). Bollettino dell'Istituto di Entomologia "Guido Grandi" della Università degli studi di Bologna, 48: 75-91.

Pröse, H., 1992. Rote Liste der gefährdeten Netzflügler (Neuropteroidea) Bayerns. Bayerisches Landesamt für Umweltschutz: Beiträge zum Artenschutz, 15: 137-139.

Pröse, H. \& Gruppe, A. [V.], 2003. Rote Liste gefährdeter Netzflügler (Neuropteroidea) Bayerns. Schriftenreihe Bayerisches Landesamt für Umweltschutz, 166: 95-98.

Pueyo, J., 1906. Excursión por las orillas del Gállego efectuada por la Sociedad Aragonesa de Ciencias Naturales.
Boletín de la Sociedad Aragonesa de Ciencias Naturales, 5: 246-248.

Putman, W. L., 1932. Chrysopids as a factor in the natural control of the oriental fruit moth. The Canadian Entomologist, 64: 121-126. http://dx.doi.org/10.4039/Ent64121-6

Putman, W. L., 1937. Biological notes on the Chrysopidae. Canadian Journal of Research (D), 15: 29-37. http:// dx.doi.org/10.1139/cjr37d-003

Putman, W. L., 1956. Differences in susceptibility of two species of Chrysopa (Neuroptera: Chrysopidae) to DDT. The Canadian Entomologist, 88: 520.

Rambur, J. P., 1837-1840. Faune entomologique de l'Andalousie. Vol. 2. Paris.

Rambur, J. P., 1838. Faune entomologique de l'Andalousie. Vol. 2. Paris. (La parte de neurópteros nunca fue publicada, salvo la lámina 9, fechada el 31 de Diciembre de 1838).

Rambur, J. P., 1842. Histoire Naturelle des Insectes, Névroptères. Librairie encyclopédique de Roret. Paris. [xviii]+534 pp.

Ramos, P., Campos, M. \& Ramos, J. M., 1983. The economic importance of predators in reducing infestation of olive fruits by Prays oleae Bern. in Granada (Spain). Boletín de información de la Red Europea de Investigación Cooperativa en Oleicultura, septiembre 1983: 30-31.

Ren, D. \& Guo, Z.-g., 1996. On the new fossil genera and species of Neuroptera (Insecta) from the Late Jurassic of northeast China. Acta Zootaxonomica Sinica, 21: 461-480.

Ren, D. \& Hong, Y.-c., 1994. A cladistic study on the familial phylogeny of fossil and living Raphidioptera (Insecta). Bulletin of the Chinese Academy of Geological Sciences, 29: 103-117.

Ren, D. \& Makarkin, V. N., 2009. Ascalochrysidae - a new lacewing family from the Mesozoic of China (Insecta: Neuroptera: Chrysopoidea). Cretaceous Research, 30: 1217-1222. http://dx.doi.org/10.1016/j.cretres. 2009. 06.004

Ren, D., Makarkin, V.N. \& Yang, Q., 2010. A new fossil genus of Mesochrysopidae (Neuroptera) from the Early Cretaceous Yixian Formation of China. Zootaxa, 2523: 50-56.

Ribeiro, F. N., 1997. Protecção integrada em pomares de macieiras na rigião de Alcobaça 4. Contribução para o conhecimento da fauna útil em Quercus coccifera L. Boletim da Sociedade Portuguesa de Entomologia, 169: 253-264.

Riek, E. F., 1967. Structures of unknown, possibly stridulatory, function of the wings and body of Neuroptera; with an appendix on other endopterygote orders. Australian Journal of Zoology, 15: 337-348.

Robertson, C., 1917. Feeding habits of adult Chrysopidae (Neur.). Entomological News, 28: 301.

Robinson, A. G., 1951. Annotated list of predators of tetranychid mites in Manitoba. Proceedings of the Entomological Society of Ontario, 82: 33-37.

Robinson, K. A., Jonsson, M., Wratten, S. D., Wade, M. R. \& Buckley, H. L., 2008. Implications of floral resources for predation by an omnivorous lacewing. Basic and Applied Ecology, 9: 172-181. http://dx.doi.org/10.1016/j. baae.2007.01.002 
Röhricht, W., 2002. Neuroptera.com. Neuropteren im Internet - nutzt das was? Galathea, Supplement 13: 31-36.

Röhricht, W., 2004. Rote Liste der Netzflügler i. w. S. (Neuropterida) des Landes Sachsen-Anhalt (2. Fassung, Stand: Februar 2004). Berichte des Landesamtes für Umweltschutz Sachsen-Anhalt, 39: 249-251.

Röhricht, W. \& Tröger, E. J., 1998. Rote Liste der Netzflügler (Neuropteroidea). In: Binot, M., Bless, R., Boye, P., Gruttke, H. \& Pretscher, P. (eds.). Rote Liste gefährdeter Tiere Deutschlands. Schriftenreihe für Landschaftspflege und Naturschutz, 55: 231-234.

Ros, J., Moner, P., Roig, V., Castillo, E. \& Lorite, P., 1988. Eficacia del hidrolizado de proteína en las pulverizaciones-cebo contra Ceratitis capitata Wied. Boletín de Sanidad Vegetal, Plagas, 14: 5-9.

Rosenhauer, W.G., 1856. Die thiere Andalusiens nach dem Resultate einer Reise zusammengestellt, nebst den Beschereinbungen von 249 neuen order bis jetzt noch unbeschreibenen Gattungen und Arten. T. Blaesing. Erlangen. 429 pp. http://dx.doi.org/10.5962/bhl. title. 66016

Rossi, P., 1790. Fauna Etrusca sistens insecta quae in provinciis Florentina et Pisana praesertim collegit Petrus Rossius. Vol. 2. T. Masi \& Sociorum. Liburni. 348 pp. http://dx.doi.org/10.5962/bhl.title.15771

Rostock, M., 1888. Neuroptera germanica. Die Netzflügler Deutschlands mit Berücksichtigung auch einiger ausserdeutscher Arten nach der analytischen Methode unter Mitwirkung von H. Kolbe bearbeitet. Jahresbericht des Vereins für Naturkunde zu Zwickau, 1887: 1-198.

Rousset, A., 1966. Morphologie céphalique des larves de planipennes (Insectes Névroptéroïdes). Mémoires $d u$ Museum Nationale d'Histoire Naturelle (A), 42: 1-199.

Rousset, A., 1984. Reproductive physiology and fecundity. In: Canard, M., Séméria, Y. \& New, T. R. (eds.). Biology of Chrysopidae. W. Junk. The Hague: 116-129.

Ruano, F., Lozano, C., García, P., Peña, A., Tinaut, A., Pascual, F. \& Campos, M., 2004. Use of arthropods for the evaluation of the olive-orchard management regimes. Agricultural and Forest Entomology, 6: 111-120. http:// dx.doi.org/10.1111/j.1461-9555.2004.00210.x

Ruano, F., Lozano, C., Tinaut, A., Peña, A., Pascual, F., García, P. \& Campos, M., 2001. Impact of pesticides on beneficial arthropod fauna in olive groves. Pesticides and Beneficial Organisms, 24(4): 113-120.

Ruberson, J. R., Tauber, C. A. \& Tauber, M. J., 1989. Development and survival of Telenomus lobatus, a parasitoid of chrysopid eggs: effect of host species. Entomologia Experimentalis et Applicata, 51: 101-106. http://dx.doi. org/10.1111/j.1570-7458.1989.tb01219.x

Ruiz Torres, M. \& Montiel Bueno, A., 2000. Introducción al conocimiento de la Entomofauna del olivar en la provincia de Jaén. Aspectos cualitativos. (I). Boletín de Sanidad Vegetal, Plagas, 26: 129-147.

Ruiz Torres, M. \& Montiel Bueno, A., 2001. Introduccción al conocimiento de la entomofauna del olivar en la provincia de Jaén. Aspectos cuantitativos (II). Boletín de Sanidad Vegetal, Plagas, 27: 531-560.

Ruiz Torres, M. \& Montiel Bueno, A., 2002. Efectos del dimetoato usado en aplicaciones terrestres y aéreas sobre la entomofauna de olivar en la provincia de Jaén. Boletín de Sanidad Vegetal, Plagas, 28: 525-560.

Růžička, Z., 1994. Oviposition-deterring pheromone in Chrysopa oculata (Neuroptera, Chrysopidae). European Journal of Entomology, 91: 361-370.

Růžička, Z., 1996. Oviposition-deterring pheromone in Chrysopidae (Neuroptera): intra- and interspecific effects. European Journal of Entomology, 93: 161-166.

Růžička, Z., 1997a. Persistence of the oviposition-deterring pheromone in Chrysopa oculata (Neur.: Chrysopidae). Entomophaga, 42: 107-112. http://dx.doi.org/10.1007/ BF02769886

Růžička, Z., 1997b. Recognition of oviposition-deterring allomones by aphidophagous predators (Neuroptera: Chrysopidae, Coleoptera: Coccinellidae). European Journal of Entomology, 94: 431-434.

Růžička, Z., 1997c. Protective role of the egg stalk in Chrysopidae (Neuroptera). European Journal of Entomology, 94: 111-114.

Růžička, Z., 1998. Further evidence of oviposition-deterring allomone in chrysopids (Neuroptera: Chrysopidae). European Journal of Entomology, 95: 35-39.

Růžička, Z., 2010. Detection of oviposition-deterring larval tracks in Chrysopa oculata and Chrysopa perla (Neuroptera: Chrysopidae). European Journal of Entomology, 107: 65-72. http://dx.doi.org/10.14411/eje.2010.008

Růžička, Z. \& Havelka, J., 1998. Effects of ovipositiondeterring pheromone and allomones on Aphidoletes aphidimyza (Diptera: Cicidomyiidae). European Journal of Entomology, 95: 211-216.

Sagné, J. C. \& Canard, M., 1984. Les limites de la resistance au froid et à l'immersion des prenymphes en diapause de Chrysopa perla (L.) (Neuroptera, Chrysopidae). Neuroptera International, 3: 73-78.

Samson, P. R. \& Blood, P. R. B., 1979. Biology and temperature relationships of Chrysopa sp., Micromus tasmaniae and Nabis capsiformis. Entomologia Experimentalis et Applicata, 25: 253-259. http://dx.doi.org/ 10.1111/j.1570-7458.1979.tb02877.x

Samson, P. R. \& Blood, P. R. B., 1980. Voracity and searching ability of Chrysopa signata (Neuroptera: Chrysopidae), Micromus tasmaniae (Neuroptera: Hemerobiidae) and Tropiconabis capsiformis (Hemiptera: Nabidae). Australian Journal of Zoology, 28: 575-580. http:// dx.doi.org/10.1071/ZO9800575

San Martin, G., 2004. Clé de détermination des Chrysopidae de Belgique. Jeunes \& Nature. Wavre. 42 pp.

Saure, C., 1997. Nineta guadarramensis (Pictet, 1865) -eine für Deutschland neue Florfliege (Neuroptera: Chrysopidae). Galathea, Supplement 3: 3-6.

Saure, C. \& Gerstberger, M., 1991. Standardliste und Rote Liste der Neuropteroidea (Netzflügler s.1.) von Berlin. In: Auhagen, A., Platen, R. \& Sukopp, H. (eds.). Rote listen der gefährdeten Pflanzen und Tiere in Berlin. Landschaftsentwicklung und Umweltforschung, 6: 237-241.

Schedl, W., 1970. Planipennia (Insecta, Neuroptera) der subalpinen und höheren Stufen der Ötztaler Alpen (Tirol, Österreich). Bericht des NaturwissenschaftlicheMedizinischen Vereins in Innsbruck, 58: 305-312. 
Schlüter, T., 1975. Nachweis verschiedener Insecta-Ordines in einem mittelkretazischen Harz Nordwestfrankreichs. Entomologica Germanica, 1: 151-161.

Schlüter, T., 1982. Cimbrochrysa moleriensis n. g. n. sp. und Hypochrysa hercyniensis n. sp., zwei fossile Chrysopidae-Arten (Insecta: Planipennia) aus dem europäischen Tertiär. Neues Jahrbuch für Geologie und Palaontologie, Monatshefte, 1982: 257-264.

Schlüter, T., 1984. Phylogeny of Chrysopidae. In: Canard, M., Séméria, Y. \& New, T. R. (eds.). Biology of Chrysopidae. W. Junk. The Hague: 1-8.

Schlüter, T., 1986. The fossil Planipennia - a review. In: Gepp, J., Aspöck, H. \& Hölzel, H. (eds.). Recent Research in Neuropterology (Proceedings of the 2nd International Symposium on Neuropterology, Hamburg, 1984). Graz: 103-111.

Schneider, W. G., 1845. Verzeichniss der von Herrn Oberlehrer Zeller im jahre 1844 in Sicilien und Italien gesammelten Neuroptera, mit beschreibung einiger neuen arten. Stettiner Entomologische Zeitung, 6: 338-346.

Schneider, W. G., 1851a. Symbolae ad monographiam generis Chrysopae, Leach. Sexaginta picturarum tabulis, in lapide acu delineatis illustratae, quarum quinquaginta quatuor coloribus impressae sunt, illustratae. Ferdinandum Hirt. Vratislaviae. 175 pp. http://dx.doi.org/10.5962/ bhl.title. 8500

Schneider, W. G., 1851b. Die in Schlesien einheimishen Arten der Gattung Chrysopa. Zeitschrift für Entomologie, 5(2): 16.

Schrank, F. von Paula, 1781. Envmeratio insectorvm Avstriae indigenorum. Klett \& Franck. Avgvstae Vindelicorvm. [xxii]+548 pp. 4 plates. http://dx.doi.org/10.5962/bhl. title. 15091

Schwartzberg, E. G., Kunert, G., Röse, U. S. R., Gershenzon, J. \& Weisser, W. W., 2008. Alarm pheromone emission by pea aphid, Acyrthosiphon pisum, clones under predation by lacewing larvae. Entomologia Experimentalis et Applicata, 128: 403-409. http://dx.doi.org/ 10.1111/j.1570-7458.2008.00721.x

Scopoli, J. A., 1763. Entomologia Carniolica, exhibens insecta Carnioliae indigena et distributa in ordines, genera, species, varietates, methodo Linneana. Ioannis Thomae Trattner. Vindobonae. [38]+418+[1] pp. http:// dx.doi.org/10.5962/bhl.title.34434

Scudder, S. H., 1890. Tertiary Insects of North America. Report of the United States Geological and Geographical Survey of the Territories. Report of the United States Geological [and Geographical] Survey of the Territories, 13: 1-663.

Séméria, Y., 1974. Recherches sur deux biocenoses contigues de Chrysopinae (Plannipenia, Chrysopidae) au niveau de la strate arbustive. Entomops, 35: 85-94.

Séméria, Y., 1980. L'equipement sensoriel de la face superieure de la region tympanale des ailes anterieures chez les Chrysopinae (Neuroptera, Planipennia, Chrysopidae). Examen en microscopie photonique et électronique à balayage. Bulletin Mensuel de la Société Linnéenne de Lyon, 49: 290-296, 345-349.

Séméria, Y., 1981. Signification de deux formes de surparasitisme, dont une inedite, chez les adultes de Chrysopinae (Planipennia, Chrysopidae) produites par le braconide
(Hymenoptera): Chrysopophthorus chrysopimaginis Goid. sur-parasitisme experimental et sur-parasitisme periodique. Neuroptera International, 1: 207-209.

Séméria, Y., 1982. Anisochrysa (Anisochrysa) inornata (Navás) (Planipennia, Chrysopidae), espèce nouvelle pour la faune de Corse. Neuroptera International, 2: 85-87.

Séméria, Y., 1984a. Some caryotypes in Chrysopidae. In: Canard, M., Séméria, Y. \& New, T. R. (eds.). Biology of Chrysopidae. W. Junk. The Hague: 42-48.

Séméria, Y., 1984b. Savannah: Mediterranean climates. In: Canard, M., Séméria, Y. \& New, T. R. (eds.). Biology of Chrysopidae. W. Junk. The Hague: 167-180

Séméria, Y., 1984c. Introduction générale a l'étude du problème du mimétisme chez les Chrysopinae. I. Signaux olfactifs et groupements optiques, en relation avec quelques données écologiques. In: Gepp, J., Aspöck, H. \& Hölzel, H. (eds.). Progress in World's Neuropterology (Proceedings of the 1st International Symposium on Neuropterology, Graz): 179-182.

Séméria, Y., 1992. Données numériques relatives aux genitalia mâles des Chrysoperla Steinmann et leur valeur dans la discrimination spécifique (Insecta: Neuroptera: Chrysopidae). In: Canard, M., Aspöck, H. \& Mansell, M. W. (eds.). Current Research in Neuropterology (Proceedings of the Fourth International Symposium on Neuropterology, Bagnères-de-Luchon, 1991). Toulouse: 333-339.

Séméria, Y. \& Berland, L., 1988. Atlas des Névroptères de France et d'Europe. Mégaloptères, Raphidioptères, Nèvroptères Planipennes, Mécoptères. Nouvelle [2nd] édition revue et augmentée. Boubée. Paris. 190 pp.

Séméria, Y. \& Nel, A., 1990. Paleochrysopa monteilsensis gen. et sp. nov., a new fossil of Chrysopidae from the Upper Eocene Formation of Monteils (France), with a review of the known chrysopid fossils (Insecta: Neuroptera). In: Mansell, M. W. \& Aspöck, H. (eds.). Advances in Neuropterology (Proceedings of the Third International Symposium on Neuropterology, Berg en Dal, 1988). South African Department of Agricultural Development. Pretoria: 27-32.

Séméria, Y. \& Vannier, G., 1983. Données numeriques et graphiques relatives à la biologie et à l'écologie de Parachrysopa pallens (R.) (=Chrysopa septempunctata Wesmael) (Neuroptera, Planipennia). Neuroptera International, 2(4): 199-212.

Séméria, Y. \& Vannier, G., 1984. Note sur un cas de transport accidentel chez les insectes chrysopides (Neuroptera). Neuroptera International 3: 89-91.

Sengonça, C., 1980. Türkiye Chrysopidae (Neuroptera) faunasi üzerinde Sistematik ve taksonomik arastirmalar. Gida-Tarim ve Hayvancilik Bakanligi. Ankara. 138 pp.

Senior, L. J. \& McEwen, P. K., 2001. The use of lacewings in biological control. In: McEwen, P. K., New, T. R. \& Whittington, A. E. (eds.). Lacewings in the Crop Environment. Cambridge University Press. Cambridge: 296-302. http://dx.doi.org/10.1017/CBO9780511666117.014

Sewify, G. H. \& El Arnaouty, S. A., 1998. The effect of the entomopathogenic fungus Verticillium lecanii (Zimm.) Viegas on mature larvae of Chrysoperla carnea Stephens (Neuroptera, Chrysopidae) in the laboratory. In: Panelius, 
S. P. (ed.). Neuropterology 1997 (Proceedings of the Sixth International Symposium on Neuropterology, Helsinki, 1998). Acta Zoologica Fennica, 209: 233-237.

Shakarami, J., 1997. Fauna of lacewings (Neuroptera: Chrysopidae) in Lorestan Province and study on the efficiency of the dominate species in control of two spotted mite (Tetranychus urticae) and Heliothis $s p$. Master's thesis. Tharbiat Modares University. Tehran. 116 pp.

Shaw, M. R., 1996. Chrysopophthorus hungaricus (ZilahiKiss) (Hymenoptera: Braconidae, Euphorinae) new to Britain, a parasitoid of adult Chrysopidae (Neuroptera). Entomologist's Gazette, 47: 185-187.

Sherborn, C. D., 1937. On the dates of publication of Costa (O. G.) and (A.) Fauna del Regno di Napoli, 1829-1886. Journal of the Society for the Bibliography of Natural History, 1: 35-47. http://dx.doi.org/10.3366/ jsbnh.1937.1.2.35

Sidor, C., 1960. A polyhedrosal virus disease of Chrysopa perla (L.). Virology, 10: 551-552.

Smith, R. C., 1921. A study of the biology of the Chrysopidae. Annals of the Entomological Society of America, 14: 27-35. http://dx.doi.org/10.1093/aesa/14.1.27

Smith, R. C., 1922a. The biology of the Chrysopidae. Memoirs of the Cornell University Agricultural Experiment Station, 58: 1287-1372.

Smith, R. C., 1922b. Hatching in three species of Neuroptera. Annals of the Entomological Society of America, 15: 169-176. http://dx.doi.org/10.1093/aesa/15.2.169

Smith, R. C., 1926. The trash-carrying habit of certain lace wing larvae. Scientific Monthly (New York), 23: 265-267.

Spiegler, P. E., 1962. The origin and nature of the adhesive substance in larvae of the genus Chrysopa (Neuroptera: Chrysopidae). Annals of the Entomological Society of America, 55: 69-77. http://dx.doi.org/10.1093/ aesa/55.1.69

Statz, G., 1936. Ueber neue Funde von Neuropteren, Panorpaten und Trichopteren aus den Tertiären Schiefern von Rott on Siebengebirge. Decheniana, 93: 208-255.

Stelzl, M., 1991. Untersuchungen zu Nahrungsspektren mitteleuropäischer Neuropteren-Imagines (Neuropteroidea, Insecta) mit einer Diskussion über deren Nützlichkeit als Opponenten von Pflanzenschädlingen. Journal of Applied Entomology, 111: 469-477. http:// dx.doi.org/10.1111/j.1439-0418.1991.tb00349.x

Stelzl, M., 1992. Comparative studies on mouthparts and feeding habits of adult Raphidioptera and Neuroptera (Insecta: Neuropteroidea). In: Canard, M., Aspöck, H. \& Mansell, M. W. (eds.). Current Research in Neuropterology (Proceedings of the Fourth International Symposium on Neuropterology, Bagnères-de-Luchon, 1991). Toulouse: 341-347.

Stelzl, M. \& Devetak, D., 1999. Neuroptera in agricultural ecosystems. Agriculture, Ecosystems \& Environment, 74: 305-321. http://dx.doi.org/10.1016/S0167-8809(99) 00040-7

Stephens, J. F., 1836. Illustrations of British entomology; or, a synopsis of indigenous insects: containing their generic and specific distinctions; with an account of their metamorphoses, times of appearance, localities, food, economy, as far as practicable. Mandibulata Vol. 6 .
Baldwin and Cradock. London. 240 pp. http://dx.doi. org/10.5962/bhl.title.8133

Stitz, H., 1909. Zur Kenntnis des Genitalapparats der Neuropteren. Zoologische Jahrbücher. Abteilung für Anatomie und Ontogenie, 27: 377-448.

Stitz, H., 1927. Ordnung: Netzflügler, Neuroptera. In: Brohmer, P., Ehrmann, P. \& Ulmer, G. (eds.). Die Tierwelt Mitteleuropas, vol. 6. Quelle and Meyer. Leipzig: 1-23.

Stitz, H., 1928. Die Neuropteren des arktischen Gebietes. Fauna Arctica, 2(5): 634-638, 955.

Sugg, P. M., Greve, L. \& Edwards, J. S., 1994. Neuropteroidea from Mount St. Helens and Mount Rainier: dispersal and immigration in volcanic landscapes. Pan-Pacific Entomologist, 70: 212-221.

Sulc, K., 1914. Über die Stinkdrüsen und Speicheldrüsen der Chrysopen. Sitzungsberichte der K. Böhmischen Gesellschaft der Wissenschaften, Mathematisch-naturwissenschaftliche Klasse, 1914(11): 1-50.

Szabó, S. \& Szentkirályi, F., 1981. Communities of Chrysopidae and Hemerobiidae (Neuroptera) in some apple-orchards. Acta Phytopathologica, Academiae Scientiarum Hungaricae, 16: 157-169.

Szentkirályi, F., 1989. Aphidophagous chrysopid and hemerobiid (Neuropteroidea) subguilds in different maize fields: Influence of vegetational diversity on subguild structure. Acta Phytopathologica et Entomologica Hungarica, 24: 207-211.

Szentkirályi, F., 2001a. Ecology and habitat relationships. In: McEwen, P. K., New, T. R. \& Whittington, A. E. (eds.). Lacewings in the Crop Environment. Cambridge University Press. Cambridge: 82-115. http://dx.doi. org/10.1017/CBO9780511666117.006

Szentkirályi, F., 2001b. Lacewings in fruit and nut crops. In: McEwen, P. K., New, T. R. \& Whittington, A. E. (eds.). Lacewings in the Crop Environment. Cambridge University Press. Cambridge: 172-238. http://dx.doi. org/10.1017/CBO9780511666117.011

Szentkirályi, F., 2001c. Lacewings in vegetables, forests, and other crops. In: McEwen, P. K., New, T. R. \& Whittington, A. E. (eds.). Lacewings in the Crop Environment. Cambridge University Press. Cambridge: 239-290. http:// dx.doi.org/10.1017/CBO9780511666117.012

Szentkirályi, F. \& Kristín, A., 2002. Lacewings and snakeflies (Neuroptera, Raphidioptera) as prey for bird nestlings in Slovakian forest habitats. Acta Zoologica Academiae Scientiarum Hungaricae, 48(Suppl. 2): 329-340.

Sziráki, G., 1996. Ecological investigations of the Neuropteroidea of oak forests in Hungary (Insecta: Raphidioptera, Neuroptera). In: Canard, M., Aspöck, H. \& Mansell, M. W. (eds.). Pure and Applied Research in Neuropterology (Proceedings of the Fifth International Symposium on Neuropterology, Cairo, 1994). Toulouse: 229-232.

Sziráki, G., 1998. Baëtis buceratus Eaton, 1870 (Ephemeroptera: Baëtidae) and Chrysoperla renoni (Lacroix, 1933) (Neuroptera: Chrysopidae) - insects new to the fauna of Hungary from the Fertö Hansag National Park. Folia Entomologica Hungarica, 59: 272-273.

Sziráki, G., 2007. A Kárpát-medence recésszárnúi. In: László, F. (ed.). A Kárpát-medence állatvilágának kialakulása. Magyar Természettudományi Múzeum. Budapest: 65-76. 
Tauber, C. A., 1969. Taxonomy and biology of the lacewing genus Meleoma (Neuroptera: Chrysopidae). University of California Publications in Entomology, 58: vi+1-94.

Tauber, C. A., 1974. Systematics of North American chrysopid larvae: Chrysopa carnea group (Neuroptera). The Canadian Entomologist, 106: 1133-1153.

Tauber, C. A., 1975. Larval characteristics and taxonomic position of the lacewing genus Suarius. Annals of the Entomological Society of America, 68: 695-700. http:// dx.doi.org/10.1093/aesa/68.4.695

Tauber, C. A. \& Adams, P. A., 1990. Systematics of the Neuropteroidea: present status and future needs. In: Kosztarab, M. \& Schaefer, C. W. (eds.). Systematics of the North American Insects and Arachnids: Status and Needs. Virginia Agricultural Experiment Station Information Series, n. 90-1. Virginia Polytechnic Institute and State University. Blacksburg: 151-164.

Tauber, C. A., Mantoanelli, E., Albuquerque, G. S., Reguilón, C., González Olazo, E. \& Tauber, M. J., 2011. A taxonomically significant polymorphism in Leucochrysa (Neuroptera: Chrysopidae): nomenclature, larval and adult descriptions, and biological notes. Zootaxa, 3130: 1-29.

Tauber, C. A., Ruberson, J. R. \& Tauber, M. J., 1995. Size and morphological differences among the larvae of two predacious species and their hybrids (Neuroptera: Chrysopidae). Annals of the Entomological Society of America, 88: 502-511. http://dx.doi.org/10.1093/aesa/88.4.502

Tauber, C. A. \& Tauber, M. J., 1973. Diversification and secondary intergradation of two Chrysopa carnea strains (Neuroptera: Chrysopidae). The Canadian Entomologist, 105: 1153-1167.

Tauber, C. A. \& Tauber, M. J., 1977a. A genetic model for sympatric speciation through habitat diversification and seasonal isolation. Nature (London), 268: 702-705. http://dx.doi.org/10.1038/268702a0

Tauber, C. A. \& Tauber, M. J., 1977b. Sympatric speciation based on allelic changes at three loci: evidence for natural populations in two habitats. Science (New York), 197: 1298-1299. http://dx.doi.org/10.1126/ science.197.4310.1298

Tauber, C. A. \& Tauber, M. J., 1989. Sympatric speciation in insects: perception and perspective. In: Otte, D. \& Endler, J. A. (eds.). Speciation and its consequences. Sinauer. Sunderland: 307-344.

Tauber, C. A., Tauber, M. J. \& Albuquerque, G. S., 2009. Neuroptera (lacewings, antlions). In: Resh, V. H. \& Cardé, R. T. (eds.). Encyclopedia of Insects, 2nd Edition. Elsevier. Amsterdam: 695-707.

Tauber, C. A., Tauber, M. J. \& Albuquerque, G. S., 2014. Debris-carrying in larval Chrysopidae: unraveling its evolutionary history. Annals of the Entomological Society of America, 107: 295-314. http://dx.doi.org/10.1603/ AN13163

Tauber, M. J. \& Tauber, C. A., 1981. Seasonal responses and their geographic variation in Chrysopa downesi: ecophysiological and evolutionary considerations. Canadian Journal of Zoology, 59: 370-376. http:// dx.doi.org/10.1139/z81-055

Tauber, M. J. \& Tauber, C. A., 2015. Phenological responses of Pseudomallada (Neuroptera: Chrysopidae): comparative data from three Nearctic species and interspecific hybrids. European Journal of Entomology, 112(1): 49-62. http:// dx.doi.org/10.14411/eje.2015.015

Tauber, M. J., Tauber, C. A., Daane, K. M. \& Hagen, K. S., 2000. Commercialization of predators: recent lessons from green lacewings (Neuroptera: Chrysopidae: Chrysoperla). American Entomologist, 46: 26-38. http:// dx.doi.org/10.1093/ae/46.1.26

Tauber, M. J., Tauber, C. A. \& Masaki, S., 1986. Seasonal Adaptations of Insects. Oxford University Press. Oxford. 411 pp.

Tellería, J. L., 2013. Pérdida de biodiversidad. Causas y consecuencias de la desaparición de las especies Loss of biodiversity: causes and consequences of the species loss. Memorias de la Real Sociedad Española de Historia Natural, $2^{\mathrm{a}}$ época, 10: 13-25.

Thierry, D. \& Adams, P. A., 1992. Round table discussion on the Chrysoperla carnea complex (Insecta: Neuroptera: Chrysopidae). In: Canard, M., Aspöck, H. \& Mansell, M. W. (eds.). Current Research in Neuropterology (Proceedings of the Fourth International Symposium on Neuropterology, Bagnères-de-Luchon, 1991). Toulouse: 367-377.

Thierry, D. \& Canard, M., 2015. Contribution to the knowledge of green lacewings of Croatia (Insecta: Neuropterida: Chrysopidae). Acta Entomologica Slovenica, 23(1): 21-28.

Thierry, D., Canard, M., Deutsch, B., Ventura, M. A., Lourenco, P. \& Lode, T., 2011. Ecological character displacement in competing common green lacewings in Europe: a route to speciation? Biological Journal of the Linnean Society, 102(2): 292-300. http://dx.doi. org/10.1111/j.1095-8312.2010.01569.x

Thierry, D., Canard, M. \& Mirmoayedi, A., 2004. Chrysoperla mutata (McLachlan, 1898) Looking at the live adult, description of its larva ans some bioeconomical remarks. Entomofauna, 25(23): 345-356.

Thierry, D., Canard, M., Ventura, M., Lourenço, P. \& Lodé, T., 2013. Is Chrysoperla agilis Henry et al., 2003 (Neuroptera: Chrysopidae) a shadow species as an outcome of common green lacewings' character displacement in Europe? Açoreana, 9: 73-82.

Thierry, D., Cloupeau, R. \& Jarry, M., 1992. La chrysope commune Chrysoperla carnea (Stephens) sensu lato dans le centre de la France: mise en évidence d'un complexe d'espèces (Insecta: Neuroptera: Chrysopidae). In: Canard, M., Aspöck, H. \& Mansell, M. W. (eds.). Current Research in Neuropterology (Proceedings of the Fourth International Symposium on Neuropterology, Bagnères-de-Luchon, 1991). Toulouse: 379-392.

Thierry, D., Cloupeau, R. \& Jarry, M., 1994. Variation in the overwintering ecophysiological traits in the common green lacewing west Palearctic complex (Neuroptera, Chrysopidae). Acta Oecologica, 15: 593-606.

Thierry, D., Cloupeau, R. \& Jarry, M., 1996. Distribution of the sibling species of the common green lacewing Chrysoperla carnea (Stephens) in Europe (Insecta: Neuroptera: Chrysopidae). In: Canard, M., Aspöck, H. \& Mansell, M. W. (eds.). Pure and Applied Research in Neuropterology (Proceedings of the Fifth International Symposium on Neuropterology, Cairo, 1994). Toulouse: 233-240. 
Thierry, D., Cloupeau, R., Jarry, M. \& Canard, M., 1998. Discrimination of the West-Palaearctic Chrysoperla Steinmann species of the carnea Stephens group by means of claw morphology (Neuroptera, Chrysopidae). Acta Zoologica Fennica, 209: 255-262.

Thierry, D., Rat-Morris, E. \& Caldumbide, C., 2002. Selective attractivity of artificial overwintering chambers for the common green lacewing species of the Chrysoperla carnea (Stephens) complex in western Europe (Neuroptera: Chrysopidae). Acta Zoologica Academiae Scientiarum Hungaricae, 48(Suppl. 2): 351-357.

Thierry, D., Ribodeau, M., Foussard, F. \& Jarry, M., 1997. Allozyme polymorphism in a natural population of Chrysoperla carnea sensu lato (Neuroptera: Chrysopidae): A contribution to the status of the constitutive taxons in Western Europe. European Journal of Entomology, 94: 311-316.

Tillier, P., Thierry, D., Dobosz, R. \& Canard, M., 2014. Chrysopa gibeauxi (Leraut, 1989): reinstatement as valid species and remarks on its distribution (Neuropterida, Chrysopidae). Bulletin de la Société entomologique de France, 119(4): 521-528.

Tillyard, R. J., 1916. Studies in Australian Neuroptera. No. 3. The wing-venation of the Chrysopidae. Proceedings of the Linnean Society of New South Wales, 41: 221-248.

Tjeder, B., 1936. Schwedisch-chinesische wissenschaftliche expedition nach den nordwestlichen provinzen Chinas, unter leitung von Dr. Sven Hedin und Prof. Sü Ping-chang. Insekten gesammelt vom schwedischen arzt der expedition Dr. David Hummel 1927-1930. 62. Neuroptera. Arkiv för Zoologi, 29A(8): 1-36.

Tjeder, B., 1944. Norwegian Neuroptera and Mecoptera in the Bergen Museum, with a note on Forcipomyia eques Joh. (Dipt., Ceratopogonidae). Bergens Museums Arbok, Naturvitenskapelig Rekke, 1: 1-12.

Tjeder, B., 1952. Specimina typorum insectorum a Carolo Linnaeo descriptorum in Museo Degeeriano asservata. Pars III. Neuroptera. Entomologisk Tidskrift, 73: 203-206.

Tjeder, B., 1966. Neuroptera-Planipennia. The Lace-wings of Southern Africa. 5. Family Chrysopidae. In: Hanström, B., Brinck, P. \& Rudebec, G. (eds.). South African Animal Life. Vol. 12. Swedish Natural Science Research Council. Stockholm: 228-534.

Tjeder, B., 1971. Redescriptions and lectotype designations of some Exotic Chrysopidae (Neur.). Entomologica Scandinavica, 2: 110-118. http://dx.doi.org/10.1163/ $187631271 \mathrm{X} 00121$

Torralba Burrial, A., 1995. Contribución al conocimiento de la entomofauna del Valle de Xanobas (Pirineo Aragonés). Boletín de la Sociedad entomológica Aragonesa, 11: 47-49.

Toschi, C. A., 1965. The taxonomy, life histories, and mating behavior of the green lacewings of Strawberry Canyon (Neuroptera, Chrysopidae). Hilgardia, 36: 391-433. http://dx.doi.org/10.3733/hilg.v36n11p391

Tóth, M., Bozsik, A., Szentkirályi, F., Letardi, A., Tabilio, M. R., Verdinelli, M., Zandigiacomo, P., Jekisa, J. \& Szarukan, I., 2006. Phenylacetaldehyde: a chemical attractant for common green lacewings (Chrysoperla carnea s.1., Neuroptera: Chrysopidae). European
Journal of Entomology, 103: 267-271. http://dx.doi. org/10.14411/eje.2006.033

Tóth, M., Szentkirályi, F., Vuts, J., Letardi, A., Tabilio, M. R., Jaastad, G., Knudsen, G. K., 2009. Optimization of a phenylacetaldehyde-based attractant for common green lacewings (Chrysoperla carnea s.1.). Journal of Chemical Ecology, 35: 449-458. http://dx.doi.org/10.1007/ s10886-009-9614-8

Tröger, E. J., 1993. Vorläufige Rote Liste gefährdeter Netzflügler (Neuropteroides) in Baden-Wüttemberg (Stand Juli 1992). Arten- und Biotopschutzprogramm Baden-Württemberg, 1(3B): 27-28.

Trouvé, C., Thierry, D. \& Canard, M., 2002. Preliminary survey of the lacewings (Neuroptera: Chrysopidae, Hemerobiidae) in agroecosytems in northern France, with phenological notes. Acta Zoologica Academiae Scientiarum Hungaricae, 48(Suppl. 2): 359-369.

Tsukaguchi, S., 1977. Biology and rearing of green lacewings. Insectarium, 14: 180-184.

Tsukaguchi, S., 1978. Descriptions of the larvae of Chrysopa Leach (Neuroptera, Chrysopidae). Kontyû, 46: 99-122.

Tsukaguchi, S., 1995. Chrysopidae of Japan (Insecta, Neuroptera). Private edition. Osaka. [ii]+[224] pp.

Urbaneja, A., Muñoz, A., Garrido, A. \& Jacas, J. A., 2001. Incidencia de Chrysoperla carnea (Stephens) (Neuroptera: Chrysopidae) en la depredacion de Phyllocnistis citrella Stainton (Lepidoptera: Gracillariidae). Boletín de Sanidad Vegetal, Plagas, 27: 65-73.

Van Noort, S., 1995. An association of Italochrysa neurodes (Rambur) (Neuroptera: Chrysopidae) with Platypleura capensis (Linnaeus) (Hemiptera: Cicadidae). African Entomology, 3: 92-94.

Vannier, G., 1986. Accroissement de la capacite de surfusion chez les adultes de Chrysoperla carnea (Insectes Nevropteres) entrant en diapause hivernale. Neuroptera International, 4: 71-82.

Vannier, G., 1987. Diminution de la capacite de surfusion chez les adultes de Chrysoperla carnea (Insectes Nevropteres) au cours de la diapause hivernale. Neuroptera International, 4: 211-219.

Vannier, G. \& Canard, M., 1989. Cold hardiness and heat tolerance in the early larval instars of Nineta pallida (Schneider) (Neuroptera: Chrysopidae). Neuroptera International, 5: 231-238.

Vas, J., Ábrahám, L. \& Markó, V., 1999. Study of nocturnal and diurnal activities of lacewings (Neuropteroidea: Raphidioptera, Neuroptera) by suction trap. Acta Phytopathologica et Entomologica Hungarica, 34: 149-152.

Ventalló, D., 1904. Neuropters de Tarrasa. Butlletí de la Institució Catalana d'Història Natural, 8(9): 113-115.

Ventura, M. A., Garcia, V. \& Canard, M., 2000. Antibiosis effect caused by the entomopathogenic fungus Metarhizium anisopliae (Metschnikoff) Sorokin variety anisopliae Tulloch, to a "common green lacewing" Chrysoperla kolthoffi (Navás) (Neuroptera: Chrysopidae). Journal of Neuropterology, 3: 33-41.

Ventura, M. A., Ribeiro, C. \& Garcia, V., 1996. Susceptibility of third instar larvae of the green lacewing Chrysoperla kolthoffi (Navás) to the entomopathogenic fungus Metarhizium anisopliae (Metschnikoff) Sorokin 
var anisopliae Tulloch in the laboratory (Insecta: Neuroptera: Chrysopidae). In: Canard, M., Aspöck, H. \& Mansell, M. W. (eds.). Pure and Applied Research in Neuropterology (Proceedings of the Fifth International Symposium on Neuropterology, Cairo, 1994). Toulouse: 241-249.

Ventura, M. A., Thierry, D. \& Coderre, D., 2002. Origins and composition of the "Chrysoperla carnea complex" (Neuroptera: Chrysopidae) in the Azores and Madeira islands. In: Leyens, T. (ed.). Proceedings of the IV Symposium on Fauna and Flora of the Atlantic Islands, Praia. Ministerio do Ambiente, Agricultura e Pescas, Praia: 135-141.

Venzon, M., Carvalho, C. F. \& Silva, R. L. X., 1996. Effects of various diets and temperature on larval development in the Neotropical green lacewing Ceraeochrysa cubana (Hagen) (Insecta: Neuroptera: Chrysopidae). In: Canard, M., Aspöck, H. \& Mansell, M. W. (eds.). Pure and Applied Research in Neuropterology (Proceedings of the Fifth International Symposium on Neuropterology, Cairo, 1994). Toulouse: 251-157.

Vicente, M., 1902. Algunos insectos de Ortigosa, Boletín de la Sociedad Aragonesa de Ciencias Naturales, 1: 186-189.

Vidal y López, M., 1943. Catálogo provisional de Neurópteros de la región levantina. Graellsia, 1(6): 13-24.

Vilajeliu, M., Vilardell, P. \& Lloret, P., 1998. Dinámica poblacional de la psilla (Cacopsylla pyri L.) y de sus enemigos naturales en plantaciones comerciales de peral de Gerona. Boletín de Sanidad Vegetal, Plagas, 24: 231-238.

Villenave, J., Deutsch, B., Lodé, T. \& Rat-Morris, E., 2006. Pollen preference of the Chrysoperla species (Neuroptera: Chrysopidae) occurring in the crop environment of western France. European Journal of Entomology, 103: 771-777. http://dx.doi.org/10.14411/eje.2006.104

Villenave, J., Thierry, D., Al Mamun, A., Lodé, T. \& Rat-Morris, E., 2005. The pollens consumed by common green lacewings Chrysoperla spp. (Neuroptera: Chrysopidae) in cabbage crop environment in western France. European Journal of Entomology, 102: 547-552. http://dx.doi.org/10.14411/eje.2005.078

Viñuela, E., Händel, U. \& Vogt, H., 1996. Evaluación en campo de los efectos secundarios de dos plaguicidas de origen botánico, una piretrina natural y un extracto de neem, sobre Chrysoperla carnea Steph. (Neuroptera: Chrysopidae). Boletín de Sanidad Vegetal, Plagas, 22: 97-106.

Volkovich, T. A., 1987. Role of light and temperature in the control of the active development and diapause of the lacewing Chrysopa carnea Steph. (Neuroptera, Chrysopidae). I. Photoperiodic reaction at the constant and gradually changing day length. Entomologicheskoe Obozrenie, 64: 3-12, 221 (abstract).

Volkovich, T. A., 1988. Role of light and temperature in the control of the active development and diapause of the lacewing Chrysopa carnea Steph. (Neuroptera, Chrysopidae). II. Seasonal development in the Belgorod Province. Entomologicheskoe Obozrenie, 67: 3-10, 235 (abstract).

Volkovich, T. A., 1996. Effects of temperature on diapause induction in Chrysopa perla (Linnaeus) (Insecta: Neuroptera: Chrysopidae). In: Canard, M., Aspöck, H.
\& Mansell, M. W. (eds.). Pure and Applied Research in Neuropterology (Proceedings of the Fifth International Symposium on Neuropterology, Cairo, 1994). Toulouse: 259-267.

Volkovich, T. A., 1997. Effect of constant and variable temperature on diapause induction in the lacewing Chrysopa phyllochroma Wesm. (Neuroptera, Chrysopidae). Entomologicheskoe Obozrenie, 76: 241-250, 491 (abstract).

Volkovich, T. A., 1998. Environmental control of seasonal cycles in green lacewings (Neuroptera, Chrysopidae) from the forest-steppe zone of Russia. In: Panelius, S. P. (ed.). Neuropterology 1997 (Proceedings of the Sixth International Symposium on Neuropterology, Helsinki, 1998). Acta Zoologica Fennica, 209: 263-275.

Volkovich, T. A., 2003. Photoperiodic responses of the green lacewing Chrysopa nigricostata Brauer (Neuroptera, Chrysopidae). Entomologicheskoe Obozrenie, 82: 257-263.

Volkovich, T. A. \& Blumental, N. A., 1997. Photothermoperiodic responses in some species of lacewings (Neuroptera: Chrysopidae): their role in diapause induction. European Journal of Entomology, 94: 435-444.

Volkovich, T. A. \& Sokolova, I. V., 2000. Thermoperiodic control of diapause in two green lacewing species (Neuroptera, Chrysopidae): a comparative effect of sharp and slow changes of temperature. Entomologicheskoe Obozrenie, 79: 753-761, 941 (abstract).

Walker, F., 1853. List of the specimens of neuropterous insects in the collection of the British Museum. Part II. (Sialides-Nemopterides). British Museum. London. [iii]+193-476.

Wallengren, H. D. J., 1863. Bidrag till kännedomen af Sveriges Neuroptera. Öfversigt af Kongliga VetenskapsAkademiens Forhändlingar, 20: 15-26.

Wallengren, H. D. J., 1871. Skandinaviens Neuroptera. Kungliga Svenska Wetenskaps Academiens Handlingar (N.F.), 9(8): 1-76.

Wattebled, S., Bitsch, J. \& Rousset, A., 1978. Ultrastructure of pheromone-producing eversible vesicles in males of Chrysopa perla L. (Insecta, Neuroptera). Cell and Tissue Research, 194: 481-496. http://dx.doi.org/10.1007/ BF00236167

Wattebled, S. \& Canard, M., 1981. La parade nuptiale et l'accouplement chez Chrysopa perla (L.) (Insecta, Neuroptera, Chrysopidae). Rôle des vésicules exsertiles du mâle et variations de la parade en fonction de la réceptivité de la femelle. Annales des Sciences Naturelles, Zoologie et Biologie Animale, 3(13): 129-140.

Weber, N. A., 1942. A neuropterous myrmecophile, Nadiva valida Erichs. Psyche, 49: 1-3. http://dx.doi. org/10.1155/1942/38909

Wedmann, S. \& Makarkin, V.N., 2006. A new genus of Mantispidae (Insecta: Neuroptera) from the Eocene of Germany, with a review of the fossil record and palaeobiogeography of the family. Zoological Journal of the Linnean Society, 149: 701-716. http://dx.doi.org/ 10.1111/j.1096-3642.2007.00273.x

Weele, H. W. van der, 1909. Ascalaphiden. Collections Zoologiques du Baron Edm. de Selys Longchamps, Catalogue Systématique et Descriptif, 8: 1-326. 
Weitschat, W. \& Wichard, W., 1998. Atlas der Pflanzen und Tiere im Baltischen Bernstein. Friedrich Pfeil. München. 256 pp., 92 pls.

Wells, M. M., 1993. Laboratory hybridization in green lacewings (Neuroptera: Chrysopidae: Chrysoperla): evidence for genetic incompatibility. Canadian Journal of Zoology, 71: 233-237. http://dx.doi.org/10.1139/ z93-033

Wells, M. M., 1994. Small genetic distances among populations of green lacewings of the genus Chrysoperla (Neuroptera: Chrysopidae). Annals of the Entomological Society of America, 87: 737-744. http://dx.doi.org/ $10.1093 /$ aesa/87.6.737

Wells, M. M. \& Henry, C. S., 1992a. Behavioural responses of green lacewings (Neuroptera: Chrysopidae: Chrysoperla) to synthetic mating songs. Animal Behaviour, 44: 641-652. http://dx.doi.org/10.1016/S0003-3472(05) 80292-1

Wells, M. M. \& Henry, C. S., 1992b. The role of courtship songs in reproductive isolation among populations of green lacewings of the genus Chrysoperla (Neuroptera: Chrysopidae). Evolution, 46: 31-42. http://dx.doi. org/10.2307/2409802

Wells, M. M. \& Henry, C. S., 1994. Behavioral responses of hybrid lacewings (Neuroptera: Chrysopidae) to courtship songs. Journal of Insect Behavior, 7: 649-662. http://dx.doi.org/10.1007/BF01997437

Wells, M. M. \& Henry, C. S., 1998. Songs, reproductive isolation and speciation in cryptic species of insects: a case study using green lacewings. In: Howard, D. J. \& Berlocher, S. H. (eds.). Endles Forms: Species and Speciation. Oxford University Press. New York: 217-233.

Welty, C., 1995. Survey of predators associated with European red mite (Panonychus ulmi, Acari, Tetranychidae) in Ohio Apple Orchards. Great Lakes Entomologist, 28: 171-184.

Wesmael, C., 1841. Notice sur les Hémérobides de Belgique. Bulletins de l'Académie Royale des Sciences et BellesLettres de Bruxelles, 8(1): 203-221.

Whiting, M. F., Carpenter, J. C., Wheeler, Q. U. \& Wheeler, W. C., 1997. The Strepsiptera problem: Phylogeny of the holometabolous insect orders inferred rom $18 \mathrm{~S}$ and $28 \mathrm{~S}$ ribosomal DNA sequences and morphology. Systematic Biology, 46: 1-68. http://dx.doi.org/10.1093/sysbio/46.1.1

Whittington, A. E., 2002. Resources in Scottish Neuropterology. Acta Zoologica Academiae Scientiarum Hungaricae, 48(Suppl. 2): 371-387.

Wildermuth, V. L., 1916. California green lacewing fly. Journal of Agricultural Research, 6: 515-525.

Williams, C. B. \& Killington, F. J., 1935. Hemerobiidae and Chrysopidae (Neur.) in a light trap at Rothamsted Experimental Station. Transactions of the Society for British Entomology, 2: 145-150.

Willmann, R., 1993. Insekten aus der Fur-Formation von Dänemark (Moler, ob. Paleozän/unt. Eozän?) 8. Zwei neue Vertreter der Chrysopidae (Neuroptera). Neues Jahrbuch für Geologie und Palaontologie, Monatshefte, 1993(4): 239-245.

Willmann, R. \& Brooks, S. J., 1991. Insekten aus der Fur-Formation von Dänemark (Moler, ob. Paleozän/unt. Eozän?). 6. Chrysopidae (Neuroptera). Meyniana, 43: 125-135.
Wilson, M. V. H., 1978. Paleogene insect faunas of Western North America. Quaestiones Entomologicae, 14: 13-34.

Winterton, S. L., 2003. Molecular phylogeny of Neuropterida with emphasis on the lacewings (Neuroptera). Entomologische Abhandlungen, 61: 158-160.

Winterton, S. L. \& Brooks, S. J., 2002. Phylogeny of the Apochrysine green lacewings (Neuroptera: Chrysopidae: Apochrysinae). Annals of the Entomological Society of America, 95: 16-28. http://dx.doi.org/10.1603/00138746(2002)095\%5B0016:POTAGL\%5D2.0.CO;2

Winterton, S. L. \& Freitas, S. de, 2006. Molecular phylogeny of the green lacewings (Neuroptera: Chrysopidae). Australian Journal of Entomology, 45: 235-243. http:// dx.doi.org/10.1111/j.1440-6055.2006.00537.x

Winterton, S. L. \& Garzón-Orduña, I. J., 2015. A new species of Glenochrysa Esben-Petersen from Australia (Neuroptera, Chrysopidae). ZooKeys, 541: 79-85. http://dx.doi. org/10.3897/zookeys.541.6643

Winterton, S. L., Hardy, N. B. \& Wiegmann, B. M., 2010. On wings of lace: phylogeny and Bayesian divergence time estimates of Neuropterida (Insecta) based on morphological and molecular data. Systematic Entomology, 35: 349-378. http://dx.doi.org/10.1111/j.1365-3113.2010. 00521.x

Withycombe, C. L., 1922. Notes on the biology of some British Neuroptera (Planipennia). Transactions of the Royal Entomological Society of London, 70: 501-594. http://dx.doi.org/10.1111/j.1365-2311.1923.tb02844.x

Withycombe, C. L., 1923. Chrysopa dorsalis, Burm., at Oxshott. Surrey Entomologist, 55: 165.

Withycombe, C. L., 1924. Further notes on the biology of some British Neuroptera. The Entomologist, 57: 145-152.

Withycombe, C. L., 1925. Some aspects of the biology and morphology of the Neuroptera. With special reference to the immature stages and their possible phylogenetic significance. Transactions of the Royal Entomological Society of London, 72: 303-411. http://dx.doi.org/ 10.1111/j.1365-2311.1925.tb03362.x

Wu, T.-k., 1992. Feasibility of controlling citrus red spider mite, Panonychus citri (Acarina: Tetranychidae) by green lacewing, Mallada basalis (Neuroptera: Chrysopidae). Chinese Journal of Entomology, 12: 81-89.

Yadav, R. \& Pathak, P. H., 2010. Effect of temperature on the consumption capacity of Chrysoperla carnea (Stephens) (Neuroptera: Chrysopidae) reared on four aphid species. Bioscan, 5: 271-274.

Yan, H.-x., Wei, G.-s., Wu, W.-g., Yan, H.-y., Zhang, H.-q. \& Li, Z.-b., 2007. Spectral sensitivity of the compound eye in the lacewing Chrysopa sinica Tjeder. Acta Entomologica Sinica, 50: 1099-1104.

Yang, I.-f., Lin, J.-t. \& Wu, C.-y. 1998a. Spectral sensitivity of the compound eye in the green lacewing, Mallada basalis (Neuroptera: Chrysopidae). Chinese Journal of Entomology, 18: 117-125.

Yang, I.-f., Lin, J.-t. \& Wu, C.-y., 1998b. Fine structure of the compound eye of Mallada basalis (Neuroptera: Chrysopidae). Annals of the Entomological Society of America, 91: 113-121. http://dx.doi.org/10.1093/aesa/91.1.113

Yang, Q., Makarkin, V.N. \& Ren, D., 2012. A new fossil Mesochrysopidae (Neuroptera) from the Mesozoic of China. Zootaxa, 3594: 1-14. 
Zelený, J., 1964. Ergebnisse der Albanien-Expedition 1961 des Deutschen Entomologischen Institutes. 24 Beitrag: Neuroptera. Beiträge zur Entomologie, 14: 323-336.

Zelený, J., 1965. Lace-wings (Neuroptera) in cultural steppe and the population dynamics in the species Chrysopa carnea Steph. and Chrysopa phyllochroma Wesm. Acta Entomologica Bohemoslovaca, 62: 177-194.

Zelený, J., 1971a. Green lace-wings of Czechoslovakia (Neuroptera, Chrysopidae). Acta Entomologica Bohemoslovaca, 68: 167-184.

Zelený, J., 1971b. Neuroptera, Megaloptera und Mecoptera aus Bulgarien. Acta Faunistica Entomologica Musei Nationalis Pragae, 14: 153-163.

Zelený, J., 1984a. Flight activity of Czechoslovak Hemerobiidae and Chrysopidae: investigation by light trap. In: Gepp, J., Aspöck, H. \& Hölzel, H. (eds.). Progress in World's Neuropterology (Proceedings of the 1st International Symposium on Neuropterology, Graz): 173-178.

Zelený, J., 1984b. Chrysopid occurrence in west Palearctic temperate forests and derived biotopes. In: Canard, M., Séméria, Y. \& New, T. R. (eds.). Biology of Chrysopidae. W. Junk. The Hague: 151-160.

Zhang, H.-q., Zhu, N., Fan, F. \& Wei, G.-s., 2007. External morphology and microstructure of the compound eye of Chrysopa pallens Ramber (Neuroptera: Chrysopidae). Acta Entomologica Sinica, 50: 454-460.

Zhang, J.-f., 1991. A new family of Neuroptera (Insecta) from the Late Mesozoic of Shandong, China. Science in China (Series B), 34: 1105-1112.

Zhang, Q.-h., Schneidmiller, R. G., Hoover, D. R., Young, K., Welshons, D. O., Margaryan, A., Aldrich, J. R. \& Chauhan, K. R., 2006a. Male-produced pheromone of the green lacewing, Chrysopa nigricornis. Journal of
Chemical Ecology, 32: 2163-2176. http://dx.doi.org/ 10.1007/s10886-006-9137-5

Zhang, Q.-h., Sheng, M., Chen, G.-f, Aldrich, J. R. \& Chauhan, K. R., 2006b. Iridodial: a powerful attractant for the green lacewing, Chrysopa septempunctata (Neuroptera: Chrysopidae). Naturwissenschaften, 93: 461-465. http:// dx.doi.org/10.1007/s00114-006-0132-z

Zheng, Y., Daane, K. M., Hagen, K. S. \& Mittler, T. E., 1993a. Influence of larval food consumption on the fecundity of the lacewing Chrysoperla carnea. Entomologia Experimentalis et Applicata, 67: 9-14. http:// dx.doi.org/10.1111/j.1570-7458.1993.tb01645.x

Zheng, Y., Hagen, K. S., Daane, K. M. \& Mittler, T. E., 1993b. Influence of larval dietary supply on the food consumption, food utilization efficiency, growth and development of the lacewing Chrysoperla carnea. Entomologia Experimentalis et Applicata, 67: 1-7. http:// dx.doi.org/10.1111/j.1570-7458.1993.tb01644.x

Zimmerman, E. C., 1957. Insects of Hawaii: A Manual of the Insects of the Hawaiian Islands, including an Enumeration of the Species and Notes on their Origin, Distribution, Hosts, Parasites, etc. Vol. 6. University of Hawaii Press. Honolulu. xi+209 pp.

Zimmermann, D., 2005. Alle gleich und doch verschieden ... Der Chrysoperla carnea-Komplex (Neuropterida: Neuroptera: Chrysopidae) - Zusammenfassung der Ergebnisse von 20 Jahren Forschung. Linzer Biologische Beitrage, 37: 145-152.

Zimmermann, D., Randolf, S., Metscher, B. D. \& Aspöck U., 2011. The function and phylogenetic implications of the tentorium in adult Neuroptera (Insecta). Arthropod Structure \& Development, 40(6): 571-82. http://dx.doi. org/10.1016/j.asd.2011.06.003 